\title{
Émile BRÉHIER
}

\author{
Historien, Philosophe français
}

(1876-1952)

\section{La philosophie $\mathrm{du}$}

Moyen Age

Un document produit en version numérique par Jean-Marc Simonet, bénévole, professeur retraité de l'enseignement de l'Université de Paris XI-Orsay

Courriel: jmsimonet@wanadoo.fr

Dans le cadre de la collection: "Les classiques des sciences sociales"

Site web: http://classiques.uqac.ca/

\author{
Une collection développée en collaboration avec la Bibliothèque \\ Paul-Émile-Boulet de l'Université du Québec à Chicoutimi \\ Site web: http://bibliotheque.uqac.ca/
}




\section{Politique d'utilisation de la bibliothèque des Classiques}

Toute reproduction et rediffusion de nos fichiers est interdite, même avec la mention de leur provenance, sans l'autorisation formelle, écrite, du fondateur des Classiques des sciences sociales, Jean-Marie Tremblay, sociologue.

Les fichiers des Classiques des sciences sociales ne peuvent sans autorisation formelle:

- être hébergés (en fichier ou page web, en totalité ou en partie) sur un serveur autre que celui des Classiques.

- servir de base de travail à un autre fichier modifié ensuite par tout autre moyen (couleur, police, mise en page, extraits, support, etc...),

Les fichiers (.html, .doc, .pdf, .rtf, .jpg, .gif) disponibles sur le site Les Classiques des sciences sociales sont la propriété des Classiques des sciences sociales, un organisme à but non lucratif composé exclusivement de bénévoles.

Ils sont disponibles pour une utilisation intellectuelle et personnelle et, en aucun cas, commerciale. Toute utilisation à des fins commerciales des fichiers sur ce site est strictement interdite et toute rediffusion est également strictement interdite.

L'accès à notre travail est libre et gratuit à tous les utilisateurs. C'est notre mission.

Jean-Marie Tremblay, sociologue

Fondateur et Président-directeur général,

LES CLASSIQUES DES SCIENCES SOCIALES. 


\section{Émile Bréhier \\ La philosophie du Moyen âge}

Cette édition électronique a été réalisée par Jean-Marc Simonet, ancien professeur des Universités, bénévole.

Courriel : Jean-Marc_Simonet@uqac.ca

À partir de :

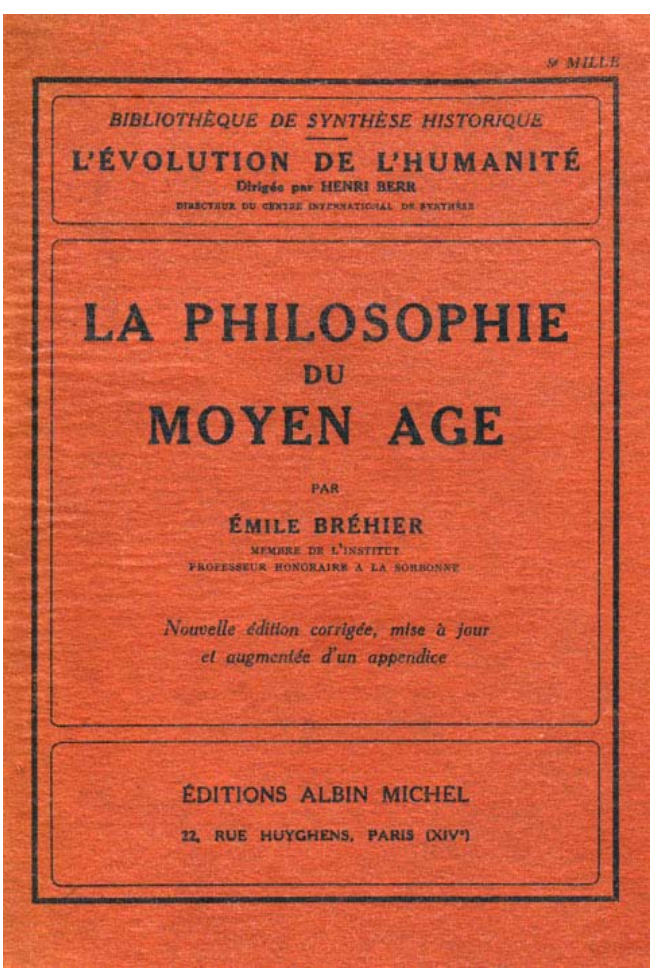

\section{Émile Bréhier}

Historien, Philosophe français

(1876-1952)

\section{La philosophie du Moyen Age}

Nouvelle édition corrigée, mise à jour et augmentée d'un appendice.

Albin Michel, Paris, 1949, 470 p.

Collection : L’Évolution de l’Humanité Synthèse collective, dirigée par H. Berr

Polices de caractères utilisées :

Pour le texte: Times New Roman, 14 et 12 points.

Pour les notes de bas de page : Times New Roman, 10 points.

Édition électronique réalisée avec le traitement de textes Microsoft Word 2008 pour Macintosh.

Mise en page sur papier format : LETTRE US, 8.5'” x 11',

Édition numérique réalisée le 27 mai 2010, révisé le 14 novembre 2014 à Chicoutimi, Ville de Saguenay, Québec.

Fait avec

Macintosh 


\section{Table des matières}

$\underline{\text { AVANT-PROPOS }}$

$\underline{\text { INTRODUCTION }}$

\section{PREMIÈRE PARTIE}

\section{Le sommeil de la philosophie (VI ${ }^{\mathrm{e}}-{ }^{-}$III ${ }^{\mathrm{e}}$ siècles)}

CHAPITRE PREMIER. - La philosophie en Occident

I. Boèce. - II. Une polémique antiaugustinienne aux $\mathrm{V}^{\mathrm{e}}$ et $\mathrm{VI}^{\mathrm{e}}$ siècles. -

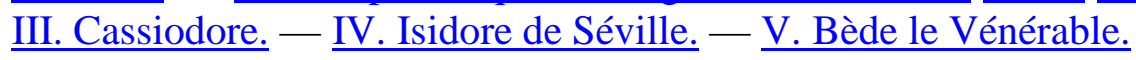

CHAPITRE II. - La philosophie en Orient

I. Conflits dogmatiques. - II. Le Corpus théologique de Jean Damascène. - III. La philosophie chez les Syriens.

\section{DEUXIÈME PARTIE}

\section{La renaissance de la philosophie $\underline{\text { (IX }}^{\underline{\mathrm{e}}} \underline{\text { et }}^{\underline{\mathrm{e}}} \underline{\text { siècles) }}$}

\section{CHAPITRE PREMIER. — Les conditions historiques}

CHAPITRE II. - La renaissance carolingienne et ses suites

I. Alcuin. - II. Jean Scot ou Érigène. - III. Le panthéisme. - IV. Les compilateurs et humanistes. $-\mathrm{V}$. Augustinisme et prestige de l'Orient. -

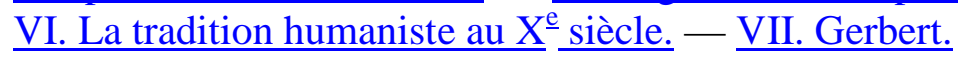




\section{Émile Bréhier \\ La philosophie du Moyen âge}

CHAPITRE III. - Les débuts de la philosophie arabe

I. Interprétation platonicienne d'Aristote. - II. La réaction de l'Islam. III. Al Kindî. - IV. Al Farâbi. - V. Yayha ben Adi. - VI. Israëli et Saadja Gaon. - VII. La philosophie à Byzance.

\section{TROISIÈME PARTIE}

\section{Le développement de la philosophie $\underline{\mathrm{XI}}^{\underline{\mathrm{e}}} \underline{\mathrm{Xt}}^{\mathrm{XII}}{ }^{\mathrm{e}}$ siècles)}

CHAPITRE PREMIER. - Les conditions historiques

CHAPITRE II. - Divers courants philosophiques en Occident

I. Les Écoles et la dialectique. - II. Dialectique et théologie au XI ${ }^{\mathrm{e}}$ siècle. - III. Le début des hérésies et l'autorité. - IV. Saint Anselme. - $\underline{\text { V. Ros- }}$ celin. - VI. La philosophie de la nature et le platonisme chartrain. - VII. La raison et la foi : les Sentences. - VIII. Abélard. - IX. Saint Bernard et

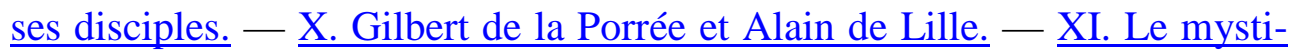

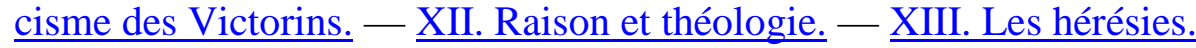

CHAPITRE III. - L'apogée de la philosophie arabe

I. Avicenne. - II. Al Gazali. - III. Averroès. - IV. La philosophie juive : Avicébron. - V. Maïmonide. - VI. La philosophie byzantine.

QUATRIÈME PARTIE

\section{$\underline{\text { Le tournant du XIII }} \underline{\text { siècle }}$}

CHAPITRE PREMIER. - Les conditions historiques

CHAPITRE II. - Les débuts de l'aristotélisme latin

I. Les traductions latines d'Aristote. - II. Dominique Gondisalvi. - III. Guillaume d'Auvergne. - IV. Alexandre de Halès. - V. Robert Grosseteste. 


\section{Émile Bréhier \\ La philosophie du Moyen âge}

CHAPITRE III. - Saint Bonaventure

I. Platonisme et antiaristotélisme. - II. L’hylémorphisme universel. - III. Connaissance, volonté et amour.

CHAPITRE IV. - Saint Albert Le Grand et Saint Thomas d'Aquin

I. Le problème de l'incorporation de l'aristotélisme. - II. Albert le Grand (1206-1280) et Saint Thomas (1227-1274). - III. La philosophie d'Albert

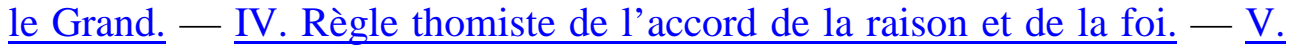
La position métaphysique de l'intellect humain. - VI. Les preuves de l'existence de Dieu. - VII. Monothéisme et création. - VIII. L'analogie de l'être. - IX. L'essence et l'existence. $-\underline{X}$. La pluralité des formes. $\underline{X I . ~ L e ~ p r i n c i p e ~ d ' i n d i v i d u a t i o n . ~}-\underline{X I I}$. Vertus acquises et vertus infuses.

- $\underline{\text { XIII. Bien surnaturel et bien naturel. }}$

CHAPITRE V. - L'averroïsme latin

$\underline{\text { I. Siger de Brabant. - }} \underline{\text { II. La condamnation de } 1277 .}$

CHAPITRE VI. - L'opposition thomiste au XIII ${ }^{\mathrm{e}}$ siècle

I. Le problème de la connaissance. - II. La pluralité des formes. - III.

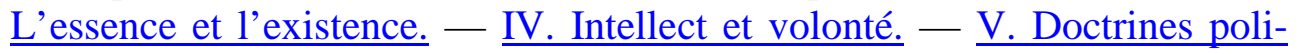
tiques.

CHAPITRE VII. - Philosophie et expansion de la Chrétienté

I. Roger Bacon. - II. La science expérimentale. - III. L'avenir chrétien. - IV. Raymond Lulle.

CINQUIÈME PARTIE

\section{La dissolution de la scolastique $\underline{\text { (XIV }} \underline{\underline{\text { siècle })}}$}

CHAPITRE PREMIER. - Duns Scot

I. La dialectique au XIV ${ }^{\mathrm{e}}$ siècle. - II. Jean Duns Scot : l'univocité de l'être,

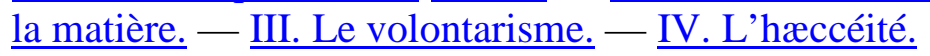




\section{Émile Bréhier \\ La philosophie du Moyen âge}

\section{CHAPITRE II. - Guillaume d'Occcam}

I. Prélude du nominalisme. - II. Guillaume d'Occam : son attitude politique. - III. Critique du réalisme : la connaissance intuitive. - IV. Logique et théorie de la connaissance. $-\underline{V}$. La métaphysique. $-\underline{V I}$. Les notions fondamentales. - VII. La Nature et la Grâce.

CHAPITRE III. - Les occamistes

Le scepticisme : Nicolas d'Autrecourt.

CHAPITRE IV. - Le mysticisme spéculatif

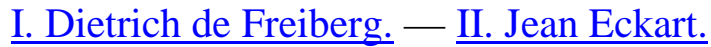

$\underline{\text { CONCLUSION }}$

BIBLIOGRAPHIE

$\underline{\text { INDEX }}$

APPENDICE 


\section{AVANT-PROPOS \\ La raison et la foi \\ Leurs rapports et leur conflit au Moyen âge.}

Nous avons, dans des volumes antérieurs, ou naître, croître, s'affermir le psychisme. Par l'action des individus, dans les sociétés, - où la coopération sert le développement de l'esprit, mais où l'institution souvent l'entrave ${ }^{1}$, - la pensée impersonnelle et suprasociale, la raison humaine se constitue. Léon Robin et Abel Reg ont marqué le rôle décisif de la Grèce travaillant avec son génie propre sur le " patrimoine commun » que lui ont légué les Empires orientaux, "A considérer l'évolution de la pensée humaine, la pensée grecque, aux $\mathrm{VI}^{\mathrm{e}}$ et $\mathrm{V}^{\mathrm{e}}$ siècles, en est à la fois la résonance totale et la pointe avancée. " Chez un peuple et en un temps privilégié, ce ressort profond de logique, qui, d'après notre hypothèse, anime toute activité, et, par conséquent, fournit le principe essentiel de l'explication historique, - apparaît à la conscience réfléchie dans le besoin désintéressé de comprendre, exerce largement son pouvoir, se traduit en méthode rationnelle : et c'est là un des aspects, ce n'est pas - nous l'avons dit — l'aspect le moins important, du miracle grec ${ }^{2}$.

La pensée avait cherché à dégager ses éléments purs du complexe où l'impatience d'explication les avait mêlés aux pii imaginations les plus diverses et parfois les plus extravagantes, au produit contingent des milieux physiques, des caractères ethniques et individuels. Rappelons, toutefois, que, comme l'a noté Abel Rey, c'est la poussée téméraire de l'esprit, la hardiesse imaginative, qui a mû la raison, tout en l'égarant : c'est l'esprit mythique qui a développé «le besoin qu’a

En marge de l’Histoire universelle, p. 292.

Ibid., pp. 228, 230, 282, 287. 
l'homme d'être satisfait par une réponse à ses étonnements " ${ }^{3}$; et le positif a été enfanté dans la mystique.

Mais après l'éclair du miracle grec, dans la période hellénistique, une lassitude intellectuelle, une crise morale provoquent le débordement du mysticisme oriental. « La vague de foi montante balaye, pour bien des siècles, le travail de la raison grecque ${ }^{4}$. " Rome, on l'a vu, était plus douée pour l'action que pour la spéculation : dans la décomposition de l'Empire, ce qu'elle avait recueilli de philosophie et de science a été submergé "par le torrent de religiosité venu de l’Orient $»$.

Nous avons, ailleurs, défini ce qu'on appelle le Moyen Age, — expression contestable, mais qui répond à quelque chose d'historiquement réel. Nous avons cru pouvoir affirmer que, - si les limites du Moyen Age sont difficiles à fixer, varient selon le point de vue où l'on se place, - il y a un «homme du Moyen Age », un homme dont la mentalité "plonge ses racines dans le lointain Orient », chez qui la révélation annule l'effort de connaître et dont tout l'être est tendu vers l'au-delà, l'homme sentimental ${ }^{6}$.

Ce que montre le livre d'Émile Bréhier, c'est, d'abord, cette raison, si lentement mûrie et par le génie de la Grèce rendue si vigoureuse, sombrant dans la ruine du monde antique ; c’est, ensuite, la pensée grecque, effacée mais non piii abolie, qui reparaît, qui, par des voies diverses, s'infiltre en Occident, qui s'impose à la réflexion chrétienne. Et, de nouveau, la mystique tout à la fois excite et gêne la spéculation. Là est l'intérêt profond du présent volume : pour une longue période, le Moyen Age intellectuel, — c'est-à-dire, selon la définition de Bréhier, «l'époque où l'enseignement philosophique est donné par le clergé, régulier ou séculier ${ }^{7}$, - il suit l'effort pour unifier deux données irréductibles : le christianisme et ce qui subsiste de la civili-

Ibid., p. 286.

Ibid., p. 230.

LOT, La fin du Monde antique et le début du Moyen Age, pp. IX, XIII, 26, 211.

Voir RobIN, t. XIII ; Boulanger, t. XI ; Jouguet, t. XV ; GUIGNEBERT, t. XXVIII bis.

Pp. 1 et 433. 
sation gréco-romaine ; il met en vive lumière les rapports, les essais de conciliation, les conflits de la raison et de la foi.

Il ne faut pas exagérer la solution de continuité entre l'antiquité et le Moyen Age et prendre à la lettre l'expression de «nuit intellectuelle ». Si la culture s'effrite, si l'Orient ne s'intéresse qu'aux choses divines, en Occident, " un mince filet coule de connaissances positives ", qui se rattache à l'érudition romaine ; et la pensée philosophique est transmise, non sans rétrécissements, par des ouvrages comme ceux de Boèce ou de Martin de Braga, qui veulent joindre la logique et la théologie, la sagesse antique et la morale chrétienne. Le rôle capital, ici, a été joué par saint Augustin ${ }^{8}$. Combattu par des influences orientales, l'esprit augustinien triomphe à la fin $\mathrm{du}^{\mathrm{VI}} \mathrm{e}^{\mathrm{e}}$ siècle.

Le VII ${ }^{\mathrm{e}}$ siècle voit se constituer - en Espagne, par exemple, avec Isidore de Séville, en Angleterre avec Bède le Vénérable - des encyclopédies, où sont plutôt juxtaposées que fondues des connaissances hétérogènes. Prêtres et moines font effort pour maintenir l' « armature intellectuelle ». piv Cependant, l'époque mérovingienne est celle où l'«atonie », pour employer une expression de Pirenne, a été le plus profonde. Un "regroupement des forces intellectuelles» (p. 41) s'opère aux $\mathrm{VIII}^{\mathrm{e}}$ et $\mathrm{IX}^{\mathrm{e}}$ siècles dans les trois empires : byzantin ${ }^{9}$, arabe, carolingien. Charlemagne recueille les moines chassés d'Irlande et d'Angleterre par l'invasion des Vikings ; et les grandes abbayes — Saint-Gall, Fulda, Reichenau, Corbie — deviennent les centres d'une culture qui est « une pièce intégrante de la notion d'empire, tel que l'a conçu Charlemagne » (p. 42) ${ }^{10}$.

Mais cet empire est une théocratie, en sorte que le savoir n'a d'autre fin que de servir la foi: "les sept arts libéraux comme moyen ${ }^{11}$, la théologie comme fin » (p. 46). Il n'y a rien à inventer : il ne s'agit que de conserver et de transmettre ce que les hommes sages

Voir les tomes XXX et XXXI.

Voir pp. 38, 105, 252.

Pour la renaissance carolingienne, nous renvoyons au tome XXXIII.

Trivium : grammaire, rhétorique, dialectique ; quadrivium : arithmétique, musique, géométrie, astronomie. 
ont trouvé dans les choses et fixé dans les livres (pp. 43-45). Nisi credideritis non intelligetis, dira Scot Érigène : on vient à la raison par la foi, et la raison confirme la foi. "Philosophie pieuse », qui ne veut pas être confondue avec la " philosophie du monde », — où les idées divines informent la matière, et qui « voit revivre... tout l'essentiel des conceptions platoniciennes, fortement altérées par l'idée chrétienne et gnostique de la fin des temps ${ }^{12}$.

Dans cet esprit, sous l'influence d'Alcuin, de ses disciples, - notamment Raban Maur et Loup Servat, - et des disciples de ceux-ci, les études se développent dans les monastères, et entre les monastères se forment des liens intellectuels. Mais le rapport qu'avaient eu les arts libéraux, pv chez les Gentils, avec le culte des idoles et les arts magiques exposait aux soupçons ceux qui s'y adonnaient. "C'est un fardeau maintenant que de vouloir apprendre, » déclare Loup Servat (p. 71).

D'ailleurs, au $\mathrm{X}^{\mathrm{e}}$ siècle, la dissolution de l'empire carolingien, les invasions normandes et hongroises, la ruine des monastères enrayeront ce mouvement, jusqu'au rétablissement de l'unité impériale par Otton le Grand. Alors, Cluny et Saint-Gall, mais aussi les écoles épiscopales de Reims, de Chartres seront les foyers d'un humanisme subordonné toujours à des fins religieuses ${ }^{13}$.

Parallèlement à la Renaissance carolingienne, l'Orient, aux IX ${ }^{\mathrm{e}}$ et $\mathrm{X}^{\mathrm{e}}$ siècles, présente un éveil de la pensée arabe qui a pour point de départ le kalifat d'Haroun-al-Raschid. Émile Bréhier montre la complexité de ce travail intellectuel où une spéculation d'origine grecque, qui cherche à concilier Platon et Aristote, et des éléments purement orientaux - cultes solaires, mysticisme - se mêlent au Coran. Un collège de traducteurs fondé en 832 par le calife de Bagdad Al Ma-

12 P. 64. Cf. p. 76. De Scot Érigène, néoplatonicien à tendance panthéiste, un courant panthéiste est sorti. Voir H. DELACROIX, La Philosophie médiévale latine, dans la Rev. de Synth, hist., t. V, pp. 105-106.

13 Gerbert, le futur Silvestre II, Abbon, abbé de Fleury, travailleront même à la restauration des sciences. Voir A. VAN DE VYVER, L'évolution scientifique du haut Moyen Age, dans Archeion, mars 1937, et ultérieurement, Abel Rey, t. XLVI. 
moûn met en langue arabe, parmi de nombreux textes grecs, l'œuvre complète d'Aristote. Événement considérable par ses conséquences ultérieures. Mais le monde matériel, objet principal d'Aristote, est subordonné, dans l' « arabisme ", à l'être transcendant, de qui il emprunte la nécessité. La métaphysique d’Al Farâbi, le plus célèbre des philosophes arabes de ce temps, s'accommode même d'un mysticisme et d'un prophétisme qui ne s'y relient pas directement.

A celle époque également, une école philosophique juive étudie Aristote et se sert de la raison " comme machine de pvi guerre en faveur de la religion ». "Le monothéisme et l'hellénisme créèrent certainement, au cours du $\mathrm{X}^{\mathrm{e}}$ siècle, à Bagdad, un terrain commun de discussion entre mahométans, chrétiens et juifs, et l'on y voyait des sortes de conférences philosophiques, où participaient même des athées » (p. 102).

Dans les régions où se répand l'Islam, la philosophie atteindra son apogée aux $\mathrm{XI}^{\mathrm{e}}$ et $\mathrm{XII}^{\mathrm{e}}$ siècles, avec Avicenne, Al Gazali et Averroès, qui représentent des courants divers de la pensée musulmane. Le premier, qui se rattache à Al Farâbi, amalgame à sa façon Aristote, le néo-platonisme et des idées coraniques. Le deuxième, qui enseigne à Bagdad, Damas, Jérusalem, Alexandrie, puis retourne en Perse, son pays natal, propage « une mystique proprement orientale et persane qui ne pouvait s'accommoder d'un péripatétisme d'origine grecque ». Averroès, lui, s'oppose et au néoplatonisme et au mysticisme. Il enseigne en Espagne, où se trouvent, au XII ${ }^{\mathrm{e}}$ siècle, les centres intellectuels de l'Islam, Grenade, Cordoue. «Son dessein est de revenir... au sens authentique d'Aristote », cet " exemplaire que la nature a créé pour montrer la suprême perfection où arrive l'homme revêtu d'un corps ${ }^{14}$. »

Mêmes influences dans la philosophie juive, en Espagne : elle est de tendance platonicienne avec Avicébron, au $\mathrm{XI}^{\mathrm{e}}$ siècle, de tendance péripatéticienne avec Maïmonide, au XII ${ }^{\mathrm{e}}$. Pour celui-ci, qui retient dans sa doctrine le prophétisme, « la Science de la Loi est une chose à part, et la philosophie est une chose à part ». Il demande à la philosophie de confirmer les vérités de la Loi, mais non sans voir leur anta-

14 Pp. 216, 237 ; 220, 222 ; 225, 226, 235. 
gonisme. Ses adversaires orthodoxes provoquent son exil et font brûler ses écrits ${ }^{15}$.

$$
* * *
$$

Cependant, aux $\mathrm{XI}^{\mathrm{e}}$ et $\mathrm{XII}{ }^{\mathrm{e}}$ siècles, la chrétienté s'était pvii dressée contre l'Islam, opposant impérialisme à impérialisme. L'expansion, au nom de la foi chrétienne, résultait naturellement de l'intensité de celle foi.

Et si ardent, si profond est le sentiment religieux qu'il s'agit toujours de philosopher, non pour philosopher, mais uniquement pour penser la foi. On la pense pour la formuler mieux, et ainsi la propager plus efficacement chez les infidèles, la défendre plus sûrement contre les hérétiques. Le clerc, qui seul est philosophe, n’a pas à chercher des vérités nouvelles, puisqu'il détient la Vérité absolue ${ }^{16}$. Mais comment empêcher qu' « à l'universalité de la foi chrétienne, qui naît et se développe en des conditions définies, s'oppose l'universalité rationnelle de la philosophie, indépendante de toute foi » ? Opposition latente, mais réelle, en sorte que peu à peu, invinciblement, les éléments intellectuels, que la foi prétendait absorber, manifesteront des exigences propres.

Dès la seconde moitié du $\mathrm{XI}^{\mathrm{e}}$ siècle et au $\mathrm{XII}^{\mathrm{e}}$, enseignement et contrôle s’organisent : de la spéculation, qui va se développant, on se demande si elle n'est pas, " plutôt qu'un soutien, l'invention d'un orgueil diabolique $»{ }^{17}$.

A mesure que s'affermira la raison, la défiance s’aggravera. Et rien n'est plus attachant que de voir, dans le clair, pénétrant et solide exposé d’Émile Bréhier, s’intensifier ces audaces et ces scrupules de la pensée médiévale. Effort émouvant, et rendu parfois tragique par des débats de conscience ou par des conflits publics, pour affranchir l'esprit de l'explication imaginative et fidéiste des choses.

Dans les villes, dont l'importance croît, le rôle des écoles épiscopales grandit, en attendant que naissent les Universités. Les études du

\footnotetext{
Pp. 245, 249, 251.

Voir pp. 145, 146, 186-187.

P. 146. Cf. p. 120.
} 
trivium et du quadrivium tendent, en général, à se libérer. La dialectique, en rapports de plus en plus étroits avec la théologie, mais appuyée sur les œuvres d'Aristote, de pviii Porphyre, va jusqu'à prétendre "déterminer les natures des choses "; elle se heurte à certains dogmes qui lui apparaissent obscurs ou absurdes; et le danger, qui menace, du " primat de la raison » entraîne l'avertissement des condamnations ${ }^{18}$. Par ailleurs, au nom d'un savoir plus profond, sous l'influence de l'Orient, des doctrines ascétiques s'opposeront à la « philosophie mondaine » (p. 120).

De questions soulevées par des moines, des discussions d'un monastère, sont sorties les œuvres d'Anselme, dont É. Bréhier montre bien les préoccupations et la portée. Anselme précise et limite le rôle de la ratio. Elle n'a d'autre office que la méditation de la foi. C'est ce que traduit sa formule célèbre, Fides quaerens intellectum, - transposition de la non moins célèbre phrase d’Isaïe, reprise par Scot Érigène : Nisi credideritis, non intelligetis ${ }^{19}$.

On voit, au XII ${ }^{\mathrm{e}}$ siècle, des écoles diverses - les Chartrains, les Sententiaires - s'appliquer, inlassablement, au problème insoluble. Et ici se place l'épisode - dont É. Bréhier souligne l'importance et le dramatique intérêt — du grand duel entre Abélard et Saint Bernard.

La raison humaine, même en se soumettant, ne pouvait, dès lors qu'elle était éveillée, ne pas rencontrer de l'inintelligible : la trinité, la transsubstantiation, l'accord de la prescience divine et de la liberté humaine. Le nominalisme, - la doctrine qui considère les termes par lesquels on désigne les genres et les espèces, les universaux, comme des flatus vocis, de simples mots - conduisait, en rendant la trinité impensable, à l'erreur du trithéisme ${ }^{20}$. Le réalisme, en allant du supérieur à l'inférieur, en substantialisant les espèces par les genres, les individus par les espèces, permettait, dans la théologie, pix de concilier Dieu et la Trinité. Comme on l'a fait observer ${ }^{21}$, le terme « réa-

\section{Voir pp. 114-116.}

19 Pp. 122, 124. - Sur la preuve ontologique de l'existence de Dieu, reprise par Descartes, voir pp. 126-129.

20 P. 129. Sur Roscelin, nominaliste, condamné par le concile de Soissons en 1092, voir pp. 129-131.

21 WeLLS, Esquisse de l'Hist. univ., p. 372. 
lisme ", quand il attribue une réalité aux abstractions les plus générales, a un sens très différent de celui qu'il a pris en art, où il marque la préoccupation du détail précis dans l'étude du réel. En logique, le nominalisme est plus près de la réalité que le réalisme.

Abélard n'était pas un pur nominaliste ; et ce n'était pas non plus le rationaliste que certains modernes ont voulu voir en lui (p. 151). Son originalité et son mérite sont d'avoir été, dans une large mesure, psychologue. Il croit que les universaux, sans être des réalités, répondent à des manières d'être des choses, sont de légitimes abstractions, le fait de l'esprit. Il ne résolvait pas le problème de la Trinité, qui, pour lui, échappait - ainsi que beaucoup d'autres - au " petit raisonnement humain » (p. 153).

Abélard pratique et défend la dialectique, mais en limite l'emploi. Il est de ceux qui ont préparé une dialectique purement formelle, et non " solidaire de la réalité des universaux », " moyen de discuter, et non moyen de connaître ». Il rapproche la philosophie de la théologie, mais ne se dissimule pas que c'est en "détournant » parfois les textes des anciens vers la foi, en y cherchant un christianisme virtuel. En morale, c'est dans la conscience qu'il trouve la loi, et sa conviction que le péché, comme le mérite, est personnel, tend, sinon à infirmer, à diminuer tout au moins le rôle médiateur du Christ. Philosophe et croyant, somme toute, Abélard veut l'accord de la raison et de la foi ; et là où commence la difficulté, il s'arrête, pour faire triompher la foi ${ }^{22}$.

Dans la présentation, tout abstraite, qu'en fait Émile Bréhier, telle que le comporte le déroulement de la pensée médiévale, la pensée propre d'Abélard est singulièrement attirante. Elle l'est plus encore, et éclaire la mentalité collective de son ${ }_{\mathrm{px}}$ temps, si on la relie à la vie romanesque de cette curieuse personnalité. On voit alors toutes les forces de vie, toutes les impulsions de nature rejoindre les besoins de pensée, pour préparer les affranchissements ultérieurs. Quand un traitement barbare l'a, comme il le dit lui-même, «rendu d'autant plus propre au service des saints autels que les souillures des voluptés de la chair ne pouvaient plus réveiller en lui les passions ${ }^{23}$, Héloïse, elle,

\footnotetext{
22 Voir pp. 156, 161, 177-178.

23 Lettres d'Abélard et d'Héloïse, trad. Gréard, p. 98.
} 
dans son ardeur passionnée, ne se plie à ce service des saints autels que « par obéissance à celui qu'elle aime ». Elle emploie toute sa raison à adoucir la règle monastique ${ }^{24}$. Comme Abélard lui-même, d'ailleurs, elle rabaisse les œuvres ${ }^{25}$. Le travail de l'esprit religieux se situe alors, il ne faut pas l'oublier, dans un milieu où l'économie se développe, où vont bientôt fleurir les lettres et les arts, et subit l'action d'une sorte de poussée vitale. Nous y reviendrons.

Mais il y a des résistances et des hostilités. Pour un Saint Bernard, chercher l'accord de la philosophie et du dogme, c'est introduire la confusion entre le dogme et la philosophie : l'« intelligence » nuit à la foi ; l'orgueil fait sortir l'homme de la mesure ${ }^{26}$. En 1121, au concile de Soissons, en 1141, au concile de Sens, il obtient la condamnation de deux ouvrages d'Abélard. En 1140, le silence est imposé à celui-ci, par rescrit du pape, et ses partisans sont excommuniés ${ }^{27}$.

Chez Saint Bernard et chez ceux qu'il inspire, le scepticisme sur les recherches des philosophes mène au mysticisme.

pxi Toute spéculation est vaine : il faut tout accepter et du dogme et des institutions de l'Église, qui échappent à l'intelligence humaine, et chercher la connaissance pleine dans l'amour divin. Saint Bernard n'est philosophe que contre la philosophie.

Le monastère de Saint-Victor, à Paris, s'accordait, sur ces questions, avec l'abbaye de Cîteaux, réformée par Saint Bernard. Opposé également aux « philosophes mondains ", Hugues de Saint-Victor leur objecta que, parlant d'une "nature gâtée par le péché originel », ils ont prétendu atteindre Dieu par la seule lumière d'une raison «incomplète et déficiente » (p. 189). Pour tous ces mystiques, la raison ne

24 Ibid., p. 117 (certains ménagements seraient conformes « au vœu de la nature »).

25 Ibid., voir pp. 123, 125, 127, 128. - On peut se demander si les lettres d’Héloïse n’ont pas été « fabriquées » par Abélard : quoi qu’il en soit, il y a, dans ces lettres, des sentiments, des traits passionnés, qui viennent certainement d'Héloïse. Voir $\mathrm{M}^{\mathrm{e}}$ CHARRIER, Hélö̈se dans l'histoire et dans la légende, et Émile HenRIOT, La vraie Héloïse, Temps du 25 sept. 1934.

26 Pp. 165, 167.

27 Sur Gilbert de la Porrée, condamné en 1148, voir p. 174. 
saurait fournir qu'un passage de la foi banale à l'illumination, soit de l'amour, soit de la contemplation ${ }^{28}$.

On ne bannit donc pas la raison, même dans ces milieux monastiques ; mais on ne lui accorde qu'un caractère "préparatoire et préliminaire ». Cependant, les écoles théologiques de Paris et, à côté d'elles, des écoles nouvelles, - qui devaient bientôt devenir la Faculté des Arts, - développaient, avec la dialectique, un goût de discussion inquiétant pour la piété intérieure. Le duel d'Abélard et de Saint Bernard est aussi le duel entre les écoles épiscopales et les monastères, entre la théologie spéculative et la vie chrétienne. Ennemis comme amis de la raison, tous sont préoccupés de préciser son rôle. Et, pour Bréhier, un caractère " foncier et presque inexprimable » de la pensée médiévale consiste en un effort, « puissant et douloureux », pour donner à nos facultés naturelles leur sens dans la vie surnaturelle ${ }^{29}$.

Avec le XIII ${ }^{\mathrm{e}}$ siècle, nous atteignons ce que notre collaborateur ${ }_{\text {pxii }}$ appelle le tournant. "Nous trouvons ici ... un jaillissement de forces nouvelles et indépendantes qui sont foncièrement différentes de l'Église, et, d'autre part, une interprétation mystique de ces forces qui les asservit à l'Église et à la papauté » (p. 257). Et c'est le lieu d'insister sur les traits généraux de ces temps, pour mieux comprendre les luttes spirituelles et leur fatale aggravation.

Le Moyen Age, d'après Gustave Cohen ${ }^{30}$, est l'âge de toutes les genèses. Une civilisation originale y est née, en France, qui a rayonné largement, - le fait s'est reproduit aux $\mathrm{XVII}^{\mathrm{e}}$ et $\mathrm{XVIII}^{\mathrm{e}}$ siècles, nous le verrons ${ }^{31}$, - et dont le caractère était complexe : civilisation chrétienne, ou l'élan des croisades el la montée des cathédrales ont exprimé la foi ardente, mais où la chevalerie, puis la commune, ont préservé ou émancipé l’individu. Henri Pirenne, dans son ouvrage pos-

28 Sur le mysticisme et, en particulier, le culte de la Vierge, voir RÉAU, t. XL, p. 42.

Pp. 197, 203-205.

T. XL, p. 281.

31 Voir RÉAU, ibid., pp. 114 et suiv. Cf. t. LXX, L'Europe française, qui paraîtra prochainement. 
thume, Histoire de l'Europe, a fait de cette " civilisation française " un magnifique tableau ${ }^{32}$. Il souligne l'influence de l'Université de Paris, - dont l'attraction, dit-il, " était irrésistible et est restée sans exemple ». C'est que, à Paris, l'Association générale des maîtres et des étudiants, Universitas magistrorum et scolarium, dépendante du pape, — qui la reconnut en 1231, — protégée par le roi, s’était affranchie de l'autorité épiscopale. Il y avait là un fait " analogue à celui des communes : comme les communes sont à côté de la hiérarchie féodale, l'Université est en dehors de la hiérarchie ecclésiastique; comme la commune est aspiration à un développement économique plus libre et plus étendu, l'Université, pxiii faisant suite aux écoles du $\mathrm{XII}^{\mathrm{e}}$ siècle, recherche, au milieu de toutes les difficultés d'une orthodoxie pointilleuse, un développement de la pensée qui corresponde à ses exigences internes ${ }^{33}$ ».

Aristote fait, à ce moment, sa " grande entrée ", et c'est lui qui est le principal agent des progrès de la pensée, — avant d'en devenir l'obstacle ${ }^{34}$. Par l'intermédiaire des Arabes, l'Occident recueille cette philosophie et cette science helléniques, dont il n'avait encore que des lambeaux. Les traductions se multiplient, — de l'arabe, ou même directement du grec. Comme Aristote, Platon, dont l'influence s'était prolongée avec les Augustiniens, va être mieux connu. Mais Aristote favorisait une spéculation purement rationnelle, relative au monde physique.

32 P. 268. - On connaît les thèses - conciliables — de NORDSTRÖM, qui situe la vraie Renaissance dans la France des XII ${ }^{\mathrm{e}}$, XIII ${ }^{\mathrm{e}}$ siècles et y rattache la Renaissance italienne, et de Toffanin, qui oppose au rationalisme français l'humanisme chrétien du Quattrocento. Voir RENAUDET, L'humanisme italien, dans Science, avril 1937, et ITAlo Siciliano, Medio evo e Rinascimento, notamment pp. 33, 108, 117, 131.

33 Sur l’Université de Paris, voir LOT, t. XLI, pp. 221, 292 ; Delacroix, art. cité, p. 119 ; CH. V. LANGLOIS, Les Universités du Moyen Age, dans Questions d'Histoire et d'Enseignement, pp. 34 (« le Studium generale de Paris fut, à partir du XIII ${ }^{\mathrm{e}}$ siècle, une grande démocratie cléricale », hardie et turbulente), 38.

34 Sur Aristote, voir Lot, ibid., p. 193 ; DelACROIX, ibid., pp. 110-112 ; LANGLOIS, ibid, p. 76 : " L’impression produite dans les écoles de Paris, qui étaient alors, pour ainsi dire, le cerveau de la chrétienté, par l'apparition d'Aristote, fut immense. Impression mélangée d'enthousiasme, de méfiance, d'horreur. " 
Une philosophie naît, distincte de la théologie, soutenue par les uns, combattue par les autres, et d'autant plus suspecte à ceux-ci que, jaillie d'une curiosité de l'esprit qui ignore la foi chrétienne, elle ne laissait plus à la raison «cette fonction intermédiaire que la culture chrétienne lui assignait» (p. 296). Un Saint Bonaventure, par exemple, déclare que s'arrêter aux choses de l'expérience, qui ne sont que des signes, s'abaisser à leur connaissance, c'est tomber de la contemplation véritable et "goûter de l'arbre défendu de la science du bien et du mal $»{ }^{35}$.

Albert le Grand et Saint Thomas, son élève, dominicains tous deux, interprètes d'Aristote, détachent complètement la pxiv philosophie de la théologie : pour eux, la raison, qui, chez les Augustiniens, était un intermédiaire et " comme une illumination d'ordre inférieur » (p. 305), n’est pas orientée vers les choses spirituelles : elle n’a, en principe, que la nature - nature physique, nature morale, nature sociale - pour domaine. Sans doute, Saint Thomas croit que l'homme, par sa raison, peut remonter jusqu'à Dieu; et il énumère cinq " voies » qui mènent à lui ; mais il y a un amour naturel et un amour surnaturel de Dieu. Il y a une surnature, - celle que la foi exprime et que l'Église représente; et la philosophie reste "servante de la théologie », en ce sens que, si une vérité de la raison était contraire à une vérité de la foi, c’est celle-ci qui serait la vérité vraie.

Albert le Grand et Saint Thomas se sont opposés à la fois aux théologiens qui niaient la philosophie d'Aristote en faveur de la théologie et aux averroïstes qui niaient la théologie en faveur de la philosophie (p. 339). Ces derniers sont condamnés en 1270. Mais, en 1277, les efforts des maîtres séculiers de l'Université de Paris font condamner 219 propositions « qui portaient indistinctement sur la doctrine péripatéticienne, en général, et la doctrine averroïste, en particulier » (p. $342)^{36}$.

Ce vivant XIII ${ }^{\mathrm{e}}$ siècle voit, tout ensemble, un essor de la pensée qui comporte toutes les hardiesses, et un réveil de christianisme intérieur auquel répondent les ordres mendiants et les sectes. La fin en est rem-

Pp. 280, 281, 284, 293.

36 Sur Siger de Brabant, voir pp. 336 et suiv. ; Delacroix, art. cité, p. 117 ; LANGLOIS, dans l'ouvrage cité, pp. 51-103, notamment pp. 62, 86, 91. 
plie par des luttes entre Franciscains et séculiers augustiniens, d'une part, Dominicains et séculiers thomistes, d'autre part, — ces derniers plus ou moins soutenus par la papauté. Des conceptions de toutes sortes se confrontent ou s'affrontent. L'œuvre de Roger Bacon est un curieux mélange d'empirisme et de mysticisme ; celle de Raymond Lulle est un approfondissement ${ }_{\mathrm{pxv}}$ de la dialectique. L'un et l'autre sont préoccupés surtout d'expansion de la foi, d'organisation de la terre par l'Occident chrétien. L'un compte sur la science expérimentale pour consolider la théocratie: malgré des réminiscences des sciences occultes, il est un précurseur de son homonyme François, et aussi, comme le remarque Bréhier, d'un Jules Verne ${ }^{37}$. L'autre, en dehors du courant des sciences de la nature, conçoit un art d'invention et de découverte qui contienne les principes de toutes les sciences particulières (p. 373).

En ces temps de fermentation intense, dans ces années où « les maîtres ès arts de Paris furent à la fois le plus dangereusement hardis en innovations de toutes sortes: athéismes, immoralités, astrologie, déterminisme, scientisme, panthéismes, etc., et le plus durement traqués par les autorités de l'Église ", dans celle même rue Saint-Jacques où Saint Thomas écrivait sa Somme contre les Gentils, un clerc, libre d'esprit, Jean de Meung, donnait une suite au Roman de la Rose : véritable Somme, à la fois croyante et frondeuse, scolastique et poétique, où une philosophie de la Nature et de la Raison s'enveloppait d'un christianisme, — sans doute sincère, quoique illogique :

$$
\text { Rien n’a pouvoir contre raison }{ }^{38} \text {. }
$$$$
* * *
$$

Le $\mathrm{XIV}^{\mathrm{e}}$ siècle est le siècle de l'argumentation dialectique cultivée pour elle-même, le siècle du pour et du contre, le siècle des thèses subversives que l'on introduit " en vue de la discussion ", " que l'on approuve secrètement, mais que l'on est d'ailleurs prêt à révoquer » (p. 376). La raison, qui pxvi $\mathrm{y}$ règne, n'est pas seulement raisonnante, comme on l'a cru longtemps, elle est aussi critique, et par là même constructive.

P. 370. Voir le t. XLVI.

38 Voir M. GoRCE, Le Roman de la Rose, notamment pp. 44, 52, 67, 209. 
Chez Duns Scot, chez Guillaume d'Occam, «la foi et la raison tendent à s'isoler chacune en sa sphère "; « la science de Dieu et la science de la nature pourraient suivre des voies si différentes qu'elles n’arriveraient jamais à rencontrer la même vérité ; il n’y a entre elles ni pénétration comme le rêvait Saint Anselme, ni hiérarchie comme le pensait Saint Thomas ${ }^{39}$.

L'aristotélisme thomiste avait introduit l'idée d'une nature à laquelle une métaphysique donne sa fixité : le nominalisme occamiste abattait toute superstructure métaphysique, pour limiter la connaissance humaine à l'intuition et à la contingence. Dans l'universel, il voit non une réalité, mais une production spontanée de l'esprit ; l'ordre de l'univers n'existe pas dans les choses, mais dans l'esprit. Une physique nouvelle s'oppose à celle d'Aristote, qui ruine la preuve cosmologique de l'existence de Dieu. « Le chrétien est certain, par la Bible, que Dieu a créé le ciel et la terre ; mais la création n’est aucunement démontrable. » Le " rasoir » d'Occam fait des ravages dans la scolastique, et toute une pléiade d'occamistes — moines et maîtres de la Faculté des Arts - séparent radicalement, à sa suite, la philosophie et la théologie. Plus de théologie philosophique ; foi, d'une part, empirisme, de l'autre, ou scepticisme : on collectionne les cas d'intuitions sans réalité, rêves, hallucinations, — collection qui, des anciens sceptiques, passera à Montaigne et à Descartes ${ }^{40}$.

pxvii Cette conception nouvelle de la nature mène à la physique ; cette conception nouvelle de la foi peut mener jusqu'au mysticisme panthéiste. Eckart a poussé à la rigueur une tendance commune à tous les néoplatoniciens ; l'Être est identique à Dieu, et il n'y a de connaissance qu'en Dieu ${ }^{41}$.

$$
* * *
$$

\section{Pp. 378, 396.}

40 Pp. 397, 401, 411, 414, 417. - Avec H. Delacroix, pp. 101-102, nous croyons qu'il faut distinguer philosophie seolastique et philosophie médiévale, la première étant celle « où le dogme chrétien s'assimile la philosophie antique, où l'esprit chrétien opère la synthèse de ces deux données ", la seconde, celle où l'esprit philosophique cherche son indépendance.

41 P. 430 ; DelacroiX, art. cité, p. 122, et Le Mysticisme spéculatif en Allema-

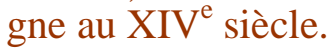


La longue période qu'embrasse ce volume a vu se produire l'effort le plus considérable pour réaliser l'unité à la fois religieuse et politique de la chrétienté ${ }^{42}$. On parlera ailleurs des conflits entre la papauté et l'Empire ${ }^{43}$. Le pouvoir temporel a lutté pour n'être pas absorbé par la théocratie, comme la raison pour n'être pas étouffée par la tradition religieuse.

Cette tradition soulevait, la ratiocination multipliait, des problèmes, - dont les uns étaient vains, et les autres prématurés : nature de Dieu et des anges, rapports de l'existence et de l'essence, de la matière et de la forme, de l'âme et du corps, de Dieu et des êtres, portée de la connaissance. A côté des chantiers gothiques, il y eut des chantiers dialectiques où s'érigèrent des cathédrales de raisonnements. Et les bâtisseurs intellectuels, dans tout l'Occident, circulaient d'un monastère, d'une école à l'autre, — tantôt admirés, applaudis, tantôt persécutés, condamnés. De cette prodigieuse activité, qui voulait consolider la tradition, et dont l'œuvre était vouée à l'écroulement, quelque chose d'efficace devait résulter : le progrès de l'instrument intellectuel et surtout de la réflexion sur la nature de cet instrument.

Ce que j'ai essayé, ici, de rendre, c'est le mouvement, si pxviii passionnant à suivre, et à la longue libérateur, de la pensée médiévale. De cette pensée on trouvera le riche détail lumineusement exposé dans le présent volume.

«L'histoire de la philosophie médiévale, disait Henri Delacroix en 1902, est en somme toute récente et ne s'est franchement développée que dans les trente dernières années ${ }^{44}$. " Dans les trente-cinq années qui se sont écoulées depuis cette date, beaucoup de textes ont été publiés : rien d'essentiel ne fait défaut. D’importants travaux ont paru, notamment ceux de Gilson, du P. Mandonnel, de Grabmann, de Mi-

\footnotetext{
Voir pp. 1, 107-108, 121, 204-205, 255, 359-360.

T. XXXIX.

Art. cité, p. 98.
} 


\section{Émile Bréhier \\ La philosophie du Moyen âge}

chalski. Émile Bréhier avait tous les éléments nécessaires pour établir sa vigoureuse synthèse ; et, historien averti de la philosophie générale, il a pu situer la pensée médiévale dans l'évolution de l’esprit humain.

HENRI BERR.

$\underline{\text { Table des matières }}$ 
Émile Bréhier

La philosophie du Moyen âge

\title{
LA PHILOSOPHIE
}

\author{
DU
}

MOYEN ÂGE 


\section{INTRODUCTION}

Le Moyen Age est l'époque, à limites assez indéterminées, qui s'écoule entre la dissolution de l'Empire d'Occident et la formation des États modernes ${ }^{45}$. Cet intervalle de temps, qui va du $\mathrm{VI}^{\mathrm{e}}$ siècle environ jusqu'à la Réforme, a vu naître des efforts considérables pour réaliser l'unité politique et religieuse de l'Occident : empire de Charlemagne, saint empire romain germanique, papauté, union de tous les peuples chrétiens dans les expéditions des croisades, telles en sont les grandes manifestations.

Au point de vue de l'histoire des idées, les limites du Moyen Age sont assez bien marquées par la circonstance suivante : c'est l'époque où, en Occident tout au moins, toute l'initiative intellectuelle revient à l'Église ; seule héritière des anciennes écoles, elle enseigne, autant que cela lui paraît exigé ou permis par sa fin surnaturelle, la philosophie et les sciences dans les monastères, les écoles-cathédrales et les universités. Le Moyen Age commence au $\mathrm{VI}^{\mathrm{e}}$ siècle, après les grandes synthèses néo-platoniciennes ${ }_{\text {p002 }}$ orientales des païens Plotin, Proclus et Damascius et du chrétien Denys l'Aréopagite, et après la grande synthèse occidentale de saint Augustin. Il se termine au $\mathrm{XV}^{\mathrm{e}}$ siècle par une transformation de la culture où l'Église ne joue plus le rôle essentiel ${ }^{46}$.

Longtemps négligée, l'histoire intellectuelle du Moyen Age, n’a commencé à attirer l'attention que bien après l'histoire politique. De-

45 Cf. G.-L. BuRR, XXXIII : le mot paraît avoir été employé pour la première fois en 1469.

46 Il serait hors de propos d'indiquer dès maintenant les traits généraux de la pensée médiévale ; ils ressortiront peu à peu ; l'on trouvera la meilleure perspective pour les saisir d'ensemble, au chapitre II de la troisième partie. 
puis une trentaine d'années, les travaux qui lui sont consacrés sont considérables ; la publication des Beiträge zur Geschichte der Philosophie des Mittelalters par Bauemker en Allemagne, l'impulsion donnée en France par les admirables travaux de M. Gilson, marquent la vitalité de ces études, qui reposent sur une documentation qui s’enrichit tous les jours de textes inédits.

Les débuts sont difficiles : le latin se corrompt et disparaît comme langue vulgaire au $\mathrm{VI}^{\mathrm{e}}$ siècle ; les parlers qui naissent de lui ne sont pas employés comme langue écrite (cette répugnance du savant pour la langue vulgaire durera jusqu'au $\mathrm{XVI}^{\mathrm{e}}$ siècle) ; la production intellectuelle n'a pu se rétablir avant que le latin fût de nouveau appris dans les écoles comme une langue morte : ce qui n'eut lieu que sous Charlemagne.

Vers le $\mathrm{XI}^{\mathrm{e}}$ siècle encore, les chances d'avenir de l'Occident auraient peut-être paru petites à qui l'aurait mis en regard avec l'éclatante civilisation de l'Islam. « Avec leurs palais, leurs cités, leurs bains publics, les cités (de l'Espagne islamique) ressemblaient plus aux villes de l'empire romain qu'aux misérables groupes de bicoques de bois qui, en France et en Germanie, s'élevaient à l'abri de quelque abbaye ou de quelque forteresse féodale »; l'Islam débordait alors l'Occident jusqu'en Portugal et en Sicile ; aussi bien « ce p003 ne fut pas avant le XIII ${ }^{\mathrm{e}}$ siècle, ce ne fut qu'après le temps des croisades et après la grande catastrophe des invasions mongoles que la civilisation de la chrétienté occidentale commença d'atteindre une position de relative égalité avec l'Islam. Au XV $\mathrm{X}^{\mathrm{e}}$ siècle seulement, avec la Renaissance et la grande expansion maritime des États européens, l'Occident chrétien devait réussir à s'assurer cette primauté de civilisation que nous considérons aujourd'hui comme une sorte de loi de nature » ${ }^{47}$. Pourtant, dès l'abord, l'Occident présente un trait bien particulier ; tandis que, en pays d'Orient, toute l'activité intellectuelle, dès la fin de l'antiquité, chez les païens comme chez les chrétiens, semble avoir été accaparée par la science des choses divines, en Occident, il en est tout autrement ; un mince filet coule de connaissances positives qui, par leur nature et leur essence, échappent à la vie religieuse : ce sont d'abord les sept arts libéraux : grammaire, rhétorique, dialectique,

47 Christopher Dawson, XXXIV p. 176-177. 
arithmétique, géométrie, astronomie, musique ; c'est l'ensemble des connaissances géographiques et naturelles qui sont ramassées dans un ouvrage tel que celui de Pline l'Ancien ; c'est une morale rationnelle, telle qu'on la trouve dans le traité Des Devoirs de Cicéron, dans les œuvres de Sénèque, dans la Pharsale de Lucain, dans la Consolation de la Philosophie de Boèce : grâce à toutes ces œuvres, une certaine atmosphère humaniste se maintient, qui est propre à la latinité, et qui amènera la floraison du XII ${ }^{\mathrm{e}}$ siècle. Il y a là une tradition purement occidentale, dont il faut souligner l'importance : elle se rattache à l'érudition romaine. Rome n'a pas engendré la science, mais elle a eu sa manière à elle de recevoir et de maintenir la science des Grecs : dès que l'hellénisme s'étend au $\mathrm{I}^{\mathrm{er}}$ siècle avant Jésus-Christ, on trouve des hommes pour y faire ce qui était le plus nécessaire à leurs concitoyens qui ne possédaient pas la tradition des études, c'est-à-dire des p004 Ouvrages d'ensemble, des résumés, des collections ; Varron et Cicéron sont en tête de ce mouvement d'érudits : Varron avec ses Antiquités romaines et les œuvres où il résumait la science grecque, Cicéron avec ses exposés de la philosophie des Stoïciens, des Épicuriens et des Académiciens ; plus tard vient l'Histoire naturelle de Pline l'Ancien, la vaste collection de cosmologie, de géographie, de zoologie, de botanique, de pharmacologie, de minéralogie, où il entasse toutes ses notes de lecture, le meilleur comme le pire. Ces auteurs furent, directement ou indirectement, les maîtres des sciences profanes en Occident.

L'autorité de saint Augustin fit sans doute beaucoup pour maintenir cette tradition érudite : on ne trouverait nul autre père de l'Église dont les œuvres contiennent des traités philosophiques comme le Contra Academicos ou le De Ordine, des manuels d'arts libéraux comme le De Musica, enfin de copieux extraits ou résumés des Antiquités romaines de Varron, surtout dans la Cité de Dieu.

Les fameuses Noces de Mercure et de la Philologie, de Marcianus Capella, suivent aussi les traces de l'érudition romaine : le prologue, écrit dans un style alambiqué, expose avec un parfait sérieux une mythologie ; l'auteur paraît avoir oublié qu'il est chrétien ; il l'expose pourtant en pur littérateur, sans y attacher la moindre croyance et 
avec, parfois, une précision de détails qui sent la recherche érudite ${ }^{48}$ : c'est Varron qu'il a mis ici à contribution ; pour les sept traités qui suivent, c'est encore Varron qui a la plus grande part dans les livres sur la Grammaire, la Dialectique, l'Arithmétique et l'Astronomie, tandis que les autres viennent d'autres érudits romains, la Rhétorique, d'Aquila, la Musique, d'Aristide p005 Quintilien, la Géométrie (qui contient, au début, une description de la terre), de Pline et de Solinus.

Le livre IV, sur la Dialectique, résume le contenu des premiers ouvrages de l'Organon d'Aristote jusqu'au premier livre des Premiers Analytiques ; mais il ajoute, sur le syllogisme conditionnel, des considérations qui dérivent de la logique stoïcienne ${ }^{49}$. Sa géométrie est en même temps une géographie élémentaire; son astronomie contient quelques traces d'héliocentrisme (le soleil tourne autour de la terre, mais Vénus et Mercure tournent autour du soleil) ; mais sa représentation du monde est bien plus fidèle à l'hellénisme que celle du moine syrien Cosmas Indicopleustes, qui, à l'autre bout du monde chrétien, opposait à l'image grecque de l'univers une terre oblongue, sans antipodes, liée par ses extrémités aux extrémités du ciel ${ }^{50}$.

48 Cette forme littéraire est celle de la Satyre de Varron avec son mélange de prose et de vers ; chacun des sept arts y est décrit sous la forme d'une Vierge avec les attributs qui lui conviennent: ces personnifications, qui viennent peut-être de Varron, sont celles qui se retrouveront sculptées sur le portail des cathédrales.

49 Avec quelques modifications comp. DiogènE, Vie des philosophes liv. VII, § 79, avec CAPELLA, § 420.

50 Migne, V, t. LXXXVIII, 79-d. 


\title{
PREMIÈRE PARTIE
}

\section{Sommeil de la philosophie $\mathrm{VI}^{\mathrm{e}}$-VIII ${ }^{\mathrm{e}}$ siècles}

Table des matières

\author{
Chapitre premier
}

\section{LA PHILOSOPHIE EN OCCIDENT}

I.

BOECE.

Le Moyen Age, en Occident, a eu pour condition des œuvres telles que celles de Marcianus Capella, qui n'appartiennent pas au Moyen Age proprement dit, mais qui, héritières directes de la pensée philosophique grecque et latine, constituent comme des réserves où viendront s'approvisionner, à mesure qu'ils en deviendront capables, les hommes qui cherchent à maintenir la culture. Parmi elles et au premier plan est l'œuvre de Boèce, à la fois logique, théologique et morale.

Anicius Manlius Severinus Boetius, un Romain d'illustre famille, né en 480, fut consul en 510 et eut d'abord la complète confiance de Théodoric ; accusé de complot et de magie, il fut exécuté en 525. Il faut voir, dans l'œuvre de Boèce, bien plutôt qu'une continuation, une renaissance des études poos philosophiques en Occident, renaissance dont pourtant la pensée occidentale ne tira que peu de fruits immé- 
diats, d'abord à cause de l'interruption tragique de la carrière de Boèce, qui n'eut pas le temps d'accomplir tous ses projets, puis à cause des guerres qui, au milieu du $\mathrm{VI}^{\mathrm{e}}$ siècle, mirent fin à toute civilisation en Italie.

Mais, même à son époque, Boèce fut dans des conditions exceptionnellement favorables; il reçut la culture grecque la plus complète que l'on pût alors avoir, à l'école d'Athènes, où, sans doute sous la direction d'Isidore, qui, après Marinus, le successeur de Proclus, était diadoque, au début du $\mathrm{VI}^{\mathrm{e}}$ siècle, l'on enseignait à lire et à commenter Platon et Aristote, peut-être aussi Épictète ${ }^{51}$, et où l'on apprenait également les quatre sciences élémentaires, arithmétique, géométrie, astronomie, musique, indispensables à la lecture de Platon.

Boèce rêva certainement de transmettre aux Latins toute cette culture sous la forme où elle apparaissait aux derniers élèves de l'école d'Athènes: le but était de montrer l'accord doctrinal de Platon et d'Aristote, au moyen de commentaires méticuleux de chacun de leurs ouvrages suivant le texte phrase à phrase, reproduisant et discutant les opinions des précédents commentateurs ${ }^{52}$. On commençait par Aristote, qui traitait surtout du monde matériel et sensible, pour finir par Platon, qui conduisait aux plus hautes réalités intelligibles. « Aristote, écrivait Simplicius, va, par les choses physiques, vers celles qui sont au-dessus de la nature ; il considère celles-ci dans le rapport qu'elles ont avec celles-là, tandis que Platon considère les choses naturelles en tant qu'elles participent à celles qui sont au-dessus de la nature. » On allait ${ }_{\text {p009 }}$ d'ailleurs, dans les ouvrages, du plus facile au plus difficile, commençant par les ouvrages logiques d'Aristote et finissant par le Parménide de Platon. On faisait précéder l'étude de l'Organon de celle de l'Introduction de Porphyre, pour continuer par les Catégories, le traité De l'interprétation, les Topiques, les Premiers et Seconds Analytiques, les Réfutations des Sophistes : tâche si lourde que l'on devait en rester souvent au début; il faut ajouter que l'on rédigeait deux sortes de commentaires, l'un plus simple pour les débutants, l’autre plus compliqué.

51 Simplicius, le grand commentateur d'Aristote, que Boèce connut peut-être à Athènes, est l'auteur d'un commentaire du Manuel d'Épictète.

52 Simplicius, par exemple, utilise douze commentaires des Catégories. 
Boèce annonce formellement ${ }^{53}$ son intention de suivre ce plan en traduisant tout Aristote, tout Platon et en montrant l'accord de leurs doctrines. En fait, il n'a pas été plus loin que l'Organon: il est d'abord parti de la traduction latine, faite par Marius Victorinus, de l'Isagoge de Porphyre, et il a expliqué et critiqué cette traduction. Puis, il a lui-même traduit et commenté l'Isagoge ; de chacun des deux traités, des Catégories et De l'Interprétation, il a fait un double commentaire, l'un pour le débutant, l'autre plus long (le long commentaire des Catégories est perdu). Enfin il a traduit les Analytiques, les Topiques et les Réfutations des Sophistes (ces traductions sont perdues), et il a écrit des traités Sur les syllogismes hypothétiques, Sur les syllogismes catégoriques, Sur la division, Sur la définition, Sur les différences topiques, avec un commentaire des Topiques de Cicéron.

Boèce montre peu d'originalité dans ses commentaires ; il se sert beaucoup de Marius Victorinus et de Porphyre, à qui son premier commentaire des Catégories est presque tout emprunté ${ }^{54}$; il se soucie fort peu d'arriver à une interprétation cohérente de l'œuvre, et il veut surtout faire connaître les opinions diverses ; c'est ainsi que, au début du commentaire court, il annonce qu'il se propose d'écrire pour les savants un autre p010 commentaire où il exposera une opinion différente de son opinion actuelle (qui est celle de Porphyre) sur le but, l'utilité et l'ordre du traité.

Les traités de Boèce, avec le traité De l'Interprétation d'Apulée et le livre de Marcianus Capella, ont été, jusqu'au XII ${ }^{\mathrm{e}}$ siècle, la source, en Occident, de la connaissance de la logique grecque : autant du moins que le Moyen Age put les recevoir, car, écrit M. Van de Vyver, et c'est une remarque d'une portée très générale, « on a négligé de constater que les œuvres latines héritées par le Haut Moyen Age ne furent que lentement remises en circulation, selon ses aptitudes progressives à les comprendre ${ }^{55}$ ». Les traités logiques de Boèce ont été en fait fort longtemps abandonnés.

\footnotetext{
De Interpretatione.

J. BIDEZ, XXXVI, p. 189-201.

Les Étapes du développement philosophique du Haut Moyen Age (Revue belge de philologie et d'histoire, t. VIII, 1929, p. 426). Ce n'est qu'an $\mathrm{X}^{\mathrm{e}}$ siècle qu'on recommence à utiliser, et fort incomplètement, les œuvres de Boèce.
} 
Les opuscules théologiques de Boèce sont étroitement liés à son œuvre logique; il se demande, par exemple, si les catégories s'appliquent à Dieu, si l'on peut dire de lui, au même sens que des choses sensibles, qu'il est une substance et qu'il a des attributs ${ }^{56}$, en quelle catégorie doivent rentrer les trois Personnes. C'est par des recherches de ce genre qu'il prétend « joindre la foi et la raison », c'està-dire, en somme, découvrir le statut logique des propositions que la foi nous enseigne sur Dieu ${ }^{57}$.

Les nombreux ouvrages que les moralistes anciens ont écrits sous le nom de Consolations s'adressent aux parents d'un mort et sont destinés à adoucir la douleur d'un deuil récent. La Consolation de la Philosophie de Boèce est assez différente : jeté en prison, attendant la mort, passé du faîte des honneurs à l'extrême misère, Boèce cherche à se démontrer à lui-même que le changement de fortune n'atteint pas la véritable félicité. p011 C'est là un thème familier à la diatribe grécoromaine, et c'est en effet à ce genre littéraire qu'appartient l'œuvre de Boèce ; on y voit la Philosophie personnifiée user, comme médecin des âmes, des réprimandes familières à la diatribe, rappeler, comme elle, l'exemple des anciens philosophes ${ }^{58}$; on y trouve cette alternance de vers et de prose, dont le modèle est dans les satires de Varron, elles-mêmes très proches parentes de la diatribe du cynique Menippe ${ }^{59}$; le style, brillant et imagé, est bien aussi celui de ces allocutions morales, si différentes à la fois du traité moral et du sermon.

Pourtant, avec la théodicée complexe qui en fait le fond, la Consolation dépasse de beaucoup le thème des diatribes : c'est qu'il faut $\mathrm{y}$ distinguer deux parties, les deux premiers livres et les trois derniers. Cette distinction correspond aux préceptes de direction morale que donne le stoïcisme: dans la thérapeutique des passions, Chrysippe conseille de ne pas entreprendre la guérison au fort de la passion, mais d'attendre qu'elle soit calmée. Se conformant à cette règle, Philosophia, devant la douleur et le chagrin de Boèce, remet d'abord à plus

\footnotetext{
56 Cf. De Unitate Trinitatis, ch. IV ; P. L., t. LXIV, 1252-b. Comparer Plotin, Ennéade VI, 1, 2.

Ibid., fin.

Livre I, ch. III.

59 Cf. A. Oltramare, XL, p. 97-110, et Klingner, XXXVIII.
} 
tard le remède efficace : « Puisqu'il n'est pas encore temps d'user des remèdes les plus forts et que, naturellement, l'esprit, en rejetant les opinions vraies, accueille des erreurs, dont naît l'obscurité des passions qui brouille l'intelligence, je tenterai de diminuer peu à peu cette obscurité, pour que, les ténèbres des passions trompeuses dissipées, tu puisses connaître l'éclat de la vraie lumière ${ }^{60}$. "

Dans cette cure à deux étapes, le livre II contient les thèmes ordinaires de la diatribe qui sont les « remèdes moins forts ", c'est-à-dire les raisons de se résigner à la Fortune.

Viennent maintenant les «remèdes plus violents ». Philosophia, qui reprend la parole, prétend conduire au vrai ${ }_{\text {p } 012}$ bonheur ${ }^{61}$ en faisant retrouver à l'âme sa patrie perdue ${ }^{62}$; ce qu'elle propose, c'est un itinéraire vers Dieu. Le livre II contenait une apologie de la Fortune par elle-même ; il va être démontré maintenant (c'est la conclusion du livre IV) qu'il n'y a pas du tout de fortune, mais, partout, l'universelle Providence; l'âme n'a donc pas à se retrancher en elle-même pour échapper aux coups du sort, mais à avoir, en tout cas, confiance en Dieu.

L’idéal philosophique de Boèce, c'est l'idéal philosophique du vrai bien qui rend l'homme indépendant, en lui donnant la véritable puissance, la véritable gloire et là véritable joie. Selon lui, l'aspiration même vers ce Bien démontre qu'il existe ; car « tout ce que l'on appelle imparfait n'existe que par la diminution du parfait ${ }^{63}$ ". Ainsi est posé Dieu, le Souverain Bien, l'Un auquel aspirent tous les êtres. Les bienheureux qui ont atteint leur fin par la vertu ont pour récompense de « devenir des dieux ».

Vainement opposera-t-on à l'existence d'une souveraine et parfaite providence l'existence du mal ; Boèce répond avec toute la théodicée stoïcienne ${ }^{64}$ : le mal physique a un rôle providentiel ; il éprouve les

Livre I, ch. VI.

Liv. III, ch. I, 1. 14, édit. Gothein.

Liv. III, ch. XII, 1. 23 ; IV, ch. I, l. 30 ; V, ch. I, l. 7.

Livre III, ch. X, début.

64 Bien que, contrairement au stoïcisme et comme Proclus (De Providentia Opera inedita, édit. Cousin, 1864, p. 157, 1. 34), il subordonne le destin à la Providence. 
bons et il corrige les méchants ; le mal devient un bien quand on sait en user comme il faut. Mais pour concilier cette universelle Providence ou Prescience avec la liberté humaine, il use plutôt des arguments platoniciens : la difficulté du problème de la liberté naît de ce que nous concevons la connaissance divine sur le modèle de la connaissance humaine ; mais « élevons-nous, si nous pouvons, au sommet de l'Intelligence suprême ; la raison y verra ce qu'elle ne peut pas voir en elle, à savoir de ${ }_{\text {p013 }}$ quelle manière il y a, en cette Intelligence, une connaissance certaine et définie des choses qui n'ont pas une issue certaine, non pas une opinion, mais la simplicité d'une science suprême qui n'est enfermée dans aucune borne ${ }^{65}$ ". Tout est présent à Dieu d'une présence intemporelle. Ainsi sont levés les derniers obstacles qui s’opposaient à l'universalité de la Providence divine.

La Consolation de la Philosophie ne présente aucune discordance positive avec le christianisme ${ }^{66}$, mais elle ne développe en fait que des thèmes stoïco-platoniciens. Il est sans doute surprenant pour nous de voir ce chrétien, au moment de mourir, chercher des consolations dans la philosophie et non pas dans sa foi. Car, plus qu'au rapport personnel de l'âme à Dieu dans le Jugement, il songe à cette éternelle nature qui, à chaque moment du temps, assure son véritable bonheur. Faut-il dire que la Consolation est une œuvre conventionnelle, qui n'exprime pas sa dernière pensée, et que Boèce ne fait que suivre un usage ${ }^{67}$ ? Il est plus vraisemblable que cet élève de l'école néoplatonicienne d'Athènes trouvait ici une direction morale que l'on ne voit pas qu'il ait trouvée ni même cherchée dans le christianisme, si l'on en juge par le caractère purement formel de ses écrits théologiques ${ }^{68}$. Quoi qu'il en soit, la Consolation, lue et imitée surtout à partir du $\mathrm{XI}^{\mathrm{e}}$ siècle, fit connaître à l'Occident tout un aspect de la pensée antique.

Livre V, ch. VI, 1. 41-46.

66 A l'exception de la négation du commencement du monde dans le temps (V, 6, 1. 25).

67 Cf. R. CARTOn, XXXVII.

68 Comme le fait remarquer R. BonNAud (L'Éducation scientifique de Boèce, Speculum, vol. IV, 1929, p. 201), Boèce n’a écrit ses traités que sur des sujets de dogme catholique touchant de près au néoplatonisme. 
Le rationalisme humaniste des Anciens persiste ailleurs dans une morale qui, si elle n'est pas en désaccord avec la croyance chrétienne, est indépendante de son inspiration.

p014 Cette morale est enseignée dans les cloîtres espagnols, un des derniers refuges de la culture au $\mathrm{VI}^{\mathrm{e}}$ siècle. Martin, fondateur du monastère de Dume, et évêque de Braga en 561, à la suite de la conversion au catholicisme du roi arien Théodomir, est l'auteur d'un assez grand nombre de traités moraux inspirés de Cicéron et de Sénèque. L'on trouve chez lui les deux types d'ouvrages moraux qui se rencontrent pendant tout le Moyen Age : d'une part, le traité des Vertus, inspiré du De Officiis de Cicéron et de celui de saint Ambroise ; d'autre part, une collection de Sentences, plus ou moins inspirées, par la forme et par le fond, des Sentences de Sextius le Pythagoricien, traduites en latin par Rufin. Au premier type appartient la Formula vitae honestae, qui traite successivement de la prudence, de la magnanimité, de la continence et de la justice : c'est là l'objet du De Officiis de Cicéron au livre I jusqu'au chapitre XXVI ; il est facile de retrouver ses formules, par exemple, dans le chapitre sur la justice ${ }^{69}$; l'ouvrage se termine, comme le livre de Cicéron à partir du chapitre XXVII, par l'étude de la " mesure » caractéristique des diverses vertus; il y donne les définitions aristotéliciennes des vertus comme justes milieux, mais en l'appliquant non seulement, comme Aristote, aux vertus dites morales (le courage milieu entre la timidité et l'audace, la continence milieu entre le luxe et l'avarice), mais à des vertus comme la prudence (juste milieu entre la sottise et la subtilité) ou la justice (milieu entre l'indulgence et la dureté), qui, chez Aristote, n'admettent point de pareilles définitions.

Au second type, celui des Sentences, appartient le De Moribus, collection d'aphorismes, dont certains sont du ton pessimiste des cyniques : "Quid homini est inimicissimum ? Homo. Patria tua est ubicumque bene es. » Un petit traité de Martin de Braga, que l'on trouve dans les œuvres d'Hildebert de Lavardin ${ }^{70}$, p015 le De Remediis fortuitis liber, contient des aphorismes de ton stoïcien présentés sous la

69 Correspondant à De Officiis, I, ch. VII : omnibus prodesse, nulli nocere nocentes prohibere.

70 VI, t. CLXI, 1028-1031. 
forme d'un dialogue entre le Sens et la Raison. «Tu mourras, dit le Sens. C'est la nature de l'homme, et non un châtiment, répond la Raison ; je ne suis entré qu'à condition de sortir » ; il cite ensuite Juvénal et Lucain.

Ainsi, comme saint Nil conserve Épictète en Orient, Martin de Braga en Occident garde quelque chose de cette sagesse qui, à la fin de l'antiquité païenne, s'exprime en sentences et se condense dans les vers des poètes latins.

Table des matières

II.

UNE POLEMIQUE ANTIAUguSTINIENNE AUX $\mathbf{V}^{\mathrm{E}}$ ET VI ${ }^{\mathrm{E}}$ SIECLES.

Saint Augustin a été incontestablement le grand maître de l'Occident Chrétien ; mais il est important de savoir que sa pensée ne s'établit pas sans résistance et qu'on lui opposa, vers l'époque de Boèce ou un peu avant, des traditions encore vivantes en Orient.

La théorie augustinienne de la grâce ne fut pas acceptée uniformément ; dans le sud de la Gaule se trouvaient des monastères restés en liaison étroite avec les moines orientaux, et l'on sait quelle place leur ascétisme, comme celui des Cappadociens, laisse à la maîtrise de soi et à la liberté. Cassien, l'abbé de Saint-Victor de Marseille, mort en 448, qui avait séjourné dans les monastères d’Égypte et de Palestine, y avait reçu, sur «la philosophie chrétienne " ${ }^{71}$, des enseignements bien différents de ceux de saint Augustin; il y avait appris ${ }^{72}$ que l'intellect donné à l'homme par la nature suffit à saisir dans leur lettre et à avoir à sa disposition les préceptes ${ }_{\text {p016 }}$ de la Loi ; mais, pour la saisir plus pleinement et pour la comprendre d'une manière spirituelle, il fallait une illumination particulière dont Dieu éclairât l'intelligence. D’une manière générale, il est dans la tradition orientale de concevoir Dieu comme achevant ou consommant ce qui a été commencé par la nature : c'est ce que pense Cassien : " Grâce au bien naturel, qui nous a été concédé par Dieu, peuvent parfois se produire des commencements qui pourtant, s'ils ne sont pas dirigés par Dieu, ne peuvent arri-

71 L'expression se trouve Collationes, IV, ch. I, VI, t. XLIX, col. 583-c.

72 Ibid., III, ch. XV, col. 576-d. 
ver à la consommation des vertus ${ }^{73}$. " La grâce attend en quelque sorte notre initiative. Cassien fut suivi dans un grand nombre de monastères du Sud de la Gaule ${ }^{74}$; saint Vincent de Lérins, en 432, prenant l'offensive, veut montrer que la thèse augustinienne, arrivant à faire de Dieu l'auteur du mal et de la damnation, rend impossible la théodicée édifiée par la philosophie et la théologie grecques. Un autre abbé de Lérins, Faustus, devenu évêque de Riez en 452, reprend des idées analogues sur le pouvoir, en Dieu, de consommer la nature : « Le créateur de l'homme lui a laissé l'usage de la bonne volonté, mais il s'est réservé l'effet ${ }^{75}$. »

En même temps que sa notion de la grâce, c'est tout le platonisme spiritualiste de saint Augustin que l'on rejette : Augustin avait affirmé que l'âme était incorporelle, et il avait déclaré insoluble à l'esprit humain la question de son origine : les «semipélagiens » affirment que l'âme est corporelle, et ils assurent que chaque âme a été créée par Dieu. Traités pour et contre se succèdent pendant près d'un siècle. L'important, dans ce débat, c'est la nature des autorités sur lesquelles s'appuient les deux partis : pour les Gaulois, seule compte la tradition des saints ; ils sont hostiles aux philosophes antiques; les Augustiniens relèvent au contraire la valeur des arguments p017 des philosophes. Faustus de Riez, le semipélagien, écrit à un prêtre qui lui avait demandé «quelles choses dans l'homme doivent être jugées corporelles, et quelles incorporelles ${ }^{76}{ }^{\prime}$. Selon l'opinion des saints, lui répond-il, et en particulier de saint Jérôme, rien n'est incorporel que Dieu ; " les âmes ont un corps par lequel elles subsistent, bien que ce corps soit incomparablement plus subtil que les nôtres ». On peut d'ailleurs le démontrer : l'âme a un corps, puisqu'elle est dans un lieu, et elle est dans un lieu, puisqu'elle est insérée dans nos membres et liée à nos entrailles. Opposera-t-on la mémoire et l'imagination qui paraissent en effet (c'est l'argument des Augustiniens) transporter l'âme au dehors de son prétendu lieu ? Il faut répondre que, dans la pensée, l'âme n'a affaire qu'à « des mouvements intérieurs à elle-

\footnotetext{
73 Collat., VI, t. XLIX col. 920.

74 Cf. deux lettres de saint Prosper et de saint Hilaire adressées à ca sujet à saint Augustin (lettres 225 et 226 dans la collection des Lettres augustiniennes).

75 De gratia, I, 9 (VI, t. LVII1).

76 VI, t. LVIII, 840-d.
} 
même »; " quand je pense à vous, c'est par l'affection de mon cœur, ce n'est pas par la réalité de ma substance que j'arrive jusqu'à vous ». Au surplus (et l'on voit ici le lien étroit avec la discussion précédente sur la grâce), la thèse de l'incorporéité aurait pour résultat de confondre l'âme avec Dieu : "Si elle n'est pas contenue dans un lieu, elle se répand partout, emplit tout, est partout présente ; créature, elle s'unit à son créateur ; sa fragilité se joint à son auteur, et l'on doit voir en elle non une chose de Dieu, mais une partie de Dieu ${ }^{77}$. »

Claudien Mamert (mort vers 474), dans son De Statu animae, proteste contre cette manière de traiter les philosophes; saint Paul luimême, dans l'Épître aux Romains ${ }^{78}$, les a accusés non pas de ne pas connaître Dieu, mais de ne pas le glorifier ${ }^{79}$; c'est paresse d'esprit, non foi véritable, de ne pas les étudier : abandonner Platon, «c'est, pour le genre humain, négliger un grand bien, surtout en notre siècle, où, par la divine révélation, la religion a été proclamée de telle manière que, presque sans travail de la part des croyants, on se saisit, par la foi, 018 du fruit de la science, et l'on reçoit le fruit d'un travail que l'on n'a pas entrepris. Et c'est pourquoi je ne puis assez admirer l'esprit de Platon qui, tant de siècles avant l'enfantement par la Vierge, a découvert l'unité de Dieu et trois personnes dans la divinité $^{80}$ ". C'est sans doute dans le Timée, cette « citadelle et ce sommet de la philosophie ${ }^{81}$, que Claudien trouvait la trinité platonicienne. Son œuvre personnelle n'est d'ailleurs qu'une doxographie fort composite, où il accumule tous les témoignages des philosophes en faveur de la spiritualité de l'âme ; les Pythagoriciens d'abord, puis Platon,

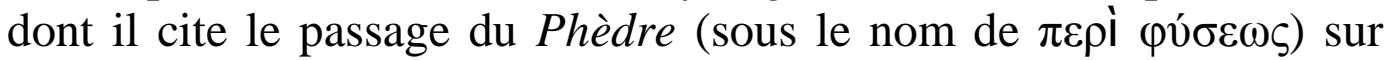
l'âme " mouvement qui se meut lui-même ». Viennent ensuite les philosophes romains, les Sextii, à propos desquels il fait de nouveau une sortie vigoureuse contre les cloîtres endormeurs de pensée, et, faisant allusion à la lettre de Faustus, s'élève contre « ceux qui décident que leur âme, liée à leurs entrailles, est enfermée dans les cloîtres de leur corps ».

\section{4-b.}

$1,20-21$.

79 Liv. II, ch. II (VI, t. LIII, 737-a).

80 746-d.

81 749-b. 
Malgré la faiblesse de la pensée philosophique de Claudien, dont l'érudition paraît intarissable, puisqu'il cite encore, avec les titres de huit dialogues de Platon, le nom de Porphyre, de Varron, de Zoroastre, des Brachmanes, d'Anacharsis, de Caton, de Cicéron et de Chrysippe, son traité n'en témoigne pas moins d'une vive polémique, $\mathrm{au} \mathrm{V}^{\mathrm{e}}$ siècle, sur la direction de la vie spirituelle ; ceux qui affirment avec le plus de force l'indépendance de l'homme sont en même temps les plus hostiles à la philosophie païenne (de même que les cyniques, avant les moines, avaient été fort souvent les ennemis des philosophes) ${ }^{82}$ (3), tandis que les partisans les plus radicaux de la grâce divine se trouvent des alliés chez les platoniciens et les pythagoriciens ${ }^{83}$ (4).

p019 Cette polémique contre les philosophes continua ; à la fin du $\mathrm{V}^{\mathrm{e}}$ siècle, Salvien de Marseille voit, dans les malheurs arrivés aux Romains, des châtiments pour l'impudicité dont avaient fait preuve les sages antiques et notamment le plus grand de tous, Socrate, qui, dans la République, a légitimé la promiscuité ${ }^{84}$. Gennadius de Marseille, au même temps, reprend les arguments de Faustus contre la spiritualité de l'âme, et il nie du même coup l'incorporéité des anges ${ }^{85}$. Mais il vise aussi, dans sa critique, des théories d'origine orientale et platonicienne qui dédoublent l'âme, soit en plaçant, comme « Jacques et les autres Syriens », au-dessus de l'âme animale, qui anime le corps, une anima spiritualis qui confère la raison ${ }^{86}$, soit, comme Didyme, en ajoutant à l'âme et au corps une troisième substance, l'esprit ${ }^{87}$ : première protestation contre une scission intérieure qui, pour sauvegarder la pure spiritualité, brise l'unité de la personne.

Contre Gennadius, Licinianus, évêque de Carthage vers la fin du $\mathrm{VI}^{\mathrm{e}}$ siècle, dans sa Lettre au diacre Épiphane, renvoie à Claudien Mamert, dont il répète les arguments : arguments surtout platoniciens, qui font valoir la présence totale de l'âme en tous les points du corps, cure.

84

Il faut lire, à cet égard, le discours de Julien contre les cyniques.

Avec les mêmes adversaires : Claudien Mamert (liv. II, ch. XII, 13) raille Épi-

De gubernatione Dei, VII, 23 (VI, t. LIII, 150-d sq.).

De ecclesiasticis dogmatibus, IX (VI, t. LVIII, 984-a).

Ibid., 984-c.

Ibid., 985-b. 
et l'existence de la mémoire, que la plus ou moins grande quantité des souvenirs ne fait ni augmenter ni diminuer ; il faut ajouter que la substance de l'âme est la volonté, qui n'est pas un corps, et enfin que l'âme est capable de s'approcher de Dieu, ce qui est impossible à un corps ${ }^{88}$. L'inspiration augustinienne ressort surtout dans les arguments suivants : l'âme, étant meilleure que le corps, ne peut être contenue par le corps ; de plus, lorsqu'elle sent, elle ne s'éparpille pas entre les parties du sensible : " tota videt, tota audit »; enfin elle ne peut contenir en elle, sinon à la manière ${ }_{\text {p020 }}$ de pensées, « illocaliter », les espaces immenses dont elle a l'idée ${ }^{89}$.

Ces deux traits, solidaires entre eux, de l'antiaugustinisme, semipélagianisme et négation de la spiritualité de l'âme, sont complétés par un troisième qui apparaît spécialement dans le Commonitorium de saint Vincent de Lérins (434) : il y exclut toute autre source de la foi que l'autorité de l'Écriture et la tradition de l'Église; si la raison a encore un rôle, c'est pour distinguer la véritable autorité de la fausse, au moyen de critères purement extérieurs, dont le principal est la continuité dans le temps et l'extension dans l'espace ${ }^{90}$. Sans, doute l'on admet bien, dans l'Écriture, la distinction des trois sens, littéral, typique (ou anagogique) et moral ou tropologique ; cette distinction, partie de Philon d'Alexandrie et d'Origène, est acceptée par Cassien et par saint Grégoire le Grand ; mais tout ce qu'il pouvait y avoir de dangereux dans une interprétation allégorique, qui, à nos yeux modernes, n'est que fantaisie personnelle, est supprimé par ce précepte du Commonitorium ${ }^{91}$ : «Que la ligne de l'interprétation des prophètes et des apôtres soit dirigée selon la forme du sens que donnent le catholicisme et l'Église. » On cherche donc, même ici, une universalité de fait qui n'a plus rien à voir avec l'universalité rationnelle ; le «judicium universitatis » dont parle Cassien ${ }^{92}$ est un jugement de fait. Mais il est clair que l'on ne peut trouver une universalité de fait qu'à condition de choisir et d'exclure : en fait, au $\mathrm{V}^{\mathrm{e}}$ et au $\mathrm{VI}^{\mathrm{e}}$ siècle, avec des décrets tels que De libris recipiendis, les autorités s'occupent

\footnotetext{
VI, t. LXXII, 697-d.

Ibid., 695-b.

Quod ubique, quod semper, quod ab omnibus creditum est.

2, 27. 29.

De incarnatione, I, 6.
} 
à déterminer le canon qui indique les livres authentiques de l'Écriture, à dire quels sont les Pères qui font autorité, à déterminer dans quelles limites peut s'opérer le développement de la pensée religieuse, « de telle manière, dit Vincent de Lérins, qu'il y ait p021 bien un progrès dans la foi, mais non un changement ${ }^{93}$ ": ce progrès ne consistera qu'à donner plus de précision aux dogmes sans en changer du tout le sens ; cette précision sera obtenue en rapprochant les autorités les unes des autres, et en les éclairant par un travail continuellement renouvelé de mise au point.

Cette polémique est d'ailleurs suivie d'une victoire incontestable, et pour longtemps définitive, de l'augustinisme ; le concile d'Orange, en 529, approuva de nombreuses propositions sur la grâce, que Césaire, évêque d’Arles, avait tirées des œuvres de saint Augustin : ce n'est pas à la fin, pour récompenser le mérite, c'est au début, pour produire la volonté bonne, qu'agit la grâce divine ; elle est purement gratuite et ne nous est pas due ${ }^{94}$. L'esprit augustinien, combiné avec des vues de Denys l'Aréopagite sur la nature purement spirituelle des Anges, allait prévaloir avec Grégoire le Grand, pape de 590 à 604 . Cette victoire a été de la plus grande importance dans l'histoire de la pensée occidentale.

Table des matières

III.

\section{CASSIODORE.}

Ce fut, au $\mathrm{VI}^{\mathrm{e}}$ et au $\mathrm{VII}^{\mathrm{e}}$ siècle, la préoccupation principale des chefs des grands monastères de faire, en suivant la division des sept arts, des recueils des connaissances utiles aux clercs. Telle fut l'entreprise de Magnus Aurelius Cassiodorus, le fils d'un préfet du prétoire de Théodoric, et lui-même questeur à vingt ans, en 497. Retiré en 540 au monastère de Vivarium, en Sicile, il écrivit jusqu'à l'âge de quatre-vingt-treize ans ses Institutiones divinarum et saecularium lectionum sur le plan ${ }_{022}$ des Noces de Marcianus Capella ; elles com-

\footnotetext{
93 Commonitorium, 23.

94 Cf. La proposition 9 : «Quoties enim bona agamus, Deus in nobis atque nobiscum ut operemur operatur. »
} 
prennent une double série de manuels, l’une (livre I), plus développée, qui forme le degré supérieur, l'autre (livre II), un abrégé à l'usage des moines moins lettrés. Au chapitre XVII du livre I, il rattache maladroitement à l'Écriture les sept arts libéraux. Sa grammaire est celle de Donat ; sa rhétorique, celle de Cicéron, commentée par Marius Victor ; pour la dialectique, il suit l'ordre, dès maintenant traditionnel : les cinq voix ou Isagoge de Porphyre, les Catégories d'Aristote, préface naturelle des livres rhétoriques ou dialectiques, le De interpretatione, la théorie des syllogismes catégoriques et hypothétiques d'après Marius Victor ; son arithmétique vient de Nicomaque de Gérasa, traduit par Boèce et par Apulée ; son traité de musique, de Gaudentius et de saint Augustin; sa Géométrie, de la traduction d'Euclide par Boèce ; son astronomie, de Sénèque ${ }^{95}$.

Le traité de Cassiodore De Anima, écrit sans doute avant 540, sur la demande de quelques amis, se rattache à la polémique dont nous avons précédemment parlé, sans que, pourtant, Cassiodore s’y engage directement : il a le plus grand soin de distinguer, sur chaque question, l'opinion des philosophes (magistri saecularium litterarum) de l'autorité des docteurs chrétiens (auctoritas veracium doctorum); il traite assez mal les philosophes «qui suivent non pas la loi du créateur, mais plutôt l'erreur humaine ${ }^{96}$; et ayant d'abord opposé deux définitions de l'âme, celle des philosophes et celle des docteurs, c'est celle des docteurs qu'il suit dans son développement. L'âme, disent les philosophes, est « une substance simple, une forme naturelle (speciem naturalem), distincte de la matière corporelle, possédant un organisme et la vertu de la vie ${ }^{97}$ ". Mais les docteurs disent : " L'âme est une ${ }_{\text {p023 }}$ substance créée par Dieu, spirituelle et particulière (propria), donnant la vie à son corps, raisonnable et immortelle, capable de se tourner vers le bien et vers le mal. » Suivant l'ordre des docteurs, Cassiodore parle successivement de la création de l'âme, qu'il prouve par l'autorité, de sa spiritualité, qu'il fonde sur sa tendance naturelle aux choses spirituelles, de sa relation avec le corps qu'elle conserve et en qui elle répartit les aliments ; c'est cette relation seule

VI, t. LXX, 1149-1219.

VI, t. LXX, 1279-1307, ch. X.

97 Cette définition se rattache à Platon pour le premier et le troisième caractère, à Aristote pour le second et le quatrième. 
qui engendre en elle des passions telles que la douleur physique, qui prouve « qu'elle est insérée substantiellement dans le corps », ou la crainte de la mort ; il passe à la raison, la faculté discursive, « qui pense les choses une à une, comme on parle », par opposition aux sens dont les connaissances sont simultanées. Quant à l'immortalité, Cassiodore connaît fort bien les preuves des "lettres séculières ", et il énumère quatre d'entre elles (il ne nomme pas le Phédon, la République et le Phèdre d'où elles dérivent) : l'âme est principe de vie, elle est simple, elle n'est pas détruite par le vice, elle se meut elle-même. Mais à ces preuves compliquées, il préfère la preuve si facile de l'Écriture : l'âme est l'image de Dieu, formule qui suggère la notion d'une vie indépendante du corps, où l'âme " connaîtra toutes choses spirituellement ».

Cassiodore est hostile d'instinct au platonisme comme au matérialisme : il ne veut pas que l'âme soit la vertu du corps, que la chaleur soit le principe de la vie; il ne veut pas davantage que l'âme soit " une partie de Dieu ou des Anges », ni que les sciences soient des réminiscences. Il n'en est pas moins vrai que, dans son spiritualisme chrétien, il adopte des pensées platoniciennes, venues sans doute de saint Augustin, notamment sur la présence totale de l'âme dans toutes les parties du corps. Dans les sujets plus spéciaux, vertus morales ou naturelles de l'âme ${ }^{98}$, siège de l'âme ${ }^{99}$, il se contente d'énumérer ${ }_{\mathrm{p} 024}$ les opinions de philosophes: la distinction des quatre vertus cardinales, la division des vertus intellectuelles en contemplation, jugement et mémoire, la division des facultés de l'âme soit en sensitive, impérative (volonté), principale (réflexion), vitale et appétitive, soit (et c'est une division d'origine médicale) en attractive, rétentive et expulsive.

Mais cette introduction d'éléments philosophiques ne change pas le caractère plutôt pratique et religieux que théorique du traité de Cassiodore. Il doit conduire l'âme à la connaissance de Dieu : l'âme, plutôt qu'une chaleur, est une lumière, puisqu'elle est à l'image de Dieu ; dès lors la connaissance de Dieu est « un secret (arcanum) qu'une âme très pure et se donnant à Dieu peut sentir en quelque façon ». L'on arrive à Dieu par trois degrés : il faut d'abord franchir l'étendue

\footnotetext{
98 Ch. v et VI.

99 Ch. VIII.
} 
de notre âme et faire silence sur nous-mêmes ; il faut ensuite franchir les puissances célestes; il faut enfin "vénérer Dieu sans chercher à définir ses qualités et sa grandeur " ${ }^{100}$. L'ascension mystique vers Dieu et les espérances, divinement révélées, de la vie future sont les seules questions qui peuvent conduire le chrétien à étudier la nature de l'âme. Le Commentaire des Psaumes, où Cassiodore a repris les Enarrationes in Psalmos de saint Augustin, son Histoire de l'Église qu'il a compilée d'après les Grecs Socrate, Sozomène et Théodoret, indiquent ses principales préoccupations.

Table des matières

IV.

\section{ISIDORE DE SEVILLE.}

L'établissement des Goths en Espagne vit la fin de l'enseignement de l'État ; au V $\mathrm{V}^{\mathrm{e}}$ siècle, Sidoine Apollinaire célèbre encore l'éclat de l'école de Cordoue sous Théodoric II ; en revanche, en 506, les lois d'Alaric admettent tous les articles du p025 Code théodosien relatifs aux écoles. C'est alors que se fondèrent en Espagne les écoles abbatiales et épiscopales et, presque simultanément, les écoles juives, où se maintenait la culture orientale. A Séville, par exemple, existait un collège pour la formation des clercs, où les études régulières duraient quatre ans ${ }^{101}$. C'est par rapport aux besoins de ces écoles que doivent se juger les œuvres d’Isidore, né vers 570, qui fut évêque de Séville en 601 et mourut en $636^{102}$. Leur enseignement est défavorable à la culture d'autrefois : Isidore, dans sa Regula monachorum ${ }^{103}$, défend expressément aux moines de lire les livres des païens. «L'éloquence des fables, dit-il, correspond à leur absence de sagesse... L'amour de la science mondaine ne fait rien qu'exalter l'homme par ses mérites. Plus on étudie les lettres, plus l'âme se gonfle d'orgueil. Le psaume dit bien : «Parce que je ne connais pas les lettres, j'entrerai dans la

\footnotetext{
100 Ch. III.

101 Ad. Bonilla y SAN Martin, X, p. 235 sq.

102 Isidore fait prendre par le quatrième concile de Tolède un décret rendant obligatoire l'étude du grec et de l’hébreu dans les écoles épiscopales.

103 Ch. VIII.
} 
puissance du Seigneur ${ }^{104}$. » Ce n'est pas que beaucoup de la culture antique n'ait passé dans les nombreux ouvrages qu'Isidore a écrits pour l'enseignement du clergé ; mais c'est seulement ce qui est utilisable pour les chrétiens.

L'œuvre d'Isidore de Séville, écrite pour les clercs d'Espagne, a été un modèle pour le Moyen Age ; elle nous fait comprendre, par son ampleur, quelles seront les directions principales de la pensée médiévale. On peut y distinguer trois images de l'univers, d'origine assez différente, et qui ne se recouvrent nullement : la première, toute positive, est empruntée à l'astronomie grecque et à la météorologie : elle explique la marche des planètes sur laquelle est fondé le calendrier, et ensuite les météores et les principaux phénomènes terrestres, mer, rivières, tremblements de terre : c'est l'objet p026 du De Natura rerum $^{105}$. La seconde dépeint le même univers, mais en en considérant les parties comme le séjour d'êtres spirituels, classés selon l'ordre hiérarchique de perfection : au-dessous de Dieu, viennent les anges, les eaux qui sont au-dessus du firmament, les cieux, le paradis, la région inférieure, la terre, le lieu des châtiments : tels sont les principaux titres du De Ordine creaturarum: le monde se peuple d'êtres spirituels. La troisième image de l'Univers, enfin, est celle qui nous est révélée par le christianisme; elle se développe non dans l'espace, mais dans le temps: Dieu tout-puissant crée le monde, avec les hommes et les anges ; puis vient la chute ; le Christ, dont l'Église continue l'œuvre au moyen des sacrements, rachète l'homme, jusqu'à ce que le monde finisse, à la suite de la venue de l'Antéchrist : tels sont les événements divins dont le livre I des Sententiae raconte l'histoire, tandis que le livre II traite de la grâce qui doit assurer à l'homme la béatitude, et le livre III des conditions de la vie terrestre et du droit naturel.

Ces trois conceptions, fort différentes, puisqu'elles viennent l'une de la science antique (surtout des Questions naturelles de Sénèque), l'autre, avec sa hiérarchie d'êtres, du néoplatonisme, la troisième enfin, de la révélation chrétienne, sont ici simplement juxtaposées sans se contredire ni davantage se pénétrer.

104 Etymologiae, III, 13; cité par BonILla, X, p. 249.

105 Éd. Gustav Becker, Berlin, 1857. 
Si nous considérons la grande œuvre qui a fait surtout la célébrité d'Isidore, Originum sive Etymologiarum libri $X X$, nous y trouvons la même juxtaposition. Cet ouvrage, qui se donne lui-même comme une simple collection de résumés de lectures ${ }^{106}$, est une sorte d'encyclopédie où sont condensés tous les arts : au début les sept arts libéraux, auxquels s’ajoute la médecine, puis les arts qui regardent la religion et la société, ensuite ceux qui se rapportent aux choses de la nature, enfin ${ }_{\mathrm{p} 027}$ les arts manuels. Il y a là tout un mélange confus de notions théoriques et pratiques, avec, toutefois, un semblant de groupement en arts libéraux (livres I à III), sciences morales (livres $\mathrm{V}$ à $\mathrm{X}$ ), sciences naturelles (livres XI à XVI), agriculture et arts manuels (livres XVII à XX). De ces quatre groupes, il est clair que le premier et les deux derniers renferment une tradition positive, tout à fait étrangère à la vie chrétienne et qui se juxtapose à elle. Mais, à l'intérieur du second groupe, dans les livres qui concernent la vie morale de l'homme, on peut faire aussi un départ entre deux traditions : à côté des prescriptions relatives à l'Église et au culte divin, l'on trouve au livre V une théorie du droit, toute empruntée aux Institutes de Gaius. Selon cette théorie, qui a été fort remarquée à l'époque scolastique, et notamment par saint Thomas ${ }^{107}$, le droit (jus) s'exprime par la loi, qui est écrite, et par la coutume (mores), qui est comme une loi non écrite. Le droit se distingue en droit naturel, droit civil et droit des gens. Le droit naturel existe en dehors de tout décret humain, par instinct de nature ; de droit naturel sont par exemple l'éducation des enfants, la propriété commune de toutes choses, la liberté de tous, la restitution des dépôts. Le droit civil est l'ensemble des lois établies par une cité ; cette loi sera l'expression de la raison, à condition « qu'elle soit honnête, juste, possible, conforme à la nature et à la coutume, convenable aux circonstances, ...portée non dans un intérêt particulier, mais pour l'utilité commune des citoyens »; elle n'existe d'ailleurs que par une décision populaire (constitutio populi), prise à la fois par les sénateurs (majores natu) et la plèbe.

Ainsi les connaissances positives et rationnelles, en morale, tout aussi bien que dans les sept arts libéraux et en physique, forment, chez Isidore, un bloc tout à fait distinct, qui a son intérêt par lui-même ; si

106 VI, t. LXXXII, p. 73 : ex veteris lectonis recordatione collectum.
107 Somme théologique, I $\mathrm{I}^{\mathrm{a}}, \mathrm{II}^{\text {æ}}$, qu. 95, art. 4 et 5 ; cf, BonILlA, X, p. 245. 
faibles que soient ses connaissances p028 en astronomie, par exemple, où la Science grecque ne lui arrive guère qu'à travers saint Augustin et saint Ambroise, cette science, comme l'a remarqué Duhem ${ }^{108}$, « n'apparaît plus simplement, ainsi que chez les Pères, comme un instrument d'apologétique et d'exégèse ; elle est reconnue comme une fin, bonne en soi, que l'intelligence chrétienne a le droit et le devoir de poursuivre ». C'est pourquoi, chez Isidore, la place des arts libéraux reste indécise : plutôt qu'un organe ou qu'un prélude à la philosophie, comme ils l'étaient dans la tradition néoplatonicienne et orientale, ils en sont une partie constitutive. Isidore cite ${ }^{109}$ la division tripartite de la philosophie en physique, éthique et logique, dont la dernière subdivision contient la dialectique et la rhétorique ${ }^{110}$. Dans la division bipartite, qu'il connaît aussi, en théorique (inspectiva) et pratique (actualis), il subdivise la théorique en physique (naturalis), doctrinale et théologique (divinalis). Or la partie doctrinale contient les quatre sciences du quadrivium : arithmétique, musique, géométrie, astronomie $^{111}$. Isidore emprunte, il est vrai, de toutes mains, sans avoir le moindre désir de systématiser ses connaissances. Pourtant, il faut remarquer que la distinction du début des Étymologies, empruntée à Marius Victorinus, entre Vars, qui se rapporte à ce qui change, et la disciplina, qui porte sur l'immuable, est incompatible avec la dénomination d'arts libéraux, appliquée aux études du trivium et du quadrivium, s'ils sont vraiment des disciplines philosophiques.

Parmi les traditions qu'entretient Isidore, est celle de la dialectique, où il répète surtout Cassiodore et Marius Victorinus et quelque peu Boèce. Il suit l'ordre ordinaire : Isagoge, Catégories, Interprétation, Syllogismes catégoriques et ${ }_{\mathrm{p} 029}$ hypothétiques, Topiques. Il est à remarquer que le chapitre sur les oppositions, au lieu de faire corps avec les Catégories, vient tout à la fin après les Topiques : c'est qu'il est emprunté au Commentaire de Boèce sur les Topiques de Cicéron ${ }^{112}$.

\footnotetext{
108 XV, t. III, 1915, p. 11.

109 Etymol., II, 24.

110 Ces divisions viennent de Cassiodore.

111 Il faut remarquer aussi que, dans cette division, qui est d’origine aristotélicienne, la morale, appartenant à la partie pratique, est tout à fait séparée dé la théologie.

112 PRANTL, XXVIII, I, p. 12 sq.
} 
Le rôle du hasard est grand dans la disposition des matières. C'est ainsi que, dans l'exposé des syllogismes hypothétiques, il préfère à Boèce Marius Victorinus, dont il reproduit la division en sept modes, qui se trouve aussi chez Marcianus Capella.

Ainsi vont côte à côte, chez Isidore, la curiosité scientifique, qui se manifeste par des compilations érudites, et la vie religieuse, qui s'exprime non seulement dans son livre des Sentences, mais dans sa Chronique, où il relate les principaux événements arrivés dans le monde depuis la création, jusqu'en 616, dans des livres d'exégèse sur l'Ancien ou le Nouveau Testament, des ouvrages sur la liturgie, la hiérarchie ecclésiastique et la règle monastique, enfin les Synonyma, de lamentatione animae peccatricis, où, dans le style des Soliloques de saint Augustin, il se lamente sur ses propres péchés, prenant à témoin la nature entière : "Flete me, caelum et terra ; lugete me, omnes creaturae ; plorate me, omnia elementa ». Dans sa pensée religieuse, Isidore est un témoin du triomphe de l'augustinisme ; comme Grégoire le Grand, il affirme l'absolue spiritualité des âmes et aussi celle des anges ; il admet la grâce entièrement gratuite et prévenant tout mérite ; il déclare enfin, comme saint Augustin, que l'origine des âmes est inconnue ${ }^{113}$.

Le type d'esprit d'Isidore de Séville a dû être fréquent dans le haut clergé espagnol ; Isidore, fils de Severianus, un gouverneur de Carthagène, qui avait épousé la sœur du roi des Wisigoths Léovigilde, et frère de Léandre, qui le précéda à l'évêché de Séville et qui était allé jusqu'à Byzance demander des secours contre la persécution des Wisigoths ariens, p030 qu'il finit par convertir, représente vraiment la culture de son époque ; jusqu'au désastre de l'invasion arabe, et même après, à Cordoue, l'inspiration d'Isidore continua : Taius, évêque de Saragosse, au milieu du $\mathrm{VII}^{\mathrm{e}}$ siècle, écrivit cinq livres de Sentences racontant, comme celles d'Isidore, le drame chrétien depuis la création jusqu'au jugement final et à la gloire des élus : un premier livre porte sur Dieu, la Trinité, les Anges et les démons, la création des six jours, la chute et l'histoire juive (on y trouve un chapitre sur l'interprétation allégorique) ; au livre II, c'est l'histoire du Christ, de l'établissement de l’Église, avec des chapitres sur les sacrements, les

113 J. TiXeront, XXIX, t. III, 4 e édit., p. 344-353. 
vertus théologales et la grâce ; le livre III décrit les vertus de la vie religieuse ; le livre IV traite des tentations et des vices, et le livre V de la consommation des choses.

\section{V. \\ BEDE LE VENERABLE.}

$\mathrm{Au} \mathrm{VI}{ }^{\mathrm{e}}$ et au VII ${ }^{\mathrm{e}}$ siècle, en Angleterre, une fois que les invasions anglo-saxonnes furent terminées par l'assujettissement d'une partie du pays aux envahisseurs, se prépara, avec la diffusion du christianisme, le mouvement qui devait aboutir à la grande part que prit la chrétienté anglaise, au VIII ${ }^{\mathrm{e}}$ et au $\mathrm{IX}^{\mathrm{e}}$ siècle, dans la culture du continent. L'on connaît ce mouvement par l'Historia ecclesiastica gentis Anglorum que composa, au monastère de Jarrow, Bède le Vénérable (672-735) et qu'il mena jusqu'en 731. Il nous raconte les résistances que rencontra la papauté chez les chrétiens d'Irlande et qui ne cessèrent que dans les dernières années du VII ${ }^{\mathrm{e}}$ siècle. Plus encore qu'au Sud de la Gaule, les moines irlandais résistaient aux thèses augustiniennes sur la grâce et gardaient, dans le libre arbitre, la confiance du grand ennemi de saint Augustin, Pelage, qui était de même race qu'eux. Les papes leur reprochaient ${ }_{\mathrm{p} 031}$ encore de maintenir, pour la fête de Pâques, une date qui leur était commune avec les Juifs ${ }^{114}$. Au milieu du siècle, les moines irlandais avaient envahi presque toute l'Angleterre; la soumission extérieure de l'Irlande en 617 ne fit peut-être pas cesser ce particularisme, dont nous trouverons des témoignages chez les Irlandais célèbres du VIII ${ }^{\mathrm{e}}$ siècle.

Au VII ${ }^{\mathrm{e}}$ siècle, Bède le Vénérable fit tous ses efforts pour fournir au catholicisme anglais cette armature intellectuelle qu'Isidore lui avait donnée en Espagne. Son œuvre répond aux mêmes besoins que celles d'Isidore : rassembler des extraits de toutes les connaissances humaines. La difficulté était sans doute encore plus grande qu'en Espagne : beaucoup de prêtres ne savaient même pas le latin, et Bède

114 Cf. la lettre du pape Jean, dans Historia ecclesiastica, ch. XIX (VI, t. XCV, 113-114). 
recommande ${ }^{115}$ de leur faire apprendre l'oraison dominicale et le symbole des Apôtres en latin, s'il se peut, sinon, dans la traduction en langue vulgaire qui vient d'en être faite. Si l'on suppose, tombant sur ce milieu inculte, tous les résultats de la culture littéraire et scientifique de l'antiquité, on voit qu'il n'était ni possible ni désirable que Bède tentât autre chose que ce qu'il a tenté : conserver, en extraits, ce qu'il pouvait de cette culture.

Nous trouvons, dans le De Natura rerum, la même image du monde physique que dans le traité de même nom d'Isidore, qu'il a souvent copié : cette image, empruntée à Pline l'Ancien ${ }^{116}$ et venue, à travers le temps, de la science aristotélicienne, est indépendante de toute référence à un dogme religieux quelconque, sinon que, comme Isidore, Bède place au-dessus du firmament le ciel aqueux emprunté à la Bible, atteignant ainsi avec le ciel des fixes et ceux des sept planètes ${ }_{\mathrm{p} 032}$ le nombre de dix cieux ; pour le reste, ce sont des éléments d'astronomie, de météorologie et de géographie. Un ouvrage intitulé De Mirabilibus sacrae scripturae, que l'on trouve dans les œuvres de saint Augustin, et qui a été écrit en Angleterre en 660, témoigne, en quelques endroits, notamment dans la théorie des marées, du même genre de curiosité.

Table des matières

VI, t. XCIV, 639.

116 VI, t. XC, ch. XIV, p. 229 ; sa théorie des planètes et celle des marées prouvent un emprunt direct à Pline; au sujet des marées, son livre contient aussi des observations personnelles (Duhem, XV, t. III, 19). 
La philosophie du Moyen âge

Table des matières

\section{Chapitre II}

\section{LA PHILOSOPHIE EN ORIENT}

I.

CONFLITS DOGMATIQUES.

Dans le dernier grand conflit relatif à la nature du Christ qui se produisit en Orient au VIII ${ }^{\mathrm{e}}$ siècle, on peut voir se perpétuer les idées qui régnaient dans la philosophie grecque sur le divin et l'humain ; c'est avec des notions platoniciennes que les monophysites avaient essayé de penser le miracle de l'Homme-Dieu : l'âme, dans son ascension vers le Principe suprême, se transforme en intelligence, puis l'intelligence dans l'Un, sans qu'il reste à chaque étape aucun résidu de l'étape précédente ; arrivés au niveau de l’Un, nous ne pouvons parler de nous-mêmes ; nous ne subsistons plus comme âme. Les monophysites enseignaient que, à plus forte raison, quand le Verbe se fait chair, il ne laisse point subsister en lui la nature humaine ${ }^{117}$. Une fois le monophysitisme écarté, comment comprendre les rapports des deux natures, humaine et divine ? Ici encore, une thèse, issue de la mystique platonicienne, s'impose d'abord. On sait que le platonisme concevait le rapport de l'âme avec le corps comme celui d'un agent avec un p034 organe ou un instrument; et il faut se rappeler que l'âme est une essence divine. Dans la divination inspirée, telle que celle des Sibylles ou de l'oracle d'Apollon, le devin passait pour un simple instrument du dieu ; passif, sans volonté propre, il ne parle et n'agit que selon la volonté du dieu. Le monoénergisme ou monothélisme, qui se répandit en Orient au VII ${ }^{\mathrm{e}}$ siècle, soutenait de même, au sujet des rap-

Selon Apollinaire, là où il $\mathrm{y}$ a nature humaine, il $\mathrm{y}$ a raisonnement, et là où il y a raisonnement humain, il y a péché ; s’il y a deux natures dans le Christ, il est fatal que chacune suive sa voie propre. 
ports des deux natures dans le Christ, que toute l'initiative de ses actes revient à la nature divine, dont la nature humaine n'est que l'instrument passif. La parenté de cette thèse avec celle des monophysites est évidente : il s'agit, dans les deux cas, de résorber la nature en Dieu. C'est même cette parenté qui lui a donné sa raison d'être : elle fut en quelque manière fabriquée sur mesure en 619 par Sergius, patriarche de Constantinople, dans l'intérêt de la politique de l'empereur Héraclius; il y avait beaucoup de chrétiens monophysites chez l'adversaire perse, qui, après 634, fut remplacé par l'adversaire arabe ; l'affirmation de monoénergisme qui fut publiée en Égypte, en Arménie, en Perse, devait être un moyen de gagner à sa cause les monophysites de ces divers pays. L'affaire paraissait réussir, lorsque en 633, la thèse trouva des contradicteurs, en Orient même, chez les moines Sophonius et Maxime, dont le second devint, en 634, patriarche de Jérusalem. Le conflit fut porté devant le pape et, après beaucoup de discussions compliquées, aboutit, en 681, à la condamnation du monothélisme par le Concile de Constantinople : c'était une victoire éclatante de la papauté sur l'idéalisme spiritualiste encore très fort en Orient : on proclamait que, comme il y avait dans le Christ deux natures, il y avait aussi deux volontés naturelles et deux opérations naturelles ${ }^{118}$.

On peut dire que ce fut aussi la fin de cette interprétation mystique et philosophique des dogmes qui avaient engendré ${ }_{\text {p } 035}$ tant de conflits en Orient. Les dogmes, tels qu'ils s'expriment maintenant, tendent à maintenir, à l'intérieur de la nature divine, des distinctions que le mysticisme voulait supprimer ou négligeait : l'affirmation dogmatique se détache de plus en plus de la vie mystique.

Table des matières

II.

Le Corpus theologique de Jean Damascene.

Dès qu'une proposition est acceptée comme vraie par l'autorité ou par la tradition, le raisonnement n'a que faire de l'établir. Mais, comme il faut formuler les vérités, on est contraint d'emprunter, lors-

118 VI, t. LXXXVII, p. 1216-1248. 
qu'il s'agit des choses divines, les manières de s'exprimer dont usait la philosophie grecque et latine et, avec elles, les cadres de la pensée philosophique, quitte à corriger, à étendre ou à restreindre le sens des mots que l'on emploie : et par là, la théologie, en se développant, contracte alliance avec la philosophie grecque et spécialement avec la dialectique, qui détermine le sens des mots. L'exemple de l'hérésie monophysite ou monothélite fait voir à quel point il est nécessaire d'employer des concepts corrects dans la formule des choses divines ; de plus, si la preuve rationnelle de pareilles vérités est inutile ou impossible, la dialectique reste pourtant indispensable pour discuter les assertions contraires à la vérité que les hérétiques veulent fonder sur les mêmes autorités que les croyants : par là encore, la théologie garde l'usage de la philosophie grecque; car, selon la vieille image stoïcienne, la dialectique était faite pour défendre et attaquer, pour réduire un adversaire au silence, bien plutôt que pour prouver ; et elle prend, dans cette attaque un point de départ accepté par l'adversaire : c'est de cette manière qu'un néoplatonicien comme Plotin use de la discussion : en revanche, lorsqu'il énonce la vérité, il prend, comme les stoïciens d'ailleurs, p036 un ton prophétique et inspiré qui n’a plus rien à voir avec la discussion.

La dialectique sous ses deux aspects, classement de concepts et moyen de défense contre un adversaire, était donc, dès l'époque grecque, la servante de la philosophie ${ }^{119}$, et saint Jean Damascène (mort en 749) n'ajoute rien à la tradition, lorsqu'il dit que la théologie se sert de la dialectique, comme une reine de ses servantes ; car, « si la vérité n'a pas besoin d'un arsenal varié d'arguments, l'on en usera pour renverser les adversaires et la fausse connaissance " ${ }^{120}$. C'est pourquoi, dans son grand ouvrage, la Source de la connaissance, il a fait précéder l'exposé de la foi orthodoxe par un long livre sur la dialectique. Remarquons de suite que la dialectique n'occupe pas, dans cet ouvrage, la même place que chez les théologiens occidentaux du même temps : chez ceux-ci, elle est un des sept arts libéraux, et elle est traitée de pair avec les autres ; chez Jean, elle reste indépendante des autres arts, et elle a la place qu'elle avait chez les Stoïciens ou plutôt chez les Péripatéticiens ; car elle est pour lui, comme pour

119 Cf. Philon d'Alexandrie, De congressu, § 11 . —

120 V, t. XCIV 532-b. 
ceux-ci, un « instrument » (organon) et non pas, comme pour ceux-là, une partie de la philosophie. Cette différence correspond à une autre : de même que son ouvrage ne comporte pas l'enseignement des sept arts, de même il ne contient pas l'image d'ensemble de l'univers qui y est liée : on sent, dans cette œuvre qui servira plus tard de modèle à l'Occident, l'absence de l'érudition romaine qui a tant de place en Occident, et la vitalité de la tradition grecque qui n'admet d'autre objet d'études que les choses divines.

La dialectique contient chez lui, outre une introduction sur les définitions et les divisions de la philosophie ${ }^{121}$, une série de chapitres qui suit l'ordre, dès maintenant traditionnel, p037 de l'Organon d'Aristote, étudiant d'abord l'Isagoge de Porphyre et les cinq voix, puis les dix catégories, ensuite le De interpretatione, enfin le début des Analytiques sur le syllogisme et ses éléments. Il y a, dans cet amas, beaucoup de formules que Jean a dû transcrire sans en comprendre du tout la portée, notamment la série des définitions, aristotélicienne platonicienne, stoïcienne, de la philosophie ${ }^{122}$. Il n'en défend pas moins la certitude de la philosophie contre les sceptiques ${ }^{123}$. Il montre, comme Boèce, les limites de l'application des catégories dans le domaine de la théologie. Il est particulièrement intéressant de voir comment il oppose à la philosophie certaines conceptions chrétiennes qui lui sont irréductibles : pour les "philosophes du dehors ", toute réalité ou hypostase distincte a une seule nature, la « nature » se définissant comme l'être informé par des différences spécifiques ou comme espèce spécialissime ; pour les chrétiens, une réalité unique peut avoir deux natures, par exemple l'homme fait d'une âme et d'un corps, ou le Christ chez qui s'unissent la divinité et l'humanité ${ }^{124}$.

Jean Damascène, bien qu'aristotélicien en parole, garde dans sa théologie beaucoup d'éléments platoniciens : identité du Bien avec la volonté de Dieu ${ }^{125}$, mal non être ${ }^{126}$, définition de l’âme.

\footnotetext{
121 Les six définitions de la philosophie se retrouvent les mêmes à la fin de la Dialectique.

122 V, 94, 533-b.

123 Id., 538-b.

124 Id., 661-b.

125 Id., 1548-c, comparé à Plotin, VI Enn., 8, 16.

126 1549-a. Sur son influence en Occident, cf. J. DE GHELLINCK XLI.
} 
III.

\section{LA PHILOSOPHIE CHEZ LES SYRIENS.}

Entre l'époque où l'Orient monophysite se détacha du reste de la chrétienté et celle où commença, dans les mêmes pays, la civilisation de langue arabe, se développe un mouvement philosophique, d'ailleurs peu original, et très distinct ${ }_{\mathrm{p} 038}$ de celui de l'Occident, sur lequel il devait pourtant avoir une influence considérable. Les derniers platoniciens païens, dont plusieurs étaient originaires de Syrie, avaient introduit dans l'enseignement le commentaire des œuvres d'Aristote et principalement des œuvres logiques ou Organon : les chrétiens de langue grecque les imitèrent d'ailleurs et il y eut, après Jean Philopon, quelques commentateurs byzantins comme David et Elias ; mais cette activité se ralentit de bonne heure, et elle ne reprit, et très sporadiquement, que beaucoup plus tard, par exemple avec Michel d'Éphèse, au $\mathrm{XI}^{\mathrm{e}}$ siècle ${ }^{127}$. En revanche, l'étude d'Aristote continua aux $\mathrm{VII}^{\mathrm{e}}$ et $\mathrm{VIII}^{\mathrm{e}}$ siècles dans les monastères orientaux ; on fit des traductions en syriaque de beaucoup d'œuvres d'Aristote ; comme c'est par leur intermédiaire qu'Aristote fut connu des Arabes et devint chez eux le Philosophe, comme c'est par l'influence arabe que fut réintroduite au $\mathrm{XIII}^{\mathrm{e}}$ siècle en Occident l'étude d'Aristote, on voit l'importance historique qu'ont eue les travaux de ces moines orientaux, sans lesquels Aristote, formateur de l'esprit scolastique, n'aurait sans doute jamais été un éducateur de l’Occident.

Peut-être y avait-il une affinité entre le nestorianisme et l'aristotélisme. Théodore de Mopsuète avait commenté Aristote ; Ibas, évêque d'Édesse, après Rabbula, ainsi que deux autres membres de l'école d'Édesse, sont cités dès le $\mathrm{V}^{\mathrm{e}}$ siècle comme ayant traduit en syriaque Aristote et son commentateur ${ }^{128}$. Puis, Sergius de Reschaïna, vers la fin du même siècle, traduisit en syriaque, outre les œuvres médicales de Galien ${ }^{129}$ et celles de Denys l'Aréopagite, l'Isagoge de

\footnotetext{
127 Cf. l’article de Praechter, B. Z., 1909.

128 SAUTER, XLII, p. 21.

129 Cf. Meyerhof, Sur les versions arabes et syriaques de Gallien, Byzantion, III, 1928.
} 
Porphyre, les Catégories d'Aristote, le pseudo-De Mundo, et un traité De l'Ame. Il était lui-même l'auteur de traités sur la logique, sur les causes de l'univers d'après les principes d'Aristote, p039 sur le genre, l'espèce et l'individu, sur l'affirmation et la négation, sur le prologue du De Interpretatione. Au VII ${ }^{\mathrm{e}}$ siècle, au monastère de Kennesre, sur l'Euphrate, Severus Sebokt écrit un commentaire sur les Analytiques et sur le De Interpretatione ; Athanase en 645 traduit l'Isagoge ; un peu plus tard, Georgius traduit l'Organon tout entier, et Jacques d’Édesse, les Catégories.

Il ne faudrait pas surestimer ce mouvement d'idées : plus près des textes et mieux informés que leurs contemporains occidentaux, ils travaillent pourtant dans le même esprit ; seule, comme saint Jean Damascène, les intéresse la logique d'Aristote, et, dans cette logique, on leur interdit d'aller au-delà de ce qui est indispensable pour soutenir la foi ; en fait, à l'exception de Georgius, on ne voit pas que les traducteurs syriens aillent plus loin que l'exposé des trois figures du syllogisme composé de propositions portant sur le réel, c'est-à-dire jusqu'au VII ${ }^{\mathrm{e}}$ chapitre du premier livre des Premiers Analytiques; ils ignorent, tout comme en Occident, et le mécanisme compliqué des propositions modales et surtout les théories de la définition et de la démonstration des Seconds Analytiques. Ce n'est que plus tard, aux $\mathrm{IX}^{\mathrm{e}}$ et $\mathrm{X}^{\mathrm{e}}$ siècles, avec la civilisation arabe, que nous verrons les traducteurs syriaques et arabes s'attaquer à l'œuvre presque entière d'Aristote. Pourtant, il est possible que, dès ce moment, se prépare, en Orient, l'interprétation néoplatonicienne de la pensée d'Aristote, qui sera caractéristique de la philosophie arabe. La langue syriaque n’avait pas jusqu'alors de vocabulaire philosophique répondant à celui du grec ; d'autre part, les mots de la langue d'Aristote étaient employés couramment par les néoplatoniciens grecs dans un sens nouveau; le mot voũ , Intelligence, signifie couramment chez eux une hypostase divine et non plus une faculté de l'âme humaine ; le mot Elỉo $\zeta$ désigne non seulement la forme immanente aux choses, mais l'Idée transcendante ; le mot $\lambda o ́ \gamma o s$, le Verbe, plus que la p040 raison humaine. Il était sans doute inévitable que, dans le milieu syrien pénétré de néoplatonisme, les mots syriaques prissent quelque chose de la 


\section{Émile Bréhier \\ La philosophie du Moyen âge}

nuance qu'ils avaient dans le néoplatonisme ${ }^{130}$ : l'on en verra plus loin la conséquence.

$\underline{\text { Table des matières }}$

${ }^{130}$ G. PolLAK, Entwicklung der arabischen und jüdischen Philosophie (A. G. P., XVII, 1904, 216-217). 


\title{
DEUXIÈME PARTIE
}

\section{La renaissance de la philosophie (IX ${ }^{\mathrm{e}}$ et $\mathrm{X}^{\mathrm{e}}$ siècles)}

Table des matières

\author{
Chapitre premier
}

\section{LES CONDITIONS HISTORIQUES}

Ce n'est qu'aux $\mathrm{VIII}^{\mathrm{e}}$ et $\mathrm{IX}^{\mathrm{e}}$ siècles que s'opéra d'une manière nette le regroupement des forces intellectuelles qui s'estompait déjà au $\mathrm{VI}^{\mathrm{e}}$ siècle : c'est l'époque des trois empires : l'empire arabe en Orient et en Méditerranée méridionale, l'empire byzantin, l'empire carolingien en Occident ; chacun d'eux permit une sorte de renaissance intellectuelle, quoique dans des conditions bien différentes: l'empire arabe avec ses grandes villes cosmopolites et la bigarrure de ses croyances, l'empire byzantin avec le triomphe de l'hellénisme qui suivit la fin du mouvement iconoclaste, l'empire carolingien avec cette mobilisation des forces spirituelles de la chrétienté que favorisa Charlemagne.

Modoin, évêque d'Auxerre sous Charlemagne, voyait en son siècle une renaissance du siècle d'Auguste : p042

Rursus in antiquos mutataque saecula mores : Aurea Roma iterum renovato nascitur orbe. 
La culture intellectuelle est une pièce intégrante de la notion de l'empire, tel que l'a conçu Charlemagne. Cet empire est une théocratie ; son but est de «défendre par les armes partout à l'extérieur la sainte Église du Christ contre les incursions des païens et les dévastations des infidèles, et de la fortifier à l'intérieur dans la connaissance de la foi catholique ${ }^{131}$ ». L'idée impérialiste n’a pas sa valeur en ellemême, comme dans la monarchie franque ; elle est tout entière subordonnée à l’idéal religieux. "Plût au Dieu tout-puissant, écrit Agobard, que, sous un seul roi très pieux, tous les hommes fussent gouvernés par une seule loi : cela profiterait grandement à la concorde de la cité de Dieu et à l'équité parmi les peuples ${ }^{132}$. "

Dans ces conditions, la rénovation de la culture intellectuelle devait être déterminée par le rôle et la place qu'elle allait avoir dans cet immense plan d'organisation delà chrétienté qui n'aboutit pas moins aux massacres des Saxons qu'aux écoles d'Alcuin : "C'est comme chef religieux de l'État franc que Charles prend en mains la cause de la réforme intellectuelle, parce qu'il y voit la condition de la réforme du clergé ${ }^{133}$. " Si une place d'honneur est donnée à l'enseignement des lettres, des sciences et de la philosophie, c'est seulement en raison de l'intérêt que ces disciplines peuvent avoir pour la connaissance des choses divines. Ce n'est pas de la Gaule ignorante, où l'on avait perdu même la connaissance du latin, que pouvait venir l'initiative d'une pareille réforme. Le seul pays où s'était maintenue la culture depuis le $\mathrm{VI}^{\mathrm{e}}$ siècle, c'était, comme on l'a vu, l'Irlande et l'Angleterre ; et c'est aux Anglo-Saxons que Charles fit appel, quand il p043 manifesta, dès 769, la volonté d'organiser dans son royaume les études préliminaires indispensables à la connaissance des Écritures. En 785, il s'attache Alcuin ${ }^{134}$, maître de l'église épiscopale d'York, qui, avec plusieurs de ses élèves, vint en France organiser l'enseignement, tant l'enseignement élémentaire auprès des paroisses que l'enseignement à l'usage des clercs. Cet enseignement reste augustinien d'esprit ; pour Alcuin comme pour tous les hommes de ce temps, il n'aurait point d'excuse et serait une curiosité vaine, si l'on ne pouvait prouver qu'il conduit

\footnotetext{
131 Epistolae Caroli, 10, cité par H.-X. ArQuilliÈre, XLV, p. 114,

132 Liber adversus legem Gundobaldi, VI, t. CIV, p. 128.

133 L. HALPHEN, XVIX. p. 262.

134 Alcuin, Lettre 82 dans VI, t. C, p. 29.
} 
indirectement au salut; il s'agit d'ailleurs non pas d'inventer, mais d'apprendre ce qui a été découvert auparavant par les hommes sages ; et les sages ne sont pas les créateurs des arts qu'ils ont transmis ; il les ont trouvés, créés par Dieu, dans les choses mêmes (in naturis rerum). Il y a, dans les sept arts libéraux, dont les traits sont fixés par une tradition déjà longue, une impersonnalité qui ne laisse aucune place à l'intrusion d'un progrès individuel ; l'œuvre personnelle ne peut être qu'une œuvre d'organisation et de transmission.

La culture celtique et anglo-saxonne, dont profita ainsi le continent, était fort menacée dans son pays d'origine ; elle y fut détruite au cours du IX ${ }^{\mathrm{e}}$ siècle par l'invasion des Vikings venus de Norvège, d'abord en Irlande dès 832, puis en Angleterre de 835 à 867 . Il en résulte que, sous les successeurs de Charlemagne, beaucoup de moines « scots » passent en France; avec eux, s'introduit un esprit nouveau qui se marque par des œuvres originales et des discussions dogmatiques ; par eux, surtout par ceux d'entre eux qui savaient lire le grec, s'introduit, à côté de l'augustinisme, l'influence tout à fait nouvelle d'une œuvre d'un chrétien néoplatonicien d'Orient, celle de Denys l'Aréopagite; nous trouvons en Jean Scot Érigène, le traducteur de Denys, une inspiration d'origine néoplatonicienne ; 044 et il était tout à fait nouveau, en Occident, de voir une œuvre de construction métaphysique, telle que son De divisione naturae.

Les efforts conjugués de Charlemagne et des moines anglais et irlandais eurent pour effet d'assurer, pendant cette période anarchique et troublée qui s'étend de 850 à 950, la continuation de la culture intellectuelle dans ces grandes abbayes, Saint-Gall, Fulda, Reichenau, Corbie, qui furent en même temps les seuls centres prospères d'activité économique : avec leurs immenses domaines et leur population nombreuse, ces abbayes prirent le rôle qu'avaient autrefois les villes elles ne sont capables pourtant d'aucun autre effort que de maintenir et de transmettre. Ailleurs, toute vie intellectuelle a cessé : Rome, qui comptait encore, jusqu'à la mort de Jean VIII (832), quelques auteurs qui gardaient la tradition classique, mérite, à la fin du IX ${ }^{\mathrm{e}}$ siècle, cette apostrophe d'un poète italien réfugié dans les villes méridionales, Naples, Amalfi ou Salerne, qui gardaient quelques traces de la culture classique : 


\section{Émile Bréhier}

La philosophie du Moyen âge

Nobilibus quondam fueris constructa patronis :

Subdita nunc servis heu male, Roma, ruis ${ }^{135}$.

Cette interruption eut pour effet de supprimer, pour l'Italie, l'attraction de Byzance. L'Europe occidentale prend alors conscience d'elle-même, de son unité intellectuelle et politique.

A cette époque, les Latins voient dans la philosophie à la fois une séduction et une nécessité : une séduction qui, selon les paroles de saint Paul ${ }^{136}$, pourrait entraîner à l'erreur, mais une nécessité pour l'éducation des clercs. Mais jamais l'idée ne leur serait venue que l'homme peut constituer cette p045 philosophie en dehors d'une « doctrine », d'un enseignement que l'on peut trouver dans les livres ; la philosophie leur apparaît comme une chose déjà faite, avec ses principes définis, qu'il n'y a qu’à restituer dans sa pureté par des interprétations et des méditations.

135 Chr. DAwson, XXXIV, p. 235, citant les Monumenta Germaniae historica, Poetae aevi carolini, t, III, édit. Traube, p. 555.

136 Ep. ad. Coloss., t. II, p. 8. 


\section{Chapitre II}

\section{LA RENAISSANCE CAROLINGIENNE ET SES SUITES}

I.

AlCUin.

Au début du $\mathrm{IX}^{\mathrm{e}}$ siècle, à cette époque de grande construction, l'œuvre d'Alcuin (735-804) a eu une réelle importance dans la direction intellectuelle de l'Europe pendant tout le Moyen Age. Né l'année même de la mort de Bède le Vénérable, Alcuin avait reçu à York la tradition d'un enseignement libéral ; devenu maître de l'école épiscopale d'York, il fut appelé en 785 par le roi Charles, et il devint dans l'empire franc l'organisateur des études ${ }^{137}$ : œuvre pratique plus que théorique, mais dans laquelle se manifeste cette sorte d'architecture intellectuelle qui se maintiendra pendant tout le Moyen Age : les sept arts libéraux comme moyens, la théologie comme fin, voilà la formule qui résumerait le mieux ses desseins : elle n'a rien d'inattendu ; elle est l'œuvre non d'un spéculatif, mais d'un homme qui a à diriger des monastères et à défendre la foi dans les conciles ; mais Alcuin insiste avec une force singulière sur la nécessité des arts libéraux : il sanctifie

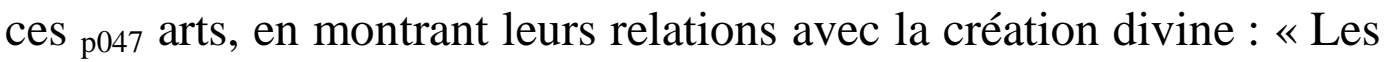
philosophes n’ont pas créé mais ont seulement découvert ces arts ; c'est Dieu qui les a créés dans les choses naturelles (in naturis) ; et les hommes les plus sages les y ont trouvés ${ }^{138}$. " La philosophie consiste à lire l'œuvre de la création ; les connaissances qu'elle donne corres-

137 Alcuin pourtant ne vécut guère à la cour de Charles ; il séjourne encore en Angleterre de 790 à 793 et, à partir de 796, est abbé du monastère SaintMartin de Tours.

138 VI, t. C, p. 269. 
pondent à la révélation, la physique à la Genèse, la morale aux livres des Sagesses, la logique aux Évangiles ${ }^{139}$. Mais surtout il en montre la nécessité pour l'interprétation des Écritures ; il en appelle au grand maître, à saint Augustin, selon qui « des raisonnements dialectiques sont nécessaires, et les questions les plus profondes au sujet de la sainte Trinité ne peuvent s'expliquer que par la subtilité des catégories ${ }^{140}$ ". Dans une lettre à Charlemagne, il vante non seulement la douceur des mathématiques et l'agrément de la connaissance des choses célestes, mais leur utilité dans l'interprétation des Écritures.

A côté des arts libéraux, il est une autre tradition antique que maintient Alcuin, c'est celle de la morale cicéronienne. En son traité Des vertus et des vices ${ }^{141}$, après avoir parlé des vertus proprement chrétiennes, foi, charité, espérance, etc., et des vices qui leur sont opposés, il ajoute: "De tous ces guides de la religion chrétienne que nous avons opposés à l'armée de l'impiété diabolique, il est quatre chefs qui sont les plus glorieux : la prudence, la justice, le courage et la tempérance "; et de ces quatre vertus, il donne les définitions du De Officiis.

$\underline{\text { Table des matières }}$

\section{II.}

\section{JEAN SCOT OU ÉRIGENE.}

Venu d'Irlande en France avant 847, Jean Scot fut accueilli à la cour de Charles le Chauve, qui lui confia la traduction des 048 œuvres de Denys l'Aréopagite, dont l'empereur Michel le Bègue avait fait cadeau à Louis le Pieux en 827. Il prit part à un débat sur la prédestination et il fut à ce propos accusé d’hérésie ; il mourut vers 877.

« Nisi credideritis non intelligetis » (Isaïe 7,9), ce mot, qu’il répète souvent, paraît avoir été le programme même de sa vie ${ }^{142}$ (1) ; la rai-

\footnotetext{
139 Cf. Grabmann, XXII, t. I, p. 194.

140 VI, CI, p. 11.

141 VI, CI, p. 613-638.

142 Dom CAppuyns, LII, a exposé avec beaucoup de force qu'Érigène n’est pas un rationaliste, mais un théologien qui cherche à comprendre le sens de l’Écriture.
} 
son a la foi pour base et ne peut être destinée qu'à la confirmer. Comme l'a remarqué l'éditeur de son Commentaire de Boèce, rien n'était plus loin de l'esprit de Jean Scot que la recherche d'une pensée libre et personnelle ; il condamne l'hérésie avec la même force que tous ses contemporains ${ }^{143}$. Par exemple, en son De divisione naturae, écrit au milieu du siècle, il se montre favorable aux formules des Grecs sur la procession du Saint-Esprit ; mais, dès que le pape Nicolas I a condamné l' « hérésie grecque ", il la repousse avec force en son Commentaire de Boèce ${ }^{144}$. Jean Scot et, après lui, Abélard, écrit M. Rand, "voulaient seulement rendre la foi plus intelligible par leur dialectique ; mais, étant des hommes, ils ne renonçaient pas volontiers à leurs propres explications ». D'ailleurs, cette confirmation de la foi par le raisonnement n'est pas l'affaire de tous : « Beaucoup ont la foi, dit Jean Scot, et fort peu (les sages seuls) ont la raison ; mais c'est par la foi qu'on vient à la raison, d'où la parole de l'Évangile : nisi credideritis, non intelligetis... Il en est peu qui soient capables de confirmer leur foi par la raison ; et il y a deux apôtres qui concourent au monument de l'Écriture Sainte, Jean qui est la raison, Pierre qui est la foi. Jean est allé plus loin, parce que la raison est plus agissante (vivacior), et la foi plus lente ; il n'a pourtant pas commencé avant Pierre, parce que l'on ne parvient à la perfection complète que par la foi ${ }^{145}$. »

p049 Il ne faut pas, parce que le raisonnement ne vient qu'après l'autorité, penser que l'autorité est antérieure en nature et en dignité ; tout à l'inverse, «l'autorité procède de la vraie raison, mais jamais la raison de l'autorité. Toute autorité qui n’est pas appuyée par la vraie raison apparaît infirme ; mais la vraie raison, en s'appuyant, fixe et immuable, sur sa propre vertu, n'a besoin d'être renforcée par nulle autorité $^{146}$ ». L'emploi de la raison s'impose d'ailleurs ; lorsque les

143 E.-K. RAND, LVI, p. 23.

144 Ibid., p. 24-25.

145 Commentaire de Boèce (dans LVI, p. 49) ; cf. Comm. sain edt? VI, t. CXXII, p. 284 ; De div., 556-6 : «Il n’y a pas d'autre salut pour les âmes fidèles que de croire ce qui est dit avec vérité du principe unique de toutes choses et de comprendre ce qu'elles croient. » (Cf. encore, 459-b.)

146 VI, p. 122, 513 ; il tient peu de compte des simples (rudes) ; il se fait dire par son disciple : «Je ne m’effraye pas de l'autorité de l'Écriture qui paraît aller contre la doctrine, parce qu'il ne faut jamais traiter de pareils sujets qu'entre savants (inter sapientes). " Au reste, il ne prend pas comme règle uniforme de suivre l'autorité des Pères : «Il ne faut introduire l'autorité des Pères que là 
Pères donnent des interprétations divergentes, l'on est bien forcé de choisir «par la seule considération de raison" ${ }^{147}$. Les sens de l'Écriture sont aussi multiples que les couleurs de la queue d'un paon ${ }^{148}$; puisqu'il y en a une infinité, il est clair que l'on a le droit de choisir a celui qui convient le mieux à la discussion présente ». Il est même loisible d'y ajouter une interprétation personnelle ${ }^{149}$. Mais il s'agit en tout cela d'une raison qui interprète l'Écriture et qui juge les interprétations d'autrui. De même les physiciens philosophes sont des sortes d'interprètes de la nature ${ }^{150}$ qui s'étend devant nous à la manière d'un texte : leur autorité est, par rapport à la nature, de même espèce que celle des Pères par rapport à l'Écriture, et il faut en user de

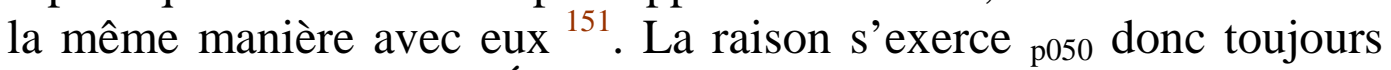
par rapport à un donné, Écriture ou Nature, qui est la réalité même ; s'il y a des autorités qui interprètent et que l'on peut juger par la raison, il y a une autorité qui marque les limites de cette interprétation, c'est celle de l'Église : quant à l'Église, « il faut tenir la route et ne dévier ni à droite ni à gauche; ne soustrayons donc rien à ceux que l'Église a prononcé posséder la souveraine et sainte autorité, mais ne méprisons pas ceux dont nous savons qu'ils ont compris simplement ${ }^{152}$, puisqu'ils se tiennent dans les bornes de la pureté de la foi catholique ${ }^{153}$. Ainsi sont distingués : l’Église et l'Écriture, les interprètes autorisés par l’Église, les interprètes libres. On voit alors comment Jean Scot est en droit de conclure : « Il y a union de la droite rai-

où il est absolument nécessaire de renforcer le raisonnement, en vue de ceux qui, ignorants du raisonnement, cèdent plus à l'autorité qu'à la raison » (De div., 781-c) ; il ne juge pas utile de suivre le procédé des commentateurs de l’Écriture, qui, sur chaque point, exposent toutes les opinions, 813-c ; cf. 530a.

147 549-a.

148 740-c.

149 530-a : «Ici suffit ma simplicité, puisque la sagacité des autres ne convient pas ».

150 Inquisitores naturarum, 738-c.

151 Cf. 723-b une curieuse défense de la physique mise sur le même pied que l’Écriture.

152 C’est-à-dire, qui ont interprété l’Écriture directement et sans s’appuyer sur une autorité.

153 814-a. 
son et de la véritable autorité, si bien que nulle autorité ne doit détourner de ce que persuade la contemplation droite ${ }^{154}$. »

Ajoutons que le mot ratio est employé encore par lui, mais incidemment, en deux sens qui peuvent se réclamer de saint Augustin : d'abord la raison est source autonome de certaines connaissances philosophiques ; par exemple, on sait par la raison que Dieu est cause des contraires, ou encore, avant de l'avoir montré par l'autorité, que, en toutes choses, le principe est identique à la fin. D'autre part, dans la hiérarchie des facultés de connaître, depuis les sens jusqu’à la vision de Dieu, la raison est considérée comme une faculté intermédiaire et propre à l'homme ; en ce sens, la raison, qui est discursive, est alors opposée à l'intelligence, qui est intuition et connaissance des principes ${ }^{155}$; la raison est la faculté qui, par ses abstractions, fragmente indûment le réel ${ }^{156}$. Par opposition ${ }_{\text {p051 }}$ aux sens qui atteignent les corps, la raison est pourtant parfois mise au rang de l'intellect ; ainsi que lui, elle connaît la matière des corps et Dieu ${ }^{157}$.

Lorsque Jean Scot vient à parler de la procession et de la génération des personnes en Dieu, c'est alors surtout qu'il superpose à la raison un mode de connaissance approchée «par les théophanies » ${ }^{158}$, une « lumière » qui nous donne une révélation directe, « sans laquelle tout l'effort de notre raison ne nous servirait de rien ${ }^{159}$.

Pour atteindre cette connaissance, dont le type est dans le prologue de l'Évangile de saint Jean, Jean Scot commence donc par aligner toutes ses autorités, c'est-à-dire l'Écriture avec l'interprétation des Pères. Mais il ne faut pas oublier que les œuvres des Pères charriaient en elles une quantité énorme de données philosophiques, indications plus ou moins développées d'un grand nombre de doctrines grecques, anonymes ou non ; il y avait là un trésor de données, mais de données

\section{1-b.}

155 564-a-b ; cf. 544-a : c'est par l'intuition de l'âme (contuitus animi) et le pur intellect que l'on connaît les raisons primordiales.

156 Ainsi, c’est elle qui distingue Dieu principe et Dieu fin : ce sont là des formes non de Dieu, mais de notre raison.

157 459-b.

158 557-b ; les théophanies désignent la vision de Dieu par les anges et par les élus ; cf. 449-a-c, où il s’appuie sur Maxime le Confesseur.

159 601-c. 
éparses, qui, en l'absence des œuvres originales, étaient impossibles à systématiser, surtout pour des hommes qui n'en éprouvaient nullement le besoin. La philosophie grecque y est donc présente à l'état d'excerpta. De plus, il y a contre elle, même chez Jean Scot, cette méfiance de principe qui dérive d'un fameux verset de saint Paul ; il ne confond pas la «philosophie pieuse » ${ }^{160}$, c'est-à-dire la raison appuyée sur l'Écriture, avec celle des « sages du monde ». " Chez ceux qui s'exercent à l'étude de cette philosophie du monde, il n'est pas nécessaire de demeurer trop longtemps ${ }^{161}$. »

Quel séjour y a-t-il fait lui-même ? Dans le De divisione naturae, il parle souvent des philosophes, et il introduit, sous le nom des Pères,

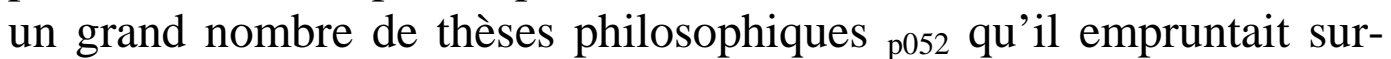
tout à leurs commentaires sur la création des six jours. Il est peu curieux des subtilités logiques, et il s'attache comme spontanément aux thèses des platoniciens qui critiquent Aristote. Le titre même de son ouvrage, De divisione naturae, revient, par Maxime le Confesseur, à la fameuse division initiale du Timée en être et devenir; il classe moins qu'il ne hiérarchise ; il ne parle guère de la définition que pour en discuter la possibilité ${ }^{162}$, des catégories que pour dire qu'elles s'appliquent seulement aux créatures ${ }^{163}$; mais c'est surtout à Platon, par Chalcidius, que revient son image du monde. C'est en platonicien qu'il pense à la matière et à la forme : certes, ses idées sur la matière sont assez incertaines : mais il donne la définition du Timée, dont il rapproche celles de saint Augustin et, de Denys ; dans les commentaires de plusieurs des Pères sur la Genèse, il retrouve cette matière, ce quasi-néant, sous les mots de ténèbres et de vide ${ }^{164}$ : il n'a pas la moindre idée de la thèse aristotélicienne qui fait de la matière un terme relatif. La notion de la forme est également toute platonicienne. En Dieu sont les Idées ou formes éternelles, qui sont des «volontés divines »; ces formes sont supérieures à la matière corporelle et au

\footnotetext{
160 De divisione naturae, VI, t. CXXII, 600-a.

161 Ibid., p. 713-a.

162 De divisione, 483-a ; 586-d ; 587-a ; cf. 499-d.

163 462-d, 463-d.

164 500-c-d ; cf. 548-b. Cf. aussi le Commentaire de Boèce, LVI, p. 36, 13-19. Il est vrai que, auparavant $(34,31)$, il identifiait la matière aux quatre éléments ; cf. aussi De divis. ; 604-e ; 605-c ; 606-a.
} 
temps ; ce sont les " véritables formes », et c’est par abus que l'on appelle formes les genres et les espèces qui sont dans les corps et qui donnent leurs noms aux choses ${ }^{165}$. Jean Scot, platonicien, n'est donc pas réaliste ; car l'objet propre de la dialectique, ce ne sont pas pour lui ces formes éternelles, mais les noms des espèces qui, dans les choses matérielles, proviennent de ces formes ${ }^{166}$.

p053 La théorie platonicienne des idées a une parenté certaine avec la théorie des germes (semina) que soutenait saint Augustin et que Jean Scot attribue aux "philosophes " ${ }^{167}$; le germe est, dans l'individu, une raison séminale qui contient ses caractères essentiels.

Le monde provient donc de l'information de la matière par les Idées : de cette thèse est solidaire, chez les néoplatoniciens, celle de l'éternité du monde. Jean connaît les " philosophes du siècle » qui ont proclamé la matière extérieure et coéternelle à Dieu ${ }^{168}$, ceux aussi qui ont affirmé l'éternité du monde. Et il semble qu'il ait cru lui-même, sinon à l'éternité, au moins à la " sempiternité » du monde. "La sempiternité, écrit-il dans le Commentaire de Boèce, est ce qui s'écoule à travers le temps, sans fin ni commencement, tels que sont les étoiles et le ciel qui ont été créés sans commencement. C’est pourquoi le psalmiste dit : « Il dit et les choses furent faites », c'est-à-dire il engendra le Fils par l'intermédiaire de qui, en même temps, tout fut créé. Et il n’y a en effet aucun intervalle de temps entre la génération du Fils et la création du monde, parce que la génération du Fils a été la création du monde ${ }^{169}$. » Tout se passe ici comme dans la doctrine de Plotin, où un monde intelligible éternellement engendré par l'Un n'a jamais cessé de projeter ses reflets sur la matière pour créer le monde sensible. Le temps et le lieu sont les conditions propres à cet univers ${ }^{170}$; ils

165 De divisione, 610-b ; Commentaire de Boèce, LVI, p. 37, 5-13 et 33-35. Il connaît aussi, d'après Boèce, le nombre substance de Pythagore qu'il oppose au nombre arithmétique, 651-b et 652-a.

166 Comment. à Marcianus Capella, p. 8 ; cf. PrantL, XXVIII, p. 28 ; cf. aussi De div., 869-d, où il assimile la rhétorique et la grammaire à la dialectique.

167 584-b.

168 637-a, 664-c.

169 LVI, 42, 30 sq. ; l'éternité des arts, dont parle Jean Scot (De divis., 486-c), était un argument courant pour démontrer l’éternité du monde.

170 De divis., 467-d ; 489-a ; 507-d. 
sont eux-mêmes des êtres incorporels et non pas, comme certains le disent du lieu, des corps ${ }^{171}$. Jean Scot connaît enfin la thèse platonicienne qui complète toutes celles-ci, celle de l'animation universelle de toutes choses et celle de l'âme du monde : cette vie universelle, il la trouve affirmée dans le Timée, mais aussi chez le poète Ovide et chez le naturaliste ${ }_{\text {p054 }}$ Pline, et les Pères eux-mêmes, saint Augustin, Basile, Grégoire de Nysse, s'accordent ici avec les philosophes ${ }^{172}$, sans pourtant qu'ils paraissent admettre avec eux une âme du monde. Ainsi l'univers que se représente Jean Scot est l'univers platonicien, celui dans lequel les causes, qui sont de nature spirituelle, ont une multiplicité d'effets ${ }^{173}$, tandis que les corps ne sont causes d'aucun effet $^{174}$; chaque élément, par exemple, doit son action à la qualité immatérielle qui réside en lui, et avec laquelle on peut même l'identifier ${ }^{175}$.

Les connaissances astronomiques de Jean Scot sont liées à cette image platonicienne de l'univers ; il ne sait rien de la physique aristotélicienne des sphères qui implique un géocentrisme absolu; et si, avec le Timée, il place la terre au centre du monde ${ }^{176}$ et affirme son absolue stabilité, il se complaît pourtant dans un héliocentrisme partiel, que Chalcidius lui fait connaître d'après Héraclide : Jupiter, Mars, Vénus et Mercure tournent en effet, selon lui, autour du soleil ${ }^{177}$.

Les excerpta philosophiques de Jean Scot ne sont pas, on le voit, malgré quelque fatras d'érudition, juxtaposition incohérente ; sans intention bien nette de sa part, ils tendent vers un système dont les traits (dédain de la dialectique, opposition des idées et de la matière, animation universelle, microcosme, possibilité d'une astronomie héliocentrique), qui s'ajustent ensemble, sont tous d'origine platonicienne. Mais ce n'est ni le but ni le désir de Jean Scot de faire de cette image

\footnotetext{
171 Ibid., 886-a-b ; 487-c.

172 476-c ; 728-a-b ; 735-c.

173 602-b.

174 606-c.

175 604-d ; 605-c ; 712-6. Selon le dogme platonicien, Jean Scot compose les corps de tous les éléments (713-c ; 606-a), qui se modèrent l'un l'autre (Cf. Plotin, Ennéade II, 1, 7).

176 476-a. -

177 698-a ; cf. DUHEM, XV, t. II, p. 58.
} 
un système autonome, dont la vérité pourrait être prouvée par l'expérience ou par le raisonnement. Il s'agit seulement de savoir si ces « doctrines des sages » peuvent nous aider à comprendre les vérités de foi du christianisme.

Pourtant ces doctrines acquièrent une singulière importance, à cause de la nouvelle autorité patristique que Jean Scot p055 utilise en Occident, celle de Denys l'Aréopagite, qui ne cessera de s'exercer pendant tout le Moyen Age. Ce n'est pas Jean Scot qui a introduit Denys : dès 758, le pape Paul I ${ }^{\mathrm{er}}$ envoya à Pépin le Bref les écrits de l'Aréopagite ; mais il ne reste pas de trace de l'influence qu'ils ont pu avoir à cette époque ; en revanche, en 827 , les envoyés de l'empereur Michel le Bègue apportèrent en présent à Louis le Pieux la collection en grec des ouvrages de Denys : Hilduin, abbé de Saint-Denis depuis 815, ne fut sans doute pas étranger à cet envoi, qui enrichissait son monastère de l'œuvre de celui qui était alors considéré comme le juge de l'Aréopage, converti par saint Paul à Athènes, et comme le patron de la France. Entre 827 et 835, Hilduin traduisit ou fit traduire la collection complète des écrits de Denys ${ }^{178}$. L'autorité de Denys était donc déjà bien établie lorsque, vers 860 , Jean Scot entreprit à son tour de traduire les œuvres de Denys : peu avant cette époque, en 859, Hincmar de Reims citait Denys dans la traduction d'Hilduin ${ }^{179}$. Hilduin lui-même, dans un récit de la passion de saint Denis, qui a été lue très fréquemment pendant tout le Moyen Age, consacre toute une série, de chapitres (IX-XVI) aux écrits de l'Aréopagite et à sa correspondance ${ }^{180}$. L'aréopagitisme latin n'est donc pas dû à l'initiative de Jean Scot : pas plus en ce domaine qu'en tout autre, il n'a voulu introduire de nouveauté ${ }^{181}$.

Sa traduction, qui a sans doute utilisé Hilduin, avec les Commentaires qu'il écrivit, est en tout cas une œuvre importante, puisque aucune autre ne fut entreprise jusqu'à la fin $\mathrm{du}^{\mathrm{XII}}{ }^{\mathrm{e}}$ siècle. La méthode

178 Le R. P. Théry a retrouvé cette traduction complète d’Hilduin dans le manuscrit 903 de la Bibliothèque royale de Bruxelles ; cf. ses Études dionysiennes, I Hilduin traducteur de Denys, LVIII, p. 37.

179 LVIII, p. 147-155 ; dans le De Praedestinatione.

180 LVIII, p. 20-22 ; cf. p. 155. Le P. Théry a retrouvé la main d’Hilduin dans des fragments d'écrits attribués à Scot (P. L., t. CXXII, p. 265-268), p. 157.

181 Cf. 829-b, où il se défend contre le reproche qui lui en a été fait. 
de traduction qui consiste à mettre ${ }_{\mathrm{p} 056}$ un mot latin sous chaque mot grec n’arrive pas toujours à la rendre exacte et compréhensible ; il n'en découvrit pas moins, chez ce platonicien chrétien, une image de la réalité métaphysique qui cadrait admirablement avec les excerpta des philosophes.

Le De divisione naturae, où Denys et son commentateur Maxime sont cités une cinquantaine de fois, peut nous apprendre ce qu'il y trouvait : d'abord l'assurance que Denys ne dépasse pas, dans sa théologie, l'Écriture sainte ${ }^{182}$; puis la théologie négative issue du platonisme ne déterminant Dieu que comme non être ${ }^{183}$; la cause première, d'une fécondité illimitée, est le Bien ${ }^{184}$; il y retrouve cette fusion de la transcendance et de l'immanence qui caractérise la théologie néoplatonicienne: Dieu est à la fois en tout et au-dessus de tout ${ }^{185}$; il devient tout ${ }^{186}$; il est tout en tout ${ }^{187}$; tout est participation à son essence ${ }^{188}$; car tout préexiste éternellement dans le Verbe ${ }^{189}$, qui est en somme un monde intelligible, un Dieu à la fois créateur et créé ${ }^{190}$. De cette manière de concevoir la causalité dépend l'aspect que prend chez Denys le grand thème commun de la pensée chrétienne : l'origine de l'homme à partir de Dieu et son retour à Dieu : il a une couleur platonicienne bien marquée : Dieu ou la cause est à la fois principe et fin des êtres ; mais c'est surtout à titre de fin qu'il apparaît : l'Amour, comme chez Platon, est le principe de l'union de la créature avec Dieu ${ }^{191}$; c'est aussi un principe néoplatonicien que toute multiplicité est une ${ }^{192}$; l'homme peut être ainsi un en Dieu ${ }^{193}$, d'une union sans confusion analogue à celle des rayons lumineux dans

\footnotetext{
182 509-b.

183 458-b-c ; 461-b. : supériorité de la théologie négative ; 516-c : Dieu non-être ; cf. 757-c, 759-c.

184 627-c ; 786-a.

185 645-a ; 645-b.

186 671-b.

187 682-a-d ; cf. 633-a : il fait tout et devient en tout.

188 644-a.

189 640-d.

190 650-c.

191 519-b.

192 737-d.

193 879-b-c.
} 
leur source ou à celle des sons dans un accord ${ }^{194}$ : Jean Scot remarque chez ${ }_{\text {p057 }}$ Denys et chez Maxime ces métaphores, issues du platonisme et peut-être, plus loin, du mazdéisme, qui flottent dans toute la pensée théologique du Moyen Age : il y a une lumière immatérielle qui remplit pourtant le monde sensible ${ }^{195}$. Jean Scot trouve chez Denys bien d'autres pièces de sa vision de l'univers : la hiérarchie angélique ${ }^{196}$, la théorie des causes primordiales ${ }^{197}$; mais sa pensée s'ordonne autour des grandes thèses que nous avons indiquées.

Denys l'Aréopagite n'est pourtant pas, pour Jean Scot, la plus grande des autorités ; au-dessus de lui, il place saint Augustin et Grégoire de Nysse ; mais il est clair que, chez l'un comme chez l'autre, il trouve surtout de quoi confirmer et compléter le platonisme de Denys : à l'un et à l'autre, il demande certes les interprétations de l'Écriture que l'on ne trouvait pas chez Denys, notamment sur la création des six jours, à propos de laquelle il utilise aussi saint Ambroise. Mais, sous tous les autres rapports, il voit dans saint Augustin un platonicien qui affirme que les idées sont éternelles ${ }^{198}$, que tous les siècles existent, incréés, dans le Verbe ${ }^{199}$, qui nie (ainsi qu'après lui Boèce) que les catégories puissent s'appliquer à Dieu ${ }^{200}$, qui voit la substance de la créature dans son être en Dieu ${ }^{201}$, qui fait de la matière un quasi-néant ${ }^{202}$. Jean Scot a pourtant retenu quelques traits plus spécifiquement augustiniens, concernant la dignité et la valeur de l'âme, et la hiérarchie des perfections qui place l'âme d'un ver audessus du soleil ${ }^{203}$, l'image «très fameuse » de la Trinité en l’homme ${ }^{204}$, la connaissance des vérités éternelles par l’âme hu-

\footnotetext{
194 883-b.

195 526-a : cf. 608-6 : sur la manière dont le rayon solaire devient visible.

196773 c-d ; 863-c ; cf. 596-d : sur la nature du savoir angélique.

197 554-c ; 617-a ; 622-b-623-c.

198 558-d ; cf. 482-b : sur l'antériorité du nombre par rapport au temps et à l'espace qui en expriment les rapports.

199 640-b. -

200 463-b. -

201 770-c. -

202 500-c.

203 531-b ; 766-a ; 784-c-d.

204 568-d.
} 
maine ${ }^{205}$, sans compter des détails épars de la psychologie augustinienne ${ }^{206}$. p058 Tous ces traits du subjectivisme occidental sont étrangers au platonisme oriental de Denys, qui tend à absorber le sujet dans la contemplation, et ils ont pu, jusqu'à un certain point, faire échec à ce platonisme dans l'esprit de Jean Scot.

Malgré cette réserve, son De divisione naturae n'en reste pas moins une des œuvres qui ont le plus contribué à affirmer dans l'Occident le platonisme, considéré comme contemplation de la structure de l'univers plutôt que comme vie intérieure de l'âme religieuse. Jean Scot traite en cette œuvre l'unique sujet de toute la pensée médiévale : comment la nature humaine, venue de Dieu comme principe, retournera-t-elle à Dieu comme fin ? C'était déjà le plan des Sentences d'Isidore de Séville, ce sera aussi celui des Sentences de Pierre Lombard et, après lui, des Sommes du XIII ${ }^{\mathrm{e}}$ siècle : toutes les choses n'ont de réalité et d'essence que par rapport à cette origine, de sens et de valeur que par rapport à cette fin. L'originalité des penseurs consistera dans la manière dont ils conçoivent ce thème qui leur est imposé. Et Jean Scot le traite sans en avoir pleinement conscience ; car il ignore l’origine dernière des autorités patristiques dont il use en platonicien.

Maxime le Confesseur lui suggère la division des êtres en quatre espèces : celui qui crée et n’est pas créé, c’est Dieu, comme principe ; celui qui crée et qui est créé, c’est le Verbe ; celui qui ne crée pas et qui est créé, c'est l'homme ; celui qui ne crée pas et qui n'est pas créé, c'est Dieu comme fin. L'aboutissement (ou le salut) est l'union des créatures en Dieu, où le monde s'anéantit. Mais le Dieu, qui est notre fin, n'est différent que par la pensée du Dieu qui est principe ${ }^{207}$; et le mouvement qui mène de l'un à l'autre n'est pas un mouvement temporel qui tombe sous les catégories ${ }^{208}$. p059 Il faut éviter de penser à Dieu comme à un être déterminé. Dieu lui-même ignore qui il est (quid sit) ; car quiddité implique finité ; mais cette ignorance est chez lui la science suprême ${ }^{209}$. Cherchant en Dieu les causes primordiales

\footnotetext{
205759.

${ }^{206}$ La sensation, passio corporis, 569-b; la distinction entre l'image et l’imagination, 659-b ; la division de l'âme, 755-c.

207 528-b-d. -

208 598-b-d.

209 589-a ; 598-b. : cf. la Docta ignorantia de Nicolas de Cuse.
} 
des êtres finis, nous divisons en lui ces causes et nous les classons en genres et en espèces : mais c'est l'intelligence qui, en les contemplant, les isole et les sépare ainsi les unes des autres ${ }^{210}$. De ces causes primordiales, qui sont les formes éternelles, nous séparons les choses créées à leur image : séparation encore fausse : toutes les choses sont à la fois éternelles et créées (aeterna et facta); de même que, dans l'unité, sont éternellement tous les nombres avec toutes leurs propriétés, que l'arithmétique découvre une à une, de même, dans le développement temporel, il n’y a rien qui n'ait été dans l'éternité, et comme, dans l'éternité, tout est Dieu, l'on peut dire que, dans le temps, tout est Dieu également ${ }^{211}$. Et l'on ne peut dire que ce mouvement par lequel Dieu parcourt toutes choses s'oppose en rien à son immutabilité ; Dieu ne se meut qu'en tant qu'il est principe du mouvement ; " on dit qu'il " court », non parce qu'il court hors de lui, mais parce qu'il fait courir toutes choses de la non-existence à l'existence ${ }^{212}$; ce mouvement est identique à son éternelle volonté créatrice, qui n'est elle-même que son être ou sa nature ; c'est pourquoi l'on peut dire qu'il est créé en même temps que créateur, créé en ce sens que le Verbe divin naît dans l'esprit par la vertu, ou en ce sens que l'intellect, d'abord invisible et inconnu, se manifeste dans l'âme au contact des choses sensibles ${ }^{213}$; la créature, prise à part de Dieu, n'est rien, et en ce sens elle a été créée ex nihilo ; elle est alors Dieu se manifestant ; la création est théophanie ${ }^{214}$.

p060 Dès lors, la Trinité, chez Scot, ressemble plus à la triade plotinienne qu’à la Trinité orthodoxe, le Père unité indistincte, le Fils contenant les causes primordiales dans toute leur simplicité et leur unité, le Saint-Esprit les divisant et les distribuant en genres et en espèces ${ }^{215}$; chaque personne est comme une étape dans le passage de l'un au multiple. Jean Scot le fait comprendre par l'image de la Trinité dans l'âme humaine, qui est le ternaire des facultés: intellectus

\footnotetext{
210 619-b ; 630-a.

211 634-a ; 690-b.

212 Comme chez Plotin, le mouvement divin est un mouvement éternellement achevé.

213 Livre I, ch. XII.

214 Ibid., ch. XIII, 454-d ; 455-b.

215 556-a ; 566-d.
} 


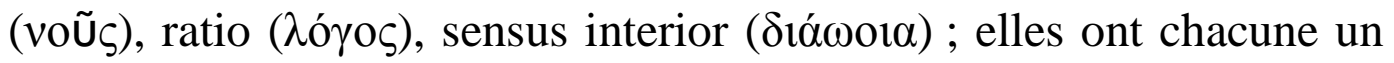
objet distinct qui est respectivement Dieu, le Principe et la diversité des genres ; mais le mouvement de chacune vient de la précédente et, après avoir été jusqu’à la dernière, revient à la première ${ }^{216}$.

Jean Scot a donc parfaitement saisi la sorte de rythme compensateur, qui est l'essentiel dans l'intuition néoplatonicienne des choses. Il tente même d'y faire voir, avec les faibles moyens dont il dispose, une propriété universelle des êtres. Le cycle qui ramène les choses à leur origine est partout dans la nature : période des astres, période des saisons, période du flux et du reflux, tout témoigne en faveur de l'adage : «Finis totius motus est principium sui ${ }^{217}$. " Les arts libéraux sont appelés en témoignage : la dialectique avec sa classification qui progresse du genre suprême aux espèces infimes pour revenir, par degrés, au genre suprême, l'arithmétique qui, partant de l'unité pour découvrir progressivement les nombres et leur rapport, remonte vers l'unité qui les mesure ${ }^{218}$. Enfin il en trouve une nouvelle preuve dans « l'appétit d'être » commun à tous, bons et méchants ${ }^{219}$.

C’est par ce schéma néoplatonicien que sont interprétés et rendus clairs à la vraie raison les dogmes chrétiens, création, chute, rédemption et fin des temps. Cette interprétation suppose ${ }_{\text {p061 }}$ une théorie de l'homme considéré comme microcosme, telle qu'on pouvait la trouver chez Philon et bien des interprètes de la Bible : la nature entière est solidaire de l'homme ; le Paradis, dans lequel Dieu a créé l'homme et les animaux, représente le monde intelligible où tous les êtres sont éternellement produits par Dieu, dans leur variété et leur unité. Le péché qui a causé la chute consiste pour l'homme à se donner tout entier à l'animalité, qui n'est qu'un élément de sa nature. Il n'y a donc pas d'autre Paradis dont l'homme ait été chassé que la nature humaine elle-même ; par ses désirs charnels et ses appétits, il est devenu semblable aux bêtes. Cette chute, Jean Scot l'a comprise comme Plotin faisait la «descente » de l'âme ; il n’y a pas réellement descente, car

\footnotetext{
216 566-d :579-a.

217 866-c sq.

218 869-a sq.

219 868, Appetitus essendi, qui est aussi bene essendi et perpetualiter essendi, en somme le désir de Dieu.
} 
la partie supérieure de l'âme reste au monde intelligible ; de même Jean Scot admet que la nature n'a pas réellement abandonné son principe, et c'est ainsi qu'elle peut y revenir ; « elle reviendra d'où elle est partie, surtout parce qu'elle n'en est pas tellement partie qu'elle ait tout à fait abandonné son principe ${ }^{220}$, et il est toujours vrai de dire avec l'Apôtre : «En lui nous avons l'être, le mouvement et la vie. » Cela peut se dire de toutes les natures : en effet avec la chute commencent le déroulement du temps, et toutes les misères qui lui sont attachées ; la mort, les désirs, la tristesse ${ }^{221}$; or, peut-on dire que les substances des choses créées s'éloignent à ce moment des causes primordiales pour aller dans le lieu et dans le temps ? Nullement : «De même que les causes primordiales ne quittent jamais la Sagesse, les substances qu'elles produisent subsistent toujours en elles et ne peuvent s'écouler en dehors de leurs causes ${ }^{222}$ " ; il n’y a d'ailleurs entre les Causes, identiques au Verbe, et les substances d'autre différence que celle qu'il y a entre le genre et les espèces infimes ou raisons singulières, si bien que les substances ne sont pas dites créatures au sens propre, mais 062 seulement par image ${ }^{223}$. Ce qui est dans le temps et dans l'espace, ce sont des accidents ou des agrégats d'accidents ${ }^{224}$ : le monde temporel a, chez Jean Scot, la même irréalité substantielle que chez un platonicien.

Jean Scot prend donc toutes ses précautions pour que la chute n'introduise pas un hiatus dans la continuité du réel. L’incarnation du Verbe est pourtant nécessaire pour assurer plus solidement cette continuité : " Le Verbe de Dieu, qui contient en lui toutes les causes, est venu dans les effets de ces causes, c'est-à-dire dans le monde sensible, afin de sauver, selon son humanité, les effets de ces causes qu'il a éternellement en lui et de les ramener à leurs causes. " Le Verbe incarné prend donc l'initiative du retour à Dieu à partir du point extrême où la réalité s'en est le plus éloignée ; mais sa mission n'a rien d'une initiative d'amour ; c'est son être même qui est en jeu : " Si la Sagesse de Dieu ne descendait pas dans les effets des causes, la notion même

\footnotetext{
220 871-c.

221 862-b.

222 885-d ; 886-d.

223 887-a ; 888-a.

224 886-a-b.
} 
des causes (ratio causarum) disparaîtrait; les effets disparaissant, nulle cause ne persisterait, comme nul effet ne resterait après la disparition des causes ${ }^{225}$ "; ce sont là termes relatifs qui s'impliquent : le Verbe n'est que l'instrument de cet immense rythme compensateur grâce auquel il y a de l'être.

Ici, Jean Scot quitte le néoplatonisme : dans le néoplatonisme, où l'homme est capable de se racheter par la connaissance de sa propre origine, la descente du Verbe ne serait qu'un inutile doublet de la chute de l'homme. Chez Jean Scot, bien que par suite d'une incohérence, la notion de la grâce persiste ; il faut distinguer, venant de Dieu, le don naturel (datio), participation à Dieu par laquelle les choses existent et sont à lui comme le langage est à l'intelligence, et la grâce (donatio), par laquelle les choses, écartées de leur origine, y reviennent ; la grâce est le rétablissement de l'état primitif ${ }^{226}$ : c'est par ${ }_{\text {p063 }}$ suite de cette incohérence qu'il a pu donner place à la rédemption.

Quant au retour des choses à leurs principes, il est dominé, chez Jean Scot, par une notion qui est étroitement liée à la théorie de l'Homme: c'est la notion que l'on pourrait dire alchimique de la transmutation, qui, elle aussi, est étrangère au platonisme de Plotin. Les étapes de ce retour sont au nombre de cinq : la mort de la chair, que l'on devrait plutôt appeler mors mortis, la résurrection, la transmutation du corps en esprit, le retour de l'esprit aux causes primordiales, et enfin le mouvement de l'esprit avec ses causes jusqu'en Dieu. Jean Scot reconnaît qu'il est fort peu aidé par les autorités pour comprendre ce retour ${ }^{227}$; chez les Latins, les Pères s'arrêtent en général à la deuxième étape, dont ils ne disent même rien de précis ; il faut demander aux Grecs, surtout à Grégoire de Nysse et à Maxime, comment le corps se transmue en esprit ${ }^{228}$. Il a donc conscience d'arriver ici à des questions où la réflexion des Pères n’a guère pénétré, bien qu'il s'agisse d'un dogme essentiel au christianisme, celui de la fin des temps Son idée foncière est que la transmutation d'un être en un être supérieur n'est pas du tout un anéantissement, mais un salut;

\footnotetext{
225 910-с ; 913-с.

226 630-а ; 634-a ; 903-906.

227 741-c; 744-b.

228 877-b ; 879-a ; 899-a.
} 
c'est là un processus universel de la nature : « Les choses inférieures sont attirées et absorbées naturellement (naturaliter) par les supérieures, non pas pour ne pas être, mais pour être sauvées en elles et ne faire qu'un ${ }^{229}$ " ; la substance, même des corps, est intelligible, et il ne faut pas s'étonner que les substances intelligibles puissent s'unir de façon à ne faire qu'un, bien que chacune ne cesse de garder sa propriété et sa subsistance ; c'est le monde intelligible de Plotin avec ses intelligibles qui restent singuliers, tout en s'interpénétrant, et l'on trouve, chez Jean Scot, l'exemple d'union que Plotin a si souvent emprunté à Aristote : toutes choses sont unies à p064 Dieu, de même que « ce qui comprend est un avec ce qui est compris " ${ }^{230}$. Le retour à Dieu aboutit donc à un mode d'union qui conserve tous les êtres, en les rendant éternels : "Alors seront éternelles non seulement les causes, mais leurs processions, que les savants appellent effets (effectus), à cette condition pourtant que les processions ne persistent pas en elles-mêmes, mais qu'elles retournent à leurs causes ${ }^{231}$. " Avec la nature humaine, qui comprend tout, tout revient ainsi à Dieu, mais pourtant à des degrés différents ; Jean Scot distingue en effet, du retour général, des retours spéciaux, "dans les êtres qui non seulement seront rappelés aux principes de la nature, mais iront, au delà de toute dignité naturelle, jusqu'à la cause de toutes choses qui est Dieu ${ }^{232}{ }$. Ainsi se maintiendra dans l'union une hiérarchie qui projette dans l'éternel l’idéal social de l'époque.

Pareille théorie impliquait le salut des démons et la négation des peines éternelles. Jean Scot ne recule pas devant ces conséquences. La vraie raison enseigne que rien de contraire à la bonté de Dieu ne peut lui être coéternel. Sa bonté absorbera la malice, comme sa vie éternelle la mort, et sa béatitude la misère ${ }^{233}$. Et Jean Scot invoque une autorité pour lui, celle du " grand Origène », dont il cite un long passage du livre Des Principes ${ }^{234}$.

\footnotetext{
229 879-a.

230 876-b.

231 909-a.

232 1001-c.

233 926-d.

234 929-a.
} 
Avec Jean Scot, l'Occident voit revivre, comme vraie philosophie et produit de la vraie raison, tout l'essentiel des conceptions platoniciennes, fortement altérées par l'idée chrétienne et gnostique de la fin des temps, L' " érigénisme » a pour caractères essentiels de substituer à la foi et à l'expérience religieuse la considération de la structure métaphysique des choses et de remplacer le drame personnel et individuel du salut par la nécessité universelle d'une loi qui fait retourner tout à son principe ${ }^{235}$ : ou plutôt le cours de la nature y est ${ }_{\text {p065 }}$ confondu avec l'événement surnaturel du salut, et la notion de toute loi précise et constante finit par se perdre dans l'indétermination absolue de Dieu : " Beaucoup de choses arrivent contrairement au cours de la nature, afin qu'il nous soit montré que la Providence divine peut tout conduire d'une infinité de manières et non d'une seule ${ }^{236}$. »

Table des matières

III.

LE PANTHEISME.

S'il y a un mouvement panthéiste au $\mathrm{IX}^{\mathrm{e}}$ siècle, ce n'est pas chez Jean Scot qu'on le trouvera, chez un penseur attentif, suivant la tradition plotinienne et dionysienne, à sublimer l'individu en Dieu et non à le supprimer. Le panthéisme du $\mathrm{IX}^{\mathrm{e}}$ siècle se rattache à une influence toute différente, à la théorie de l'âme du monde que l'on trouvait dans le Commentaire du Songe de Scipion de Macrobe. Dans un ouvrage attribué à Bède, le De mundi caelestis terrestrisque constitutione, mais qui ne peut avoir été écrit qu'au $\mathrm{IX}^{\mathrm{e}}$ siècle et peut-être même après Jean Scot qui ne paraît guère connaître Macrobe ${ }^{237}$, l'auteur se plaint de voir se répandre une doctrine dont les termes sont empruntés au chapitre XIV du livre I du Commentaire de Macrobe. D'après cette doctrine, "de même qu'un visage unique peut se montrer dans plusieurs miroirs, que plusieurs visages peuvent se refléter dans un seul miroir, de même une âme unique se trouve en toutes choses, et, partout, elle est en possession de toutes ses puissances, bien qu'elle les

\footnotetext{
235 Il est bien entendu qu'il faut admettre avec Dom Cappuyns, que jamais Jean Scot n'y a vu autre chose qu'une interprétation du christianisme.

236 De div. nat, III, 16 ; cf. Aug. FAUsT, XVII, t. II, p. 70 sq.

237 DUHEM, XV, 7, t. III, p. 77-78.
} 
exerce diversement dans les divers corps selon l'aptitude de chacun d'eux ${ }^{238}$. L'auteur va tirer les conséquences : " Un homme ne saurait être pire ${ }_{\mathrm{p} 066}$ qu'un autre, car dans tous les corps réside une même âme qui est par nature bonne et immaculée... L'homme ne meurt jamais ;... on dit qu'il meurt lorsque l'âme cesse d'exercer en lui ses puissances de la manière qu'elle les exerçait jusque-là. » Ce mouvement vient peut-être de l'Irlandais Macarius Scot, qui eut ses partisans à l'abbaye de Corbie ${ }^{239}$ : il se continue sans doute dans bien des hérésies du Moyen Age ; il rejoindra plus tard l'averroïsme.

Table des matières

IV.

\section{LES COMPILATEURS ET HUMANISTES.}

L'esprit d'Alcuin, c'est-à-dire celui de Bède et d'Isidore de Séville, se propagea sur le continent au $\mathrm{IX}^{\mathrm{e}}$ et au $\mathrm{X}^{\mathrm{e}}$ siècle. La plupart de ceux que nous allons citer sont à la tête des grandes abbayes de la chrétienté, Saint-Martin de Tours, Fulda, Corbie; plusieurs sont évêques ; aucun n'est étranger à la politique ; tous sont des humanistes qui ne conçoivent pas que la culture des clercs soit possible sans la lecture de ce qui reste des auteurs classiques.

Sous l'influence des " Scots », on se remet à apprendre le latin : on écrit des collections d'extraits de manière à avoir à sa disposition, pour les sermons et les commentaires, un trésor de maximes morales et de modèles littéraires. Sedulius Scotus, qui écrivit sous Charlemagne un De rectoribus christianis, où il enseignait les devoirs d'un roi chrétien, est l'auteur d'extraits de ce genre. A côté des écrivains littéraires et historiens comme Orose, les auteurs de l'Histoire auguste, quelques discours de Cicéron, on y trouve des moralistes et des philosophes, les Sentences de Sextius le Pythagoricien, le De Moribus attribué à Sénèque, 0067 les Tusculanes et les Paradoxes de Cicéron, le Songe de Scipion de Macrobe, les Mémorables de Valère-Maxime, une collection de proverbes grecs. Les Irlandais recouraient, semble-til, non seulement aux manuscrits qu'ils avaient collectionnés dans leur

\footnotetext{
${ }^{238}$ P. L., t. XC, p. 902-903.

239 RENAN, Averroès et l'averroïsme, p. 101-102.
} 
pays, mais à ceux qu'ils trouvaient sur le continent ${ }^{240}$. Il n’y a rien dans tout cela que de fragmentaire, rien qui les poussât à comprendre d'ensemble les doctrines qu'ils touchaient. Ils y trouvaient en revanche quantité de notions morales définies : le livre IV des Tusculanes, que Sedulius connaît presque en entier, contient les définitions des passions, classées par genres et par espèces, et des discussions sur l'impassibilité du sage, et le livre V, qu'il connaît aussi, soutient que la vertu est suffisante au bonheur. De Valère-Maxime, il a retenu des passages sur le bonheur du sage (VII, 1-2) et sur la vie simple (IX) ; si l'on y ajoute la définition des vertus cardinales qu'il a recueillies au De Inventione (II, 159) de Cicéron, l'on verra que ses préoccupations répondent à celles de saint Nil en Orient, de saint Martin de Braga, de saint Ambroise, de tant d'autres qui introduisirent dans le cloître un peu de la sagesse morale des anciens.

Les extraits du Songe de Scipion de Macrobe, tirés des chapitres XIV à XVI du livre II, ont pour sujet les objections que les platoniciens adressaient à Aristote au sujet de la nature de l'âme ; c'était le commentaire du fameux passage du Phèdre, où Platon définit l'âme un « mouvement qui se meut lui-même "; Aristote, au VIII ${ }^{\mathrm{e}}$ livre de la Physique, montrait qu'il y avait là un concept contradictoire, puisque le moteur doit toujours être distinct du mobile ; ce sont les objections d'Aristote que réfute Macrobe, qui voit dans l'âme le principe de son propre mouvement, et qui en conclut « qu'elle ne peut naître de rien autre ; car, si elle naissait de quelque chose, elle ne serait pas principe ». Sedulius cherchait, semble-t-il, dans ces textes p068 des éclaircissements sur le problème de la nature et de l'origine de l'âme, dont s'était tant inquiétée la génération précédente. Il complétait son information métaphysique par des extraits des Pères, de Lactance ${ }^{241}$, sur l'origine de la matière, de saint Ambroise ${ }^{242}$ sur diverses opinions relatives à l'origine du monde.

Fridugise, venu d'Angleterre avec Alcuin, lui succéda à l'abbaye de Saint-Martin de Tours, et, de 819 à 834, fut chancelier de Louis le

\footnotetext{
240 S. HellmanN, LXI, p. 99-102 ; cf. p. 107-114. L’édition du De rectoribus christianis se trouve p. 19-91.

241 Institution Divine, L. II, § 9.

242 Exameron, L. I, § 1-4.
} 
Pieux ; il écrit une lettre De nihilo et tenebris, où, à la suite d'Isidore de Séville, il s'essaye timidement à découvrir par le raisonnement et l'autorité le sens du mot nihilum dans l'expression creatio ex nihilo ; il faut avouer qu'on croirait lire quelque sophisme d'un Euthydème qui se prendrait au sérieux ; en disant : le rien est néant, on lui attribue 'être ; d'autre part, tout nom a une signification : le nom nihil veut donc dire quelque chose ; « les ténèbres étaient », dit l'Écriture, il faut donc qu'elles soient quelque chose ${ }^{243}$.

Un autre élève d'Alcuin, Raban Maur, né à Mayence vers 780, élève à Saint-Martin de Tours, fut maître à l'abbaye de Fulda, dont il devint l'abbé en 822 ; il fut archevêque de Mayence en 847 et mourut en 856. Il expose ainsi, dans le De Universo ou De rerum naturis, ce qu'était l'idéal d'un clerc instruit à cette époque : scientiae plenitudo, c'est-à-dire là science des saintes écritures, avec un commentaire à la fois historique et allégorique, qui suppose la connaissance des arts libéraux ; vitae rectitudo, eruditionis perfectio, c'est-à-dire l'élégance de langage que l'on acquiert par la pratique des bons auteurs. Luimême, il accomplit ce programme, en faisant des extraits des commentaires allégoriques de la Bible ${ }^{244}$, en écrivant une encyclopédie, qui est une sorte de p069 réédition des Étymologies d'Isidore de Séville, le De Universo (vers 844) ; il est l'auteur d'un livre de pédagogie pour les moines, le De Institutione clericorum (819), où il reproduit les trois derniers livres de la Doctrine chrétienne de saint Augustin et les vues de ce Père sur l'utilité des arts libéraux dans le De Ordine ${ }^{245}$. Mais il a aussi écrit des poésies et des hymnes.

A l'égard de l'usage des philosophes par les chrétiens, il reproduit la théorie de l’injuste possession, si fréquente chez les Pères : «Si les philosophes ont dit des choses véritables et d'accord avec notre foi dans leurs écrits, et surtout les platoniciens, non seulement il ne faut pas les craindre, mais il faut les leur reprendre comme à d'injustes

243 VI, t. CV, p. 751-756.

244 De Institut. cleric., L. III, § 2, indique la nécessité d’une interprétation allégorique et les règles de cette interprétation.

245 II, 13. Cf. Grabmann, XXII, p. 195-96. On lui attribue aussi, mais à tort, semble-t-il, des commentaires de Porphyre et des œuvres logiques de Boèce, PRANTL, XXVIII, p. 37. 
possesseurs » ${ }^{246}$. Il est vrai qu'il leur emprunte fort peu ; il possède et reproduit cette doxographie qui donne à presque tous les auteurs de ce temps une connaissance superficielle et faite de détails, de la philosophie antique ${ }^{247}$; mais il n'emprunte d'eux que ce qui est indispensable; c'est ainsi qu'il remplace l'explication physique des cieux d'Isidore de Séville par une explication allégorique, qui n'exige aucune connaissance philosophique, et qu'il supprime beaucoup de citations d'auteurs profanes ${ }^{248}$. S'agit-il des arts libéraux, il en justifie l'emploi de telle manière qu'il peut les limiter à la portion congrue : la grammaire est utile, parce que l'on y apprend la métrique, nécessaire à l'intelligence du psautier ; la dialectique, en nous apprenant les formes de raisonnement, nous fait voir ce qui peut se déduire légitimement de l'Écriture ; la rhétorique n'est, elle, que l'occupation des tout jeunes gens ; l'arithmétique, en apprenant les propriétés des nombres, nous sert souvent à pénétrer le sens secret des Écritures ; la géométrie, dont les règles ont servi aux constructeurs du tabernacle et du temple, est indispensable p070 pour découvrir le sens spirituel des passages de la Bible qui s'y rapportent ; enfin, le comput ecclésiastique, pour déterminer la date des fêtes, ne saurait se passer de l'astronomie ${ }^{249}$.

C'est un utilitarisme pédagogique sans restriction dont Raban Maur fait d'ailleurs la théorie : si tout va à l'Écriture, c'est que tout en est venu: "Les choses que l'on trouve véritables et sages dans les livres des savants du siècle ne doivent être attribuées à rien qu'à la Vérité et à la Sagesse ; ce n'est pas ceux dans les écrits de qui on les lit qui les ont d'abord établies ; émanant éternellement de Dieu, elles sont découvertes autant que l'a permis la Vérité ou Sagesse, maîtresse et lumière de tous ; et c'est pourquoi il faut tout rapporter à un terme unique, et ce qui est utilisable dans les livres des Gentils, et ce qui est salutaire dans l'Écriture ${ }^{250}$. » C'est donc la théorie augustinienne du maître intérieur qui amène des hommes comme Raban Maur à borner ainsi le savoir. Il sait que les arts libéraux étaient liés, chez les Gentils,

\footnotetext{
246 De Instit. cleric., liv. III, § 26 ; P. L., t. CVII, p. 404.

247 De Universo, liv. XV, ch. I.

248 DUHEM, XV, t. III, p. 21.

249 De Instit. cleric, L. III, § 16 ; VI, t. CVII, 395-403.

250 De Institut. cleric., L. III, § 2.
} 
au culte des idoles et aux arts magiques ${ }^{251}$; l'esprit, laissé à sa propre curiosité, mêle immédiatement l'erreur à la vérité.

De Tours, la science d'Alcuin parvint ainsi à Fulda. De Fulda, elle rayonna par plusieurs de ses disciples devenus abbés de grands monastères, par Servatus Lupus, qui fut abbé de Ferrières, de 842 à 862 ; par Walafried Strabo, qui mourut abbé de Reichenau, en 849 ; par Candidus aussi, qui succéda à Raban Maur en 822, comme maître de l'école du monastère.

Loup Servat paraît bien avoir été l'érudit selon le cœur de Raban Maur ; il est familier avec Horace, Virgile, Cicéron, Aulu-Gelle, Macrobe ; il sent les dangers que court cet humanisme, que beaucoup traitent de superstition : "L'amour des lettres, raconte-t-il, est né en moi dès ma jeunesse, et je ne $\mathrm{p}_{071}$ m'ennuie pas de leurs loisirs, qu'on appelle maintenant superstitieux ; c'est un fardeau maintenant que de vouloir apprendre ; les ignorants, dès qu'ils trouvent quelque faute en ceux qui ont fait des études, l'imputent non au défaut de l'homme mais à la qualité des doctrines »; aussi, par crainte de ce jugement, voit-on beaucoup de gens s'éloigner de l'étude ${ }^{252}$. Lui-même il a, avec Éginhard et d'autres amateurs des lettres, une correspondance qui ne paraîtrait pas déplacée en plein $\mathrm{XVI}^{\mathrm{e}}$ siècle ; il demande à Éginhard son édition de la Rhétorique de Cicéron, pour corriger son propre exemplaire, qu'il sait fautif ; il le prie de lui envoyer les Nuits attiques ${ }^{253}$ d'Aulu-Gelle; ailleurs, il lui signale quelques passages de l'Arithmétique de Boèce, qui lui semblent obscurs ${ }^{254}$. Il remercie un autre correspondant de ses corrections à Macrobe ${ }^{255}$. Il écrit au métropolite de Tours pour le prier de lui envoyer le Commentaire de Boèce sur les Topiques de Cicéron ${ }^{256}$. Toute sa correspondance, si variée, donne une assez haute idée des liens intellectuels entre les monastères de ce temps; les "disciplines libérales " étaient cultivées dans la forêt germanique; les écrivains latins étaient estimés à ce

\footnotetext{
251 De institutione clericorum, liv. III, ch. XVI ; VI, t. CVII.

252 Lettre à Eginhard, VI, t. CXIX, 433-a-b.

253 VI, p. 435.

254 Faute de savoir le grec, 447-b.

255 452-a.

256 464-a.
} 
point que tel prêtre de Mayence composait une "satire » où l'on voyait « Cicéron et Virgile et les hommes les plus célèbres admis dans le collège des élus pour que le Seigneur n'ait pas versé en vain son sang ni perdu son temps aux Enfers ${ }^{257}$.

Cela n'empêche d'ailleurs pas que Servat Loup n'écrive des livres théologiques, où s'exprime le mieux l'augustinisme du temps, un $D e$ tribus quaestionibus, composé d'un De libero arbitrio, d'un De paedestinatione et d'un De sanguinis Domini taxatione. Écrivant contre les pélagiens, il remarque tout ce qu'ont de choquant pour un chrétien les idées de Cicéron et de Virgile, cette autonomie stoïcienne qui leur fait ${ }_{\mathrm{p} 072}$ dire que l'homme ne doit qu'à lui-même son bonheur et qu'il est lui-même son seul espoir ; la splendeur des mots ne doit pas cacher l'orgueil du gentil ${ }^{258}$.

De l'abbaye de Fulda sort aussi Walafried Strabo, abbé de Reichenau, mort en 849 ; il écrit des poèmes, il compose ou plutôt il compile, à l'usage des clercs, un assez bref commentaire de l'Écriture, la Glossa ordinata, qui, jusqu'au XIII ${ }^{\mathrm{e}}$ siècle, servira d'instrument de travail ; c'est un de ces commentaires en chaîne, dont le type remonte à Philon d'Alexandrie, qui explique l'Écriture verset par verset ${ }^{259}$.

Candidus enfin utilise le De natura deorum de Cicéron pour prouver l'existence de Dieu : dans la hiérarchie des êtres, l'homme raisonnable est au sommet ; or, l'homme n'est pas indépendant et n'a pas la toute-puissance ; il faut donc qu'il y ait un être meilleur que lui et dont il dépend. Dieu est donc l'achèvement nécessaire de la ligne hiérarchique que l'on voit commencer par l'être, et continuer par l'être vivant et l'être raisonnable.

\footnotetext{
257 Cf. p. 470-a, où il s’agit de Probus, prêtre de Mayence.

258 VI, t. CXIX, 633-6. -

259 Cf. Grabmann, XXII, p. 197.
} 


\section{V.}

\section{AugustinisMe ET PRESTIGE DE L'ORIENT.}

Avec le développement de l'augustinisme, ce sont les rapports renouvelés avec l'Orient et Byzance qui dominent la vie intellectuelle en Occident ; avec les relations politiques se rétablissent, sous Charlemagne, les relations intellectuelles ; déjà, un archevêque de Cantorbery, originaire d'Orient, Théodore de Tassa, avait introduit en Angleterre l'étude du grec ; au $\mathrm{IX}^{\mathrm{e}}$ siècle, on connut les œuvres de Denys l’Aréopagite, de Maxime, de Jean Damascène.

L'augustinisme, qui imprègne tous les esprits de ce temps, n'est pas toujours d'accord avec les conceptions théologiques p073 des Orientaux. Il y a plus de vie intérieure chez saint Augustin et, en Orient, plus de construction métaphysique. Dans les Confessions et les Colloques, on saisit l'âme en ses rapports vivants et actifs avec Dieu : chez les Orientaux, on veut atteindre, par une contemplation objective, la structure même du divin.

Nous en avons une preuve en lisant les traités sur l'Eucharistie, qui abondent à cette époque, et notamment le De corpore et sanguine Domini, composé en 831 par Paschase Radbert, qui fut abbé de Corbie de 842 à 860 . La question du mode de présence du corps et du sang du Christ dans l'hostie engage des questions de principe, qui touchent à la philosophie : les théologiens occidentaux, sous l'influence de saint Augustin, étaient disposés à croire que la vertu du sacrement dépendait de la foi de celui qui le recevait, et ils laissaient en une ombre assez mystérieuse la question de la présence réelle. Paschase Radbert est augustinien autant que tout Occidental de son temps ${ }^{260}$, mais, avec les Grecs, il tient à se représenter d'une manière réaliste la présence du Christ. Or, il emploie pour cela deux notions qui jouent aussi un rôle de tout premier plan dans la philosophie de Jean Scot. La première, c'est celle d'un Dieu d'une toute-puissance insondable, dont les actes ne sont soumis à aucune espèce de loi ${ }^{261}$; rien ne s'oppose donc à ce miracle « contre nature » qu'est la présence réelle du Christ historique dans l'hostie, qui s’opère par l'intermédiaire de formules sacramen-

\footnotetext{
260 Cf. De corp. et sangu., ch. VI, 2.

261 Cf. De corp., Introduction. La volonté de Dieu est la cause dernière, et l’on peut appeler ses actions aussi bien naturelles que contre nature.
} 
telles. La seconde, c'est l'idée, foncièrement grecque, de la possibilité d'un corps immortel et incorruptible ; d'abord le corps présent dans l'hostie est le " corps vrai » du Christ, c'est-à-dire son corps pneumatique ou spirituel ; de plus, par l'union de ce corps avec le nôtre, le sacrement a pour effet non seulement « de ${ }_{\mathrm{p} 074}$ nourrir notre âme, mais d'élever notre chair elle-même à l'immortalité et à l'incorruptibilité » ${ }^{262}$. Ce qui importe, c'est qu'aucune notion fixe de nature ne s'impose ici à l'esprit ; Paschase Radbert est hostile à une représentation grossière d'un changement «naturel » du corps des éléments dans le corps du Christ; et il s'agit, dans sa théorie de l'Eucharistie, d'une transformation tout à fait analogue à celle que Jean Scot décrit quand il parle du retour des choses à leur principe, qui est le Verbe.

Ces idées des Grecs n’étaient pas acceptées sans résistance. Raban Maur était disposé à croire que le vrai corps présent dans l'hostie n'était pas le corps historique du Christ né et ressuscité, mais un corps produit par la consécration de l'Esprit-Saint ${ }^{263}$. Ratramne, qui fut, comme Paschase, moine à Corbie et qui mourut vers 868, écrivit sur le même sujet un traité assez confus, où il s'oppose pourtant avec quelque force à l'idée de la transmutation de l'hostie en corps du Christ ${ }^{264}$ et où il ramène positivement l'Eucharistie à une simple figure ou commémoration de la Passion ${ }^{265}$; et l'on sent chez lui l'absence de toute notion de cette structure métaphysique présente chez Paschase Radbert comme chez Jean Scot.

Le conflit sur la prédestination, qui occupa le $\mathrm{IX}^{\mathrm{e}}$ siècle, est encore une preuve de la force des idées augustiniennes; et, dans un de ses épisodes, il montre nettement l'Orient en lutte avec l'Occident. De la théorie de la grâce suivait celle de la prédestination : comme c'est par une volonté, antérieure à tout mérite de leur part, que Dieu a décidé de faire passer certains hommes du mal au bien, c'est aussi par une volonté immuable et éternelle qu’il a décidé de sauver de la « masse de

\footnotetext{
262 De corp., ch. XIX, X.

263 VI, t. CXII, p. 1510.

${ }^{264}$ Il s’appuie sur l’expérience, ch. XII; cf. ch. XV : «Qu’on dise sous quel rapport les éléments sont transmués ; car, corporellement, on ne voit en eux aucune transmutation. »

265 Ch. C.
} 
perdition » quelques élus : un moine du couvent d'Orbais, p075 Gottschalk, écrivit vers 847 un traité où il soutenait, dans toute sa rigueur, la thèse augustinienne; c'est un abandon complet à la volonté de Dieu, qui a décidé éternellement de tout homme qu'il serait damné ou qu'il serait sauvé ; il est contraire à l'immutabilité divine de croire que cette décision a pu être prise après que l'homme a mérité ou démérité Non pas que la venue du Christ ait été inutile ; mais il est venu non pas pour modifier les décisions du Père, mais pour annoncer aux hommes que, dans la masse de perdition, tous n'étaient pas prédestinés à la damnation, mais quelques-uns aussi au salut. Le radicalisme de l'exposé de Gottschalk inquiéta les autorités ecclésiastiques du pays franc. Raban Maur fit condamner au concile de Mayence (848) une théorie qui lui paraissait affirmer l'inutilité de la foi et des œuvres pour le salut, donc l'inutilité de l'Église ; Hincmar, évêque de Reims (806-881), la fit aussi condamner au synode de Chiersey (849). Toutefois, la pensée de Gottschalk parut à beaucoup si proche de saint $\mathrm{Au}-$ gustin qu'il trouva des défenseurs, notamment en Rémy, évêque de Lyon. Une polémique s'éleva entre Hincmar et Rémy, qui, pourtant, ne semblent être séparés que par des nuances ; y a-t-il une double prédestination, celle des élus et des réprouvés, comme le prétend Gottschalk (après, d'ailleurs, Isidore de Séville) ou seulement une prédestination des élus ? Le Christ est-il mort pour les seuls croyants (thèse de Gottschalk) ou pour tous les hommes? Le choix de l'une ou l'autre alternative n'empêchait pas les deux partis d'être augustiniens: la seule question, au fond, était de concilier l'augustinisme avec l'efficacité des sacrements ; mais les deux partis l'avaient également à cœur ; aussi, avec l'aide de la politique de conciliation des trois successeurs de Charlemagne, se mit-on d'accord au synode de Toucy (860), tandis que Gottschalk restait en prison, où il mourut en 869.

Rien ne fait mieux voir l'accord profond de ces augustiniens désunis qu'un incident de la lutte qui eut lieu en 850

p076 A cette date, Hincmar chargea Jean Scot d'écrire une réfutation de Gottschalk ${ }^{266}$ : de là est né le De divina praedestinatione ; dans cette œuvre apparaissait déjà le néoplatonisme qui devait s'affirmer dans le De divisione naturae: Jean Scot veut avant tout réfuter la

${ }^{266}$ VI, t. CXXII, 355-c. 
double prédestination : il n’y a pas de prédestination de damnés ; sa réfutation repose sur une certaine notion de l'essence divine. L'essence divine est une ; on ne peut donc lui attribuer deux volontés. Une seule et même cause ne peut produire deux effets contraires, ce qui arriverait si Dieu contraignait d'une part à la justice, d'autre part à l’injustice. Enfin, Dieu ne peut être cause du péché ; étant la suprême essence, il ne peut être cause que des réalités positives ou du bien ; il ne peut être cause du mal, qui, selon la thèse platonicienne (et augustinienne), n'est rien. Il y a, dans le ton même du raisonnement, dans la manière d'employer des principes généraux sur la nature de la cause, quelque chose d'insolite, à cette époque, en Occident : c'est la manière de raisonner des Grecs. Jean Scot se croit et se dit philosophe : « La vraie philosophie est la vraie religion, » dit-il en s'appuyant sur saint Augustin. Dans sa théorie personnelle du libre arbitre, il a grand soin de montrer que le libre arbitre appartient à l'homme par nature : l'homme, étant image de Dieu, doit posséder une volonté libre et raisonnable ; le péché originel ne peut donc pas faire perdre à l'homme sa liberté, mais seulement en diminuer l'efficacité et la vigueur.

Table des matières

\section{VI. \\ LA TRADITION HUMANISTE AU $\mathbf{X}^{\mathrm{E}}$ SIECLE.}

Jusqu'au $\mathrm{X}^{\mathrm{e}}$ siècle se continue, dans les monastères, la tradition des

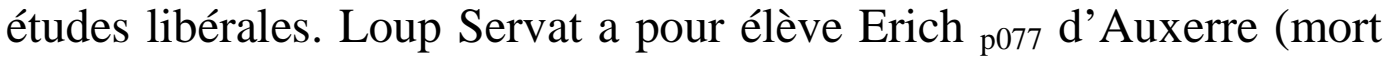
en 876), qui reçut aussi à Laon la tradition de l'enseignement de Jean Scot, qu'il utilise soit dans des gloses à une vie versifiée de saint Germain dont il est l'auteur, soit dans des gloses au De Dialectica de saint Augustin. Le hasard a conservé quelques-unes de ses œuvres logiques, toutes des commentaires, des notes marginales à la traduction par Boèce du De Interpretatione d'Aristote et au De Dialectica de saint Augustin. Dans un Commentaire aux Catégories du pseudoAugustin, la formation des trois degrés successifs d'universaux, espèce, genre et terme généralissime, est ramenée à l'impossibilité de garder en sa mémoire les innombrables noms des choses individuelles que l'on rassemble en espèces, et les noms, innombrables aussi, des 
espèces que l'on rassemble en genres ${ }^{267}$. On voit que les lecteurs de Boèce ne sont pas du tout, en ce Haut Moyen Age, des réalistes : Un annotateur anonyme de l'Isagoge à la même époque oppose, comme deux choses radicalement distinctes, les universaux (genres et espèces) et les idées platoniciennes ${ }^{268}$.

Rémy d'Auxerre (841-908) est, comme son maître Erich, un humaniste, un exégète à la fois des poètes latins, Térence, Juvénal, Prudence, ou des Distiques de Caton, et de la Genèse ou des Psaumes. Il a aussi naturellement commenté Boèce, la Consolation et les Opuscules théologiques, tout au moins ${ }^{269}$. Rand, qui a édité les notes de Rémy au quatrième de ces opuscules, en fait voir la parenté étroite avec le commentaire de Jean Scot, sans d'ailleurs que Rémy paraisse toujours bien comprendre la portée des notes qu'il transcrit. Par exemple, s’il écrit : « dans la génération du fils toutes choses ont été créées sans aucun intervalle ${ }^{270}$ », il avait dit auparavant : "Les choses n'ont pas été engendrées de Dieu, comme son Fils l'a été, mais créées par création, non par génération ${ }^{271}$. " Son ${ }_{\mathrm{p} 078}$ commentaire de Martianus Capella répand aussi bien des idées de Jean Scot : à la manière platonicienne, il considère le genre comme l'unité substantielle d'où les espèces dérivent par partage (partitio substantialis), et les espèces infimes comme les unités substantielles des individus. L'on trouve aussi chez lui un écho de la théorie platonicienne de la réminiscence : les arts appartiennent à la nature humaine, mais oubliés par suite du péché d'Adam, ils sommeillent dans la mémoire d'où ils ne peuvent être rappelés à la présence de l'intelligence (in presentiam intelligentiae) que par l'instruction.

Les circonstances politiques du $\mathrm{X}^{\mathrm{e}}$ siècle, dissolution de l'empire carolingien, invasions normandes et hongroises, ruine des monastères, arrêtent presque entièrement, jusqu'au milieu du siècle, cette reprise du mouvement spirituel qui, au $\mathrm{IX}^{\mathrm{e}}$ siècle, donnait de si beaux espoirs. A peine trouve-t-on encore ici et là quelques commentateurs ; Bovo,

\footnotetext{
267 HAURÉAU, XXIV, t. I, p. 194,

268 Cousin, Ouvrages inédits d'Abélard, p. LXXXII sq.

269 RAND, VII, liv. I § 2, 97 ; p. 91.

270 RAND, p. 100, 26.

271 P. 89.
} 
abbé de Corbie, mort en 919, qui commente, avec Macrobe, les célèbres vers 724 à 729 du livre VI de l'Énéide (Mens agitat molem...), où l'on trouve cette thèse de l'animation universelle sur laquelle Jean Scot revient si souvent; il est platonicien aussi dans son commentaire d'un passage de la Consolation (III, 10), où Boèce décrit le gouvernement divin du monde en des vers qui rappellent l'hymne à Zeus de Cléanthe ${ }^{272}$.

La situation ne change qu'avec le rétablissement de l'unité impériale par Otton le Grand, couronné par le pape en 962 et salué comme empereur et Auguste. Les monastères sont réformés; l'abbaye de Cluny notamment rétablit et fait rétablir ailleurs la règle bénédictine. Vers la fin du siècle, l'abbaye de Saint-Gall devient un centre d'études comparable à ce qu'avait été l'abbaye de Fulda : on y lit et on y commente à nouveau tous les maîtres. Notker Labeo, abbé de Saint-Gall, mort en 1022, est un humaniste et un commentateur à la façon ${ }_{\mathrm{p} 079}$ des hommes de l'époque carolingienne ; il traduit en allemand les Bucoliques, le Distique de Caton, l'Andrienne de Térence, peu après qu'Hroswita, une nonne de l'abbaye de Gandersheim, cherche à imiter le dialogue de Térence, et que, à Saint-Gall même, un auteur inconnu imite l'Énéide dans le récit épique des aventures du preux Walter. Notker continue aussi la tradition de Rémy d'Auxerre dans son commentaire de Marcianus Capella ; il commente des ouvrages logiques d'Aristote, les Catégories et le De interpretatione, et aussi la Consolation de Boèce et l'opuscule sur la Trinité ; il extrait d'Alcuin un traité dialogué, De artibus, et il écrit un De partibus logicae.

Table des matières

\section{VII. \\ GERBERT.}

Dans l'ancienne Gaule, les écoles épiscopales se réveillent à Liège et à Reims. De 972 à 982, le maître de l'école de Reims est Gerbert, dont le rôle intellectuel et politique est immense en cette fin du $\mathrm{X}^{\mathrm{e}}$ siècle. Gerbert, né vers 950, était élève du monastère d'Aurillac, monastère réformé par Odon de Cluny, élève de Rémy d’Auxerre. Mais,

${ }^{272}$ ENDRES, P. J. 1912, 364-367. 
curieux et voyageur, il parcourt la France et l'Espagne ; chez lui la tradition classique et humaniste des grands monastères carolingiens s'unit à une curiosité inventive, si rare à cette époque. Abbé de Bobbio en 982, archevêque de Reims en 992, il devient en 998 archevêque de Ravenne, la résidence préférée des Ottons en Italie ; en 999 il devient pape sous le nom de Sylvestre II, et il meurt en 1003. Ses préoccupations sont celles d'un humaniste ; il achète à grand prix des livres dans tous les pays; il voit dans la philosophie une culture à la fois morale et littéraire, indispensable au repos comme aux affaires; " puisque la morale et la rhétorique, écrit-il à Egbert, abbé de SaintMartin de Tours, ne sont pas séparés de la philosophie, j'ai toujours uni l'étude ${ }_{\text {p080 }}$ de l'une à l'étude de l'autre. Sans doute il est plus important de bien vivre que de bien dire, et, une fois affranchi des soins du gouvernement, l'un est assez sans l'autre ; mais pour nous, qui nous occupons des affaires publiques, l'un et l'autre sont nécessaires ${ }^{273}$ ». Comme Boèce, il voit dans la philosophie un moyen de mépriser la fortune et le seul remède aux soucis des affaires ${ }^{274}$; il se souvient du De Officiis quand il définit l'Église sanctissima societas generis humani ${ }^{275}$.

D'esprit très positif, il distingue nettement le trivium du quadrivium, comme la logique de la matesis ${ }^{276}$. Comme Jean Scot et bien d'autres commentateurs de l'Écriture sainte, il trouve la dialectique indispensable: "Avant de nous appuyer sur l'autorité de tels hommes, je veux dire Cyrille et Hilaire, nous entreprenons de résoudre la divergence de leurs paroles au moyen de quelque argument dialectique. » S'il utilise la dialectique avec confiance, c'est qu'il y voit non une invention humaine, mais une science qui touche à la nature : « créée dans la nature par l'auteur de tous les arts qui sont vraiment des arts, elle y a été découverte par les sages et elle a été employée pour les besoins de la recherche savante ${ }^{277}$ ». Nous savons, par

273 Lettre 44 ; VI, t. CXXXIX, p. 180. Cf. lettre 82, p. 224, sur l'art rhétorique qu'il vient de composer. Il utilise les poètes latins : Virgile, Stace, Térence, Juvénal, Perse, Horace, Lucain.

274 Lettre 45, à Raimond, moine d'Aurillac.

275 Lettre 80, p. 221.

276 VI, t. GXXXVIII, p. 102.

277 VI, t. CXXXIX, 185-b ; cela revient à dire que la division des choses en genres et en espèces n'est pas arbitraire, mais naturelle. 
l'historien Richer, quelle était l'étendue de son cours de dialectique à Reims; il y expliquait l'Isagoge de Porphyre dans la traduction de Victorinus avec le commentaire de Boèce, les Catégories et le De Interpretatione d'Aristote, les Topiques de Cicéron avec les commentaires de Boèce ; enfin tous les traités logiques de Boèce. Le petit traité De rationali et ratione uti qu'il adressa à Otton III est destiné à résoudre une question soulevée dans une discussion orale à propos du texte suivant ${ }_{\mathrm{p} 081}$ de l'Isagoge (ch. VII) : « Raisonnable étant une différence spécifique, user de la raison se dit de raisonnable en tant que différence, et non seulement de raisonnable, mais de toutes les espèces comprises sous ce terme. " La proposition : le raisonnable use de la raison n'a aucune nécessité logique, objecte-t-on à Porphyre, puisque raisonnable est la puissance dont user de raison est l'acte, et qu'il est toujours possible que la puissance ne passe pas à l'acte. Gerbert donne raison à Porphyre, grâce à une distinction qui suppose le platonisme, mais peut-être en même temps le nominalisme : quand raisonnable désigne une essence éternelle et divine, Porphyre dit vrai, puisque cette essence est toujours en acte ; il a tort si le mot raisonnable désigne la disposition rationnelle des individus qui naît dans le temps et ne passe pas toujours à l'acte.

Mais Gerbert est aussi un mathématicien ; dans sa correspondance, il donne les règles de la multiplication et de la division, une théorie de la sphère, des explications sur la Musique et l'Arithmétique de Boèce ; il écrit une Géométrie. Son esprit pratique se laisse voir dans son traité Sur l'Astrolabe ; il l'a fort probablement composé d'après un traité traduit de l'arabe ${ }^{278}$, et, en introduisant ainsi en Occident les règles d'emploi d'un instrument astronomique, il a été l'initiateur d'un important mouvement scientifique.

D’après des découvertes récentes, Abbon (945-1004), qui fut abbé de Fleury à partir de 988, travailla, en même temps que Gerbert et en relation avec lui, à la restauration des sciences ; il est l'auteur de traités sur les Syllogismes catégoriques et hypothétiques; il a, dans un commentaire du Calculus de Victorius d'Aquitaine, introduit des règles pratiques de calcul sans aucune trace de l'influence arabe ; il a

278 Duhem, XV, t. III, p. 265, d'après Gerberti Opera mathematica, édités, par Bulnov, p. 370-375. 
écrit de petits traités d'astronomie, contenant des catalogues d'étoiles ; enfin, il est l'auteur d'un comput où sont discutées les dates d'origine p082 de l'ère chrétienne. On le voit, dans sa correspondance, chercher à étendre sa documentation ; il recherche en Espagne des traités scientifiques ${ }^{279}$.

La fin du $\mathrm{X}^{\mathrm{e}}$ siècle vit enfin, en 990, s'ouvrir, à Chartres, une école épiscopale sous la présidence de Fulbert, un élève de Gerbert, qui fut évêque de Chartres de 1006 à 1028. Il y avait, dès cette époque, à Chartres, une importante bibliothèque d'historiens et de poètes latins, classiques et chrétiens ${ }^{280}$; tout l'humanisme et le goût de la science de Gerbert se transmettent à Chartres. Il met pourtant ses disciples en garde, tout comme autrefois Jean Scot, contre une sagesse mondaine qui voudrait «resserrer les secrets de Dieu dans les limites de son ignorance et comprendre ce qui est au delà d'elle »; elle cherche et ne trouve pas; les mystères sont révélés «non à la discussion des hommes, mais aux yeux de la foi ${ }^{281}$ ».

279 Cf. VAN DE Vyver, Les Euvres inédites d’Abbon de Fleury (Revue Bénédictine, mars 1935).

280 VI, t. CXLI, p. 284 ; cf. CLERVAL, LXXX, p. 110.

281 VI, t. CXLI, p. 196 : dans une lettre dont l'authenticité est cependant contestée par Hauréau. 


\section{Chapitre III}

\section{LES DÉBUTS DE LA PHILOSOPHIE ARABE}

Comme l'empire de Charlemagne en Occident, le kalifat d'Haroun-al-Raschid (785-809) en Orient a été le point de départ d'un développement intellectuel intense, mais dans des conditions fort différentes. La pensée arabe se développe, au $\mathrm{IX}^{\mathrm{e}}$ et au $\mathrm{X}^{\mathrm{e}}$ siècle, dans des pays de très antique civilisation, en Syrie ou en Perse, où, depuis longtemps, se combinent et s'affrontent les tendances religieuses et intellectuelles les plus diverses et les plus opposées. Le Coran et la philosophie grecque ne sont pas tout : s'il y a des théologiens orthodoxes qui s'en tiennent à la lettre du Livre, on trouve une théologie libérale qui garde fort peu de l'Islam, un mouvement schiite dont l'inspiration se relie au culte persan de la lumière, un mysticisme qui n’est pas loin du bouddhisme. La pensée philosophique n'est pas limitée à ceux qu'on appelle falasifa, c'est-à-dire à ceux qui s'inspirent d'Aristote.

Table des matières

I.

INTERPRETATION PLATONICIENNE D'ARISTOTE.

Une des ambitions des derniers philosophes de la Grèce avait été de concilier Aristote et Platon ; de nombreux traités p084 deux philosophes n'étaient qu'apparentes; elles viennent de ce qu'ils n'envisagent pas, l'un et l'autre, le même niveau de réalité ; Aristote parle des choses sensibles, et Platon du monde intelligible ; leurs doctrines, à elles deux, embrassent le rée tout entier depuis les choses sujettes à la génération et à la corruption jusqu'à l'origine ineffable des 
êtres : d'ailleurs, par son extrémité supérieure, par la doctrine des Intelligences motrices des cieux, la doctrine, d'Aristote rejoignait en quelque façon celle des néoplatoniciens.

Le faussaire qui, vers le $\mathrm{VI}^{\mathrm{e}}$ siècle, écrivit, sous le nom d'Aristote, un ouvrage intitulé Théologie, fit mieux : dans la préface de cet ouvrage, l'on voit Aristote lui-même déclarer qu'il donne ici le couronnement de son œuvre ; sa métaphysique avait pour but d'étudier les quatre causes de l'être ; ces causes se ramènent, la cause, finale à Dieu, la cause formelle à l'Intelligence, la cause motrice à l'Ame, la cause matérielle à la Nature. Le but de la Théologie est de montrer la génération de ces causes elles-mêmes à partir de Dieu ; " c'est la théorie et l'explication du règne de Dieu; il est le fondement dernier ; le temps et l'éternité sont au-dessous de lui... La lumière de Dieu rayonne sur l'Intelligence et, de Dieu, par l'intermédiaire de l'Intelligence, sur l'âme totale du ciel ; mais de l'Intelligence, par l'intermédiaire de l'âme, sur la Nature; et de l'Ame, par l'intermédiaire de la Nature, sur les choses qui naissent et périssent ${ }^{282}$ ». Bref, ce traité vise à exposer la théorie platonicienne des trois hypostases en la complétant par des vues sur la Nature ; c'est du moins l'intention du faussaire ; mais, comme il est facile de s'en apercevoir, les dix livres du traité ne contiennent que des extraits des Ennéades de Plotin, dont l'ensemble ne forme pas du tout l'exposé systématique annoncé par l'auteur de l'introduction : si ces extraits ont un sujet unique, c'est moins la théorie d'ensemble des hypostases que p085 la spiritualité de l'âme et le rapport de l'âme à la réalité intelligible. Le livre I reproduit Ennéade $I V$, 8, 1-2 sur la descente de l'âme dans le monde sensible ; le livre II, Ennéade IV, 4, 1-4, sur les conditions dans lesquelles l'âme acquiert la mémoire, et sur l'inutilité de la mémoire pour l'âme une fois arrivée à la contemplation des intelligibles ; le livre III (Ennéade IV, 7, 8) réunit les arguments contre la théorie de l'âme des Stoïciens, des Pythagoriciens et d'Aristote; le livre IV (Ennéade $V, 8,1-4$ ) est le début du traité de la beauté intelligible ; il décrit les degrés que parcourt l'âme dans son ascension vers le beau pour arriver aux dieux du monde intelligible ; le livre V (Ennéade $V I, 7,1-2$ ) traite de l'action créatrice et montre qu'elle ne peut être de l'ordre de la pensée discursive ; le livre VI (Ennéade IV, 4, 39- 
45) montre comment le sage peut échapper à la magie du monde sensible ; le livre VII (Ennéade IV, 8, 5-8) concerne la double vue de l'âme tournée tantôt vers le sensible, tantôt vers l'intelligible ; le livre VIII contient deux extraits, l'un (Ennéade VI, 7, 11-15) sur la pénétration mutuelle des intelligences dans le monde intelligible, l'autre (Ennéade $I V, 4,5)$ faisant suite à celui du livre II sur la mémoire dans les âmes ; le livre IX traite d'abord (Ennéade IV, 7, 1-5) de la réfutation du matérialisme, à laquelle fait suite l'extrait du livre III, puis (Ennéade $V, 1,11-12)$ de la démonstration de l'existence des intelligibles ; le livre $\mathrm{X}$ enfin commence (Ennéade $V$, 2) par le traité sur la procession des trois hypostases, et se termine (Ennéade VI, 7, 2-11) par des considérations sur l'homme sensible et intelligible auxquelles fait suite le début du livre VIII.

Le faussaire a donc utilisé les traités 4,7 et 8 de la $I V^{e}$ Ennéade, sur l'âme et sa destinée, les traités 1 , 2 et 8 de la $V^{e}$, sur la génération des hypostases, et le traité 7 de la $V I^{e}$ Ennéade sur le monde intelligible et sur le Bien. Tout se passe comme si l'auteur de la préface n'était pas le même que celui qui a rassemblé les extraits. Quoi qu'il en soit, ces extraits ${ }_{\text {p086 }}$ qui n'aboutissent pas à un exposé systématique du platonisme, contiennent, à côté des détails les plus subtils sur la vie de l'âme, une vue d'ensemble sur la doctrine, au livre X. Or le traité tout entier a été traduit en arabe, au milieu du $\mathrm{IX}^{\mathrm{e}}$ siècle, par le chrétien Ibn Abdallah Naïma, et il a fait loi, au moins jusqu'au XII ${ }^{\mathrm{e}}$ siècle, dans l'interprétation d'Aristote ${ }^{283}$. Au X $\mathrm{X}^{\mathrm{e}}$ siècle, par exemple, Al Farâbi, dans son traité de l'Harmonie entre Platon et Aristote ${ }^{284}$, fait appel à la Théologie, sur tous les points où la discordance des deux philosophes s'exagère : il y renvoie, par exemple ${ }^{285}$, lorsqu'il s'agit de montrer qu'Aristote n'a pas nié le monde intelligible, bien que, dans sa Physique, il n’ait attribué la substantialité qu'aux seuls individus.

283 Les Latins ont travaillé sur une version latine de la Théologie qui diffère beaucoup de l'édition arabe jusqu'ici connue ; on la prenait pour un abrégé ou un remaniement du texte, ce qui sans doute a jusqu’ici empêché les médiévistes, qui s'occupent de l'Occident, de voir avec quelle fidélité elle suivait les Ennéades dans l'original ; mais elle reproduit exactement une autre recension arabe récemment découverte (A. BORISON, LXIV, p. 83-98).

284 Traduit en allemand par DIETERICI, LXV, p. 3-53.

285 P. 43. 
Les Arabes trouvaient en revanche dans le livre Des Causes un exposé tout à fait systématique de la pensée néoplatonicienne, puisque ce livre n'est que la traduction des Éléments de théologie de Proclus, composé d'une suite de théorèmes à la manière d'Euclide et démontrant tour à tour la nature et les propriétés des trois hypostases : l'Un, l'Intelligence et l'Ame. Parmi les modifications que le traducteur arabe a fait subir à son texte, il en faut citer une qui a pour but de le rendre plus acceptable à l'orthodoxie de l'Islam : la première hypostase ou Dieu possède la puissance créatrice absolue, tandis que les autres ne font que donner une forme à une matière préexistante.

Si le prétendu platonisme d'Aristote transformait l'interprétation de sa Physique et de sa Métaphysique, par un mouvement inverse, le péripatétisme transformait à son tour les p087 notions platoniciennes. La considération des êtres spirituels est liée à la structure de l'astronomie ; ce sont les Intelligences motrices et les âmes des cieux qui remplacent les hypostases platoniciennes; et leur série hiérarchique où chaque terme produit le suivant ressemble plus encore aux séries gnostiques d’hypostases qu'à la métaphysique aristotélicienne.

Enfin, il faut bien admettre que, malgré les traits qu'elle emprunte au néoplatonisme, la philosophie arabe dépend, avec le néoplatonisme lui-même, d'un plus large courant d'idées, très répandu en Orient, que l'on a quelquefois appelé la "métaphysique de la lumière " ${ }^{286}$. L'action de l'être originaire est imaginée moins comme une émanation proprement dite, à la façon d'une source qui déborderait, que comme l'irradiation d'une lumière qui, en s'épandant, s'obscurcit peu à peu : image qui, présente dans les cultes solaires les plus anciens de la Mésopotamie, puis dans le culte de Mithra, a dominé pendant des siècles dans l'Orient, et se retrouve, jusqu'au XIX ${ }^{\mathrm{e}}$ siècle, dans le Babisme. Cette image contribue à renforcer le néoplatonisme. 


\section{II.}

\section{LA REACTION DE L'ISLAM.}

Créationisme, aristotélisme et astrolâtrie, doctrine gnostique des hypostases, métaphysique de la lumière, tels sont les traits qui viennent modifier ou renforcer le néoplatonisme. Il en reste l'essentiel, une doctrine et une méthode : l'affirmation de la présence de Dieu dans les choses par son rayonnement, et l'affirmation que nous pouvons connaître cette présence par la simple spéculation. Par là, le néoplatonisme venait se heurter à l'Islam : si l'Islam affirmait la présence de Dieu, p088 il ne s'agissait pas du même mode de présence ni de la même méthode pour le connaître ; ici l'aspect social domine l'aspect cosmique : le Prophète est l'homme élu en qui se manifeste Dieu, et la foi dans le Prophète est le moyen d'accès vers Dieu. Le continuisme platonicien, qui englobe une explication totale de l'univers et qui relie la théologie à la cosmologie, se heurte au discontinuisme de l'Islam qui affirme une suite d'actes discontinus, explicables par la puissance toute nue de Dieu, création volontaire, révélation, par le Prophète, de la Parole de Dieu, du Coran dont les théologiens se demandent si elle est créée ou incréée. Le néoplatonisme met Dieu dans le lointain, au delà de tous les intermédiaires qu'il faut parcourir pour l'atteindre ; et cet éloignement ne peut être corrigé que par le mysticisme, l'affirmation d'une intuition immédiate et exceptionnelle de Dieu. La foi islamique, au contraire, met Dieu tout près du croyant, sans s'embarrasser d'aucune considération cosmologique ; c'est la révélation opposée à l'émanation. Cette notion peut admettre bien des nuances : mais toujours la lumière divine, au lieu de s'épandre selon une sorte de loi nécessaire, se concentre en une suite de personnages historiques réels, dont le dernier, selon l'orthodoxie, est Mahomet, tandis que, pour les schiites perses, la révélation de Dieu doit continuer par la série des douze Imams.

Le discontinuisme, élément d'une vision du monde qui se rattache à la religion islamique, se développe dans ce groupe de théologiens musulmans, étrangers à la pensée grecque, que l'on appelle les Mutekallemin, "ceux qui disputent ». Groupe très varié puisqu'il comprend des hérésies opposées l'une à l'autre, celle des Gabarites qui, poussant l'unité de Dieu jusqu'à nier de lui tout attribut, sont des fatalistes, jusqu'aux Kadarites qui sont indéterministes. De plus à ce Kalam purement théologique vient s’ajouter un Kalam à demi philoso- 
phique, celui des Motazilites ou séparés, strictement monothéistes sans doute et affirmant la création du monde dans le p089 temps, mais admettant aussi la libre recherche : Wasil, le fondateur de la secte, né à Médina en 699, "se sépare » des théologiens radicaux qui n’admettaient pas d'état intermédiaire entre le croyant juste et l'impie. Abou'l Hodéil de Basra, né en 757, cherche à concilier l'unité de Dieu avec la multiplicité des attributs, en voyant en eux des modes sous lesquels apparaît l'essence divine; Dieu est savant non par une science distincte de lui, mais par une science qui est son essence.

A cette sorte de libéralisme en théologie, l'orthodoxie musulmane réagit, au début du $\mathrm{X}^{\mathrm{e}}$ siècle, par un atomisme radical avec Abul Hassan al Ascari (873-935) : l'école ascarite devient à ce moment théologie officielle. Comme on l'a très bien vu, d'ailleurs, Ascari, dans l'expression de sa doctrine, s'inspire non pas de la tradition épicurienne, mais des exposés qu'Aristote avait donnés de la doctrine de Démocrite, et même de certaines notions proprement aristotéliciennes, car l'atomisme ascarite n'est pas seulement un atomisme physique, mais aussi un atomisme de la durée : le temps est fait d'indivisibles comme le monde physique est constitué par une quantité innombrable d'atomes répandus dans l'espace vide ; mais Ascari n'est pas du tout un mécaniste cherchant une explication rationnelle des phénomènes ; aussi juge-t-il que, pour rendre compte du changement, il faut ajouter à la notion d'atome une autre notion, celle d'accident ; un phénomène n'est pas seulement groupe d'atomes, il est production d'un accident, couleur, odeur, etc., dont ce groupe est le sujet. Entre ce sujet et cet accident, il y a nul rapport intelligible; nul rapport intelligible non plus entre les accidents qui se succèdent dans le sujet. Les accidents doivent donc être chaque fois créés par Dieu. De plus, comme le temps est formé d'atomes instantanés, il n'y a pas de raison pour que l'accident, existant dans le sujet en un instant, y existe à l'instant suivant ; il doit être à chaque instant créé par Dieu. Ce qui p090 importe aux théologiens ascarites, à ces prédécesseurs lointains de Malebranche, c'est moins la discontinuité dans l'espace que la discontinuité dans la durée; l'une et l'autre, mais surtout la seconde, sont l'expression de la volonté souveraine et incompréhensible de Dieu. Nulle vision du monde n'est plus opposée au continuisme non moins radical des platoniciens. 


\section{III.}

\section{AL KINDI.}

Au même siècle où Jean Scot essayait une interprétation néoplatonicienne du dogme chrétien, les califes de Bagdad et tout spécialement Al Mamoûn, qui monta sur le trône en 813, favorisait la diffusion de la culture hellénique par l'institution d'un collège de traducteurs, fondé en 832 ; alors, on put lire en langue arabe l'œuvre complète d'Aristote (moins la Politique) et de son commentateur Alexandre d'Aphrodise, les dialogues de Platon, sans compter les œuvres scientifiques d'Euclide, de Ptolémée et de Galien. La connaissance de ces œuvres se répandit d'abord dans ce pays perse, si disposé à accepter les mouvements d'idées les plus divers.

Dans quel esprit ces Arabo-Perses reçurent la révélation d'Aristote, c'est ce que montre l'œuvre d'Al Kindî, qui, mort en 872, a écrit quantité de commentaires sur Aristote. Pour lui, la méthode de la philosophie est la démonstration, et sa fin est de s'approcher de Dieu : " Avec l'exercice, écrit-il, la science démonstrative se multiplie, et l'âme se fortifie pour imaginer les formes spirituelles dépouillées de matière. Alors elle s'y assimile et devient en puissance telles qu'elles sont ; séparée du corps par la mort, elle devient en acte telles qu'elles sont ${ }^{287}$. " La fin du savoir, c'est donc, selon une formule p091 d'Aristote souvent reprise par Plotin, l'identité de celui qui sait et de ce qui est su. Quant à la méthode démonstrative, Al Kindî aime à commenter la théorie qu'en donnent les Seconds Analytiques par la géométrie d'Euclide. Il conseille, avant d'employer la démonstration logique, de s'exercer longtemps à la géométrie, dont les exemples sont plus sensibles ${ }^{288}$ : c'est en elle qu'on voit le mieux la valeur des règles d'Aristote : ne point entreprendre de démonstration sur un objet avant de savoir d'abord s'il est (an sit) et ensuite ce qu'il est (quid sit) ; partir des premières données de l'intelligence connues par soi (prima intellecta), telles que les axiomes d'Euclide.

\footnotetext{
287 BAUEMKER, II, t. II, 5, p. 64.

288 BAUEMKER, II, p. 58.
} 
La prétention d'atteindre une physique et une métaphysique démonstratives vient se heurter, chez lui, aux mêmes difficultés que rencontreront toutes les tentatives de ce genre le long du Moyen Age oriental et occidental, et qui tient à une défectuosité profonde de l'œuvre d'Aristote ; les célèbres théories arabes de l'intellect ont pour but avant tout de pallier cette difficulté. Elles veulent établir les principes d'où doit partir la démonstration : leur sens est mis en évidence par ces deux assertions d'Al Kindî : l'objet de la démonstration est la connaissance des formes constitutives des choses ; le point de départ de la démonstration est la connaissance de la quiddité. La première assertion vise un procédé discursif, tel que la pesée, qui permet de connaître le poids, directement inconnaissable, ou l'acte de compter qui nous révèle la quantité ; l'argumentation va ainsi des propriétés les plus connues aux moins connues, de l'accident à l'essence ; la seconde se rapporte à la démonstration euclidienne classique, qui part des définitions. Mais, entre les deux, il y a contradiction, et cette contradiction, comme chez Aristote, ne pourrait être levée que si l'on indiquait un procédé distinct de la démonstration, p092 pour arriver aux quiddités. Le livre d'Al Kindî tourne autour du problème sans le résoudre : les trois procédés de la division, de la résolution et de la définition qui permettent de déterminer avec certitude les genres, les individus et les espèces ne donnent point une solution, puisque $\mathrm{Al}$ Kindî ne songe nullement à faire, des universaux de la logique, des formes de la réalité ${ }^{289}$. Tandis que l'existence est connue par les sens, dit-il ailleurs, la quiddité est atteinte «par la méditation, par la spéculation et par la réflexion ${ }^{290}$ ». La solution d'Al Kindî est une solution toute verbale, qui est empruntée à Aristote et à ses commentateurs : elle consiste à supposer d'abord le problème résolu par l'existence d'une « intelligence en acte » qui pense actuellement et éternellement tous les intelligibles: cette intelligence n'est pas "dans l'âme »; dans l'âme se trouve une intelligence en puissance, qui est capable de passer à l'acte, non point d'elle-même (car « rien ne passe par soi de la puissance à l'acte »), mais sous l'influence de l'intelligence en acte, grâce à laquelle elle devient effectivement intelligente. Alors naît dans l'âme « l'intelligence acquise » (intellectus adeptus), qui garde en elle

289 BAUEMKER, II, t. II, p. 42-44.

290 Id., p. 50 : meditatione et consideratione et cogitatione. 
les intelligibles. Naîtra ensuite la quatrième intelligence, l'intelligence démonstrative, qui part des quiddités conçues par l'intelligence ${ }^{291}$. Al Kindî, qui attribue cette théorie des quatre intelligences « à Platon et à son disciple Aristote ", est très sobre de détails et sur la nature de l'intelligence en acte et sur la manière dont l'intelligence en puissance y participe.

Ce qui est certain, c'est la confusion inextricable dans la théorie des notions premières où s'entassent les universaux, les formes intellectuelles, les notions propres à chaque science, constituées en général par des adages tout à fait arbitrairement choisis : par là, Al Kindî pensait pouvoir démontrer p093 les grandes thèses de la physique péripatéticienne : il n'y a pas de vide dans le monde ; il n'y a ni vide ni plein en dehors du monde; l'âme est cause du mouvement organique; l'âme est une substance ${ }^{292}$, et atteindre ainsi par le savoir la réalité même des choses. Mais il démontrait aussi, contrairement à Aristote, que le monde devait finir, grâce à cet adage : «Tout ce qui est possible, si seulement on pose un temps infini, doit nécessairement arriver. » Et, puisque le mouvement du ciel est produit par un moteur distinct du ciel, il peut finir, donc il finira ${ }^{293}$.

Table des matières

IV.

Al FARABI.

Avec Al Farâbi, qui, né vers la fin du IX $\mathrm{X}^{\mathrm{e}}$ siècle, enseigna à Bagdad et mourut à Alep vers 950, le péripatétisme arabe a noué d'un lien indissoluble la théorie du Ciel, celle des Intelligences motrices et celle du Prophétisme ${ }^{294}$. Disons que, dans le commentaire des livres d'Aristote, il s'est efforcé de saisir le rapport entre le livre VIII de la Physique sur le premier moteur, le livre $\mathrm{V}$ de la Métaphysique sur Dieu et les intelligences motrices des cieux, le chapitre VI du livre IV du traité de l'âme sur la fonction cognitive de l'intellect: ainsi

\footnotetext{
291 De Intellectu, BAUEMKER, II, t. II, p. 2 ; p. 6-9.

292 P. 58-60.

293 P. 60-61. C'est un adage plus platonicien qu’aristotélicien.

294 IB. MAKDOUR, LXVIII, p. 43.
} 
s'unissaient en un tout théologie, cosmologie et psychologie : un lien précis existe entre Dieu et les moteurs des cieux, entre ces intelligences motrices et l'intelligence qui pense en l'homme. Seulement l'unité de ces trois thèmes aristotéliciens n'est pas trouvée chez Aristote.

Nous avons déjà vu $\mathrm{Al}$ Kindî introduire à point une idée néoplatonicienne pour prouver la réalité du commencement et de la fin du monde : l'exemple d'Al Farâbi nous montre ${ }_{\text {p094 }}$ que les Arabes semblent avoir été très peu sensibles à la contradiction qu'ils introduisaient dans la physique d'Aristote, dont, d'autre part, ils acceptaient les principes ; car il va jusqu'à dire ${ }^{295}$ qu'Aristote a bien pu être sur ce point de l'opinion de Platon, qu'il n'a jamais parlé de l'éternité du monde que dans les Topiques pour y donner l'exemple d'une question sur laquelle il y avait divergence, qu'il nie seulement que le ciel ait un commencement dans le temps sans nier que son origine soit intemporelle, enfin que l'on trouve, dans la Théologie, l'affirmation de la création ex nihilo ${ }^{296}$.

Il est sûr qu'une interprétation si visiblement erronée sur un point qui tient autant à cœur à Aristote que la thèse de l'éternité du monde doit trahir quelque méconnaissance profonde des principes de celui qu'il considère comme le maître : c'est que la structure du monde physique, objet principal d'Aristote, l'occupe moins que la question de l'origine spirituelle des choses.

Pour Al Farâbi, comme pour les platoniciens, c'est là une question première, dont la suppression anéantirait la philosophie ${ }^{297}$ : en son fond, elle est posée comme chez Plotin, et l'on y retrouve, nous allons le voir, la triade Un, Intelligence, Ame : seulement, tandis que, chez Plotin, il s'agissait d'une production spirituelle, d'un mouvement vital auquel l'âme était en quelque sorte conviée à participer, la métaphysique d'Al Farâbi, entièrement tournée vers l'explication du monde matériel, identifie l'Intelligence et l'Ame de Plotin avec l'Intelligence et l'Ame motrice des cieux des Péripatéticiens. Tandis que certains

Suivant d'ailleurs en grande partie le traité d'Ammonius sur la Concordance de Platon et d'Aristote.

296 DIETERICI, LXV, p. 37-39. -

297 DiETERICI, LXV, p. 12. 
néoplatoniciens tendaient à faire du ciel un être entièrement spirituel, pour pouvoir lui garder sa place et son rôle dans la vie de l'esprit ${ }^{298}$, Al Farâbi insiste p095 sur le caractère matériel du ciel. Fusionnant le platonisme et l'aristotélisme, il enlevait à l'un sa spiritualité en le rendant solidaire de représentations physiques fixes et déterminées, et il enlevait à l'autre son caractère essentiel en attribuant une initiative productrice à l'être transcendant.

Un autre élément vient s'ajouter, qui complique encore l'aspect de la métaphysique farabienne. La triade platonicienne, en un certain sens, tend vers la trinité chrétienne comme vers une limite; cette triade, que tant d'auteurs occidentaux, notamment au XII ${ }^{\mathrm{e}}$ siècle, ont rapprochée de la Trinité chrétienne, lui est en effet assimilable dès qu'on admet que la génération et la procession ne s'opposent pas à l'égalité des termes de la Triade. Mais par là même, un philosophe musulman, tenant avant tout au dogme de la simplicité de Dieu, devait rejeter du même coup la Trinité chrétienne et la triade platonicienne : il est impossible que Dieu soit composé de trois hypostases ; entre l'Un et l'Intelligence, il y a un abîme beaucoup plus large que ne l'indique Plotin; l'Un ou Dieu est nécessaire par lui-même; l'Intelligence n'est par elle-même que possible et doit son existence non à sa nature, mais à Dieu, qui l'a produite ; le passage du possible à l'existence n'est pas, comme chez Aristote, le passage d'un être déjà existant en puissance à un être existant en acte, mais bien le passage de la non-existence à l'existence, passage qui est de même nature, qu'il s'agisse de l'intelligence ou de toute autre réalité, excepté Dieu. Al Farâbi commence ses Questions essentielles en déclarant que les notions indéfinissables de l'être, du nécessaire et du possible sont indispensables à la métaphysique ${ }^{299}$, faisant ainsi intervenir, pour expliquer le passage du possible à l'être, une notion de toute-puissance qui manque à Aristote.

De tous ces éléments réunis naît cette métaphysique bizarre ${ }_{\mathrm{p} 096}$ qui devait avoir tant de prestige en Occident, dès qu'elle y fut connue. Au sommet de la réalité, Dieu est l'être nécessaire, la cause première qui ne peut avoir son être de quelque autre chose, donc le seul être véri-

298 Cf. JAMBLIQUE, Des mystères, ch. XIV.
299 LXV, p. 92-94. 
table et sans restriction : en lui, l'existence ne s'ajoute pas à l'essence comme dans les autres êtres, mais elle est identique à l'essence. Al Farâbi insiste moins sur la théologie négative, sur l'ineffabilité, que sur la nécessité de l'être divin : c'est de cette nécessité qu'il déduit sa simplicité et son unité, puisque l'être nécessaire ne saurait provenir du rapprochement de plusieurs éléments, ni se diviser. Ainsi se marque l'action de la théologie musulmane d'origine sémitique ; s'il donne à Dieu des attributs d'origine grecque (le Bien, la Pensée), il l'appelle aussi, selon la tradition, le Sage, le Vivant, le Tout-Puissant ${ }^{300}$.

En revanche, le mode de production des choses par Dieu est conçu à la manière platonicienne : son Dieu n'est ni une nature qui produit sans connaissance, ni une volonté arbitraire et intentionnelle qui produit sans ordre. Dieu produit en tant qu'il se connaît éternellement luimême ; il ne peut donc produire qu'éternellement, et qu'un être éternel ; de plus, il ne peut produire immédiatement qu'un seul être, puisqu'il est lui-même unique, et un être qui, comme lui, a la capacité de se connaître : c'est la Première Intelligence ; en ce Premier créé, il y a cependant pluralité, puisqu'elle se connaît comme possible par son essence, et comme nécessaire par Dieu. En tant qu'elle se connaît nécessaire, elle engendre une autre Intelligence ; en tant qu'elle se connaît comme possible, elle engendre la matière du premier ciel ou ciel des fixes ; en tant qu'elle connaît sa propre essence, elle engendre la forme ou l'âme de cette sphère. Par un mécanisme exactement semblable, la deuxième Intelligence engendre un deuxième ciel et une troisième Intelligence, et ainsi de suite, jusqu'à une dernière ${ }_{\text {p097 }}$ Intelligence, créée par celle qui a engendré l’orbe de la lune.

Par l'intermédiaire des Intelligences et des cieux naît le monde de la génération. La matière première commune aux éléments, les quatre formes élémentaires, le mélange des éléments, la génération et la corruption, tout cela se rattache aux intelligences motrices et aux cieux, si bien que le monde sublunaire apparaît comme une image affaiblie des cieux. Si tous les corps sublunaires ont une matière commune, c'est que tous ont part au mouvement circulaire ; s'il y a quatre éléments, c'est à cause des différences de vitesse qu'il y a entre les mouvements circulaires de chaque ciel ; s’il y a transmutation des éléments les uns

${ }^{300}$ LXV, p. 92-94. 
dans les autres, c'est en vertu de l'imagination qui appartient aux intelligences motrices ; en effet une intelligence, en tant qu'elle connaît le passage de la sphère d'un lieu à un autre, possède l'imagination ; de l'ordre des images liées ensemble provient l'ordre du changement des éléments. De même que la matière et le mouvement des cieux, avec l'imagination des Intelligences, produit tout ce qu'il y a de corporel dans la région sublunaire, de même la dernière Intelligence produit les âmes qui animent les corps vivants.

Insistons bien sur la valeur absolue que prend, chez les Arabes, la cosmologie d'Aristote ; empruntant sa nécessité à celle de Dieu et par suite aussi nécessaire que Dieu même, le cosmos n’obéit plus, comme chez Aristote, aux souples lois de la convenance et de la beauté, pas plus qu'il n'est la création arbitraire d'un Dieu tout-puissant. L'effet bienfaisant du platonisme, qui, en faisant accéder à une réalité spirituelle, libérait l'esprit de la hantise d'une structure physique toute faite, ce qui était la condition du progrès dans la physique elle-même, a complètement disparu dans ce qu'on peut appeler l'arabisme, tellement les cieux physiques y sont liés à des nécessités métaphysiques. Ce n'est pas du tout qu'Al Farâbi partage les croyances astrologiques contre lesquelles ${ }_{0098}$ il a au contraire écrit un traité ${ }^{301}$; mais il y critique moins le déterminisme en lui-même que le déterminisme des astrologues, qui, contrairement à l'astronomie, croient à un ciel sans cesse changeant, parce qu'ils prennent, pour des modifications réelles des astres, des modifications accidentelles dues à la perspective sous laquelle nous les voyons.

La théorie de la connaissance intellectuelle est liée à la structure de l'univers. La dernière des dix intelligences émanées de Dieu, l'intellect actif, a imprimé aux choses matérielles sublunaires des formes qui n'ont d'existence que dans la matière ; la connaissance intellectuelle, chez l'homme, consiste en l'opération inverse, celle de l'abstraction qui les sépare des conditions matérielles et sensibles ; les formes sensibles conduites par les sens jusqu'au sens commun, puis jusqu'à la faculté de discerner, arrivent à l'intellect en puissance, qui possède la capacité d'abstraction; les formes, abstraites par lui, l'informent, et il devient intellect en acte. D'autre part, il y a des

${ }^{301}$ LXV, p. 170-186. 
formes par elles-mêmes séparées, telles que les intellects eux-mêmes ; Al Farâbi imagine un intellect qui pense toujours ces formes, c'est l'intellect acquis. L'intellect en acte peut les penser à son tour, lorsqu'il s'unit à l'intellect acquis comme une matière à une forme. Ainsi l'intellect en puissance est matière de l'intellect en acte, qui est matière de l'intellect acquis ; et l'intellect acquis est forme de l'intellect en acte qui est forme de l'intellect en puissance. Au-dessus des trois intellects, ou peut-être identique avec l'intellect acquis, se trouve l'intellect actif, qui, contenant toutes les formes, fait passer chaque intellect à l'acte, à la manière du soleil qui rend visible en acte le visible en puissance ${ }^{302}$.

La théorie de la Cité d'Al Farâbi, dont les principes sont p099 empruntés à la République de Platon, marque un effort pour retrouver dans la Cité l’ordre du monde ; le chef idéal, doué de toutes les vertus intellectuelles et pratiques, a tous les traits du philosophe de la République ; mais, comme ce chef est purement idéal, Al Farâbi se contente d'une république aristocratique, où ces vertus, au lieu de se concentrer sur un seul, seront partagées entre plusieurs. D'autre part, il oriente la Cité non pas vers des fins terrestres, mais vers une fin surnaturelle : son but est de préparer le bonheur après la mort.

Il ne faut pas chercher à toute force, chez un auteur tel qu'Al Farâbi, un système cohérent. Un de ses amis, qui a écrit une préface pour un de ses livres, nous dit comment il composait : " Il réunit des notes sur un sujet et en compose un livre ${ }^{303}$. " Il y a deux traits chez lui dont il est difficile de voir le lien systématique avec sa doctrine : c'est son mysticisme et sa théorie de la prophétie. Il parle d'une connaissance de Dieu combinée avec une jouissance suprême : "l'âme satisfaite se mêle à l'objet de cette jouissance suivant le mode de l'union » ; dans cette vision du vrai, elle s'oublie elle-même et, revenue à elle, elle se trouve mauvaise ; un pareil état est comparable à l'expérience d'une saveur, qu'on ne peut connaître, si on ne l'a éprouvée ; la méthode pour y arriver consiste à se dégager du sensible, « à

\footnotetext{
${ }^{302}$ La connaissance intellectuelle n'a donc d'autre rôle, comme chez Proclus, que de " réunir ce qui a été divisé ", $\mathbf{L X V}$, p. 77.

303 Préface à la Valeur de l'Astrologie, LXV, p. 171.
} 
être dans le corps comme si l'on n’y était pas » ${ }^{304}$. Dieu est alors conçu moins comme l'origine première des choses que comme une personne qu'il faut aimer pour elle-même avant de l'aimer pour ses bienfaits envers les créatures ${ }^{305}$; et, insistant sur le rapport personnel qu'il y a entre Dieu et la créature, il s'efforce de montrer contre Aristote qu'il y a, en Dieu, à côté du savoir de sa propre essence, un savoir indéfiniment divisible de la totalité qui vient de lui ; " son unité devient toute-puissance, p100 et la conséquence nécessaire est le deuxième savoir qui comprend la pluralité » ${ }^{306}$; son Dieu n'est pas un Dieu caché derrière des intermédiaires, mais un Dieu sans voile, qui a prédéterminé par sa toute-puissance l'ordre de succession des événements, si bien que sa science dépend de sa puissance, et que, sa puissance admise, «il est clair que tout le bien et tout le mal qui sont ici-bas, s’appuient sur la volonté éternelle ${ }^{307}$ ».

De la même manière, sa théorie du prophète introduit toutes sortes de relations personnelles et mystérieuses entre les réalités métaphysiques; le prophète est l'homme qui, par son pouvoir, commande à la nature et reçoit des révélations ${ }^{308}$.

Table des matières

\section{V. \\ YAYHA BEN ADI.}

Dans les discussions que le chrétien monophysite Yayha ben Adi, contemporain d'Al Kindî et d'Al Farâbi, qui vécut à Bagdad et traduisit en arabe plusieurs œuvres d'Aristote, soutint contre les Musulmans pour défendre la Trinité et l'Incarnation, nous voyons les adversaires convenir de n'employer que des arguments philosophiques. A vrai dire, il ne s'agit pas, dans ces discussions, de la réalité ou de la vérité de ces dogmes, mais seulement de leur possibilité ; il s'agit de savoir si, certains principes étant admis en commun, les dogmes restent pen-

\footnotetext{
304 Les Gemmes de la Sagesse, § 15 à 24.

305 Ibid., § 23.

306 Ibid., § 8-13. -

307 Ibid., § 48-49 et suivants.

308 Ibid., §27-29 et §46.
} 
sables. Par exemple, dans la Défense du dogme de la Trinité contre les objections d'Al Kindî, où ben Adi fait suivre chaque objection d'une réponse, le philosophe musulman demande si l’Unité de Dieu, admise par tous, est compatible avec la Trinité des personnes: car chaque personne, étant un composé de la substance et des propriétés, p101 est un effet, et aucun effet n'est éternel ; de plus, la personne doit rentrer dans une des cinq voix de Porphyre, genre, espèce, différence, accident, individu, ce qui, dans tous les cas, aboutit à nier l'éternité de Dieu. Ben Adi accepte la discussion sur ce terrain. Parmi ses répliques, il en est une qui doit nous frapper particulièrement ; Al Kindî prenait pour accordé qu'aucune chose causée n'est éternelle ; il est certain, au contraire, que, chaque fois qu'une cause fait exister un effet (ainsi le soleil produisant la lumière), l'effet est contemporain de la cause. Or, cette affirmation d'un effet éternel est précisément l'axiome de la métaphysique arabe des Intelligences ${ }^{309}$ : Ben Adi l'emploie pour justifier la Trinité, alors que les philosophes musulmans s'en servent pour expliquer l'éternité des créatures.

Citons encore la manière dont Ben Adi utilise la théorie des intellects pour justifier l'union de Dieu à l'homme dans la personne du Christ ${ }^{310}$ ou la possibilité de la Trinité ${ }^{311}$.

Table des matières

VI.

ISRAËLI ET SAADJA GAON.

Au temps d'Al Kindî et d'Al Farâbi, l'œuvre d'Israëli (845-940) et celle de Saadja Gaon (882-942), qui, tous deux, écrivent en arabe, montrent une véritable renaissance de la philosophie chez les Juifs d'Égypte et d'Asie Mineure : c'est l'époque où la Kabbale recule devant la philosophie rationnelle, " période classique » qui, comme la philosophie arabe, durera à peu près jusqu'au XII ${ }^{\mathrm{e}}$ siècle, après quoi la Kabbale tend à redevenir l'élément unique de la pensée juive ${ }^{312}$. Dans

\footnotetext{
309 Aug. PÉRIER, LXX, p. 121-122.

310 Aug. PÉrIer, Yahya ben Adi, p. 104 ; LXX, p. 75.

311 Aug. PÉRIER, p. 160-161.

312 D. NEUMARK, LXXI, t. I, p. 109.
} 
cette période, on paraît oublier les rêveries du Jezira sur ${ }_{\mathrm{p} 102}$ les combinaisons de lettres d'où est issue la création; comme chez les Arabes, mais indépendamment d'eux, on lit et on commente Aristote. Le monothéisme et l'hellénisme créèrent certainement, au cours du $\mathrm{X}^{\mathrm{e}}$ siècle à Bagdad, un terrain commun de discussion entre mahométans, chrétiens et juifs, et l'on y voyait des sortes de conférences philosophiques, où participaient même des athées.

Isaac ben Salomon Israëli a été surtout un compilateur ; médecin, il a écrit sur les éléments un livre où il utilise surtout Galien et Hippocrate ; logicien, il a rassemblé dans son Livre des Définitions bien des formules, qui devaient être plus tard utilisées par la scolastique latine ; conformément à l'esprit du temps, il essaye de concilier les définitions divergentes que Platon et Aristote donnent de l'âme ; l'âme est-elle une substance unie à un corps, comme le veut Platon, ou une substance qui complète le corps dont elle est l'acte, comme veut Aristote ? Ces deux définitions s'appliquent à deux moments de l'existence de l'âme, la première à celui où elle est mise en rapport avec le corps (par exemple la sphère céleste) dont le mouvement commence ; la seconde concerne le résultat de l'action de l'âme ; mais il ajoute que c'est là une distinction pour la pensée, puisqu'il n'y a pas de moment où l'âme soit entrée dans la sphère précédemment immobile ${ }^{313}$. Israëli connaît aussi la théorie aristotélicienne delà connaissance intellectuelle ; la distinction entre l'intelligence toujours en acte, auprès de laquelle les formes sont toujours présentes, l'intelligence en puissance, et l'intelligence qui passe de la puissance à l'acte ${ }^{314}$. Comme métaphysicien, il a cette conception d'une hiérarchie des formes métaphysiques découlant l'une de l'autre, qui est celle de ses contemporains arabes et que l'on trouve dans le Livre des Causes: l'intelligence, l'âme raisonnable qui est à l'horizon de l'intelligence et qui p103 est issue de son ombre, et, au-dessous, l'âme animale, puis l’âme végétative.

Il semble qu'il y ait eu, vers cette époque, dans les milieux juifs de Mésopotamie, deux formes de rationalisme assez différentes, toutes deux d'ailleurs se rattachant au Livre. Dès le VIII ${ }^{\mathrm{e}}$ siècle, les Karaïtes

\footnotetext{
313 GuTTMAnN, LXXVII, p. 38.

314 Ibid., p. 33.
} 
(ou Scripturaires), dont l'origine est à Babylone, rejettent non moins l'autorité des commentaires du Talmud que les croyances de la Kabbale ; ils se proposent de revenir purement et simplement à l'Écriture, en en tirant par la dialectique tout ce qui peut en être tiré. De même que beaucoup de Musulmans soutenaient que le Coran, comme parole de Dieu, était incréé, bien des Juifs croyaient aussi à l'éternité de la Thora ; contre cet attentat à l'unité et la simplicité de Dieu, les Karaïtes protestent comme les Motazilites dans l'Islam. D'autre part, partisans de l'interprétation littérale et hostiles à l'allégorisme, certains d'entre eux, comme le juif persan Nahawendi (vers 830), expliquent les anthropomorphismes de la Bible, en admettant qu'ils s'appliquent à un archange Logos que Dieu a créé et qui a, à son tour, créé l'univers, envoyé des prophètes et donné des lois ; ils insistent en revanche sur la simplicité de Dieu en déclarant que ses attributs sont identiques à son être.

Le rationalisme de Saadja Gaon, né en Égypte et chef de l'école juive à Babylone en 892, est aussi différent de celui des Karaïtes que le rationalisme des philosophes musulmans l'est de celui des Motazilites. Le rabbin Saadja est certes, autant que les Karaïtes, attaché à l'Écriture, qu'il n'a pas d'autre objet que d'interpréter : mais, tandis que les Karaïtes l'interprètent par elle-même en tirant logiquement les conséquences de ce qu'ils y voient écrit, Saadja demande, en outre, à la philosophie grecque des preuves des grandes affirmations de la religion. On ne peut du tout se fonder sur la spéculation seule; seule et sans la foi, elle peut conduire à l'erreur ; mais elle peut en revanche vérifier les données de la prophétie ${ }_{\mathrm{p} 104}$ et réfuter les objections contre la religion ${ }^{315}$; seule, elle permet, dans la discussion, d'éviter le cercle vicieux qui consiste à supposer ou à attendre la foi chez l'adversaire à convaincre. On peut, par exemple, prouver par la raison la création ex nihilo : une preuve est empruntée à la physique d'Aristote : d'après elle, tout corps limité n'a qu'une force finie et ne peut, par conséquent, durer un temps infini ; or le monde est un corps fini ; une autre, à l'adage aristotélicien qu'il est impossible de parcourir l'infini : puisque, en effet, on ne peut remonter l'infini dans le temps a parte ante à partir du présent, cet infini n'a pu être descendu ; par ces arguments, on peut réfuter les thèses hostiles à la création, parmi les-

315 VENTURA, LXXIII, p. 87-88. 
quelles Saadja cite, avec trois doctrines grecques (le démiurge du Timée composant le monde avec des triangles, le Dieu stoïcien tirant le monde de sa propre substance, le monde né d'une rencontre fortuite d'éléments), la théorie des deux principes du manichéisme; on peut également venir à bout des sceptiques qui affirment à la fois le pour et le contre. Ainsi, dans l'intention de Saadja, la raison est employée comme machine de guerre en faveur de la religion. Il applique une méthode analogue aux préceptes de la loi ; il y a des préceptes qui s’imposent en dehors de toute révélation ; «la raison exige que des lois nous soient données par Dieu..., que le créateur ordonne à ses créatures de le servir ", tandis que les préceptes révélés, indifférents en soi, ne deviennent lois que par la volonté de Dieu.

Table des matières

\section{VII.}

\section{LA PHILOSOPHIE A BYZANCE.}

Pendant la période de réveil en Occident, la philosophie, qui, à Byzance même, dans cette ville de juristes et de théologiens, p105 mêlés à la politique, n'a jamais eu grand succès, n'y a alors aucun représentant. Photios (840-897) est un érudit plus qu'un philosophe : il appliqua heureusement son érudition à rassembler, dans un ouvrage intitulé Bibliothèque, des extraits ou des résumés d'ouvrages philosophiques anciens qui nous sont des plus précieux : tout au plus peut-on dire qu'il manifestait quelque indépendance de jugement en préférant à Platon Aristote, dont l'Organon, à commencer par les Catégories et les Topiques, paraît avoir été pour lui le principal ouvrage. Son élève Aréthas (860-932), un Grec de Patras qui fut en 907 évêque de Césarée, fut aussi un érudit qui s'attacha particulièrement à la conservation des manuscrits de Platon.

C'est sans doute dans les monastères grecs qu'il faudrait chercher ce qui reste de vie spirituelle dans l'Empire, dans ces monastères où un ascétisme, d'une, veine toute populaire, directement issu du cynisme, se mêle à la vie contemplative telle que l'a comprise la patristique grecque, « qui, recueillie, continuée et amplifiée par ses héritiers directs et légitimes, est un monde à part, tôt fermé aux infiltrations du 
dehors ${ }^{316}$ ». Encore ne peut-on citer, pour la période qui nous intéresse, aucune initiative nouvelle ; on ne fait que suivre les modèles qui ont été donnés dans la période précédente, en matière d'ascétisme, par saint Nil et saint Jean Climaque, en matière de contemplation, par Maxime le Confesseur, qui suit lui-même Denys l'Aréopagite : et ce n'est pas à Byzance, mais plutôt dans la Syrie et l'Égypte qu'il faut chercher l'origine de ce mouvement : c'est la reprise, non sans doute sans une influence au moins indirecte, du thème platonicien du Phédon : la divinisation de l'âme par une purification des passions qui s'unit à la contemplation de Dieu; le «saint amour » que le moine cherche à entretenir en son cœur, c'est p106 l'amour pour Dieu, qui, " nous faisant abandonner toute beauté sensible, nous fait adorer sa gloire seule ${ }^{317}$. Il est aisé de reconnaître, dans cet idéal monastique, quelques traits fonciers de la philosophie grecque, et en particulier celui qui voit en Dieu plutôt un objet aimable qu'un sujet aimant.

${ }^{316} \mathrm{M}^{\mathrm{me}}$ LOt-Borodine, LXXIV, p. 5.

${ }^{317}$ Grégoire DE NysSE, cité par $\mathrm{M}^{\mathrm{me}}$ LOT-Borodine, Ibid., p. 71. 


\section{TROISIÈME PARTIE}

\section{LE DÉVELOPPEMENT DE LA PHILOSOPHIE (XI ${ }^{\mathrm{e}}$ ET XII ${ }^{\mathrm{e}}$ SIÈCLES)}

Table des matières

\section{Chapitre premier}

\section{LES CONDITIONS HISTORIQUES}

Le $\mathrm{XI}^{\mathrm{e}}$ et le $\mathrm{XII}^{\mathrm{e}}$ siècle sont dominés, en Occident, au point de vue intellectuel comme au point de vue politique, par un effort pour établir l'unité de la chrétienté ; il s’affirme dans la lutte de Grégoire VII contre l'empereur et le roi de France, et, à l'entrée du XIII ${ }^{\mathrm{e}}$ siècle, dans le pontificat d'Innocent III ; il se manifeste aussi bien par les Croisades que par la formation des royaumes chrétiens d'Espagne contre les Musulmans au $\mathrm{XII}^{\mathrm{e}}$ siècle et, au $\mathrm{XI}^{\mathrm{e}}$ siècle, la reprise par les Normands de l'Italie méridionale et de la Sicile sur les Arabes : ainsi se consolident, au Sud et à l'Orient, les frontières de la chrétienté, tandis que, vers la Russie, les missionnaires chrétiens arrêtent, par la conversion des Russes, l'expansion de l'Islam.

p108 L'unité de la chrétienté consiste avant tout dans la conviction commune, exprimée avec une force égale, par les partisans du pape et par ceux de l'empereur, que tout pouvoir, celui du pape comme celui 
du roi, est de nature spirituelle et d'origine divine ; le roi est un oint du Seigneur, dont la tâche unique est de veiller au salut éternel de ses sujets : il ne doit pas compter parmi les laïques : « il est justement séparé d'eux, dit l'un des polémistes d'alors ; car l'onction de l'huile sainte l'a fait participer au ministère sacerdotal ${ }^{318}$ ". Il n'est pas question de droit au sens moderne du mot ; la justice (mot qui revient souvent sous la plume de Grégoire VII) est une justice surnaturelle, la justification de l'homme auprès de Dieu par la grâce et la charité, justification qui n'est obtenue que dans l'Église ${ }^{319}$, la justice telle que l'a comprise, avant saint Augustin, saint Paul. L’Église, elle, n’est pas une société à part, en face d'une puissance séculière distincte ; pour Pierre Damien, comme pour beaucoup d'autres, la puissance séculière est partie intégrante de l'Église, " comme un de ses nombreux services, destinés à collaborer au salut des âmes ${ }^{320}$ ".

L’unité spirituelle de la chrétienté se manifeste, depuis la fin du $\mathrm{XI}^{\mathrm{e}}$ siècle, par la croisade ; l'idée de la croisade ne prit tout son sens et son développement qu'avec saint Bernard, abbé de Clairvaux, lorsque, en 1146, il prêcha la deuxième croisade ; elle devait, dans sa pensée, être la lutte contre les païens sur toutes les frontières de la catholicité, aussi bien vers l'Espagne et vers les bords de l'Elbe que vers la Syrie $^{321}$.

De même que l'on voit ainsi se développer aux $\mathrm{XI}^{\mathrm{e}}$ et $\mathrm{XII}^{\mathrm{e}}$ siècles un " augustinisme politique » qui voudrait absorber dans l'Église la société tout entière, de même on trouve un "augustinisme intellectuel ", qui tend à régler tout savoir ${ }_{\text {p109 }}$ sur le savoir des choses divines ; et comme, en politique, l'augustinisme entre en conflit avec des forces sociales qui lui sont étrangères, dans les choses de la pensée, les éléments intellectuels qu'il voudrait absorber commencent à prendre une sorte d'indépendance et à manifester des exigences propres.

318 Guy D’Osnabruck, Monumenta Germaniae, t. I, p. 467, cité par ARQUILLIÈRE. tXXXvllI, p. 359.

319 ARQUILLIÈRE, LXXXVIII, p. 265.

320 LXXVIII, p. 292.

321 Louis BréHIER, LXXIX, 4 e édit., p. 105. 
Émile Bréhier

La philosophie du Moyen âge

Table des matières 


\section{Chapitre II}

\section{DIVERS COURANTS PHILOSOPHIQUES EN OCCIDENT}

I.

\section{LES ÉCOLES ET LA DIALECTIQUE.}

La seconde moitié du $\mathrm{XI}^{\mathrm{e}}$ siècle et le $\mathrm{XII}^{\mathrm{e}}$ siècle sont, en Occident, une époque de jeunesse et d'épanouissement intellectuels, liés à ce renouveau politique que furent, d'une part, le développement des villes et l'établissement des communes, d'autre part la naissance d'une grande politique de la chrétienté dans les Croisades. Alors la culture cesse d'être cantonnée dans les abbayes ; des écoles épiscopales se fondent dans les villes, et, dès la première moitié du XII siècle, l'enseignement, à Paris du moins, se détache de l'évêché et tend vers la forme qu'il prendra au XIII ${ }^{\mathrm{e}}$ siècle dans les Universités. La tradition humaniste, qui s'était en somme maintenue depuis Charlemagne, s’affirme avec plus de force ; ces siècles ne connaissent pas encore la barbarie du style scolastique : de saint Anselme à Jean de Salisbury, il y a une prose latine excellente qui s'inspire de saint Augustin et des modèles classiques, Cicéron et Sénèque. Mais il est incontestable que la grande affaire intellectuelle du temps, c'est le renouvellement de l'enseignement de la théologie par l'emploi de la dia-

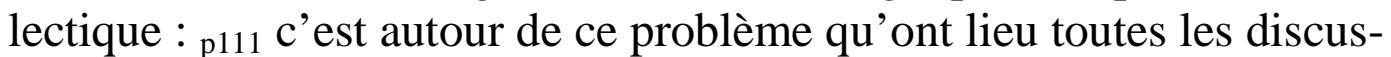
sions et tous les conflits ${ }^{322}$. Les sciences du quadrivium qui avaient eu autrefois une fonction religieuse, du temps de l'interprétation allégorique où l'on cherchait dans la Bible la source de tout savoir, sont en quelque manière libérées de cet office : mathématiques et astrono-

322 Sur tous ces points, cf. G. Paré, A. Brunet, P. Tremblay, LXXXII. 
mie s'apprêtent à exister pour elles-mêmes. Parmi les arts du trivium, la grammaire et la rhétorique ne sont que des arts préliminaires. La dialectique a donc la première place, Mais la notion s'en complique toujours davantage, à mesure que, à la logica vetus, c'est-à-dire à la partie de la logique d'Aristote connue par Boèce, s'ajoute sous le nom de logica nova la partie, jusque-là inconnue, de l'Organon, particulièrement la théorie des Seconds Analytiques sur la démonstration.

Le trivium et le quadrivium ne forment plus, dès le $\mathrm{X}^{\mathrm{e}}$ siècle, un programme d'études suivi avec une progression régulière : il y a toujours, comme au VII ${ }^{\mathrm{e}}$ siècle, des encyclopédistes, mais ils se bornent à l'humble tâche que doivent avoir des encyclopédistes, à une collection de matériaux; ils ne dirigent plus les études. En fait, l'ordre des études est laissé à la volonté de chacun, et l'importance d'une matière change avec le plus ou moins de célébrité d'un professeur ; avant le milieu du XII ${ }^{\mathrm{e}}$ siècle, un homme comme Jean de Salisbury allait de maître en maître, étudiant la dialectique avec Abélard, puis le quadrivium avec Richard, s’adonnant ensuite à la théologie, et revenant à la logique avec Gilbert de la Porrée, puis à la théologie avec Robert Pullus ${ }^{323}$. Des études faites dans ces conditions, où il s'agissait d'apprendre beaucoup de textes avec des commentaires, duraient fort longtemps ; celles de Jean de Salisbury, par exemple, durèrent douze ans, et Guillaume de Conches estime à huit ans le temps minimum des études.

p112 Pour comprendre le sens de ce triomphe de la dialectique et les conflits auxquels elle a donné lieu, il est indispensable, de ne pas oublier que la dialectique n'est pas prise seulement par le penseur médiéval comme un art formel de discussion : rappelons que la dialectique comprend, outre l'Introduction de Porphyre, tous les traités de l'Organon d'Aristote. Or, le premier d'entre eux, les Catégories, comme l'Introduction de Porphyre, contient, à côté de notions purement formelles, des éléments physiques et métaphysiques ; les Catégories sont considérées par beaucoup d'interprètes comme une classification des êtres réels et non pas seulement des mots ; et cela fait aussi question de savoir si les universaux de Porphyre désignent des choses ou seulement des noms ; et nous avons vu, depuis Boèce, que

323 ROBERT. LXXXIII, p. 47 sq. 
le théologien se demande la limite du domaine où s'appliquent les catégories ${ }^{324}$.

La principale et la plus vivante des écoles au début du $\mathrm{XI}^{\mathrm{e}}$ siècle, l'école épiscopale de Chartres, dirigée en 990 par l'évêque Fulbert, élève de Gerbert, donnait une grande place à l'étude des livres connus d'Aristote, de Boèce et de Cicéron, sur la logique et les Topiques, auxquels on ajoutait le De ratione uti de Gerbert. Fulbert, qui a ainsi favorisé l'enseignement de la dialectique, a pourtant prévenu ses élèves contre le danger qu'il y aurait à employer, en matière de théologie et de dogmes, les notions de la dialectique. De Denys et de Scot Érigène, il recueille la notion de la superessentia deitatis, qui place Dieu au-dessus de toutes les notions dialectiques ${ }^{325}$. Tout, dans les desseins de Dieu, nous échappe : "La profondeur incompréhensible du divin conseil, la sagesse humaine ne peut la comprendre par la pure intuition de la connaissance ; notre âme, quand elle désire s'élever audessus d'elle-même jusqu'à la région inaccessible des secrets divins, est repoussée par l'obstacle de sa faiblesse, et, resserrée dans les p113 limites de son ignorance, elle ne peut ni comprendre ce qui est au delà d'elle-même, ni estimer ce qui est en elle-même ; » la sagesse mondaine reste vide de la science de la vertu; elle cherche et ne trouve pas ; les mystères divins " sont révélés non à la discussion humaine, mais aux yeux de la foi ». L'esprit humain ne peut, par des arguments, expliquer "les causes de l'ordre divin »; il ne peut "présumer les choses invisibles d'après les visibles, ni mesurer les choses incorruptibles..., de peur que, prisonnier de ses propres définitions et suivant son sens aveugle, il ne tombe dans le précipice de l'erreur ${ }^{326}$ ". Il s'agit évidemment ici des définitions de la dialectique qui voudraient expliquer le réel. Fulbert et toute une partie de la pensée médiévale doivent au néoplatonisme le sentiment d'une réalité profonde qui échappe entièrement à ces cadres ; mais, dans ce sentiment, il voit surtout un moyen de défendre les dogmes, et particulièrement le dogme de la transsubstantiation, qui allait être attaqué au nom de la dialectique : «Si vous croyez, écrit-il, que Dieu peut tout, il faut croire que ces créatures qu'il a pu créer de rien, il peut à plus forte raison les éle-

\footnotetext{
324 Clerval, LXXX, p. 117.

325 Lettre de 1003 à Abbon, VI, t. CXLI, p. 199.

${ }^{326}$ Lettre à Enhard, VI, t. CXLI, p. 196.
} 
ver à la dignité d'une nature plus excellente et les faire passer dans la substance de son propre corps ${ }^{327}$. » Par une sorte d'ambiguïté qui explique bien des traits de la pensée médiévale, on pouvait mettre en effet, dans cette région inaccessible à la pensée humaine, soit la réalité ineffable de la mystique néoplatonicienne, soit les dogmes révélés.

Table des matières

II.

\section{DiALECTIQUE ET THEOLOGIE AU XI ${ }^{\mathrm{E}}$ SIECLE.}

Tout le milieu du $\mathrm{XI}^{\mathrm{e}}$ siècle allait être précisément occupé par des conflits concernant la légitimité de l'application de la ${ }_{\text {p114 }}$ dialectique aux choses divines et mettant, par conséquent, en doute la division des sciences, si fortement marquée, entre sciences des choses divines et sciences des choses humaines. A vrai dire ce furent à ce moment-là presque tous les dogmes qui furent attaqués au nom d'une dialectique que l'on apprenait dans le commentaire de Marius Victorinus au De Inventione de Cicéron : virginité de la mère du Christ, résurrection, immortalité de l'âme ${ }^{328}$; mais la plus célèbre de ces attaques fut celle que mena contre la transsubstantiation un élève de Fulbert, Bérenger, directeur de l'école de Saint-Martin de Tours, archidiacre à Angers en 1040 , et mort en 1088. Bérenger soutient que la consécration ne change pas le pain et le vin dans le corps du Christ ; le pain et le vin sont un sacrement au sens qu'a donné au mot saint Augustin, un signum sacrum, un signe visible qui nous fait aller, au delà de l'apparence sensible, à une idée ; mais le Christ n'a été immolé qu'une fois ; son corps, après la résurrection, reste incorruptible, et l'on ne peut concevoir sans contradiction qu'il puisse de nouveau pâtir et être brisé. " Si le pain et le vin sont appelés chair et sang du Christ, c'est parce que, en mémoire de la chair crucifiée, on célèbre un sacrifice qui rappelle la passion, et, par ce souvenir, nous invite à crucifier notre chair. » Bérenger rappelle à ses contradicteurs les règles de la dialectique ; le pain et le vin, que l'on appelle corps du Christ, sont appelés "in sacris litteris » species, similitudo, figura, signum, sacramentum, autant de termes qui, désignant des relatifs, ne peuvent

327 Ibid., p. 204.

328 ENDRES, LXXXV, p. 23. 
être identiques au terme auquel ils sont relatifs, c'est-à-dire ici au corps du Christ. Toute l'argumentation revient donc à dire, sous différentes formes, que le dogme de la transsubstantiation ne peut s’énoncer sans absurdité ${ }^{329}$.

p115 La doctrine de Bérenger fut condamnée en 1050 par Léon IX au concile de Verceil, en même temps que celle de Scot Érigène, où l'on voyait aussi le danger du primat de la raison ; il fut forcé à l'abjuration en 1059 et en 1079. Il trouva contre lui bon nombre de clercs sortis de Chartres, parmi lesquels Hugues, évêque de Langres depuis 1031. Dans la lettre d'ailleurs fort respectueuse ${ }^{330}$, qu'il lui adresse, Hugues lui reproche de ne pas connaître «la nature des choses qui existent», de ne pas tenir compte de "l'ampleur de la puissance divine qui dépasse la portée de nos sens »; sa doctrine paraît faire obstacle au Dieu invaincu ${ }^{331}$. Un autre élève de Chartres, Adelman de Liège, dans une lettre écrite avant qu'il connût bien la doctrine de Bérenger, s'élève en général contre la confiance accordée aux philosophes ; ceux-ci commettent bien des erreurs même en physique, par exemple lorsqu'ils supposent cette « absurdité » que le ciel et les astres sont en repos et que la terre est en mouvement (la théorie d'Héraclide du Pont qu'Adelman a pu lire dans le Commentaire du Timée de Chalcidius), et il cite bien d'autres «monstruosités »: ne trouve-t-on pas chez eux que le soleil ne chauffe pas et que la neige est noire ? Ce ne sont ni le sens ni la raison qui nous feront comprendre la transsubstantiation, pas plus que nous ne pouvons connaître par eux Dieu lui-même, " dont l'énigme surpasse tout entendement », et il attaque d'une manière générale les maîtres qui prétendent atteindre par la raison les réalités intelligibles et qui, de leur autorité propre, veulent imposer à leurs élèves des formules qu'ils ne comprennent même pas; il reproche tout spécialement à Bérenger de ne pas s'en tenir aux auteurs éprouvés, Priscien, Donat et Boèce ${ }^{332}$.

329 Doctrine exposée dans le De Sacra Cena adversus Lanfrancum, édité en 1834 à Berlin par Vischer. Lanfranc en a donné des résumés exacts dans son Liber de corpore, VI, t. CL, p. 410-442.

330 Cf. HEURTEVENT, LXXXVIII, p. 126, note.

331 VI, t. CXLII, p. 1325-1334.

332 VI, t. CXLIII, p. 289-302. 
Le traité d'Alger de Liège, De sacramento corporis, appartient au contraire à la période finale de la controverse. Alger a à cœur de résoudre la question « non point par la raison ${ }_{\text {p116 }}$ humaine, qui n’a aucune compétence là-dessus, mais par le témoignage du Christ luimême et des saints " ${ }^{333}$ : la transsubstantiation est « de ces choses qui sont obscures pour la raison et manifestes pour la foi ». Il est à noter pourtant qu'il se sert de notions dialectiques sinon pour faire comprendre le dogme, au moins pour l'exprimer par des mots. Ces notions sont celles de la substance, qui est comprise par le seul intellect, et des accidents sensibles ou apparences, qui sont données au sens; et il admet que le pain et le vin, quant à l'aspect et à la forme, ne soient appelés le corps du Christ que par similitude, tandis qu'ils sont réellement ce corps quant à la substance. Alger cède donc quelque peu sinon à la doctrine de Bérenger, du moins à sa méthode.

Mais ce mouvement de recul et cette impossibilité de se passer de la dialectique sont encore plus nets dans la discussion détaillée que Lanfranc, abbé du Bec, né en 1010, a faite de la doctrine de Bérenger, dans son Liber de corpore ${ }^{334}$, discussion dont les termes ont été repris par Bernold de Constance. Dans ce traité écrit après plusieurs condamnations, Lanfranc commence bien par reprocher à Bérenger « d'abandonner les saintes autorités et de se réfugier dans la dialectique "; lui-même, dit-il, il préférerait, quand il s'agit d'un mystère de la foi, s'en tenir à l'autorité ; mais il ne s'en place pas moins, pour répondre à son adversaire, sur le terrain de la dialectique ; il s'en excuse, il est vrai, en une phrase où s'unissent l'attrait et la répulsion pour cet art: " Bien que ses règles permettent de s'expliquer plus aisément, je cache, autant que je puis, cet art par des propositions équivalentes pour ne pas paraître me fier à lui plus qu'à l'autorité des Saints Pères ${ }^{335}$. » Il n'en est moins vrai qu'il cherche à détruire les raisonnements de Bérenger, en y montrant des fautes contre les règles, une proposition particulière prise ${ }_{\text {p117 }}$ pour une universelle, un syllogisme ayant pour prémisses deux particulières. Il voit d'ailleurs dans l'armature logique de la doctrine une manière d'éblouir les ignorants.

\footnotetext{
333 VI, t. CLXXXII, p. 740-c-d.

334 VI, t. CL, p. 410-442.

335 VI, t. CL, p. 417-a.
} 
De ces discussions qui se sont poursuivies tant d'années, tend à se dégager un résultat positif qui dissipe un peu l'ambiguiité de la notion de dialectique : on distingue la dialectique comme prétention à déterminer les cadres du réel et la dialectique comme simple art formel de la discussion ; ce que les adversaires de Bérenger réprouvent, c'est la dialectique au premier sens, qui prétend s'arroger le droit de limiter la puissance divine, en lui interdisant par exemple de changer la nature d'une chose, sous prétexte que les essences sont constantes; cette conversion du pain dans le corps du Christ est ineffable, incompréhensible, miraculeuse, mais non pas du tout impossible. «Quelle philosophie, demande Ascelin à Bérenger après le concile de Verceil, a éclairé la nature de tout? N'est-il pas plus vrai de dire que toutes les natures avec tout ce qui en découle sont causées par la volonté de Dieu ${ }^{336}$. » Si la dialectique ne compte pas comme moyen de déterminer les natures des choses, elle garde son rôle entier comme art de discussion.

Table des matières

III.

\section{LE DEBUT DES HERESIES ET L'AUTORITE.}

Au cours du $\mathrm{XI}^{\mathrm{e}}$ siècle, ce ne fut pas seulement la dialectique qui fut un danger pour le dogme et qui explique la répulsion qu'on trouve chez Pierre Damien et d'autres contre tout autre argument que celui d'autorité. A ce moment commencèrent à se répandre, venues d'Orient par des voies obscures, des sectes qui se refusaient à la discipline de l'Église. Au p118 synode d'Arras, par exemple, en 1025, comparurent devant Gérard, évêque d'Arras, des «manichéens " qui se disaient disciples de l'Italien Gondolfe ; tout en étant chrétiens, ils refusaient tous les sacrements et n'accordaient la vénération qu'aux apôtres et aux martyrs ; ils pensaient que l'homme n'était justifié devant Dieu que par sa conduite et ses mérites propres, et non par la grâce : leur idéal ascétique était celui des moines ; ils voulaient quitter le monde pour échapper à la concupiscence et pratiquer la charité en ne vivant que du travail de leurs mains ${ }^{337}$.

\footnotetext{
336 Cité par HeURTEVENT, LXXXVIII, p. 149.

337 Acta Synodi Atrebatensis, VI, t. CXLII, p. 1271 sq. ; 1311.
} 
C'est cet ensemble de faits qu'il faut avoir dans l'esprit pour comprendre les idées de Pierre Damien ; né en 1007 à Ravenne, il y ouvrit une école, puis se retira en 1035 dans un ermitage, jusqu'à ce qu'il fût appelé en 1057 comme évêque à Ostie, où il mourut en 1072. Il est en effet le propagateur de l'ascétisme dans les cadres de l'Église, dont il défend les dogmes contre les dialecticiens. C'est un de ceux qui cherchent cet équilibre entre l'ascétisme, le mysticisme et l'autorité que viennent déranger à la fois les ascètes, qui jugent l'autorité inutile à la discipline morale, et les dialecticiens, qui veulent rendre intelligibles les dogmes. Sur ce dernier point, il veut surtout limiter étroitement le domaine de la dialectique. On sait, d'après le De Fato de Cicéron, comment les Stoïciens établissaient le destin, en appliquant le principe de contradiction aux propositions concernant l'avenir, puisqu'il est éternellement vrai que, à un moment quelconque du temps, A sera ou ne sera pas. C'est cette doctrine que Pierre Damien a en vue dans le chapitre $\mathrm{V}$ de son De divina omnipotentia, où il traite des futurs contingents et de l'usage de la philosophie dans les discussions théologiques ; les Stoïciens sont ces imperiti sapientes, qui ont le tort de rapporter à Dieu un principe qui est d'usage dans l'art de discuter, et de limiter par lui la toute-puissance de ${ }_{\mathrm{p} 119}$ Dieu ; « des gens qui n’ont même pas appris les éléments du langage ruinent le fondement de la foi avec l'obscurité de leurs arguments. Ce qui vient de l'argumentation des dialecticiens ou des rhéteurs ne doit pas s'adapter facilement aux mystères du pouvoir divin ; ce qui a été inventé pour servir à organiser les syllogismes et à polir les phrases, que l'on n’aille pas l'introduire obstinément dans les saintes lois ni opposer la nécessité de leur conclusion à la puissance divine. Si pourtant l'on emploie parfois dans l'éloquence sacrée cette habile trouvaille de l'art humain, elle ne doit pas s'emparer avec arrogance du droit du maître ; qu'elle soit comme une servante prête à obéir à sa maîtresse (velut ancilla dominae quodam famulatus obsequio) ". Nous avons, dans ces paroles énergiques, la revendication, si souvent renouvelée depuis Philon d'Alexandrie, qui soumettait Agar à Sarah comme les arts libéraux à la philosophie, d'un savoir du réel profond contre les combinaisons artificielles de l'esprit humain ; et, bien que ce soit la foi révélée qui tienne la place de ce savoir, on retrouve ici le même rythme de pensée selon lequel Plotin écartait de l'intuition métaphysique toutes les subtilités de la dialectique. Seulement, lorsque Pierre Damien dit : « Les contraires ne peuvent appartenir à la fois à un seul et même su- 
jet : impossibilité véritable, si l'on se rapporte à la faiblesse de la nature, mais que l'on n'aille point l'appliquer à la majesté divine ${ }^{338}$, » ces termes ont un bien autre sens que chez Plotin, car ils s'appliquent à un Dieu créateur et à ses actes : tandis que l'Un, supérieur en luimême au principe de contradiction, s'accommode d'une nature ordonnée qu'il produit nécessairement ; le Dieu créateur, s’il est supérieur en lui-même au principe de contradiction, doit l'être aussi dans ses actes, et il ne doit rencontrer aucun obstacle dans une nature ordonnée ; il doit pouvoir ce qui est logiquement impossible : dans cet arbitraire complet, on ne peut plus parler ${ }_{\mathrm{p} 120}$ de la nature des choses. L’on verra comment les théologiens du Moyen Age se sont départagés sur cette importante question.

C'est des écoles épiscopales de France que partait le mouvement dialectique : c'est dans un monastère d'Italie que se trouve son principal contradicteur, Pierre Damien, mais on l'attaque aussi dans les monastères d'Allemagne. Otloh, né en 1010, écolâtre du monastère de Saint-Emmeram, où il mourut en 1073, est un Augustinien fervent qui déclare que la science mondaine est interdite aux moines, que les vrais habiles ce sont plutôt ceux qui sont instruits dans l'Écriture que les dialecticiens, enfin qu'il a plus à cœur de suivre la parole des saints que les théories d'Aristote, de Platon ou même de Boèce ${ }^{339}$; et l'on doit sans doute considérer comme une critique positive des catégories d'Aristote sa remarque que « la substance, comme être par soi et existant sans l'aide de rien autre, ne désigne que Dieu, tandis que la substance créée a tout son être au pouvoir d'un autre ».

La ratio philosophica (doctrine philosophique), que condamne Manegold de Lautenbach (mort en 1103) dans son Opusculum contra Wolfelmum, écrit vers 1083, est l'ensemble des théories exposées dans le Commentaire de Macrobe au Songe de Scipion. Il voit, dans le foisonnement des écoles philosophiques, une invention du diable ${ }^{340}$, et il trouve particulièrement détestables la transmigration pythagoricienne des âmes, la composition de l'âme avec deux essences selon Platon, la théorie soutenue par Macrobe de zones habitables séparées de nous

\footnotetext{
338 VI, t. CXLV, 612-a.

339 VI, t. CXLVI, p. 89 ; 60-a. ; 62-S.

340 Ibid., 245-6.
} 
par des espaces infranchissables ${ }^{341}$; « le créateur n’a pas appelé les amants de la vie éternelle à mesurer les dimensions du ciel et à déterminer le concours des planètes ou les mouvements des étoiles, pas plus qu'à l'étude de la philosophie mondaine ${ }^{342}$, la philosophie mondaine, c'est-à-dire celle qui accepte une conception de la destinée incompatible avec le christianisme, p121 des vies successives pour une seule âme, ou une géographie qui imagine toute une moitié de l'humanité échappant à l'influence rédemptrice du Christ. Il s'agit moins, on le voit, de la dialectique que d'une conception philosophique d'une nature ordonnée, conception que des dogmes comme la naissance du Christ ou la résurrection suffisent, selon lui, à réduire à néant ${ }^{343}$. S'il s'agit au contraire de la morale mystique de Platon, qu'il connaît également par Macrobe, de l'ascension de l'âme à partir des vertus politiques jusqu'aux vertus purifiées (purgatae) en passant par les vertus purifiantes (virtutes purgatorae), il admet toute la conception de la vie spirituelle qui est contenue dans ces formules. Ajoutons que Manegold consacre les deux derniers chapitres de son livre Contra Wolfelmum à combattre les Allemands qui veulent échapper à l'obédience de Rome et qui considèrent l'empereur comme le seul pontife ; l'empereur est l'élu du peuple, le simple dignitaire d'un office, dont il peut être déposé par ceux mêmes qui l'ont élu, s’il ne satisfait pas au devoir que lui impose son contrat avec le peuple ${ }^{344}$.

Table des matières

IV.

SAINT ANSELME.

Le conflit entre la dialectique et la théologie devait aboutir à la fin du $\mathrm{XI}^{\mathrm{e}}$ siècle à un équilibre dans l'œuvre de saint Anselme, dont la pensée est une des plus fortes du Moyen Age. Anselme, né à Aoste, en 1033, suivit au monastère du Bec les leçons de Lanfranc après 1060 ; il devint prieur du monastère en 1063, puis abbé en 1078. La plupart

\footnotetext{
341 VI, t. CLV, 158-a.

342 Ibid., p. 168.

343 Ibid., p. 155 et 163.

344 Cf. Liber ad Gerardum, dans Libelli de lite imperatorum et pontificum, t. I, p. 365, 392.
} 


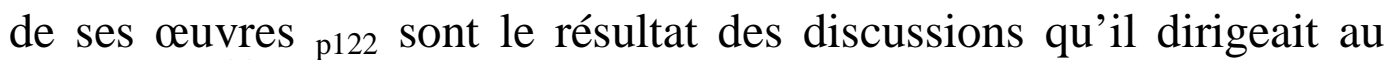
monastère $^{345}$ : entre 1070 et 1078 , il composa d'abord le Monologium, dont le titre primitif était : Exemplum meditandi de ratione fidei, puis le Proslogium, qui s'intitulait d'abord Fides quaerens intellectum ; c’est dans cette période, mais après le Monologium, qu'il composa ses quatre dialogues: De Veritate, De Libero arbitrio, De Casu diaboli, De Grammatico. En 1093, il fut archevêque de Canterbury et il mourut en 1109 ; c'est vers 1098 qu'il composa le Cur Deus Homo avec son complément, le De conceptu virginali.

L'existence du Dieu créateur et tout-puissant, la conciliation de la liberté et de la grâce, la rédemption, tels sont les thèmes, purement théologiques, de ces œuvres, où, comme l'indiquent les titres donnés d'abord à ses plus importants traités, il a l'ambition de démontrer par la raison des assertions qui lui sont préalablement données comme vraies par la foi ; le raisonnement n'ajoute rien à leur absolue certitude. Il ne faudrait pas compter sur la raison, laissée à elle seule, pour nous faire atteindre la certitude en de tels sujets ; ainsi que l'avait déjà dit un des adversaires de Bérenger, Durand de Troarn, la raison, si elle n’est soutenue par la révélation, n'atteint que le vraisemblable ${ }^{346}$.

Cette raison, saint Anselme ne l'a jamais appliquée à une autre matière qu'à la théologie, et elle ne semble pas avoir dans sa pensée d'autre usage que la méditation de la foi ; restant pur théologien, jamais il ne paraît se demander si la raison a un domaine indépendant de celui de la foi. Aussi bien, si l'on cherche à saisir, par l'emploi qu'il fait du mot, ce qu'est pour lui la ratio, l'on verra qu'elle consiste surtout dans les règles de la dialectique : le rationis ${ }_{\mathrm{p} 123}$ robur inflexibile se réfère, par exemple, à une démonstration en forme de l'identité du Verbe avec l'Être suprême ; il faut voir dans le De Grammatico des exercices préliminaires par lesquels il assouplissait l'esprit de ses élèves: on demande dans quelle catégorie il faut faire entrer tel terme ; on insiste sur la nécessité, pour savoir si un syllogisme est correct ou non, d'envisager non seulement la forme verbale des termes, mais leur sens (par exemple lorsqu'un même terme est employé en

345 Cf. les détails qu’il donne sur la rédaction du Monologium, sur la manière dont il est né de discussions et de conversations que les frères le prièrent de rédiger comme exemplum meditationis.

346 VI, t. CLVIII, p. 363. 
deux sens) ${ }^{347}$. La ratio se réduit-elle pourtant à la forme syllogistique ? Il semble qu'elle ait gardé chez Anselme quelque chose du caractère semi-intuitif qu'elle avait chez Plotin et chez saint Augustin ; la science humaine, selon lui, saisit tout au moins les images et les ressemblances des choses telles qu'elles sont dans le Verbe divin ${ }^{348}$, c'est-à-dire des essences dont la science serait la science absolue et complète ; pour Anselme comme pour saint Augustin, l'acte par lequel nous reconnaissons en nous-mêmes la figure de la Trinité est un acte de ratio.

C'est, si l'on tient compte de ce second sens du mot raison, que l'on peut s'expliquer quelle importance saint Anselme a attachée en théologie à un emploi de la raison qui, à lui tout seul, ne nous conduirait qu'à des vraisemblances et qui ne sert même pas à vérifier des conclusions que la foi rend par elle-même d'une certitude qui ne peut être surpassée ${ }^{349}$. En effet, à la foi, qui connaît les choses divines ex auditu, s'oppose la contemplation (species) par laquelle on les voit elles-mêmes ; mais cette vision est réservée aux élus ; or, entre la foi et la vision, se trouve l'intellectus, l'intelligence des vérités de la foi comme une étape intermédiaire. p124 C'est cette étape qui est atteinte par la ratio $^{350}$; la recherche rationnelle devient ainsi non pas la satisfaction d'un vain orgueil humain, mais un degré dans la vie du salut et comme une préparation à la béatitude.

L'on comprend alors pourquoi la recherche rationnelle suppose la foi ; toute la doctrine de saint Anselme est un commentaire du mot d'Isaïe $(7,9)$ : « nisi cridideritis, non intelligetis », si souvent cité par Jean Scot et par Anselme lui-même, qui en a tiré la formule célèbre : fides quaerens intellectum. La foi est à la recherche de la vision complète et arrive au moins à cette ébauche de vision qu'est l'intellect. Il est très loin de ce que l'on appela plus tard la théologie rationnelle ; il ne demande pas « qu'on accède à la foi par la raison, mais que l'on se plaise à l'intelligence et à la contemplation de ce que l'on croit et que

\footnotetext{
347 VI, t. CLVIII, p. 561, sq. ; ch. IV.

348 Monolog., ch. XXXVI ; VI, t. CLVIII, p. 190-a.

349 Cur Deus Homo, ch. II; VI, t. CLVIII, p. 362 : etiam si nulla ratione quod credo possim comprehendere, nihil tarnen est quod me ab ejus firmitate valeat evellere.

350 De Fide Trinitatis, VI, t. CLVIII, p. 259.
} 
l'on soit prêt, autant que possible, à satisfaire à tout homme qui demande raison de l'espoir qui est en nous ${ }^{351}{ }^{\prime}$. La délectation intellectuelle se mélange à l'utilité pratique ; il faut répondre aux objections des infidèles, bien que, en ce qui les concerne, il s'agisse moins de les convaincre que de leur montrer que la foi chrétienne ne répugne pas à la raison ${ }^{352}$. Cette méditation intellectuelle de la foi est pour tous, pour les illettrés (illiterati) comme pour les lettrés ; elle ne doit employer que des arguments simples et compris de tous ; Anselme luimême fait un effort incessant vers la clarté lorsqu'il passe de la multitude des arguments du Monologium, dont l'enchaînement est difficile à saisir, à la preuve unique et simple du Proslogium ${ }^{353}$. Mais en aucun cas le raisonnement ne précède la foi : « Je ne cherche pas à comprendre pour croire ; je crois ${ }_{\text {p125 }}$ pour comprendre ${ }^{354}$. » Ajoutons que cette intelligence, non moins que cette foi, est un don de Dieu : " Domine, qui das fidei intellectum... », dit-il au chapitre II du Proslogium et, à la fin du chapitre IV, il insiste : «Ce que d'abord j'ai cru grâce à votre don, je le comprends maintenant grâce à votre lumière » (te illuminante). On voit combien il est absurde de croire que la raison puisse jamais s'opposer à la foi, et Anselme donne sur ce point les deux règles suivantes : " $\mathrm{Si}$ on tire une conclusion par un raisonnement évident et s'il n'y a nulle contradiction de la part de l'Écriture, par là même cette conclusion est reçue par son autorité. Mais si l'Écriture répugne à cette évidence, bien que notre raisonnement nous paraisse impossible à combattre, il ne faut pas croire pourtant que ce raisonnement s'appuie sur la vérité ${ }^{355}$. " Ainsi l'Écriture sainte est l'autorité sur laquelle s'appuient toutes les vérités de raison, soit qu'elle les affirme, soit qu'elle ne les nie pas.

Cette méditation est infinie, et saint Anselme ne se figure pas du tout la théologie intellectuelle sous forme d'un système clos; les apôtres et les Pères ont laissé beaucoup à dire : c'est que « la doctrine

\footnotetext{
351 Cur Deus Homo, ch. I, VI, t. CLVIII, p. 361 ; cf. De Fide Trinitatis, p. 150.

352 Cur Deus Homo, début.

353 Cf. De Casu diaboli, ch. XII: sur la nécessité de retenir à la fois tous les détails d'une argumentation quasi sub uno intuitu.

354 Credo ut intelligam ; Proslogium, ch. I.

355 De Concordia praescientiae, etc., ch. VI ; VI, t. CLVIII, p. 528.
} 
de vérité est si ample et si profonde qu'elle ne peut être épuisée par les mortels » ${ }^{356}$.

Malgré toutes les précautions que prend saint Anselme, il est douteux que le dogme révélé s’accommode toujours de l'interprétation rationnelle qu'il en donne : par exemple dans le Cur Deus Homo, il veut montrer la nécessité de l'incarnation ; même si on ne savait rien historiquement du Christ, la raison devrait confesser que les hommes ne peuvent être heureux que si un Homme-Dieu apparaît et meurt pour eux et que Dieu n'aurait pu nous sauver par une autre personne ou par une ${ }_{\mathrm{p} 126}$ décision volontaire : quel est le caractère de cette «nécessité » et que doit-elle être pour être compatible avec la souveraine liberté de Dieu et avec le caractère foncièrement historique des décisions divines, c'est ce qu'Anselme n'a pas montré, et c'est sans doute là la fissure qui, au $\mathrm{XIV}^{\mathrm{e}}$ siècle, amènera la ruine de l'édifice scolastique qu'il a véritablement fondé. Il semble que la conception anselmienne de la triade fides intellectus contemplatio, qui, par saint $\mathrm{Au}-$ gustin, remonte au platonisme ${ }^{357}$, ne puisse guère s'accommoder que d'une doctrine qui, comme le plotinisme, permet, dans l'ascension de la connaissance, une résorption de l'inférieur dans le supérieur et ne laisse place à aucune histoire véritable.

Ces préliminaires étaient indispensables pour comprendre la portée de la doctrine elle-même. Le Monologium est un ensemble de réflexions sur l'essence de Dieu qui est en même temps une démonstration de son existence. Tout le traité repose sur un adage de métaphysique platonicienne qui peut s'exprimer ainsi : partout où il $\mathrm{y}$ a une multiplicité de termes de même propriété, différentes du plus au moins, il y a une nature unique possédant cette propriété par soi. Affirmant ainsi, au-dessus des choses bonnes, l'existence du Bien, saint Anselme montre que ce Bien est un être unique, créateur, possédant un Verbe, simple et éternel. De même, dans le De Veritate, il passe des propositions vraies à la Vérité suprême.

356 De Fide Trinitatis, préface, VI, t. CLVIII, p. 260-1 ; cf. p. 364 : « quoi que l'homme puisse en apprendre et en savoir, les raisons profondes d'une si grande réalité lui sont encore cachées ».

357 Platon, République, VI, fin. 
On comprend mieux la fameuse preuve de l'existence de Dieu du Proslogium, cette preuve qui a été appelée "ontologique » et où le $\mathrm{XVII}^{\mathrm{e}}$ siècle, après Descartes, a vu une pièce importante de la " théologie naturelle », lorsque l'on voit l'atmosphère dans laquelle elle est née. Elle est précédée d’une prière qui finit ainsi : " Donc, Seigneur, qui donnez l'intelligence à la foi, accordez-moi de comprendre que vous êtes ainsi que nous le croyons, et que vous êtes celui que nous p127 croyons. » Quelle est cette croyance ? « Nous croyons (credimus) que vous êtes tel que rien de plus grand que vous ne peut être pensé. » Cette définition de foi est acceptée par l'insipiens, celui qui dit dans les Psaumes (XIII, 1) : Dieu n'est pas. Or, lui est-il permis de donner, comme il le fait, cette signification au mot Dieu et de dire qu'il n'existe pas? «Du moins l'insipiens lui-même, quand il entend ce que je dis : un être tel qu'on ne peut en penser de plus grand, comprend ce qu'il entend, et ce qu'il comprend est dans son intellect, même s'il ne comprend pas qu'il existe ; car autre chose est d'avoir une réalité dans l'intellect, autre chose de comprendre qu'elle existe » : c'est ainsi que le peintre possède en idée le portrait qu'il doit faire, alors qu'il n'existe pas encore ; et c'est de la même manière que l'insipiens croit que l'on peut avoir Dieu dans sa pensée sans qu'il existe. Mais le cas n'est pas le même : "L'être tel que rien de plus grand ne peut être pensé ne peut être dans le seul intellect. Si, en effet, il est dans le seul intellect, on peut penser qu'il est aussi en réalité, ce qui est plus. Si donc l'être tel que rien de plus grand ne peut être pensé est dans le seul intellect, l'être tel que rien de plus grand ne peut être pensé est tel que quelque chose de plus grand peut être pensé : mais cela n'est pas possible ; il est donc hors de doute que l'être tel que rien de plus grand ne peut être pensé est et dans l'intellect et dans la réalité. " Ainsi Dieu a l'être vrai (vere est), et l'on ne peut pas penser qu'il n'est pas, une fois pourtant que l'on a admis par la foi (credimus) que Dieu est, par définition, l'être souverainement grand.

Il y a en effet deux interprétations possibles de la célèbre preuve, mais dont la seconde seule s'accorde avec le texte d'Anselme pris intégralement. La première, la plus généralement acceptée, consiste à faire de la formule : " être tel que rien de plus grand ne puisse être pensé », une définition arbitraire du mot Dieu, qui doit être acceptée indifféremment par p128 tous ; la seconde fait voir au contraire que cette formule appartient à la foi et ne peut être émise que par un 
homme de foi. L'insipiens n'est nullement un rationaliste, c'est un homme qui, croyant en l'existence de l'être souverainement grand, ne comprend pas cette existence ; et la signification propre de l'argument de saint Anselme, c'est de lui faire voir qu'il suffit de méditer sur cet être, de l'avoir dans sa pensée pour être sûr qu'il existe effectivement. Dire, comme on l'a fait ${ }^{358}$ (1), qu'il n'y a pas là du tout de preuve de l'existence de Dieu, c'est fort exagéré ${ }^{359}$ (2) ; mais il est bien vrai que c'est une spéculation sur cet être vrai, dont la non-existence est inconcevable, dès que l'on médite sur la nature de cet être ; pourtant saint Anselme ne dit pas seulement, comme ferait un platonicien : l'être vrai est un être dont, par définition, on ne peut dire qu'il n'est pas, il prétend encore montrer qu'il existe un pareil être.

L'insipiens a répondu à Anselme par la bouche de Gaunilon, un moine de l'abbaye de Marmoutiers, près de Tours. Le fond de la critique de Gaunilon, c’est, bien qu'il soit inexprimé, le principe aristotélicien que l'on ne peut poser l'essence d'un être avant d'avoir posé son existence, si bien que toute affirmation tirée de l'essence de Dieu (et en particulier cette affirmation : il existe) suppose son existence préalablement établie. Anselme déduit de l'esse in intellectu l'esse in re ; il est ainsi passé sur la difficulté principale, qui consiste à établir l'esse in intellectu; il a cru à tort qu'il suffisait de penser à Dieu pour pouvoir affirmer qu'il est dans l'intellect, c'est-à-dire qu'il a une essence ; mais, à ce compte, une fiction quelconque posséderait également une essence. C'est dire que, si l'existence de Dieu ne peut être constatée, elle ne peut jamais être qu'un objet de foi ; c'est atteindre, dans son principe, la méthode même de saint Anselme ; ${ }_{\text {p129 }}$ nous verrons comment saint Thomas, qui reconnaissait (avec Gaunilon le défaut de la preuve de saint Anselme, a pu pourtant sauver une méthode dont il acceptait tous les principes.

Table des matières

358 S. STOLZ, XCVIII, p. 1-24.

359 Cf. la discussion de GILsON, XCV. 


\section{V. \\ ROSCELIN.}

Dès l'époque d'Anselme pourtant, cette méthode trouva des contradicteurs du côté des dialecticiens: si des hommes comme Pierre Damien et Manegold, avaient, au début du siècle, protesté contre l'abus que l'on faisait de la dialectique contre la foi, il se trouva alors d'autres hommes pour critiquer, au moins implicitement, l'usage que l'on en faisait pour comprendre la foi. Aux yeux de ceux que saint Anselme appelle les " hérétiques de la dialectique », c'est-à-dire de Roscelin et de ses partisans que l'on appela plus tard les nominalistes, les concepts employés par la dialectique ne désignent aucune réalité différente de celle que nous percevons par les sens. Roscelin, né à Compiègne en 1050, et qui enseigna en diverses parties de la France, à Soissons, à Reims, à Compiègne, à Loches, à Besançon et à Tours, fut en effet forcé par le concile de Soissons, en 1092, d'abjurer sa doctrine sur la Trinité. Cette doctrine tendait vers le trithéisme, qui voit dans les trois personnes trois Dieux distincts. Et, dans l'opinion de saint Anselme, cette erreur théologique était liée étroitement à la conception nominaliste en dialectique : "Qui ne comprend pas encore comment plusieurs hommes sont spécifiquement un seul homme, de quelle façon comprendrait-il comment, dans la nature la plus mystérieuse, plusieurs personnes, dont chacune est un Dieu parfait, soient un seul Dieu ${ }^{360}$ ? " Saint Anselme attribue le nominalisme, qui voit dans les ${ }_{\mathrm{p} 130}$ universaux, selon son expression, de simples flatus vocis, à une incapacité intellectuelle d'hommes qui, par là même qu'ils ne peuvent comprendre l'unité d'une pluralité dans une espèce, pourront encore moins élever la foi à l'intelligence. La théorie, qu'on peut appeler réaliste, des universaux apparaît donc nettement, dans cette critique, comme une préface nécessaire à l'intellectualisation de la foi. C'est surtout par des critiques de ce genre que l'on connaît le nominalisme de Roscelin qui, lui-même, n'a rien écrit ${ }^{361}$, et c'est d'ailleurs moins la querelle des nominaux et des réaux, en elle-même, que son rapport à la théologie qui devait passionner les hommes de ce temps.

\footnotetext{
360 VI, t. CLVIII, p. 265-b.

361 Avant Roscelin, au début du $\mathrm{XI}^{\mathrm{e}}$ siècle, un commentaire de Porphyre édité par Cousin (Ouvr. inédits d'Abélard, p. LXXVII) indique les arguments du nominalisme. Cf. J. REINERS, C.
} 
Mais que pouvaient être les arguments positifs de Roscelin ? On ne peut que l'inférer. Son nominalisme nous apparaît à travers les critiques d'Anselme et d'Abélard comme composé de trois thèses distinctes : la négation de la réalité des universaux, la négation de la réalité des accidents ${ }^{362}$, la négation de la réalité des parties d'un tout ${ }^{363}$. Ces trois thèses paraissent bien dépendre de la thèse positive suivante : il n'existe que des individus au sens fort, c'est-à-dire des indivisibles, non point à la façon des atomes, mais comme des touts que toute décomposition anéantirait comme tels, comme si l'on voulait enlever la sagesse à l'âme ou la couleur au corps. C'est sans doute chez Aristote, connu à travers Boèce, que Roscelin a pris le principe de cet exposé ; Boèce était d'opinion que les Catégories d'Aristote classaient, sous les dix genres, non pas des êtres, mais des mots ; d'où il ressortait que les voix de Porphyre, c'est-à-dire les universaux, étaient elles-mêmes des mots. Ajoutons que la ${ }_{\mathrm{p} 131}$ critique des idées platoniciennes, d'où résultait que l'individu seul possédait l'existence, était en partie connue. Enfin, Abélard dit : « Roscelin, pseudo-chrétien autant que pseudo-dialecticien, en même temps qu'il dit dans sa dialectique que le mot seul, et non la réalité, a des parties, change impudemment le sens de l'Écriture sainte, si bien que, au passage où il est dit que le Seigneur mangea la partie d'un poisson, il est forcé d'entendre la partie de ce mot qui est un poisson non la partie d'une chose $^{364}$ »; sous cet exposé intentionnellement malveillant, il est bien facile de reconnaître l'adage répandu d'Aristote : " Le bras séparé du corps n'est plus un bras que par homonymie. »

Le «trithéisme » de Roscelin se rattache à son nominalisme ; si, selon la troisième thèse, il n'y a pas en une substance de division réelle en parties, il faut admettre, si la distinction des personnes est réelle, qu'elles sont « distinctes entre elles comme trois réalités, trois anges ou trois âmes " ${ }^{365}$; toutefois il ne dit pas qu'il y a trois dieux, mais qu' « on pourrait dire qu'il y a trois dieux, si l'usage le permet-

362 D’après saint Anselme (VI, t. CLVIII, 265-a), la couleur n’est rien que le corps, et la sagesse de l'homme rien que son âme.

363 D’après ABÉLARD : sicut solis vocibus species, ita et partes adscribebat (Ouvrages inédits, p. 471).

364 VI, t. CLXXVIII, p. 538-6.

365 D’après Anselme, VI, t. CLVIII, p. 1192 et 266. 
tait ${ }^{366}$. Cette réticence prouve que Roscelin prétendait rester l'interprète fidèle du dogme. Il ne voit d'ailleurs d'autre alternative, si l'on n'admet pas le trithéisme, que de faire des trois personnes une réalité unique (res una), d'où résulterait, contrairement au dogme, que le Fils ne s'est pas seul incarné. On voit comment les nominalistes sont conduits, par leur interprétation de la dialectique, à trouver des difficultés dans le dogme plutôt qu'à l'interpréter : nous verrons plus tard comment les nominalistes du XIV ${ }^{\mathrm{e}}$ siècle ont renoncé à résoudre ces difficultés et ont ainsi séparé la dialectique de la théologie.

Table des matières

VI.

\section{LA PHILOSOPHIE DE LA NATURE ET LE PLATONISME CHARTRAIN.}

p132 D'un bout à l'autre, le XII ${ }^{\mathrm{e}}$ siècle témoigne de luttes ardentes au sujet de la place exacte de la dialectique et de la philosophie à l'intérieur de la culture chrétienne. La politique d'une chrétienté qui veut s'organiser et qui a à son service des hommes comme Bernard, abbé de Clairvaux, le droit canonique qui se développa surtout en Italie, le mysticisme qui trouva à cette époque de nouveaux interprètes, ont nécessairement leur écho dans ces luttes, qui sont moins des discussions d'idées abstraites que des essais d'organisation spirituelle qui s'imposent souvent par l'autorité des conciles et des synodes. En même temps, l'Occident prend de plus en plus connaissance de l'Orient; les arts du quadrivium se nourrissent des traductions de l'arabe. Dès le début du siècle, un homme comme l'Anglais Adélard de Bath, après avoir fait son éducation à Laon et à Tours, voyage en Italie, en Sicile, en Grèce et en pays arabe ; il traduit d'arabe en latin les Éléments d'Euclide, l'Arithmétique d'Alchwarismi (Liber algorismi). Cette curiosité universelle des esprits se traduit par un sentiment neuf de la nature, qui semble absent de la pensée du $\mathrm{XI}^{\mathrm{e}}$ siècle, et avec lequel renaît l'influence du platonisme, celui du Timée et celui de Scot Érigène.

Il nous faut d'abord parler de ce mouvement naturaliste et platonicien qui tendait à une philosophie de la nature, liée sans doute à la

366

Ibid., 1192-d. 
théologie, mais pourtant distincte d'elle. A ce point de vue, il faut souligner l'extrême importance du médecin Constantin l'Africain, né à Carthage, qui, dès la seconde moitié du $\mathrm{XI}^{\mathrm{e}}$ siècle, après des voyages à travers l'Égypte et l'Orient, traduisit de l'arabe en latin de fort nombreux médecins ${ }_{\mathrm{p} 133}$ arabes, juifs et grecs ; c'est ainsi que l'on put connaître, à Salerne d'abord, puis à Chartres, les Aphorismes d'Hippocrate avec les commentaires de Galien et plusieurs œuvres de Galien. Constantin l'Africain rappela aussi l'attention sur la théorie atomique, qui, d'ailleurs, pouvait être connue en Occident par d'autres sources, par Lucrèce lui-même ainsi que par Chalcidius et Isidore.

Dans un dialogue, dont la forme littéraire rappelle Marcianus Capella et la Consolation de Boèce, et dont le titre, De eodem et diverso, est tiré d'un passage du Timée sur la composition de l'âme du monde, Adélard de Bath paraît avoir oublié toute référence à l'autorité et à la révélation. Il oppose la raison, d'une part aux sens, d'autre part à l'autorité. Quant aux sens, que Platon appelle irrationnels, ils sont incapables de juger dans les très grandes choses et dans les très petites (nec in maximis nec in minimis) : les maxima doivent désigner ici l'univers, et les minima, ces atomes, dont Lucrèce montrait si abondamment qu'ils ne sont connus que par la raison ${ }^{367}$; quant à l'autorité, la raison est seule capable de distinguer entre le vrai et le faux. Sur l'origine de cette raison dans l'homme, il reprend entièrement le mythe platonicien de la réminiscence, sans paraître se soucier de son incompatibilité avec le christianisme : l'âme (noys), à l'état de pureté, connaît les choses et leurs causes ; puis jetée "dans la prison du corps", elle perd une partie de sa connaissance, mais "elle cherche ce qu'elle a perdu et, à défaut de mémoire, elle use de l'opinion ${ }^{368}$ "; l'âme, qui a perdu sa divinité, est ainsi longtemps troublée par le tumulte des sens ${ }^{369}$. La conception de la dialectique, ainsi introduite, rappelle Platon plus qu'Aristote ; elle recherche une vision des essences plutôt que le mécanisme du syllogisme : la dialectique, écrit-il, " saisissant, grâce à l'admirable subtilité de sa lumière,

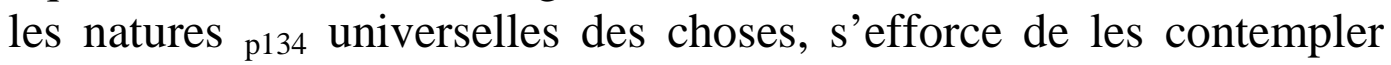

\footnotetext{
367 Édit. Willner, dans BAUEMKER, XCI, t. IV, p. 13.

368 Ibid., p. 10.

369 P. 13 ; p. 16 ; cf. Timée, 44-a.
} 
(intueri) comme elles ont été conçues avant le temps dans l'esprit du démiurge ${ }^{370}$.

Pourtant il est platonicien à la manière de ses modèles lointains dont il a connu l'esprit par Boèce ; il renouvelle l'éclectisme des derniers platoniciens qui ne voulaient pas sacrifier à Platon l'œuvre si bien construite d'Aristote. Parmi les objections contre la philosophie auxquelles il veut répondre se trouve la discordance des philosophes et, notamment, le désaccord de Platon et d'Aristote sur la question des universaux, l'un admettant l'existence des Idées, l'autre des seuls individus. Il y a en réalité accord, dit Adélard, car ils considèrent les mêmes réalités, mais à rebours. Platon entreprend de connaître les choses « d'après leurs principes mêmes ( $a b$ ipsis initiis), et il exprime ce qu'elles étaient avant d'entrer dans les corps, en les définissant les formes archétypes des choses. Aristote, lui, part des réalités sensibles et composées »: c'est l'analyse opposée à la synthèse. Aussi les genres et les espèces d'Aristote, que l'on ne peut connaître que dans les choses sensibles et en s'aidant de l'imagination, ne sont pas les idées platoniciennes purement immatérielles. "Le genre et l'espèce sont les noms des sujets ; car si vous considérez les réalités (sensibles) les noms de l'essence, du genre, de l'espèce et de l'individu sont appliqués à la même réalité, mais non sous le même rapport. Les philosophes qui veulent traiter des réalités sensibles les ont appelées individus, en tant qu'elles sont désignées par des noms propres et numériquement diverses ; les considérant plus profondément, à savoir non en tant qu'elles sont diverses pour les sens, mais en tant qu'elles sont désignées par le mot homme, ils les ont appelées espèces; en tant qu'elles sont désignées par le mot animal, genres. Cependant, en considérant les espèces, ils ne suppriment pas les formes individuelles, p135 mais ils les oublient parce qu'elles ne sont pas posées par le nom de l'espèce... De même pour le genre : le mot animal dénote, en la chose désignée par lui, la substance, plus l'animation et la sensibilité ; le mot homme dénote tout cela, plus la rationalité et la mortalité ; le mot Socrate tout cela, plus la diversité numérique des accidents. » On voit ici comment un nominalisme aristotélicien s'accorde parfaitement avec le réalisme platonicien; c'est que les genres et les espèces ne sont pas les idées ; ce sont des formes qui sont inhérentes à la matière

${ }^{370}$ P. 22, 13. 
et dont on oublie la matière en les pensant, non pas des formes immatérielles et simples, qui sont dans l'intelligence (noys) divine : les universaux sont « les choses sensibles elles-mêmes, quoique considérées avec plus de pénétration » ; mais, en eux-mêmes, ils ne sont ni genres ni espèces ${ }^{371}$.

Le platonisme d'Adélard s'accompagnait d'un vif sentiment de la rationalité de la nature : "Certes la volonté du Créateur, écrivait-il à propos du texte connu de la Genèse, est que les herbes naissent de la terre, mais cette volonté n'est pas sans raison. »

C’est dans l'école épiscopale de Chartres que se développa le platonisme. C'est seulement par un auteur de la seconde moitié du siècle, par Jean de Salisbury, que nous connaissons le premier de ces platoniciens chartrains, Bernard, qui fut maître de l'école épiscopale de 1114 à 1119 et chancelier de 1119 à 1124 et que Jean appelle perfectissimus inter platonicos saeculi nostri, un platonicien qui d'ailleurs, comme Adélard et sans doute de la même manière, conciliait Platon avec Aristote $^{372}$. Lorsque, d'après Jean, les disciples de Bernard de Chartres disent que «les genres et les espèces ne sont rien en dehors des idées ", l'idée étant, selon une définition qui paraît venir de Sénèque ${ }^{373}$, « un modèle éternel des choses naturelles ", p136 il faut sans doute comprendre que les genres et les espèces sont liés à ces choses singulières «qui, à cause de leur continuel écoulement, ne méritent même pas le nom de substance et dont les propriétés sont si variables que leur être ressemble moins à un état stable qu'à une transformation sans cesse changeante ». Jean fait remarquer que cette thèse, qui reproduit la grande division du Timée entre être et devenir, " est complètement étrangère à l'opinion d'Aristote ». Nous savons, d'autre part, comment Bernard interprétait en pur platonicien le passage du premier chapitre des Catégories d'Aristote sur les "paronymes ", c'est-à-dire un ensemble de termes, tels que : albedo, albet, album ; « ces mots, disait-il, signifient par leur racine (principaliter) la même chose, mais diffèrent par la signification qui s’y joint : blancheur désigne une vierge pure, il blanchit cette même vierge quand elle s'unit

\footnotetext{
371 Cf. p. 11 et 12.

372 Jean DE SALISBURY, Metalogicus, VI, t. CXC1X, p. 875.

373 SÉNÈQUE, Lettres à Lucilius, 58, § 19,
} 
à son époux, chose blanche la même une fois corrompue ; c'est-à-dire la qualité elle-même, puis la qualité admettant la participation d'un sujet, enfin la qualité mélangée à ce sujet » ; dans ces images, très caractéristiques du style un peu affecté des Chartrains, on trouve la triade du livre des Causes : participant, participé et intermédiaire entre les deux.

Cette liberté à l'égard de l'autorité, qui se manifeste au moins par le choix précis et raisonné d'une thèse, est liée au sentiment de la possibilité du progrès, qui se manifeste sans doute pour la première fois au Moyen Age. Jean de Salisbury, ayant cité ce mot d'Abélard qu'un moderne serait capable de composer une dialectique qui ne le céderait en rien aux livres des anciens, ajoute que Bernard disait: "Nous sommes comme des nains montés sur les épaules des géants, si bien que nous pouvons voir plus de choses qu'eux et plus loin qu'eux, non que notre vision soit plus perçante ou notre taille plus haute, mais parce que nous sommes transportés et élevés plus haut grâce à leur taille de géants ${ }^{374}$. »

p137 Le frère de Bernard, Thierry de Chartres, qui fut maître à Chartres, en 1121, enseigna à Paris, en 1140, puis devint chancelier à Chartres, en 1150, où il mourut vers 1154 , est à la fois un métaphysicien platonicien qui interprète d'après le Timée le récit de la création de la Genèse et un " artiste » qui écrit un Heptateuchon, manuel des sept arts libéraux ; dans l'étude du quadrivium il ne se contente plus de la tradition occidentale; il utilise, en dialectique, les traductions des Premiers Analytiques, les traductions en latin par Hermann le Dalmate d'œuvres astronomiques arabes et du Planisphère de Ptolémée ainsi que de divers écrits médicaux. L'usage qu'il fait du Timée dans le De sex dierum operibus pour commenter la Genèse apparaît dans les assertions suivantes : "La souveraine Trinité opère dans la matière qui est l'ensemble des quatre éléments : en tant qu'elle est cause efficiente, elle crée cette matière ; en tant qu'elle est cause formelle, elle l'informe et la dispose ; en tant qu'elle est cause finale, elle la chérit et la gouverne. Car le Père est la cause efficiente, le Fils, la cause formelle, le Saint-Esprit, la cause finale et la matière, la cause

${ }^{374}$ Metalogicus, liv. III, § 4 ; VI, t. CXCIX, p. 900-c. 
matérielle ${ }^{375}$. » Plus loin, l'Esprit-Saint, au lieu d'être la cause finale, devient la vertu du démiurge par laquelle la matière est informée ${ }^{376}$. Quoi qu'il en soit de ces flottements, il est facile de voir que le texte de Thierry suppose à la fois une assimilation des notions du Timée, paradigme, démiurge, âme du monde et éléments, aux quatre causes d'Aristote et une assimilation des trois premières de ces notions aux trois personnes de la Trinité. Pour la première de ces assimilations, il n'est pas besoin de recourir à Avicébron, ni même, comme le fait Duhem, à des traductions de la Physique d'Aristote; car cette assimilation se trouve dans un texte familier aux Chartrains, dans les Lettres à Lucilius de Sénèque. « Il y a cinq causes, dit Platon, ce dont une chose est faite, ce par quoi, p138 ce en quoi, ce selon quoi, ce en vue de quoi ;... comme dans une statue, ce dont elle est faite est l'airain, ce par quoi, l'ouvrier, ce en quoi, la forme qui lui convient, ce selon quoi, le modèle, ce à cause de quoi, le dessein de l'ouvrier... Et le monde a aussi tout cela, dit Platon : un créateur (facientem), c'est Dieu ; ce dont il est fait : c'est la matière ; une forme : c'est la manière d'être et l'ordre du monde; un modèle selon qui Dieu a fait cette grande et belle œuvre ; un dessein pour lequel il l'a faite ${ }^{377}$. » Quant à la seconde assimilation, il la rencontrait, entre autres, dans la tradition de Jean Scot, qui, avec ce renouveau du platonisme, commençait à redevenir vivante; il retrouve d'ailleurs l'Esprit saint non seulement dans l'âme du monde de Platon, mais dans le spiritus de l'Asclepius d'Apulée.

C'est dire combien, à Chartres, était libre l'interprétation des dogmes ; non pas qu'il s'agisse ici d'une philosophie indépendante de la foi ; il ne peut en être question en Occident au XII siècle ; mais plutôt que « la foi recherchant l'intelligence », on pourrait dire que la philosophie des Chartrains est "l'intelligence en quête de la foi ", c'est-à-dire cherchant dans les dogmes, en particulier dans ceux de la Trinité et delà Création, les correspondants des notions platoniciennes. C'est bien ce que prouve encore le De universitate sive megacosmus et microcosmus que Bernard Silvestre (peut-être identique à Bernard de Moélan, chancelier de Chartres vers 1156 et évêque de Quimper,

\footnotetext{
375 HAUrÉAU, III, t. XXXII, $2^{\mathrm{e}}$ partie, p. 173.

376 Ibid., p. 179.

377 Epist. 65, § 8-10.
} 
de 1159 à 1167) adressa à Thierry de Chartres vers 1150. Cette œuvre, tout à fait chartraine de forme, avec une recherche de style et un mélange de prose et de vers qui rappelle Capella et la Consolation de Boèce, est un dialogue dont l'auteur présente ainsi l'argument : « $\mathrm{Na}$ tura en pleurs adresse une plainte à Noys, c'est-à-dire la Providence de Dieu, au sujet de la confusion qui règne dans la matière première ou hyle, et elle demande que le monde soit mieux façonné. Noys, ému p139 par ses prières, consent volontiers à sa demande, et il sépare l'un de l'autre les quatre éléments. Au premier livre on décrit l'ordre des éléments ; au second livre, intitulé Microcosmus, Noys s'adresse à $\mathrm{Na-}$ ture; elle se glorifie de la beauté du monde, et elle promet que, en complément de son œuvre, elle façonnera l'homme. Physis forme l'homme de ce qui reste des quatre éléments. " Sous ces images, on reconnaît facilement et la cosmogonie d'Ovide, avec la division des éléments, et le Timée, avec ce "résidu d'éléments » dont l'homme est formé, et la Genèse, avec la dernière place réservée à la création de l'homme. Mais l'essentiel de cette cosmogonie est pourtant la Trinité platonicienne, Bien, Intelligence, Ame du Monde qu'il fait correspondre à la Trinité des personnes, Père, Fils, Saint-Esprit, comme chez Jean Scot. Le Bien est la suprême divinité ; de lui émane le Logos ou le Noys, " première image de la vie vivante, Dieu issu de Dieu, substance du vrai, teneur de l'éternel conseil ;... il est l'intelligence du Dieu souverain qui surpasse tout ; il est une nature née de sa divinité ; en elle sont les images de la vie vivante, les notions éternelles, le monde intelligible, la connaissance fixée d'avance de toutes choses ; là, on pouvait voir comme en un miroir bien poli tout ce que Dieu, dans sa volonté la plus secrète, avait destiné à être engendré et produit ; là-bas était inscrit, dans son genre, dans son espèce, dans sa singularité individuelle, tout ce qu'enfantent la Hyle, le monde et les éléments. Là, se montrent le doigt de l'organisateur suprême, le tissu du temps, la série du destin, la disposition du siècle ; là, les larmes des pauvres et la fortune des rois ». Dans cette conception du Verbe, monde intelligible qui contient, sous forme éternelle, toute la série des événements qui se dérouleront dans le temps, il est aisé de reconnaître le platonisme de la Consolation et celui de Jean Scot ; mais lorsque, plus loin, il assimile Noys à " l'Usia primitive et éternelle, persévérance féconde, unité dans la pluralité », ajoutant : " Cette Usia est une, elle est seule, la nature ${ }_{\mathrm{p} 140}$ de Dieu tout entière vient d'elle et est en elle ; cette unité est l'être unique de toutes choses », il est impossible 
de ne pas reconnaître l'inspiration de Jean Scot, bien que l'on ne trouve rien, chez Bernard, d'analogue au mouvement de conversion par lequel, chez Jean Scot, le temporel se résorbe dans l'éternel. De Noys émane l'âme qu'il appelle Endelecheia et qui, d'après le modèle qu'elle contemple dans l'Intelligence, informe la nature. Enfin l'attribution du mal à la matière accentue encore le platonisme de Bernard.

L'œuvre de Guillaume de Conches (1080-1145) est, elle aussi, une des manifestations de l'esprit chartrain. Il commente le Timée et la Consolation; il écrit une morale (Moralis philosophia de honesto et utili) inspirée du De Officiis de Cicéron et du De Beneficiis de Sénèque. Son De Philosophia mundi, de forme dialoguée, est avant tout une philosophie de la nature, ainsi que le Dragmaticon philosophiae. Il ne veut pas que l'on prenne toute innovation pour une hérésie : «Non quia scriptum non est, haeresis est, sed si contra fidem est ${ }^{378}$. » Sa théorie de la Trinité est, comme toutes les théories chartraines, orientée vers l'explication de la création ; avec Abélard, il identifie les trois personnes avec la Puissance, la Sagesse et la Volonté ${ }^{379}$. La Sagesse ou Fils est engendrée "quand Dieu prévoit de quelle façon il créera les choses et les disposera, une fois créées ». La procession du Saint-Esprit consiste « à étendre la volonté divine de la puissance et de la sagesse jusqu'à la création et au gouvernement du monde ». Il fait d'ailleurs quelques efforts pour insérer dans cette théorie les dogmes de l'incarnation et de la rédemption : l'union des deux natures dans le Christ est l'effet de la sagesse, et la rémission des péchés ${ }_{\mathrm{p} 141}$ vient de la Bonté ou Volonté ${ }^{380}$. Mais il continue en traitant de l'âme du monde, que l'on peut, dit-il, soit identifier avec le Saint-Esprit (c'est l'opinion d'Abélard), soit considérer comme « une force naturelle, insérée par Dieu dans les choses, par laquelle certaines vivent, d'autres vivent et sentent, d'autres vivent, sentent et discernent » ; soit prendre enfin « comme une substance incorporelle qui est tout entière

378 VI, t. CLXXII, p. 46-c ; cf. ses plaintes, 56-d : «Si inquirentem aliquem sciant, illum esse haereticum clamant. » Il dit des Pères de l’Église : Etsi majores nobis, homines fuere.

379 Qu'il retrouve dans le Timée ; et. son Commentaire du Timée, VI, t. CLXXII, p. 249.

380 De philosophia mundi, liv. I, ch. V à XIV. 
en chaque corps ». Il aboutit donc à une sorte de panthéisme naturaliste, greffé sur le théisme, puisque la dernière hypostase divine, identique ou inférieure au Saint-Esprit, se confond avec la Nature. L'ensemble des êtres forme une série hiérarchique, Dieu, âme du monde, démons, âmes, ciels, météores, terre, que la philosophie a mission d'étudier dans son ensemble ${ }^{381}$; les arts du trivium, grammaire, dialectique et rhétorique, qui ne se rapportent qu'au langage (eloquentia), sont extérieurs à la philosophie ; celle-ci comprend au contraire les arts du quadrivium et la théologie ; " aidés des arts du trivium, nous devons aborder l'étude de la philosophie dont l'ordre consiste d'abord dans le quadrivium, ensuite dans l'Écriture sainte, lorsque, par la connaissance de la créature, nous parvenons à la connaissance du créateur ${ }^{382}$ ».

Faire entrer le quadrivium dans la philosophie même était bien conforme à l'esprit de Chartres ; mais ainsi sans doute était-il amené à une image de la nature, fort différente de l'image traditionnelle, et qui n’alla pas sans inquiéter par sa nouveauté. En effet, après Constantin l'Africain et Adélard de Bath, il introduit les atomes, "particules simples et très petites, qui sont comme les premiers principes "; et il le fait avec grande précaution; c'est " en tant que physicien » que Constantin a admis les atomes, c'est-à-dire en tant qu'il étudie la nature des corps singuliers; mais " traitant de la création du monde et non des corps singuliers, les philosophes ont p142 parlé des quatre éléments visibles ». Il trouvait contre lui tous ceux qui n'admettaient pas que l'on pût connaître les choses matérielles autrement que par les sens, " ces gens qui, comme des paysans, ignorent tout ce qu'ils ne peuvent saisir par les sens » et qui ne connaissent des éléments que « leurs propriétés ou leurs qualités apparentes, sec, froid, humide, chaud $^{383}$ ». Mais, ce qui était plus grave, il rencontrait l'hostilité des platoniciens mêmes sortis de l'école de Chartres, pour qui la réalité sensible, fuyante et indéterminée, ne saurait se fixer en corpuscules ; le chartrain Gilbert de la Porrée croit, suivant en cela le Timée et Plotin, qu'il n'y a pas ici-bas d'éléments à l'état pur, mais que la plus petite particule est déjà un mélange des quatre éléments ; les Idées ou

\footnotetext{
381 Ibid., liv. I, ch. I : VI, t. CLXXII, p. 43-6.

382 Ibid., t. IV, ch. XL.

383 VI, t. CLXXII, p. 49-c-d, 50-a.
} 
modèles des éléments sont des substances pures (substantiae sincerae) ; pour lui, en outre, les éléments sont non pas la matière, mais la détermination d'une matière par une forme. Guillaume lui oppose avec quelque fermeté les principes de l'atomisme : les vrais éléments sont des corpuscules indivisibles qui sont matière et non pas forme, et ce que nous appelons mélange est une juxtaposition due à la porosité des corps ${ }^{384}$.

A cette théorie corpusculaire s’associait chez lui le désir de rendre raison naturellement des faits. Il admettait, comme Adélard de Bath et bien des Chartrains, une natura operans dont la raison pouvait trouver les règles : c'est ainsi que, avec Lucrèce, il cherche une théorie naturaliste de l'origine des animaux et des hommes, traitant ainsi une question qui paraissait être du ressort de l'autorité de l'Écriture ; il rencontrait ici ceux qui voyaient dans cette notion de la nature une ${ }_{\mathrm{p} 143}$ limite au pouvoir de Dieu ; il leur répond qu'il appartient à la puissance de Dieu « de donner aux choses telle nature et ainsi, par l'opération de cette nature, de créer le corps humain "; il n'est pas contraire à l'Écriture d'expliquer «de quelle façon (qualiter) la chose se fait »; l'objection vient d'hommes «qui ignorent les forces de la nature. Nous, nous disons au contraire qu'il faut partout rechercher la raison, mais que, si elle fait défaut, il faut nous confier au Saint-Esprit et à la Foi ». Il ne manque pas d'ailleurs de recourir à l'explication allégorique de l'Écriture en des matières où il croit pouvoir rendre raison des choses, par exemple à propos de la création de la femme ou de la nature du firmament fait d'eau congelée ${ }^{385}$. « Je sais, écrit-il à ce propos, ce qu'ils diront; nous ne savons comment la chose se fait, nous savons que Dieu peut la faire. Malheureux ! quoi de plus malheureux que semblables paroles! Dieu peut-il faire une chose et ne pas voir comment elle est, et n'avoir pas de raison pour qu'elle soit ainsi, et ne pas rendre manifeste l'utilité qu'elle a ? »

384 VI, t. CLXXII, p. 51-54. Sans doute cette vision mécaniste se relie-t-elle à sa thèse sur la nature de l'âme ; selon lui, il faut attribuer aux corps toutes les actions communes à l'homme et aux bêtes (croître, sentir) et à l'âme, ce qui est particulier à l'homme (intelligence, raisonnement, mémoire), dualisme platonicien qui fait pressentir de loin le dualisme cartésien (Philos, mundi, liv. IV, ch. XXIX-XXXI).

385 VI, t. CLXXII, p. 56-a ; 58-d. 
Les « erreurs » de Guillaume de Conches furent rassemblées en un traité par Guillaume de Saint-Thierry, qui l'adressa à saint Bernard de Clairvaux, lequel surveillait sur tous les points de la chrétienté l'éclosion de l'hérésie. Guillaume de Conches, qui proclamait: "Christianus, non academicus sum », qui confessait que, " en ce qui concerne la foi et la morale, il n'est pas permis de contredire Bède ni aucun des saints Pères », ne fut, non plus qu'aucun Chartrain, un naturaliste, mais il rechercha, peut-être assez vainement et maladroitement, à concilier, en se servant des schèmes néoplatoniciens, l'idée d'une nature ayant des lois fixes avec la théologie.

L'usage du platonisme pour traduire en un langage rationnel et intellectuel les dogmes du christianisme ne se trouve pas seulement dans le milieu des Chartrains ; nous entendons ${ }_{\text {p144 }}$ le platonisme tel qu'il est interprété par Jean Scot. Avant la nouvelle condamnation du De divisione naturae, qui eut lieu en 1211, au Concile de Paris, où l'on condamna en même temps l'hérésie d'Amaury de Bène, le scotisme se répandit librement. Guillaume de Malmesbury, né vers 1095, écrit vers le premier tiers du XII ${ }^{\mathrm{e}}$ siècle au moine Pierre, qui lui avait demandé des renseignements sur le lieu de naissance et de mort de Jean Scot et sur ses opinions ; il est fort doux dans ses appréciations. Le De divisione naturae est un livre fort utile, "si seulement on lui pardonne les quelques passages où il a dévié de la route des Latins pour jeter ses regards sur les Grecs ». Il sait bien qu'on l'a taxé d'hérésie et pourtant il conclut avec indulgence : « Divers écrits alternativement le louent et le décrient, bien que les éloges aient depuis longtemps né ${ }^{386}$. »

Vers la même époque, un moine de l'Allemagne du Sud, caché sous le pseudonyme d'Honorius d'Autun, écrivait un traité intitulé Clavis physicce qui débutait ainsi : "Comme je vois que non seulement beaucoup d'ignorants, mais bien des gens qui brillent de l'éclat de leur sagesse dévient trop du chemin de la vraie physique, j'entreprends de ramener à la voie de la vérité tous ceux qui veulent me suivre à travers ce que m'a fait voir mon raisonnement avec l'aide de la grâce divine. » Or, ce qui est annoncé si pompeusement, c’est, presque pour la moitié de l'œuvre, des extraits du De divisione natu-

${ }^{36}$ VI, t. CXXII, p. 92. 
rae. Dans ses autres œuvres, la Cognitio vitae, qui traite de la connaissance de Dieu, l'Imago mundi, qui contient la géographie, la météorologie et l'astronomie avec le calcul des temps, l'Elucidarium, on trouve d'ailleurs la même métaphysique: l'existence d'une même créature à deux niveaux différents, en Dieu, comme vie immuable, et en soi, comme vie changeant dans le temps ; l'opposition de l'être vrai et de la p145 vérité à la créature, qui est l'ombre de la vie et de la vérité ; et surtout, ce qui est proprement scotiste, la résorption finale du corporel dans le spirituel et du spirituel dans le divin.

Table des matières

\section{VII.}

\section{LA RAISON ET LA FOI : LES SENTENCES.}

Bien que d'esprit différent de la pensée de saint Anselme, la philosophie des Chartrains comme l'érigénisme pur n'ont d'autres motifs de développement que de penser la foi : la nécessité, nécessité pratique encore plus que théorique, de formuler, de propager, de transmettre la foi chrétienne est bien la cause pour laquelle il y a au $\mathrm{XI}^{\mathrm{e}}$ et au XII ${ }^{\mathrm{e}}$ siècle une philosophie. Jamais, sans ce puissant motif, l'esprit occidental ne serait sans doute revenu à la philosophie ; jamais l'idée d'une spéculation autonome, d'une recherche de la vérité pour ellemême n'aurait pu naître. Lorsque l'on songe à la recherche de la vérité, l'on entend vérité dans le sens augustinien, dans le sens de la Vérité qui est le Dieu suprême qui nous a créés et qui nous sauve. En ce sens, la philosophie a sa place marquée dans l'idéal d'une culture chrétienne ; elle se coordonne à l'ensemble des activités multiples, religieuses, mystiques et politiques qui constituent la chrétienté. Seulement cette coordination ne va pas sans peine ; la philosophie, à mesure qu'elle se développe, a ses exigences propres ; à l'universalité de la foi chrétienne, qui naît et se développe en des conditions historiques définies, s'oppose l'universalité rationnelle de la philosophie, indépendante de toute foi : opposition peu consciente et certainement non voulue, puisque tous sont d'accord pour assigner à la philosophie la tâche que nous avons dite, penser la foi, opposition bien réelle pourtant, puisque les écarts des philosophes sont sans cesse surveillés et réprimés par ceux qui ont plus spécialement la charge de ${ }_{\mathrm{p} 146}$ maintenir l'unité de la chrétienté, comme saint Bernard ; sans cesse, on se 
demande si la philosophie n'est pas, plutôt qu'un soutien, l'invention d'un orgueil diabolique : il semble pourtant impossible de s'en passer, et toujours l'on cherche un équilibre nouveau, presque toujours aussitôt rompu. Le problème qu'a voulu résoudre le Moyen Age est peutêtre insoluble, peut-être même absurde : mais il est vivant et passionnant, et, seul, il a produit cette tension d'esprit qui a forcé l'Occident chrétien à continuer la grande œuvre de la civilisation grecque.

Le problème se complique, si l'on songe que, à l'époque à laquelle nous arrivons, la foi s'énonce en une foule d'autorités diverses, souvent contradictoires, au moins en apparence, et que peu d'hommes peuvent dominer ; et ce qui est vrai de la foi doit se dire aussi de la discipline et des règles des mœurs : au milieu de tant de textes de l'Écriture et des Pères, de décisions conciliaires, de canons, de décrets des papes, il est difficile de s'y reconnaître ; il est de plus en plus urgent qu'il y ait des spécialistes pour organiser et classer tant de matériaux divers et en dégager l'unité. Ces spécialistes, ce sont les « Sententiaires » du XII ${ }^{\mathrm{e}}$ siècle, dont Mgr Grabmann a retracé l'histoire ${ }^{387}$. Leur travail, qui n'était fait que pour dégager explicitement la foi, mettait pourtant en jeu la raison pour déterminer la valeur des matériaux et même utilisait parfois la philosophie pour ajouter, à l'autorité, des preuves rationnelles. Mgr Grabmann signale, à cet égard, de grandes différences entre les auteurs. Il y a ceux qui, créateurs véritables de la méthode du Sic et Non, dont on voyait autrefois l'origine chez Abélard, rangent face à face les autorités contradictoires sur chaque question; tel Bernold de Constance, qui indique en même temps les règles à suivre pour résoudre ces contradictions : comparaison plus attentive des textes, détermination du ${ }_{\mathrm{p} 147}$ sens d'après les circonstances de lieu et de temps où ils ont été écrits, etc. : excellentes règles philologiques, qui accoutument l'esprit à des recherches positives, bien différentes de ces commentaires allégoriques que l'on employait quand la lettre d'un texte était gênante ${ }^{388}$. Il y a ceux qui cherchent un exposé systématique de la foi : et c'est bien là ce qui plus tard portera le nom de Sentences : tel est le Decretum d'Yves de Chartres, mort en 1116 ; le Decretum, en dix-sept livres, étudie la foi

387 XXII, t. I, p. 234 sq. ; t. II, p. 133. 
et les mœurs ${ }^{389}$; le premier, le deuxième et le dix-septième exposent la foi en se fondant sur une collection de citations des Pères. De même, dans leurs Sentences inédites, Garnier et Alger de Liège traitent successivement, avec la même méthode, des dogmes de la création et de la chute, des lois et de la chute des empires, de l'institution du christianisme, du droit canonique et de la mystique. Une forme d'exposé de plus en plus fréquente, et où Mgr Grabmann voit la source de ce qu'il appelle la méthode scolastique, c'est d'énoncer, sur chaque point litigieux, les raisons pour et contre. Honorius d'Autun, dans son Elucidarium, procède de cette manière. Guillaume de Champeaux et Anselme de Laon séparent les problèmes en articles, dont chacun pose une question précise ; mais ils renoncent souvent à résoudre par la raison des questions qui ne sont pas résolues par l'autorité : « Cela, disent-ils, doit être laissé au jugement de Dieu », ou bien : " Je n’ai lu nulle part d'une façon précise, si cela est vrai ». Pourtant cette forme des Sentences, qui sera celle des Sommes du $\mathrm{XIII}^{\mathrm{e}}$ siècle, appelle, pour ainsi dire, l'argument rationnel. De fait, dans les livres des Sentences, issus de l'école d'Anselme de Laon, et qui contiennent un exposé systématique du dogme, on ajoute des déductions et des preuves rationnelles par exemple, dans l'un d'eux, une preuve de la Trinité que l'on considère au moins comme ayant la force de persuader ${ }_{\text {p148 }}$ (vis suasiva). L'importance historique de ces livres, c'est qu'ils précisent et rendent définitif un procédé qui, d'ailleurs, était lié depuis longtemps à la pensée philosophique : c'est celui de l'argumentation dialectique.

Ainsi tandis que, chez les Chartrains, la philosophie donne une interprétation raisonnée du dogme, chez les sententiaires son rôle peut s'amenuiser jusqu'à fournir seulement des raisonnements corrects dont les prémisses sont empruntées aux autorités, ou s'enfler au contraire jusqu'à substituer des démonstrations rationnelles aux arguments d'autorité. Cette instabilité dans la conception des rapports de la foi et de la philosophie est rendue manifeste par la philosophie d'Abélard et ses controverses avec saint Bernard. 


\section{VIII.}

ABELARD.

On se rappelle que le problème de la réalité des universaux se pose dans l'Isagoge de Porphyre, c'est-à-dire dans le traité d'introduction à la dialectique, et que, d'autre part, selon saint Anselme, la solution donnée à ce problème engage déjà le théologien, puisque le nominalisme équivaut à l'impossibilité déclarée de penser la Trinité. Il importe donc de bien comprendre la dialectique d'Abélard pour comprendre sa théologie. Abélard, né en 1079, a d'abord enseigné la dialectique à Melun, à Corbeil et à Paris ; c'est en 1113, après une vaine tentative à Laon, qu'il enseigna la théologie à l'école cathédrale de Paris ; après son aventure avec Héloïse, il se réfugia à Saint-Denis, puis enseigna à Nogent-sur-Seine, au " Paraclet », d'abord en 1121, puis en 1129 ; il reprit ses leçons sur la montagne Sainte-Geneviève de 1136 à 1140 et mourut en 1142. La Dialectica est d'ailleurs sans doute un des premiers livres qu'il ait écrits (avant 1121), et ses ennemis lui ont ${ }_{\text {p149 }}$ souvent reproché d'être entré en intrus dans la théologie.

Quant à la question des universaux, Abélard prend une position critique à l'égard de deux de ses maîtres, le nominaliste Roscelin et le réaliste Guillaume de Champeaux. On connaît déjà Roscelin. Pour Guillaume de Champeaux, de neuf ans l'aîné d'Abélard (il est né en 1070), il devint de 1113 à 1121 un haut dignitaire de l'Église, évêque de Châlons et ami de saint Bernard; il avait été élève d'Anselme de Laon et de Roscelin, puis maître à l'école épiscopale de Paris, où Abélard fut son auditeur, puis, à partir de 1108, maître de chœur dans cette abbaye de Saint-Victor où se développa dès ce moment un mouvement mystique.

La doctrine de Guillaume nous est connue par la tardive mention qu'en a faite Abélard dans son Historia Calamitatum. Les termes qu'il emploie pour la définir suffisent à faire voir que, comme saint Anselme, c'est le souci de la théologie qui l'y amena. Rappelons encore que les universaux, chez les réalistes comme chez les nominalistes, désignent uniquement les genres et les espèces des êtres naturels, c'est-à-dire les voix de Porphyre, et ne désignent jamais les archétypes qui pourraient être en Dieu. On s'accorde aussi sur ce point que, dans la connaissance, l'on commence toujours par les individus pour 
aller de là au genre et à l'espèce ; mais, selon les réalistes, et c'est là que commence la différence, l'ordre par nature n'est pas le même que celui de la connaissance ; comme dit un exposé anonyme et hostile au réalisme, "selon cette opinion fort ancienne et cette erreur invétérée, chaque terme est antérieur par nature (naturaliter) au terme inférieur ; il est par nature un sujet pour les formes (spécifiques) qui, en y survenant, amènent la nature du genre jusqu'aux espèces » ${ }^{390}$. Guillaume en tire la conclusion : " La même réalité est tout entière à la fois dans chacun des individus d'une ${ }_{\mathrm{p} 150}$ espèce ; il n'y a en ceux-ci nulle diversité d'essence, mais la variété y vient de la seule multitude des accidents ${ }^{391}$ ». L'important est ici le tota simul inesse ; l'ubiquité de l'essence reproduit en quelque sorte, dans les limites de l'espèce, l'ubiquité de l'être vrai à travers toute la réalité, ou l'identité de la substance divine à travers les personnes ; selon un exposé du réalisme dû à Robert Pullus, " l'espèce est toute la substance des individus, et on la trouve, totale et la même, en chacun d'eux ; l'espèce est comme la substance dont les individus sont de multiples personnes ${ }^{392}$ ". Le réalisme est un fruit de la méthode augustinienne qui cherche, dans la nature, des images de la réalité divine. Dans sa Dialectique, Abélard nous apprend que, commentant le chapitre des Catégories sur la quantité continue, son maître Guillaume appelait le point une natura specialis, et la ligne un individu composé : il faisait de la ligne un agrégat de points, n'ayant pas plus de substance qu'un peuple ou un troupeau, et, du point, que l'on retrouvait partout, en quelque endroit qu'on coupât la ligne, l'essence de la ligne, de même que le nombre, n'est qu'un agrégat d'unités; on remarquera ici aussi que l'individualité de la ligne vient d'un accident, la composition.

Il est vrai que, sous l'influence des critiques de son disciple, Guillaume aurait modifié sa thèse ; il aurait abandonné cette ubiquité de l'essence spécifique, qui, au début du Parménide, faisait l'objet des critiques de Parménide à Socrate ; l'humanité de Pierre est la même que celle de Paul, non essentialiter, sed indifferenter ${ }^{393}$, c'est-à-dire

\footnotetext{
390 HAURÉAU, III, t. XXXI, $2^{\mathrm{e}}$ partie, p. 201 sq.

391 VI, t. CLXXVIH, p. 119-a.

392 VI, t. CLXXXVI, p. 676-d.

393 VI, P. L., t. CLXXVIII, p. 119-6 ; HAURÉAU, XXIV, t. I,p. 336, lit individualiter pour indifferenter.
} 
que, si l'on peut compter autant d'humanités que d'hommes, si par conséquent on peut se passer de l'hypothèse étrange de l'ubiquité d'une seule essence, l'humanité, comme telle, chez Pierre et chez Paul, n’offre aucune différence pour la pensée. Est-ce poussé par la p151 dialectique d'Abélard qu'il aurait encore cédé sur ce point, pour dire que l'humanité de Pierre et celle de Paul n'étaient, les mêmes dans aucun de ces deux sens, mais qu'elles étaient seulement semblables ${ }^{394}$ ? Comment, en effet, aurait-on pu admettre des humanités qui n'étaient que numériquement différentes ? Quoi qu'il en soit, abandonner la thèse de l'ubiquité, c'était, semble-t-il, abandonner l'essentiel du réalisme, tout ce qui pouvait faire sa valeur pour la théologie. Et c'est pourquoi, sans doute, dans ses Sentences, Guillaume a tenu à marquer qu'il fallait détendre le lien entre la théologie et le problème des universaux: on peut rejeter le réalisme lorsque l'on parle des espèces des choses créées; mais alors « le mode d'unité (de l'espèce dans les individus) ne doit pas être transporté à la nature de la divinité, de peur que, contrairement à la foi, nous ne soyons forcés de reconnaître trois dieux comme trois substances ${ }^{395}$ ». Alors aussi, doiton ajouter, l'intellectualisation de la théologie, que cherchait saint Anselme, se trouve bien compromise.

Abélard a cherché, en dehors de la voie du réalisme, une solution neuve et originale au grand problème du Moyen Age : comment penser la foi ? Jamais il n’eut l'ambition ni même l'idée de créer une philosophie autonome ; le prétendu rationalisme d'Abélard est une invention moderne ; c'est en toute franchise qu'il écrivait à Héloïse : « Je ne veux pas être philosophe s’il faut résister à saint Paul ; je ne veux pas être Aristote s’il faut me séparer du Christ ${ }^{396}$. " Il a exalté la vie monastique, qu'il mettait bien au-dessus de celle du clergé séculier; il oppose la simple fonction (officium) du prêtre et de l'évêque à la religion (religio) du moine et de l'ermite, saint Augustin à saint Jérôme, mais il trouve dans le stoïcisme de l'évêque l'expression du vieil idéal monastique $^{397}$.

\footnotetext{
394 Le troisième état de la pensée de Guillaume est connu par ses Sentences ; cf. le fragment I dans G. Lefèvre, CVI, p. 25.

395 Fragments dans G. LEFÈVRE, Ibid., p. 25. -

396 Lettre XVII.

397 VI, t, CLXXVIII, p. 343-352 ; il cite les Lettres à Lucilius, 51, § 4 sq.
} 
p152 S'il a abandonné le réalisme, ce n'est pas pour arriver au nominalisme de son second maître Roscelin ; il n'a pas assez de sarcasmes contre celui « dont la vie et le bavardage ont rendu la dialectique méprisable à presque tous les religieux ${ }^{398}$ ". Pourtant sa théorie des universaux, autant qu'on peut la préciser, se rapproche plutôt du nominalisme. Il part de la définition qu'Aristote a donnée de l'universel dans le De Interpretatione : "L'universel est ce qui, par nature, se dit de plusieurs choses, ainsi homme ; l'individuel, ce qui ne se dit pas de plus d'une chose, comme Callias »; l'universalité n'est donc pas dans le mot comme tel (vox), mais dans le mot en tant qu'il est capable d'être prédicat (sermo praedicabilis) ; on pourrait presque dire : l'universalité est une certaine fonction logique d'un mot. Par là même et en vertu du vieil adage : res de re non praedicatur, il ne peut être une réalité. Pourtant le mot universel, bien que ne désignant pas une réalité, a été donné aux sujets dont il se dit à cause d'une ressemblance en laquelle ils conviennent tous ; tous ces sujets, par exemple, sont des hommes et, par leur état d'hommes (status hominis), ne diffèrent pas ${ }^{399}$. L'originalité d'Abélard, à propos des universaux, paraît donc avoir été de n'avoir jamais considéré l'espèce à part des individus ni les individus à part les uns des autres, mais d'avoir cherché l'universel dans un rapport entre eux. C'est pourquoi il a été le premier à remarquer l'aspect psychologique du problème, la formation des universaux à partir de la connaissance des individus, et à se servir de ce que Boèce, en son commentaire des Topiques, avait inséré de la théorie d'Aristote sur la formation du concept : le sens touche légèrement la chose, l'imagination la fixe dans l'esprit, l'intelligence vient de l'attention prêtée non plus à la chose, mais à une de ses propriétés. C'est le procédé d'abstraction ; l'intelligence connaît l'abstrait séparément de la chose, p153 mais non séparé (séparation non separata, division non divisa); sans quoi, remarque Abélard, cette connaissance serait vaine, puisqu'elle ne se rapporterait pas du tout à la réalité ${ }^{400}$.

Bien que différente du nominalisme de Roscelin, cette théorie d'Abélard ne pouvait prétendre guider l'esprit vers une intelligence de la foi, et particulièrement de la Trinité. La dialectique échouait donc

\footnotetext{
398 Cousin, CIV, p. 1215 c-d.

399 Glossulae Porphyrii, éd. Geyer, p. 112. 400

Glossulae, p. 126 sq.
} 
ici à résoudre le grand problème d'Anselme. A l'époque d'Abélard, ce n'était pas le seul échec de ce genre ; par ses œuvres mêmes, nous savons que fourmillaient alors les essais d'employer les notions ou adages de la dialectique pour penser les choses divines ; car Abélard les dénonçait lui-même et les critiquait violemment : "Telle est leur arrogance, disait-il, qu'ils pensent qu'il n'est rien qui ne puisse être saisi et pénétré par leurs petits raisonnements (ratiunculis) ; méprisant toutes les autorités, ils se font gloire de ne croire qu'en eux seuls... Quelle plus grande indignation pour les fidèles que de professer un Dieu tel que le petit raisonnement humain peut le comprendre ${ }^{401}$. » Les hérésies qu'il cite et qu'il condamne dans l'Introduction à la Théologie proviennent toutes d'une fâcheuse application des procédés de connaissance humaine à la réalité divine ; si l'on appliquait les règles de la dialectique à la Trinité, on obtenait les résultats les plus contraires à la foi ; par exemple, si Dieu est une substance unique, il s'ensuit que, le Père et le Fils étant une seule substance, Dieu s'engendre lui-même : ainsi concluait Albéric de Reims. La dialectique nous enseigne que chaque être distinct a une essence distincte ; si donc les personnes sont distinctes, il faudra admettre au-dessus d'elles trois essences, la paternité, la filiation et la procession : ainsi pensait Gilbert l'Universel, qui enseigne vers 1127. Les Catégories d'Aristote classent les choses en substances et en accidents : si les personnes ne sont pas substances, elles sont accidents ; dès lors ${ }_{\mathrm{p} 154}$ il n'y a aucun moyen de les distinguer d'autres attributs divins, tels que la justice et la miséricorde, qui sont, eux aussi, des « formes essentiellement distinctes de Dieu ", comme leurs attributs le sont des créatures: c'était la thèse soutenue par Ulger, le maître de l'école d'Angers, entre 1113 et 1125 . D'autres dogmes que la Trinité étaient d'ailleurs atteints par cette méthode : l'universelle prescience de Dieu contradictoire avec la liberté, la création dans le temps qui contredit l'adage que la cause ne peut exister sans l'effet ${ }^{402}$.

Avec son goût de la souplesse dialectique, Abélard classe même toutes les hérésies possibles sur la Trinité. La dialectique ne connaît

Theologia Christiana, p. 1217-c ; 1224-a.

402 Cf. Introductio ad Theol., p. 84-85 (Cousin), Theologia Christiana, p. 322 ; 522-523 ; c'est RoBERT, LXXXIII, p. 193 sq. qui a identifié les auteurs des hérésies mentionnées par Abélard. 
que deux espèces de distinctions, celle de mots et celle de choses ; les personnes de la Trinité sont donc distinctes entre elles d'une de ces deux distinctions ; si c'est d'une distinction de mots, cette distinction n'est pas éternelle, puisque les mots sont d'invention humaine, et, de plus, il y aurait autant de personnes qu'il y a de noms donnés à Dieu (c'est l'hérésie d'Angers); si elle est réelle, ou bien Dieu est un en substance, et la réalité des personnes se confond en un ; ou bien les personnes sont distinctes, et il est triple aussi en substance. Ajoutons que trois choses impliquent une multitude réelle et, par suite, une composition en Dieu. Voilà comment le mystère se dissout, dès qu'on veut le penser en dialecticien. Un exemple montrera tout le verbalisme de ce procédé. Aristote, dans le De Interpretatione, avait dit que la proposition : « homo ambulat », revient à " homo est ambulans " ${ }^{403}$; si l'on dit "personae sunt ", on pourra mettre à la place, selon cette règle, personae sunt entia ou sunt essentiae, ce qui amène une hérésie voisine de celle de Gilbert l'Universel.

Il est vrai que, pour réfuter ces hérésies, Abélard tente de se ${ }_{\mathrm{p} 155}$ placer d'abord au point de vue de ses adversaires et d'en appeler d'une dialectique grossière à une dialectique plus subtile. Le mouvement tournant est bien marqué dans le passage suivant : "Dans cet opuscule ${ }^{404}$, dit-il, nous entendons non pas enseigner la vérité, mais la défendre, surtout contre les pseudo-philosophes qui nous attaquent par des raisonnements philosophiques ; aussi c'est par les mêmes raisonnements philosophiques qu'ils reçoivent seuls et avec lesquels ils nous attaquent que nous avons résolu de leur donner satisfaction ${ }^{405}$. " Tous leurs mauvais raisonnements viennent de ce que l'on confond les sens qu'a donnés Porphyre, dans l'Isagoge, aux mots idem et diversum. Plusieurs choses sont les mêmes, ou bien essentiellement, lorsqu'une essence numériquement la même (Socrate) est désignée par plusieurs expressions (ce corps, cette substance), ou bien par leurs propriétés, comme une chose blanche est aussi dure si elle participe à la dureté, ou bien par leur définition, comme mucro et ensis, ou bien par leur ressemblance, comme les espèces d'un même genre ; enfin une chose

\footnotetext{
403 Assertion qui d'ailleurs a été critiquée par Guillaume de Champeaux comme l'apprend Abélard, dans sa Dialectique, p. 230.

404 Il s'agit de l’opuscule De eodem et diverso, écrit pour combattre les hérésies. 405 P. 519.
} 
peut être dite la même parce qu'elle ne reçoit aucun changement, comme Dieu. Pour détruire les hérésies, il suffit de dire que les personnes divines sont identiques au premier sens, essentiellement, puisqu'elles désignent une substance unique, Dieu, mais non pas au second sens ni au troisième, par leurs propriétés et par leurs définitions : faute de faire cette distinction, les dialecticiens n'avaient pas compris qu'il y avait des cas où une multiplicité n’implique pas qu'il existe des choses multiples ${ }^{406}$.

Abélard, s'il craint un emploi brutal et sans nuances de la dialectique, est donc partisan de la dialectique ; il cherche un appui chez saint Augustin, qui a appelé la dialectique "disciplinant disciplinarum » et qui a dit d'elle : " haec docet docere, p156 haec docet discere »; et il fait ressortir, comme on l'a vu plus haut, la nécessité de son usage pour déjouer les fausses argumentations des hérétiques ${ }^{407}$. Il insiste beaucoup sur ce dernier motif ; sa disposition d'esprit est loin d'être, à cet égard, celle de saint Anselme ; il s'agit moins de cette méditation entre chrétiens qui prépare de loin la contemplation des élus que de la défense contre l'adversaire ; Abélard est plus combatif que méditatif ; au sujet de la Trinité, écrit-il dans l'Introductio ad Theologiam ${ }^{408}$, « nous ne promettons pas d'enseigner la vérité, à laquelle nous pensons que ni nous-mêmes ni aucun mortel ne pouvons atteindre; mais du moins quelque chose de vraisemblable qui s'apparente à la raison humaine et ne soit pas contraire à la foi, voilà ce que nous voulons proposer contre ceux qui se font gloire d'attaquer la foi avec des raisonnements humains et qui ne songent qu'aux raisonnements qu'ils connaissent ». Il insiste très souvent sur le caractère purement vraisemblable que garde, en théologie, le raisonnement dialectique : "Il ne faut pas estimer bien haut ce que le raisonnement humain suffit à discuter, et il ne faut pas réputer comme de foi ce que l'on reçoit pour manifeste sous l'impulsion d'un raisonnement humain ${ }^{409}$. " Il faut se rappeler d'ailleurs que le langage humain est fait pour exprimer les choses qui tombent sous les dix catégories ${ }^{410}$. Or,

\footnotetext{
406 Cousin, CIV, p. 483-500.

407 VI, t. CLXXVIII, p. 351 ; 354-c.

408 Livre II, p. 67 (CousIN).

409 Theologia Christ., liv. IV, p. 462.

${ }^{410}$ Ibid., p. 481-483 ; cf. p, 478 sq,
} 
une catégorie telle que celle de la substance, définie comme sujet des accidents contraires, ne convient nullement à Dieu ${ }^{411}$. Abélard connaît et rappelle les thèses de l'Aréopagite sur la théologie négative et la théologie symbolique ${ }^{412}$. S'il blâme ceux qui suivent purement et simplement l'autorité, en disant qu'il ne faut faire aucune recherche rationnelle touchant les mystères de la foi catholique et que, en toutes choses, il faut croire de suite à l'autorité, il ajoute dans la Théologie : p157 « Tant que la raison est cachée, contentons-nous de l'autorité »; et il donne contre l'abus de la dialectique un argument ad hominem bien frappant : si Boèce, qui est la grande autorité en matière de logique, n'a pu appliquer le raisonnement au dogme, comment ceux qui tirent de Boèce toute leur science logique pourraient-ils le faire ${ }^{413}$ ? Ainsi s’oppose à la dialectique l'autorité du plus grand des dialecticiens.

Ce perpétuel va-et-vient dans la réflexion d'Abélard l'amène à une construction philosophico-théologique bien différente de celle de saint Anselme. On ne trouve chez Abélard aucun essai de preuve dialectique de l'existence de Dieu, ni de l'Incarnation. Tandis que, chez saint Anselme, il y a les dogmes et la dialectique qui les démontre, chez Abélard, il y a d'une part les dogmes, d'autre part les doctrines philosophiques, spécialement celles du Timée et du Songe de Scipion, et l'ambition d'Abélard est de montrer que les doctrines rationnelles disent la même chose que les dogmes révélés, et notamment que la triade d'hypostases divines que l'on trouve en ces deux ouvrages équivaut à la Trinité chrétienne. Le "credo ut intelligam » est sans doute à la base de cette intellectualisation de la foi ; il n'en est pas moins vrai que la vérité philosophique que l'on confronte avec le dogme est donnée comme du dehors. Bien entendu, une confrontation de ce genre ne peut réussir qu'en interprétant Platon et Macrobe dans un certain sens qui les rapproche du dogme : que cette interprétation fausse leur pensée, c'est ce qui nous apparaît, à nous, avec une évidence aveuglante ; mais, malgré le peu de souci d'exactitude historique de l'époque, cela n'échappait pas à Abélard lui-même. Comment il a pu se servir d'une interprétation de Platon, qu'il savait luimême inexacte, pour l'assimiler au dogme, cela est caractéristique des

\footnotetext{
411 Introductio, liv. II, p. 88. sq.

${ }^{412}$ Ibid., p. 91-92.

413 Sur ces derniers points, cf. ROBERT, LXXXIII, p. 184, note.
} 
habitudes d'esprit médiévales: est légitime non seulement l'interprétation exacte d'un p158 texte, mais toute interprétation qui permettra une méditation fructueuse ; il y a dans un texte non seulement ce que l'auteur a voulu y mettre, mais tout ce que l'on peut y trouver d'utile ; c'est Abélard qui le dit lui-même ; après le sens un peu forcé qu'il a donné d'un passage de Macrobe pour assimiler l'âme du monde à l'Esprit-Saint, il ajoute : « Si l'on m'accuse d'être un interprète inopportun qui fait violence aux textes, en détournant vers notre foi, par une explication impropre, les termes des philosophes et en leur attribuant des pensées qu'ils n'ont jamais eues, qu'il songe à la prophétie que le Saint-Esprit a proférée par la bouche de Caïphe, en lui donnant un sens auquel ne songeait pas celui qui la prononçait. » L'interprétation que donne Abélard des philosophes n'est donc valable, selon lui-même, que si les philosophes ont été, à la manière des prophètes, des inspirés qui ignoraient la portée de leurs paroles; c'avait été autrefois la thèse d'apologistes comme Justin ; seulement, puisque les doctrines philosophiques sont ainsi considérées comme des sortes de doublets des dogmes, le problème de l'intellectualisation de la foi n'en est pas plus avancé ; Platon ou bien ne sert à rien, s’il est un inspiré, ou bien est nuisible, si l'on prend ses paroles dans leur sens. Telles étaient les difficultés dans lesquelles s'embarrassait Abélard, dans la solution qu'il voulait donner au grand problème du Moyen Age.

Abélard commentait Platon comme on commentait la Bible : la manière de parler par énigme, dit-il, « est aussi familière aux philosophes qu'aux prophètes "; tout ce que Platon a dit de l'âme du monde doit se comprendre en un sens enveloppé (per involucrum) ${ }^{414}$; et il en donne la même raison que l'on donnait, depuis Philon, pour chercher un sens allégorique dans la Bible; c'est que le sens littéral est absurde ; il est absurde de dire, comme le fait Platon, que le monde est un p159 animal raisonnable, puisque le monde n'a pas d'organes sensibles et puisque, d'ailleurs, l'âme du monde, animant tout, rendrait toutes les autres âmes inutiles ; en réalité, Platon (ainsi que Macrobe) a voulu dire que, comme nos âmes confèrent à nos corps la vie animale, l'Ame du monde, qui est le Saint-Esprit, est pour nos âmes

${ }^{414}$ Introduction, p. 46 ; p. 48 (COUSIN). 
un principe de vie spirituelle ${ }^{415}$. Grâce à un procédé de ce genre, Abélard retrouvera chez Platon tous les détails du dogme ; par exemple, Platon dit, avec les Latins et contre les Grecs, que le Saint-Esprit procède à la fois du Père et du Fils : le démiurge (Saint-Esprit), dit Platon, contemple, dans l'Intelligence divine, les formes exemplaires qu'il appelle idées ; cela veut dire que le Saint-Esprit procède du Fils ou par le Fils, « puisque c'est par la raison universelle de la sagesse divine qu'il gouverne les œuvres de Dieu et qu'il fait passer dans la réalité les conceptions de son intelligence ${ }^{416}{ }$. Il n'est pas de difficulté dont on ne vienne ainsi à bout: Macrobe emploie le mot creare pour désigner la procession du Saint-Esprit ;on dira que c'est un emploi abusif ${ }^{417}$. L'âme du monde est forgée par Dieu dans le Timée ; cela n'empêche qu'elle soit le Saint-Esprit, puisqu'elle est faite, comme lui, avant la création du monde, c'est-à-dire éternellement ${ }^{418}$. L'âme du monde, chez Platon, n’est pas simple, mais composée de deux essences, celle de l'indivisible et celle du divisible : c'est que le Saint-Esprit est simple en soi et multiple par ses dons. Au besoin, on a même deux explications toutes prêtes : le Timée met dans l'âme du monde du même et de l'autre, ou cela veut dire que le Saint-Esprit est identique aux autres personnes par la substance et autre par sa propriété ; ou bien cela désigne son immutabilité jointe à la diversité de ses effets ${ }^{419}$. S’il y a des images trop matérielles, on les efface : le Timée dit que les âmes humaines sont faites des résidus de l'âme du monde, lisons : " nos âmes imitent l'âme ${ }_{\mathrm{p} 160}$ du monde (le Saint-Esprit) en ses puissances et ses facultés, mais sont loin au-dessous d'elle en dignité ${ }^{420} »$.

Cette insistance sur l'interprétation de l'âme du monde du Timée s'explique sans doute par l'opposition d'Abélard à certains Chartrains comme Bernard Silvestre, qui, identifiant l'âme du monde à la troisième personne de la Trinité, gardait cependant l'exégèse littérale du texte de Platon ; c'est cette doctrine même qu'il vise dans la Dialec-

\footnotetext{
415 Ibid., p. 49.

416 Ibid., p. 109.

417 Ibid.

418 Ibid., p. 37.

419 P. 39-44.

420 P. 45.
} 
tique, lorsqu'il oppose à l'équivalence entre la triade Tagathon, Noys, Ame du monde et la Trinité chrétienne, que l'âme du monde n'est pas coéternelle à Dieu ${ }^{421}$. L'abandon de cette exégèse était la condition à laquelle il pouvait unir Platon et l'Évangile. Il y manifestait ce même goût augustinien des similitudes que l'on trouve dans sa comparaison familière de la génération du Fils à l'image modelée dans la cire : cire et image sont une quant à la substance, bien que diverses quant aux propriétés.

L'Ethica ou Scito te ipsum, un des derniers ouvrages d'Abélard, n'est pas, d'intention, plus rationaliste que ses autres travaux : c'est un dialogue entre un philosophe et un chrétien ; le philosophe lui-même adhère au christianisme, puisqu'il dit : "Admettons donc cette opinion sur le souverain bien, qui n'est pas inconnue non plus à nos prophètes » ; mais Abélard y est représenté par le chrétien qui reproche au philosophe de traiter d'insanités les doctrines des apôtres qui ont pourtant convaincu des philosophes. Sa prétention n'est donc pas de créer une morale autonome, mais de retrouver par la raison la morale du christianisme. Il admet que la volonté de Dieu, guidée d'ailleurs par son intelligence, est la règle suprême de la conduite ; l'amour de Dieu est pour l'homme le bien suprême, et la haine de Dieu le plus grand des maux ; le commandement suprême est d'aimer Dieu et son prochain. Seulement il ajoute que cette loi n'est pas connue directement, p161 mais intérieurement par la conscience, à laquelle nous devons obéir, même si, extérieurement, Dieu commande ou paraît commander autre chose : le bien est uniquement dans cette conformité à la conscience et non dans l'action (opus) qui n'a par elle-même aucune valeur morale ; de plus, la conscience connaît la règle morale comme une loi naturelle ; elle est une raison, ou un discernement du bien et du mal qui est commun à tous, Le péché qui consiste à donner notre assentiment (consensus) à un désir que nous reconnaissons comme injuste et donc à mépriser la volonté de Dieu, telle qu'elle se manifeste à notre conscience, est purement personnel, et il ne peut y avoir rien de tel qu'un péché hérité, de telle manière que le péché d'Adam pût retomber sur nous ${ }^{422}$. De même, et pour les mêmes raisons, le mérite est

421 Dialectique, p. 475.

422 On attribue souvent cette négation au nominalisme d'Abélard (Cf. O. DITTRICH, XII, III, 71) ; mais de fait le réalisme, selon qui le genre humain est 
personnel et la doctrine de la réversibilité des mérites du Christ sur chaque chrétien est incompréhensible. Cette doctrine paraît donc nier la valeur des œuvres, rendre inutile la révélation spéciale accordée à Moïse et aux chrétiens, abolir la nécessité du Christ médiateur, revenir au pélagianisme. Abélard s'efforce bien de garder les notions chrétiennes ; mais la grâce n'est plus chez lui le don divin de la permanence dans le bien, elle est la connaissance du royaume des cieux, comme but et fin de notre action : la médiation du Christ y est nécessaire, mais du Christ considéré comme un maître qui enseigne.

Ainsi, comme le montre surtout l'Ethica, la doctrine d'Abélard aboutit beaucoup moins à une intelligence de la foi qu'à une sorte de confusion de la foi et de l'intelligence. Dialecticien d'abord, n'ayant mis, raconte-t-il, sa virtuosité dialectique au service de la théologie, que sur la demande de ses disciples ${ }^{423}$, p162 il connaît assez mal l'Écriture ; les textes qu'il a recueillis dans le Sic et Non ne prouvent pas le contraire; car il les trouvait rassemblés chez Yves de Chartres ${ }^{424}$. De là sans doute sa facilité à assimiler tant de choses différentes. Comme Bérenger au XI ${ }^{\mathrm{e}}$ siècle, Abélard trouva en face de lui des adversaires qui, dans ses erreurs de méthode, virent un danger pour l'Église même. Une fois de plus allait éclater le vieil anathème paulinien contre la sagesse de ce monde.

Les ennemis de la philosophie n'avaient d'ailleurs jamais cessé leurs diatribes. Au début du siècle, Bruno, évêque de Ségovie (mort en 1123), déclare "sots et complètement insensés ceux qui veulent discuter de la souveraine Trinité avec des syllogismes platoniciens et des arguments aristotéliciens » ${ }^{425}$. Au chapitre IV du livre II de ses Sentences, cet ennemi de la philosophie étudie les quatre vertus cardinales et en donne les définitions classiques qu'il trouve chez les philosophes ; mais, à propos de la première, la prudence, qu'il identifie à la sagesse et dont il donne la définition stoïcienne : "divinarum humanarumque verum cognitio », il écrit qu'il envisage ici « non la sagesse

une essence qui se trouve tout entière en chaque homme, en Adam comme, en ses descendants, n'a rien à voir avec la doctrine du péché originel, commis par l'individu Adam.

423 VI, t. CLXXVIII, p. 979.

424 GRABMANN, XXII.

425 GraBMANN, Ibid., p. 118 ; VI, t. CLXV, p. 477. 
de ce monde, mais celle qui touche à l'honnêteté des mœurs et au salut des âmes, non pas celle qu'enseignent philosophes et orateurs, mais celle que prêchent apôtres et docteurs ${ }^{426}$ ».

Le grand adversaire d'Abélard est saint Bernard, abbé de Clairvaux : la lutte entre les deux hommes, qui aboutit à la condamnation d'Abélard, est un des épisodes qui peuvent le mieux nous faire comprendre l'esprit médiéval, bien qu'il faille reconnaître d'hommes comme saint Bernard que, "s'ils ont place dans l'histoire de la philosophie, c'est en dépit d'eux-mêmes, car ils ne l'ont jamais aimée ${ }^{427}$. »

Table des matières

IX.

\section{SAINT BERNARD ET SES DISCIPLES.}

p163 Toute la pensée antique, surtout vers sa fin, était habituée à distinguer nettement la spéculation philosophique, faite de raisonnements ou de discussions, et la vie du sage ou philosophie véritable. C'est le thème continuel des entretiens d'Épictète : il déteste ses disciples trop savants qui savent résoudre un syllogisme et qui ne connaissent ni pudeur ni conscience ; c'est le souci constant de Plotin qui a écrit ses Ennéades pour que l'âme, en se nettoyant de toutes les impuretés dont l'a souillée son contact avec la matière, retrouve son origine et sa noblesse et revienne à sa "vraie patrie », aux réalités divines auxquelles elle doit s'assimiler.

On trouve une ligne de démarcation analogue pendant tout le Moyen Age, mais surtout au XII ${ }^{\mathrm{e}}$ siècle ; aux enseignements proprement philosophiques des écoles épiscopales de Chartres ou de Laon, s'oppose la vie monastique, et plus particulièrement la réforme de l'abbaye bénédictine de Cîteaux avec saint Bernard. "Cîteaux, Clairvaux et Signy vont se dresser, écrit M. Gilson, contre Reims, Laon, Paris et Chartres, écoles contre écoles, et revendiquer, en terre chrétienne, un enseignement plus chrétien que celui dont on empoisonnait une jeunesse avide du Christ ${ }^{428}$. " Souvent, chez saint Bernard, l'on

426 VI, t. CLXV, p. 911-c.

427 GILsON. dans AHL VII, 1933, p. 22.

${ }^{428}$ La Théologie mystique de Saint Bernard, Paris, Vrin, 1934, p. 80. 
trouve de ces oppositions balancées qui, par le style même, rappellent Épictète et surtout Sénèque. " Je me réjouis, dit-il aux moines, que vous soyez de cette école, à savoir de l'école de l'esprit, où vous apprenez la bonté, la doctrine et la science. Est-ce parce que j'ai compris les arguties de Platon ou la subtilité d'Aristote ? Non pas, mais parce que j’ai recherché ${ }_{p 164}$ des témoignages » ${ }^{429}$, ou encore : «Que nous enseignent les saints apôtres ? Non pas à lire Platon ni à tourner et retourner les subtilités d'Aristote, non pas à toujours apprendre pour ne jamais parvenir à la connaissance de la vérité ; ils m’ont appris à vivre. Crois-tu que c'est une petite chose de savoir vivre ? C'est une grande chose et même la plus grande ${ }^{430}$. »

Seulement, dans l'antiquité, la vie morale et mystique, véritable et unique objet de l'enseignement des écoles philosophiques, était la vraie philosophie par opposition à la vaine philosophie de parade des commentaires et des discussions ; maintenant, chez les penseurs chrétiens, la situation change : la philosophie est le fait de la raison humaine, avec ses précepteurs humains qui cherchent une vaine gloire ; et la véritable vie du sage, si elle était bien, chez Épictète ou Plotin, l'assurance et la foi en Dieu, est devenue la vie chrétienne qui n'atteint la foi que par l'intermédiaire du Christ et des sacrements. La Schola spiritus de saint Bernard est donc soutenue par une vaste organisation spirituelle dont elle émane. Tandis que les écoles antiques étaient tenues d'appuyer leur règle de vie sur une doctrine philosophique qu'il fallait d'abord enseigner par des preuves humaines, ici la règle de vie, devenant consubstantielle à la doctrine, rend inutile toute recherche philosophique spéculative. C'est le motif du grand duel entre Abélard et saint Bernard ; la philosophie d'Abélard ne lui apparaissait que vanité, à lui qui ne cherchait rien qu'une règle spirituelle de la vie monastique. Guillaume de Saint-Thierry, l'ami de saint Bernard, avait, sur ces écoles que sont les monastères, des idées que M. Gilson résume ainsi : « Le maître des novices, le prieur et l'abbé sont ces professeurs (d'amour); le monastère est cette école ; on ne

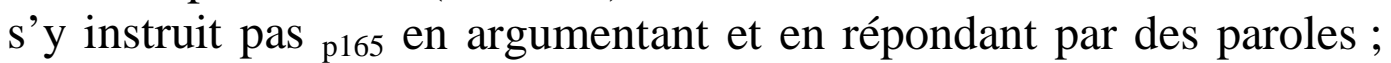

\footnotetext{
429 Sermo III, 5 ; VI, t. CLXXXIII, col. 331 (cité par GILSON, p. 86).

430 Sermo I, 3, VI, t. CLXXXIII, col. 647 (GILSON, p. 86). Cf. SÉNÈQUE, Ep. 108, 23 : Aliquid praecipientium vitio peccatur qui nos docent disputare non vivere. De Brevit. Vitae, ch. VII: Vivere tota vita discendum est.
} 
car la doctrine qui s'y enseigne est une vie, et les disputes s'y concluent par des actes. Un monastère où se donne un tel enseignement et où il est reçu dans cet esprit est la seule véritable école de philosophie qui soit. Non seulement les âmes, mais les corps mêmes reflètent la charité dont sont animés tous ses membres, si bien que la communauté monastique devient une vie sociale, aussi semblable qu'il est possible sur terre à celle des bienheureux dans le ciel ${ }^{431}$ (1). »

Ce mysticisme est lié, chez saint Bernard, à une ardente défense de la foi et des institutions de l'Église ; il trouve l'une et les autres mises en danger par la confusion qu'Abélard laisse s'introduire entre le dogme et la philosophie : il fait condamner, au concile de Soissons, en 1121, le traité De unitate et trinitate et la Theologia, et, au concile de Sens, en 1141, l'Introductio ad Theologiam. La correspondance de saint Bernard, surtout en l'année 1140, contient les lettres qu'il adressa à la Curie et au pape pour se plaindre d'Abélard : «Blessures faites à la foi, injures au Christ, insultes aux Pères et mépris pour eux, c'est un scandale pour le présent et un danger pour l'avenir ; on se moque de la foi des simples, on met à jour les secrets divins, on traite témérairement les questions sur les plus hauts sujets; on reproche aux Pères d'avoir dit qu'il fallait les laisser en sommeil plutôt que les résoudre... Ainsi l'intelligence humaine usurpe tout pour elle, ne laissant rien à la foi ; elle veut aller trop haut, en des recherches qui dépassent sa puissance ; ce qui est bien clos et scellé, elle ne l'ouvre pas, elle le rompt ; ce qu'elle ne trouve pas d'un accès facile pour elle, elle pense que ce n'est rien, et elle dédaigne de croire. » Le péril est d'autant plus pressant que la Théologie d'Abélard se trouve en toutes les mains ; mais le livre où il signale le plus d'hérésies, c'est l'Éthique ; et, bien que citant ${ }_{\mathrm{p} 166}$ les graves défaillances de la doctrine du péché originel et de la grâce, il indique, en premier lieu, les erreurs sur la personne du Christ (l'adoptianisme) et sur le pouvoir de remettre les péchés, qu’Abélard en effet contestait aux évêques ${ }^{432}$. "Nouvel évangile, nouvelle foi ", tel est le reproche, le plus grand qui soit, qu'il adresse à Abélard dans une lettre de 1140 au pape Innocent II ; il ne remplit aucune des exigences requises pour qui se permet de discu-

\footnotetext{
${ }^{431}$ La Théologie mystique de Saint Bernard, p. 219, citant MiGNE, VI, CLXXXIV, col. 404-406.

432 Lettre aux évêques et aux cardinaux de La Curie, VI, t. CLXXXII, p. 331.
} 
ter de dogmes et de morale : «Il discute des vertus et des vices sans moralité, des sacrements sans la foi, du mystère de la sainte Trinité sans simplicité ni sobriété. " "En raillerie contre les docteurs de l'Église, il comble d'éloges les philosophes, et il préfère leurs inventions et ses propres nouveautés à la doctrine et à la foi des Pères catholiques. »

Le scandale est si évident que saint Bernard refusa la proposition que lui faisait l'archevêque de Sens de se rendre à Sens pour discuter avec Abélard devant les évêques : " Je jugeais indigne, écrit-il au pape, de permettre qu'on dût, avec de petits raisonnements humains, agiter la doctrine de foi (rationem fidei), qui est appuyée sur une vérité aussi certaine et aussi solide... Les écrits d'Abélard suffisent à l'accuser, et ce n'est pas mon affaire, mais celle des évêques qui ont, dans les attributions de leur ministère, le jugement des dogmes. » Saint Bernard, provoqué par Abélard qui répandait partout le bruit que l'abbé de Clairvaux serait présent à Sens, y vint pourtant ; mais aucune discussion n'eut lieu; dès le début de la lecture des articles de ses livres, Abélard sortit, en faisant appel au siège apostolique, et l'examen en fut fait en son absence ${ }^{433}$. Saint Bernard voyait chez lui a plupart des grandes hérésies: "Parle-t-il de la Trinité, c’est de l'Arius ; de la grâce, c'est du Pelage ; de la personne du Christ, c'est du ${ }_{\text {p167 Nestorius }}{ }^{434}$. » Toutes ces hérésies ont même source, l'orgueil : "l'homme est sorti de sa mesure » ${ }^{435}$. On obtint enfin en 1140 un rescrit du pape, qui condamnait Abélard au silence et excommuniait ses partisans ${ }^{436}$.

La doctrine d'Abélard est, aux yeux de saint Bernard, une mauvaise solution du grand problème du Moyen Age; en "cherchant l'intelligence », il a oublié «la foi », qui est le point de départ et la règle de cette recherche : mais, pas même selon saint Bernard et ceux qu'il inspire, cette condamnation ne supprime le problème : il ne peut s’agir de séparer la foi de la théologie, ni la théologie des expressions empruntées à la philosophie. Un des plus fidèles disciples de saint

\footnotetext{
433 VI, t. CLXXXII, p. 354 sq.

434 Ibid., p. 357, Ep. 192.

435 Ibid., Ep. 193.

436 Ibid., p. 359.
} 
Bernard, Guillaume de Saint-Thierry, rappelle la simplicité évangélique et le style propre aux écrits canoniques : on n'y lit aucune des formules employées par les théologiens sur la Trinité et l'unité substantielle des trois personnes; et Guillaume paraît ressentir quelque nostalgie "de ces temps heureux de la simplicité évangélique » où n'existait pas encore «la science des saints docteurs, si enveloppée d'obscurités qu'elle ne peut être saisie que par très peu d'hommes ${ }^{437}$ ». Il sait bien pourtant que cette science est indispensable : «Lorsque les hérésies ont commencé dans l’Église, on a commencé à inventer des mots nouveaux pour protéger la foi contre la nouveauté des mots et des idées »; non cependant que la nature ineffable du Bien se soit abaissée "jusqu'à l'étroitesse de la raison humaine " (usque ad angustias humanae rationis), mais l'homme, obligé de se servir de dénominations, qui sont des instruments de la raison commune relatifs à des choses communes, doit du moins fidèlement les adapter à la doctrine de la foi ${ }^{438}$. "Cette doctrine ne rejette pas complètement ces noms apportés par les hommes ; mais elle les prend pour elle ; les adaptant un à un à ses règles, elle réduit en quelque me-

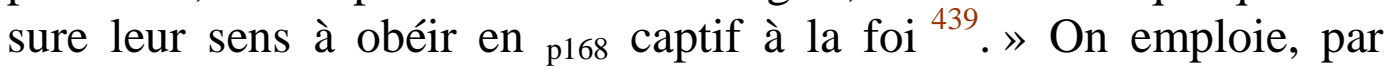
exemple, à l'égard de Dieu, des noms d'accidents comme magnus, bonus, qui ne peuvent signifier des accidents en un être chez qui la foi n'en admet aucun.

Remarquons que le point de départ de Guillaume de Saint-Thierry est celui même d'Abélard, et, partant de l'idée de Dieu que l'Aréopagite a prise aux Néoplatoniciens et transmise aux chrétiens, ne pouvait être différent : le reproche fait à Abélard n'était pas d'user de la philosophie, mais d'en mal user. Tel est aussi celui que Guillaume de Saint-Thierry fait à Guillaume de Conches dans l'espèce de lettre-rapport qu'il adressa à saint Bernard au sujet de la Philosophia mundi. Il a, comme Abélard, une doctrine erronée de la Trinité, où les Personnes ne sont plus que des appellations de Dieu, sans distinction vraie de nature, au même titre que les attributs de vertu et de charité ; identifiant le Père à la Puissance et le Fils à la Sagesse, Guillaume de Conches avait cherché à montrer comment la sagesse procède de la

\footnotetext{
437 Ænigma Fidei, VI, t. CLXXX, p. 407-c sq.

438 Ibid., p. 409-a sq.

439 Ibid., p. 418-b sq.
} 
puissance ; mais, répond Guillaume de Saint-Thierry : "Que la sagesse naît de la puissance, nous n'avons nulle autorité qui l'affirme, ni nul raisonnement qui le conclut ; bien plus, en usant de la seule raison humaine, nous voyons plutôt la puissance naître de la sagesse que la sagesse de la puissance ${ }^{440}$. " Guillaume de Conches a de même employé mal à propos la notion philosophique de nature, en réduisant Dieu à n’être qu' « un concours d'éléments et un mélange bien réglé », ou en interprétant comme une production naturelle la création de la femme dans la Genèse ${ }^{441}$.

Dans la Discussion ${ }^{442}$ contre Abélard que Guillaume de SaintThierry adresse à Godefroi de Chartres et à saint Bernard, c'est bien encore sur la maladresse d'Abélard à employer la philosophie qu'il insiste et non sur cet emploi : Abélard, en 169 identifiant les trois personnes aux attributs de puissance, sagesse et volonté ${ }^{443}$, était coupable d'avoir confondu des mots qui désignent la nature de Dieu prise en elle-même, comme Père et Fils, et d'autres qui considèrent Dieu dans son rapport à la créature ; d'une manière générale, il condamne chez lui une tendance à dire de Dieu ce qui ne peut être dit que de l'homme et des créatures, par exemple la comparaison du Père avec la matière ou le genre, et du Fils avec la forme ou l'espèce. En rapprochant à contre-temps les philosophes de la Bible, Guillaume de SaintThierry pense qu'il n'a d'ailleurs pas moins travesti le sens du Timée. « Platon enseigne avec prudence son opinion sur Dieu, d'après ce que révèle de lui la créature, mais, ignorant tout le reste avec un respect philosophique, il renvoie aux Idées qui, placées selon lui dans l'intelligence divine, contiennent les formes originaires et les causes rationnelles de toutes choses ${ }^{444} "$ : le recours aux idées ne serait donc pour Platon qu'un humble aveu d'ignorance. Cette inintelligence des idées philosophiques a été également reprochée à Abélard par un auteur anonyme qui dit avoir été autrefois un de ses familiers ; il con-

\footnotetext{
440 VI, t. CLXXX, p. 338-d.

441 Ibid., p. 339-340.

442 Disputatio adversus Abaelardum, VI, t. CLXXX, p. 249-282.

443 Ce qu'avaient fait d'ailleurs d'autres théologiens que cite RÉMUSAT CVIII, II, 307 ; BÈDE, Didascalicon, livre I : Pierre LOMBARD, Sentences, I, dist. 27 et 33.

444 VI, 180, p. 270-c.
} 
teste surtout son interprétation de l'âme du monde ; car, "selon les philosophes eux-mêmes, l'âme du monde diffère beaucoup du créateur et de l'intelligence divine $»{ }^{445}$.

A la scolastique des écoles épiscopales, s’oppose la vie chrétienne telle qu'elle peut se réaliser dans les monastères, par la méditation sur les vérités chrétiennes concernant la destinée. L'amour de Dieu pour l'homme, l'amour de l'homme pour Dieu, tel est le thème unique de ces méditations qui voient moins dans la réalité divine un objet à connaître qu'une personne à aimer. L'amour universel de Dieu pour tous les êtres ${ }_{\mathrm{p} 170}$ raisonnables, qui fait que tous sont d'abord prédestinés au salut, tel est le principe de ces méditations. Comment, dans ces conditions, tout homme n’est-il pas sauvé ? Il y a, selon saint Bernard, une triple liberté, ou plutôt une triple libération : la libération de la contrainte, la libération du péché et la libération du mal. L’homme reçoit de Dieu le pouvoir d'être toujours délivré de la contrainte, ou le libre arbitre ; il consiste en ce que l'assentiment de la volonté n'est jamais forcé, comme chez l'animal, par le désir naturel : ce libre arbitre, l'homme ne peut le perdre ; c'est une "grâce de création " ${ }^{446}$. Dieu l'a donné à l'homme pour que, en se décidant au bien et à la vertu, il acquière les deux autres libertés, la libération du péché et celle du mal, et qu'il fasse ainsi son salut. Mais l'homme, choisissant le mal, perd ainsi les deux dernières espèces de liberté, et, dans ces conditions, son libre arbitre ne peut, par lui-même, que l'enfoncer davantage dans le péché : le choix du bien reste une possibilité vide. L'homme ne pourra se sauver que par une nouvelle grâce, une grâce de salut, qui est rendue possible par la mort du Christ. Ainsi s’ouvre aux chrétiens la voie du salut qui consiste avant tout à suivre le Christ ; de l'obéissance à la volonté divine et aux supérieurs qui ont été institués par Dieu, on arrive, par étapes, à la vision mystique qui élève l’homme au-dessus de son corps et de lui-même, et qui suppose, dans l'extase, un contact direct avec le Christ : cette vision mystique, qui n'est pas encore la visio beata des élus, est pourtant réservée aux seuls parfaits. Cette

\footnotetext{
445 Ibid., p. 321-c.

446 Cf. De gratia et libero arbitrio, IX, 28 ; P. L. t. CLXXXII, p. 1016. « Seul le libre arbitre ne souffre absolument pas de défaut ni de diminution, parce qu'il y a, imprimée en lui, une image de la divinité éternelle et immuable. » Cf. DesCARTES, Méditation IV, Ed. Adam. t. IX, p. 45.)
} 
mystique de saint Bernard est chrétienne avant tout en ce qu'elle considère l'union mystique comme le résultat d'un retour à Dieu, conditionné par l'histoire de l'homme, telle qu'elle est racontée par la révélation chrétienne, mais aussi ${ }_{\mathrm{p} 171}$ parce que la déification est non pas une sorte d'anéantissement de l'individu dans l'être infini, mais une communauté de volonté, qui est amour, et qui conduit à agir, "à laisser le vin de la contemplation pour nourrir ses enfants du lait de la connaissance qui remplit sa poitrine ${ }^{447} »$. Comment l'amour de Dieu pour les hommes rend possible et effectif, malgré le péché et grâce à la médiation du Christ, l'amour des hommes pour Dieu et par conséquent leur salut, voilà la somme de l'enseignement de saint Bernard.

Dans leurs méditations sur l'ascension mystique, les disciples de saint Bernard utilisent un schéma analogue à celui de l'ascension des connaissances, que Platon avait donné à la fin du $\mathrm{VI}^{\mathrm{e}}$ livre de la République et que l'on retrouvait chez Plotin et saint Augustin : on le rencontre par exemple dans les Meditativae orationes de Guillaume de Saint-Thierry: la connaissance part des sens, elle s'élève à l'imagination, puis à la raison (ratio) et enfin à l'intelligence ${ }^{448}$. Mais, ce qui est nouveau, c'est la condition que met le mystique au passage des étapes inférieures à l'étape supérieure : du sens qui est trouble et de l'imagination trompeuse, la raison ne peut se dégager que sous l'influence de la grâce ; sous cette influence naissent l'humilité et l'obéissance, d'où vient la foi ; et c'est la foi qui instruit la raison, mais cette raison, constituée par les raisonnements dialectiques, n'est pas encore l'intelligence qui, elle, est plutôt vision ; l'intelligence ne peut être obtenue que par une action d'en haut (desursum), et elle est un don parfait, qu'on obtient par l'intermédiaire de la foi ; il ne faut pas confondre cette intelligence qui vient d'en haut avec la simple « intelligence raisonnable qui n'est pas encore en mesure d'atteindre Dieu $^{449} »$.

Ainsi tout est surnaturel dans ce progrès de la connaissance; il n'est pas simple découverte d'un objet nouveau, mais ${ }_{\mathrm{p} 172}$ transmutation intérieure de la volonté et de l'affection ; aussi, plus profonde que

\footnotetext{
447 Sermon sur le Cantique II, § 7.

448 Édition M.-M. DAVY, p. 50 sq. ; p. 88.

449 Ibid., p. 88.
} 
l'ascension intellectuelle est celle de l'activité qui la sous-tend : voluntas magna, deinde illuminata, deinde affecta, telles sont les trois étapes de cette ascension: une volonté forte, qui a été donnée à l'homme dès la création ; une volonté éclairée qui est un don de Dieu ; une volonté affectueuse par laquelle Dieu nous informe et nous rend semblables à lui ${ }^{450}$. La volonté éclairée qu'il appelle intellectus ne lui paraît pas différente de l'intelligentia, terme suprême de l'ascension des connaissances; au-dessus donc, il y a la volonté affectueuse ou amour : ou plutôt faut-il dire que la volonté était dès le début amour ; la volonté forte est simplement amor ; la volonté éclairée est amor Dei ; la volonté affectueuse est le sentiment actuel de cet amour ( $a f-$ fectus amoris Dei) ; "l'amour est de nature, l'amour de Dieu est de grâce ; le sentiment de l'amour est la manifestation actuelle de cette grâce ${ }^{451}$ ». Comme il l'indique ailleurs, ces trois moments répondent à trois moments de l'efficace divine : subsister, ce qui dépend de sa puissance ; désirer Dieu, ce qui dépend de sa grâce ; trouver Dieu, ce qui est l'effet de sa miséricorde ${ }^{452}$.

L'amour de Dieu, pour Guillaume, est véritablement une forme supérieure de connaissance : comme le sens corporel ne peut sentir une chose qu'en s'assimilant à elle, l'amour «qui est le sens que l'âme a du Dieu bon » ne peut sentir ce bien que si l'âme se change en âme bonne ; l'âme se transforme en celui qu'elle aime, non pas en lui devenait identique, mais en se conformant à lui dans ses sentiments ${ }^{453}$. Mais, Dieu étant sans forme, l'amour de Dieu ne peut luimême avoir de forme ; c'est un amor infinitus.

Dans les milieux inspirés par saint Bernard, ce mysticisme était lié au scepticisme touchant les recherches des philosophes sur la nature de l'homme et surtout sur celle de l'âme : c'est dans p173 ce scepticisme que naît l'idée de la spiritualité complète de l'âme, suivant un rythme de pensée que l'on trouve chez Philon d'Alexandrie. Guillaume de Saint-Thierry, suivant ici Cassiodore, donne deux descriptions de l'âme, la définition philosophique : «L'âme est une substance

\footnotetext{
Ibid., p. 268.

P. 274 sq.

Ibid., p. 54.

Ibid., p. 82-84.
} 
simple, une forme naturelle, distincte de la matière de son corps, possédant un organisme et la force vitale, » et la description religieuse : " substance spirituelle, créée par Dieu, raisonnable, immortelle et capable de se tourner vers le bien ou vers le mal »; et, prenant parti pour la seconde, il ajoute: "Personne ne comprend ce qu'elle est, parce qu'elle n'a pas de matière, parce qu'elle est une chose spirituelle, intellectuelle, et très semblable à Dieu. " Son union avec le corps n'est pas moins incompréhensible, et l'on ne peut faire appel qu'à la volonté de Dieu : " Dieu a voulu qu'il y eût entre l'âme et le corps une association et une liaison ineffables et inintelligibles. " Partant de cette conception, il ne veut pas admettre l'existence d'une âme chez les bêtes : "Si un être différent de l'homme participe à la vie, nous disons abusivement qu'il a une âme (animatum), non qu'il y ait en lui une âme complète, mais parce qu'il a quelques opérations qui, dans leurs principes, sont aussi inhérentes à l'homme. " Dans cette âme spirituelle et semblable à Dieu, il est impossible de distinguer entre la faculté et la substance, par exemple entre l'âme et la pensée : «C'est par sa substance même qu'elle pense ; ...elle pense donc tout entière, parce qu'elle est tout entière pensée. " L'âme se refuse donc, comme Dieu lui-même, à l'application des catégories logiques. Aussi, un autre mystique du XII ${ }^{\mathrm{e}}$ siècle, Adam le Prémontré, fait comprendre la toute présence de Dieu dans le monde par la toute présence de l'âme dans le corps; cette toute présence est prouvée par la douleur: «Quand une particule quelconque du corps est lésée, étant spirituelle, elle sent tout entière la douleur ${ }^{454}$. »

Table des matières

X.

Gilbert De LA Porree et Alain De LiLle.

p174 En Gilbert de la Porrée, saint Bernard fit condamner, au concile de Reims en 1148, un autre théologien dont il considérait la dialectique comme également dangereuse pour la foi. Gilbert de la Porrée, né à Poitiers en 1076, est un chartrain de formation : chancelier à

454 De triplici genere contemplationis, VI, t. CXCVIII, p. 806. On voit comment ces écrivains mystiques, les vrais continuateurs du platonisme, ont préparé, bien plus que les dialecticiens, le spiritualisme moderne. 
Chartres jusqu'à ce que, en 1141, il devînt maître à Paris, il fut de 1142 à 1154 évêque de Poitiers. Celle de ses thèses qui fut condamnée est la suivante : «Le Dieu unique en trois personnes est une déité ou divinité, une forme unique en Dieu, par laquelle il est Dieu. » Gilbert appliquait à Dieu une distinction qu'il a longuement analysée dans son commentaire du De Trinitate de Boèce, la distinction entre l'être qui est (subsistens) et la forme par laquelle il est ce qu'il est (subsistentia) ; les subsistentae, ce sont des attributs tels que corporéité, sensibilité, rationalité ; le subsistens, c'est le corps qui possède le premier de ces attributs, l'animal qui en possède deux, l'homme qui possède les trois à la fois. Par ce même principe, l'on distinguait le subsistens, Deus, et la subsistentia, Deitas.

La question de savoir si cette manière d'envisager la structure d'un être est aussi applicable à Dieu rentre dans une question d'ordre plus général, que Gilbert essaye de résoudre dans ce Commentaire : Quelles sont les règles qui sont communes à la théologie et à la science des choses naturelles? Quelles sont celles qui sont particulières à l'une et à l'autre ? La solution de cette question devait être le préliminaire méthodique de ce qui restait le but unique de tous les penseurs : fides quaerens intellectum. Gilbert généralise ainsi quelque peu p175 la question posée par Boèce au De Trinitate : Boèce se demandait si les dix catégories d'Aristote pouvaient se dire de Dieu. Gilbert, qui connaît et a médité les Seconds Analytiques d'Aristote, cette logica nova ou logique de la démonstration, sait que chaque science comporte deux sortes de principes, des principes communs et des principes propres, dépendant de la nature de son objet, et il essaye, en ce qui concerne la physique et la théologie, de faire la distinction. Mais encore quel est le fondement de cette distinction ? Gilbert connaît la vieille et habituelle division aristotélicienne des sciences spéculatives : la physique qui s'occupe des formes engagées dans la matière et dans l'état où elles sont engagées ; la mathématique qui s'occupe de ces mêmes formes, mais en les séparant, parla pensée, de la matière ; la théologie qui a pour objet les formes séparées et Dieu. Le procédé de chacune de ces sciences est différent : la physique procède rationnellement (rationabiliter), c'est-à-dire qu'elle emploie le raisonnement pour chercher comment sont unies dans un être concret la subsistenda ou quo est et le subsistens ou quod est ; les mathématiques, doctrinalement (disciplinabiliter) ; la théologie, intellectuellement (in- 
tellectualiter) ${ }^{455}$. Mais à cette donnée d'Aristote, Gilbert joint des considérations issues du néoplatonisme : c'est la notion de forme qui fait l'unité des trois groupes de sciences; or le nom de forme, dont celui d'essence est l'équivalent, ne s'applique proprement et rigoureusement qu'à l'être même (ipsum esse), «qui ne reçoit pas d'autre chose cet attribut esse, mais qui le communique aux autres par une participation extrinsèque ; la forme créée est appelée forme plutôt qu'elle ne l'est véritablement ; ce qui fait qu'elle mérite ce nom, c'est que c'est elle qui, en se liant à un sujet (subsistens), fait de ce sujet ce qu’il est ». Par conséquent, qu’il s’agisse de Dieu ou de la créature, l'être vient toujours de la forme : ${ }_{\text {p176 }}$ c'est là une règle commune aux naturalia et aux theologica ${ }^{456}$. Seulement en Dieu la subsistentia par laquelle Dieu est (quo est) est identique au subsistens qu'il est, quoi est ; l'être ne lui vient pas d'ailleurs que de lui-même : "Deus est ipsa essentia $"{ }^{457}$. Au contraire, au sujet créé sont transférés d'abord l'être, puis la série des formes qui le définissent, par exemple la corporéité, l'animation, la rationalité, puis ses propres, comme la risibilité ; elles sont d'ailleurs hiérarchisées de telle façon que la présence de chacune entraîne la présence de toutes celles qui la précèdent, comme rationalité entraîne animalité, corporéité et être,

Il faut ajouter que ces formes inhérentes à la matière sont individuelles comme les sujets auxquels elles appartiennent ; Gilbert admet la dernière des thèses de Guillaume de Champeaux : l'humanité de Socrate, avec toutes les formes qu'elle implique, est différente de celle de Platon ; il n’est pas réaliste comme saint Anselme ; il ne croit pas que la même forme spécifique soit tout entière à la fois en chaque individu de l'espèce ; si, de ces trois propositions : Platon est homme, Cicéron est homme, Caton est homme, on peut tirer celle-ci : Platon, Cicéron et Caton sont trois hommes, c'est « à cause de la diversité des formes, qui sont dénommées d'un seul nom, si bien que, chacun étant nommé homme d'après sa propre forme (subsistentia) qui n'est pas celle d'un autre, pris ensemble, on dit qu'ils sont trois hommes ", L'erreur du trithéisme vient de ce qu'on applique aux trois personnes

VI, t. LXIV, 1265-c-1268-b.

456 Règle toute verbale qui revient à dire qu'on ne peut penser un être qu'avec des caractères positifs, fût-ce au moins celui d'être.

457 Ibid., 1268-c-1269-d. 
divines une règle qui doit se borner aux créatures : le Père, le Fils et l'Esprit sont non pas trois dieux, mais un seul Dieu, parce qu'ils ont même essence ou subsistentia. On pourrait dire que le réalisme est l'inverse du trithéisme, introduisant, entre les individus d'une espèce, une identité d'essence qui n'est qu'entre ${ }_{\text {p177 }}$ les trois personnes ${ }^{458}$. Dans les naturalia, chaque personne (par exemple Platon ou Socrate) est une par elle-même, parce qu'elle est, par essence, différente des autres : il n'en est pas du tout ainsi des personnes divines ${ }^{459}$.

Gilbert de Poitiers est avant tout un logicien : il a écrit, sur les six dernières catégories, qu'Aristote avait presque entièrement négligées dans les Catégories, un traité (De sex principiis) qui est devenu bientôt classique et que l'on expliquait avec les œuvres logiques d'Aristote et de Porphyre. Sa préoccupation a donc été surtout de formuler des règles et de déterminer le domaine de leur application. Au total, ce dialecticien a surtout montré les limites de l'application de la dialectique en théologie, mais il a suggéré que la théologie avait pourtant, elle aussi, des règles sur lesquelles pouvait se construire une science. Ainsi se dégageait peu à peu, de la dialectique mélangée à la métaphysique, l'idée d'une dialectique purement formelle, attendant de son objet (les naturalia ou les theologica) les règles spécifiques d'où tirer des prémisses. La dialectique s'introduisait donc à titre de moyen de discuter et non de moyen de connaître. De cette discussion, Gilbert donne des règles qui seront celles de tout le $\mathrm{XIII}^{\mathrm{e}}$ siècle : la discussion commence par une question. Il y a question lorsque, de deux propositions contradictoires, l'une et l'autre paraît être vraie ; cela peut provenir soit d'un sophisme, soit d'un tour figuré que l'on prend au sens propre, soit de ce que l'on applique dans un domaine des règles qui conviennent à un autre ${ }^{460}$. L'objet propre du dialecticien n'est donc pas de prouver une proposition, mais de sauvegarder le principe qui veut que, de deux propositions contradictoires, l'une soit vraie et l'autre fausse.

Le temps est donc bien passé où l'on considérait la théologie comme solidaire de la réalité des universaux. Sur la théorie p178 des

Ibid., 1270-1279.

459 Cf. p. 1294 sq. les longs développements relatifs à la personne.

460 VI, t. LXIV, p. 1268. 
universaux, Abélard a eu une influence décisive : plusieurs traités ou fragments anonymes du XII ${ }^{\mathrm{e}}$ siècle nous sont conservés qui trahissent cette influence. On a à cœur de montrer en général que la pensée (intellectus) d'un universel, pour ne pas représenter la chose telle qu'elle est, n'est pas pour cela inutile et vaine (cassus et vanus) ${ }^{461}$, ce qui est montrer la valeur de l'abstraction. D'après un de ces fragments, Guillaume de Champeaux avait fait l'objection suivante au nominalisme : la proposition, Socrate est homme, si homme ne désigne aucune autre réalité que l'individu Socrate, est une proposition identique et vide. La vérité, c'est en effet que « la chose singulière et la chose universelle sont la même chose, mais considérée sous des modes différents ». Si l'on fait attention à Socrate, comme tel, on trouvera qu'il ne coïncide avec rien autre ; mais, en tant qu'animal raisonnable, il n'est pas différent de Platon et d'autres. On répond que l'homme est toujours tel ou tel homme ; mais cela n'implique pas que je le conçois tel ou tel. Les diverses opinions sur les universaux mentionnées par Jean de Salisbury dans le Metalogicus (II, 18) se rapprochent presque sans exception de cette doctrine, qu'on pourrait appeler celle de l'abstraction légitime. C'est Gauthier de Mortagne qui écrit : «Platon, en tant qu'il est Platon, est individu ; en tant qu'il est animal, un genre subalterne ; en tant qu'il est substance, un genre suprême » ; c'est Ghislain de Soissons qui, faisant intervenir l'idée de collection, «attribue l'universalité à la collection des individus, en la refusant à chacun pris à part »; ce sont ceux qui disent, avec Abélard, que les universaux sont des manières d'être des choses (status rerum). Les formules attribuées par Jean de Salisbury aux disciples de Gilbert de la Porrée réunissent bien tous ces aspects: l'universel est, dans les choses, une forma nativa, c'est-à-dire ${ }_{\mathrm{p} 179}$ une forme qui naît avec elle et leur est naturelle ; elle se rapporte à l'Idée, qui est dans l'intelligence divine, comme une imitation à un modèle : "Sensible dans la chose sensible, elle est conçue non sensible par l'esprit ; elle est singulière dans les choses singulières, et universelle dans les choses prises toutes ensemble. »

461 Cf. De intellectibus, dans les Euvres d'Abélard, de Victor Cousin, p. 742743 ; cf. les fragments publiés par HAURÉAU, III, 5, p. 293 et 296, et réédités par BAUEMKER, II, IV, 1, 105 et 108. 
Alain de Lille, né en 1125, qui enseigna à Paris et à Montpellier et qui mourut en 1203 à Cîteaux, s'efforça de réaliser d'une façon complète le projet de Gilbert de la Porrée, de déterminer les règles particulières à la théologie, en partant du principe tiré des Seconds Analytiques : "Toute science s'appuie sur des règles propres ${ }^{462}$ ". Ses Regulae fidei contiennent cent vingt-cinq règles qui sont en théologie comme sont en grammaire, en dialectique, en rhétorique, en morale, les règles particulières à chacun de ces arts. Mais, tandis que les règles de la grammaire sont conventionnelles et que les règles de la nature se réfèrent au cours ordinaire des choses, les règles de la théologie ont une nécessité absolue, qui tient au caractère immuable de leur objet. Il faut, pour les comprendre, quitter le monde des sens et « considérer ces secrets avec le regard plus pur de la philosophie ».

Alain de Lille a pris le modèle de son exposé, dans le Liber de Causis, identique aux Éléments de théologie, de Proclus, qu'il est, parmi les Occidentaux, un des premiers à connaître ; comme chez Proclus, chaque règle $\mathrm{y}$ est en effet suivie d'une démonstration de forme euclidienne. Un très grand nombre de règles (8 à 53) sont consacrées à la question importante de l'époque, celle du rapport des règles de la théologie avec celles de la dialectique et de la grammaire : le théologien énonce, au sujet de Dieu, des propositions et y emploie des formes verbales; la dialectique est l'étude des propositions, et la grammaire, celle des mots ; les règles du dialecticien et du grammairien ${ }_{\text {p180 }}$ s'appliquent-elles en théologie? Nullement : tous les prédicats qui, dans les propositions ordinaires, signifient une qualité (pieux) ou une quantité (grand), appliqués à Dieu, désignent sa substance ; tous ceux qui, d'ordinaire, signifient non une propriété inhérente et substantielle, mais un accident, ne peuvent chez Dieu désigner qu'une propriété substantielle ; et ainsi est supprimée tour à tour la possibilité de propositions qui sembleraient énoncer de Dieu un accident, un universel, une diversité, une partie du sujet, un attribut différent du sujet lui-même (règle 11) ; bien plus, les conditions auxquelles on peut construire une proposition quelconque ne se rencontrent pas chez Dieu : car, il y faut un attribut distinct d'un sujet et un attribut qui informe ou détermine le sujet, deux conditions qui ne sont pas remplies en Dieu (règles 12 à 18). Le théologien semble réduit par là

462 Regulae theologicae, VI, t. CCX, p. 621-a. 
au silence de l'Aréopagite dans sa théologie négative : il n’en est pas moins vrai qu'il énonce des propositions et même que leurs attributs peuvent se classer selon les dix catégories; il faut seulement qu'il sache que ceux qui se placent sous les trois premières catégories, la substance, la qualité et la quantité (tels que être, sage, grand) ne désignent que l'essence, et ceux qui se groupent dans les six autres (tels que créateur) signifient une relation des choses à Dieu, et la diversité des effets de Dieu en nous plus que la diversité d'essence en Dieu (règles 21 à 26).

La théologie apprend donc à parler comme il faut de Dieu, tout en employant à son égard le langage vulgaire : si bien qu'Alain est amené à donner une sorte de lexique théologique dans lequel il indique l'acception des mots de la langue vulgaire, lorsqu'on les applique à Dieu (règles 24 à 53).

C'est la nécessité de formuler la foi dans la langue commune qui force le théologien à énoncer ces règles. Et, d'autre part, la nécessité de défendre la croyance contre des hérétiques qui n'acceptent pas les autorités force à chercher des preuves des articles de foi par des arguments dialectiques : c'est ce ${ }_{\mathrm{p} 181}$ que fait Nicolas d'Amiens dans le De Arte seu Articulis catholicae fidei. Ce traité est conçu à la manière de la Géométrie d'Euclide, avec des définitions, des notions communes et des postulats (petitiones) ; dans ses cinq livres, il essaie de montrer l'enchaînement logique des vérités de la foi depuis l'existence de Dieu ( $\mathrm{I}^{\mathrm{er}}$ livre) jusqu'à la résurrection des morts $\left(\mathrm{V}^{\mathrm{e}}\right.$ livre) en passant par la création des anges et de l'homme (II livre), la chute et la rédemption (III livre), l'Église et ses sacrements (IV livre). C'est tout le contenu du livre des Sentences, où les autorités sont remplacées par des preuves rationnelles. Toutefois, il faut remarquer que Nicolas, pas plus qu'aucun des théologiens qui l'ont précédé, ne se fait illusion sur la valeur de ces preuves: la dialectique est faite de raisonnements probables et non de démonstrations, alors que la foi, elle, est tout à fait indubitable, bien que "ses raisons certaines ne suffisent pas à la science $(I, 17) »$.

Ce n'est plus l'attitude de saint Anselme, chez qui l'emploi de la dialectique suppose d'abord la foi et devient une méditation des vérités de la foi entre croyants ; c'est plutôt l'arsenal des moyens dont le croyant pourra user dans sa lutte avec l'incroyant, moyens de dispute 
et non pas de démonstration : il s'agit moins de méditer que de surpasser l'hérétique ; le croyant n’a pas à se convaincre lui-même, mais il a le devoir d'extirper l’hérésie.

Il n'y a donc aucune science de Dieu, pour Alain de Lille, pas même de son existence : cette existence se démontre à condition qu'on admette comme postulat indémontable la nécessité de s'arrêter dans la série des causes à une cause première ; cette cause, étant première, est créatrice ; c’est, on le voit, la preuve aristotélicienne (I, 9). La Trinité est moins démontrée qu'elle n’est imaginée par un de ces rapprochements qu'avait introduits Abélard. Dans chaque être concret, Aristote avait distingué trois termes, la matière, la forme et le composé des deux; c'est par là que «l'on convainc qu'il y a ${ }_{\text {p182 }}$ une Trinité dans le Créateur » : à la matière, comme fondement, répond le Père ; la forme qui naît dans la matière (innascitur) répond au Fils ; le composé des deux « qui contient en lui non pas seulement l'union des extrêmes, mais encore leur ordre " convient à l'Esprit (I, 25-26) ; si le Fils seul est envoyé pour racheter les hommes, c'est qu'il est naturel que la forme première (auctor formae) se charge de "reformer l’homme déformé par le péché ». Ainsi la métaphore alterne avec la preuve et, souvent, la remplace. Au reste, Alain appuie souvent sur le caractère contingent, et par conséquent indémontrable, des faits qui doivent être crus parle chrétien : "fuit convenientius, decuit », tels sont les expressions qui reviennent continuellement : par exemple, à propos de la rédemption par le Christ, il écrit que « Dieu aurait pu racheter efficacement le genre humain d'une autre manière » (III, 15) ; l'incarnation du Fils, sa génération par une Vierge ont des raisons de convenance et ne sont pas nécessaires.

Le raisonnement, en théologie, n'est donc possible, pour celui qui le fait, que s’il est appuyé sur la foi : la foi seule est le motif qui pousse au raisonnement; "credit ut sciat », dit Alain du théologien $^{463}$. Au-dessous de la théologie, Alain conçoit une science de la nature, mais fort différente, semble-t-il, de celle de Guillaume de Conches ; elle se rapporte à la théologie comme la nature se rapporte à Dieu ; or la Nature dit d'elle-même, en se comparant à Dieu dans son De Planctu naturae : "Son opération est simple, et la mienne est mul-

${ }^{463}$ VI, t. CX, p. 445. 
tiple ; ... il crée, je suis créée ; ... il produit de rien, et je mendie une matière pour mon œuvre »; de là un rapport différent de l'homme à Dieu et à la nature : « L'homme est procréé par moi pour mourir, il est recréé par lui pour vivre ». La science de la nature est, pour Alain, ce vaste symbolisme, qu'ont transmis au Moyen Age les néoplatoniciens, les hermétistes ${ }_{\mathrm{p} 183}$ et les alchimistes qui trouvent de mystérieuses correspondances entre les choses, des pierres qui symbolisent des planètes, et surtout l'homme, qui, étant microcosme, contient en lui des parties correspondantes à toutes les parties du monde : il est fait de quatre humeurs qui correspondent aux quatre éléments; comme dit le Timée, le mouvement de sa raison correspond au mouvement diurne du ciel des fixes, d'Occident en Orient, et celui de la sensibilité au mouvement oblique des planètes d'Orient en Occident ; des trois facultés que distingue Platon, la prudence, qui est en la tête, correspond à Dieu ; le courage, qui est dans le cœur, aux Anges ; la partie sujette, qui est dans les reins, à l'homme ${ }^{464}$. De ce type de philosophie de la nature, qui prête à chaque être les pouvoirs qui dépendent de ses affinités symboliques avec d'autres êtres, on rencontre aussi des traces chez Abélard, quand il écrit en son Éthique : «Il y a, dans les herbes ou dans les graines, dans les natures tant des végétaux que des pierres, des pouvoirs capables d'émouvoir et d'apaiser nos âmes ; celui qui les étudierait avec soin arriverait facilement à le faire ${ }^{465}$. " La science de la nature est une science opérative, reposant sur la connaissance de sympathies qui permettent en particulier de comprendre et d'éviter les maléfices des démons. Telle est la manière dont Alain entend les lois naturelles: des pouvoirs émanant du tout en chaque chose : mais, comme il le dit dans les Regulae fidei (reg. 59), ces pouvoirs naturels ne sont pas du tout une limite pour la toute-puissance de Dieu : «Tout ce qui est possible selon la cause inférieure est possible selon la cause supérieure, mais l'inverse n'est pas vrai » (reg. 57). Le pouvoir de Dieu n'est limité que par le principe de contradiction (Dieu ne peut faire qu'une chose ne soit pas ce qu'elle est), mais non par la Nature.

p184 L'usage de la philosophie, chez Alain, se manifeste dans son traité Contra Haereticos ${ }^{466}$, en quatre livres, dirigés le premier contre

\footnotetext{
464 VI, t. CX, p. 443-444.

465 Édition Cousin, t. II, p. 608.

466 VI, t. CCX, p. 305-430.
} 
les Albigeois, qui ne sont pas nommés, le second contre les Vaudois, le troisième contre les Juifs, le quatrième contre les Arabes. La discussion est un mélange de discussion philosophique et de recours aux autorités, dans la mesure où les adversaires les admettent. Une hérésie, telle que celle des Albigeois, par exemple, était fondée sur une interprétation de la Bible : comme les gnostiques et les manichéens, dont la doctrine s'était répandue jusqu'en France à travers l'Europe centrale, ils voyaient, dans la création et dans la loi mosaïque, l'œuvre du principe du mal ${ }^{467}$, tandis que le Dieu de l’Évangile représente le principe du bien qui vient sauver les âmes impures, prisonnières du monde du mauvais démiurge. L'hérétique albigeois s'appuie donc sur l'Écriture, comme le chrétien. De plus, il emploie l'argumentation philosophique : que le monde soit l'œuvre d'un principe mauvais, il le prouve par ce principe qu'un effet muable et imparfait implique une cause également muable et imparfaite ${ }^{468}$. Alain répond par deux arguments philosophiques: l'un tiré du livre VIII de la Physique d'Aristote, qui montre que le mouvement et le changement supposent un moteur immobile, l'autre fondé sur la distinction entre la cause efficiente et la cause formelle : de la cause formelle, il est vrai que, suivant qu'elle est immuable ou muable, son effet a pareilles propriétés ; la cause efficiente, comme l'artisan ou Dieu, peut produire des effets qui changent et se corrompent, tout en restant, elle, sans changement. De même, à la possibilité de la présence réelle dans l'Eucharistie, les Albigeois opposaient que les accidents du pain et du vin seraient alors privés de tout sujet; Alain, poussant aussi loin que possible l'explication physique, admettait, entre les deux formes de changement ${ }_{\text {p185 }}$ indiquées dans la Physique (l'altération qui, changeant les accidents, laisse intactes la forme substantielle et la matière, la corruption-génération qui, changeant accidents et forme, ne touche pas à la matière), une troisième, la transsubstantiation, où, les accidents restant, changent seules la forme et la matière ; il avoue d'ailleurs qu'on ne peut expliquer comment les accidents du pain sont inhérents à une autre substance que celle du pain ; mais il a recours alors à ses Regulae theologicae, qui montrent que le possible n'est pas mesuré par la nature.

\footnotetext{
467 Liv. I, ch. II, III et XXXV. 
Les Albigeois niaient l'immortalité de l'âme de l'homme, qui, comme celle des bêtes, périssait avec le corps. Comme Alain s’appuie sur Aristote dans les sujets qui touchent la physique, il a ici recours au platonisme, aux livres hermétiques, au paragraphe 2 du Liber de Causis qu'il cite sous le nom de Aphorismi de essentia summae bonitatis, à Virgile, à la Rhétorique de Cicéron, au Timée (il connaît même le titre et le sujet du Phédon) ; ce sont d'ailleurs, pour la plupart, des autorités philosophiques empruntées à Claudien Mamert : comme celuici, il déduit l'incorruptibilité de l'âme de son incorporéité, et il prouve cette incorporéité par huit arguments ${ }^{469}$, dont il faut retenir surtout le dernier : "On peut avoir la notion de (intelligere) ce qui fait vivre le corps, sans avoir la notion de la corporéité ; donc ce principe de vie n'est pas un corps » : il rappelle, dans sa forme, un célèbre argument par lequel Descartes montre que la substance de l'âme consiste en la pensée seule. Ajoutons qu'en lisant, dans la traduction de Boèce, le livre III des Topiques qui porte "sur le choix entre deux thèses proposées ", Alain a eu l'idée d'un autre argument, " dont, dit-il, certain religieux a usé contre le philosophe ». " Ou l'âme est mortelle, ou elle est immortelle ; si l'âme est mortelle et si vous la croyez immortelle, il ne s'ensuit pour vous nul ${ }_{\mathrm{p} 186}$ désavantage ; mais si elle est immortelle, et si vous la croyez mortelle, il peut s'ensuivre pour vous quelque désavantage. » Nous avons ici le principe du pari de Pascal ; on choisit, entre deux propositions, également douteuses pour l'intelligence, selon la ligne de l'intérêt que nous avons à croire l'une ou l'autre.

Si l'on considère dans son ensemble et dans son esprit l'œuvre d'Alain de Lille, on verra bien la place que pouvait avoir la philosophie dans la pensée du XII ${ }^{\mathrm{e}}$ siècle. Dans le Moyen Age chrétien, on ne spécule pas par goût pur de la recherche et pour aligner des vérités nouvelles ; on ne fait pas de philosophie de gaieté de cœur, mais parce que l'on y est forcé ; la philosophie est un élément nécessaire de la chrétienté. La raison profonde pour laquelle elle est nécessaire aux yeux du clerc qui, seul, philosophe, c'est l'état présent de l'Église : l'homme est actuellement in via, dans la voie qui conduit au salut; il a des gages de salut dans la foi ; mais cette foi est un état passager qui ne doit aboutir que dans l'au-delà, à la vision heureuse des élus ; la foi est universelle et l'Église chrétienne est catholique ; mais elle est sans 
cesse menacée par les hérétiques et les infidèles. Deux motifs impérieux de philosopher pour l'homme qui a reçu la raison en partage : d'une part la méditation des vérités de foi, qui, arrivant à jeter sur elles la lumière de l'intelligence, oriente le voyageur vers son état final ; car « cette foi qui recherche l'intelligence » ne cherche pas ainsi à se confirmer, mais à s'élancer ; la philosophie est comme un degré dans la voie qui nous mène au salut ; d'autre part, la lutte pour la foi par la raison contre des adversaires qui n'acceptent d'autre juge qu'elle. Dans les deux cas, c'est un motif pratique et religieux qui pousse le clerc à philosopher: la philosophie n'est jamais qu'un moyen d'ascension ou de lutte. Mais, par suite, elle est essentiellement et foncièrement dialectique, puisque les vérités qu'elle a à éclairer ou à ${ }_{\text {p187 }}$ prouver, elle les emprunte d'ailleurs et ne peut ni leur conférer ni leur ajouter aucune certitude ; la dialectique est une arme défensive, non une méthode créatrice ; l'important est de vaincre par elle dans la dispute et non pas proprement de prouver : la plupart des auteurs se rendent compte que, en ces matières, la dialectique en reste toujours au probable, peu leur importe; ce n'est pas à la certitude, dont ils sont comblés par ailleurs, mais à la victoire qu'ils songent. Mais c'est là un idéal : une foi assurée qui a la dialectique à son service. En vérité, on trouve parfois, dans cette dialectique qu'on emploie comme une arme, des exigences qui sont difficilement compatibles avec le rôle qu'elle a à remplir : la dialectique, telle qu'on la trouve chez Boèce, suppose en effet une structure du réel qui est loin de celle de la réalité suprême, de la réalité divine. D’où, à l'intérieur même de l'Église, un conflit continuel sur l'opportunité et les conditions d'emploi de la dialectique, à laquelle l'objet même qu'on prétend penser semble devoir échapper : de là une tension nouvelle qui s'exprime au XII ${ }^{\mathrm{e}}$ siècle par la lutte entre les écoles et le mysticisme monastique.

On voit à quels intérêts puissants répondait la philosophie. Ajoutons que les débats que dirigeait la dialectique gardaient rarement un intérêt théorique ; il est très rare en effet qu'une hérésie sur un point de dogme n'entraîne pas avec elle un bouleversement plus ou moins complet de tout le système des sacrements et de la discipline de l'Église : c’est ainsi que les hérésies sur la Trinité signalées par Abélard se complètent par la négation de règles disciplinaires telles que le célibat des moines ou par des protestations contre des pratiques abu- 
sives, comme la mise à prix de la remise des péchés. Le manichéisme des Albigeois aurait certainement été considéré comme moins dangereux, s’il ne s'était accompagné de la négation de la valeur de tous les sacrements, sauf le baptême pour les adultes, et du refus de considérer les églises comme des lieux sacrés ; p188 ils niaient notamment la valeur de la pénitence et n'admettaient que la confession intérieure. Les Vaudois, qu'Alain attaque au second livre, niaient toute autorité, et ils attaquaient particulièrement l'absolution des péchés et les indulgences. Quant à la négation de la Trinité en Dieu chez les Juifs et les Musulmans, elle prend, bien entendu, toute son importance, de ce qu'elle entraîne avec elle l'impossibilité de l'incarnation du Fils et de tout le système chrétien. Enfin la doctrine musulmane du prophète, faisant de l'inspiration du prophète une sorte d'intermédiaire entre Dieu et les créatures, rend inutile l'intercession du Christ. C'est cette liaison du dogme à la vie entière de l'Église qui donne aux discussions philosophiques un tel mouvement et une telle âpreté ; c'est que la philosophie doit se faire le soutien d'un dogme qui est lié à l'ensemble de la vie religieuse et politique de la chrétienté.

Table des matières

XI.

LE MYSTICISME DES VICTORINS.

Au monastère parisien de Saint-Victor non moins qu'à l'abbaye de Cîteaux, on était opposé à la philosophie mondaine qui prétendait scruter les secrets divins, et l'on était porté à un mysticisme qui se terminait en amour plus qu'en contemplation. Les Commentaria in Hierarchiam caelestem, que Hugues, prieur de Saint-Victor, écrit " selon l'interprétation de Jean Scot » ${ }^{470}$, commencent par un chapitre où il oppose, d'après le fameux texte de Saint-Paul (Corinth., I, 1), la théologie divine et la philosophie mondaine: "Le monde a voulu contempler les œuvres de Dieu qu'il avait faites pour être admirées, et il n’a pas voulu vénérer ce qu'il avait proposé ${ }_{p} 189$ à imiter... Il a énoncé sur Dieu des propositions qu'il avait conçues dans la superbe de son cœur pour ne pas paraître ignorer la vérité. » Ce n’est pas que tout

${ }^{470}$ Ce qui prouve quelle était encore la faveur de Jean Scot au milieu du XII ${ }^{\mathrm{e}}$ siècle. 
soit erreur chez ces philosophes mondains : «Combien ils ont laissé de monuments d’un excellent génie ! » Hugues de Saint-Victor songe surtout à la logique, à l'éthique, aux mathématiques et à la physique ; « et, ajoute-t-il, ils ont fait assez de progrès pour appréhender la vérité en ces matières, une vérité qu'ils avaient la charge de rechercher ». Mais partant d'une vérité qui n'importe pas à la vie, ils ont prétendu arriver par elle à la théologie et à la science des choses invisibles ; partant d'une nature gâtée par le péché originel, ils ont prétendu atteindre Dieu par la seule lumière si « obscure et douteuse " que donnent les créatures. Sans doute, «la nature, par son aspect, montre qu'elle a un auteur, mais elle ne peut éclairer les yeux de qui la contemple ». Il est possible de démontrer les choses invisibles au moyen des choses visibles, selon le mot de saint Paul ; mais une pareille démonstration est tout autre chose que l'œuvre religieuse de restauration (opera restaurationis). Le rôle de la raison dans la vie humaine est marqué beaucoup moins par la nature de l'homme que par sa situation actuelle et transitoire. L'homme, qui, avant le péché originel, possédait à la fois «l'œil de la chair » pour regarder les choses sensibles, « l'œil de la raison » pour se connaître lui-même, et « l'œil de la contemplation » pour voir Dieu et ce qui est en lui, possède l'œil de la chair, mais a perdu la contemplation, et n'a gardé qu'une raison incomplète et déficiente : d'où la nécessité de la foi "par laquelle on croit ce qu'on ne voit pas ; par elle existe en nous ce qui n'est pas présent par vision (per speciem) ${ }^{471}$ ». Voilà donc, bien précisée, la place de la raison ; ajoutons que la foi, qui n'a jamais l'évidence de la raison, n'est non plus jamais contraire à la p190 raison, mais toujours selon la raison ou au-dessus d'elle ${ }^{472}$.

Hugues de Saint-Victor revenait, dans son monastère, à l'idéal d'éducation de l'époque carolingienne : une éducation libérale qui ne se mêlât aucunement de théologie et qui fût, dans son domaine, aussi poussée que possible ${ }^{473}$, mais à condition qu'elle se contentât de son rôle de servante de la théologie ${ }^{474}$. Le tout est de maintenir l'ordre

\footnotetext{
471 De Sacramentis, I ; VI, t. CLXXVI, p. 329-330.

472 Ibid., p. 231-232 : Secundum rationem aut supra rationem.

473 Omnia disce, videbis postea nihil esse superfluum, VI, t. CLXXVI, p. 800-c.

474 Constat quod omnes artes naturales divinae scientiae famulantur; et inferior sapientia recte ordinata ad superiorem conducit, VI, t. CLXXVI, p. 185-bc.
} 
juste (recte ordinata) et de ne pas plus souffrir dans les sciences que dans la vie religieuse l'atteinte à une hiérarchie qui constitue la structure même du réel. Aussi écrit-il, en sept livres, un traité intitulé Eruditio didascalica, dans la tradition d'Isidore de Bède et de Raban Maur ; les trois premiers livres sont consacrés aux arts libéraux et les trois suivants à la théologie. Dans les trois premiers, on retrouve, en un état d'assez grande confusion, des classifications des sciences, venues en partie d'Isidore et remontant finalement à Aristote, mêlées à la classification en trivium et quadrivium. Suivant une division que monseigneur Grabmann ${ }^{475}$ a retrouvée dans un traité anonyme de la même époque, il divise les connaissances en sagesse ou philosophie, et éloquence ou logique. La sagesse, qui est « la connaissance vraie des choses, se divise en théorie, pratique et mécanique ; la théorie à son tour, en théologie, physique et mathématiques, et les mathématiques contiennent les quatre arts du quadrivium: astronomie, musique, géométrie, arithmétique ; la pratique se divise en éthique, économique et politique ». C'est, on le voit, la division aristotélicienne, à laquelle on ajoute la mécanique. Le quadrivium n'est qu'une partie de la philosophie, celle ${ }_{\mathrm{p} 191}$ qui étudie les formes matérielles, abstraction faite de la matière à laquelle elles sont jointes ${ }^{476}$; et le trivium (dialectique, rhétorique et grammaire) est rejeté au dehors de la philosophie $^{477}$. On pourrait donc attribuer à Hugues un sentiment assez net de la distinction entre la science du réel et la science du langage, si cette distinction n'était pas due en grande partie au hasard des influences, et si elle avait une répercussion sensible dans sa manière de traiter le sujet. La confusion des idées est extrême : il ne semble pas qu'il voit la moindre contradiction à dire, au Didascalicon (II, 18), que l'objet de la physique est de considérer, en dehors de l'état de mélange, les quatre éléments dont les choses sont formées, tandis que, dans le De Sacramentis christianae fidei, il soutient l'atomisme, en le rattachant à un vers de Perse qui reproduit Lucrèce ${ }^{478}$.

XXII, II, 31.

476 Mathematicae proprium est actus confusos inconfuse per rationem attendere, VI, t. CLXXVI, p. 758-b.

477 Didascalicon, VI, t. CLXXVI, p. 752-764.

478 De nihilo nihil, in nihilum nil posse reverti, PERSE, Satires, III, 84 ; VI, t. CLXXVI, p. 746-6. 
Ce qui intéresse Hugues, c'est d'ailleurs moins l'accroissement que l'approfondissement des connaissances qui, à leur sommet, touchent à Dieu : on commence par penser : la cogitatio, « c'est le contact passager avec les choses, lorsqu'une chose se présente tout à coup à l'âme par son image, qu'elle pénètre par les sens ou surgisse de la mémoire »; puis on médite sur elles ; « la méditation, c’est le maniement continuel et sagace d'une pensée qui s'efforce de débrouiller ce qui est embrouillé et de pénétrer ce qui est caché " ; enfin l'on contemple ; « la contemplation, c'est une intuition (contuitus) de l'âme pénétrante et libre, qui se répand sur toutes les faces de l'objet à voir » : cette contemplation, qui commence à la créature, va jusqu'au créateur ${ }^{479}$. On voit que ce qui donne à la pensée d'Hugues sa tension et sa vie, c'est une direction ${ }_{\mathrm{p} 192}$ qui n'est jamais perdue de vue et dont sa doctrine consiste surtout à marquer les étapes.

C’est là ce qui marque la place des «Victorins » dans la pensée du XII ${ }^{\mathrm{e}}$ siècle. Mais, si Hugues fait songer, avec une pensée plus sûre, à l'organisation spirituelle des monastères carolingiens, Richard de Saint-Victor, son élève et son successeur, rappelle plutôt saint Anselme : à lui aussi, sa maxime est fides quaerens intellectum, et il s'agit de chercher les "raisons nécessaires » des vérités de foi ; il pousse très loin ses exigences sur ce point, puisqu'il écrit : « Je suis fermement convaincu que, quant à l'explication des réalités dont l'être est nécessaire (et la Trinité et l'existence de Dieu sont de celles-là), il doit y avoir des arguments non seulement probables, mais nécessaires, bien qu'ils se trouvent parfois échapper à nos recherches ${ }^{480}$. " Contrairement aux dialecticiens qui ne pensaient à atteindre en pareils sujets que le probable, il veut arriver à la certitude : mais, comme saint Anselme aussi, il pense que la tâche est infinie, et que l'homme ne pourra jamais arriver à comprendre pleinement par ses recherches les réalités divines ${ }^{481}$.

Sa méthode est pourtant différente de celle de saint Anselme par le rôle qu'il assigne à l' « expérience ». Il a sur ce point des déclarations de principe formelles : « tout progrès du raisonnement prend son point

\footnotetext{
${ }^{479}$ VI, t. CLXXV, p. 116-117.

480 De Trinitate, I, 4 ; VI, t. CXCVI, p. 892.

481 VI, t. CXCVI, p. 72-a.
} 
de départ en ce que nous connaissons par expérience ", ou encore : «c'est par les choses connues par expérience que nous devons conclure par raisonnement ce qu'il nous faut penser des choses qui sont au-dessus de l'expérience ${ }^{482}$ ». Toutefois il faut se rappeler que ces formules ne sont dites qu'à propos des recherches sur Dieu et ne font qu'énoncer sous une autre forme le fameux adage paulinien : per visibilia ad invisibilia ; et, en l'espèce, l'expérience dont il s'agit se borne au spectacle de la génération ${ }_{\mathrm{p} 193}$ et de la corruption continuelles que « ne nous permet pas d'ignorer l'expérience quotidienne ». Partant de là, Richard conclut qu'il doit y avoir un être qui existe par lui-même et qui, partant, est dès l'éternité. "Sinon il y a eu un moment où rien n'était ; et alors aucune des choses qui devaient venir ne serait venue, puisqu'il n'y aurait rien eu qui leur eût donné ou eût pu leur donner le principe de son existence ${ }^{483}$. » Dans cette preuve de l'existence de Dieu, si différente de celle de saint Anselme, on voit qu'il s'agit de l'expérience en général, telle que l'avait définie Aristote ; car le fond de la preuve consiste bien dans l'application du célèbre adage aristotélicien : « il est impossible qu'une chose en puissance passe d'ellemême à l'acte ${ }^{484}$ ».

Ce rôle donné à l'expérience paraît naître, chez Richard, du désir, qui lui est commun avec Hugues, de placer, dans une progression unique, tous les degrés de connaissance jusqu'à la vision de Dieu, comme il le fait dans le De gratia contemplationis ${ }^{485}$. Dans la progression à trois termes (imaginatio, ratio, intelligentia) qu'il y indique, le premier et le troisième impliquent la présence de leur objet ; mais l'imagination connaît la présence d'un corps, et l'intelligence la présence d'une essence intelligible ; entre elles deux, la raison connaît les choses absentes et cachées au moyen de ce qui est présent ; elle connaît, par exemple, la cause par ses effets. Tandis que la raison a toujours besoin de l'appui du sensible, l'intelligence, atteignant directement son objet, peut se passer des sens et de la raison à condition d'entendre « la simple intelligence sans l'office de la raison, et la pure

\footnotetext{
482 VI, t. CXCVI, p. 894-895.

483 Ibid., 894.

484 Richard paraît s’y référer (VI, t. CXCVI, p. 894-b) : « Nous voyons que les choses qui n’étaient pas auparavant passent à l'acte. »

485 Cf. M. LENGLART, CXIII, ch. II et III.
} 
intelligence sans le concours de l'imagination ». Au sommet de l'intelligence est la contemplation qui dépasse l'intelligible ou essence p194 pour arriver à l'intellectible ou Dieu; et l'on y distingue encore trois degrés selon que l'on est plus ou moins près du modèle : la dilatation de l'esprit (dilatatio mentis), lorsque l'on voit Dieu en figure, l'élévation de l'esprit (sublevatio mentis), lorsqu'on le voit comme en un miroir, l'aliénation de l'esprit (alienatio mentis) « lorsqu'on le contemple en sa simple vérité ». Cette contemplation a pour condition la pureté du cœur ; car le «miroir » en lequel on voit Dieu, c'est l'âme même, et c'est " par la connaissance de soi qu'on monte à la connaissance de Dieu »; il faut donc que ce miroir soit pur ; mais cette préparation n'aboutit pas d'elle-même à l'état suprême d'aliénation que l'âme doit atteindre et qui ne peut venir d'elle. Toujours d'ailleurs, remarquons-le, d'un bout à l'autre de la chaîne, le degré supérieur ne provient jamais de l'inférieur, mais s'ajoute à lui comme quelque chose qui le dépasse.

On aura remarqué un certain contraste entre ce mysticisme des Victorins et celui de saint Bernard ; l'un aboutit plutôt à la connaissance, et l'autre à l'amour. Comparons, par exemple, le De gratia contemplationis de Richard de Saint-Victor au De triplice genere contemplationis d'Adam Scot, de l'ordre des Prémontrés, qui, vers le milieu du XII ${ }^{\mathrm{e}}$ siècle, suit l'inspiration de saint Bernard : le progrès est à trois stades comme chez Richard ; mais ces stades sont purement religieux : " Au premier, je vous vois absolument incompréhensible ; au second, terrible ; au troisième, aimable ${ }^{486}$ »; il n’y a là aucune trace de pensée philosophique ; mais, dans la méditation des Écritures, on voit le Dieu mystérieux et terrible de l'Ancien Testament se changer dans le Dieu aimable de l'Évangile. Si le premier stade de contemplation élève l'esprit dans les hauteurs, le second rabat l'orgueil qu'il pourrait en concevoir, tandis que le troisième relève l'esprit ${ }_{\text {p195 }}$ et l'encourage en lui donnant confiance : c'est, on le voit, une dialectique plus affective qu'intellectuelle.

Pourtant, en réfléchissant sur les caractères de cet amour de Dieu, plusieurs penseurs du XII ${ }^{\mathrm{e}}$ siècle se rendirent compte de la nécessité d'établir ses rapports avec la volonté raisonnable. Beaucoup de ces

${ }^{486}$ VI, t. CXCVIII, De triplice genere, § 22. 
penseurs, et parmi eux Pierre de Blois, étaient des lecteurs fervents des œuvres morales classiques entre autres, du De Amicitia, où Cicéron, écho lui-même de la Morale à Nicomaque d'Aristote, avait montré la supériorité d'une amitié fondée sur la raison. Pierre de Blois, qui, en 1153, était archidiacre auprès de l'évêque de Canterbury, était un lettré et un juriste qui se défend contre le reproche d'utiliser les écrivains païens. «S'il y a quelque ouvrage païen qui me plaise, écritil, je puis bien le prendre pour moi, afin qu'il en naisse, dans la foi, des fils spirituels... Vous m'accusez, parce que, dans les conseils que j'ai donnés quelquefois à Bologne sur la demande de mes collègues, j'ai prononcé des paroles qui sentaient le droit civil ; or le droit civil est chose sainte et belle, et approuvée par les constitutions crées ${ }^{487}$. " Il ne veut pas d'ailleurs que l'on abuse des lettres de l'érudition, et il adresse une lettre assez dure à un maître de Beauvais, qui lui reprochait sa vie mondaine à Canterbury : "Vous qui discutez continuellement de bagatelles, vous frappez l'air de sons inutiles; et, si l'on peut dire, c'est en enfant de cent ans et en vieillard écolier (elementarius senex) que vous enseignez la sagesse. Priscien et Cicéron, Lucain et Perse, voilà vos dieux ${ }^{488}$. » Cette éducation purement littéraire et grammaticale devait être fréquente à cette époque si nous en jugeons par une autre lettre de Pierre de Blois qui réprimande son correspondant d'avoir perdu son temps à l'étude des lois et des poètes et d'avoir dit que « le style de l'Évangile était rude, insipide ${ }_{\mathrm{p} 196}$ et enfantin ${ }^{489}$ ". Ne voit-on pas Pierre de Riga, chanoine de Reims vers 1160 et mort en 1209, mettre en distiques, sous le titre d'Aurora, la Genèse et d'autres livres de la Bible, en disant qu'il n'a pu le refuser à des camarades, avec qui il a été en relation dès l'enfance à l'école et avec qui il a lu les livres de grammaire et les ouvrages fleuris de Cicéron? "J'ai pénétré quelque peu, ajoute-t-il, dans le labyrinthe d'Aristote, en prenant pour guide non le fil de Dédale, mais le fils de Dieu (non filo Daedali sed filio Dei Duce) ; je l'ai vu, mais je n'y suis pas entré à fond ${ }^{490}$. » Cette éducation littéraire, Pierre de Blois l'a reçue, mais sans de pareils excès; et il l'utilise dans un traité Sur

\footnotetext{
487 VI, t. CCVII, p. 23-a.

488 Ibid., p. 18-a.

489 Ibid., p. 231. -

490 VI, t. CCXII, p. 19-a.
} 
l'Amour de Dieu, qu'il a écrit vers 1185. "L'amour, écrit-il, est une tendance vers des objets que nous choisissons en suite de notre désir et que nous embrassons pour en jouir ${ }^{491}$. " Mais lorsque ce choix est délibéré, lorsqu'il vient d'un jugement réfléchi, l'amour devient amitié au sens que Cicéron a donné au mot ; dans la définition de Cicéron, l'amitié a à la fois un caractère intellectuel (elle est accord d'opinions entre les amis), un caractère affectif (elle est charité) ${ }^{492}$, un caractère volontaire (elle est bienveillance mutuelle). A côté de l'amour instinctif (celui de la mère pour ses enfants), de l'amour charnel, et de l'amour par devoir, Pierre de Blois distingue un amour purement raisonnable (amor rationalis), et un amour qui vient à la fois de la raison et de l'affection ${ }^{493}$. La raison seule, en effet, suffit à produire e désir, d'où vient l'amour; le désir est même d'autant plus sûr et plus pur qu'il vient de la raison : ainsi se produira l'amour raisonnable de Dieu qui vient de la considération de notre intérêt, puisqu'il y va de notre salut et de la dignité ${ }_{\mathrm{p} 197}$ de Dieu, qui est le Souverain Bien ${ }^{494}$; en général, nous aimons raisonnablement une personne, lorsque nous l'aimons pour sa seule vertu. Cet amour, Pierre de Blois, suivant son modèle antique, le met au-dessus de l'amour qui naît de la simple affection (ex affectu) ${ }^{495}$. Mais, au-dessus de l'amour raisonnable, il met celui qui vient à la fois de la raison et de l'affection. L'affection peut être raisonnable, lorsqu'elle vient par exemple d'une admiration justifiée ; mais au-dessus de l'affection raisonnable se trouve l'affection spirituelle (affectus spiritualis), celle qui naît soit de la grâce de Dieu, soit de la tentation du démon : l'amour supérieur de Dieu joint à la raison cette sorte d'affection qu'il nous donne pour lui par grâce ${ }^{496}$; encore est-ce un amour réglé (amor regulatus), toujours accompagné d'un assentiment de la volonté.

On voit le rôle d'intermédiaire que joue encore ici la raison; le rythme de la théorie de l'amour est le même que celui de la théorie de

\footnotetext{
491 é dit. M.-M. DAVY, p. 108.

492 Charitas, mot que Pierre de Blois est un peu étonné de rencontrer chez Cicéron et qu'il lui reproche de ne pas bien comprendre.

493 Ibid., p. 122.

494 Ibid., p. 512-514.

495 Cf., p. 526, les sources diverses de l’affection.

496 P. 492.
} 
la connaissance : on ne peut se passer de la raison pour monter des sens à l'intelligence des essences, pour aller de la foi à la contemplation; de même, on ne peut se passer de la raison pour aller de l'affection informe à l'affection qui nous vient d'en haut ; alors seulement viendra, selon le bon plaisir de Dieu, une douceur neuve et non éprouvée » ; et, avec elle, « la chaleur du désir, l’illumination de l'œil intérieur, les flammes de l'affection ${ }^{497}$ ».

Table des matières

\section{XII.}

\section{RAISON ET THEOLOGIE.}

Les Sentences de Pierre Lombard sont écrites après beaucoup d'autres ouvrages du même genre; peu originales, de p198 pensée faible et incertaine, elles ne doivent leur célébrité qu'à ce qu'elles ont servi de texte de commentaire aux théologiens pendant les siècles qui ont suivi. Conformément à un plan déjà habituel : Dieu, la création, la rédemption, l'institution de l'Église et la fin des temps, il divise chaque sujet en questions ou "distinctions ", sur lesquelles il accumule les autorités. Il méprise les dialecticiens, qu'il appelle « des raisonneurs bavards plus vaniteux que capables », et il prétend citer des cas où leur grand principe de contradiction est en défaut. Comme tous les ennemis de la dialectique, il n'use pas moins d'elle, ne fût-ce que pour concilier des autorités de sens opposé. De plus, on le voit admettre que des vérités telles que l'existence de Dieu, la création, l'immortalité de l'âme et même la Trinité, ont pu, jusqu'à un certain point, être atteintes par les païens « selon des raisonnements philosophiques ». Lui-même, il suit en général saint Augustin, bien qu'il cite beaucoup d'autres pères et, en particulier, le premier en Occident, Jean Damascène, dont Burgundio de Pise avait traduit la Source de connaissance en 1157.

Bien d'autres, vers la même époque, ont écrit de ces Sentences ou de ces Sommes dans lesquelles on classait tous les dogmes, toutes les questions qui s'y rapportaient, avec les autorités pour et contre. Avant le Lombard, une Summa Sententiarum est attribuée (sans doute faus-

497 Ibid., p. 562. 
sement) à Hugues de Saint-Victor. Robert Pullus, cardinal et chancelier du Siège apostolique, mort en 1146, écrit une Summa Sententiarum ${ }^{498}$. Puis viennent les Sententiae divinitatis de Robert de Melun ${ }^{499}$, un Anglais, élève d'Abélard et d'Hugues de Saint-Victor, à qui il emprunte sa classification des sciences. Bandini ${ }^{500}$ écrit un abrégé des Sentences du Lombard. Pierre de Poitiers, maître à Paris depuis 1169 et mort en 1206, écrit ${ }_{\mathrm{p} 199}$ cinq livres de Sentences ${ }^{501}$, après un commentaire de celles du Lombard; ainsi font tous les maîtres de théologie qui se succèdent alors à Paris : Pierre Comestor, qui y fut chancelier en 1164 et mourut en $1178{ }^{502}$; Pierre le Chanteur, maître de théologie à l'école cathédrale de Paris en 1169 et mort en $1177^{503}$; Simon de Tournai, né en 1130, qui enseigna à Paris dès la fin du XII ${ }^{\mathrm{e}}$ siècle en $1165^{504}$; Prevostin de Crémone, son successeur, qui y est maître de théologie de 1206 à $1209^{505}$, et bien d'autres encore.

On voit que cette littérature est étroitement liée à l'enseignement de la théologie à l'école épiscopale de Paris ; à la faveur de cet enseignement, s'introduisent les habitudes de discussion ; si, naturellement, on ne met pas en question les dogmes, on discute sur leur détail : « Si grande que soit la certitude (des dogmes), écrit Pierre de Poitiers, il nous est pourtant permis de douter des articles de foi et d'en discuter ; je ne dis pas de douter de la vérité de ces articles, mais de douter et de disputer du mode de la passion et du mode de la résurrection ${ }^{506}$. » On pressent jusqu'à quelles subtilités peut descendre la discussion ainsi engagée. Aussi, pour l'alimenter, on a recours au nouvel acquis de l'érudition philosophique; Pierre de Poitiers, en ses gloses sur le

\footnotetext{
498 VI, t. CLXXXVI, 639-1010 ; cf. R.-M. MARTIN, CXIV, t. I : Quaestiones de divina pagina, Louvain, 1932.

499 Grabmann, XXII, II, p. 328 sq.

500 VI, t. CXCII, p. 965-1112.

501 VI, t. CCXI, p. 783-1280.

502 Cf. Grabmann, XXII, II, p. 393.

503 Édition dans PITRA, Analecta sacra, II, 6-154, 585-623, et Spicilegium solesmense, III, 1-108.

504 J. WARICHEZ, Les « Disputationes » de Simon de Tournai, Louvain, 1933. Extraits dans HAURÉAU, XXIV, III, 250-259, et analyse dans GrABMANN, XXII, II, p. 537 sq. et 543.

505 Analyse dans GraBmanN, XXII, II, p. 552 sq.

506 VI, t. CCXI, p. 1092.
} 
Lombard, se réfère pour la première fois à la Métaphysique d'Aristote. Cette méthode permet naturellement toutes les divergences philosophiques possibles ; on voit par exemple Simon de Tournai s'inspirer de Gilbert de la Porrée et d'Alain de Lille ; en revanche, il se montre parfois antiplatonicien ${ }^{507}$.

p200 Une phrase de Pierre le Chanteur indique bien la place de cette discussion : «L'exercice sur l'Écriture sainte consiste en trois choses : lecture, discussion et prédication. La lecture est le fondement et le soutien de ce qui suit ; en cet édifice, la discussion est comme la muraille, puisque rien n'est pleinement compris ou prêché avec foi, s’il n’a d'abord été brisé par la dent de la discussion ; la prédication est comme le toit qui protège les fidèles de la tempête des vices ${ }^{508}$. » On voit la place intermédiaire que prend ici, dans la pratique théologique, comme partout, la raison ; elle part d'une donnée qui lui est extérieure, et elle prépare une œuvre pour laquelle elle n’est pas faite.

Cette débauche de discussions, qui caractérise la fin du XII ${ }^{\mathrm{e}}$ siècle, spécialement aux écoles de Paris, ne va pas sans inquiéter la piété plus intérieure, qui s'était développée dans les milieux monastiques. C’est aux discussions du genre de celles qui se traitent dans les livres des Sentences que Frowinus, abbé du Mont-des-Anges, dans un De libero arbitrio tout pénétré de l'esprit de saint Bernard, adresse ce titre de chapitre : "Que des sots cherchent la manière dont Dieu s'est uni à l'homme ${ }^{509}$.» L'évêque de Chartres, Pierre de Chelles (mort en 1187), s'adresse directement aux Parisiens : "O Paris, comme tu es apte à prendre et à décevoir les âmes; heureuse école, où le Christ enseigne ! Là, on n'achète pas de livres ; là, la vie sert plus que la lecture ${ }^{510}$. " L'on a vu plus haut les plaintes de Pierre de Blois, dont la dialectique heurtait les goûts classiques, mais qui se scandalisait surtout, comme Étienne de Tournai, mort en 1203, de voir discuter, sur la place publique, de la Trinité et de la génération du Fils. Du monastère de Saint-Victor partit aussi une sévère critique à p201 l'adresse des an-

507 Cf. J. WARICHEZ, CXVIII, loc. cit., et M. LEHMAN.

508 VI, t. GCV, p. 25.

509 Liv. III, ch. IV ; VI, t. CLXXIX. Ce traité montre (liv. V) que le libre arbitre est l'image de Dieu en nous et que «Science et Sagesse, Justice et Béatitude consistent et sont fondés daus le libre arbitre ».

510 Cité par GraBmann, XXII, II, p. 125. 
ciens comme des nouveaux sententiaires, le Contra quatuor labyrinthos Franciae, par Gauthier de Saint-Victor (mort après 1180); il y critique l'auteur des Sententiae divinitatis, qu'il croit être Abélard, Gilbert de la Porrée, Pierre Lombard et Pierre de Poitiers. Ces quatre personnages, " inspirés du seul esprit d'Aristote, en traitant avec une légèreté scolastique les secrets ineffables de la Sainte-Trinité et de l'Incarnation, ont vomi une foule d'hérésies. O folie ! Le dialecticien propose : tout homme est homme par l'humanité ; l'hérétique assure : l'humanité n'est rien; le diable conclut: donc l'homme n'est rien ${ }^{511}$. »

Ajoutons que, à côté des écoles théologiques, il s’était fondé, avec Adam du Petit-Pont, dès le milieu du siècle, des écoles (la future faculté des arts) qui, n’ayant pas le droit d'enseigner la théologie, se bornaient à des exercices formels de dialectique. Jean de Salisbury, au Metalogicus ${ }^{512}$, fait un portrait peu flatté de ces puri philosophi : «Dédaignant tout en dehors de la logique, ils y passent leur vie entière ; devenus vieux, ce sont des douteurs puérils ; ils discutent toute syllabe et même toute lettre des paroles et des livres ; ils hésitent en tout, ils cherchent toujours et ils ne parviennent jamais à la science ;... ils compilent les opinions de tous ; par manque de jugement, ils se réfèrent à des livres qui n'ont pas la moindre valeur ; la masse des opinions qui s'y opposent est telle que le propre auteur du livre peut à peine les connaître. » Cette dialectique, qui développe la verbosité, la volubilité dans la parole, la capacité de la mémoire, la subtilité d'esprit, est finalement sans usage ; "ni chez soi, ni à l'armée, ni au tribunal, ni au cloître, ni à la cour, ni à l'Église, nulle part sinon à l'école, elle ne sert de rien ». On voit bien le danger de cette science parasite qui continua à connaître de beaux p202 jours, et l'on s'en plaindra encore au cours du XIII ${ }^{\mathrm{e}}$ siècle ${ }^{513}$.

Jean de Salisbury, né vers 1110, séjourna en France de 1136 à 1148 et suivit les leçons de tous les maîtres de l'époque ; il fut évêque de Chartres de 1176 à 1180. Humaniste et lettré, s’intéressant à

511 Cité par Grabmann, XXII, II, p. 125.

512 Liv. I, ch. VII et VIII, VI, t. CXCIX.

513 Grabmann, XXII, t. II, p. 112, sq. ; on voit aussi ce que devient au Moyen Age la «philosophie pure » laissée à elle seule. 
l'histoire et à la politique, il fit un grand effort dans le Metalogicus, œuvre qu'il acheva vers 1159 , pour dégager de la masse des études logiques ce qui pouvait en être profitable; loin de s'attarder à l'Isagoge, il voit la partie vraiment utile de l'œuvre d'Aristote dans les Topiques, à cause de leur caractère pratique et de leur clarté : les Topiques ou art de la discussion se rattachent à la découverte, tandis que les Analytiques premiers « concernent surtout le jugement». En bon académicien ${ }^{514}$, il se plaît à la probabilité des Topiques ${ }^{515}$, et il considère la démonstration comme impossible. La théorie qu'il en trouve dans les Seconds Analytiques le rebute à cause de sa difficulté intrinsèque, de sa grande obscurité et de son peu d'usage. Jean de Salisbury ne lui voit d'application qu'en astronomie et en mathématiques ; dans la plupart des cas, la nature des choses est trop cachée pour que l’homme puisse distinguer le possible du nécessaire : « La démonstration est ébranlée en général en matière de science naturelle ; elle a toute sa force en mathématiques ${ }^{516}$. " Il n'a trouvé, dans les Seconds Analytiques, que l'occasion de développer une théorie des degrés de la connaissance $^{517}$, où il a fait un effort, d'ailleurs peu réussi, pour y intégrer tous les éléments qu'il trouvait chez Aristote, Platon et saint Augustin. D'Aristote, il prend la progression : sens, imagination, opinion, science (en intercalant entre l'opinion et la science, d'après le De Officiis de Cicéron, la prudence). A la science il superpose ${ }_{\mathrm{p} 203}$ la sagesse, définie "connaissance des choses divines ». Puis il fait entrer, dans la série, la foi, définie comme un intermédiaire entre l'opinion et la science. Mais à la série ainsi formée, il en juxtapose une autre, celle de la raison (ratio), de l'intelligence (intellectus) et de la sagesse. La raison, faculté qui connaît les vérités éternelles, prépare l'intelligence "suprême faculté spirituelle, qui, réglant les choses humaines, possède en elle les causes divines de toutes les raisons qui lui sont naturellement perceptibles ». Au-dessus, la sagesse est la saveur des choses divines.

514 VI, t. CXCIX, p. 882 : « en ces matières qui sont douteuses pour le sage, j’ai déclaré depuis longtemps être académicien ».

515 Ibid. ; 859-d ; cf. liv. I, ch. V à X.

516 Liv. I, ch. V et XIII, fin.

517 Liv. IV, ch. XI-XX. 
De ces deux séries dont la première est faite de termes assez hétérogènes, et dont la seconde a une couleur augustinienne fort nette, Jean de Salisbury tente une unification, en se plaçant au point de vue du perfectionnement religieux, mettant la seconde au bout de la première ; la première série a pour aboutissant la science, c'est-à-dire la vie active, vie faite d'obéissance envers l'autorité ; à un degré supérieur, cette obéissance est raisonnée (ratio), puis elle est comprise (intellectus) et enfin goûtée en sa saveur (sapientia) : c'est la vie contemplative. On voit nettement, dans cet essai un peu informe, à quoi il veut faire servir la philosophie.

Ici apparaît encore le caractère préparatoire et préliminaire de la raison ; on le voit encore beaucoup mieux dans les appréciations de Jean sur la théorie platonicienne des Idées ${ }^{518}$. Relativement à ces Idées qui sont considérées comme des vérités éternelles résidant en l'Intelligence de Dieu, il admet une triple forme de la raison : la raison divine qui voit la vérité universellement, la raison des anges qui la voit par portion (particulariter), la raison humaine qui est à la recherche du vrai et qui est susceptible d'erreur : de cette raison humaine, l'objet légitime n'est ni l'univers physique, ni la vérité divine ; ce n'est pas l'univers physique (opinion contraire à p204 tous ceux qui croient la raison chez elle dans la nature), parce que la raison n'a pour objet que l'être et que les choses sensibles contiennent trop de nonêtre, parce que cette connaissance serait inutile à la seule qui importe, celle de nous-mêmes, enfin parce que l'homme ne peut rendre raison de la moindre des choses ${ }^{519}$. Ce n'est pas davantage la vérité divine, trop spirituelle pour une raison attachée au sens dont elle découle; « et parce que tant le sens que la raison humaine errent fréquemment dans l'intelligence de cette vérité, Dieu en a placé le premier fondement dans la foi ${ }^{520}$ ». On voit donc la raison ballottée de la nature à Dieu ; l'impossibilité de la science des choses divines la renvoie vers

\footnotetext{
518 Liv. IV, ch. XXXIV sq.

519 Jean a fait dans le Polycraticus (VI, t. CXCIX, p. 640) la liste des sujets interdits à l'intelligence : ce sont, outre les sujets physiques généraux (par exemple le temps, le lieu, la matière et le mouvement, les principes des corps), les problèmes classiques (les marées, les sources du Nil, etc.) et même beaucoup de problèmes moraux (usage, origine et fin des vertus, si tous les péchés sont égaux, etc.).

Ch. XXXXI.
} 
la nature, mais le non-être des choses sensibles la renvoie vers les choses impérissables : elle cherche une place dans l'intermédiaire ; elle la cherche passionnément, sans arriver à la fixer : de là, les luttes émouvantes qui ont duré pendant tout le moyen âge.

Dans le Polycraticus, se dessine nettement l'aspect social et politique de la pensée de Jean de Salisbury : c'est la théocratie. Le livre IV enseigne les thèses suivantes: "Le prince est le ministre des prêtres, et il est moindre qu'eux. Il est constant que c'est par l'autorité de la loi divine que le prince est soumis à la loi de justice. Il doit avoir toujours présente à l'esprit et aux yeux, la loi de Dieu. » Le prince est intermédiaire entre le sacerdoce et les sujets, comme la raison entre Dieu et la nature, et, dans ce domaine encore, c'est cette notion de l'intermédiaire qui vivifie la pensée médiévale. En bon humaniste, c'est dans la fausse lettre de Plutarque à Trajan qu'il ${ }_{\text {p205 }}$ va chercher, au livre VI, les principes du pouvoir du prince. « La république, écritil, est un corps qui est animé grâce à la magnificence divine, qui est conduit par la volonté de la souveraine équité et qui est régi par une règle de la raison ${ }^{521}$ "; dès lors, si le prince est le chef de la république, c'est par l'élection populaire que son pouvoir et ses privilèges sont assurés. A l'intérieur même de l'État, l'ordre (analogue à celui que nous montre dans la nature la société des abeilles) n’est assuré que parce que le prince y est «l'image de la divinité ». La correspondance parfaite entre cette conception hiérarchique de la société et celle de la connaissance nous fait deviner un caractère foncier et presque inexprimable de la pensée médiévale : une sorte d'effort puissant et douloureux pour établir un ordre naturel qui soit comme enclavé dans l'ordre surnaturel, si bien que nos facultés naturelles aient leur rôle et leur sens dans la vie surnaturelle. Le rationalisme, la connaissance par pure raison, ne peut avoir son sens en lui-même ; aussi lorsque l'on trouve, hors de la révélation, chez les païens, une philosophie rationnelle, on est fort étonné et il en faut une explication ; Helinand de Froidmont, dans ses Flores ${ }^{522}$, raconte très sérieusement que le démon Apollon a volé à la Bible la maxime divine : "Connais-toi toimême »; il ajoute que Macrobe, au Songe de Scipion, a rendu cette maxime nuisible, en en faisant le commentaire le plus faux qui soit,

\footnotetext{
521 VI, t. CXCIX, p. 540-a.

522 VI, t. CCX1I, p. 721.
} 
« inspiré par l'esprit menteur qui avait donné cet oracle non pour instruire, mais pour tromper »; elle veut dire d'après Macrobe : sache que tu es issu de la race des dieux et que, par la conscience de ton origine, tu retrouveras toutes les vertus dont ton âme a été privée en tombant dans le corps. Ces remarques assez naïves d'un moine, hanté par l'idée des démons, et d'ailleurs fort au courant des lettres classiques ${ }^{523}$, rend manifeste ${ }_{\text {p206 }}$ cette croyance que la raison ne peut trouver sa place que dans le contexte de la vie chrétienne.

Table des matières

\section{XIII.}

\section{LES HERESIES.}

C'est cette passion de rationalisme qui explique que l'on condamna au début du XIII ${ }^{\mathrm{e}}$ siècle des hérésies, dont le caractère commun était de nier que l'homme fût actuellement in via, dans cet état transitoire qui mène au salut ou à la perdition et qui exige, avec toute l'organisation de l'Église, l'œuvre rationnelle de la théologie, et d'affirmer qu'il était déjà in patria, ce qui rendait inutiles l'une et l'autre. Que l'homme fût actuellement dans une media aetas, dans une époque intermédiaire entre l'annonce de la rédemption par le Christ et la fin des temps, c'est ce que Joachim de Flore, né en 1145, abbé du monastère de Saint-Jean en Calabre, mort en 1202, est d'accord pour nier avec les disciples d'Amaury de Bennes, ce maître de théologie de Paris qui mourut en 1206. Joachim croit que l'histoire de l'humanité se déroule en trois périodes, correspondant aux trois personnes de la Trinité ; l'ère du Père s'est accomplie avec l'Ancien Testament ; l'ère du Fils, qui a commencé avec l'incarnation et qui s'est manifestée dans l'Évangile, est près de finir, et, au début du XIII ${ }^{\mathrm{e}}$ siècle, doit commencer l'ère de l'Esprit ou de l'Évangile éternel : l'Évangile éternel doit donner, par l'intelligence que communique le Saint-Esprit, le sens purement spirituel de l'Évangile du Christ. Cette doctrine était naturellement liée, dans la pensée de Joachim, à une réforme profonde de l'Église, qui devait abandonner tout contact avec le monde et se spiritualiser. La doctrine historique de Joachim, qui séparait à ce point

523 Il cite, entre autres, avec Macrobe, la lettre de Plutarque à Trajan que connaît Jean de Salisbury, ainsi que Juvénal, Ovide et Virgile. 
les personnes de la Trinité, avait une tendance au trithéisme qui fut condamnée, chez lui, au concile de Latran p207 de 1215. Mais tout au long du $\mathrm{XIII}^{\mathrm{e}}$ siècle et jusqu'au $\mathrm{XIV}^{\mathrm{e}}$, une pareille doctrine, qui réprouvait autant l'œuvre rationnelle de la théologie que l'institution de l'Église, eut la faveur de cette communauté spirituelle que formaient les Franciscains et dut être condamnée plusieurs fois.

Les disciples d'Amaury de Bennes affirmaient eux aussi que l'époque du Saint-Esprit avait commencé, que les sacrements étaient désormais inutiles, que, à la foi, allait succéder la science ${ }^{524}$, retrouvant d'ailleurs ainsi tout ce qui avait fait condamner les Albigeois et les Vaudois ; mais, comme il est naturel chez un théologien de Paris ${ }^{525}$, Amaury avait lui-même fondé ces conséquences sur toute une métaphysique religieuse, qui n'était autre que celle du De divisione naturae de Jean Scot. La science, qui devait remplacer la foi, avait en effet comme principe : "Dieu est l'essence de toutes les créatures et l'être de toutes choses » ${ }^{526}$, ce qui, comme le remarque Martin de Pologne, mort en 1278, dont la Chronique nous fait connaître quelques traits de la doctrine d'Amaury, était la doctrine de Jean Scot, ainsi d'ailleurs que tous ceux qu'il indique encore : « Les idées de la pensée divine créent et sont créées ; toutes choses doivent retourner à Dieu pour y reposer immuablement. De même que la nature d'Isaac et d'Abraham est la même, ainsi tous les êtres sont un seul être et tous les êtres sont Dieu. ${ }^{527}$ " Il suivait Jean Scot jusque dans le détail, enseignant par exemple que la distinction des sexes résulte du péché et disparaîtra à la fin des temps.

Il est fort difficile de comprendre comment, ainsi que le veut Duhem ${ }^{528}$, les propositions, qui auraient été orthodoxes p208 chez Jean Scot, seraient devenues hérétiques chez Amaury: Amaury soutiendrait le panthéisme, c'est-à-dire l'anéantissement de tous les individus

\footnotetext{
524 D’après le Contra Amaurianos composé par GARNIER DE ROCHEFORT vers 1210 (édit. Bauemker).

525 D'après Gulllaume Le Breton, De Gestis Philippi Augusti (dans A. Bouquet, Recueil des historiens, t. XVII, p. 83), il était fort habile en logique.

526 Esse omnium.

527 Chronique, Anvers, 1574, p. 393.

528 XV, t. V, p. 248-9.
} 
en Dieu, tandis que Jean Scot prend grand soin d'affirmer que, dans ce retour à Dieu, chaque substance conserve sa propriété. Lorsque l'on songe aux contresens qu'on a pu à cet égard commettre sur Spinoza, dont nous avons le texte sous les yeux, il est prudent de ne pas imputer à la doctrine d'Amaury les conséquences ridicules qu'en a tirées un écrivain anonyme, tout à fait analogues à celles que Bayle tirait de Spinoza: "Dieu est pierre dans la pierre et Godin dans Godin ? Qu'on adore donc Godin, puisque Godin est Dieu ${ }^{529}$. " Si l'on fut si sévère pour Amaury dont on exhuma le corps en 1210 pour le jeter en terre non sainte et dont la doctrine fut condamnée au concile de Latran en 1215, pour ses disciples dont plusieurs furent brûlés la même année, ce n'est pas parce qu'on distinguait ses idées de celles de Jean Scot, dont le De divisione fut d'ailleurs condamné aussi au concile de Paris de 1210 : c'est bien plutôt parce qu'Amaury, avec plus de décision encore que Joachim de Flore, niait les conditions que l'Église mettait à la déification et au retour à Dieu de toutes choses, conditions dont les études rationnelles, qui conviennent à l'homme in via, faisaient partie intégrante, par opposition à la vision que l'homme doit atteindre in patria.

L’hérésie de David de Dinant, un contemporain d'Innocent III, dont la doctrine fut condamnée en 1210, est d'une tonalité assez différente de celle d'Amaury d'après les maigres renseignements conservés par Albert le Grand et saint Thomas : ce qui l'a conduit à admettre une unité parfaite entre les trois réalités qu'il distingue d'abord : la matière, l'intelligence (noys) et Dieu ${ }^{530}$, ce sont visiblement des principes aristotéliciens, p209 et, plus particulièrement, empruntés aux chapitres V et VI du traité De l'Ame. En premier lieu, il tire, du fond commun des idées, ce principe que Dieu est simple et que la matière est simple : la simplicité du premier était un truisme, celle de la seconde ressort du fait qu'elle est définie comme un élément irréductible du composé ${ }^{531}$. D'autre part, on sait que, selon Aristote, dans la connaissance des choses simples, non composées de matière et de forme,

529 Dans HauréAu, XXIV, II, p. 83 sq.

530 Duhem, XV, V, p. 252, fait remarquer que ce principe se trouve dans la Source de Vie d'AVICEBRON.

531 Dans un ouvrage dont le titre De tomis rappelle celui du livre de Jean Scot. Cf. SAINT Thomas, Sup. Sent., II, dist. XVII, qu. 1. 
le connaissant est identique au connu ; par conséquent l'Intelligence, qui perçoit Dieu et la matière, est identique à Dieu et à la matière ${ }^{532}$. Enfin, il est assuré que, entre choses du même genre, il y a un principe commun et que la distinction ne peut venir que de formes distinctes qui se surajoutent à lui ${ }^{533}$; il faut donc que des choses distinctes ne soient pas simples, mais composées; donc Dieu, la matière et l'Intelligence, étant simples, sont identiques. Telle est la série des raisonnements qu'on peut reconstituer en partant des données de saint Thomas et d'Albert. Cette doctrine n'est pas plus un panthéisme qu'un matérialisme ; elle admet l'existence d'un genre universel qui n'est pas plus Dieu que l'intelligence ou la substance ; c'est plutôt un monisme qui, poussé à la rigueur, rendrait inintelligible la production d'une diversité quelconque ou en ferait une apparence incompréhensible ; c’est ce que dit Albert : «Toute diversité provient des accidents et des propriétés adventices ; nulle diversité ne vient de la substance ni de la matière ${ }^{534}$. » De ce monisme parménidien, qu'Albert rattache d'ailleurs aux idées de Xénophane d’Élée, la conséquence était de supprimer p210 tous les dogmes chrétiens, et la base même de la vie chrétienne, la croyance à la chute et à la rédemption : l'hérésie purement dogmatique comptait peu à côté de ce bouleversement.

${ }^{532}$ Albert, De causis, I, I, 1 ; SAINT Thomas, Contra Gent., liv. I, ch. XVII.

533 Albert Le Grand, Summa theologica, pars I, tr. II, quest. 72, membre 4, art. 2, et Summa de creaturis, pars II, quest. 5, art. 2.

${ }^{534}$ Metaphysica, liv. I, tr. IV, ch, vII. 


\section{Chapitre III}

\section{L’APOGÉE DE LA PHILOSOPHIE ARABE}

Entre l'Islam et la philosophie grecque, les rapports étaient tout autres qu'entre christianisme et philosophie : il n'y a, dans l'Islam, ni cette dogmatique compliquée qui emploie des notions néoplatoniciennes, ni une Église qui surveille les hérétiques et dirige, par les sacrements, la vie spirituelle de l'homme ; le philosophe n'est pas nécessairement un clerc, et le théologien n'est pas nécessairement philosophe. Le conflit est donc moins à l'intérieur de la religion qu'il n'est entre l'Islam, d'origine arabe, et les courants de pensée qu'il n'a ni produits ni entretenus et qui restent très vivants dans les vastes régions où il se répand. Tantôt l'autorité accueille bien les philosophes, tantôt l'Islam se défend contre eux. Il ne faut pas d'ailleurs se figurer ces philosophes, pas plus dans l'Islam qu'en Occident, comme des libres penseurs, réclamant les droits de la raison ; c'est par suite d'une confusion qu'Averroès put devenir, quand ses œuvres eurent passé en Occident, le type du libre penseur. Tout comme Avicenne, il prétend penser dans les cadres de l'Islam.

I.

AVICENNE.

p212 Avicenne (Ibn-Sîna) (980-1036) a bien précisément tous les caractères du philosophe musulman : il est d'origine persane ; il naît à Bokhara, dont son père est gouverneur ; de profession, il est médecin, et son Canon de Médecine est longtemps resté classique en Europe ; lui-même, il est vizir à Hamadan, puis à Ispahan. Il ne faut pas chercher beaucoup d'originalité chez lui : la plupart des thèses qu'il expose l'ont été par Al Farâbi. Au reste il n’y prétendait pas. Au début 
d'Al Schifâ (la Guérison), sorte d'encyclopédie philosophique, résumé dans Al Nadjah (la Délivrance), il fait cette déclaration caractéristique : le péripatétisme qu'il y expose n'est pas la vérité tout entière : cette vérité, nous dit-il, est contenue dans sa Philosophie orientale. Cela suppose qu'il y a comme différents niveaux de l'esprit auxquels la vérité apparaît de plus ou moins près. C'est à un de ces niveaux que s'est placé Aristote, et il s'agit donc surtout d'exposer fidèlement sa pensée ${ }^{535}$.

Cet aristotélisme est mis dans les cadres du néoplatonisme : vaste hiérarchie, stable et fixe, allant de Dieu aux êtres sublunaires, en passant par les cieux et leurs intelligences motrices, et faisant voir la destinée de l'âme humaine dans un retour vers les Intelligences dont elle est issue. Dieu, être nécessaire et unique parce qu'il est nécessaire, est une Intelligence où s'identifient le sujet, l'objet, et l'opération par laquelle le sujet appréhende l'objet. Étant principe de toutes choses, il connaît toutes choses dans leur singularité, même les choses variables et corruptibles, mais non pas ${ }_{\text {p213 }}$ sous leur forme corruptible ${ }^{536}$. Il est aisé de reconnaître, en ce Dieu, un composé du Dieu d'Aristote (la Pensée de la pensée), et de l'Intelligence des néoplatoniciens qui renferme les modèles éternels des individus. Avec Plotin, Avicenne refuse à Dieu toute autre action qu'une action nécessaire ; la volonté réfléchie est au-dessous de sa perfection ; car pareille volonté suppose que l'on tend vers quelque chose que l'on ne possède pas; elle implique imperfection ${ }^{537}$; pas non plus de providence singulière s'exerçant en vue de chacun de nous. Ajoutons ce principe, également platonicien, que tout effet produit est inférieur à la cause qui l'a produit, et nous verrons se dessiner, à partir de Dieu, la série hiérarchique des êtres issus nécessairement l'un de l'autre : intelligences ${ }^{538}$, âmes, corps célestes incorruptibles, corps corruptibles, dont chacun n'est pas fait, comme on le prétend parfois, en vue de celui qui le suit, mais est une conséquence nécessaire de celui qui le précède. L’éternité du monde est une suite de cette thèse : « Il y a une preuve rigoureuse que

\footnotetext{
535 MunK, CXXVIII, p. 352 sq.

536 DUHEM, XV, t. IV, p. 430.

537 DUHEM, p. 436.

538 Le mode de production da' intelligences motrices et des cieux est lt même que chez Al Farâbi.
} 
les cieux sont incréés, dit Avicenne, c’est leur incorruptibilité »; mais comment accorder cela avec la thèse coranique du Dieu créateur? «Ce qui est enseigné dans l’Écriture, répond Avicenne, veut dire seulement qu'ils ne sont pas la cause de leur existence, mais que la cause de leur existence les a précédés, à savoir leurs intellects immatériels ; si, dans l'Écriture, il est question d'antériorité dans le temps, c'est une remarque pour ceux qui avent comprendre. Il est dit, dans le Coran, que le trône de domination est avant toutes les choses existantes, c'est-à-dire que leur cause était et est plus sublime qu'elles ${ }^{539}$. »

Dans cette chaîne d'êtres nécessaires, il faut distinguer la nécessité

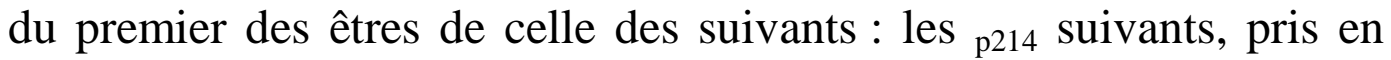
eux-mêmes, sont simplement possibles, et ils ont besoin d'un autre être qui les fasse exister d'une manière actuelle. C'est le grand principe de la métaphysique d'Aristote: "Aucun être en puissance ne peut passer à l'acte sinon sous l'influence d'un autre être déjà en acte, " ce qui suppose un acte pur au sommet de la hiérarchie ${ }^{540}$. L'acte pur est devenu l'être nécessaire, et l'être en puissance, le possible. Si l'on ajoute, avec le néoplatonisme, que l'être nécessaire agit aussi d'une manière nécessaire, on en conclura que l'être qui, de possible, devient existant sous son influence, est lui-même nécessaire, mais d'une nécessité dérivée. Comme le dit Algazel, dans son exposé de la philosophie: "Ce mode d'existence auquel correspond cette question : Est-elle ? est un accident de ce qu'est la chose elle-même, c'est-à-dire de ce dont on demande : Qui est-elle ? Or tout accident est un effet produit ${ }^{541}$. » De là résulte que l'être premier dont l'existence est nécessaire par elle-même est incomparable avec les êtres qui tiennent de lui l'existence : ce qui revient en somme à l'affirmation du principe de causalité et de l'existence d'une cause première.

Cette dualité entre le possible et l'existant n'est pas du tout, comme il le paraît à Duhem ${ }^{542}$, la dualité entre l'essence et l'existence : le cheval possible n'est pas même chose que l'équinité. Le sujet du possible est en effet lui-même existant en tant qu'il a reçu

\footnotetext{
539 WORMS, dans BAUEMKER, II, t. III, p 30.

540 DUHEM, XV, t. IV, p. 477.

541 Cité par DuHEM, t. IV, p. 479.

542 Ibid., p. 482-485.
} 
l'existence d'autre chose que soi ; le possible est défini d'une manière purement négative, ce qui n'est pas par soi : tout au contraire, une essence, l'animal pris en soi, est une nature positive et existante en Dieu ; " son existence est proprement appelée existence divine (esse divinum) ; en effet la cause qui fait qu'une chose est ce qu'elle est provient de la représentation de Dieu ${ }^{543}{ }^{\prime}$.

L'action qui fait passer un possible à l'existence peut se ${ }_{\text {p215 }}$ produire éternellement, comme dans le cas des intelligences motrices et de leur sphère : c'est cette action éternelle, passage du non-être à l'être, qui est proprement la création, puisqu'elle ne suppose nulle matière préexistante : chez Avicenne, contrairement à la doctrine chrétienne, la création ne peut être qu'éternelle ; et en revanche le passage du possible à l'être, qui commence et se termine dans le temps, est non pas création mais génération : la génération suppose, elle, une matière préexistante, et ce qui explique le caractère temporaire de cette action, c'est que la matière est plus ou moins bien disposée à la recevoir. Dans le néoplatonisme arabe, en effet, la cause première et les causes créées qui dépendent d'elles, intelligences motrices et cieux, agissent immuablement d'une action éternelle, comparable à un rayonnement; et les essences qui sont en Dieu sont toujours prêtes à produire leur plein effet. Ces causes ne sont pas comme des volontés qui prendraient à un certain moment la décision d'agir : "Leur but n'est pas de produire quelque chose d'inférieur à elle, mais d'être elles-mêmes dans la plus grande noblesse et dignité possible ${ }^{544}$. " Mais la matière doit être préparée à la recevoir. Pour qu'un être vivant existe par exemple, il faut une mixtion déterminée d'éléments qui, une fois préparée comme il faut, accueillera telle âme spécifiquement et même individuellement déterminée ${ }^{545}$.

Resterait à voir de quelle façon les choses sublunaires, composées de matière et de forme, émanent des cieux, comme les cieux ont éma-

543 DUHEM, t. IV, p. 484.

544 Liber aphorismorum Avicennae de anima, § 23.

545 Ibid., § 6: «Toutes les fois qu’il se produit dans la nature un complexe convenant à une âme, alors l'âme arrive ». Cf. Compendium de anima, ch. III, toute âme arrive $a b$ extra, d'où ne suit pas d'ailleurs la possibilité de la métempsychose, à cause de la proportion parfaite de chaque corps à chaque âme (Aphor., § 22). 
né de la cause première. Car matière et forme ne peuvent être causes l'une de l'autre, et, d'autre part, elles sont inséparables et doivent venir d'une même cause. En p216 considérant les éléments dont tout est composé, il faudra dire qu'il y a en eux quelque chose d'un, qui est la matière, et une diversité de formes : au gré d'Avicenne, on aura suffisamment expliqué leur origine lorsque l'on aura déterminé ; dans les cieux d'où elles doivent émaner, quelque chose d'un et d'identique, qu'on nommera pour cette raison cause de la matière, et quelque chose de divers, qu'on appellera cause des formes. Ce qui est identique en tous les cieux, c'est le mouvement circulaire ; cette chose identique produira un effet un par l'intermédiaire de la dernière des Intelligences ; « de cette Intelligence, par l'effet de l'accord des mouvements célestes, découle une certaine chose (la Matière) dans laquelle toutes les formes du monde inférieur se trouvent inscrites d'une manière passive ; » et là diversité des formes dérive aussi de cette Intelligence avec le concours des divers corps célestes dont chacun imprimera sur la matière une forme différente. Bref, Avicenne accommode le fatalisme astrologique avec la théorie de l'émanation.

Dieu, le ciel créé éternellement et tout immatériel, une région sublunaire faite d'êtres composés de forme et de matière, et, partant, soumis à la naissance et à la corruption, tel est le monde d'Avicenne. Dans ce monde, l'âme humaine occupe une certaine place, d'où résulteront la nature et les limites de sa connaissance. La connaissance qui convient à l'âme est certainement autre que les sensations ; pourtant, à cause de son rang dans la hiérarchie, elle ne peut (contrairement aux intelligences séparées) connaître les intelligibles que par les sensibles : séparée du corps, elle pourra sans doute connaître sans cet intermédiaire, comme, déjà actuellement, l'homme connaît dès l'enfance les principes premiers sans l'aide des sens ; alors seulement, elle pourra connaître son essence : « Ce qu'elle imagine actuellement n'est pas sa quiddité ni son essence, ce n'est qu'un objet des sens ». D’une manière générale, la connaissance des essences est refusée à l'âme ${ }_{\text {p217 }}$ humaine ; elle peut en revanche connaître des " propres ", et, par eux, elle est capable de raisonner sur des réalités dont elle ignore la nature. Par exemple, elle sait, de l'être premier, qu'il est nécessaire, et elle peut par raisonnement en conclure qu'il est un, et tous ses autres attributs; nous ne connaissons pas pour cela « celui à qui il appartient d'être par soi ». De même de la substance, nous savons 
qu'elle est l'être qui n'est pas en un sujet ; du corps, qu'il a trois dimensions ; de l'animal, qu'il possède la puissance de connaître et d'agir ; mais d'aucun de ces êtres nous n'atteignons l'essence, pas plus d'ailleurs que celle des cieux ni des éléments. Le savoir de l'âme reste donc à la superficie : " l'être divin » de l'essence nous est caché, et nos raisonnements ne portent que sur des caractères abstraits et détachés des choses ; dans la définition, toujours composée, notre intelligence divise en parties ce qui ne l'est pas.

Il faut tenir compte de cette place et de cette capacité limitée de l'âme, lorsque l'on étudie la doctrine de la connaissance intellectuelle, qu'Avicenne, à son tour, tire du De anima d'Aristote. L'âme raisonnable, que l'on appelle aussi intellect matériel, ou en puissance, ou possible, est la capacité d'appréhender les intelligibles ; cet intellect se trouve dans toute l'espèce humaine, et il est par lui-même, comme la matière, vide de toute forme. Les formes arrivent en lui de deux manières : soit qu'elles dérivent d'une émanation divine, sans l'aide de l'instruction ni des sens, et c'est ainsi qu'arrivent les premiers principes communs à tous, tels que : le tout est plus grand que la partie ; soit au contraire qu'elles viennent des sensibles par une opération d'abstraction. Considérons à part ce second mode d'acquisition : son but est de dégager des sensibles les universaux qui se rangent sous les cinq rubriques de Porphyre et à partir desquels on peut définir et raisonner sans plus avoir recours aux sens : dès lors « l'intelligence agit par soi, en dépouillant les formes de la matière chaque fois qu'elle l'aura voulu » ; l'intelligence, pensant actuellement les ${ }_{\mathrm{p} 218}$ formes, est l'intelligence en acte, identique, selon le mot d'Aristote, à l'objet qu'elle pense. Mais l'intellect en puissance ne devient ainsi intellect en acte que sous l'influence d'une Intelligence active et impérissable qui est comme une lumière qui éclaire les données sensibles conservées par l'imagination.

Telle est la seconde voie normale de la connaissance intellectuelle ; l'intelligence en puissance reçoit, des sens, le contenu de sa connaissance, et, de l'Intellect actif, le pouvoir d'abstraire : remarquons à quel point elle diffère de la connaissance infuse des premiers principes donnée par la première voie, connaissance dont nous avons marqué les limites et l'insuffisance. Avicenne admet que ces deux voies se disent de l'âme encore attachée au corps. Il pense en revanche que l'âme parfaite, en sortant du corps, peut acquérir de nouvelles perfec- 
tions par une union plus intime avec l'intelligence agente : dès cette vie, il voit, dans le songe, l'expérience d'un état où cette séparation a lieu. Or, tandis que, dans la connaissance intellectuelle ordinaire, l'on commence par l'image pour aboutir à l'intelligible, dans le songe, la marche est inverse : l'intellect agent déverse d'abord sur notre intellect possible des intelligibles qui se déversent de là sur notre faculté imaginative, d'où le caractère prophétique des images du rêve. Les songes témoignent donc de la communication directe de notre âme avec l'intellect agent. Les songes nous donnent ainsi l'idée de ce que peuvent être les âmes des planètes : en celle-ci aussi il y a une connaissance imaginative représentant tout ce qui arrivera, connaissance qui émane de l'Intelligence motrice correspondante. Une connaissance de ce genre est exactement l'envers de la précédente, et, tandis que, dans la précédente, il faut préparer l'âme en n’y admettant que les images voulues, le prophète peut et doit se livrer à son imagination.

Le progrès, pour Avicenne, n'est donc pas dans une ascension poursuivie toujours dans le même sers, mais bien dans ${ }_{\text {p219 }}$ un renversement de sens, la connaissance discursive qui vient d'en bas étant remplacée par l'inspiration qui vient d'en haut. Ajoutant que, dans la description de la connaissance abstraite à partir des sens, Avicenne a cherché, en s'inspirant du De anima, à indiquer les facultés intermédiaires entre les sens et l'intelligence, chacune marquant un nouveau stade vers l'abstraction : la «formative » ou fantaisie, qui, retenant la forme sensible, la dégage partiellement des conditions de lieu, de quantité, de mode, sorte de degré embryonnaire de la mémoire ; la « cogitative » ou imaginative, consistant en un travail confus de séparation ou de groupement, sorte d'associations d'images qui ne sont pas encore des universaux ; "l'opinion » qui groupe en jugement les notions de la cogitative, tel que par exemple ce jugement qui fait que la brebis a peur du loup ; la "mémoire » qui conserve les jugements élaborés par l'opinion. Ces facultés, Avicenne les fait dépendre de conditions physiologiques, et il les place naïvement dans les cavités du cerveau de l'avant à l'arrière. Elles accomplissent un travail préparatoire indispensable pour l'abstraction qui en est la cause finale. 


\section{II.}

\section{Al GaZAli.}

La conception de l'univers, commune à Al Farâbi et à Avicenne, trouva dans le monde arabe deux contradicteurs passionnés, l'un, Al Gazali, parce qu'elle nie les vérités religieuses, l’autre, Ibn Roschd, parce qu'elle est infidèle à Aristote, qu'il prétendait suivre.

Comme Avicenne, Al Gazali, né dans le Khorasan en 1058, est d'origine persane ; et le monastère soufi qu'il fonda, à la fin de sa vie dans son pays natal, après avoir enseigné à Bagdad, Damas, Jérusalem et Alexandrie, montre qu'il fut, dans p220 sa lutte contre Avicenne, moins le représentant de l'Islam orthodoxe que celui d'une mystique proprement orientale et persane qui ne pouvait s'accommoder d'un péripatétisme d'origine grecque. La Destruction des philosophes, ouvrage dans lequel il commence par un exposé de la philosophie péripatéticienne uniquement destiné à préparer l'attaque, s'achève par une longue argumentation critique. A la Destruction devait succéder un autre ouvrage, intitulé les Bases de la croyance, où Gazali aurait exposé ses propres idées. En son absence, il est difficile de connaître Gazali sous un autre aspect que sous celui d'un critique : tel, comme Averroès ${ }^{546}$, a nié la réalité de ce scepticisme ; tel autre, comme Ibn Tofaïl, affirme chez lui l'existence d'une doctrine ésotérique, qu'il aurait communiquée à peu de personnes. Averroès l'accuse de n'avoir attaqué les philosophes que pour complaire aux théologiens et se garantir de leur haine. Il s'est donné lui-même pour un sceptique qui doute de la vérité des sens parce qu'ils sont contredits par la raison (par exemple la grandeur visible du soleil apparaît illusoire à l'astronome), et des principes de la raison parce qu'ils pourraient aussi bien être contredits par des principes inconnus ${ }^{547}$.

Sa critique est en tout cas d'un théologien qui veut défendre les dogmes de l'Islam. Il s'agit avant tout, pour Gazali, de sauver la souveraine indépendance de Dieu qui était compromise par l'idée d'un monde complètement nécessaire : d'où résultait la thèse de l'éternité du monde, qui faisait de la création une émanation nécessaire. Gazali

\footnotetext{
546 Destruction de la Destruction, édit. de 1552, fol. 17, col. 3, 1. §5. Cf. WormS dans BAUEMKER, II, t. III, p. 51.

547 Carra de Vaux, p. 45.
} 
y fait voir le résultat d'affirmations tout à fait arbitraires ; dire que le monde, étant éternellement possible, existe éternellement parce que le possible ne serait pas tel s'il n'avait un sujet d'attribution, c'est ne pas voir que le possible n'est pas un ${ }_{\text {p221 }}$ attribut réel des choses, mais un simple jugement de notre intelligence, le jugement qu'une chose dont nous avons l'idée ne trouve aucun obstacle à son existence. Dire que, si le monde était créé dans le temps, il faudrait attribuer à Dieu une volonté d'indifférence, ne prouve rien, puisque, en fait, il faut bien lui donner une pareille volonté, par exemple dans la détermination du mouvement diurne qui n'a pas plus de raison pour s'opérer de l'Orient à l'Occident que dans le sens inverse. Dire que le temps est infini et, par conséquent, aussi le mobile dont le mouvement est mesuré par lui, c'est céder à la même imagination que condamnent les philosophes lorsqu'ils disent que l'espace infini que nous concevons au delà du monde est imaginaire, c'est, avec la régression à l'infini des causes, nier Dieu, c'est enfin admettre le nombre infini qui n'est ni pair ni impair.

Gazali reproche aux philosophes d'avoir mesuré la réalité aux règles de leur raison : ils abusent de la notion de la simplicité de Dieu pour nier en lui tout attribut qui ne soit pas identique à son essence. Ils veulent que l'âme soit entièrement spirituelle et dégagée de tout corps, à cause de la notion tout à fait arbitraire qu'ils se font du corps; le considérant comme divisible à l'infini, ils disent qu'il ne peut être le sujet de la connaissance, puisqu'elle est indivisible ; mais l'atomiste n'admet-il pas de corps indivisibles ? Rien ne prouve que l'âme s'oppose au corps, comme un sujet qui peut admettre les deux contraires (science et ignorance), à un sujet qui ne peut en admettre qu'un ; que l'intelligence s'oppose aux sens comme une connaissance qui se saisit elle-même parce qu'elle est sans organe, à une connaissance qui, opérant par des organes, s'ignore elle-même. Enfin les philosophes veulent qu'il y ait un lien nécessaire entre la cause et l'effet ; or affirmer la cause n'est pas affirmer l'effet, puisque cause et effet sont deux choses distinctes créées par Dieu à la suite l'une de l'autre : la régularité de leur liaison dépend de la ${ }_{\text {p222 }}$ volonté qui les crée et qui est tout à fait libre de cesser de répéter la liaison.

Gazali oppose au monde des philosophes un monde où tout dépend de la volonté absolue et absolument imprévisible de Dieu ; il introduit les notions de liberté, d'indifférence et d'atomisme ; il met partout, 
dans le tissu même des événements, la discontinuité, reprenant ainsi les idées des Motekallemîn. En pays d'Islam, au XI ${ }^{\mathrm{e}}$ siècle, la science astronomique se lie d'ailleurs fort souvent à l'affirmation d'un naturalisme athée, qui détermine avec nécessité tous les événements : «Ce bol renversé qu’on nomme le ciel, écrit le poète Omar Khayyâm (mort en 1121), sous qui rampe et meurt la race des hommes, ne levez pas les mains vers lui comme un appel ; car il n'est pas moins impuissant que nous ne sommes. Ils (les astres) ont pétri le dernier homme avec le limon primitif, serrant en lui le grain des futures moissons; et le premier matin de la création, ils ont écrit ce que dira le jugement, définitif ${ }^{548}$. " Ce nécessitarisme, les Motekallemîn avaient pensé qu’on pouvait s'y soustraire en opposant à l'image continuiste de l'univers une image discontinuiste, où la matière se divise en atomes et le temps en instants indivisibles et discontinus. Ainsi seulement, supprimant la nécessité inhérente aux choses, ils arrivaient à tout soumettre à la volonté arbitraire d'un Dieu personnel ${ }^{549}$.

Table des matières

III.

\section{AVERroes.}

Au cours du XII ${ }^{\mathrm{e}}$ siècle, c'est l'Espagne qui devient le centre intellectuel de la civilisation musulmane. Les califes espagnols, p223 comme ceux d'Orient, favorisent les médecins, les mathématiciens, les astronomes. Le plus connu des philosophes de l'époque est Averroès, à cause de l'influence que ses commentaires d'Aristote ont exercée, à partir du siècle suivant, sur l'Occident chrétien. Mais, à côté de lui, il en est d'autres qui maintiennent, sous des formes parfois originales, la tradition du platonisme arabe.

Avempace (Ibn Badja), mort en 1138, soutient la métaphysique cosmologique, que nous avons vu se développer chez Farâbi et Avicenne : hiérarchie des choses spirituelles, depuis les formes des corps célestes, complètement indépendantes de la matière, jusqu'aux formes

\footnotetext{
548 Averrok̀s nous dit que, dans sa Philosophie orientale, Avicenne identifiait Dieu avec la sphère céleste. Cf. Munk, CXXVIII, et IBN TOFAÏL.

549 R. Berthelot, L'Astrologie et la Pensée de l'Asie (RMM, t. XLII, 1935, p. 211-213).
} 
présentes dans le sens commun et la mémoire, en passant par l'intellect émané ou actif, qui donne les formes aux choses matérielles, et par ces formes elles-mêmes qui sont engagées dans la matière, voilà une représentation bien connue de l'univers spirituel. Ce qui intéresse surtout Avempace, ce sont les conditions du mouvement ascendant par lequel l'âme, partie du sensible, s'élève jusqu'aux formes dégagées de la matière : la principale, c'est d'être, selon un mot emprunté aux Soufis, un "étranger»; et, s’il appelle l'ouvrage où il décrit l'ascension de l'âme le Régime du Solitaire, c'est qu'il suit l'antique tradition plotinienne de la solitude du mystique. Le solitaire doit se séparer de ceux qui ne sont arrivés qu'aux degrés inférieurs ; l'animal perçoit naturellement les formes sensibles et celles qui se rattachent à ses besoins vitaux (le buvable, le mangeable) ; l'homme perçoit, par la réflexion, les formes qu'il abstrait du sensible ; plus haut encore, et au-dessus de la démonstration, il connaît la vérité par des prophéties et par des songes, émanés de l'intellect actif ; toutes ces perceptions, qui sont au niveau animal et humain, servent à la vie animale ou à la vie sociale, dans ces états imparfaits, où la justice, la médecine et la morale cherchent à faire équilibre aux maux de l'humanité. Le solitaire se sépare de ceux qui restent à ce niveau et dont ${ }_{\text {p224 }}$ le contact ne peut que le dégrader ; il arrive jusqu'aux intelligibles immatériels, qui sont en même temps les intelligences séparées ; à cette hauteur, perception et objet perçu coïncident ; connaissant l'intelligence séparée, il devient l'une d'entre elles ; d'humain, il devient divin. Cette ascension est décrite, à la manière arabe, en des termes de matière et d'acte ; l'intellect en acte, qui a perçu les formes matérielles, est la matière de l'intellect acquis, capable de percevoir les formes intelligibles séparées, et matière, lui-même, de l'intellect actif, où ces formes existent dans l'unité ${ }^{550}$.

On rencontre un mysticisme du même genre chez Abubacer (Abu Bekr Ibn Tofaïl), un médecin de la cour des califes de Grenade, qui profita de son crédit pour présenter à la cour Averroès. Ce médecin est, comme Avempace, un amateur de philosophie platonicienne ; il est affilié à une secte mystique, la secte de la clarté (Ischrâq), dont les doctrines ont leur pendant dans la Perse de la même époque, chez Su- 


\section{Émile Bréhier \\ La philosophie du Moyen âge}

hrawardi, mort en $1191^{551}$. Il accentue les idées d'Avempace en écrivant une sorte de roman mystique, Le vivant, fils du vigilant, dont le héros est complètement à l'abri de toute influence sociale : il le fait naître de la terre et vivre dans une île déserte. Il y a, comme le fait remarquer Munk, une assez étrange ressemblance, entre ce roman et l'hypothèse condillacienne de la statue, et plus encore, dirons-nous, avec les imaginations de Buffon sur la formation de l'esprit du premier homme ; mais l'orientation est tout opposée : tandis que nos penseurs du XVIII ${ }^{\mathrm{e}}$ siècle font tendre leur solitaire vers la vie sociale et la communauté de la raison, Abu Bacer, après l'avoir retranché de la société des hommes, ne le fait passer par la nature que pour l'en séparer finalement ; selon les degrés bien connus de l'ascension, le solitaire isole d'abord, dans les choses sensibles, les formes de la matière ; de ces formes, connues par abstraction, p225 il passe à l'être qui a produit ces formes, puis de cet être à l'agent suprême ; dans cette montée, il se détache d'abord des sens, puis il se représente les intelligibles par des images, et il voit Dieu non en lui-même, mais à travers les intelligences des sphères, dans lesquelles elle apparaît ${ }^{552}$.

Ces philosophes acceptent donc de la tradition soufiste et néoplatonicienne, et le but et le mécanisme : union à Dieu et hiérarchie des êtres. C'est cette image qui est transformée par Averroès, tandis que, en même temps que le retour à Aristote, naît, en Espagne, un mouvement mystique affranchi des images cosmologiques, que le néoplatonisme y liait.

Averroès (Ibn Roschd) est né à Cordoue en 1126 ; son père et son grand-père y étaient juges, et il y exerça les mêmes fonctions, après avoir été juge à Séville. Il eut longtemps toutes les faveurs des califes ; médecin, en 1182, du calife Yousouf, puis, en 1184, de son successeur Al Mansour, il fut en 1195 la victime d'une violente réaction de la part des orthodoxes qui l'accusaient d'abandonner la foi de l'Islam pour la philosophie païenne ; il fut exilé au Maroc, où il mourut en 1198, et l’on brûla ses écrits.

Averroès a été appelé en Occident le Commentateur ; et en effet ses écrits philosophiques se composent d'un Grand Commentaire

551 M. Horten, Die Philosophie des Islam, p. 120 sq.
552 Munk, Mélanges de philosophie juive et arabe, p. 410. 
d'Aristote où, selon la vieille méthode des commentateurs grecs, il explique le texte phrase à phrase, en y ajoutant des discussions théoriques, un Commentaire moyen, et des Paraphrases, où il expose seulement le sens. Son dessein est de revenir, contre les interprétations d'Al Farâbi et d'Avicenne, au sens authentique d'Aristote, et, d'autre part, de soutenir la philosophie contre les attaques de Gazali, contre qui il a écrit un livre particulier : la Destruction des Destructions. Dans quel esprit écrit-il ce Commentaire, c'est ce que nous font voir ces lignes au sujet de l'opinion du De anima ${ }_{\text {p226 }}$ sur la connaissance intellectuelle : « Tous ceux qui ont cette opinion ne l'ont que d'après Aristote ; et en effet la question est si difficile que, si l'on n'avait retrouvé les paroles d'Aristote, il aurait été sans doute impossible de rencontrer cette solution. Car un homme tel qu'Aristote est une règle dans la nature et un exemplaire que la nature a créé pour montrer la suprême perfection où arrive l'homme revêtu d'un corps. » Il est vrai qu'il avait écrit quelques lignes avant: "Si même ce n'était pas l'opinion d'Aristote, il faudrait croire que c'est l'opinion vraie. » Il ne s'agit pas chez lui d'une foi aveugle en Aristote, mais d'une foi raisonnée.

Or, Averroès trouve chez Avicenne une foule d'opinions contraires à celles d'Aristote : il s'agit surtout de la théorie de la création ou émanation où Avicenne explique, avec Al Farâbi, comment de l'Un naît le multiple : on se rappelle qu'il trouve la composition dans la Première Intelligence en tant qu'elle a pour objet, d'une part, ellemême comme possible, et, d'autre part, Dieu comme la cause par laquelle elle existe nécessairement. Averroès remarque que cette prétendue composition est contraire au principe que, dans la connaissance intellectuelle, intelligence et intelligible sont identiques; il ajoute d'ailleurs que toutes ces difficultés viennent non pas d'Aristote, mais de philosophes qui ne voulaient pas que le bien et le mal et, en général, les opposés dérivassent d'une cause unique. Quant à cette thèse que chaque intelligence est possible par elle-même et nécessaire par sa cause, Averroès estime que cette prétendue possibilité n'en est point une, puisque la cause qui produit l'intelligence agit nécessairement et immuablement ${ }^{553}$. Avicenne procède comme si nécessaire et possible étaient des attributs accidentels à la manière du blanc et du noir ; or,

553 Cf. Munk, CXXVIII, p. 352 sq. 
« nécessaire ne désigne pas un attribut ajouté à l'être, tel qu'il est en dehors de l'âme, mais un attribut ${ }_{\text {p227 }}$ compris dans l'essence de l'être nécessaire et qui n'est pas ajouté à sa substance ${ }^{554}$ ».

A cette vue, il veut substituer " celle d'Aristote et de Platon, qui est le terme auquel peut parvenir l'intellect humain ». Les traits essentiels de cette conception sont exposés au chapitre XXI du livre III de la Destruction. Son premier principe est que les cieux sont des corps vivants et connaissants, puisque, comme les êtres vivants et intelligents que nous connaissons directement ici-bas, nous les voyons animés de mouvements déterminés et effectuant des opérations déterminées sur les êtres sublunaires; les saisons, qui règlent les générations et les corruptions, dérivent en effet du mouvement du soleil sur l'écliptique ; et le mouvement diurne de la sphère des fixes règle les jours et les nuits. Le deuxième principe, c'est que ces mouvements ordonnés nous renvoient à une origine supérieure : "Lorsqu’on aura considéré ces grands corps animés, raisonnables et doués de volonté qui nous conservent, lorsque l'on aura vu aussi que la providence qu'ils exercent sur les êtres sublunaires n'est pas nécessaire à leur existence, l'on comprendra que ces mouvements leur ont été ordonnés... Or, l'être qui ordonne est autre qu'eux, et il est nécessairement incorporel ; car, s'il était un corps, il serait l'un d'entre eux... ; et c'est par ordre et par crainte de celui qui les commande qu'ils sont poussés à conserver les choses sublunaires; celui qui les commande, c'est Dieu »; de plus, chaque planète, ayant un mouvement particulier, « obéit à un maître particulier (son Intelligence motrice), qui lui a été donnée par le maître de toutes choses ».

Ainsi, ce qui frappe Averroès, c'est cet ordre statique du monde qu'expose Aristote à la fin du livre A de la Métaphysique, «l'ordre qu'un général met dans une armée ou un gouvernement dans une cité ». Partant de là, il a essayé de résoudre ${ }_{\mathrm{p} 228}$ le grand problème de l’origine de la multiplicité que, selon lui, Avicenne n’a pas résolu. Avicenne partait de ce principe que d'une chose émane une seule chose: c'est là une opinion probable, venue de l'observation des agents naturels, que l'on généralise à tort, et qui rend toute multiplicité impossible. " A cette thèse, dit Averroès, s’oppose, de notre temps,

554 Destruction des Destructions, liv. III, ch. XXIII, p. 103, édit. de Venise 1560. 
cette thèse contraire ; du principe premier émanent, dès la première émanation, tous les êtres divers ; et c'est là un sujet de doute pour les hommes de notre temps. " Cette thèse, c'est celle de la création simultanée qu'Averroès n'accepte pas plus que celle d'Avicenne. En revanche la difficulté n'existe pas, pour la secte péripatéticienne, qui, à chaque degré, multiplie les principes de production : les intelligences ont pour principe unique la première intelligence ou Dieu ; la multiplication des corps célestes provient de la matière ; la multiplication des choses sublunaires provient de la matière, de la forme et des corps célestes. Il y a d'une part un être unique, d'où émane une vertu unique, par laquelle tous les êtres sont des êtres uns, mais de cet être émane aussi une multiplicité. "Qu'une chose unique émane d'une chose unique, c'est là la grande erreur des savants ». C'est par suite de cette erreur qu'Avicenne, contre Aristote, a placé Dieu au-dessus de l'Intelligence motrice de la première sphère qui, produisant plusieurs effets (l'âme de la sphère et le moteur de la sphère suivante), doit être multiple. L'erreur d'Avicenne vient de ce qu'il comprend la production d'une intelligence par une autre comme l'action d'un agent: or, l'action de l'agent consiste à faire passer à l'acte ce qui est en puissance dans un patient ; ce n'est pas là le rapport qu'il y a entre des intelligences ; il faut dire plutôt que, par l'ordre commun qu'elles mettent dans l'univers, elles se complètent l'une l'autre, «comme les œuvres des artisans d'un même ouvrage qui reçoivent leur principe l'un de l'autre et s'unissent en vue d'un seul et même art ». Le moteur supérieur est cause du moteur inférieur au p229 sens où «l'intelligible est cause de l'intelligent » ; la perfection de chaque intelligence motrice consiste à comprendre le moteur de l'ordre supérieur. Rien n'empêche en ce cas que le moteur du premier ciel soit en même temps le Dieu suprême, s'il est conçu non comme la cause d'où émane le premier moteur, mais comme la fin qui le règle.

On voit bien ici ce qui oppose Averroès à Avicenne; celui-ci voyait le monde, à la manière platonicienne, comme une série de réalités émanant éternellement l'une de l'autre; Averroès l'imagine comme un concert d'activités réglées par une même fin. Ce caractère se dégage encore mieux de la critique très vive qu'il fait de la théorie avicennienne du dator formarum. Il s'agit ici du mode de génération des êtres dans la sphère sublunaire : d'où vient la forme qui s'ajoute à la matière pour constituer l'être concret ? « Toutes les formes substan- 
tielles, répond Avicenne, viennent d’une forme extérieure séparée, qu'on appelle parfois dator formarum; cette forme est l'intellect agent », qui est la dernière des intelligences motrices, celle de l'orbe de la lune. Selon Averroès, les opinions sur l'origine des formes se classent en deux théories extrêmes, entre lesquelles se trouvent des théories intermédiaires. L'une de ces théories, c'est celle de la latitatio, d'après laquelle les formes existent cachées dans les choses; l'agent ne fait alors que les en séparer : c'est celle d'Anaxagore. La théorie opposée est celle d'après laquelle l'agent crée tout l'être ex nihilo, sans avoir besoin d'une matière sur laquelle il agisse : c'est celle « de la loi arabe et de la loi chrétienne ». Les opinions intermédiaires admettent toutes que rien ne s'engendre de rien et que la génération suppose un sujet auquel vient s'ajouter la forme. Mais les uns admettent qu'un agent extérieur à ce sujet crée la forme et la place dans la matière, que cet agent soit comme chez Avicenne, unique et séparé de la matière, ou qu’il soit multiple et lié en général à la matière, comme dans la génération du semblable par le semblable. Les autres (et c'est là p230 l'opinion réelle d'Aristote) soutiennent que l'agent (par exemple le père dans la génération), sans introduire rien d'extérieur dans la matière, la fait seulement passer de la puissance à l'acte : le feu, en échauffant le corps, n'y introduit pas la chaleur, mais fait en sorte que le chaud en puissance devienne chaud en acte; et de même, engendrer une âme n'est pas placer une âme dans la matière, mais faire passer la vie en puissance (dans la mixtion organique) à la vie en acte : la vie est en puissance dans la semence, à la manière dont la maison est dans l'âme de l'architecte : ce qui est engendré, ce n'est donc pas la forme, c'est le composé de forme et de matière. S'il en était autrement, il faudrait que l'agent créât la forme de rien : et c'est, en effet, ce que disent certains théologiens musulmans qui, attribuant toute forme nouvelle à un unique agent, Dieu, nient que le feu brûle et que l'eau humecte, professant même que l'homme, en remuant une pierre, ne la meut pas en la poussant, mais que cet agent crée le mouvement. « Pour cette raison, conclut Averroès, ils ont nié qu'il y eût de la puissance ; " ils ont nié la notion péripatéticienne caractéristique, celle d'existence en puissance, qui réintroduit dans le monde continuité et intelligibilité. Quant à l'opinion d'Avicenne, Averroès est d'avis qu'il est impossible "que les intelligences séparées donnent quelqu'une des formes qui sont mélangées à la matière ; l'intelligence séparée ne peut être motrice que quant à une intelligence en puissance 
séparée de la matière. » Mais le grand argument d'Averroès, c'est que cette théorie brise l'unité de l'être en faisant venir la forme d'un agent extérieur au sujet : matière et forme existeraient alors, l'une et l'autre, en acte. On voit, ici encore, comment l'aristotélisme est ressuscité contre le platonisme d'Avicenne.

La célèbre théorie des intelligences, qui est un commentaire du chapitre V du livre III du De anima, dérive de la même inspiration : elle consiste à détacher l'intelligence de l'âme, principe du corps vi-

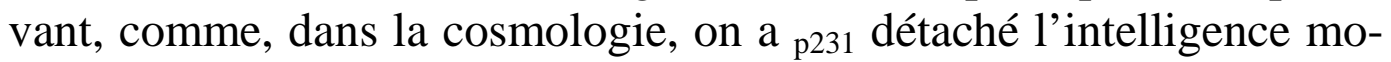
trice de la lune des formes des choses corruptibles ; aussi bien, l'âme n'est-elle qu'une forme du corps vivant ; et « c'est par équivoque que l'intelligence est appelée âme ». Dans toutes les théories grecques et arabes qu'Averroès discute et dans la sienne propre, il y a plusieurs points communs qu'il faut d'abord mettre en évidence : elles supposent toutes que, dans le composé de forme et de matière qu'est la chose sensible, la forme est l'objet propre de l'intelligence, que cette forme ou essence n'est jamais effectivement séparée de la matière et que la connaissance intellectuelle est le résultat de l'opération qu'il en sépare pour la pensée ; cette opération se pratique sur les images des sensibles, gardées en l'imagination ; les intellecta ou formes, qui sont objets de l'intelligence, y sont en puissance, et il s'agit de les faire passer à l'acte. A cette fin, deux conditions sont nécessaires : un intellect agent qui éclaire les images et qui fasse ressortir en elles la forme, à la manière dont la lumière fait ressortir les couleurs; un intellect matériel qui reçoit les formes et dans lequel elles résident d'une façon analogue à celle dont la forme réside dans une matière.

Ces points acceptés, il y a beaucoup de divergences principalement sur la nature de l'intellect matériel et sur une question qui lui est connexe, celle des rapports de la connaissance intellectuelle au moi.

En premier lieu, l'intellect matériel, s’il est nommé ainsi par analogie, n'est ni un corps, puisqu'il doit être capable de recevoir également toutes les formes, et qu'un corps, ayant une essence déterminée, n'en peut recevoir en même temps aucune autre, ni la matière première, puisque les formes qu'il reçoit sont des universaux et qu'il a la capacité de les distinguer l'une de l'autre, ce qui n'est pas vrai de la matière première. Dès lors, on a raison de conclure contre Alexandre d'Aphrodise, qui réduit l'intellect matériel à un organe corporel, à une 
certaine mixtion d'éléments capable de recevoir ${ }_{\mathrm{p} 232}$ l'intellect en acte, et de dire, avec Théophraste et Themistius, que l'intellect matériel est une substance sans génération ni corruption, impassible et simple. Mais la grande difficulté, que résolvait facilement Alexandre et qui se pose à Thémistius et à ses partisans, est celle-ci : puisque l'intellect agent est simple et donc éternel, ainsi que l'intellect matériel ou patient qui en reçoit les formes, il s'ensuit que l'action de l'un sur l'autre donne naissance à un troisième intellect, l'intellect produit, qui doit être lui-même toujours en acte et éternel : on demande alors comment la pensée peut commencer et varier dans l'âme humaine, et comment il peut y avoir, en chaque âme, des intellects spéculatifs (c'est-à-dire contemplant actuellement les formes) différents l'un de l'autre : question difficile, non résolue par Aristote, et au sujet de laquelle Averroès fait cette déclaration : " Je demande aux frères qui lisent mon ouvrage d'écrire leurs doutes, et ainsi peut-être trouvera-t-on la vérité, si je ne l'ai pas encore trouvée. »

La question se décompose en deux : d'abord comment les intellecta speculativa, les formes connues effectivement par l'âme, y sontelles engendrées, puisqu'elles dérivent de l'action d'un agent éternellement identique sur un patient également éternel ? Puis, comment les intellects spéculatifs sont-ils différents selon les individus, alors que l'intellect matériel est le même pour tous ? Sur la première question, Averroès fait remarquer que les conditions auxquelles l'intellect spéculatif pense les formes sont au nombre de deux : elles doivent être reçues par l'intellect matériel pour être intelligibles, mais elles doivent être abstraites des images sensibles pour être vraies, pour correspondre à une réalité ; sous le premier rapport, elles sont éternelles, mais, sous le second, elles sont engendrées. D’où la solution de la seconde question, puisque les images, qui sont la condition de la connaissance, sont individuelles et suivent le sort de l'individu. Thémistius a eu le tort de penser que l'intellect agent c'est nous, et que l'intellect p233 spéculatif n'est rien autre que la combinaison de l'intellect agent avec l'intellect matériel, combinaison qui devrait être éternelle. En réalité, l'intellect matériel est commun à tous les hommes, et c'est pourquoi il y a des principes nécessaires communs à tous ; mais l'intellect spéculatif est corruptible du moins en un sens et pris chez l'individu, bien que, en autre sens, il soit éternel, dans la mesure où l'espèce humaine, prise, à chaque instant, dans la totalité des 
individus, pense actuellement tous les intelligibles : la pensée individuelle de chacun est alors comme une portion accidentellement et momentanément séparée d'une pensée totale. L’intellect matériel n'est pas uni avec nous, comme il l'est avec l'intellect agent; avec l'intellect agent, il est uni par soi ; avec nous, il est uni par son union avec les images sensibles, plus précisément avec celles qui se trouvent effectivement en nous, et ce n'est que par lui que nous sommes unis avec l'intellect agent.

Pour Averroès, il est besoin d'images pour donner un contenu aux intelligibles ; mais ces images ne peuvent pas, à elles seules, faire passer l'intellect matériel de la puissance à l'acte, car elles ne sont ellesmêmes intelligibles qu'en puissance : d'où la nécessité de l'intellect agent. Il est donc clair que, puisque ces images sont liées à notre corps, il ne peut y avoir, après la mort, aucune persistance de notre individualité pensante : seul l’intellect matériel séparé est immortel. Il s'accordait, avec Alexandre, pour nier l'immortalité, mais d'une manière différente ; Alexandre la niait parce que, avec la mort, cessait la mixtion des éléments capable de recevoir l'illumination de l'intellect agent ; Averroès, parce que les conditions auxquelles l'individu peut prendre part à cette illumination, qui est éternelle, cessent de se produire.

Par les conditions qui lui sont nécessaires, l'intelligence de l'homme est toute différente de l'intelligence de Dieu. "Sa science n’est pas comparable à la science humaine ; en un ${ }_{\mathrm{p} 234}$ sens, il ne comprend que lui-même, puisque sa science n'est pas passive ; en un autre sens, il comprend autre chose que lui, puisqu'il est lui-même une science active... ; notre science est causée par les êtres, mais la science de Dieu est cause des êtres ${ }^{555}$. »

Dans la science de Dieu d'une part et la connaissance intellectuelle chez l'homme d'autre part, nous avons les deux limites, supérieure et inférieure, de l'intelligence. Entre ces deux limites s'étage une série de connaissances hiérarchisées. Dans l'état inférieur de connaissance, où nous ne pouvons penser sans images, «la nature est un voile qui nous sépare de Dieu »; mais la perfection de cette connaissance est

555

Destruction, p. 289-a, 292-e. 
d'atteindre l'intellect agent; "dès lors, il faut qu'il y ait, dans l'espèce humaine, quelques individus qui appréhendent cet intellect agent, à savoir ceux qui atteignent la perfection dans les sciences spéculatives $"{ }^{556}$. L'intellect en acte est l'intelligence d'un ordre ; l'intellect agent, qui est son objet le plus élevé, est l'intelligence du même ordre, mais d'une manière plus noble ; l'intellect agent, qui est la dernière des intelligences célestes, celle qui meut l'orbe de la lune, a lui-même, pour objet intelligible, l'intelligence motrice supérieure et ainsi de suite jusqu'au premier moteur ; l'intelligible est ainsi toujours de rang supérieur à l'intelligence qui le conçoit. Il faut ajouter que chaque intelligence ne peut comprendre ce qui est plus noble qu'elle que par analogie et comparaison ; sinon, la chose causée se transformerait en la cause ; ce qu'une intelligence comprend de l'intelligence supérieure ne peut donc être la même chose que ce que celle-ci comprend d'elle-même ${ }^{557}$; l'on arrive, à la limite, à cette science de Dieu, à cette unité simple qui ne comprend qu'une chose simple, qui est son essence.

p235 On voit bien clairement ici toute la tendance de la philosophie d'Averroès : nulle recherche pour expliquer, par voie d'émanation, la diversité, ce qui revient, dans sa pensée, à la nier; l'horreur d'Averroès est grande pour toutes les doctrines qui, avec la continuité, introduisent la confusion ; c'est une des raisons de son antipathie pour les thèses d'Alexandre, qui étaient fort goûtées de son temps et en faveur desquelles Avempace avait écrit un traité ; il y soutenait la continuité entre l'intellect matériel, réduit à être une mixtion d'éléments, et les intelligences séparées; sur quoi Averroès remarque : "C’est là une des causes pour lesquelles nous voyons dans un tel état de corruption les mœurs et les coutumes de ceux qui s'adonnent à la philosophie. » Cette réflexion laisse deviner la portée sociale de sa doctrine, qui, à chaque étage de l'être, introduit un nouveau principe qui le complique, et où la véritable et seule explication est une explication finaliste, la nécessité du maintien d'un certain ordre dans l'univers où se manifeste le désir que toute chose a de Dieu : la connaissance, à son plus bas degré, s'explique ainsi ; si elle consiste à séparer les formes de la matière, c'est que «l'intention de Dieu a été que des 556 De Animae beatitudine, trad. Calo Calonymos, Venise, 1560, p. 356-a.
557 Abrégé de la Métaphysique, traité IV, p. 133-139. 
formes, qui sont éternelles génériquement, comme universaux, atteignissent une forme numériquement une ;... il a attribué aux formes cette grâce de pouvoir parvenir à des formes complètement séparées comme à leur fin ${ }^{558}$ ».

Ainsi l'averroïsme marque une décadence certaine de la philosophie néoplatonicienne et un retour à Aristote en pays arabe : évolution de même sens que celle que nous verrons se produire un siècle plus tard en Occident. Dans son pays même, son œuvre eut peu d'influence. A cette philosophie de commentateur, à concepts durs et arrêtés, s'oppose, en Espagne, à l'époque même d'Averroès, un mouvement de mysticisme ${ }_{\text {p236 }}$ pratique qui ne garde plus rien de la philosophie spéculative.

Dans la seconde moitié du XI ${ }^{\mathrm{e}}$ siècle, Ibn Al-Arîf, d'Almeria, publie un traité mystique intitulé Beauté des Sessions, où il systématise la doctrine du soufisme oriental ; il y décrit les douze demeures : volonté, pénitence, etc., par où il faut passer pour aller à « la demeure fixe de l'anéantissement de tout ce qui n'est pas lui ». Le trait particulier de ce mysticisme, c'est que chaque "demeure » est considérée moins comme un passage que comme un obstacle, jusqu'à ce que la vertu qu'elle désigne soit transformée par l'anéantissement en Dieu : la patience, par exemple, qui est une de ces demeures, n'est pas la vertu du vulgaire, simple fermeté devant le cours des décrets divins, ni la facilité à les supporter, qui est vertu de novice, mais la « patience en Dieu ", la joie des tribulations. Donc le mystique renonce à tout ce qui n'est pas Dieu, même aux demeures de la vie spirituelle : cette attitude d'absolu renoncement se maintient plus tard chez les mystiques d'Andalousie ${ }^{559}$.

Table des matières

558 De Animae beatitudine, p. 356-e.

559 Ibn Al-Arîf, Mahâsin-al-Madjâlis, édité et traduit par M. Asin PALACIOs, Paris, 1933 ; cf. RSPT, 1934, p. 413. Sur la continuation de la pensée mystique arabe en Espagne jusqu'au $\mathrm{XV}^{\mathrm{e}}$ siècle et sur son influence sur la mystique chrétienne du $\mathrm{XVI}^{\mathrm{e}}$ siècle, cf. AsIN PALACIOS, Un précurseur hispanomusulman de San Juan de la Cruz, dans la revue Al Andalus, t. I, 1933, et la discussion de J. BARUZI, Problèmes d'histoire des religions, 1936, p. 111. 
IV.

\section{LA PHILOSOPHIE JUIVE : AVICEBRON.}

C’est en Espagne que se développe, dans la seconde moitié du $\mathrm{XI}^{\mathrm{e}}$ siècle, la philosophie juive avec Ibn Gebirol (Avicébron), tandis qu'au $\mathrm{XII}^{\mathrm{e}}$ siècle elle revient vers l'Orient, avec Maïmonide. Si différente que soit l'inspiration des Juifs et ${ }_{\text {p237 }}$ des Arabes, il y a pourtant un rythme analogue dans le mouvement qui mène d'Avicébron, le platonicien, à Maïmonide, le péripatéticien, et celui qui mène d'Avicenne à Averroès.

Avicébron, né en 1020 à Malaga et mort en 1070, est à la fois l'auteur de poésies et d'hymnes religieux et d'un traité philosophique, intitulé Source de Vie (Fons vitae), dont on possède une traduction latine de Dominique Gondissalvi, qui le répandit en pays chrétien au $\mathrm{XIII}^{\mathrm{e}}$ siècle et une traduction hébraïque, mais non l'original, écrit en arabe.

Tandis que la doctrine d'Avicenne est au croisement des influences du péripatétisme et du platonisme, Avicébron, sauf en ce qui concerne l'appareil dialectique, est pour ainsi dire étranger à l'influence d'Aristote ; et même, bien qu'il ne cite jamais ses sources, il critique quelques notions fondamentales chez lui, et tout particulièrement celle qui attribue à Dieu le mouvement du premier ciel : il est impossible, selon lui, que le Créateur, qui est infini, produise immédiatement le mouvement d'une sphère, qui est fini ; bien plus, il admet comme un axiome qu'une substance immobile, telle que le Créateur, ne peut mouvoir une autre substance : "Tout ce qui ne peut se mouvoir soimême ne peut mouvoir autre chose... Le moteur d'une substance donne en effet à la substance la puissance de se mouvoir ; mais tout ce qui donne un attribut à une autre chose mérite de l'avoir lui-même plus que ce qui le reçoit ${ }^{560}$. » Le principe immédiat du mouvement est donc ce qui se meut soi-même, ce que Platon appelait l'âme.

La Source de Vie est un des trois ouvrages philosophiques qu'Avicébron a écrits et le seul qui nous reste. Avicébron distribue en effet toute réalité en trois : l'Essence première ou le Très-Haut, la Volonté qui est la puissance créatrice du Très-Haut, enfin la Matière et la

560 Fons vitae, liv. III, ch. VII., édit. Bauemker, p. 91-93. 
Forme qui renferme toute créature. La Source de Vie ne porte que sur la Matière et la ${ }_{\text {p238 }}$ Forme ; " ce n'est là que la première partie de la Sagesse qui doit être un échelon pour la seconde et pour la troisième, pour la science de la Volonté et la science de l'Essence première ${ }^{561}$ ". La Source de Vie contient exclusivement la science des choses créées, bien qu'elle se réfère assez souvent à la Volonté et à l'Essence première.

La thèse unique de la Source de Vie, c'est que toutes les choses créées sont composées de forme et de matière, thèse de la composition « hylémorphique » universelle, qui a été considérée au XIII ${ }^{\mathrm{e}}$ siècle occidental comme la caractéristique d'Avicébron. La notion de matière est d'origine aristotélicienne ; mais, chez Aristote, la matière au sens propre ne se trouve que dans les choses où il $\mathrm{y}$ a changement, et c'est ce qui reste permanent dans le changement : dans la région sublunaire, il y a génération et corruption ; pour qu’il y ait génération, il faut qu'une forme substantielle s'ajoute à une matière qui contenait cette forme en puissance ; dans les sphères célestes, le seul changement est le changement local ; il n'y a donc en elle qu'une matière locale, dont la propriété est d'être en puissance dans tous les lieux occupés par la sphère. Quant aux intelligences, il y a bien dans l'intellect humain, qui reçoit les formes de l'intellect agent, quelque chose d'analogue à la matière, mais ce n'est pas la matière au sens propre. Il n'en était pas ainsi dans le néoplatonisme : d'abord, pour Plotin, dans les choses corporelles, la matière désigne uniquement ce qu'Aristote appelait matière première, c'est-à-dire la matière qui est en deçà des éléments : sur cette matière qui ressemble au «lieu » du Timée, les idées envoient des reflets qui sont comme des ombres sur une ombre, qui ne forment avec elle aucune substance véritable ; la matière, incapable de retenir aucune forme, reste toujours près du néant (prope ni-

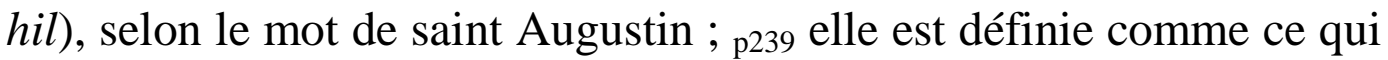
s'écarte au maximum du Bien. D'autre part, Plotin admet que le monde intelligible possède une "matière intelligible ", qui forme comme un fond commun pour toutes les intelligences ; si, dans la variété des intelligences, il y a unité, c'est à cause de la matière. La notion de matière se trouve ainsi à tous les niveaux de la réalité, à part le niveau de l'Un. C'est là la thèse d'Avicébron, sauf les modifications

561 Liv. V, ch. I, p. 257 ; cf. liv. I, ch. VII, p. 9. 
importantes qu'il y apporte : il n'y a pas chez lui un aussi grand contraste que chez Plotin entre la matière intelligible et la matière corporelle ; chez Plotin, il y a une coupure entre l'Un pris avec les hypostases émanées de lui, d'une part, et les reflets qui constituent le monde sensible, d'autre part ; or, la matière intelligible est d'un côté de la division et la matière corporelle de l'autre ; chez Avicébron, la coupure est entre le Dieu créateur, sans multiplicité, avec sa volonté créatrice, et la créature qui contient à la fois les substances simples ou intellectuelles et les substances corporelles ; matière intelligible et matière corporelle sont du même côté, de celui de la créature. De là suit une seconde modification : au-dessus de la matière intelligible et de la matière corporelle, Avicébron place la matière universelle : la notion de matière universelle naît chez lui d'exigences systématiques inhérentes au néoplatonisme : partout où il $\mathrm{y}$ a des termes divers et semblables, il faut poser au-dessus un terme unique d'où ils découlent ; au-dessus de la diversité matière intelligible et matière corporelle, il faut donc poser une matière universelle d'où découlent les deux autres ; cette matière " qui existe par soi, qui est d'une seule essence, qui est le sujet de toute diversité, qui donne à toute chose son essence et son nom », contient, dans son unité, la matière intellectuelle et la matière corporelle ${ }^{562}$, comme la forme ${ }_{\mathrm{p} 240}$ universelle dont elle est le sujet contient les formes intelligibles et les formes des corps. A l'intérieur de la matière corporelle, on distingue encore une série de termes hiérarchisés, du plus au moins compréhensif : matière céleste, matière naturelle universelle, matière naturelle particulière, matière artificielle avec autant de formes correspondantes, la forme du ciel, la nature, l'essence des corps naturels, l'art. La doctrine d'Avicébron consiste à classer les formes et les matières en deux séries se correspondant terme à terme et telles que chaque terme d'une série, joint au terme correspondant de l'autre, fasse un être concret ayant sa place marquée dans une hiérarchie qui va de l'universel au particulier, des êtres intellectuels aux êtres corporels, de la nature à l'art.

562 Cf. Fons vitae, liv. IV, ch. X : «La communauté de toutes choses et leur rapport à l'unité montrent clairement qu'il y a une chose universelle commune à toutes et à laquelle toutes participent ; sinon, elles ne conviendraient en rien, et la diversité des leurs racines empêcherait la convenance dans leurs rameaux ». 
Ce qui complique la doctrine, c'est qu'Avicébron, en bon néoplatonicien, ne veut pas qu'il s'agisse là d'une simple classification statique ; il a la prétention de faire comprendre la genèse de la multiplicité des formes et de celle des matières à partir de la forme universelle et de la matière universelle. Mais il y a, dans son explication, une ambiguïté foncière : le principe de diversité paraît être en effet tantôt du côté de la forme, tantôt du côté de la matière : selon la première explication, la matière est une et indéterminée dans les êtres, et ce qui les distingue, ce par quoi ils sont ce qu'ils sont, c'est la forme, comme un bloc de marbre qui peut devenir plusieurs choses; la diversité des formes est donc ici le principe. Selon la seconde explication, la forme est une, à la façon de la lumière qui provient du soleil ; mais comme cette lumière, selon qu'elle est reçue en des matières plus ou moins subtiles ou épaisses, s'obscurcit plus ou moins, la diversité des êtres, dérivée de ces divers degrés d'obscurcissement, est à attribuer uniquement à la matière, indispensable même aux plus hautes formes de l'être, puisque, dans la transparence absolue, la lumière ne se manifesterait p241 pas. Ces deux aspects de la pensée d'Avicébron, que nous verrons courir à travers la philosophie occidentale du XIII ${ }^{\mathrm{e}}$ siècle, paraissent bien irréductibles : à l'image aristotélicienne d'un ensemble statique de formes discrètes et séparées s'oppose celle d'une lumière unique que les matières sont plus ou moins aptes à recevoir ; à une classification de concepts, l'image d'un éloignement plus ou moins grand. Il semble qu'Avicébron devrait choisir entre ces deux conceptions de la diversité ${ }^{563}$; mais, en fait, sa pensée s'oriente vers un pur parallélisme des formes et des matières : pour lui, la forme supérieure contient à l'état d'enveloppement les formes inférieures ; ainsi, « les formes sensibles, quantité continue, figure, couleur et qualités premières, sont réunies dans l'essence de la substance simple ; elles n'y sont pas à la manière dont elles sont dans les substances composées, mais d'une autre manière plus simple ; elles sont les formes ellesmêmes séparées de leur matière, perçues par l’âme et dépouillées de leurs substances; et puisque ces formes simples ont des forces qui émanent d'elles, il est nécessaire, lorsqu'elles se sont déversées sur la

563 Cf. p. 246, ligne 16, la gêne du disciple se demandant comment, puisque la diversité vient de la forme, les formes peuvent se réduire à une seule : à ce thème aristotélicien, le maître oppose le thème néoplatonicien dont il va être question. 
substance qui leur est opposée et se sont jointes à elle, que s'engendrent les formes sensibles, soutenues dans la substance composée ${ }^{564}$ ». Ainsi, si la forme corporelle s'engendre au moment où elle rencontre la substance corporelle, c'est qu'elle était déjà, d'une autre manière, dans la substance supérieure au corps : " la substance simple n'imprime (dans la substance corporelle) que ce qu'elle a dans son essence ", et la matière est le sujet que recherchent les forces émanées de la substance simple pour s'unir à elle. Le mouvement inverse, par lequel notre intelligence connaît les formes p242 séparées de la matière, prouve bien d'ailleurs l'origine intellectuelle de ces formes ${ }^{565}$.

Ce que l'on dit des formes, on peut le dire des matières : " de même que la diversité des formes n'empêche qu'elles ne soient une seule forme en elle-même ", de même «la diversité des matières n'empêche qu'elles ne s'accordent en tant que matière et ne fassent toutes une seule matière ${ }^{566}$ ». Chaque matière, dans sa différence avec les autres, est définie en effet par sa capacité de recevoir les formes à un certain état d'unité ou de division; donc elle est elle-même d'autant plus multipliée et diversifiée qu'elle est plus éloignée de son origine, et d'autant plus une et simple qu'elle en est plus proche ${ }^{567}$ : le mouvement par lequel la matière universelle qui reçoit les formes dans leur absolue unité se dégrade en matière de l'intelligence, puis de l'âme, puis du corps, est le même que celui par lequel les formes se divisent et se multiplient en cette matière.

C'est ce parallélisme qui, par rapport au néoplatonisme du livre des Causes, constitue l'élément neuf de la doctrine d'Avicébron. Si cette nouveauté est possible, c'est que, contrairement au néoplatonisme, il distingue radicalement l'illumination, par laquelle l'intelligence éclaire une matière de la création ; dans le néoplatonisme, l'illumination ou émanation appartenait au principe suprême ; ici, elle appartient à une créature; la différence, c'est que l'intelligence imprime seulement ce qui est en son essence ; «si elle

\footnotetext{
564 Fons vitae, liv. III, §25.

565 Fons vitae, liv. III, § 28, p. 145,1. 2-5.

566 IV, § 15.

567 IV, § 6 (p. 223), et II, § 20 (p. 61).
} 
imprimait ce qui n'est pas dans son essence, son action ne pourrait être une impression, elle serait créatrice ex nihilo; mais il n'y a d'autre créateur ex nihilo que l'agent premier, le Très-Haut et le TrèsSaint ${ }^{568}$; " la forme qui imprime son action « est elle-même créée parce que la forme est, et l'être n'est pas une impression; car l'impression a besoin d'un soutien... ; n'étant pas impression, p243 il est création ${ }^{569}$ ". Tandis que, dans le néoplatonisme, l’Un, principe radical, produit l'Intelligence par une illumination ou impression de même nature que celle par laquelle l'intelligence produit l'âme, et l'âme, le monde, chez Avicébron, Dieu, principe radical, produit l'intelligence et les substances simples par création, tandis que celles-ci agissent par impression sur une matière. Sans doute, Avicébron assimile parfois la création à une émanation ${ }^{570}$, mais cette émanation est radicalement différente de l'action de la forme sur la matière qui va s'affaiblissant : car elle consiste à donner l'être et elle a toujours même force ${ }^{571}$. Avant la création, la forme et la matière existaient séparément l'une de l'autre, avec toutes leurs richesses, dans la science de Dieu : la création a consisté à leur donner l'être pour qu'elles agissent l'une sur l'autre et s'unissent. Leur correspondance leur vient de cette unité supérieure. « Ce qui lie la matière à la forme, ce qui les unit et conserve leur union, c'est l'unité, qui leur est supérieure ${ }^{572}$. La volonté créatrice est ce qui fait que la matière reçoit la forme, bien que la matière ne reçoive pas l'être de ce dont elle reçoit la forme ${ }^{573}$. "

Il faut remarquer pourtant que la notion de création, telle que l'exprime Avicébron, reste liée à l'ordre hiérarchique néoplatonicien : Dieu crée non par lui-même, mais par l'intermédiaire de sa volonté ou de son Verbe ${ }^{574}$, et il imprime la forme sur la matière corporelle par l'intermédiaire des substances simples; partout Avicébron intercale des intermédiaires ; ainsi les formes sensibles ne s’impriment pas im-

\footnotetext{
568 Liv. III, § 25, p. 139.

569 L. IV, § 13, p. 240.

570 L. V, § 41.

${ }^{571}$ L. III, § 55, p. 201.

${ }^{572}$ L. V, § 31, p. 315.

573 L. V, § 41, p. 330.

574 Point n'est besoin, pour expliquer cette doctrine, d'avoir recours à une influence chrétienne, comme le fait Duhem, tellement est liée au judaïsme la doctrine d'un Verbe créateur, plus ou moins hypostasié.
} 
médiatement sur la matière, mais sur la « corporéité » qui les soutient, comme elle est elle-même soutenue par la matière corporelle. C'est avec un luxe extraordinaire d'arguments p244 qu'il montre la nécessité de l'intermédiaire des substances simples entre Dieu et les corps, et il invoque en particulier des arguments d'analogie : de même, dit-il par exemple, que dans le microcosme, l'intelligence n'est jointe au corps que par l'âme et le souffle vital (spiritus), de même il faut des intermédiaires entre Dieu et la substance corporelle ; l'intermédiaire est nécessité par l'écart entre l'éternité divine et la temporalité du monde sensible, entre l'infinité de Dieu et les limites du lieu où se meut le monde $^{575}$; sans posséder l'éternité, les substances simples sont douées «d'un mouvement qui n'est pas dans le temps » ${ }^{576}$. On voit donc combien, dans son mode d'action, le Créateur est déterminé par une série de règles hiérarchiques précises auxquelles il se soumet.

Table des matières

\section{V. \\ MAÏMONIDE.}

Moïse Maïmonide, né à Cordoue en 1135, vécut d'abord à Fez, puis en Palestine ; il mourut en Égypte en 1204. C'est un rabbin et un talmudiste : il a écrit de longs commentaires destinés à organiser le Talmud. Mais il a profondément réfléchi sur les rapports de la religion et de la philosophie.

Dans le Guide des Égarés, il fait la critique de l'attitude des Motekallemîns, musulmans ou juifs : ceux-ci prennent pour point de départ la révélation et utilisent les concepts philosophiques qu'ils choisissent et qu'ils transforment arbitrairement pour les accorder avec la révélation et exprimer par eux des vérités connues par l'autorité. Maïmonide conçoit tout autrement les rapports de la religion et de la philosophie : lui-même, il n'est pas un philosophe ; il trouve "suffisants » les p245 livres qui ont été composés sur la physique, la métaphysique et l'astronomie; "ces sujets, dit-il, ont été traités dans beaucoup de

\footnotetext{
575 Fons vitae, liv. III, § 2 et 3, p. 78.

${ }^{576}$ In non-tempore, liv. III, § 3, p. 80,1 : C’est le mouvement éternellement achevé que Plotin attribue à l’intelligence.
} 
livres et on en a, pour la plupart, démontré la vérité ». La philosophie est donc chose achevée, et elle a, en elle-même, son principe de certitude : si elle doit avoir quelque rapport avec la foi, c'est donc à condition qu'elle soit prise telle qu'elle est, dans sa valeur intrinsèque. Mais encore à quoi peut-elle servir ? Maïmonide se donne, à la façon de tous les rabbins juifs, comme un interprète du Livre, et un interprète qui veut en pénétrer le sens caché. " Mon but dans ce traité, écrit-il, a été d'expliquer les obscurités de la Loi et de manifester le vrai sens des allégories qui sont au-dessus des intelligences vulgaires... Le traité porte en particulier sur ce qu'il est possible de comprendre du récit de la création et du récit du char céleste d’Ézéchiel, ainsi que sur l'éclaircissement des obscurités inhérentes à la prophétie et à l'existence de Dieu. » Or, comme Philon d'Alexandrie, pour une pareille interprétation, il estime la philosophie indispensable : " Ce traité, déclare-t-il, n’a été composé que pour ceux qui ont étudié la philosophie et qui connaissent ce qu'elle a exposé au sujet de l'âme et de ses facultés ; » la philosophie est donc comme une " clef » pour comprendre certains passages des livres prophétiques. Donc, «la science de la Loi est une chose à part, et la philosophie est une chose à part ; celle-ci consiste à confirmer les vérités de la Loi au moyen de la spéculation vraie ${ }^{577}$ ». Il s'agit donc bien, pour lui comme pour saint Anselme, de comprendre la foi, mais non tout à fait dans le même sens : saint Anselme utilisait les règles et les concepts de la dialectique pour prouver les vérités de foi ; Maïmonide, qui connaît la philosophie d'Aristote, confronte, avec les dogmes religieux, les opinions des philosophes accompagnées de leurs preuves. La philosophie achevée à laquelle se réfère Maïmonide est p246 celle d'Aristote, telle qu'il est interprété surtout par Avicenne. Il est certain que les grandes thèses théologiques de Maïmonide : négation des attributs en Dieu, monothéisme, existence de la prophétie, providence et solution du problème du mal, sont présentées par lui comme liées substantiellement à la philosophie. De ces thèses, il indique les démonstrations purement philosophiques. La thèse de la négation des attributs en Dieu se rattachait à une des préoccupations les plus profondes des théologies juives et musulmanes ; en disant de lui dans l'Exode : " Je suis celui qui suis », Dieu écartait de lui tout attribut différent de son être ; or, cette thèse

577 T. III, p. 459. 
résulte, selon Maïmonide, de l'analyse que les philosophes donnent des propositions : tout attribut, selon eux, exprime soit l'essence du sujet, soit un accident ; au premier cas, il est la pure explication d'un nom ; qu'il s'exprime par une définition telle que : l'homme est un animal raisonnable, ou par une de ses parties (comme : l'homme est raisonnable), il ne saurait convenir à Dieu, parce qu'il y introduirait la composition ; dans le second cas, il introduit la composition en Dieu ; on ne saurait lui donner une qualité, ce qui serait faire de Dieu un substratum, ni un relatif, puisque, selon la Physique, il n'y a de relation qu'entre deux choses de même espèce ; Dieu a bien des attributs d'action : créateur, providentiel, etc. ; mais la physique montre que les actions diverses ne supposent pas l'existence d'autant de formes diverses dans l'agent ; par exemple le feu liquéfie et coagule, blanchit et noircit, sans que l'on puisse lui assigner autant de vertus différentes, puisqu'elles devraient être contradictoires. D'autre part, la physique nous apprend que Dieu ne saurait avoir de passions, en nous enseignant que la passion n'appartient qu'à un être imparfait, ni de privation, puisque la privation n'appartient qu'à l'être en puissance et que Dieu est acte pur ${ }^{578}$. Si, après cela, on énonce de Dieu des p247 attributs de même nom que ceux que l'on assigne à l'homme : puissance, volonté, etc., il faudra que ces mêmes noms désignent des choses toutes différentes chez Dieu et chez l'homme et qu'ils soient seulement homonymes; car toute similitude suppose que les semblables sont de même espèce. Si l'on énonce de lui l'existence, ce n'est pas comme chez nous où, selon la thèse d'Avicenne, l'existence s'ajoute comme un accident à la qualité, tandis que, chez Dieu, l’être nécessaire, l'essence est l'existence même. Si on lui attribue l'unité, c'est à titre de négation, parce que l'on nie en lui toute quantité discrète ; et, d'une manière générale, si on énonce de lui des négations (comme dans la théologie négative), ce n'est pas pour lui donner, mais pour lui enlever des attributs; toute négation nouvelle peut ainsi passer pour un accroissement de connaissance ${ }^{579}$.

Du monothéisme, du Dieu unique, il y a aussi une démonstration philosophique. Maïmonide l'appuie sur vingt-six théorèmes qui ne sont rien que l'ensemble des thèses de la métaphysique péripatético-

578 Guide des Égarés, liv. I, ch. LI-LVI.

579 Ch. LVII-LX. 
avicennienne : impossibilité de la régression à l'infini, théorème de la Physique sur le changement, le temps et la nécessité d'un moteur extérieur au mobile, axiomes d'Avicenne sur le nécessaire et le possible et d'Aristote sur l'être en puissance et l'être en acte, enfin éternité du monde, tel est le point de départ de la démonstration. Grâce à tout cet appareil, on donnera quatre démonstrations de l'unité de Dieu : la première montre comment tous les mouvements de la région sublunaire dépendent de proche en proche du mouvement du ciel qui, luimême, ne saurait avoir qu'un moteur immobile ; la deuxième se rattache à la Physique d'Aristote et à l'explication qu'en donne Alexandre d'Aphrodisias ${ }^{580}$ : s'il y a un moteur qui est mû, et un mû n'est pas moteur, il faut, par raison de symétrie, accepter un moteur immobile ; la $\mathrm{p}_{\mathrm{p} 48}$ troisième repose sur Avicenne, montrant que le possible existant, qui est donné, doit avoir pour fondement un être nécessaire par soi ; la quatrième montre la nécessité d'un acte pur, pour que puisse se produire le passage de la puissance à l'acte, tel que nous l'expérimentons ${ }^{581}$.

Il est vrai que, à ces démonstrations péripatéticiennes, Maïmonide en ajoute deux autres, assez différentes: l'unité de Dieu est tirée d'abord de sa simplicité ; car s'il y avait deux dieux, chacun serait composé, puisqu'il aurait au moins un caractère commun avec l'autre, et un caractère qui l'en distingue. L'autre preuve est tirée de l'unité de l'univers où tout est lié. Mais en somme, tout le monothéisme, au point de vue philosophique, reste uni étroitement avec les vues péripatético-avicenniennes sur le monde, dont Maïmonide fait un ample exposé $^{582}$, trouvant «qu'elles sont les moins sujettes au doute et qu'elles se présentent avec le plus de méthode », et que beaucoup sont d'accord avec la Loi. On voit assez que, pour Maïmonide, le système d'Aristote était impossible à remplacer, avec ses sphères célestes douées d'âmes et mues par des Intelligences, dont la dixième et dernière, l'intellect actif, est celle qui déverse les formes dans la région sublunaire et qui fait passer à l'acte notre intelligence, avec les influe : ces particulières qui s'écoulent de chaque planète sur chaque élément et chaque autre planète : "Cet univers ne forme qu'un seul indivi-

\footnotetext{
580 Phys., liv. VIII, ch. V, p. 256B, expliqué d’après Métaphys.,liv. XII, ch. VII.

581 Guide, liv. II, ch. I et II.

582 Liv. II, ch. III à XI.
} 
du » ${ }^{583}$, dont le cœur est la sphère céleste « qui par son mouvement gouverne les autres parties de l'univers et qui envoie à tout ce qui naît les facultés qui s'y trouvent, de sorte que tout mouvement qui existe dans l'univers a pour premier principe le mouvement de la sphère céleste, et que toute âme a son principe dans l'âme de la sphère céleste »; l'homme, qui a dans la raison sa faculté directrice, est un microcosme, et, dans les sociétés humaines, se répètent les mêmes rapports que ${ }_{\text {p249 }}$ dans l'univers : Maïmonide reste d'ailleurs fort sceptique sur les hypothèses particulières qu'ont faites Ptolémée et les autres astronomes pour rendre compte du cours des planètes.

Ce qui montre l'importance vitale de ces spéculations, c'est que, à cette doctrine du monde, Maïmonide rattache une théorie purement philosophique du prophète ; car le prophète a, chez les Juifs, un rôle religieux et social de premier plan. Cette théorie, tout à fait analogue à celle des Arabes, part du rayonnement ou épanchement perpétuel et immuable qui vient de l'intellect actif : le prophète est celui qui, par sa nature spirituelle et corporelle, est le plus apte à recevoir cet épanchement ; l'inspiration reste donc immuable comme une réalité extérieure à l'homme ; mais chaque homme est plus ou moins apte à la recevoir. " La prophétie est une émanation de Dieu qui se répand, par l'intermédiaire de l'intellect actif, sur la faculté rationnelle d'abord, puis sur la faculté imaginative »; se répandant sur la faculté rationnelle seule, elle fait la classe des savants spéculatifs, et sur l'imagination seule, celle des hommes d'État, des devins et des augures ; le prophète est celui qui réunit l'un et l'autre ; sa faculté imaginative, réglée par la raison, ne voit alors que Dieu et ses anges ; elle ne lui présente que des opinions vraies et des règles de conduite correctes. Par là, l'épanchement reçu par le prophète, suffisant et au delà à son propre perfectionnement, a assez de force pour se répandre, par lui et par les lois qu'il donne, sur les autres hommes; toute société réglée est donc à base de prophétisme, et le souverain n'a d'autre rôle que de contraindre à obéir à ses prescriptions.

Si fréquemment et continûment que Maïmonide use de la philosophie, si haut qu'il place l'autorité des philosophes, en des matières de leur compétence, il n'accepte pourtant pas leur vision du monde 
comme un dogme absolument certain. Il ne peut en être autrement ; on aura remarqué qu'une des suppositions nécessaires selon les philosophes pour démontrer ${ }_{\mathrm{p} 250}$ le monothéisme, c’est l'éternité du monde, c'est-à-dire la négation de la création dans le temps, qui est enseignée par la Loi. Aussi est-il préoccupé de montrer que, en cette matière, les arguments d'Aristote ne dépassent nullement une probabilité qui n’exclut pas la possibilité de la thèse contraire ; Aristote lui-même, contrairement à ce qu'ont dit Al Farâbi et Avicenne, ne les aurait pas donnés comme démonstratifs ; il prétend encore moins donner luimême une preuve de la création, comme ont voulu le faire les théologiens musulmans; mais il suffit de montrer que la thèse qui la nie n’est pas nécessaire ; alors, dit-il, " cette question restant indécise, j'accepte la solution donnée par la prophétie qui explique des choses auxquelles la faculté spéculative ne saurait arriver ». D’ailleurs, cela n'empêche que Maïmonide cherche les raisons qui peuvent s'opposer à l'éternité du monde : à cette éternité est liée la nécessité du monde qui lie le monde à Dieu comme l'effet à sa cause ; or, l'on peut montrer dans le monde la présence d'un dessein, puisqu'on y voit, liées en un tout, des choses de nature fort diverse. De plus, la règle de la nécessité naturelle, c'est, comme l'a vu Avicenne, qu'une chose simple produise une chose simple ; la diversité, à elle seule, s'oppose donc à la nécessité. Telles sont les présomptions en faveur de la création ; mais elles sont bien faibles, si l'on admettait, avec certains « modernes » dont Maïmonide indique l'opinion sans l'adopter, que le monde aurait pu être créé selon un dessein de toute éternité ${ }^{584}$. On ne peut même pas dire que l'éternité ainsi conçue s’oppose à la Loi ; car, si l'éternité du monde était démontrée d'autre part, il suffirait d'expliquer allégoriquement les passages de la Bible dont la lettre affirme la création dans le temps ; la seule éternité qui s'oppose à la Loi, c'est celle qu'a conçue Aristote, « une éternité telle qu'aucune loi delà nature ne puisse être changée et que rien ne puisse sortir de son cours p251 habituel; ce serait alors saper la religion par la base, taxer de mensonge tous les miracles et nier tout ce que la religion a fait espérer ou croire ${ }^{585}$ ».

584 Ch. XXI : C'est aussi ce que dit saint Thomas dans le Contra murmurantes.

585 Ch. XXV. 
Maïmonide a donc autant de répugnance que d'attrait pour cette philosophie, qui démontre sans doute le dogme monothéiste et la prophétie, mais en partant de suppositions qui sont contraires à celles de la foi ; et la philosophie d'Aristote lui apparaît, au bout du compte, comme un naturalisme qui nie l'action divine. Ne nie-t-elle pas, d'ailleurs, que Dieu connaisse le monde, sous prétexte qu'on ne peut mettre en lui la connaissance de choses sensibles, imparfaites et changeantes, et qu'il ne peut les connaître avant qu'elles soient, puisque ce serait connaître le non-être ? Et la théorie de la prophétie, par les différences naturelles qu'elle introduit entre les hommes, n'implique-telle pas que la Providence ne veille pas également sur tous les individus et ne s'applique qu'à l'espèce ${ }^{586}$ ? A quoi Maïmonide fait remarquer que toute la difficulté vient de ce que l'on assimile la science de Dieu à la nôtre sans voir qu'elles sont purement homonymes ; pour lui, à ce naturalisme péripatéticien, dont il définit fortement les traits, tels qu'on les verra en Occident du XIII ${ }^{\mathrm{e}}$ au $\mathrm{XVI}^{\mathrm{e}}$ siècle, à cette doctrine qui n'admet qu'une cause universelle n'ayant égard qu'au tout, il oppose le Dieu « qui, dans tout être, a eu pour but cet être lui-même et qui, toutes les fois que son existence était impossible sans qu'elle fût précédée d'autres choses, a d'abord produit celles-ci ».

La spéculation de Maïmonide n’amène donc qu'un équilibre très instable entre la philosophie et la foi, et d'autant plus que la philosophie a pris ici la forme concrète et solide de la doctrine d'Aristote.

Table des matières

VI.

\section{LA PHILOSOPHIE BYZANTINE.}

p252 Le XI ${ }^{\mathrm{e}}$ siècle, sous le règne de Constantin Monomaque (10421055), voit un certain réveil de la philosophie à Byzance grâce à la fondation d'une "Académie ", et grâce à la personnalité de Psellus (1018-1078), surnommé le « consul des philosophes »; il était aussi le théologien qui, sur l'ordre de l'empereur, portait contre le patriarche Michel Cérulaire l'accusation «d'hellénisme et de chaldaïsme » ${ }^{587}$,

586 III $^{\mathrm{e}}$ partie, ch. XVI à XXI.
587 LOUIS BrÉHIER, Le Schisme oriental du XI ${ }^{\mathrm{e}}$ siècle, p. 293. 
ce qui revenait à peu près à une accusation de magie. Lui-même il se vante, devant son ami Xiphilin qui l'accusait d'aimer trop Platon, de suivre les traditions des « lumières de l'Église », Grégoire ou Basile, en usant des syllogismes des philosophes pour combattre les hérésies et en acceptant celles de leurs opinions qui sont d'accord avec le christianisme. Commentateur de l'Isagoge de Porphyre, des Catégories et du De Interpretation, auteur d'une encyclopédie $(\Delta 1 \delta \alpha \sigma \kappa \alpha ́ \lambda \varepsilon 1 \alpha$ $\pi \alpha v \tau o \delta \alpha \pi \eta ́)$, il fut spécialement attiré par les parties obscures du platonisme; ses Opinions des philosophes sur l'âme, son traité sur La Psychogonie du Timée ne sont que des compilations ${ }^{588}$; il a donné aussi un commentaire ainsi qu'un résumé des fameux Oracles chaldéens, le livre sacré des néoplatoniciens depuis Porphyre, où il s'applique à indiquer les accords et les divergences entre les Oracles, Platon et le christianisme. Il a écrit deux traités Sur les Démons où, à l'exemple des platoniciens Proclus et Olympiodore, il a classé les démons soit suivant leur séjour, depuis ceux de l'air supérieur jusqu'aux démons souterrains, soit selon leur degré de spiritualité ${ }^{589}$. Il s'intéresse aussi à l'alchimie ${ }_{\mathrm{p} 253}$ et écrit dans sa jeunesse une Chrysopée, dont M. Bidez, son éditeur, a signalé l'esprit positif ; loin de tout charlatanisme, il veut expliquer les procédés alchimiques en les réduisant à la notion des éléments ${ }^{590}$. Il faut voir en lui un homme à la fois attiré et repoussé par ces doctrines et ces pratiques mystérieuses ; et, avant d'accuser Cérulaire, il fut lui-même inquiété pour ses opinions « philosophiques ${ }^{591}$.

Psellus a longtemps passé à tort pour l'auteur d’un « Abrégé de logique aristotélicienne »; ce n'est qu'une traduction grecque des Summula logices de Pierre d'Espagne, qui, au XIII ${ }^{\mathrm{e}}$ siècle, annonçait la logique terministe des occamistes ${ }^{592}$.

Tous les philosophes byzantins des $\mathrm{XI}^{\mathrm{e}}$ et $\mathrm{XII}^{\mathrm{e}}$ siècles sont du reste des commentateurs. Jean Italos a commenté l'Organon; Michel

\footnotetext{
${ }^{588}$ H. BIDEZ, Revue de philologie, 1905, p. 323, qui montre qu’il a copié souvent le commentaire du Timée de Proclus.

589 Catalogue des Manuscrits alchimiques grecs, t. VI (publié par J. Bidez), p. 97-138 ; K. SvobodA, CXXXII.

590 Catalogue, p. 25-26.

591 Catalogue, p. 115.

592 UEBERWEG, Grundriss, p. 356.
} 


\section{Émile Bréhier \\ La philosophie du Moyen âge}

d'Éphèse, un élève de Psellos, l'Organon, la Morale à Nicomaque et le traité Des parties des animaux; Eustratius, les Analytiques postérieurs et l'Éthique; Théodore de Smyrne a écrit un abrégé des opinions des anciens sur la Physique.

Table des matières 


\title{
QUATRIÈME PARTIE \\ Le tournant du XIII ${ }^{\mathrm{e}}$ siècle
}

Table des matières

\author{
Chapitre premier
}

\section{LES CONDITIONS HISTORIQUES}

Le XIII ${ }^{\mathrm{e}}$ siècle a commencé par le pontificat d'Innocent III (11981215), et il s'est, achevé à la première année de celui de Boniface VIII ; il a vu ainsi les deux représentants les plus énergiques et les moins disposés au compromis de la théocratie papale ; mais, tandis qu'Innocent III réussit dans presque toutes ses entreprises, Boniface VIII trouve en Philippe le Bel un adversaire décidé à mettre fin à l'ingérence de la papauté dans les affaires des États; c'est donc le $\mathrm{XIII}^{\mathrm{e}}$ siècle qui a vu le déclin de cet augustinisme politique qui absorbait l'État dans l'Église ; mais on voit aussi décliner, avec la découverte des œuvres d'Aristote, l'augustinisme intellectuel, qui étendait sans limites le domaine de la théologie. Il y a place pour un État indépendant de l'Église, comme pour une philosophie rationnelle, séparée de la théologie.

L'adoption des Universités par les papes et la protection des ordres mendiants, Dominicains et Franciscains, ont marqué, p256 au XIII siècle, un changement dans ce que l'on pourrait appeler la politique spirituelle de la papauté. La création de l'Université, pas plus que celle des ordres mendiants, ne revient à l'initiative du pape ; l'une et 
les autres se sont organisés spontanément; et le pape n’a eu qu'à prendre en main et qu'à utiliser des forces spirituelles qu'il n'avait pas fait naître. Jusque-là, les écoles, soit abbatiales, soit épiscopales, ne dépendaient qu'indirectement du pape ; les écoles épiscopales, devenues, au XII ${ }^{\mathrm{e}}$ siècle, les plus florissantes, étaient sous la direction immédiate de l'évêque et de son chancelier. Au début du XIII ${ }^{\mathrm{e}}$ siècle, à Paris, cette dépendance était devenue pour les maîtres une sujétion intolérable ; mais le seul moyen pour eux de se soustraire à la hiérarchie ecclésiastique, c'était de dépendre immédiatement du pape ; de la même manière, tout au long du XII ${ }^{\mathrm{e}}$ siècle, des princes ou même des rois s'étaient faits, au temporel, vassaux du Saint-Siège pour échapper aux liens de suzerainetés plus puissantes. C'est à la suite de luttes à très nombreuses péripéties, que, à Paris, l'Association générale des maîtres et des étudiants (Universitas magistrorum et scolarium) a réussi à arracher au chancelier de l'évêque la direction des études et à se faire reconnaître officiellement par le pape en 1231.

Dans tous les conflits qui ont eu lieu au cours du siècle, entre l'Université et le chancelier d'abord, puis entre elle et les papes, il ne s'agit nullement de doctrine, mais d'une aspiration générale à l'autonomie, qui se marque surtout par la prétention de conférer les grades aux étudiants et de choisir ses propres professeurs; l'Université est, en un sens, un fait social analogue à celui des communes ; comme les communes sont à côté de la hiérarchie féodale, l’Université est en dehors de la hiérarchie ecclésiastique ; comme la commune est aspiration à un développement économique plus libre et plus étendu, l'Université, faisant suite aux écoles du XII ${ }^{\mathrm{e}}$ siècle, recherche, au milieu de toutes les difficultés d'une orthodoxie ${ }_{\text {p257 }}$ pointilleuse, un développement de la pensée qui corresponde à ses exigences internes; la preuve, c'est que les conflits de doctrines sont nombreux à l'intérieur même de l'Université. Il faut ajouter, il est vrai, que ces conflits doctrinaux, dès qu'ils paraissent intéresser la foi, sont tranchés non par une discussion libre mais par les pouvoirs spirituels, l'évêque ou le pape ; les adversaires ont l'habitude d'user continuellement vis-à-vis les uns des autres d'armes bien différentes de celles de la libre discussion ; ils accusent leur adversaire d'hérésie, et ils cherchent à faire condamner des propositions qui, en apparence du moins, sont purement philosophiques. La puissance supérieure n’apparaît pas comme stimulatrice et génératrice de la recherche, mais 
comme régulatrice et gardienne sans appel de l'orthodoxie. La situation est par là très différente de ce qu'elle a été dans les siècles antérieurs; il ne s'agit plus de méditations sur la foi que promouvait l'Église, ni même d'un prolongement de cet humanisme antique dont les monastères gardaient les œuvres, mais de discussions qui ont lieu dans un domaine de notions purement rationnelles, où la foi n'a aucune place : si la foi a bien entendu encore son mot à dire, ce n'est plus que de l'extérieur, pour dire si l'opinion établie sur des raisons est ou non d'accord avec la croyance catholique. Nous trouvons ici la même ambiguïté que dans toutes les créations du XIII ${ }^{\mathrm{e}}$ siècle : un jaillissement de forces nouvelles et indépendantes qui sont foncièrement différentes de l'Église et, d'autre part, une interprétation mystique de ces forces qui les asservit à l’Église et à la papauté.

Il faut ajouter que l'on retrouve cette même dualité et cette combinaison d'éléments différents à l'intérieur même de la spiritualité chrétienne. Les deux ordres mendiants, les Franciscains et les Dominicains, qui, fondés au début du siècle, deviennent les plus fermes soutiens de la foi catholique, sont, dans leur origine, indépendants de l'action propre de l'Église. Cela est surtout vrai des Franciscains. François d'Assise, en ${ }_{\mathrm{p} 258}$ renonçant à tous ses biens et en se livrant à l'apostolat, visait le même idéal de perfection évangélique que, au $\mathrm{XII}^{\mathrm{e}}$ siècle, Pierre Valdo, ce commerçant de Lyon qui se voua à la pauvreté et qui réunit autour de lui ces nombreux pauvres de Lyon, que l'on appela les Vaudois ; mais les Vaudois aboutirent à une hérésie qui eut son clergé, indépendant du clergé catholique, tandis que les Franciscains, dans leur apostolat, qui, dès 1225, s'étendait à la chrétienté tout entière, étaient entièrement soumis à la papauté. C'est aussi d'une initiative personnelle que naquit l'ordre des Dominicains : au début du XIIIe siècle, la conversion des Albigeois avait été confiée à des moines cisterciens qui ne réussissaient pas à convaincre ces Cathares, chez qui la recherche de la simplicité évangélique était en trop grand contraste avec l'opulence des ecclésiastiques; Dominique, le sous-prieur de l'évêque d'Osma, qui traversait le Languedoc, eut l'intuition qu'on ne pouvait convaincre les Cathares qu'en luttant avec eux d'austérité ; alors commencèrent, avec l'assentiment du pape, ces prédications qui aboutirent à la fondation de l'ordre des Prêcheurs, approuvé en 1216. Ces deux ordres, ainsi nés spontanément, constituèrent, au XIII ${ }^{\mathrm{e}}$ siècle, une sorte de police spirituelle, parfaitement 


\section{Émile Bréhier}

La philosophie du Moyen âge

organisée ; chacun était sous la direction d'un supérieur unique, et il était divisé en provinces. Ainsi ces ordres qui, primitivement, étaient comme une soupape de sûreté pour satisfaire à des besoins religieux que contentaient insuffisamment la hiérarchie ecclésiastique et les ordres existants, entrent, comme éléments, dans la vaste organisation de l'Église et, en se répandant à travers l'Europe, affirment son caractère universel. 


\section{Chapitre II}

\section{LES DÉBUTS DE L’ARISTOTÉLISME LATIN}

Au XIII ${ }^{\mathrm{e}}$ siècle, comme aux siècles précédents, la raison (ratio) reste toujours l'intermédiaire entre la foi et la vision de Dieu, intermédiaire qui convient à l'homme in via : la philosophie, œuvre de la raison, est une étape de la vie chrétienne, et elle est justifiée comme telle. Mais la place de la philosophie dans la hiérarchie des valeurs chrétiennes, si difficile déjà à déterminer au $\mathrm{XII}^{\mathrm{e}}$ siècle, est, au $\mathrm{XIII}^{\mathrm{e}}$ siècle, l'objet de nouvelles et d'âpres contestations; les conditions sont en effet bien changées, dès que la philosophie, ne se bornant plus à la dialectique ni à un platonisme plus ou moins transformé dans un sens chrétien, apparaît, avec la connaissance que l'on prend de la philosophie arabe et juive, sous les espèces de l'aristotélisme. L'aristotélisme ne pouvait passer pour être issu de méditations sur la foi : il était l'œuvre de la raison toute seule, d'une raison qui sortait du cadre où l'avaient enfermée saint Augustin et saint Anselme : le XIII ${ }^{\mathrm{e}}$ siècle est l'histoire des efforts en sens opposé que l'on a faits soit pour expulser l'aristotélisme, soit pour le faire rentrer dans le cadre augustinien, réformé comme il convient. Ajoutons qu'il ne faut pas plus exagérer que sous-estimer l'importance de cette invasion de l'aristotélisme ; la dialectique, issue d'Aristote par Boèce, avait dès longtemps habitué les esprits à penser et à discuter p260 sous des formes aristotéliciennes ; elle introduisait d'ailleurs avec elle plusieurs théories appartenant à la physique et à la métaphysique ; d'autre part, la métaphysique d'Aristote est la spéculation sur « l'être en tant qu'être », c'est-à-dire la détermination des cadres où vient s'insérer toute réalité, quelle qu'elle soit ; elle maintenait donc l'esprit dans cette région moyenne où l'avait placé la dialectique; là, il s’agit moins de la réalité elle-même que des classes où on peut la distribuer, 
forme, matière, acte, puissance, mouvement ; ce n'est ni le simple verbalisme qui consisterait à nommer les choses, ni l'intuition intellectuelle qui va jusqu'à leur essence, mais une sorte de description raisonnée où les choses viennent naturellement se ranger. La philosophie d'Aristote gardait donc bien ce caractère plus discursif qu'intuitif qui était celui de la ratio, et les combats qui se livrent autour d'Aristote peuvent être considérés comme la suite de ceux qui se sont livrés autour de la dialectique, mais une suite qui comportait des développements bien originaux.

Table des matières

I.

\section{LES TRADUCTIONS LATINES D’ARISTOTE.}

Jamais l'Occident n'était resté sans relation avec l'Orient ; mais, à partir des croisades, ces relations augmentèrent beaucoup : la Sicile et l'Espagne, la France méridionale furent les terrains où les chrétiens purent prendre contact avec la philosophie arabe ; les chrétiens paraissent de bonne heure s'être rendu compte qu'ils retrouvaient par elle, dans son ensemble, la tradition de la science et de la philosophie helléniques qui ne leur était arrivée jusqu'ici que par lambeaux, à travers les compilateurs : la médecine, l'astronomie, les mathématiques, en profitent tout autant que la philosophie. Au XII ${ }^{\mathrm{e}}$ siècle, on traduit les œuvres grecques de l'arabe ${ }_{\mathrm{p} 261}$ ou de l'hébreu en latin ; et les collèges de traducteurs rappellent ceux qui, quelques siècles auparavant, avaient traduit en arabe les maîtres grecs ; au XIII ${ }^{\mathrm{e}}$ siècle, il se forme des hellénistes qui traduisent directement du grec les œuvres d'Aristote. Dès la première moitié du XII ${ }^{\mathrm{e}}$ siècle, sous la direction de Raymond, évêque de Tolède de 1126 à 1151, Jean d'Espagne traduit la Logique d'Avicenne, et Dominique Gondisalvi, avec l'aide de Jean et du juif Salomon, sa Métaphysique et des extraits de ses œuvres physiques, ainsi que la Métaphysique de Gazali, et l'écrit Sur les sciences de Farâbi ; il traduit encore la Source de vie d'Avicébron. Un autre membre du collège de Tolède, Gérard de Crémone, mort en 1187, traduit plusieurs œuvres d'Aristote, la Physique, le De coelo, le De generatione, les trois premiers livres des Météores ; mais il traduit aussi des œuvres d'Al Kindi, le Canon d'Avicenne, l'Almageste de Ptolémée, le livre des Causes, le livre Des Définitions et Des éléments 
d' Isaac Israëli. Au début du XIII ${ }^{\mathrm{e}}$ siècle, Alfred l'Anglais apprend l'arabe à Tolède et il traduit en latin un traité Des végétaux, faussement attribué à Aristote. Mais le grand traducteur de l'arabe fut Michel Scot, mort vers 1235 ; il donna les commentaires d'Averroès sur le De coelo et le De anima, et peut-être ceux du De generatione, des Météores et des Parva naturalia. Au milieu du siècle, Hermann l'Allemand, évêque d'Astorga, mort en 1272, traduit son commentaire moyen de l'Éthique à Nicomaque, puis les commentaires de la Rhétorique et de la Poétique. Dès la fin du XII ${ }^{\mathrm{e}}$ siècle, il se trouva en Sicile des hellénistes qui traduisirent directement du grec : avant 1162, Henri Aristippe, archidiacre de Catane, donna le quatrième livre des Météores ; la Syntaxe et l'Optique de Ptolémée, l'Optique d'Euclide, les Éléments physiques de Proclus furent traduits alors. En 1210, on possède à Paris une traduction de la Métaphysique d'Aristote, d'après un texte apporté de Constantinople, et l'on a trouvé à Padoue une traduction latine du même ouvrage, datant de la ${ }_{\mathrm{p} 262}$ fin du XII ${ }^{\mathrm{e}}$ siècle. Vers 1215, Alfred l'Anglais traduisait du grec le De anima, le De somno, le De respiratione ; entre 1240 et 1250, Robert Grosseteste, l'évêque de Lincoln, traduisait ou faisait traduire les différentes Éthiques d'Aristote, et peut-être les commentaires d'Eustrate et de Michel d'Éphèse. Vers 1260, Barthélémy de Messine, un familier de la cour du roi Manfred de Sicile, traduit la Grande Morale, les Problèmes, le De Mirabilibus, la Physiognomonie. Enfin Guillaume de Mœrbeke, né vers 1215, et pénitentiaire sous le pape Clément IV (1265-1268), fournit à saint Thomas d'Aquin plusieurs des textes sur lesquels il travaille ; il traduit la Politique (1260), l’Économique (1267), les Commentaires de Simplicius aux Catégories et au De coelo; la traduction qu'il donna des Éléments théologiques de Proclus permit enfin de reconnaître en eux le livre Des causes, déjà traduit en latin par Gérard de Crémone ; de Proclus il traduisit encore trois traités (De decem dubitationibus circa providentiam, De providentia et fato, De malorum subsistentia), dont l'original grec est actuellement perdu.

Tout ce travail de traduction, qui se poursuivit pendant un siècle, indique de la part des Occidentaux une curiosité active : on rencontrait pour la première fois une philosophie systématique et coordonnée, et qui, ni à sa base ni à son sommet, n’avait aucune référence à la foi chrétienne ; tandis qu'il était facile de retrouver dans le Timée ou dans Macrobe quelque chose des dogmes chrétiens, par un commentaire 
approprié, seul valait pour une pensée telle que celle d'Aristote un commentaire littéral, qui ne laissait aucun espoir d'y trouver le plus faible écho des croyances chrétiennes.

Table des matières

\section{II. \\ DOMINIQUE GONDISALVI.}

p263 De l'œuvre personnelle de Dominique Gondisalvi, cet archidiacre de Ségovie qui traduisit Avicenne et Avicébron, nous devons retenir surtout le témoignage de l'influence qu'eurent dès cette époque les philosophes arabes : son œuvre n'en est qu'une compilation. Son De divisione scientiae, écrit en 1150, fait connaître la classification des sciences d'Avicenne et celle de Gazali, toutes deux fondées sur les notions péripatéticiennes d'être immobile et immatériel (théologie) et d'être mobile (physique), objets l'un et l'autre de la science théorique ; deux des anciens arts du trivium, la grammaire, accompagnée de la poétique, et la rhétorique avec la science des lois, l'économie et l'éthique sont placés dans la science pratique ; quant à la logique, il la considère comme un " instrument » plutôt que comme une partie de la philosophie, et il en voit la partie principale non dans les Topiques, mais dans la théorie de la démonstration des Analytiques postérieurs. La conception de la physique, qui étudie les corps à la fois par l'expérience et par le raisonnement, est tout entière empruntée à $\mathrm{Al}$ Farâbi. Avec celui-ci encore, il distingue fort nettement la métaphysique, qui est la science générale de l'être et de ses propriétés, de la théologie, distinction qui n'aurait que peu de sens pour un augustinien comme saint Anselme, selon qui Dieu est le seul être vrai (esse verum).

Son De immortalitate animae naît d'un effort pour appliquer les règles aristotéliciennes de la démonstration à la question de l'immortalité de l'âme ; la démonstration doit partir de l'essence ou des caractères propres du sujet étudié : une preuve de l'immortalité, fondée sur des vérités théologiques communes comme la justice de Dieu, n'est pas démonstrative ; une telle ${ }_{\text {p264 }}$ preuve ne peut s'appuyer que sur la connaissance de l'essence de l'âme. Or c'est à Aristote exclusivement qu'il emprunte cette connaissance ; il est étonnant de voir avec quel dédain il repousse la fameuse preuve platonicienne du 
Phèdre: "Nous laissons de côté, dit-il ${ }^{593}$, les preuves de Platon, parce qu'elles ne font pas croire à l'immortalité de nos âmes, étant communes à toutes les espèces d'âme, si bien qu'elles s'étendent à l'âme brute et végétative, dont il est manifeste que l'existence après le corps et en dehors du corps est entièrement inutile. » Aussi Gondisalvi, s'appuyant sur le péripatétisme arabe, ne démontre rien que l'immortalité de l'intellect, dont l'opération est indépendante du corps et qui n'est pas susceptible de génération et de corruption, n’étant pas composé de forme et de matière ${ }^{594}$. Remarquons pourtant que, un peu antérieur à Averroès, il suit fidèlement l'Aristote d'Avicenne ; il voit, dans le rapt et l'extase sans images, la preuve d'une vie séparée de l'intellect ${ }^{595}$; il démontre encore son immortalité par la proximité où il est de la première cause ${ }^{596}$. Il est clair qu'une pareille considération tend tout droit à l'immortalité impersonnelle ; l'âme, mortelle par sa partie inférieure et jointe au corps, est immortelle par sa partie principale et la plus noble ${ }^{597}$.

Table des matières

III.

GUILLAUME D’AUVERGNE.

L'avicennisme qui s'introduit ainsi avec Gondisalvi eut, au début du XIII ${ }^{\mathrm{e}}$ siècle, un grand nombre de partisans : tous les auteurs de Sommes citent alors Aristote pour prendre parti à son égard: Guillaume d'Auxerre, archidiacre de Beauvais entre 1231 et 1237, cite, dans sa Somme sur les Sentences, p265 écrite bien avant 1231, l'Éthique et le De Anima d'Aristote; dans son commentaire à l'Anticlaudien d'Alain de Lille, il cite la Métaphysique d'Aristote avec le commentaire d'Averroès et la Physique. Philippe de Grève, chancelier de l'Université de Paris en 1218, cite le De causis, le De anima et la Métaphysique dans sa Summa de bono. Guillaume d'Auvergne, maître de théologie, puis évêque de Paris depuis 1228, est l'auteur d'un De Im-

\footnotetext{
593 P. 11, édit. G. Bülow.

594 P. 5 à 11.

595 P. 23-24.

596 P. 33.

597 P. 24-25.
} 
mortalitate animae qui résume celui de Gondisalvi ; et il critique les théories d'Avicenne, dont il prend les doctrines, ainsi que la plupart de ses contemporains, pour celles d'Aristote.

C'est bien en effet Avicenne qu'il vise dans son De universo sous le nom d' « Aristote et de ses sectateurs »; il fait un exposé précis de sa théorie des Intelligences ${ }^{598}$ et du dogme de l'éternité du monde. Il attribue d'ailleurs la plus grande importance à la connaissance de cette philosophie : «La notion de matière et la notion de forme, écrit-il, font partie des rudiments de la philosophie; et puisque la notion même de matière est définie par le très noble philosophe Averroès, il eût été bon que ces gens, qui osent parler des choses de la philosophie d'une manière si inconsidérée, eussent appris d'abord, jusqu'à ce qu'elles leur devinssent certaines et claires, les intentions de ce très noble philosophe et des autres auteurs qui sont comme les chefs de la philosophie $^{599}$. " Ainsi, dès Guillaume d'Auvergne, commence un travail d'épuration qui consiste, déjà chez lui, à isoler les notions fondamentales du péripatétisme, de la mythologie des intelligences, qui lui avait été liée par la suite.

De cette théorie des Intelligences, Guillaume d'Auvergne critique le principe : il n'est pas vrai qu'une cause unique ne ${ }_{\text {p266 }}$ puisse produire qu'un effet unique, puisque le Créateur, qui est un, meut des hommes innombrables en tant qu'il est l'objet de leur amour ; il critique la cause qu'elle assigne au mouvement des cieux, cet effort vain et " stupide » de la sphère pour acquérir sous l'influence de son moteur une position qui est à chaque instant perdue; il critique enfin la liaison si étroite que la doctrine établit entre la dernière des Intelligences et le monde sublunaire. Ce n'est pas toutefois qu'il veuille nier l'animation des cieux ; il leur donne en effet, selon la tradition platonicienne, une âme unique qui les gouverne tous ; cette âme céleste exerce bien son influence sur les opérations des corps du monde sublunaire ; mais, loin de jouer le rôle de l’intellect actif, « elle n’est pas

598 Duhem, XV, t. V, p. 263-265 ; cf. p. 271. Guillaume ne connaît de la Métaphysique d'Aristote que les dix premiers livres ; c'est dans le $\mathrm{XI}^{\mathrm{e}}$ qu'il aurait trouvé une théorie des intelligences motrices bien différente de celle d'Avicenne.

599 Cité par DuHEM, p. 272. 
celle qui donne leur perfection (c'est-à-dire leur âme) aux corps des hommes, non plus qu'aux corps des animaux et des végétaux ${ }^{600}$ ».

Guillaume critique aussi les raisons que les "péripatéticiens » donnent de l'éternité du monde: il pense réduire leur thèse à l'absurde, en montrant qu'elle rend impossible tout changement; car ils veulent que toute chose soit à chaque instant comme elle était avant. Il paraît donc soupçonner qu'il $\mathrm{y}$ a dans cette thèse quelque chose de l'identité parménidienne : il dirige d'ailleurs ces arguments non seulement contre Avicenne, mais contre les partisans de Jean Scot, qu'une bulle d'Honorius III condamnait en $1225^{601}$.

Guillaume d'Auvergne sympathise en principe avec la nouvelle philosophie et en réfute plutôt les erreurs qu'il ne réussit à s'en assimiler les notions : c'est ce que l'on voit surtout dans sa théorie de la connaissance intellectuelle où, restant augustinien, il critique non seulement la théorie de l'intelligence séparée des Arabes, mais encore les adaptations chrétiennes que l'on avait, dès cette époque, tenté d'en faire. ${ }_{\text {p267 }}$ Contre toute tentative de ce genre, il a une objection de principe, c'est qu'elle suppose que la connaissance intellectuelle consiste à abstraire l'intelligible du sensible ; s'il en était ainsi, le concept serait un fragment du sensible, et l'intelligence n'aurait aucune originalité ; effectivement, le caractère abstrait n’est pas inhérent à notre intelligence qui, par sa nature, doit saisir l'individuel, mais que le péché originel a affaiblie au point qu'elle ne voit plus les formes intelligibles que comme la vue voit un objet dans le lointain ; mais le type de la connaissance intellectuelle, c'est bien pour Guillaume, une connaissance individuelle, " celle que l'intellect a de lui-même ainsi que de ses opinions, de ses doutes, de ses joies, de ses sciences. On ne peut donc douter que la faculté intellectuelle puisse appréhender des objets particuliers, du moins spirituels ». C'est donc l'augustinisme qu'il oppose aux idées nouvelles.

Dans ces conditions, non seulement il réfute la théorie d'un intellect agent séparé, qui reste sans objet, mais il rejette une théorie anonyme des péripatéticiens chrétiens, " première forme de la théorie al-

\footnotetext{
600 Cf. les citations dans DuHEM, XV t. V, p. 26S-270.

601 Cf. A. Masnovo, Guglielmo d'Auvergne (Riv. di fllos. neosc. XIX, 1927, p. 32 sq.), citant le De Trinitate, écrit de 1223 à 1228.
} 
bertino-thomiste » ${ }^{602}$ qui logeait dans l'âme l'intellect agent et l'intellect patient, l'intellect agent ayant pour mission «d'amener à l'acte (educere) les signes intelligibles qui sont en puissance dans l'intellect patient ", Cette thèse a le tort, à ses yeux, d'admettre une dualité dans l'âme ; pour lui, l’âme ne possède que l'intellect matériel, qui n'est pas purement passif, mais qui est aussi actif ; car il a en puissance les formes intelligibles qui se développent de lui comme l'être adulte naît de la semence.

Ce qu'il oppose à Avicenne, ce n'est donc pas un Aristote christianisé, c'est l'augustinisme : pourtant, il s'est servi, en un cas, de notions purement aristotéliciennes ; c'est pour réfuter la thèse de ceux (il s'agit évidemment d'Avicébron) p268 qui ont dit « qu'il n'y avait pas de substance créée immatérielle ; puisque aucune forme ne peut être reçue sinon dans une matière propre, la matière existe en toute substance ${ }^{603}$ »; il leur oppose qu'ils ignorent les rudiments de la philosophie d'Aristote et leur interprétation par Averroès, qui montre, comme l'affirme déjà Boèce, qu'il n'y a de matière que des substances corporelles.

Enfin il n'a aucun scrupule à user d'un principe de la Métaphysique d'Avicenne, celui qui distingue Dieu des créatures, parce que, en Dieu, l'essence et l'existence sont identiques, tandis que, dans la créature, elles sont distinctes ; " tout causé est possible par soi et il reçoit sur lui-même l'existence (esse), qui est autre chose que luimême ;... elle est pour lui un accident qui lui advient ; elle est reçue par lui sur toute son essence ${ }^{604}$ "; et dans le De Trinitate, il reprend la distinction sous la forme que lui avait donnée Boèce, celle du quo est et du quod est : "L'être par qui sont (esse quo sunt) les créatures ne leur est pas essentiel, mais est pour elles un accident. »

Ainsi, en rapport avec l'avicennisme, Guillaume d'Auvergne pose la plupart des questions qui seront, au $\mathrm{XIII}^{\mathrm{e}}$ siècle, matière à de longues discussions.

Table des matières

\footnotetext{
602 M. Baumgartner, dans Beiträge, II. Il est aisé de voir qu'elle n’est rien que la théorie de la Somme d'Alexandre de Halès (cf. p. 270).

603 Cité par Duhem, XV, t. V, p. 279.

604 De universo, cité par DuHEM, XV, t. V, p. 282.
} 


\section{Émile Bréhier \\ La philosophie du Moyen âge}

IV.

\section{Alexandre de Hales.}

Alexandre de Halès, après avoir enseigné de longues années comme maître séculier à l'Université de Paris, entra sans doute en $1230{ }^{605}$ déjà âgé, dans l'ordre des Frères mineurs ; il mourut en 1245. Il fut le premier des maîtres franciscains, et son autorité dans l'ordre fut si grande que saint Bonaventure, p269 dans la préface du second livre des Sentences, mentionne qu'il s'est attaché de préférence aux opinions d'Alexandre. L'ouvrage connu sous le nom de Somme d'Alexandre, s'il contient des parties dues à Alexandre lui-même, paraît être beaucoup plus l'œuvre collective de disciples qui se sont attachés à continuer et à développer ses idées et particulièrement des maîtres franciscains qui se sont succédé entre lui et saint Bonaventure, Jean de la Rochelle, Eudes Rigaud et Guillaume de Méliton, si bien qu'elle contient l'état de la pensée franciscaine dans les années qui s'écoulent entre lui et Jean Peckham, de 1235 à 1260 : on y trouve même textuellement des passages de saint Bonaventure; il est d'ailleurs impossible d'y démêler son œuvre propre ${ }^{606}$.

La Somme nous fait connaître un moment important de la lutte contre l'avicennisme et la doctrine d'Avicébron. En disant que Dieu ne peut produire qu'un effet unique, une intelligence, par l'intermédiaire duquel se produit la multiplicité des choses, Avicenne attribue à cet intermédiaire un pouvoir plus grand qu'à Dieu luimême. Cette critique est solidaire de celle qu'elle adresse à Avicébron, qui explique, on l'a vu, la variété des formes par la résistance de plus en plus grande que trouve une forme unique à s'imprimer dans la matière, à mesure que celle-ci devient plus obscure et plus éloignée de Dieu : la raison de la multiplicité dérive alors de la matière. La Somme tient, à l'inverse, à poser que les formes sont en elles-mêmes distinctes les unes des autres; il y a là un point de doctrine sans lequel s'évanouirait, avec la distinction des êtres en eux-mêmes et par euxmêmes, toute possibilité d'envisager ce qu'impose la croyance chrétienne, la destinée individuelle de chaque âme. Les raisons que donne

\footnotetext{
605 M.-M. GorCE, CXLII, p. 99.

606 GORCE. p, 76-108.
} 
la Somme, contre Avicébron, c'est que la matière qui est sans doute divisible, n'est pourtant divisée effectivement que par les p270 formes ${ }^{607}$. Ainsi sont liées étroitement, la toute-puissance d'un Dieu créant sans intermédiaire et l'originalité des êtres, fondée sur cette création même.

Quant à la connaissance intellectuelle, Alexandre, au contraire de Guillaume d'Auvergne, admet avec les Arabes qu'elle consiste, au moins partiellement, dans l'abstraction qu'une intelligence active a le pouvoir d'opérer sur les images pour que les formes abstraites s'unissent à une intelligence en puissance. Mais il résout le doute d'Aristote autrement que les Arabes: pour lui, non seulement l'intellect actif, mais l'intellect possible est une partie de l'âme : la théorie de l'abstraction ne peut donc porter atteinte à l'individualité. D'ailleurs, il coordonne à cette doctrine deux thèses fort différentes : d'abord de l'intellect possible, il distingue « l'intelligence matérielle qui connaît les espèces à l'aide des images »; c'est dire que l'âme sensitive devient chez lui une sorte d'intelligence. De plus il admet que la lumière que possède l'intellect actif est reçue en lui d'une illumination de Dieu lui-même; il superpose donc l'augustinisme à l'aristotélisme ${ }^{608}$.

Cette position est à peu près la même que celle du franciscain Jean de la Rochelle, né vers 1200, qui fut maître de théologie à Paris vers 1240. Dans sa Summa de anima, où il utilise Avicenne et saint Augustin, il admet bien la théorie avicennienne de la connaissance par abstraction, mais « relativement à la vérité suprême (Dieu) et à ces intelligibles qui dépassent l'entendement humain, c'est Dieu qui est l'intellect agent ${ }^{609}$ ".

Dans la méditation directe du fameux chapitre d'Aristote, la Somme franciscaine s'écarte encore de l'interprétation ordinaire des Arabes : Aristote y disait que, dans l'intellect, il y a quelque chose qui est comme la forme et quelque chose qui est comme la matière. La Somme en déduit qu'il y a matière ${ }_{\mathrm{p} 271}$ aussi bien dans les êtres intellectuels que dans les substances corporelles, et elle comprend qu'il a

\footnotetext{
607 DuHEM, XV, t. V, p. 323-326.

${ }^{608}$ De anima, t. II, p. 37.

${ }^{609}$ Duhem, XV, t. V, p. 320-322 ; J. Rohmer, CL.
} 
voulu dire que, dans l'intelligence, la matière, c'est l'intellect possible et la forme, l'intellect actif : et, à son avis, tout être spirituel, même l'ange, doit être composé de la même façon, d'une lumière et de ce qui reçoit la lumière : interprétation qui, étendant à tout esprit la distinction observée dans l'âme humaine, montre que la théorie des intelligences n'implique pas nécessairement que toute connaissance se fait par abstraction. Duhem a rattaché, mal à propos, semble-t-il, cette composition hylémorphique des esprits à l'influence d'Avicébron ; comme il le dit lui-même, il n'est rien que la Somme rejette avec plus de force que la thèse d'une matière universelle, qui impliquerait l'unité des êtres ${ }^{610}$ : Duhem fait encore remarquer qu'elle rejette formellement l'argument sur lequel Plotin, puis Avicébron, appuyaient l'existence d'une matière spirituelle, à savoir la communauté générique qu'il y a entre les intelligences. Pour elle, chaque esprit a sa matière séparée ; et Alexandre n’admet même pas, avec Avicenne, qu'il y ait une matière commune aux choses célestes et aux choses sublunaires. La composition hylémorphique ne porte donc chez lui aucune atteinte à cette séparation métaphysique des êtres, condition même de la pensée chrétienne, qu'Avicenne et Avicébron venaient mettre en danger.

Tandis que les maîtres de théologie s'efforçaient de sauver la diversité des créatures contre l'avicennisme envahissant, ils défendaient aussi l'unité de Dieu contre un platonisme qui paraît avoir eu beaucoup d'adeptes au début du XIII ${ }^{\mathrm{e}}$ siècle : selon cette doctrine, Dieu a créé le monde d'après un exemplaire qui est distinct de lui. Cette doctrine se trouve exposée et réfutée chez Guillaume d'Auvergne comme chez Alexandre. Selon Guillaume, si le monde des archétypes est distinct du ${ }_{\text {p272 }}$ Créateur, il a fallu qu’il fût lui-même créé, ce qui est impossible sans régression à l'infini ; il n'est donc pas plus différent du Créateur que l'art n'est différent de l'artiste ; il s'ensuit, puisque Dieu est simple, qu'il ne peut y avoir de division entre les idées et que, par exemple, «la terre véritable, considérée selon son concept, c’est le Créateur " ${ }^{611}$. C'est aussi contre ces platoniciens que la Somme écrivait : «La première essence n’a pas besoin de modèle ; elle n’a de modèle autre qu'elle-même. » De ce platonisme est parente une inter-

${ }^{610}$ XV, t. V, p. 330.

611 DuHEM, XV, t. V, p. 284. 
prétation de l'augustinisme, qui fut condamnée à Paris en 1241 par une assemblée de théologiens présidée par Guillaume d'Auvergne, à laquelle participait Alexandre : « Il y a, disait-on, beaucoup de vérités qui ont été dès l'éternité et qui ne sont pas Dieu lui-même. » Dans toutes ces doctrines franciscaines, le christianisme, dans ses aspirations fondamentales, est donc comme la grille qui permet de choisir, dans la nouvelle philosophie qui inonde l’Occident, les éléments assimilables.

Table des matières

\section{V. \\ ROBERT GROSSETESTE.}

Pourtant il se rencontre, dans cette première moitié du XIII ${ }^{\mathrm{e}}$ siècle, des hommes qui sont des adversaires de l'esprit même de cette nouvelle philosophie. Pour Robert Grosseteste, né en 1175, professeur à Oxford en 1230 et mort évêque de Lincoln en 1253, les erreurs d'Aristote ne sont pas accidentelles ; elles sont dues à un défaut foncier qui vicie tout le système, et ce défaut consiste essentiellement à se représenter les choses spirituelles par des images sensibles ; ainsi procèdent ceux qui, comme Aristote, n'emploient que la raison discursive : par elle se démontre l'existence de choses spirituelles, p273 de Dieu ou des Intelligences ; mais s'agit-il de les penser, « ils ne les voient qu'au travers des représentations corporelles »; de là leurs erreurs, par exemple l'erreur fondamentale de l'éternité du monde ; par raisonnement, Aristote et d'autres voient que «l'éternité est simple ; et toutefois cette éternité simple, leur intelligence n’a pu la saisir ;... ils ne l'ont aperçue que sous la représentation, fournie par l'imagination, d'une étendue temporelle ; ce qui les a conduits à affirmer une foule d'absurdités, comme la perpétuité du mouvement et du temps et, par suite, l'éternité du monde » ; or, la raison en est dans la disposition affective (affectus) de ces hommes : " comme ces dispositions étaient plus étroitement liées aux choses qui passent qu'aux choses éternelles, leur intelligence n'a pu atteindre jusqu'à la simplicité de l'éternité ${ }^{612}$ ». C’est là un rappel de la tradition chrétienne ; la philosophie, chez Aristote, est une raison arrêtée à elle-même ; chez

${ }^{612}$ ED. BAuR, dans II, t. IX, p. 105, cité par DuHEM, XV, t. V, p. 341-342. 
les chrétiens et les platoniciens, c'est une raison qui s'élève vers la vision, une préparation à cette vision.

C'est sous l'autorité de saint Augustin que Robert place ses propres doctrines ; c'est de saint Augustin qu'il tire cette thèse que Dieu est la forme unique de toute chose ${ }^{613}$; le mot forme désignant d'ailleurs chez lui l'exemplaire tel qu'il existe dans l'âme de l'artiste, cette proposition n'a pas d'autre sens que, chez Guillaume d'Auvergne ou Alexandre de Halès, la thèse que le monde archétype de Platon se réduit à la simplicité du Verbe de Dieu : Avicébron, selon qui la forme unique était une créature et pour qui le Très-Haut est audessus de toute forme, n'a rien à voir avec cette théorie. C'est à saint Augustin, par l'intermédiaire de saint Anselme, qu'il emprunte la notion de vérité ; "La vérité des choses est d'être des choses telles qu'elles doivent être, leur rectitude et leur conformité au Verbe par qui elles sont dites éternellement ; ... un arbre ${ }_{\mathrm{p} 274}$ est vraiment arbre lorsqu'il a l'essence de l'arbre dans sa plénitude, et cette plénitude d'essence, qu'est-ce sinon la conformité avec la raison de l'arbre qui réside au sein du Verbe éternel ${ }^{614}$ ? »

Robert paraît donc attribuer à l'esprit humain le pouvoir d'atteindre les essences. Dans son Commentaire des Analytiques postérieurs, il décrit, à la façon des néoplatoniciens, les niveaux métaphysiques auxquels peut se trouver la forme, objet de la connaissance : d'abord comme raison en Dieu, puis comme forme exemplaire créée dans l'Intelligence créée, puis comme raison causale des choses sublunaires, comprise dans les sphères célestes, enfin comme forme substantielle d'une chose corruptible dans une matière : parallèlement à cette série d'intelligibles, il imagine une série d'intelligences décroissantes ; l'Intelligence pure, supérieure à l'intelligence humaine, peut seule saisir les raisons en Dieu ; mais l'intelligence humaine, à son degré le plus haut de purification, connaît les formes exemplaires créées, telles qu'elles sont dans l'Intelligence pure, tandis que, sous la

613 De unica forma omnium, éd. Baur, II, t. IX, p. 106-111.

614 De veritate, éd. Baur, p. 135. 
forme la plus débile, elle n’atteint que les accidents qui accompagnent les formes ${ }^{615}$.

A ce platonisme, confiant dans les forces de l'intelligence, se relie, chez Robert, une véritable rénovation des sciences de la nature ${ }^{616}$ : car, au XIII ${ }^{\mathrm{e}}$ siècle, ce n'est guère à l'aristotélisme, p275 malgré son affirmation de principe que toute connaissance dépend de l'expérience, mais bien au platonisme, qu'il faut reconnaître la plus grande efficace dans la reconstitution des sciences de la nature.

C'est une notion essentiellement platonicienne, en effet, que la notion de « corporéité » ou essence du corps, dont parle Robert ; elle désigne la forme du corps, que la matière doit d'abord recevoir pour que le corps, constitué par la liaison de la corporéité et de la matière, reçoive à son tour les autres formes ; cette notion se trouve chez Plotin et aussi chez Avicenne : la corporéité, loin d'être inférieure aux autres formes qui la supposent, « est, selon Robert, plus digne que toutes les formes suivantes ; elle les surpasse en vigueur, elle est de plus noble essence ; elle est celle qui ressemble le plus aux formes immuables et séparées ${ }^{617}$ ». Et il se flatte de la saisir jusqu'en son fond même ; « cette forme première, c'est la lumière. La lumière, en effet, se répand d'elle-même en tout sens, en sorte que, à partir du point lumineux, une sphère de lumière aussi grande qu'on veut se trouve subitement engendrée, à moins qu'un corps opaque ne fasse écran. Or, la corporéité, c'est ce qui a pour conséquence nécessaire l'extension de

615 Cité par DuHEM, XV, t. V, p. 346-348. Le Roman de la Rose, commencé par Jean de Meung vers 1240 et achevé par Guillaume de Lorris vers 1270, nous fait voir quelle était la popularité du platonisme. Le Roman parle de Dieu qui fit le monde : «Dont il portait en sa pensée La belle forme pour-pensée Toujours en pardurableté » (v. 16731-33), et ailleurs de sa " chambrière », Dame Nature, qui tisse incessamment toutes les choses : «A l'exemplaire des Idées Qui, devant les choses crées, Sont en la pensée divine » (v. 16827) ; sur le sens philosophique du Roman, voir l'édition de M. Gorce, dans la Collection des textes rares ou inédits, éditions Montaigne, 1933.

${ }^{616}$ On sent au XIII ${ }^{\mathrm{e}}$ siècle le besoin de renouveler les encyclopédies vieillies du début du Moyen Age. Un minorite, Barthélémy l’Anglais, écrit, de 1225 à 1240, un De proprietatibus rerum, encyclopédie en dix-neuf livres où il utilise les écrivains syriens et arabes ; au milieu du siècle, Vincent de Beauvais, en son Speculum majus, cite, avec Albert et saint Thomas, Al Farâbi, Isaac Israëli et Avicébron. Et l'on sait l'importance des ouvrages qu'Albert le Grand a consacrés aux sciences naturelles.

617 De inchoatione formarum, édit. Baur, p. 52. 
la matière selon trois dimensions ; il faut bien alors que cette forme soit la lumière, puisque se propager soi-même, se répandre immédiatement en tout sens, c'est l'opération propre de la lumière ». De même Avicébron, qui a pu suggérer directement à Robert cette idée, avait considéré la forme universelle comme une " lumière » qui s’étend de haut en bas, à la manière dont la lumière du soleil se répand, mais qui, en haut, est lumen purum et en bas lumen turbidum ${ }^{618}$, retrouvant luimême l'antique ${ }_{\mathrm{p} 276}$ idée de Proclus ${ }^{619}$ et de Damascius ${ }^{620}$ que le lien du monde est la lumière. Mais cette notion devient, chez Robert, une notion active et efficace, en ce sens qu'il s'efforce de déduire, de la nature de la lumière, les propriétés des corps ; en un milieu diaphane, en effet, sa propagation est instantanée ; mais elle peut, en outre, selon les cas, se distendre ou se rassembler, et alors, c'est la contraction ou la dilatation des corps ; s'engendrer selon une trajectoire déterminée, et alors, c'est le mouvement local ; expulser la lumière inhérente à un corps et la remplacer par une autre : c'est l'altération. Robert montre enfin l'utilisation possible de la géométrie dans un tel monde où « toutes les causes des effets naturels peuvent être données par des lignes, des angles et des figures ${ }^{621} »$.

Cette physique de la lumière, qui consiste à définir la force naturelle par une certaine loi de propagation, a eu, au XIII ${ }^{\mathrm{e}}$ siècle, une très grosse influence : nous la retrouvons chez Roger Bacon, et chez ceux qu'on a appelés les perspectivistes d'Oxford » Ces vues sont toujours liées à une métaphysique platonicienne : le polonais Witelo, qui vécut longtemps en Italie, y fait la connaissance de Guillaume de Mœrbeke, par les traductions de qui il put connaître, avec Aristote, Simplicius et Proclus : c’est à Guillaume qu'il dédie sa Perspective, composée vers 1270 ; en même temps que cet ouvrage il écrit un De ordine entium où il a dû traiter de la hiérarchie platonicienne des réalités » Sa Perspective étudie la loi de la propagation de la lumière, et la structure de l'œil, pour finir par les lois de la réflexion et de la réfraction. Mais la préface de ce livre expose et adopte les thèses de Proclus au livre Des Causes : comme chez Grosseteste, la lumière agit comme la forme du

\footnotetext{
618 Fons vitae, p. 25.

${ }^{619}$ In Rempublicam, édit. Kroll, p. 199, 19.

620 De Principiis, édit. Ruelle, t. II, p. 219,18.

621 De luce, édit. Baur, p. 60.
} 
corps et elle est la première des formes sensibles ; par elle, comme médium, se répandent, jusqu'aux corps, les formes supérieures ; p277 elle divise et répartit, par sa propre activité, ce qui était indivisible au niveau de Dieu.

Sur les vingt-sept petits traités de Robert Grosseteste, édités par Baur, il n'y en a pas moins de dix-sept qui portent sur des questions de sciences naturelles. Ajoutons qu'une Somme de philosophie, attribuée à tort à Robert Grosseteste, mais inspirée de son esprit et écrite vers 1270 , pose en principe l'indépendance des sciences de la nature par rapport à la théologie : en ces matières, indifférentes au salut, les théologiens ont pu se tromper ou ignorer la vérité ${ }^{622}$.

Toute la doctrine de Robert Grosseteste suppose plus ou moins explicitement que les intelligibles ne sont pas par essence des universaux, mais plutôt des choses singulières, et que c'est par accident qu'il leur arrive d'appartenir à plusieurs individus. Cette thèse est très amplement développée dans la Somme mise sous son nom : elle a à cœur de démontrer, comme Guillaume d'Auvergne, que le singulier est objet de science ${ }^{623}$. L'auteur cherche, à ce point de vue, à défendre contre Aristote la doctrine des idées platoniciennes, dont, dit-il après Averroès et avec beaucoup d'auteurs de ce temps, « nous ignorons les raisons » : ces idées si énigmatiques, il les voient comme n’étant ni la forme incréée qui est en Dieu, ni la forme substantielle qui est dans les choses, mais les genres et les espèces naturelles, qui sont à la fois dans les individus, bien qu'elles n'y soient pas individuellement, et en elles-mêmes, mais non pas universellement ; en elle-même, l'espèce est "numériquement une ", bien que ce soit parce qu'elle est commune à plusieurs êtres que l'entendement peut la penser en unissant ces êtres entre eux sous une raison commune ${ }^{624}$.

Aussi l'auteur de la Somme ne peut accepter cette thèse issue d'Aristote et acceptée par saint Thomas, que les anges ou p278 intelligences sont des formes pures et sans matière qui, pour cette raison, se distinguent entre elles comme des espèces et non comme des individus. Avec Guillaume d'Auvergne, il soutient que ces intelligences

622 Summa, traité I, ch. XII; édit. Baur, II, t. IX.

623 Traité III, ch. III.

624 Traité V, ch. XIX. 
sont composées de forme et de matière ; étant des sujets, elles doivent avoir en elles une matière qui reçoit la forme, si différente que soit leur matière de celle des corps ${ }^{625}$. L'âme raisonnable, chez l'homme, n'est pas davantage une forme dont le corps serait la matière, comme le prétendent Aristote et les modernes : l'âme est un individu, à la fois forme et matière, et ce n'est pas du corps qu'elle tient l'individuation ${ }^{626}$.

La thèse de la composition hylémorphique des êtres spirituels, chez cet auteur comme chez tous les chrétiens de cette époque qui partagent cette opinion, naît certainement du souci de rendre les esprits à la fois plus dépendants de Dieu, puisqu'ils sont, comme matière, des êtres réceptifs, et plus indépendants des corps, en tant qu'ils n'ont pas à rechercher dans les corps la réalité qui achèverait leur être.

Table des matières

${ }^{625}$ Traité X, ch. V; contrairement à Guillaume, il identifie la distinction entre forme et matière à la distinction, issue de Boèce, entre quo est et quod est.

${ }^{626}$ Traité XI, ch. IV, p. 463. 


\section{Chapitre III}

\section{SAINT BONAVENTURE}

I.

Platonisme et ANTIARistotelisme.

Dans l'école de Robert Grosseteste, les augustiniens assimilaient ce qui, du péripatétisme arabe et juif, était le moins péripatéticien et le plus platonicien ; mais ils rejetaient spontanément l'aristotélisme authentique.

Avec des préoccupations différentes et plus théologiques, c’est ce que fit, au milieu du siècle, le grand maître de théologie de l'ordre franciscain, saint Bonaventure, qui se donnait lui-même comme un disciple fervent et fidèle d'Alexandre de Halès. Né en Toscane en 1221, il l'avait eu comme maître à Paris, de 1243 à 1245 ; il y fut professeur en 1248, et il devint en 1257 général de l’ordre des Mineurs. Il mourut en 1274 .

Saint Bonaventure a gardé de la fonction rationnelle l'idée traditionnelle ; elle s'appuie sur la foi et s'oriente vers la vision : «L'ordre est de commencer par la stabilité de la foi et d'avancer à travers la sérénité de la raison pour parvenir à la contemplation »; raison suffisante pour rejeter l'attitude des philosophes ; " cet ordre, les philosophes l'ont ignoré, qui p280 négligeant la foi et se fondant complètement dans la raison, n'ont pu d'aucune façon parvenir à la contemplation ${ }^{627}$ ». C'est pourquoi il peut écrire que «la clarté de la science philosophique est grande selon l'opinion des gens du monde, mais

627 Sermo IV de rebus theologicis, 15, t. V, p. 571. Cité par GILson, CLVII, p. 115. 
petite en comparaison de la clarté de la science chrétienne »; la philosophie, par elle seule, n’a même pas pu découvrir le dogme fondamental de la création : "Cette vérité, si ouverte et lumineuse qu'elle soit pour tout fidèle, a échappé à la sagesse des philosophes qui, dans la recherche de cette question, se sont longtemps égarés ${ }^{628}$ ", Platon en soutenant que la matière existe de toute éternité, Aristote en soutenant qu'elle est éternellement liée à la forme. De même, si Platon, au Timée, divise l'âme en parties pour localiser chacune d'elles en une partie du corps, c'est que cette solution s'impose à la raison toute seule « qui ne peut comprendre qu'une essence limitée puisse être simultanément et tout entière présente dans chacune des parties du corps si elle n'est contrainte de le croire par aucune obligation de foi ${ }^{629}$ ". C'est l'expérience même qui montre combien est nuisible la raison laissée à elle-même : après le mouvement avicennien qui avait marqué le début du siècle, Bonaventure voit se développer sous ses yeux, à l'Université de Paris, le mouvement averroïste, et c'est lui qui, en 1270, obtient de l'évêque de Paris la fameuse condamnation contre la philosophie : création d'une intelligence par une autre, éternité du monde, fatalisme, unité de tous les intellects humains, mortalité de l'âme, négation de la création ex nihilo, voilà les thèses qu'il reprochait aux philosophes dans p281 ses conférences de 1268 sur les dons du Saint-Esprit, et voilà aussi les thèses qui furent condamnées en 1270 ; il leur reprochait encore d'accorder à la philosophie le pouvoir de diriger seule la vie morale, d'atteindre Dieu directement et de rendre la Loi inutile ; elle devenait ainsi une sorte de caricature de la religion ${ }^{630}$.

Aristote et ceux qui le suivent introduisent la philosophie pure au début de la théologie, en disant que l'existence de Dieu n'est pas évidente, mais qu'elle doit être prouvée par des considérations sur le monde : pour saint Bonaventure, au contraire, comme pour saint $\mathrm{Au}-$ gustin et pour les mêmes raisons, l'existence de Dieu est une évi-

${ }^{628}$ II Sententiae, 1 ; t. II, p. 16 ; GILSON, p. 180.

${ }^{629}$ GILSON, p. 320, d'après I Sentent. 8, 2 ; t. I, p. 171. Il faut remarquer à quel point la question est ici mal posée par Bonaventure ; l'ubiquité de l'âme est démontrée par Plotin parlant en pur philosophe et en disciple de ce Platon, à qui Bonaventure reproche la thèse contraire ; et saint Augustin, qui, selon Bonaventure, le sait par la foi, a en réalité emprunté la thèse de Plotin.

630 Jules D’AlBI, CLVIII, p. 164-190 ; GoRCE, CXLIII, p. 164 sq. 
dence : pouvons-nous même douter de lui, alors qu'il est, comme vérité première, la condition de l'exercice même de notre pensée ? Car « notre intellect n'entend rien que par la première vérité ; donc toute action de l'intellect, qui consiste à penser que quelque chose n'est pas, existe par la lumière première ; mais par la lumière première, on ne peut arriver à penser que cette lumière ou vérité première n'est pas ${ }^{631}$ ». Nul besoin donc de connaître la nature extérieure pour connaître l'être qui, à cause de sa simplicité suprême, « est plus intérieur à l'âme que l'âme à elle-même ", pour percevoir ce bien infini que l'âme est faite pour connaître ${ }^{632}$.

Nous voici dès la première démarche près de Dieu ; il s’agit de ne pas nous en séparer; car «si nous nous abaissons (declinamus) à la connaissance des choses de l'expérience, en cherchant plus qu'il ne nous est permis, nous tombons de la contemplation véritable, et nous goûtons de l'arbre défendu de la science du bien et du mal ${ }^{633}$ ». L'on rattachera la nature tout entière à Dieu, en disant que toutes les créatures sont des p282 "expressions » de Dieu. Saint Bonaventure pense donc la création en platonicien, ne voulant saisir les choses que dans leur rapport à l'exemplaire divin ; bien entendu, il n'admet pas plus que Guillaume d'Auvergne et qu'Alexandre de Halès la théorie qu'on attribuait à Platon lui-même, d'une multiplicité d'idées en dehors de Dieu ou même en Dieu : à l'exemple de Guillaume et d'Alexandre, il identifie le monde des idées à l'essence de Dieu ; il est vrai qu'il nous est difficile de saisir cette unité du multiple : "Quand nous voulons voir par simple intuition comment cet art divin est un et pourtant multiple, parce que l'imagination s'en mêle, nous ne pouvons penser la manière dont il est infini qu'en l'étendant en parties (per distensionem), et nous ne pouvons le voir par simple intuition, mais seulement par raison discursive (ratiocinando) $\gg{ }^{634}$ : difficulté qui est de l'ordre de celles que Plotin discute dans les Ennéades et qu'il résout de la même façon, par la multiplication de l'image de l'Un dans le discours et dont Bonaventure fait, par erreur, honneur à la seule révélation ; « l'Idée en Dieu, selon sa réalité, est la Vérité divine, et, suivant notre

\footnotetext{
631 I Sentent., 8, 1 ; t. I, p. 153 ; cité par GILSON, p. 133.

632 I Sentent., 1, 3 ; t. I, p. 41.

633 In Hexam., I ; t. V, p. 332 (GILsON, p. 141).

634 In Hexam., XII, 11 ; t. V, p. 386 (GILSON, p. 150).
} 
manière de comprendre, la ressemblance de la chose connue : cette ressemblance est raison expressive de l'acte de connaître et l'universel et le singulier, bien qu'elle ne soit elle-même, pas plus que Dieu, ni universelle ni singulière ».

De même qu'il pense en platonicien les choses comme des expressions de Dieu, c'est en platonicien qu'il exprime la raison pour laquelle Dieu a créé ; elle est dans sa volonté : « La raison pour laquelle cette causalité (créatrice) est attribuée à la volonté, c’est que la raison qui fait agir la cause est la bonté, et comme efficiente et comme finale. Car on dit que le bien a tendance à se répandre (diffusivum sui) et que c'est en vue de lui que sont toutes choses ${ }^{635}$. " Mais cette volonté est libre et la diffusion du bien n'est pas, comme dans le néoplatonisme, p283 une émanation nécessaire ; il est même faux que Dieu ait été assujetti à faire le monde le meilleur possible, et les raisons de son choix nous restent incompréhensibles. La notion de toute-puissance fait ainsi en quelque manière échec à la rationalité platonicienne ; elle introduit une contingence radicale en un monde qui, selon l'esprit platonicien, ne devrait être que l'effet nécessaire de son modèle ; et la notion d'ordre limite d'autre part la toute-puissance, « qui, bien que sans mesure, a disposé toutes choses selon le poids, le nombre et la mesure ».

C'est donc la notion de toute-puissance qui vient corriger l'exemplarisme platonicien. Lorsque saint Bonaventure écrit : "Pour manifester son immensité, Dieu produit bien des choses de ses trésors, mais non pas tout, parce que l'effet ne peut être égal à la cause première ", il s'agit bien, comme dans le platonisme, d'une manifestation et d'une participation : mais cette participation est l'effet d'une volonté toute-puissante : " les choses sont faites en vue de la gloire de Dieu, non pour l'acquérir, ou pour l'augmenter, mais pour la montrer et la communiquer ; et dans sa manifestation ou participation, il a égard (attenditur) à la souveraine utilité de la créature, à sa glorification ou béatification ${ }^{636}$ ». Loin de croire, avec les Arabes, qu'une cause unique produit un effet unique et que la création ne peut se faire que par intermédiaires, il soutient que plus une cause est parfaite, plus va-

${ }^{635}$ I Sentent., 45, 2 ; t. V, p. 804 (GILSON p. 176).
${ }^{636}$ II Sentent., 1, 2 ; t. II, p. 44-45 (GILSON, p, 192). 
riés et divers sont ses effets : il s'agit, bien entendu, de la perfection de la volonté.

Avec cette réserve constante, il peut développer sans danger l'exemplarisme platonicien : doctrine toute naturelle chez un augustinien qui veut trouver partout les ombres, les vestiges ou les images de Dieu, mais à laquelle il est plus attaché que tout autre. Considérer sous cet aspect les créatures, c'est le moyen que Platon avait employé pour

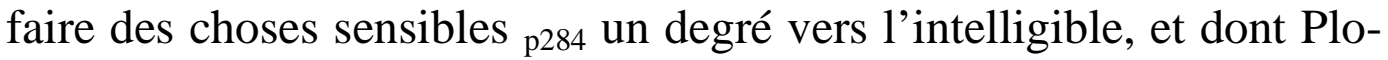
tin avait usé pour placer toute réalité dans les hypostases divines, ne laissant aux choses que la valeur "d'une ombre sur une ombre » : moyen d'exalter et d'abaisser à la fois la créature : " toute créature, quelle qu'elle soit, écrit Bonaventure, est faite pour conduire à Dieu ${ }^{637}$ "; mais il dit ailleurs : il ne s'agit point entre Dieu et la créature d'une «ressemblance de participation ", comme si toutes deux participaient à un seul et même être ${ }^{638}$, il y a la ressemblance du modèle à la copie qui met toute réalité du côté du modèle. Ce double aspect sans cesse présent ne permet pas à l'esprit de se reposer dans la créature » comme si elle était une nature qui se suffise à elle-même ; en elle, on voit au contraire la sagesse divine : "Cette sagesse est répandue en toute chose, parce que une chose, quelle qu'elle soit, selon une propriété quelle qu'elle soit, contient la règle de la sagesse divine et la manifeste ; et qui connaîtrait toutes ces propriétés connaîtrait clairement cette sagesse ; " mais la nature est souvent devant nous comme un livre ouvert dont nous ne comprenons pas le langage ${ }^{639}$. A la philosophie païenne, Bonaventure reproche de s'arrêter aux choses, tandis que la philosophie chrétienne ne les considère que comme des signes : il ne pouvait pas voir que cette philosophie chrétienne, dans la mesure où elle nous invite à la conversion vers Dieu à partir des choses sensibles, était le platonisme.

Tout, dans le détail de la pensée de Bonaventure, témoigne de ce surnaturalisme, qui refuse de faire de la nature un objet de contemplation distinct, qui aurait ses lois propres : composition hylémorphique des anges et des âmes, pluralité des formes, raisons séminales, autant

\footnotetext{
637 I Sentent., 3, 1 ; t. I, p. 72 (GILSON, p. 202).

${ }^{638}$ II Sentent., 16, 1 ; t. II, p. 395 (GILSON, p. 201).

639 In Hexam. II, 20 et 21 ; t. V, p. 340 (GILSON, 206).
} 
de thèses par où il s'opposait à un aristotélisme, qui voit dans la nature une réalité bien définie.

Table des matières

II.

\section{L'HYLEMORPHISME UNIVERSEL.}

p285 Pourquoi, suivant ainsi Guillaume d'Auvergne, a-t-il fait des anges des composés de forme et de matière et non des formes pures comme les Aristotéliciens ? Selon le physicien, la matière est sujet et principe de la génération et de la corruption pour les choses sublunaires et sujet du mouvement local pour les sphères célestes; en ce sens elle n'appartient qu'aux choses corporelles; mais, en un sens plus large, elle est sujet de la forme ${ }^{640}$, ou encore elle est la forme en puissance. "Si l'on prend la matière au sens large de ce qui existe en puissance, il faut dire que la substance de l'ange est composée de forme et de matière ${ }^{641}$; » car il n'est pas de créature qui n'ait été, au moins logiquement, en puissance avant d'avoir été en acte. La matière, chez Bonaventure, c'est donc, comme chez Avicébron, le caractère de toute créature en tant que telle ; aussi, se posant la question suggérée sûrement par la Source de vie : «Si la matière des êtres corporels est numériquement la même que celle des êtres incorporels », il n’a aucun scrupule à répondre que, «bien qu'elle n'ait pas l'unité d'un universel pas plus que celle d'un individu, elle peut être dite, selon l'essence, numériquement une par homogénéité ${ }^{642}$; » car il est impossible d'introduire, en un être en puissance comme tel, quelque distinction que ce soit. La matière n'a pas en revanche la propriété individuante qu'elle a pour Aristote ; pour celui-ci, la forme, en ellemême, est spécifique, et la différence entre les individus d'une même espèce vient des accidents ${ }_{\text {p286 }}$ ou de la matière ; il s'ensuivait que les anges, étant formes pures, différaient entre eux comme des espèces, non comme des individus. Mais, pour Bonaventure, les anges sont dis-

640 Bonaventure et tous ceux qui adhèrent à son opinion suivent ici la règle de Boèce : « La forme qui est sans matière ne pourrait être un sujet » (De Trinitate, ch. II GILSON, p. 304).

${ }^{641}$ II Sentent., 3, 1 ; t. II, p. 89.

642 II Sentent., 3,1 ; t. II p. 99. 
tincts entre eux comme des personnes, et cela non pas en raison de leur matière, mais de leur forme : " la propriété d'être une personne ne vient pas des accidents, mais d'une liaison actuelle de principes et elle est en soi quelque chose de substantiel ${ }^{643}$ ». Bonaventure n’hésite pas, certes, à repousser cette sorte d'hérésie philosophique, qui vient d'Averroès et qui sera celle de Duns Scot, d'après qui il y a, audessous des formes spécifiques, des formes individuelles; mais il ne veut pas non plus de la thèse classique, qui attribue l'individuation à la matière ; l'individu vient plutôt de la liaison actuelle de la matière avec la forme ; l'individu est un hoc aliquid dans lequel hoc vient de la matière et aliquid de la forme ${ }^{644}$; mais la personne peut être plus que la simple singularité : "En tant que la distinction de personne veut dire singularité, elle naît, comme l'individuation, d'un double principe ; en tant qu'elle veut dire dignité, elle suit principalement la raison de la forme » : il y a, à ce sujet, une évidente incertitude ; mais il est clair que la valeur qu'il attribue à la personne l'empêche de chercher dans la matière les conditions de sa nature, bien qu'elle y ait, parce qu'elle est créée, les conditions de son existence.

Comme l'ange et pour les mêmes raisons, Bonaventure considère l'âme humaine comme étant en elle-même un composé de matière et de forme, par là même qu'elle est une créature ; et c'est de cette union qu'elle tire son individualité avant toute union avec le corps. L'union de l'âme et du corps n'est donc pas, comme pour Aristote, l'union d'une forme avec une matière ; l'âme est déjà, par elle-même, comme chez Platon, une substance complète. Si elle est liée au corps, c'est que le ${ }_{\text {p287 }}$ corps a acquis, l'une après l'autre, ces formes qui l'ont rendu assez parfait pour être maintenant informé par cette nouvelle forme qu'est l'âme humaine. La liaison de l'âme avec le corps suppose donc plus ou moins explicitement la thèse de « la pluralité des formes ».

Cette thèse, par ailleurs, se lie foncièrement au platonisme de Bonaventure : l'application de la forme à la matière, si elle a pour résultat de déterminer l'être en puissance de la matière, a pour but de conférer au composé de forme et de matière une aptitude à recevoir des formes nouvelles ; ainsi, pour que la matière reçoive la forme d'un

\footnotetext{
${ }^{643}$ II Sentent., II, 3. 1 ; t. II, p. 106.

644 Ibid., p. 109.
} 
élément, il faut d'abord qu'elle ait reçu la forme universelle du corps, cette corporéité que Bonaventure, avec Robert Grosseteste, assimile à la lumière ${ }^{645}$; pour recevoir l'âme, il faut qu'elle ait d'abord reçu la forme du corps organisé ; ainsi les formes se conditionnent les unes les autres, et l'acquisition de chacune marque une possibilité de progrès.

Bonaventure suit encore le platonisme augustinien, lorsqu'il explique la production d'une nouvelle forme substantielle dans la matière non seulement par l'action d'une cause efficiente qui tire cette forme de la matière (eductio), mais en outre par l'existence de raisons séminales existant déjà dans la matière ; et si la matière est nommée être en puissance, c'est que sommeillent en elle des puissances qui, il est vrai, ne peuvent se réveiller elles-mêmes ; toute autre doctrine donnerait à la cause efficiente une puissance créatrice qui n’appartient qu’à Dieu : "Étant donné que la raison séminale est une puissance active intérieure à la matière et que cette puissance active est l'essence de la forme, puisque d'elle vient la forme grâce à l'opération de la nature qui ne produit rien de rien, il est raisonnable de poser que la raison séminale est l'essence de la forme à produire et diffère d'elle comme l'être ${ }_{\text {p288 }}$ incomplet de l'être complet, l'être en puissance de l'être en acte ${ }^{646}{ }^{\prime \prime}$.

$\underline{\text { Table des matières }}$

\section{III. \\ CONNAISSANCE, VOLONTE ET AMOUR.}

Comme il place des raisons séminales dans la matière du corps, Bonaventure considère les puissances de l'âme, l'intelligence et la volonté, non pas comme des accidents, mais comme étant « consubstantielles à l'âme et du même genre qu'elle par réduction " ${ }^{647}$, c'est-àdire que, tout en étant distinctes de la substance, elles s'y rattachent essentiellement.

645 Cf. GiLson, CLVII, p. 159 ; p. 310. La théorie de la pluralité des formes découle de sa doctrine plutôt qu'elle n'y est exposée.

646 II Sentent., 18,1 ; t. II, p. 440 (GILSON, p. 287).

${ }^{647}$ I Sentent., 3, 2 ; t. I, p. 86 (GILSON, p. 332). 
C'est pourquoi, à la manière augustinienne, il met en lumière l'activité de l'âme dans toutes ses opérations ; c'est ainsi que, dans sa théorie de la sensation, s'il va moins loin que saint Augustin qui ne peut admettre aucune action du corps sur l'âme et s'il admet que l'âme y est passive au point de vue du contenu des sensations, il croit que cette passion s'accompagne immédiatement d'une action par laquelle l'âme discerne et juge les objets : si bien que la connaissance sensitive, étant déjà active, est en continuité avec l'activité intellectuelle ${ }^{648}$.

Dans l'intellect non plus, il n'est pas possible d'admettre pure passivité ni pure activité : Bonaventure accepte sans doute la distinction aristotélicienne de l'intellect agent qui émet la lumière et de l'intellect possible, qui est illuminé ; mais, dit-il, « l’intellect possible n'est pas purement passif, car il a le pouvoir de se tourner vers l'espèce qui se trouve dans la représentation et, en se tournant vers elle, de la recevoir grâce au secours de l'intellect agent, et d'en juger ; et l'intellect agent n'est pas complètement en acte ; car il ne peut rien comprendre de soimême, s'il n’est aidé par une espèce qui, p289 séparée de l'image, peut s'unir à lui ${ }^{649}$ ". Ainsi, dans toutes les puissances de l'âme, Bonaventure fait ressortir une activité, mais une activité imparfaite qui ne peut s'exercer sans entraide et collaboration ; c'est ce que n'ont pas vu la plupart des philosophes qui « se sont trompés en enseignant une émanation de l'intelligence (séparée) sur l'âme, que n'admet pas la foi catholique ${ }^{650} »$.

Comme Guillaume d'Auvergne et Alexandre de Halès, Bonaventure donne à la connaissance intellectuelle deux objets de sorte fort distincte: d'une part les formes inhérentes aux choses sensibles, d'autre part notre propre âme et Dieu. Quant à la première sorte, il admet, avec Aristote qu'elles ne sont connues que par une abstraction qui s’applique aux images venues des sens, et il répète avec le $D e$ anima que notre entendement est une table rase. Quant à la seconde, il en est tout autrement : "L'âme connaît Dieu et se connaît elle-même et les choses qui sont en elle sans l'aide des sens extérieurs; donc, si

\footnotetext{
648 GiLsON, p. 338-340.

${ }^{649}$ II Sentent., 24,1 ; t. II, p. 569 (GILSON, p. 352).

650 ibid., t. II, p. 571.
} 
parfois le Philosophe dit que rien n'est dans l'intellect qui n'ait été auparavant dans les sens et que toute connaissance est issue des sens, il faut le comprendre de celles qui existent dans l'âme par une image (similitudinem) abstraite. " Il ne peut en être ainsi ni de Dieu, ni des vertus de l'âme. Comment, par exemple, connaît-on la charité ? Celui qui la possède la connaît par expérience : mais celui qui ne la possède pas en a une connaissance spéculative ; cette connaissance "ne peut se faire par l'essence de la charité (qu'il est supposé ne pas posséder), ni par une image acquise à partir des sens; il faut donc qu'elle se fasse par une image (similitudinem) infuse ou innée... Or l'espèce innée peut être de deux sortes : ou bien seulement une image ; comme la forme de la pierre, ou une image de ce qu'est une certaine vérité en elle-même. L'espèce de la première sorte est comme une peinture, et p290 l'âme en est créée complètement vide ; l'espèce de la seconde sorte est une impression de la suprême vérité dans l'âme; par exemple, il a été donné à l'âme, selon sa condition, une lumière qui la dirige et une direction qui lui est naturelle ; il lui a été donné aussi une affection de la volonté ; l'âme connaît donc ce qu'est rectitude et ce qu'est affection, et ainsi ce qu'est rectitude de l'affection ; et puisque c'est là la charité, elle a la connaissance de la charité par une certaine vérité qui n'est pourtant que l'image (similitudo) de la charité ${ }^{651}$ ». De même la connaissance de Dieu « est innée dans l'âme raisonnable, en tant que l'âme tient compte de l'image (imaginis), grâce à laquelle a été introduite en elle un appétit naturel, une connaissance et un souvenir de celui à l'image de qui elle a été faite et vers qui elle tend naturellement ${ }^{652}$ ».

La connaissance innée indique donc à la fois chez Bonaventure et une plus grande spontanéité de l'âme et une relation plus directe de l'âme à Dieu, non seulement en tant que connaissante, mais en tant qu'affective et voulante ; mais elle n'exclut nullement, comme voulait le faire Platon, la valeur de la connaissance empirique : Aristote doit s'unir à Platon, et cette union a été réalisée par saint Augustin parce que l'enseignement chrétien lui a appris à concevoir les diverses sortes de connaissance intellectuelle comme des moments successifs de l'itinéraire qui mène l'âme du monde sensible à Dieu :

651 I Sentent., 17, 1 ; t. I, p. 301 (GILSON, p. 359).
${ }^{652}$ De myst. Trinit., I, 1 ; t. V, p. 49 (GILSON, p. 361). 
l'Itinerarium mentis décrit ces étapes d'une route qui va des choses sensibles à la faculté de sentir, puis aux facultés naturelles de l'homme, à ses facultés réformées par la grâce, à l'idée d'Être, à l'idée de Bien, jusqu'à la joie passive de l'extase ${ }^{653}$.

La doctrine de la connaissance est presque déjà, chez Bonaventure, une doctrine de la volonté ; il ya, dans la connaissance, p291 une activité spontanée venue de Dieu et dirigée vers Dieu. La doctrine morale admet un équilibre tout à fait analogue entre la puissance innée donnée par Dieu, qui agit du fond de l'âme, et l'attraction divine. La Somme d'Alexandre de Halès avait introduit en morale l'expression, empruntée à saint Jérôme, de syntérésis, la scintilla conscientiae, qui persiste chez Adam après le péché, et qui désignait chez lui une puissance supérieure aux parties de l'âme et capable de les observer. Dans la Somme, elle désigne une " puissance habituelle » (potentia habitualis), c'est-à-dire une faculté non acquise et toujours prête à s'exercer, qui incline la volonté vers le bien; c'est une "volonté naturelle » du bien, une "lumière innée " (lumen innatum) qui est le principe de la connaissance pratique, mais que la volonté délibérée, qui, seule, peut pécher, peut suivre ou non : elle est une «loi naturelle » et immuable ${ }^{654}$. Bonaventure, réfléchissant sur les mêmes notions, distingue la conscience qui prescrit les règles de conduite et qui appartient à l'intellect, de la syntérésis qui est l'inclination naturelle vers le bien et qui n'appartient qu'à la volonté. La conscience est un habitus, une disposition prête à agir, qui est en partie une " disposition innée » et toujours vraie en tant qu'elle s'étend aux lois universelles et une « disposition acquise », qui porte sur les prescriptions morales plus spéciales qui ne peuvent s’acquérir que par l'instruction et le raisonnement : sous ce second aspect, la conscience peut être erronée, et pourtant c'est toujours un devoir d'obéir à ce qui nous apparaît comme bon après réflexion. En effet, la " syntérésis », qui est la volonté du bien, ne sait pas par elle-même discerner entre le bien et le

653 GILSON, p. 363. Il est clair que cet itinéraire est celui de Platon et surtout de Plotin : conversion des choses à soi, puis aux choses divines, jusqu'à l'extase, et qu'il a été adopté, non inventé par le christianisme.

654 O. DiTTRICH, XII, t. III, p. 97-100. 
mal et doit suivre la règle que la raison lui prescrit, même si la règle est, en elle-même, erronée ${ }^{655}$.

C'est un principe, sans doute hérité des Stoïciens par saint Augustin et saint Bernard, que la volonté ou appétit n'agit p292 pas sans que l'entendement lui propose un objet et que la raison ne peut davantage donner son assentiment à un bien, sans un appétit qui l’y pousse : c'est dans cette collaboration des deux facultés que se joue tout le drame de la vie morale : le libre arbitre consiste en leur accord ; il n'est pas une troisième faculté qui s'ajoute à l'intelligence et à la volonté ; mais il est cette disposition permanente (habitus) " grâce à laquelle l'une et l'autre sont maîtresses de leurs propres actes », par l'aide mutuelle qu'elles se prêtent l'une à l'autre, la volonté pour s'éclairer, l'intelligence pour choisir ${ }^{656}$ : comme l'avait dit saint Bernard, le libre arbitre persiste intégralement après la chute, et on ne peut le concevoir qu'égal chez tous les hommes. Dans la vie morale, où fonctionnent ces divers pouvoirs, Bonaventure fait le départ entre les vertus qui peuvent être acquises par l' " industrie humaine », et celles qui exigent l'intervention de la grâce. Les premières sont les quatre vertus cardinales, qui ont fait l'objet des préoccupation des philosophes; mais, comme Plotin, qu'il connaît par Macrobe, au-dessus de ces vertus que l'on appelle politiques parce qu'elles consistent dans l'action, il place les « vertus purifiantes » qui s'exercent par la contemplation et, plus haut encore, les « vertus purifiées » qui s'élèvent à la vision de la lumière : la vie morale tout entière est semblable au retour du rayon lumineux jusqu'à sa source, qui a lieu dans la réflexion de la lumière. La vertu acquise par des moyens humains, celle qui fait l'objet de la philosophie morale, n'a donc point sa fin en elle-même ; elle n'est qu'un début ; elle correspond, dans la volonté, au niveau des connaissances que l'âme peut acquérir en considérant les seules choses sensibles; mais la compétence des philosophes qui s'étend aux actions morales, «dont le libre arbitre est le principe selon la règle du droit naturel imprimé en chacun ", s'arrête à ces vertus supérieures, issues p293 de la grâce, « qui ne peut être connue que par la foi catholique et sans laquelle les œuvres des hommes sont vaines, bien qu'elles parais-

${ }^{655}$ II Sentent., 39, 2 ; t. II, p. 911 (GILSON, p. 404).
656 II Sentent., 25,1 ; p. 599 ; p. 603 (GILSON, p. 392-393). 
sent dignes d'éloge ${ }^{657}$ ». La nature et l'habitude sont donc capables de commencer ce que seule la grâce achève : la vertu naturelle est en soi déficiente ; c'est la charité, vertu surnaturelle, qui est « la racine, la forme et la fin des vertus, les joignant toutes à la fin dernière et liant toutes choses ensemble avec ordre ; elle conserve l'ordre dans la diversité des objets à aimer, et elle possède elle-même l'unité en tant qu'elle vise à une fin unique et à un premier aimé ».

La doctrine de Bonaventure continue donc, en morale aussi, l'augustinisme du XII ${ }^{\mathrm{e}}$ siècle, par sa conception d'une nature humaine et d'une raison qui n'est qu'un échelon dans l'ascension qui nous mène vers Dieu et à laquelle il serait dangereux de s'arrêter comme à une fin, même inférieure.

${ }^{657}$ II Sentent., 25, 1; t. II, p. 607 (GILSON, p. 410). La vertu surnaturelle de la charité est d'ailleurs susceptible de progrès chez l'homme. Cf. La France franciscaine, Documents, t. XIX, 1936, p. 143 sq. 


\section{Chapitre IV}

\section{SAINT ALBERT LE GRAND ET SAINT THOMAS D’AQUIN}

I.

\section{LE PROBLEME DE L'INCORPORATION DE L'ARISTOTELISME.}

Saint Thomas dépeint ainsi la différence d'attitude du philosophe et du fidèle en face des choses : " Le philosophe considère dans les créatures ce qui leur convient selon leur nature propre, par exemple, dans le feu, son mouvement vers le haut ; le fidèle considère en elles ce qui leur convient en tant qu'elles sont rapportées à Dieu, par exemple qu'elles sont créées par lui, qu'elles lui sont soumises., et choses de ce genre ${ }^{658}$. " Cette distinction n'était pas faite par les Augustiniens, qui refusaient au fond d'adopter en matière philosophique une attitude différente de celle du fidèle ; devant un homme comme saint Bonaventure, la nature s'ouvre comme une seconde Bible, dont l'interprétation doit le conduire à Dieu ; la nature n'a pas d'autre essence, d'autre fond que cette sorte d'exigence de progrès spirituel. Ce n'est pas autrement que pensait le platonisme : dans un cas très analogue à celui qui est cité par saint Thomas, Plotin refuse de considérer le mouvement p295 circulaire des sphères à la manière d'Aristote comme un mouvement physique, mais y voit un mouvement psychique et spirituel ; expliquer la nature, c'est en voir la signification pour l'esprit. Sur ce point précis, Plotin et les néoplatoniciens s'opposent à Aristote. On voit un conflit de ce genre se renouveler au $\mathrm{XIII}^{\mathrm{e}}$ siècle en Occident, lorsque la philosophie d'Aristote est connue dans un milieu où les esprits sont pétris de platonisme et 
d'augustinisme : cette philosophie est rebelle, autant qu'il est possible, à toute interprétation spirituelle ou allégorique de la nature ; les concepts essentiels dont elle use, acte ou puissance, forme ou matière, mouvement, sont des abstraits des choses sensibles (car « il n'y a rien dans l'intellect qui n'ait été d'abord dans les sens ») et comme les cadres universels dans lesquels on pourra classer toutes les nuances de l'être ou du devenir ; la métaphysique et la physique ne sont qu'une description, faite au moyen de ces concepts, de l'allure générale de toute réalité sensible ; elles ne donnent aucune ouverture, sinon peutêtre en un cas unique et privilégié, sur ces réalités spirituelles et profondes avec lesquelles communie l'âme religieuse.

Mais, si la philosophie aristotélicienne est donnée, dans ces conditions, comme l'œuvre achevée de la raison humaine l'équilibre entre la raison et la foi, qui s'était établi dans les meilleurs esprits du Moyen Age après saint Anselme, ne va pas pouvoir se maintenir, malgré les efforts des Augustiniens du XIII ${ }^{\mathrm{e}}$ siècle : la raison et la philosophie n’ont plus cette position intermédiaire entre les choses sensibles et la réalité intelligible, qui faisait d'elles comme l'anticipation de la vision permise à l'homme in via, puisqu'elles font retourner obstinément la pensée vers les choses sensibles, même si cette pensée s'applique à leurs formes, c'est-à-dire à celles de leurs conditions d'existence qui sont saisissables à l'intelligence. La philosophie ne devient-elle pas alors un danger irrémédiable, moins par ce qu'elle dit que par ce qu'elle empêche ? Car, si l'aristotélisme ${ }_{\mathrm{p} 296}$ arabe, avec sa doctrine de l'éternité du monde, du fatalisme astrologique et de l'intellect commun à tous les hommes, s'opposait aux croyances chrétiennes fondamentales de la création, de la liberté et de l'immortalité personnelle, cet obstacle était loin d'être invincible, et le texte d'Aristote pouvait être pris en un sens moins défavorable à la foi : restait l'esprit d'une doctrine, tout entière jaillie d'une curiosité spéculative, qui ignore la foi chrétienne et qui, par conséquent, ne laisse plus à la raison cette fonction intermédiaire que la culture chrétienne lui assignait.

On voit quelle difficulté rencontrait le problème de l'incorporation de la doctrine du "Philosophe » à la culture chrétienne : difficultés qui, au XIII ${ }^{\mathrm{e}}$ siècle et dans la suite, parurent insurmontables à beaucoup et que pourtant saint Albert le Grand, puis saint Thomas d'Aquin, s'efforcèrent de vaincre. 
II.

\section{Albert LE Grand (1206-1280) ET SAINT ThOMAs (1227-1274).}

Albert le Grand et saint Thomas ont tous deux étudié en Italie, en des milieux où, sous l'impulsion de Frédéric II, celui que les Franciscains traitaient de " roi de pestilence » et d' " antéchrist », se développait l'étude de la science arabe, Albert à Padoue, vers 1223, saint Thomas d'Aquin à Naples, où il entendit avant 1243 les leçons d'un maître ès arts averroïste, Pierre d'Irlande ${ }^{659}$. Albert entre en 1223 dans l'ordre des Dominicains et saint Thomas vingt ans plus tard, en 1243 ; les deux hommes se rencontrent à Paris, où Albert, après avoir enseigné en Allemagne entre 1228 et 1245, devient à cette date maître de théologie à l'Université de Paris jusqu'à 1248 ; saint Thomas y fut son élève pendant ces trois années. p297 A cette époque, les écrits d'Albert paraissent avoir été purement théologiques ; il composa, en effet, la Summa de creaturis, ainsi que le Commentaire des Sentences vers l'époque de son séjour à Paris ; la Summa theologiae ${ }^{660}$, qui est inachevée, appartient à sa vieillesse (1274) (il mourut en 1280); ses paraphrases sur Denys l'Aréopagite, sur le livre Des causes et sur les œuvres d'Aristote (Physique, Du ciel, l'Organon, les livres Sur l'âme), ainsi que son De unitate intellectus contra Averroistas (1256) ont été écrits dans l'intervalle. Grabmann a, en outre, découvert des fragments encore inédits de la Summa de creaturis, une Summa de bono sive de virtutibus, de sacramentis et de resurrectione, qui fait partie de la Summa de creaturis ${ }^{661}$. Mais saint Thomas suivit son maître à Cologne, d'où il ne revint qu'en 1252 à Paris, pour y rester jusqu'en 1259 ; en 1259, nouvelle rencontre entre Albert, devenu provincial de l'ordre en Allemagne, et saint Thomas, pour déterminer un programme d'études dans l'ordre des Dominicains. Albert avait dès ce moment écrit son traité contre l'erreur des Arabes sur l'unité de

659 GORCE, CXLII, p. 118.

660 Sur le problème posé par cette Somme qui, postérieure à celle de saint Thomas, ne l'utilise pas et qui revient à des opinions augustiniennes, auparavant condamnées (notamment sur la matière dans les anges), cf. GORCE, CXLII, p. 132-135, d'après qui cette Somme est une compilation.

661 Ulrich Dahnert, CLXIII, p. 3, - Fr. Pelster, CLXVI. 
l'intellect (en 1256) ; de cette période est sa réponse au pamphlet de Guillaume de Saint-Amour; elle est à peu près de même date que le Contra impugnantes Dei cultum, où saint Thomas s'oppose au même adversaire. Saint Thomas, qui avait commencé à Paris par des œuvres surtout théologiques : le Commentaire des Sentences, le De ente, le De veritate, fait un long séjour en Italie, de 1259 à 1268, où il entreprend, comme Albert, un commentaire général des œuvres d'Aristote, avec l'aide de l'helléniste Guillaume de Mœrbeke [De l'interprétation, Analytiques postérieurs, Physique, Métaphysique (douze livres), Éthique, De l'âme, Météores, ${ }_{2298}$ De coelo I à III, De generatione, Politique] ${ }^{662}$. Ses œuvres théologiques se poursuivent dans la même période avec la Somme contre les Gentils (1259-1260) et le début de la Somme théologique (en 1265), qu'il continue pendant tout le séjour qu'il fit à Paris comme maître de théologie à l'Université, de 1268 à 1272 ; il laissa la Somme inachevée en 1273. Dans ce séjour à Paris, il écrit, comme Albert en 1256, un traité contre la théorie arabe de l'unité de l'intellect, mais, semble-t-il, contre des adversaires assez différents de ceux d'Albert, qui étaient plutôt des avicenniens, tandis qu'il vise l'averroïsme proprement dit, qui se développa à Paris entre 1266 et 1270 ; mais il combat aussi les Augustiniens dans le Contra murmurantes. Saint Thomas meurt en 1274. Albert le Grand, qui, après s'être démis de l'évêché de Ratisbonne qu'il occupa de 1260 à 1262 et après avoir refusé le poste de chancelier à l'Université de Paris, enseigne à Cologne depuis 1270, lui survit encore pendant six ans, assez pour s'efforcer de réhabiliter saint Thomas, en 1277, lorsqu'il fut condamné par l'évêque de Paris, sous l'influence du Franciscain Jean Peckham ${ }^{663}$.

On voit l'étroite union des œuvres des grands Dominicains; pour l'un comme pour l'autre, Aristote est le " Philosophe » dont il s'agit, comme le dit Albert au début de son Commentaire de la Physique, de rendre « les idées intelligibles aux Latins »; l'un et l'autre sont cités par le Franciscain Roger Bacon parmi les principaux philosophes, et il

\footnotetext{
${ }^{662}$ Il commente ainsi qu'Albert les Noms divins et le livre Des causes, dont, il découvre l'identité avec les Éléments de théologie de ProcLus.

663 GorCE, CXLII, p. 313-316.
} 
ajoute qu'Albert a, de son vivant, une autorité qui n'est comparable à celle de nul autre ${ }^{664}$.

Table des matières

III.

\section{LA PHILOSOPHIE D’AlBerT LE GRAND.}

p299 Chez Albert pourtant, la philosophie aristotélicienne, dont il prétend être le fidèle interprète, sans prendre aucunement parti pour elle, se juxtapose à la théologie plutôt qu'elle ne se coordonne avec elle. La philosophie des "péripatéticiens ", au reste, est, aux yeux d'Albert, non seulement celle qui est contenue dans les livres d'Aristote, mais celle du livre Des causes et des Arabes, et tout particulièrement dans l'interprétation de Farâbi et d'Avicenne. La " philosophie péripatéticienne ", ainsi conçue, s'oppose à celle de Platon, qu'Albert rapproche d'Épicure pour son polythéisme : Albert se soucie peu du Timée; elle s'oppose aussi à la doctrine d'Avicébron. Le jugement d'Albert sur l'auteur de la Source de vie nous fait parfaitement comprendre son attitude en philosophie : s'il y avait un point sur lequel Avicébron s'accordait avec le christianisme et s'opposait au " péripatétisme ", c'était bien dans la doctrine de la création : il admet que Dieu, par sa volonté, crée simultanément plusieurs choses, tandis que, d'après les Arabes, Dieu produit non par sa volonté mais par son essence, et, étant un agent unique, ne peut produire qu'une chose unique ; la doctrine d'Avicébron a beau être celle des théologiens, Albert l'attaque, parce qu'il la propose en philosophe, comme une doctrine qui ne s'accorde pas avec les règles de la philosophie ${ }^{665}$. Il entre ainsi en conflit avec les Augustiniens, pour qui la philosophie n'était qu'un moment ou un épisode de la théologie : il est sévère pour ceux « qui confondent la philosophie avec la théologie... Les choses théologiques ne s'accordent pas, dans leurs principes, avec les choses philosophiques ; car la théologie est fondée sur la révélation p300 et sur

664 Opus tertium, éd. Brewer, p. 30. Il est vrai que, ailleurs (Opus minus, p. 325 sq), il montre l'insuffisance d'Albert « qui n’a jamais enseigné la philosophie et ne l'a entendu enseigner à aucune école », qui ignore des sciences, fondamentales comme la perspective.

665 Duhem, XV, p. 424-429, citant Albert, De Causis, lib. I, tract. III, ch. VIII. 
l'inspiration, non sur la raison. Nous ne pouvons donc, en philosophie, discuter de questions théologiques ${ }^{666}$ ". Il semblerait que la philosophie et la théologie sont comme des jeux qui ont chacun des règles absolument conventionnelles, mais qu'on ne doit pas confondre et dont on ne doit pas se départir, si l'on veut jouer.

Toutefois, Albert répète avec insistance que c'est dans ses livres de théologie et non pas de philosophie qu'il faut chercher sa propre opinion et ce qu'il croit être la vérité : il est donc bien difficile, pour ne pas dire impossible, de parler de la « philosophie » d'Albert le Grand. Dans la Physique, le premier des commentaires d'Aristote qu'il ait écrit, il adopta l'attitude de Maïmonide au sujet de la question de l'éternité du monde : après avoir cherché des raisons philosophiques contre l'éternité et en faveur de la création, il conclut : " Aucune de ces deux opinions ne saurait être démontrée ; on la peut seulement appuyer de raisons probables ${ }^{667}$. » Mais il n'en est pas resté du tout à ce probabilisme. Dans les commentaires suivants, en particulier dans la Métaphysique, il enseigna avec un grand luxe de détail la théorie avicennienne des intelligences motrices des cieux et de leur production, mais, dans les Sentences, il fait grief à ces «fous » qui ont assimilé ces intelligences motrices aux anges, et il traite la doctrine d' « erreur maudite $"{ }^{668}$.

Bon gré mal gré, Albert devait donc prendre parti, lorsque la philosophie, avec ses règles, s'oppose à la foi. Toutefois, il est au moins un cas dans lequel il s'est efforcé de construire une théorie philosophique qui répondît en même temps aux conditions de la foi : il s'agit du problème de l'individuation, duquel dépendait celui de la destinée des âmes après la mort. Il semble bien que le péripatétisme devait, en suivant ses principes, p301 résoudre cette question par la négation de l'immortalité personnelle de l'âme. Eh effet, selon les péripatéticiens, dans le composé de forme et de matière, qui constitue l'être concret, là forme est spécifique, et c'est la matière qui est le principe d'individuation : donc l'homme, composé de l'âme comme forme et du corps comme matière, doit à son corps une individualité qui périt

\footnotetext{
${ }^{666}$ DuHeM, p. 429, citant Metaphysica, lib. XI, tract. III, ch. VII.

667 Physica, liv. VIII, tract. I, ch. XV.

668 Sentent., dist. XIV, art. 6 (DUHEM, t. V, p. 447-448).
} 
avec lui. Ajoutons que l'homme, en pensant, ne peut penser que l'universel ; or puisque, dans l'intelligence, chose pensante et chose pensée ne font qu'un, il faut admettre qu'il n'y a qu'une seule intelligence en tous les hommes : c'est nier la croyance essentielle du christianisme à la destinée personnelle. Albert connaît aussi la solution qu'on en donnait chez les Franciscains et même chez bien des Dominicains à son époque, qui attribuaient l'individualité à la forme et admettaient au surplus une matière. Albert tient au principe de l'individuation par la matière : "La matière accompagne tout ce qui est telle chose déterminée, car c'est elle qui est le principe qui confère à cette chose son individualité ; elle accompagne tout ce qui se montre comme une chose déterminée, car c'est elle qui, dans les substances sensibles, est déterminée par la quantité et par la qualité sensibles. Ni l'un ni l'autre ne se rencontrent dans la forme; s'ils se rencontrent tous deux dans une substance composée de matière et de forme, ils s'y trouvent à cause de la matière ${ }^{669}$. " Il s'ensuivrait que l'individualité des substances spirituelles, qui sont sans matière, reste inexplicable à la philosophie, tout en étant assurée par la foi ; ici Albert, guidé d'ailleurs par le précédent de Guillaume d'Auvergne, cherche une solution philosophique : dans les substances séparées, comme les anges, il admet une composition qui, sans être celle de forme et de matière, à la même efficacité pour expliquer l'individuation : c'est celle du quod est, sujet de l'existence, et du quo est ou esse, p302 principe par lequel l'être existe ; cette distinction, qui est de Boèce, répond à la distinction, familière à Avicenne, entre le possible et le nécessaire ; " c’est parce que le possible dépend d'autre chose, à savoir de la cause première, qu'il est dit possible en soi ; et il particularise et divise le principe de l'être (le quo est), qui, de soi, est commun, comme l'est toute forme ${ }^{670}$ ». Mais la distinction du quod est et du quo est ne répond pas du tout aux arguments par lesquels les Arabes affirmaient l'unité de tous les intellects humains : question grave sur laquelle, après avoir exposé les opinions des péripatéticiens et de Platon, Albert croit indispensable de poser sa propre opinion « parce que, dit-il, je repousse

\footnotetext{
${ }^{669}$ Metaphysica, lib. XI, tract. I, ch. VII.

${ }^{670}$ II Sentent., dist. II, a. 2 (RolAND-Gosselin, Le De ente de saint Thomas, p. 175)
} 
absolument, dans cette question, les formules des docteurs latins ${ }^{671}$ ». Albert, pourtant, ne donne aucune solution dans son Commentaire du De anima : car ce n'est pas une solution de dire que l'intelligence, étant la faculté d'une âme qui est unie au corps par ses facultés sensibles et végétatives, et dont cette union fait un individu, est individualisée par là même ${ }^{672}$; et il reste, d'après Albert même, que « les intellects sont un en tant qu'intellects et ne sont multiples qu'en tant qu'affectés à ceux-ci ou à ceux-là ». Dans le De unitate intellectus, Albert le Grand fait valoir la force des arguments que l'on donne contre la distinction des intellects : comment l'intellect, universel par nature, et lieu des intelligibles, pourrait-il se limiter dans un lieu déterminé ? Et finalement, c'est "parce que nous supposons comme prouvée, par ailleurs, l'immortalité des âmes raisonnables, qui restent multiples après la mort », que nous sommes forcés d'admettre que « l'âme raisonnable et intellectuelle se multiplie selon le nombre des individus " ${ }^{673}$. Il paraît donc bien ${ }_{\mathrm{p} 303}$ qu'il y a là un renoncement à résoudre philosophiquement la question. Et, en effet, Albert ne trouve pas de solution dans la voie de l'aristotélisme, mais il paraît plutôt la chercher dans le néoplatonisme du De causis : il voit, dans la multiplicité des intelligences, le résultat de cette loi générale d'émanation, selon laquelle le multiple sort de l'Un : « Il y a un intellect absolument séparé, c'est l'intellect de l'Intelligence, dont l'intelligence humaine est une sorte d'image ;... l'intelligence de l'homme est en elle comme des lumières inférieures sont contenues dans une lumière supérieure dont, par influence, elles reçoivent formes et mouvements ; cette influence productrice de formes et de mouvements coule sans interruption depuis la cause première ${ }^{674}$. "

On voit bien ici l'inconsistance de la pensée d'Albert et combien mal il arrive à intégrer le péripatétisme dans la pensée chrétienne.

Table des matières

671 C'est-à-dire de ceux qui, avec saint Bonaventure, admettent une matière spirituelle. De anima, III, tr. 2, ch. I (RoLAND-GossELIN, 96).

672 Cf. ROLAND-Gosselin, p. 97-98.

673 Ed. Borgnet, t. IX, p. 452 (GORCE, CXLII, p. 141).

${ }^{674}$ Metaphysica, liv. XI, t. I, ch. IX (DuHEM, XV, V, p. 461). 
IV.

\section{REGLE THOMISTE DE L'ACCORD DE LA RAISON ET DE LA FOI.}

La philosophie cesse d'être, chez saint Thomas et chez Albert, une méditation sur la foi, un effort pour comprendre les vérités de la foi ; ou plutôt, les éléments de la philosophie étrangère à la foi, qui avaient toujours subsisté dans les sept arts et surtout dans la dialectique, reparaissent au premier plan grâce à l'introduction de la philosophie d'Aristote. La distinction que l'on avait fait au siècle précédent entre les naturalia et les theologica prend alors un sens plus plein.

Mais alors une question nouvelle s'impose: les jugements de l'homme sur la réalité viennent de deux sources distinctes : de la raison, lorsqu'il s'agit de vérités d'ordre philosophique concernant surtout la nature ; de l'autorité, en matière théologique. p304 Historiquement et humainement parlant, on sait à quel point ces sources sont différentes : d'une part, une philosophie traditionnelle, conçue chez les Grecs au $\mathrm{IV}^{\mathrm{e}}$ siècle avant notre ère, dont les concepts essentiels, ceux de puissance et d'acte, de matière et de forme, dérivent d'une analyse de la perception immédiate ; d'autre part, un ensemble de croyances, liées à l'existence d'une Église dont le rôle politique et social n'est pas moins important que le rôle proprement religieux. Rien n'est plus simple que l'accord de principe entre cette philosophie et ces croyances. Comme le dit saint Thomas, en effet, la vérité ne peut contredire la vérité : car de deux propositions contradictoires, l'une est nécessairement vraie, l'autre nécessairement fausse; d'autre part, nous savons que les dogmes de la foi ont une absolue certitude ${ }^{675}$, et il n'est pas permis au chrétien d'en douter. Dès lors, si une proposition de la philosophie contredit une affirmation du dogme, l'on peut être assuré qu'elle est fausse ; car le degré de certitude d'une proposition, obtenue par le raisonnement humain, sujet à l'erreur, ne peut jamais être l'équivalent de la certitude dérivant de l'autorité : saint Thomas garde sur ce point les idées des siècles précédents. Bien que la philosophie ne procède donc qu'avec la raison, elle trouve dans la foi un appui qui lui est nécessaire (ratio confortata fide) car la foi non seulement la garde des erreurs qu'elle pourrait commettre, si elle était

675 De veritate, II, a. 12 : L’adhésion de foi est incomparablement plus forte que toute autre, parce qu'elle provient non pas de l'intellect seul, mais de la volonté qui incline l'intellect à donner son assentiment à ce qu'elle croit. 
livrée à elle-même, mais elle lui propose et lui prescrit ses propres vérités comme des buts vers lesquels elle doit se diriger, quand même elle ne peut les atteindre : c'est en ce sens que la philosophie est la servante de la théologie.

En droit, la règle de saint Thomas pourrait et même devrait ne pas avoir à s'appliquer, puisque la raison, en elle-même, est ${ }_{\mathrm{p} 305}$ toujours d'accord avec la foi. En fait, sa philosophie péripatéticienne, telle qu'elle s'est transformée chez les Arabes au contact du néoplatonisme, contient un grand nombre de propositions qui s'opposent aux dogmes chrétiens : éternité du monde, négation de l'immortalité des individus et, d'une manière générale, tendance à nier tout ce qui, dans le réel, pourrait être personne et initiative individuelle : un pareil état de fait aboutissait soit à rejeter la philosophie, comme firent les Augustiniens, soit à appliquer strictement la règle thomiste, si on veut en faire usage en théologie : cet usage lui-même ne sera valable que si « l'on s'appuie non sur l'autorité des philosophes, mais sur la valeur de leurs raisonnements, à moins que l'on n'en use pour réfuter des erreurs ; alors, selon la règle des Topiques d'Aristote, on use de ce qui est accepté par l'adversaire comme d'une autorité ${ }^{676}$ ».

Ce qui rendait possible cette conception des rapports de la raison et de la foi et toute la structure mentale qui en dérive, c'était la philosophie péripatéticienne elle-même et, par-dessus tout, l’idée qu'elle se fait de la raison humaine. En effet, tandis que l'augustinisme platonicien essaye de faire entrer la raison comme un degré ou une étape dans la vie religieuse et comme une illumination d'ordre inférieur, il n'y a rien de pareil dans l'aristotélisme, où l'intellect humain, comme on l'a vu souvent, ne peut procéder que par un travail d'abstraction opéré sur les images venues des sens ; elle n’a donc pas, dans l'état naturel, d'autres objets directs que les formes des choses matérielles ; il n'est donc pas dans la vocation naturelle de la raison de connaître les choses spirituelles et divines. Cette doctrine de la raison, contrepied de l'augustinisme, ne risquait pas de donner à la raison un rôle prépondérant ; mais elle courait le danger inverse, celui de la cantonner dans les choses sensibles, danger qui apparut avec évidence au ${ }_{\mathrm{p} 306}$ $\mathrm{XIV}^{\mathrm{e}}$ siècle, lorsque le fidéisme, interdisant à la raison de se pronon-

${ }^{676}$ In Boet., De Trinitate, 1, qu. 2, a. 3. 
cer sur les choses divines, lui laisse le champ libre dans l'étude de la nature. Ce péril n'existe pas encore chez saint Thomas parce que, tout en admettant une théorie de l'intellect si favorable à la domination de l'autorité révélée, il l'interprète dans un esprit platonicien, ce qui va lui permettre de rétablir une certaine continuité sans laquelle tout espoir d'utiliser la raison, comme servante en théologie, était tout à fait impossible.

Le problème en effet, tel qu'il le pose lui-même ${ }^{677}$, c'est de montrer comment « notre intellect qui comprend les choses matérielles en les abstrayant des images, arrive, par les choses matérielles, ainsi considérées, à quelque connaissance des choses immatérielles (in immaterialium aliqualem cognitionem)».

Table des matières

\section{V. \\ LA POSITION METAPHYSIQUE DE L'INTELLECT HUMAIN.}

Les deux caractères essentiels de l'intelligence humaine sont les suivants : $1^{\circ}$ elle ne peut fonctionner sans phantasmes ou images, et, par conséquent, elle n’opère que par une abstraction qui sépare des choses naturellement unies ; $2^{\circ}$ elle est discursive, en ce double sens que nous ne comprenons les choses que les unes après les autres, et que nous ne parvenons que par raisonnement à la connaissance d'une conclusion. Ce double caractère est senti comme une imperfection et, plus ou moins explicitement, la connaissance humaine est décrite par rapport à une connaissance idéale qui atteindrait les intelligibles sans le détour des images et en dehors de tout discours. Saint Thomas, guidé par deux formules d'Aristote : "Dieu est pensée de la pensée » et, « dans l'intelligence, p307 le terme connu est identique au sujet connaissant », démontre que cette connaissance est réalisée en Dieu : « Le sens ou l'intellect, écrit-il ${ }^{678}$, n'est autre chose que le sensible et l'intelligible, que parce que l'un et l'autre sont en puissance "; puisque Dieu est acte pur, l'objet de son intellect n'est pas différent de cet intellect lui-même, et sa pensée n’est rien que sa substance même.

677 Summa theol., I, qu. 85, art. 1.
678 I Somme theol., qu. 14, a. 2. 
Il s'ensuit qu'il se comprend par lui-même sans le secours d'autre chose.

Il est vrai que, chez Aristote, cette thèse avait pour conséquence que Dieu ne connaissait rien autre chose que lui-même ; lui donner la connaissance des choses autres que lui, c'est introduire en lui la mutabilité, le discours et l'imperfection ; de sorte que, dans le pur aristotélisme, le rapport de l'intelligence divine à l'intelligence humaine nous échappe totalement. Dieu reste une fin extérieure à notre pensée. Aussi saint Thomas corrige-t-il l'aristotélisme par le néoplatonisme : il introduit en Dieu cette intelligence ou monde intelligible des néoplatoniciens, où toute la variété des choses existe dans l'unité, dans une parfaite transparence: selon leur inspiration, il admet que, plus est profonde et complète la connaissance de soi, plus est riche et profonde la connaissance des modèles de toute réalité ${ }^{679}$. C'est en ce sens que, selon saint Thomas, Dieu connaît les autres choses ; « il les voit non en elles-mêmes, mais en lui-même, en tant que son essence contient la ressemblance des autres choses ${ }^{680}$ ». Pas plus que Guillaume d'Auvergne, il n'admet le platonisme, tel qu'on le concevait alors, comme l'affirmation, sous le nom d'Idées, de substances immatérielles, modèles des choses sensibles et objets propre de notre entendement ${ }^{681}$; mais, comme lui, il pose, sous le nom d'idée, « dans l'intelligence divine, la forme à la ressemblance de ${ }_{\text {p308 }}$ laquelle le monde a été fait ${ }^{682}$ " ; idée qui est à la fois le modèle des choses et le principe de leur connaissance ; il y a, en Dieu, multiplicité d’idées ; sinon, comme chez Avicenne, Dieu ne pourrait créer qu'une seule chose et non un ordre multiple ; mais cette multiplicité ne lui paraît pas répugner à la simplicité divine, grâce à un principe qu'il emprunte à Denys l'Aréopagite : "Les choses inférieures sont dans les supérieures d'une manière plus éminente qu'en elles-mêmes ${ }^{683}$ ". Il pouvait lire également dans le livre Des causes que « Dieu connaît indivisiblement les choses divisibles, intemporellement les choses temporelles, nécessairement les choses non nécessaires, immuablement les

\footnotetext{
${ }^{679}$ Cf. Ennéade V, 5, 2, sur l'intériorité des intelligibles dans l'intelligence.

680 Ibid., art. 5.

681 I Somme, qu. 88, a. 1.

682 I Somme, qu. 15, a. 2.

${ }^{683}$ De celesti hierarchia, ch, XII, citée par saint THOMAs, I Somme, qu. 84, a. 2.
} 
choses muables et, en général, toutes choses à un niveau supérieur au leur propre ». On conçoit alors comment toutes les créatures peuvent avoir leur modèle en Dieu : « il faut que, toutes, elles préexistent dans le Verbe de Dieu avant d'exister dans leur propre nature. Or ce qui est en une chose est en elle selon le mode de cette chose et non selon le sien propre : la maison existe en l'architecte intelligiblement et immatériellement ; donc il faut comprendre que les choses préexistent dans le Verbe selon le mode du Verbe ; or ce mode, c'est d'être un, simple, immatériel, et non seulement vivant, mais vie. Il faut donc que les choses faites par Dieu préexistent dans son Verbe de toute éternité, immatériellement et sans aucune composition ${ }^{684}$ ». Dans ces conditions, la connaissance que Dieu a des autres choses ne saurait être discursive ; car « il voit toutes choses en une seule, qui est lui-même,... et il voit les effets en lui-même comme en leur cause ${ }^{685}$ ".

Grâce à l'introduction du néoplatonisme, on peut donc concevoir l'intellect humain comme une image, très déficiente, il est vrai, de l'intellect divin ; en effet, Dieu peut connaître, p309 d'une manière qui lui convient, la diversité des choses, même les non-êtres, les maux, les choses singulières et infinies, les futurs contingents ${ }^{686}$, et même les énonciations qui, posant l'attribut après le sujet, paraissent caractéristiques de la science humaine ; c'est que, « comme il sait immatériellement les choses matérielles et simplement les choses composées, ainsi il sait les choses énonçables non pas selon leur mode qui comporte composition et division, mais il connaît chaque chose par simple intelligence, en comprenant l'essence de chaque chose. C'est comme si nous, en comprenant ce qu'est l'homme, nous comprenions tout ce qui peut être dit de l'homme ${ }^{687}$ ».

Entre l'intellect de Dieu et l'intellect humain se trouve l'intellect angélique. L'ange saisit toujours en acte ce qu'il comprend, et il n'a donc pas besoin d'un intellect en puissance ; il saisit des formes séparées de la matière ; il n'a donc pas besoin de l'intellect agent, qui est destiné à séparer les formes de la matière. Il ne saisit, il est vrai, que

\footnotetext{
684 Contra Gentiles, IV, ch. XIII.

${ }^{685}$ I Somme th., qu. 14, a. 7.

686 Ibid., a. 6, 13.

687 Ibid, a. 4.
} 
par l'intermédiaire d' " espèces "; mais ces espèces ne viennent pas des choses et ne sont pas acquises, mais sont " connaturelles » à l'ange ${ }^{688}$. Il se connaît lui-même comme intellect en acte ; il connaît Dieu, en tant qu'il se connaît comme image de Dieu; il connaît les choses matérielles, parce que Dieu a imprimé en lui les raisons de toutes choses ${ }^{689}$; il les connaît donc dans leurs principes et non, comme nous, discursivement.

Dans la perspective de la hiérarchie des intelligences, on peut comprendre comment l'intelligence humaine, bien qu'elle ne procède que par abstraction du sensible, et bien que des formes abstraites des choses sensibles ne soient pas des êtres immatériels existant en euxmêmes comme le voulait Platon, peut avoir " quelque connaissance » des choses immatérielles : c'est que, à l'intellect au niveau humain, pris dans l'état de la ${ }_{\mathrm{p} 310}$ vie actuelle ${ }^{690}$, tout est présent comme à tous les autres, mais sous le mode humain. Il faut se rappeler que « la lumière intellectuelle qui est en nous n'est rien qu'une ressemblance participée (quaedam participata similitudo) de la lumière incréée en laquelle sont contenues les raisons éternelles ${ }^{691}$ ». On s'en apercevra en envisageant la hiérarchie entière des réalités ; pour commencer par les plus basses, la forme corporelle, qui est dans les choses matérielles, puis qui est dans la sensation, est aussi à sa façon dans l'intellect. « Les espèces des corps matériels et mobiles, l'intellect les reçoit immatériellement et sans mouvement, selon son mode ; car ce qui est reçu est en ce qui reçoit selon le mode de ce qui reçoit ${ }^{692}$. " La connaissance intellectuelle des corps peut donc, à la manière néoplatonicienne, être considérée comme une phase du retour des formes vers leur origine. «Les êtres qui ne reçoivent les formes que matériellement ne sont pas du tout connaissants ; et l'on connaît d'autant plus parfaitement que l'on possède plus immatériellement les formes. Donc l'intellect qui abstrait l'espèce non seulement de la matière, mais des conditions matérielles individuantes, connaît plus parfaitement que le sens qui reçoit la forme sans la matière, mais avec des

\footnotetext{
688 I Somme th., qu. 45, a. 2.

689 Qu. 57, a. 4.

690 Cf. la restriction, par ex. I Somme, qu. 88, a. 1 ; qu. 86, a. 5.

691 Qu. 86, a. 5.

692 I Somme, qu. 84, a. 1.
} 
conditions matérielles ; et, parmi les sens, la vision connaît le plus, parce qu'elle est la moins matérielle ${ }^{693}$. " On peut même dire, mais cela ne va pas sans quelque difficulté, que l'intellect connaît les choses singulières par « réflexion » ou par connaissance indirecte ${ }^{694}$.

Comment, enfin, perçoit-il les choses immatérielles ? Saint Thomas, sur cette question, trouvait devant lui tous les augustiniens et les platoniciens qui prétendent que, au-dessus de la connaissance des natures corporelles, l'homme a une connaissance intellectuelle indépen-

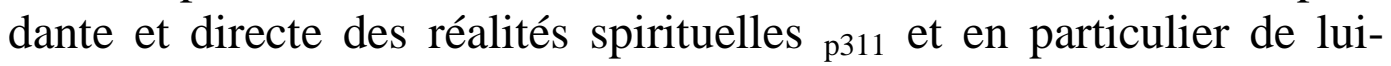
même ; il cite, sur ce point, les textes connus de saint Augustin sur lesquels on s'appuyait ${ }^{695}$; il cite l'opinion d'Avempace qui donne à l'homme une pareille connaissance, parce qu'il confond les quiddités abstraites du sensible avec des réalités spirituelles. Pour lui, il admet une connaissance de ces réalités, mais indirecte, secondaire, et dans la mesure où elle est liée à la fonction principale de l'intellect humain, qui est d'abstraire. On dirait que l'intellect humain, naturellement porté vers les choses sensibles, a bien indirectement quelque connaissance des choses spirituelles, qui sera une base naturelle suffisante pour la théologie, mais sur quoi, sans l'appel de la foi, rien ne pourrait s'édifier. La raison n'est pas spontanément orientée, comme le croient les augustiniens, vers les choses spirituelles.

Ainsi en est-il de la connaissance de soi. La parfaite connaissance de soi est liée à la connaissance de toutes choses, et elle n'existe qu'en Dieu. Rien de pareil chez l'homme : il est en quelque sorte séparé de lui-même : d'abord l'intellect n'est pas l'être même de l'âme, il n'en est qu'une puissance ; c'est en Dieu seul que l'être et l'acte de comprendre se recouvrent ; donc, la connaissance que l'intellect peut avoir de soi n'est pas une connaissance de soi ${ }^{696}$; de plus l'intellect humain est un intellect en puissance ; il ne peut donc être connu directement ; car seul est objet de connaissance ce qui est en acte ; on ne connaît l'être en puissance, par exemple la matière, que relativement à l'être

\footnotetext{
3 Ibid., a. 2.

694 Qu. 86, a. 1, (Cf. L. NoËL, CLXXVII t. I, p. 161).

${ }^{695}$ I Somme, au début des articles 1,2 , de la qu. 87 , et des art. $1^{\text {er }}$ et 3 , de la qu. 88.

${ }^{696}$ I Somme, qu. 79, a. 7.
} 
en acte ; donc, l'intellect ne peut se connaître que dans les moments où il passe à l'acte, non pas, comme le dit Platon, en participant à des réalités incorporelles (en ce cas, il se connaîtrait lui-même), mais bien grâce à la lumière de l'intellect agent éclairant les images : il ne se connaît donc que par son acte et d'une connaissance secondaire, qui

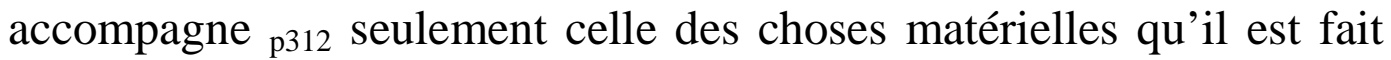
pour connaître.

On a vu comment l'ange, de la connaissance directe qu'il a de luimême, passe à la connaissance de Dieu. Ceux qui attribuent à l'homme la connaissance de soi sont portés à dire de l'homme ce qui n'est vrai que de l'ange ; mais en vérité la seule connaissance de Dieu accessible à l'homme est encore une sorte d'annexé à celle des formes sensibles ; il connaît Dieu, " comme on connaît un objet dans un miroir », par la ressemblance de Dieu qui se reflète dans les choses sensibles ${ }^{697}$. Cette connaissance «naturelle » de Dieu ne peut donc s'étendre au delà du point où ces choses peuvent la mener; elles nous conduisent à Dieu comme à leur cause, mais à une cause qui les dépasse infiniment, à une cause première ; puis, recherchant par le raisonnement ce qui convient à une cause première comme telle, nous découvrons, par une pensée discursive, ses attributs, sa simplicité, sa perfection, sa bonté, son immutabilité, etc. ${ }^{698}$. Il est donc faux, comme le croyait l'augustinien saint Anselme, que nous puissions, en partant de l'idée que nous avons de lui affirmer son existence. Selon le précepte d'Aristote, aux Seconds Analytiques, l'on pose d'abord son existence, et l'on ne passe qu'ensuite à la détermination de son idée. L'homme connaît les choses matérielles avant de connaître Dieu, et, par elles, il va jusqu'à l'existence de Dieu. Saint Augustin paraît penser autrement, qui dit que nous connaissons toute chose dans la lumière de la première vérité ; ceci est exact, à condition de comprendre que Dieu est, en soi, la première source d'où vient la lumière de notre intelligence, mais non en ce sens qu'il est son premier objet.

Voilà donc comment l'esprit humain a, par nature, quelque connaissance des choses spirituelles. Cette connaissance, discursive et inséparable de la connaissance des choses matérielles ${ }_{\text {p313 }}$ d'où elle est

${ }^{697}$ I Somme, qu. 56, a. 3.
${ }^{698}$ I Somme, qu. 12, a. 12. 
issue, ne fait nullement sortir l'homme de son plan naturel, et si, par sa direction, elle émane de la foi, par son contenu elle n'excède en rien les forces naturelles de la raison.

Table des matières

\section{VI. \\ LES PREUVES DE L'EXISTENCE DE DIEU.}

De son point de vue humain et guidée par la foi, la raison peut donc saisir la hiérarchie des êtres, dont elle est une partie, depuis le créateur jusqu'aux choses matérielles : et, de ce point de vue, prennent leur sens les preuves de l'existence de Dieu qui sont du genre de ces démonstrations qui procèdent de l'effet à la cause et qui, selon les Analytiques postérieurs d'Aristote ${ }^{699}$, s'opposent à celles qui partent de la cause pour arriver à l'effet : ce second genre de démonstration était courant dans le néoplatonisme qui s'efforçait de saisir la genèse de toutes les réalités à partir de l'Un ; rien de plus impossible chez saint Thomas où, dans l'état présent, l'esprit humain est fixé par la nature à un niveau qu'il ne peut quitter et n'a pour objet direct que les choses matérielles. Des « cinq voies " par lesquelles on peut accéder à Dieu, la première reproduit la preuve du premier moteur d'Aristote : le mouvement existe ; or, dans le mouvement, un être en puissance devient être en acte : par exemple la chose froide, qui était chaude en puissance, devient chaude en acte ; un pareil devenir n'est possible que comme effet d'un être déjà en acte (dans l'exemple donné, d'un être qui est chaud en acte), qui est le moteur du mouvement ; si ce moteur lui-même est mû, il doit l'être par un autre ; mais on ne peut procéder à l'infini de moteur en moteur ; il faut donc s'arrêter à un premier moteur immobile qui est Dieu. La « seconde voie » part de la notion de cause efficiente : nous constatons, dans l'expérience sensible, l'existence ${ }_{\mathrm{p} 314}$ de causes efficientes ordonnées ; par ordonnées (et c'est sur ce terme que s'appuie la force de la preuve), saint Thomas entend des causes qui produisent un effet par des moyens déterminés, comme le bras qui pousse une pierre avec un bâton : à l'exemple d'Aristote, il n'envisage que des processus clos de ce genre, qui impliquent trois termes, le premier, le moyen et le dernier, dont le se- 
cond d'ailleurs peut se multiplier ; dans une causalité " ainsi ordonnée », il faut nécessairement qu'il y ait un premier terme : sans quoi l'effet n'existerait plus. Si ce premier terme, dans le processus considéré, est lui-même l'effet d'une autre cause, comme on ne peut pas procéder à l'infini, il faudra s'arrêter à une cause absolument première, qui est Dieu. La troisième voie utilise les notions, familières au péripatétisme arabe, de possible et de nécessaire ; elle se fait en deux temps : du possible, on remonte au nécessaire, et du " nécessaire par autre chose » au " nécessaire par soi » : la génération et la corruption que nous constatons dans les choses sensibles nous amènent à les concevoir comme simplement possibles par elles-mêmes, c'est-à-dire comme pouvant ne pas exister ; sous peine de ne pas être, le possible doit tirer son existence d'un être nécessaire ; en fait, la génération et la corruption ont leurs principes dans le ciel, que saint Thomas paraît bien vouloir désigner en parlant du « nécessaire qui tient d'ailleurs la cause de sa nécessité » (c’est l'expression par où Avicenne désigne les intelligences motrices des cieux émanées de Dieu) ; comme, en remontant de nécessaire en nécessaire, on ne peut procéder à l'infini, il faut s’arrêter à un être nécessaire par lui-même ou à Dieu.

Les deux dernières « voies » ont un caractère un peu différent des trois premières ; elles se rattachent moins au péripatétisme qu'à la tradition de saint Anselme et à la tradition chrétienne générale : la quatrième implique comme un axiome que tout comparatif suppose un superlatif, c'est-à-dire que, si l'on constate dans les choses sensibles des degrés variables p315 d'une même qualité (de la chaleur par exemple), c'est par référence à un être tel que le feu, qui a le maximum de chaleur ; il en est ainsi pour les degrés d'être, de vérité ou de bonté qui se réfèrent à un être suprême, suprêmement vrai et suprêmement bon : seulement, il faut remarquer que saint Thomas déplace la preuve d'Anselme du plan des idées au plan du réel ; ce n’est pas par une exigence de la pensée que nous devons imaginer pareil maximum ; c'est à titre de cause réelle des effets que nous constatons. La « cinquième voie » enfin part de la finalité que nous rencontrons dans des êtres matériels et privés de connaissance ; cette finalité ne peut être attribuée qu'à une intelligence souveraine et transcendante à la nature, c'est-à-dire à Dieu.

Si le thomisme attache une telle importance à ces preuves, c'est parce que, pour lui, la raison humaine est privée de toute connaissance 
directe de Dieu. Mais il s’ensuit une conséquence importante : le néoplatonisme, partant de Dieu ou de l’Un, était amené à considérer Dieu moins comme la source des existences que comme la première d'une série de réalités hiérarchisées dont chacune engendrait la suivante. Saint Thomas, procédant de l'effet à la cause, ne préjuge rien sur la manière dont la cause suprême a produit son effet ; car l'effet, conçu à la manière qualitative dont le conçoit saint Thomas, ne donne d'abord, sur la cause, que des renseignements très généraux qui laissent ouverte la possibilité d'un accord avec la foi, fermé d'abord par le néoplatonisme. En effet, chacune des preuves de l'existence de Dieu nous a révélé autant d'aspects de la divinité, comme cause du monde: Premier moteur, cause suprême, nécessaire par soi, être et bonté souverains, ordonnateur des choses matérielles, tel il nous est apparu par ces cinq voies : partant de ces caractères, saint Thomas va préciser, par une série de déductions, ses attributs, et retrouver en lui la cause suprême, intelligente et libre, qu'enseigne le christianisme : c'est là assurément le point délicat du système, p316 puisque c'est là que sont mises à l'épreuve les assertions de saint Thomas sur la foi et la raison. En effet, la " première voie » est celle qui amenait Aristote à un premier moteur qui n'agit qu'à titre de cause finale sur un monde éternel ; la seconde voie mène à une cause qui agit par des moyens plutôt qu'à une cause créatrice ; la troisième voie conduisait Avicenne à affirmer la production nécessaire des choses ; et l’idéal suprême de la quatrième voie, pas plus que l'ordonnateur de la cinquième, n'est pas davantage le Dieu créateur révélé par la Bible.

Table des matières

\section{VII.}

\section{MONOTHEISME ET CREATION.}

Partant de la notion de Dieu des « cinq voies », saint Thomas croit pouvoir d'abord démontrer le monothéisme. Dieu est unique parce qu'il est le bien suprême (quatrième voie), parce qu'il est source d'un ordre unique (cinquième voie), parce qu'il est nécessaire par soi (troisième voie) ${ }^{700}$.

700 Parce que le concours de plusieurs principes distincts ne saurait constituer une réalité nécessaire. Saint Thomas vise moins ici le polythéisme des Gentils que 
Il croit pouvoir aussi démontrer que Dieu crée toutes choses ex nihilo en s'appuyant sur le principe d'Aristote : « Les genres sont causes des genres, et les choses particulières des choses particulières ${ }^{701}$ " : si une cause universelle avait besoin d'une matière préexistante, elle ne serait plus universelle.

Il est vrai que le péripatétisme arabe avait tiré du même principe une autre conséquence : si Dieu, disait-on, est cause universelle, il ne peut produire qu'un effet universel tel que la première intelligence. Selon saint Thomas, il faut entendre par effet universel l'être qui appartient à tous les êtres, simples ou composés ; en ces êtres, les causes particulières sont capables ${ }_{\mathrm{p} 317}$ de produire les déterminations particulières, par exemple les formes, accidentelles ou substantielles ; elles sont incapables d'y produire l'être ${ }^{702}$.

Ainsi les deux grandes affirmations où l'on voit en général les caractères distinctifs par où la pensée chrétienne se rattache au judaïsme à l'exclusion de l'hellénisme, création et monothéisme, paraissent à saint Thomas pouvoir se fonder sur les principes philosophiques des Grecs. Ce qui serait propre à la révélation et impossible à savoir sans elle, ce n’est pas que le monde a été créé, c’est qu’il a été créé dans le temps ; tous les philosophes, grecs et arabes, sont d'accord pour soutenir cette erreur que le monde est éternel ; éternel ne veut d'ailleurs pas dire incréé, puisque la création peut avoir eu lieu dès l'éternité ${ }^{703}$; ce sont là deux questions totalement distinctes dont la philosophie peut arriver à résoudre l'une, celle de la création, mais non pas l'autre, si la création a eu lieu ou non ab aeterno. En tout cas monothéisme et création, en tant qu'ils sont conçus philosophiquement, se rapportent moins au rapport religieux de l'âme à Dieu qu'à l'explication rationnelle des choses sensibles ; ce trait est inhérent à la seule philosophie qui existait pour saint Thomas, à la philosophie grecque.

La notion de création transforme, sinon dans son contenu, au moins dans sa signification et sa portée, l’image de la hiérarchie pla-

le dualisme des Manichéens ou le trithéisme des Ariens (Contra Gent., I, ch. XLII).

701 Physique, II, III, 195-6 25.

702 Qu. 45, a. 4. et 5.

703 Cf. De aeternitale mundi contra murmurantes. 
tonicienne des réalités : dans le néoplatonisme, chaque réalité n’avait de rapport direct qu'avec la réalité immédiatement supérieure ; avec la création, toute réalité, de quelque ordre et de quelque niveau qu'elle soit, a un rapport direct et uniforme avec Dieu, et son être est posé par Dieu sans intermédiaire ${ }^{704}$; elle n'a sa place dans l'ordre que par la volonté intelligente de Dieu qui l'a instituée ${ }^{705}$.

p318 On se trompe autant en croyant que Dieu ne peut créer autrement qu'en pensant que la création est arbitraire ; il y a dans la création ce que saint Thomas appelle une « justice naturelle », c'est-à-dire que chaque partie a la perfection requise pour la perfection du tout ${ }^{706}$. Il en est comme dans une monarchie absolue, où tout pouvoir émane du roi, et où, pourtant, à chaque pouvoir, est conférée, dans des limites fixées, son autonomie. Saint Thomas abandonne résolument un optimisme qui soumettrait la volonté de Dieu à la nécessité de créer le meilleur des mondes possibles ; il n'y a pas de pareil monde pour lui : comme les essences finies sont une représentation imparfaite de son essence infinie, leur perfection peut en effet croître à l'infini ${ }^{707}$; c'est seulement dans l'ordre qu'il a créé que les choses sont les meilleures possible ${ }^{708}$.

La création ainsi comprise est, chez saint Thomas, solidaire de l'espèce de réalité substantielle qu'il accorde à la nature, composée d'essences fixes, agissant chacune selon sa loi. Dans le néoplatonisme, la chose matérielle, si on voulait la saisir en elle-même, se décomposerait en un reflet fugitif et instable et en une idée, essence éternelle, placée au niveau de la réalité divine ; la réalité concrète autre que Dieu disparaissait ; elle disparaissait aussi chez ceux dont se plaignait, au XII ${ }^{\mathrm{e}}$ siècle, Guillaume de Conches, aux yeux de qui toute affirmation de règle ou de loi naturelle était incompatible avec l’absolue liberté de Dieu.

Table des matières

\footnotetext{
704 I Somme, qu. 45, a. 5.

705 Qu. 103, a. 6. Dieu gouverne immédiatement toute chose, quoiqu’il fasse exécuter ses desseins par l'action des créatures les unes sur les autres

706 Contra Gent., II, ch. XXIX.

707 Ibid., I, ch. LXVI.

${ }^{708}$ I Somme, qu. 25, a. 6.
} 


\section{VIII.}

\section{L’ANALOGIE DE L'ETRE.}

Il en est tout autrement chez saint Thomas, qui, comme Aristote, a un sentiment très vif de la réalité des substances ${ }_{\mathrm{p} 319}$ matérielles. Cette réclamation en faveur d'une nature solide et fixe se manifeste dans trois thèses liées ensemble, et par où il s'oppose aux augustiniens de son époque: celle de l'analogie de l'être, celle des rapports de l'essence et de l'existence et celle de la pluralité des formes.

C’est à Aristote, commenté par Averroès ${ }^{709}$, que saint Thomas a emprunté la théorie de l'analogie de l'être. Le mot être, avait remarqué Aristote, se dit à la fois de la substance et des accidents, mais non pas de la même manière ; l'être de la substance est l'être au sens fort ; l'être de l'accident est un être dérivé qui se dit par rapport à la substance. Entre l'être de l'un et celui de l'autre, il n'y a pas pourtant simple homonymie, mais il y a analogie ; c'est-à-dire que l'être se trouve à chaque niveau d'une manière qui est proportionnée à ce niveau. Entre l'être de Dieu et l'être de la créature, il y a une analogie de ce genre. Le mot être ne désigne ni un genre des êtres, puisque les êtres, ses espèces, le posséderaient tous également, ni une réalité qui n’aurait sa plénitude qu'en Dieu ; il est réalisé « en tous les membres de l'analogie d'une manière qui fonde un rapport de blance $^{710}$ "; objet de l'intuition fondamentale du métaphysicien, il permet d'instituer une ontologie qui englobe toute réalité, sans être lui-même une réalité concrète, mais ce caractère par où toute réalité concrète se pose et tend à se communiquer aux autres ${ }^{711}$. On voit donc comment cette ontologie justifie la réalité d'une nature ayant son être propre.

\footnotetext{
709 Cf. Eth. à Nicom., liv. I, ch. IV, et le Commentaire d'Averroès.

710 M. GrabManN, CLXXV.

711 J. Maritain, CLXXIX, p. 66.
} 
IX.

\section{L'ESSENCE ET L'EXISTENCE.}

La question de la distinction de l'essence et de l'existence était une de celles qui opposaient le plus Avicenne à Averroès. p320 Tout le monde admet que l'essence, qui désigne l'ensemble des caractères par où un être est ce qu'il est, est distincte, pour la pensée, de l'existence. Dans l'aristotélisme originaire, essence et existence n'en étaient pas moins inséparables ; à l'éternité des cieux répondent, dans le monde de la génération et de la corruption, la succession des générations où la série des individus reproduit sans fin les mêmes types spécifiques. Le péripatétisme d'Avicenne, en introduisant, comme on l'a vu, la notion de création et de possible, amenait au contraire à conclure que l'essence n'était en elle-même ni existante ni non existante; l'existence n'est donc, pour elle, qu'un accident qui lui est ajouté en vertu d'une cause extérieure, qui est la cause créatrice. Averroès, confrontant la pensée d'Avicenne avec la véritable doctrine d'Aristote, lui reproche une « erreur » qui, dit-il, vient de ce qu'il a mélangé les idées des Motekallêmin à la philosophie ; à ses yeux «la substance d'une chose quelconque est l'existence de cette chose " ${ }^{712}$ : le véritable inconvénient de la thèse avicennienne aux yeux d'Averroès, c'est de faire renaître le platonisme : en fait, lorsque nous parlons de l'essence spécifique d'un être, c'est que nous l'avons vu par expérience réalisée en un être concret; ce n'est que par abstraction que nous isolons l'humanité des hommes ; prendre cette abstraction comme antérieure à l'existence des individus concrets, c'est revenir au platonisme ${ }^{713}$.

La thèse d'Avicenne, présentée de cette manière, volatilisait en effet les êtres de la nature ; il fallait se représenter des quiddités ou essences éternelles, distinctes l'une de l'autre, attendant l'existence, que la volonté créatrice pouvait ou non leur donner. Mais alors l'étoffe du monde était ces essences éternelles, donc divines, posées seulement comme existantes ${ }^{714}$. On sait combien saint Thomas est hostile au platonisme ainsi ${ }_{\mathrm{p} 321}$ compris ; les essences n’existent dans le Verbe

DUHEM, XV, t. V, p. 487.

A. Forest, CLXXII, p. 159.

714 Cf. le passage de KLEUTGen, La philosophie scolastique, cité par Forest, p. 164, note, et DUHEM, p. 503. 
divin que sous le mode d'unité qui convient au Verbe ; mais les quiddités, avec leur variété et leur diversité, sont elles-mêmes créées, « puisque, avant qu'elles n'aient l'existence, elles ne sont rien, sinon peut-être dans l'intelligence du Créateur, où elles sont non plus créatures, mais essence créatrice ${ }^{715} »$. Saint Thomas va-t-il donc en revenir à l'averroïsme, comme si le choix s'imposait entre les deux penseurs arabes ? En un sens, et bien qu'il ait ignoré les déclarations formelles d'Averroès sur la question ${ }^{716}$, oui : l'essence et l'existence sont pour lui au même niveau, au niveau des créatures ; on peut même dire qu'elles sont inséparables l'une de l'autre : « De cela même que l'existence est attribuée à la quiddité, non seulement l'existence, mais la quiddité est alors créée, parce que, avant d'avoir l'existence, elle n'est rien ${ }^{717}$ »; rien de plus différent d'Avicenne pour qui l'essence est d'abord une réalité capable des deux opposés. Mais, chez saint Thomas, cette solution n'est plus liée à l'éternité d'un monde incréé, puisqu'il est sous-entendu que cette union de l'essence et de l'existence n'a lieu qu'autant que le monde lui-même, perpétuel ou non, est donné.

Pourtant, saint Thomas n'admet pas l'identité de l'essence et de l'existence : ce serait égaler la créature à Dieu, à l'être unique dont l'essence est l'existence ; dans toute créature l'essence est donc bien distincte de l'existence; toute créature est composée, au moins, d'essence et d'existence ; seulement, l'existence n'est pas pour cela un accident de l'essence, ce qui compromettrait l'unité de l'être existant ; elle est plutôt "l'actualité » de l'essence ou son "complément » ${ }^{718}$; elle est à l'essence comme l'acte est à la puissance ${ }^{719}$; or, la réalité en ${ }_{\mathrm{p} 322}$ puissance et la réalité en acte sont une seule et même réalité à des degrés de réalisation différents ; c’est donc une composition qui n'altère pas l'unité de l'être. Elle ressemble à la composition de matière et de forme, dans la mesure où la matière et l'être en puis-

\footnotetext{
715 De potentia Dei, qu. 3, a. 5, ad 2.

716 Cf. Roland-Gosselin, CLXXXV, p. 198.

717 De potentia Dei, ibid.

718 Quodlibet, XII, qu. 5, a. 5. «Complément » de l’essence est le mot employé par Plotin pour désigner les propriétés qui ne peuvent être séparées de la substance, tel que le blanc dans le cygne ou dans la céruse.

719 I Somme, qu. 50, a. 2.
} 
sance ; mais elle ne lui est pas identique ; car elle existe chez les anges, qui sont des créatures immatérielles ; et, dans les êtres sensibles, l'existence s'ajoute, comme un acte, à l'essence ou «nature composée de matière et de forme, qui est comme une puissance à son égard ${ }^{720}$. Dans les êtres dénués de matière, comme les anges ou les âmes, cette composition n'est pas sujette à se défaire, si bien que ces êtres n'ont par nature, et sauf la volonté de Dieu, aucune possibilité de ne plus exister, et c'est en raison de la composition de matière et déforme, non pas d'essence et d'existence, que la chose sensible est susceptible de périr.

Ce qu'il faut retenir surtout de ces spéculations, c'est que la quiddité, inséparable de son existence qui la réalise, est, chez saint Thomas, une créature qui est une nature fixe, donc qu'il n'est pas vrai que tout intelligible s'évapore, en quelque sorte immédiatement, dans le divin.

$\underline{\text { Table des matières }}$

X.

\section{LA PLURALITE DES FORMES.}

Saint Thomas apporte le même esprit dans la question de la pluralité des formes. Cette question concerne d'abord le problème de l'âme : partant de la hiérarchie des fonctions qu'Aristote admet dans l'homme, fonctions végétatives, sensitives et intellectuelles, on demande s'il faut admettre dans l'homme autant d'âmes différentes. Plus généralement, si l'on considère dans une espèce infime les caractères qu'il a fallu ajouter successivement au genre suprême pour aboutir à cette espèce ${ }_{p 323}$ (par exemple : substance, corporéité, vie, sensation, intelligence pour aboutir à l'espèce homme), l'on demande si, dans un individu de cette espèce, il existe autant de formes réellement distinctes. On voit qu'il s'agit toujours de formes hiérarchisées qui s'ajoutent les unes aux autres pour constituer l'individu ou l'espèce, et où la suivante suppose toujours les précédentes; il ne s'agit jamais de formes juxtaposées. La thèse de la pluralité des formes est platonicienne. On la trouve fort nettement exprimée chez Plotin et chez Avi-

${ }^{720}$ Quaestio disputata de spiritualibus creaturis, a. 1. 
cébron ${ }^{721}$. Saint Thomas montre effectivement qu'elle n'est qu'un cas particulier de l'erreur générale du platonisme, de cette doctrine qui consiste à croire que « ce qui est abstrait dans l'entendement est aussi abstrait en réalité ${ }^{722}$.

L'opposition est en effet profonde : pour Plotin, la montée hiérarchique des formes, de la plus pauvre à la plus riche, est incompréhensible si elle n'est pas l'envers d'une émanation qui va de la plus riche à la plus pauvre ; de l'intelligence, l'âme sensitive est le premier reflet, et d'elle viennent l'âme végétative et la puissance fabricatrice ${ }^{723}$. Ce double mouvement de montée et de descente explique le double aspect que $\mathrm{M}$. Forest a très justement remarqué dans l'argumentation thomiste, comme si elle visait deux doctrines différentes ; la première de ces doctrines considérerait les multiples formes qui se trouvent dans un individu d'une espèce donnée comme s'ajoutant les unes aux autres : d'une pareille doctrine, l'on doit dire qu'elle nie l'unité de l'individu, selon l'adage d'Avicenne et d'Aristote : "De choses diverses existant en acte ne provient pas une chose une par soi ${ }^{724}{ }$; l'homme serait composé d'autant d'êtres qu'il a d'âmes. Mais les adversaires de saint Thomas reconnaissent parfaitement ce principe, et ils ont une doctrine ${ }_{\text {p324 }}$ beaucoup moins simple, qu'ils pensent pouvoir concilier avec l'unité de l'individu: d'après cette manière de voir, plusieurs fois exposée par saint Thomas ${ }^{725}$, chaque forme supérieure est le "complément» ou 1' «acte » de la forme inférieure ; « l'âme végétative est conduite au complément de l'âme sensitive, et l'âme raisonnable est l'acte et le complément de l'âme sensitive "; « la première forme est en puissance à la seconde"; dès lors il y a d'une forme à l'autre une nécessité de passage et une unité analogue à celle que saint Thomas reconnaît lui-même entre l'essence et l'existence : toute la thèse repose sur le caractère incomplet, déficient de la forme inférieure, déficience qui s'explique par l'éloignement où elle est de son origine ; c’est ainsi qu'elle est énoncée dans la Somme

${ }^{721}$ V Ennéade, 8, 7, 18 ; II Ennéade, 7, 3.

${ }^{722}$ De spiritualibus creaturis, a. 3 ; FOREST, CLXXII, p. 174.

${ }^{723}$ II Ennéade, 7, 3.

${ }^{724}$ De spirit. creaturis, a. 3, ForEST, p. 175 ; cf. Aristote, Metaph. Z, 13, 1039, a. 3-8 (FOREST, p. 179).

${ }^{725}$ Cf. A. FoREST, p. 182, n. 1. 
attribuée à Robert Grosseteste : " On ne peut appeler complètes que les formes qui sont dans l'être de l'espèce ; les formes génériques sont incomplètes; autrement une seule chose aurait plusieurs essences ou formes substantielles, et la véritable forme substantielle, qui est le complément de la chose composée [comme dans l'homme, l'humanité complète, des formes substantielles, animalité, vie, corporéité, etc.], serait une forme accidentelle, ce qui est impossible ${ }^{726}$. »

Ce que saint Thomas critique dans cette forme de la doctrine, ce n'est pas qu'elle nie l'unité de l'être, c'est qu'elle l'obtient au prix du bouleversement des notions métaphysiques les plus sûres. Entre lui et ses adversaires, le débat porte sur la notion de forme, essence ou nature : pour eux, toute forme n'est que la phase d'un devenir qui remonte vers son origine ; la forme substantielle se parfait et s'achève peu à peu, au cours d'une génération qui est un mouvement; pour saint Thomas comme pour Aristote, en vertu de l'adage : forma dat esse rei, la forme est ce qui détermine un être à être ce qu'il est ; elle n'est pas susceptible de degrés de perfection ; elle est ou elle ${ }_{\mathrm{p} 325}$ n'est pas, sans milieu possible ; elle est indivisible ; la génération, qui est l'union actuelle d'une forme à une matière, n'est donc pas, comme le changement de qualité, un mouvement ni un progrès ; elle est instantanée ${ }^{727}$.

La théorie de l'unité de la forme est donc l'affirmation de natures ou essences, qui, dans l'ordre naturel, sont définies et immuables. Le monde thomiste, calqué sur le monde aristotélicien, forme donc bien, à ce point de vue, une nature qui, par la volonté du créateur, possède unité et autonomie. Le résultat de cette thèse, c'est que la forme unique d'un être, l'humanité par exemple, doit contenir en elle, expliquer les fonctions végétative et sensitive, toutes les perfections qui contiennent les formes spécifiques de la plante et de l'animal; il s'ensuivrait que, à la mort, la matière, privée de la forme qui seule la détermine, devrait revenir à l'état de matière première et indéterminée ; s'il n'en est pas ainsi, si le corps persiste, c'est que la mort s'accompagne de la création positive d'une forme qui est celle du corps ; le corps n’est plus alors un corps humain que par équivoque :

${ }^{726}$ Summa theologiae, IX, tract. V, cap. VI.
${ }^{727}$ I Somme, qu. 118, a. 2 : Et ideo alii. 
conséquence nécessaire, d'où les adversaires de saint Thomas tiraient contre sa doctrine un argument théologique : le corps du Christ, pendant les trois jours compris entre la mort et la résurrection, n'était plus tel que par équivoque, et il n'était donc plus digne d'être adoré : question critique où le principe thomiste de l'accord de la raison et de la foi paraît se trouver en défaut ; saint Thomas ne manque pas d'y répondre ${ }^{728}$ que, si le corps n'est plus lié à l'âme, il reste uni à l'hypostase divine du Verbe.

De là naît une critique de la conception des Platoniciens sui les rapports de l'âme et du corps : ils imaginent l'âme comme une substance existant à part et envoyant son rayonnement sur le corps ; et ils conçoivent sur ce modèle le rapport de la forme à la matière ${ }^{729}$. Tout à l'inverse, saint Thomas, voyant ${ }_{\mathrm{p} 326}$ dans la matière et la forme non pas deux réalités distinctes mais une seule et même chose ${ }^{730}$, l'une en acte et l'autre en puissance, imagine avec Aristote les rapports de l'âme et du corps sur le modèle des rapports de la forme et de la matière. Cette conception a naturellement bien des "inconvénients », en faisant rentrer l'âme dans le cours ordinaire de la nature, en lui retirant cette indépendance qu'exige sa destinée surnaturelle ${ }^{731}$. Il s'agit de trouver une combinaison où l'on maintient que l'âme est forme du corps, tandis que ses puissances peuvent se dégager de l'union avec le corps, ce qui suppose une distinction entre l'essence et les puissances, "l'essence se terminant à soi-même, tandis que le propre des puissances (telles que l'intellect), c'est de mettre l'être en contact avec le dehors ${ }^{732}$.

III Somme, qu. 50, a. 4 et 5.

Avicébron, Fons Vitae, p. 40.

730 Métaphys. Z, 6, 1045-6, 16.

731 Contra Gent., II, ch. LXVIII.

732 A. Forest, CLXXII, p. 275. 
XI.

\section{LE PRINCIPE D’INDIVIDUATION.}

Le fondement de la distinction des individus d'une même espèce entre eux (le principe d'individuation) est pour saint Thomas un problème : cette distinction n'existe pas à tous les niveaux de la réalité : avec Aristote, saint Thomas admet que les moteurs des cieux et les anges diffèrent entre eux comme des espèces. La distinction des individus au sein de l'espèce est par conséquent un problème autre que le problème général de la distinction des choses. On sait comment saint Thomas a résolu ce dernier problème ${ }^{733}$ : «Dieu a produit les choses pour communiquer sa bonté aux créatures et pour être représenté par elles ; et comme il ne peut être suffisamment représenté par une créature, il en a produit beaucoup et de diverses : de sorte que ce qui manque à l'une pour représenter la bonté divine est suppléé par

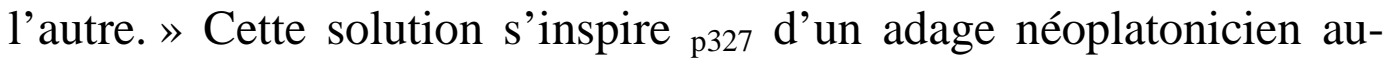
quel il se réfère d'ailleurs : "La bonté qui est en Dieu à l'état d'unité et de simplicité est dans les créatures à l'état de multiplicité et de division ». Il semblerait que cette solution, dans sa généralité, contienne implicitement celle du problème de l'individuation : il n'y a, au niveau des choses corporelles, qu'un degré de division plus avancé ; et saint Thomas paraît parfois le penser lorsqu'il écrit : " La matière des choses corporelles reçoit la forme partie à partie (particulariter) ; ... étant au plus bas degré, elle la reçoit de la façon la plus débile (la manière de recevoir se conformant à la nature de ce qui reçoit), et par là elle est très loin de la notion complète de la forme qui n'est que dans la totalité des êtres particuliers (particularitatis) qui la reçoivent. La substance intellectuelle, elle, reçoit la forme intelligible dans sa totalité $^{734}$. " Les individus paraîtraient ainsi résulter d'une sorte de monnayage de la forme spécifique. Mais, d'autre part, saint Thomas, avec Aristote, conçoit l'individu comme la substance au sens fort, tandis que la forme spécifique n'est que substance seconde ; de plus, selon la foi chrétienne, l'individu, dans l'espèce humaine, prend une valeur nouvelle, en tant que sujet de la destinée. Ce sont là les raisons pour lesquelles saint Thomas ne s'arrête pas à la solution platonicienne. Chez lui, l'essence spécifique d'une chose sublunaire, tout autant que

\footnotetext{
733 I Somme, qu. 47, a. 1.

734 De substantiis separatis, ch. VII.
} 
l'individu, est un composé de forme et de matière mais prises généralement : l'homme est un composé d'âme en général et de corps en général ; l'être individuel, Pierre, est au contraire composé de telle forme et de telle matière, de telle âme et de tel corps ; seulement, les matières peuvent se distinguer immédiatement les unes des autres par la différence des places qu'elles occupent ; dès que la matière première a reçu la " forme de la corporéité », elle est douée de dimensions qui permettent de la diviser; et c'est indirectement, parce qu'elle informé la matière affectée de telle ou telle place ${ }_{\text {p328 }}$ (materia signata), que la forme est liée désormais à certaines dimensions ; il n’y a donc pas, dans les formes mêmes, de principe de division ; mais, étant au plus bas niveau, " ces formes sont imparfaites, et, ne pouvant se soutenir elles-mêmes, elles ont besoin du fondement de la matière "; mais elles ne peuvent pas se fonder sur la matière sans s'individualiser. Cette thèse n'a pourtant pas pu être la thèse définitive de saint Thomas, parce que, supposant la matière préalablement informée par la forme de la corporéité, elle contredit le principe de l'unité de la forme ${ }^{735}$. D'après ce principe, il faudrait admettre que ces dimensions qu'elle occupe, c'est la forme elle-même qui les a déterminées pour elle; de sorte que, dans la pensée définitive de saint Thomas, la matière douée de dimensions continue bien à être principe d'individuation, mais elle n'est telle que sous l'action de la forme qu'elle individue : ne s'ensuivrait-il pas, comme certains interprètes l'admettent, que la forme individuelle contiendrait en elle la source dernière de sa propre individuation, ce qui donnerait aux individus une sorte d'autonomie tout à fait en accord avec l'esprit de la philosophie de saint Thomas?

Table des matières

XII.

VERTUS ACQUISES ET VERTUS INFUSES.

Les intentions et les effets de la réforme philosophique voulue par saint Thomas se manifestent avec clarté dans ses conceptions morales et politiques. De même qu'il y a, dans les choses de la nature et par la volonté créatrice elle-même, une sorte de densité qui les empêche de 
se résorber dans les choses divines, de même il y a dans l'homme une vie naturelle, qui est le lieu des vertus morales et intellectuelles, et une vie surnaturelle où l'homme est assimilé à Dieu. Il faut se garder de p329 confondre la première avec la seconde comme le font souvent les platoniciens : le naturel est subordonné au surnaturel ; mais il a, dans cette subordination, son existence et ses règles propres. C'est ainsi qu'il y a un amour naturel et un amour surnaturel de Dieu. Aimer Dieu au-dessus de toutes choses est le fait de tout être raisonnable ou non, même inanimé ; car il est naturel que toute chose aime ce qui le fait être ; mais ce n'est pas l'amour surnaturel, la charité ${ }^{736}$, pas plus que la béatitude naturelle n'est cette béatitude surnaturelle, à laquelle l'homme n'arrive qu'en participant à la divinité ${ }^{737}$.

Dans le passage de la nature à la surnature, ce qui change, ce n'est pas la nature humaine, mais sa disposition (habitus). Ce mot, chez Aristote, désigne une disposition acquise et devenue stable, et, lorsqu'il s'agit de la vie morale, cette disposition de la volonté tendant vers le juste milieu que l'on appelle la vertu. Pour saint Thomas, l'habitus est bien une disposition stable, mais non nécessairement une disposition acquise ; elle se distingue par le rapport qu'elle a au bien ou au mal de la nature où elle réside ; elle est bonne ou mauvaise selon qu'elle favorise ou contrarie cette nature. Il n'y a donc d'habitus que chez les êtres capables d'être disposés bien ou mal relativement à leur fin ; et on n'en trouve ni chez Dieu qui est acte pur, ni dans les corps élémentaires, célestes ou sublunaires, qui ne sont capables de passer à l'acte que d'une seule manière. L'habitus suppose une certaine marge d'indétermination, des possibilités diverses dans le passage à l'acte ou dans l'exercice d'une seule et même puissance, ce qui est le cas de l'homme.

La cause qui fait cesser cette indétermination est triple; ce peut être la nature, le corps lui-même dont les dispositions engendrent souvent certaines aptitudes intellectuelles et morales ${ }^{738}$; ce peut être aussi l'acte volontaire qui, par sa répétition, p330 engendre, comme le dit Aristote, cet habitus qui est la vertu morale ; ce peut être enfin Dieu

\footnotetext{
736 Somme, $\mathrm{II}^{\mathrm{a}}$, $\mathrm{I}^{æ}$, qu. 109, a. 3. ; $\mathrm{II}^{\mathrm{a}}$, $\mathrm{II}^{æ}$, qu. 24, a. 2.

$737 \mathrm{I}^{\mathrm{a}}, \mathrm{II}^{æ}$, qu. 62, a. 1.

738 Somme, $\mathrm{I}^{\mathrm{a}}$, II ${ }^{æ}$, qu. 63, a. 4,
} 
lui-même, dans le cas des vertus infuses. La notion d'habitus englobe donc toute la vie physique, morale et religieuse de l'homme. Entre les vertus acquises, provenant des forces naturelles de l'homme, et les vertus infuses qui viennent de Dieu, entre la tempérance, vertu cardinale qui modère la concupiscence en vue de la santé du corps et de l'exercice facile de la raison, et l'abstinence, vertu infuse, il y a une différence spécifique, et il est impossible de passer de l'une à l'autre par degrés ${ }^{739}$. Pourtant, et malgré cette différence, l'homme reste toujours un être libre et raisonnable : sa Volonté n'agit que si un bien est présenté par la raison ; l'obligation pour la volonté de suivre le bien présenté par la raison comme le plus grand est telle qu'elle ne disparaît pas. même si cette raison se trompe et prend de faux biens pour de vrais biens ${ }^{740}$; et l'homme est toujours libre, c'est-à-dire que ce qui est à faire ou à éviter est déterminé par le jugement à la suite d'une comparaison des divers biens ; saint Thomas, suivant Aristote, pense que l'acte est déterminé par la conclusion d'un syllogisme pratique qui a pour majeure une forme universelle (la santé par exemple) et pour mineure un moyen pratique et concret de l'atteindre (telle ou telle alimentation); c'est dans ces moyens qu'il existe une contingence qui laisse un libre jeu au jugement : le libre arbitre est donc libre jugement ${ }^{741}$; malgré tout, le libre arbitre est une " puissance appétitive » et non une faculté de connaître ; car, si la connaissance est requise pour la délibération, l'appétit est indispensable pour agréer ce qui a été jugé le meilleur par la raison ${ }^{742}$. On voit donc combien cette faculté est inhérente à l'homme ; en un sens, elle est capable de progrès, dans la mesure où, dans son exercice, elle dépend de la réflexion et, par conséquent, du degré d'attention volontaire ; et c'est pourquoi elle est plus grande chez les ${ }_{\mathrm{p} 331}$ anges que chez les hommes ${ }^{743}$; en un autre sens, au sens négatif de privation de la contrainte, « elle ne reçoit pas le plus et le moins ${ }^{744}$ ». Aussi, en cette vie divine qui se superpose en l'homme à la vie purement humaine, le libre arbitre n'est

\footnotetext{
739 Ibid., qu. 19, a. 5.

740 Ibid., qu. 19, a. 5.

741 I Somme, qu. 83, a. 1.

742 Ibid., a. 3.

743 Cf. Jean LApORTE, CLXXVII.

744 Somme, $\mathrm{I}^{\mathrm{a}}, \mathrm{II}^{\mathrm{x}}$, qu. 113 , a. 3.
} 
nullement supprimé : « Dieu meut tous les êtres selon le mode de chacun ; comme, en physique, nous voyons qu'il meut différemment le grave et le léger, en raison de leur nature ; or l'homme, selon sa nature propre, a part au libre arbitre ; aussi, le mouvement vers la justice qui vient en lui de Dieu n'a pas lieu sans un mouvement du libre arbitre ; et Dieu verse en lui le don de la grâce justifiante en mouvant en même temps le libre arbitre à accepter cette grâce ${ }^{745}$. "

Table des matières

\section{XIII.}

\section{BIEN NATUREL ET BIEN SURNATUREL.}

Enfin les idées politiques de saint Thomas achèveront d'illustrer l'esprit de sa philosophie. On pourrait tout ramener chez lui à cette maxime essentielle : "Le droit divin qui vient de la grâce ne supprime pas le droit humain qui naît de la raison naturelle ${ }^{746}$. " Le droit humain est fondé sur les inclinations de la nature ; tout objet qui satisfait une inclination naturelle est en effet considéré comme un bien ; et les diverses sociétés, avec les règles qu'elles impliquent, sont des moyens de les satisfaire ; l’homme trouve dans la société en général un moyen de subsister, dans la famille une satisfaction des besoins de procréation, dans la cité le pouvoir, propre à l'homme, d'étendre ses connaissances et de mener une vie conforme à la justice ${ }^{747}$. Le but de la société, c'est le bien commun de ses membres, c'est-à-dire ${ }^{748}$ la fin

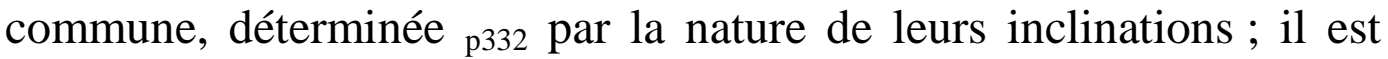
loisible à chacun, dans le cadre de ce bien commun, de rechercher son bien particulier, c'est-à-dire ce qui satisfait les inclinations naturelles dans la nuance personnelle qu'elles ont en chacun.

A la nature du bien commun se rattache la notion de loi : la loi de nature, c'est celle qui prescrit le bien déterminé par les inclinations naturelles et universelles ${ }^{749}$; loi qui est commune à tous les êtres rai-

\footnotetext{
Somme, $\mathrm{I}^{\mathrm{a}}$, II ${ }^{æ}$, qu. 113, a. 3.

Somme, $\mathrm{I}^{\mathrm{a}}$, $\mathrm{II}^{\mathrm{x}}$, qu. 10 , a. 10.

$747 \mathrm{I}^{\mathrm{I}} \mathrm{II}^{æ}$, qu. 94, a. 2.

748 Qu. 90, a. 2 ; cf. SuZANne Michel, CLXXX, p. 51.

749 Ibid., qu. 94, a. 2.
} 
sonnables par ses principes, quoique, en fait, elle trouve des obstacles dans les passions ou dans les coutumes établies ${ }^{750}$; mais elle ne peut être abolie du cœur de l'homme quant à ses principes, qui sont liés à la nature même ${ }^{751}$. Si, à cette loi de nature, doivent s'ajouter des lois humaines et positives, c'est que, dans la raison pratique, il est laissé une très grande place à la contingence el à la variété des moyens qui, suivant les circonstances et la diversité de la nature humaine, sont propres à réaliser une fin. Pour cette raison même, on doit se demander à qui il appartient d'établir la loi. Saint Thomas, qui, en ces questions, s'inspire beaucoup du livre V des Étymologies d'Isidore de Séville, répond ainsi : « La loi, au sens propre et principal, se rapporte au bien commun ; or c'est à la multitude tout entière, ou à quelqu'un qui en tient la place, de rapporter quelque chose au bien commun ; c'est donc à toute la multitude ou à la personne publique qui en a le soin, de fonder la loi, puisque, partout, ailleurs, il appartient d'ordonner les choses en vue d'une certaine fin à celui dont elle est la fin propre $»{ }^{752}$. C’est donc le peuple entier qui est qualifié pour décider les lois ; il est vrai que le peuple peut être remplacé par une "personne publique », c'est-à-dire par le Sénat ou par un roi ; en fait, saint Thomas pense que la multitude n'est guère propre à assurer l'unité sociale, qui ne peut guère venir normalement que de l'autorité d'un seul ${ }^{753}$; p333 C'est seulement « s'il s'agit d'une multitude libre et qui peut se faire la loi à elle-même que l'accord de toute la multitude à observer une règle coutumière a plus de poids que l'autorité du prince ; celui-ci en effet n'a le pouvoir de fonder la loi qu'autant qu'il tient le rôle (gerit personam) de la multitude ». Ainsi les diverses formes du gouvernement, démocratique, aristocratique ou royal, sont également légitimes, et le choix entre eux dépend de beaucoup de circonstances.

Si la source du pouvoir est toujours la volonté populaires il ne s'ensuit pas que cette volonté soit fatalement juste; saint Thomas croit que la justice ne pourra être atteinte que par un gouvernement mixte, où " un seul, d'après sa vertu, est mis à la tête de tous, où se trouvent, sous lui, des personnes qui exercent l'autorité selon la vertu

\footnotetext{
750 Ibid., a. 4.

751 Ibid., a. 6.

752 Somme, $\mathrm{I}^{\mathrm{a}}$, II ${ }^{\mathrm{a}}$, qu. 90, a. 3.

753 De regimine principum, liv. I, ch. II; J. ZEILLER, CLXXXVIII, p. 25
} 
et où pourtant une telle autorité appartienne à tous, tant parce que ces personnes peuvent être élues parmi tous que parce qu'elles sont élues par tous ${ }^{754}$ ". Ainsi l'élection populaire à des fonctions où tous sont éligibles balance l'autorité du prince. Malgré toutes ces précautions, rien n'empêche que les lois positives, étant de source humaine, puissent être injustes et contraires au bien commun ${ }^{755}$; ce sont là « des violences plus que des lois et qui n'obligent pas dans le for de la conscience, sinon peut-être pour éviter le scandale et les troubles ».

Comme il y a, d'après saint Thomas, une nature corporelle qui a ses lois fixes, et une nature humaine qui détermine les règles de la conduite, il y a donc aussi un droit humain tout à fait défini, qui est la source des relations sociales entre les hommes : cette sorte de bloc, nature physique, nature morale, nature sociale, relève de la raison naturelle de l'homme. Mais comme, en matière physique, la raison naturelle ne peut aboutir à une proposition véritable qui soit contraire à la foi, p334 si bien que cette contrariété révèle avec une absolue certitude l'erreur de cette proposition, de même, en matière pratique, le bien naturel que l'homme recherche par la société ne peut en aucun cas s'opposer au bien surnaturel, qui lui est proposé par la révélation, et à toutes les conditions de ce bien, c'est-à-dire à l'Église divinement instituée. Comme, là, la foi servait de limite et de guide à la raison, ici l'Église sert de limite et de guide à un État qui, en lui-même, est laïque ; si une loi politique est opposée au bien surnaturel ou divin, comme les lois des tyrans qui poussent à l'idolâtrie, il n'est pas permis de l'observer ${ }^{756}$; comme l'obéissance au proconsul doit céder devant les ordres de l'empereur, puisqu'elle n'avait d'autre fondement que l'obéissance à l'empereur, de même « les spirituels, guidés par la loi du Saint-Esprit, ne sont pas soumis à la loi en ce qui répugne à la conduite du Saint-Esprit ; et pourtant c'est le Saint-Esprit lui-même qui conduit les spirituels à se soumettre aux lois humaines ${ }^{757}$ ». On voit en quel sens le pouvoir civil est soumis à l’Église ; il doit aider les hommes à marcher dans la voie du vrai bien ; « or, quelle est la voie

\footnotetext{
754 Somme, $\mathrm{I}^{\mathrm{a}}$, II ${ }^{æ}$, qu. 105, a. 1 ; J. ZEILlER, CLXXXVIII, ch. III.

755 Qu. 96, a. 4 : saint Thomas songe surtout ici aux impôts qui surchargeaient le peuple et qui étaient mal distribués.

$756 \mathrm{I}^{\mathrm{a}}, \mathrm{II}^{æ}$, qU. 96, a. 4.

757 Somme, $\mathrm{I}^{\mathrm{a}}$, $\mathrm{II}^{æ}$, qu. 96, a. 5.
} 


\section{Émile Bréhier \\ La philosophie du Moyen âge}

du vrai bien et quels y sont les obstacles ? C'est la loi divine qui le marque, et son enseignement appartient au ministère de l'Église ${ }^{758}$ ". On ne trouve pourtant pas chez saint Thomas, l'exposé de l'idéal théocratique, que ses successeurs immédiats rattacheront à sa doctrine, mais il approuve toutes les lois qui mettent le pouvoir civil au service de l'Église, en particulier la loi contre les hérétiques qui, après l'excommunication prononcée par l'Église, " sont abandonnés au tribunal séculier pour être exterminés du monde par la mort », ou la confiscation des biens de l'hérétique repentant ${ }^{759}$.

758 De regimine principum, I, ch. XIII; ZEILlER, CLXXXVIII, ch. V.

759 Somme, $\mathrm{II}^{\mathrm{a}}$, II ${ }^{æ}$, qu. 11 , a. 3 et a. 4. 


\section{Chapitre V}

\section{L'AVERROÏSME LATIN}

La doctrine de saint Thomas, qui trouve en Aristote un rationalisme qui s’accorde spontanément avec la foi chrétienne, suppose, dans la masse doctrinale arrivée en Europe avec le péripatétisme arabe, une discrimination qui n'avait pas été faite au début du siècle ; saint Thomas lui-même sait très souvent distinguer Aristote de ses commentateurs. De ce travail, un témoin est un traité anonyme, le De erroribus philosophorum, qui a dû être écrit par un Dominicain espagnol entre 1260 et $1274^{760}$. L'auteur distingue avec précision les erreurs propres à Aristote de celle des péripatéticiens arabes : l'erreur fondamentale d'Aristote vient de l'ignorance de la création qui l'amène à affirmer l'éternité du monde ; une autre erreur, selon lui, c'est la thèse de l'unité de la forme. De ces deux thèses, on sait que saint Thomas jugeait la première compatible avec la création, et qu'il adoptait la seconde. En revanche, l'auteur considère comme des erreurs propres à Averroès la thèse de l'ignorance en Dieu des choses particulières et de l'unité de l'intellect ; c'est dans Avicenne et Al Gazali qu'on trouve que Dieu ne peut produire immédiatement qu'un être simple, dans Al Kindi qu'est soutenue l'absolue fatalité astrologique.

$\underline{\text { Table des matières }}$ 
I.

\section{SigER DE BRABANT.}

p336 Cette distinction précise entre Aristote et les Arabes répondait à la préoccupation qui s'était montrée chez les autorités ecclésiastiques lorsqu'elles avaient défendu la lecture d'Aristote ; il fallait séparer l'ivraie du bon grain. La nécessité en devint plus pressante encore en 1266, au moment du retour de saint Thomas à l'Université de Paris, lorsqu'il trouva Siger de Brabant enseignant à la faculté des arts une doctrine qui plaçait sous la garantie d'Aristote des thèses telles que celle de l'unité de tous les intellects humains : pareil enseignement était une sorte de réfutation par l'absurde des tentatives du maître dominicain pour concilier Aristote et la foi. Déjà, en 1256, Albert le Grand avait écrit, sur l'ordre du pape Alexandre IV, un traité qu'on intitule De unitate intellectus contra averroistas ; mais il y attaque moins une erreur professée et proprement averroïste qu'un arabisme diffus qui nie l'immortalité personnelle, en prenant quelques arguments à Averroès, mais en s'appuyant sur d'autres philosophes arabes qui lui étaient des plus contraires ${ }^{761}$. Siger, lui, sur cette question comme sur toutes les questions importantes, se rattache au contraire à l'interprétation averroïste d'Aristote. C'est ainsi que, contre Albert qui voyait dans l'existence un accident de l'essence, contre saint Thomas qui rapportait l'une à l'autre comme l'acte à la puissance, Siger suit l'enseignement d'Averroès : "L'être de l'essence dans la définition dit tout ce qui appartient à son existence, soit la puissance, soit l'acte », dit-il en visant saint Thomas ${ }^{762}$. Avec Averroès, il affirme l'éternité ${ }_{\mathrm{p} 337}$ du monde ; un individu d'une espèce ne peut en effet arriver à l'être que s’il est engendré par un autre individu de la même espèce, et ainsi les espèces existent toujours ${ }^{763}$. D'autre part, il discute les thèses d'Albert et de saint Thomas sur l'union de l'âme et du corps ; il lui semble que ni l'un ni l'autre n'ont compris les intentions du "Philosophe ", en affirmant que l'âme intellective, si, par sa puissance, elle est séparée du corps, lui est unie par sa substance: pareille thèse suppose une séparation inadmissible entre la

\footnotetext{
761 Cf. D. SALMAN, CXCIX, p. 38-64.

762 Mandonnet, CXCVI (textes), p. 68 ; comparer M. Grabmann, CXCV, p. 137, où saint Thomas est. cité.

763 MANDOnNET (textes), CXCVI, p. 133.
} 
substance et ses puissances ; Aristote pense que c'est, à la substance même de l'âme que s'assimilent les intelligibles lorsque nous les pensons en acte ; et il n’attribue pas au corps l'opération de la pensée, ce qui serait nécessaire si l'âme intellectuelle donnait sa forme au corps ; saint Thomas objecte que l'on ne dit pas que c'est l'âme qui pense, mais bien l'homme, c'est-à-dire le composé d'âme et de corps ; mais c'est que l'on attribue au composé ce qui n'est vrai que d'une de ses parties. L'âme intellectuelle a existé éternellement dans le passé, comme elle existera éternellement dans l'avenir ; si elle n'est pas unie au corps, comme le veut saint Thomas, elle n'en est jamais séparée, à la manière dont le sont les intelligences célestes, puisqu'elle ne saurait penser sans images. Enfin, et c'est là le point essentiel dans l'enseignement de l'averroïsme, cette âme est la même pour tous les hommes, n'étant pas affectée à un corps particulier, mais liée également à tous les corps qui se succèdent sans fin dans l'espèce humaine : comment pourrait-elle se multiplier, puisque la matière est la condition de toute multiplication et qu'on avoue qu'elle est immatérielle ? La grande objection consiste à dire que, si elle était une, tous les hommes seraient également savants ; il faut répondre qu'elle ne s'exerce que par les images ou phantasmes qui sont différents chez chacun.

p338 Cette âme intellectuelle unique, « venue de l'extérieur » selon le mot d'Aristote, n'est donc pas substantiellement la même que l'âme sensitive et végétative, dont les opérations sont corporelles et dont la substance, par conséquent, doit être tirée de la matière ${ }^{764}$.

Au début de ses explications sur l'unité de l'intellect, Siger écrit : « Il faut considérer diligemment cette question, autant qu'il appartient aux philosophes et selon qu'elle peut être comprise par la raison humaine et par l'expérience, en cherchant en cela l'intention des philosophes plutôt que la vérité, puisque nous procédons philosophiquement ${ }^{765}$ ». On aurait tort de trouver ici une expression de la théorie des « deux vérités », l'une atteinte par la philosophie et l'autre par la foi, qui seraient juxtaposées sans pouvoir jamais s'accorder : ou bien l'on admet la sincérité des déclarations de Siger, et alors il n’y a

\footnotetext{
764 MANDONNET, CXCVI (textes), p. 152-171.

765 MANDONNET, CXCVI (textes), p. 164.
} 
qu’une seule vérité, la vérité de foi, et le raisonnement humain, bien que correctement mené, ne peut aboutir qu'à l'erreur, et alors Siger serait fidéiste ; ou bien ces déclarations ne sont qu'une précaution contre une condamnation ecclésiastique menaçante, et alors Siger n’admet d'autre vérité que celle qui est découverte par la raison. Sans doute est-ce là la pensée véritable de Siger : dans les écrits que nous possédons de lui, il se montre aristotélicien fervent ; dans les Quaestiones logicales, il montre que le terme commun ne désigne qu'un concept de l'esprit ${ }^{766}$; dans les Impossibilia, qui sont un document important pour l'histoire de cette sophistique du Moyen Age qui avait commencé avec les hyperdialecticiens du $\mathrm{XII}^{\mathrm{e}}$ siècle, il analyse les sophismes par lesquels on prétendait démontrer des assertions contraires à celles d'Aristote : « Dieu n'est pas ; les sens n'atteignent pas la réalité ; il n’y a pas de distance entre le passé et le présent ; le grave, laissé à lui-même, ne descend pas ; le principe de contradiction

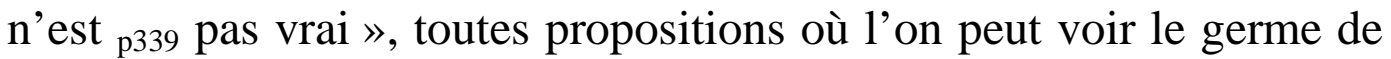
l'athéisme spéculatif, de l'idéalisme subjectif, de la physique de l'inertie, qui se développeront au $\mathrm{XIV}^{\mathrm{e}}$ siècle, moins contre les croyances chrétiennes que contre Aristote. D’autre part, dans les propositions condamnées en 1277 , se trouvent, à côté de celles que l'on a tirées des écrits de Siger connus de nous, d'autres qui dénient toute valeur à la théologie et font de la philosophie la seule source de certitude ${ }^{767}$.

Ce divorce entre la philosophie et la théologie se fondait, chez Siger, sur ce même Aristote que les Dominicains employaient à assurer la conciliation de l'une et de l'autre. Ajoutons que les attaques de Siger n'étaient pas des critiques purement théoriques, que, comme il arrive souvent au Moyen Age, elles s'étendaient à la discipline, ecclésiastique elle-même et particulièrement aux vœux de pauvreté et de chasteté prononcés par les moines ${ }^{768}$. Dans ces conditions, saint Thomas, alors présent à Paris, devait agir ; ce fut l'occasion du traité De unitate intellectus contra averroistas. Dans la Somme contre les Gentils ${ }^{769}$ et le De aeternitate mundi, il s'était élevé contre ceux qui

\footnotetext{
766 Id., p. 57-58.

767 MANDONNET, CXCVI (études critiques), p. 192-193 ; (textes), p. 176 et 189.

768 MANDONNET, CXCVI (études), p. 193 et notes.

769 II, ch. XXXI-XXXVIII.
} 
avaient entrepris de réfuter la doctrine de l'éternité du monde, non pas en s'attachant à « la solide doctrine de Dieu », c'est-à-dire à la révélation, mais en niant la vérité des théorèmes péripatéticiens; il avait montré que ces théorèmes sont tous compatibles avec la création. Il rencontre maintenant la même difficulté sous l'aspect inverse; il s'agit toujours de l'accord de la philosophie et de la foi ; mais, tandis que les murmurantes à qui s'adressait le De aeternitate mundi sont des théologiens qui nient la philosophie d'Aristote en faveur de la théologie, les averroïstes nient la théologie en faveur de la philosophie.

p340 Le De unitate intellectus ne répond pas du reste directement au De anima intellectiva de Siger ; il suffit de comparer les deux textes pour voir que plusieurs des arguments critiqués par saint Thomas ne se trouvent pas chez Siger ${ }^{770}$; que, même, plusieurs des points de vue indiqués par lui comme averroïstes (les phantasmes sujets des intellecta par exemple) sont formellement désavoués par Siger ; que Siger connaît et cite les mêmes commentateurs arabes, que saint Thomas reproche aux averroïstes de ne pas connaître ${ }^{771}$; que saint Thomas enfin laisse de côté nombre d'arguments de Siger. Le De unitate suit plutôt directement le commentaire qu'Averroès a fait d'Aristote pour en critiquer l'exactitude : nous connaissons le principe de cette réponse, qui consiste à distinguer la substance de l'âme de ses puissances, et à attribuer non à la substance, mais à la puissance ou faculté intellectuelle, tout ce que dit Aristote de l'intellect séparé. Dans un sermon prononcé en 1270, c'est le procédé même des averroïstes qu'attaque saint Thomas, le procédé de ceux qui s'excusent d'énoncer des assertions contraires à la foi en disant « qu'ils récitent les mots des philosophes "; c'est l'attitude « d'un faux prophète ou d'un faux docteur, puisque c'est la même chose de soulever un doute sans le résoudre que de l'accorder ${ }^{772}{ }^{\prime}$.

La même année, le dominicain Gille de Lessines ${ }^{773}$ écrit à Albert pour lui soumettre quinze questions «que proposent dans les écoles

\footnotetext{
770 Par exemple, clans le chapitre VII: adhuc alitent... ; procedunt autem.

771 Comparer ch. VII : patet autem... et SIGER, p. 168 : sed et sunt.

772 Cité par MANDONNET, CXCVI (études), p. 109.

773 Cf. ibid., p. 105 ; et textes, p. 29.
} 
de Paris des maîtres qui sont réputés les plus grands en philosophie » ; la première concerne l'unité de l'intellect, les autres le fatalisme astrologique, l'éternité du monde, l'ignorance des choses singulières en Dieu, et en général les principales erreurs de l'aristotélisme arabe ; Albert y répond ${ }_{\mathrm{p} 341}$ par le traité De quindecim problematibus ; il y soutient que la thèse de l'unité de l'intellect « est fausse, non seulement pour les théologiens mais pour la philosophie ; la cause de cette thèse, ajoute-t-il, est l'ignorance de beaucoup de Parisiens qui suivent non la philosophie mais les sophismes ${ }^{774}$ ". Au sujet de l'éternité du monde, il ne nie pas qu'on la trouve chez Aristote, mais seulement « en ce sens que les choses n'ont pas de commencement de leur existence ». D'une manière générale, l'intention d'Albert est donc de sauver la philosophie contre les prétendus philosophes empressés à la servir.

Les réponses d'Albert furent probablement l'origine de la condamnation que l'évêque de Paris, Étienne Tempier, prononça à la fin de 1270 , et qui porte en effet sur les treize premières propositions soumises à Albert. Mais cette condamnation laissait intacte la question des rapports de la philosophie à la théologie; et elle pouvait s'entendre en un sens défavorable aux maîtres dominicains qui désavouaient bien, il est vrai, la solidarité de ces propositions avec la philosophie, mais sans produire peut-être une entière conviction dans les esprits. D'ailleurs les deux dernières des quinze propositions soumises à Albert par Gille et mises par lui sur le même pied, concernaient non pas l'arabisme, mais deux thèses de saint Thomas, l'une sur l'unité de la forme, l'autre sur la simplicité des substances angéliques : sur l'une et sur l'autre, Albert est assez évasif.

Table des matières

II.

LA CONDAMNATION DE 1277.

Malgré les efforts de saint Thomas et d'Albert pour séparer l'averroïsme de la cause de la philosophie, la condamnation de 1270 était une arme des maîtres séculiers de l’Université de Paris qui, tous,

${ }^{774}$ Ibid., p. 35. 
étaient augustiniens ; le conflit, inévitable, p342 malgré la personnalité de saint Thomas qui quitta Paris en 1272 et mourut en 1274, eut son épilogue dans la condamnation de mars 1277 ; ayant reçu l'ordre du pape Jean XXII de faire une enquête sur les doctrines enseignées à l’Université de Paris, l'évêque de Paris, Étienne Tempier, ne se contenta pas de soumettre les résultats de cette enquête au pape, il procéda lui-même à la condamnation de deux cent dix-neuf propositions qui portaient indistinctement sur la doctrine péripatéticienne en général et la doctrine averroïste en particulier. Dans les années qui précédèrent cette condamnation, à la faculté des arts, il y avait eu une scission entre les maîtres ; une minorité, conduite par Siger de Brabant, nommait son propre recteur ; la majorité la rappelait à la règle de la faculté des arts : interdiction d'y traiter des questions purement théologiques ; interdiction d'expliquer dans les auteurs reçus les textes qui semblent contredire la foi, à moins d'en apporter des réfutations ; cette scission dura jusqu'en 1275, mais l'arrangement pris alors par le légat du pape Simon de Brion n’arrêta pas l'enseignement averroïste.

La condamnation de 1277 y mit fin, mais elle risquait (et c'est cela qu'a voulu sans doute la majorité du conseil des théologiens d'où sortit la décision d'É. Tempier) de mettre fin aussi à l'enseignement péripatéticien, c'est-à-dire de forcer les maîtres à revenir d'une philosophie, née tout entière de la raison humaine et proportionnée à son objet, à une philosophie venue de l'effort pour ajouter à la foi en Dieu la vision : sans doute l'immense majorité des propositions condamnées sont de l'averroïsme pur, et l'excommunication de Siger, qui, après comparution devant le légat du pape puis à la cour de Rome, est interné et meurt tragiquement vers 1281, marque la fin de l'enseignement averroïste à la faculté des arts ; mais plusieurs maîtres de théologie éprouvent le besoin de protester. Les propositions thomistes condamnées portaient tout particulièrement sur la conception de l'être concret, individuation p343 par la matière, participation du corps à la vertu de l'âme et à ses opérations intellectuelles, détermination de la volonté par l'entendement, autant de propositions qui interdisent de considérer comme accidentel, selon la tendance générale des augustiniens, l'union de la réalité spirituelle à la matière et qui, par conséquent, se rattachent à l'essentiel du thomisme : une thèse thomiste, importante à ce sujet, n'apparaît pas dans la condamnation, c'est celle de l'unité de la forme ; mais l'archevêque de Cantorbery, Robert Kilwardby, qui, 
bien que dominicain, était un augustinien fervent, la condamne, ainsi que les thèses concernant la composition des corps : c'était condamner non pas telle ou telle thèse, mais l'esprit même de la philosophie avec le sens qu'elle avait pris, chez Aristote, de la réalité du concret.

Il ne faudrait pas exagérer, en ce qui concerne la thomisme, la portée de condamnations qui n’étaient appliquées que dans les limites du diocèse de l'évêque. Étienne Tempier, qui voulut étendre au diocèse de Paris les condamnations portées par Kilwardby, fut arrêté par le Saint-Siège. Les évêques eurent à faire ici non plus à quelques maîtres de la faculté des arts, mais à un ordre puissant qui se défendit et défendit la mémoire de saint Thomas : la peur de l'excommunication et du scandale, qui fut d'abord assez vive ${ }^{775}$, ne tint pas devant cette puissance ; et si l'évêque de Paris ne rapporta la condamnation de Tempier qu'au moment de la canonisation en 1325, dès 1278 le Dominicain Gilles de Lessines composa son traité De unitate formae contre la condamnation du primat d'Angleterre ; en même temps, Gilles de Rome, des Ermites de saint Augustin, enseignait à Paris la même thèse et la défendait dans son Contra gradus et pluralitates formarum, en déclarant que la thèse contraire était hérétique ; et, s’il fut suspendu à ce moment par Tempier, le pape rétablit son enseignement en 1285.

775 MANDONNET, p. 237, n. 2, 


\section{Chapitre VI}

\section{L'OPPOSITION AU THOMISME AU XIII ${ }^{\mathrm{e}}$ SIÈCLE}

Pourtant, ce ne fut pas le triomphe du thomisme ; après la mort des grands protagonistes, saint Thomas et saint Bonaventure en 1270, saint Albert en 1280, le dernier quart du XIII ${ }^{\mathrm{e}}$ siècle est rempli par des polémiques ardentes pour et contre la nouvelle philosophie : mais en même temps se font jour des pensées originales qui, bien que cherchant à résoudre encore le grand problème médiéval des rapports de la raison et de la foi, annonce déjà cette dissolution de la pensée médiévale qui aura lieu au XIV ${ }^{\mathrm{e}}$ siècle, celles de Roger Bacon, de Duns Scot et de Raymond Lulle, tous trois franciscains.

Après la condamnation de 1277, Franciscains et séculiers s'unissent contre la philosophie thomiste ; Henri de Gand, maître séculier de l'Université de Paris en 1277 (mort en 1293), reprend toutes les positions augustiniennes sur les problèmes posés par saint Thomas ; ainsi font surtout les Franciscains, Mathieu d'Aquasparta, né vers 1240, et qui fut général de l'ordre en 1287 ; Jean Peckham, né en 1240 et archevêque de Canterbury en 1279 ; Guillaume de La Mare, qui publie en 1278 le Correctorium fratris Thomae ; Roger Marston, professeur à Oxford puis à Cambridge entre 1270 et 1292 ; Richard de Middletown, qui enseigna à Paris en 1283 et mourut vers 1307, sans parler de Pierre-Jean Olivi, maître à Florence en 1287, puis à Montpellier, mort en 1295. 
I.

\section{LE PROBLEME DE LA CONNAISSANCE.}

p345 Il est arrivé, au cours du XIII ${ }^{\mathrm{e}}$ siècle, que l'aristotélisme régnant a imposé sa manière d'énoncer les problèmes concernant la connaissance intellectuelle ; si celle-ci est la connaissance d'une quiddité ou forme incluse dans le sensible, il faut déterminer le mécanisme par lequel on l'extrait du sensible. Or, comme le remarque l'augustinien Roger Marston, saint Augustin ne donne aucune réponse à ce problème qu'il n'a pas posé : ce qui intéresse saint Augustin et les augustiniens, saint Bonaventure en particulier, dans la connaissance intellectuelle, c'est la certitude qui s'explique par une illumination divine. Cette explication suppose par ailleurs que la connaissance intellectuelle ne dépend pas de l'action des choses sensibles sur l'âme, tandis que l'aristotélisme fait de l'espèce produite par cette action le départ de l'opération abstractive. De là, les deux questions qui se trouvent posées chez Mathieu d'Aquasparta et surtout chez Roger Marston : d'abord comment peut-on atteindre les universaux sans abstraction? Ensuite l'illumination divine nécessaire à la certitude de l'intelligence est-elle naturelle ou surnaturelle ? Sur la première question, Mathieu d'Aquasparta répond: "Quand l'intellect atteint une première espèce, ce n'est pas en raisonnant ou en abstrayant qu'il l'assemble (ipsam colligit), mais en la transformant au dedans de soi. La vertu cogitative rassemble des images particulières et les montre à l'intellect qui fait en lui-même les notions des universaux ${ }^{776}$ ". Ces universaux ne dépendent pas du tout des choses sensibles, comme il le semblerait dans la thèse thomiste; l'essence que l'on atteint par l'intellect, p346 celle de l'homme par exemple comme animal mortel et raisonnable, est vraie indépendamment des choses sensibles qui passent; ces vérités éternelles ne peuvent pas davantage trouver leur source dans un intellect créé, mais seulement « en un exemplaire éternel, où, comme dit saint Augustin, résident les origines immuables des choses muables, où restent les raisons des choses qui passent »; il ne faut pas confondre cet exemplaire éternel avec l'objet immédiat de notre esprit ; cet objet, « c'est la quiddité même conçue par notre intellect, mais rapportée à l'art ou exemplaire éternel, en tant que, tou776 MATHIEU D’AqUASPARTA, Quaestiones de fide et cognitione, éd. Quaracchi,
1903, p. 291. Cf. E. GILson, CCVI. 
chant notre esprit, il est pour lui comme un moteur ${ }^{777}$ ". L'universel est donc atteint sans abstraction, grâce à cette relation qui met l'esprit en mouvement : la théorie thomiste « renverse tous les fondements de la pensée de saint Augustin, ce qui paraît inadmissible, alors qu'il est le principal docteur, que les docteurs catholiques et surtout les théologiens doivent suivre ${ }^{778}$ "; et c'est la certitude de la connaissance intellectuelle qui empêche de la concevoir autrement que comme une liaison à la lumière divine et incréée. Ce n'est pas que l'expérience soit inutile ; elle est au contraire un élément indispensable de la connaissance, mais elle est une matière, et notre intellect agent n'opère sur elle que grâce à la lumière divine. L'abstraction et le raisonnement discursif ne sont pas des conditions nécessaires de la connaissance intellectuelle; il y a une connaissance intuitive de l'âme par ellemême ; et d'autre part, la preuve que saint Anselme donnait de l'existence de Dieu est admissible ; on découvre son existence en méditant sur la signification de son nom.

Nous trouvons chez le Franciscain Jean Peckham, qui fut maître à Paris en 1270 et plus tard à Oxford, la même opposition irréductible au thomisme, la même affirmation de la nécessité de superposer, dans toute connaissance intellectuelle, à la lumière créée de l'entendement, qui est imparfaite, la lumière ${ }_{\text {p347 }}$ incréée, la même acceptation de la preuve de saint Anselme qui est d'ailleurs défendue par d'autres penseurs du même groupe, notamment par Nicolas d'Occam, qui enseignait à Oxford vers la fin du siècle.

Roger Marston, également franciscain, qui étudia à Paris en 1270 et enseigna à Oxford avant d'être ministre de la province anglaise en 1292, interprète Aristote comme les commentateurs arabes, donc contre saint Thomas, mais en fonction de saint Augustin : l'intellect agent, tel que le décrit Aristote, n'est rien que cette « lumière incréée dans laquelle nous voyons avec certitude toutes les choses vraies », n'est rien que Dieu lui-même ${ }^{779}$. Il n'en reconnaît pas moins, comme les autres Franciscains, un intellect agent qui est une partie de l'âme,

\footnotetext{
777 Quaestiones de fide, p. 233.

778 Ibid., p. 252.

779 Quaestiones disputatae, éd. Quaracchi, p. 207-208.
} 
mais qui n'opère que grâce à la lumière divine ${ }^{780}$; même opposition à saint Thomas qui, obligé d'accepter l'autorité de saint Augustin et sa théorie de l'irradiation, l'interprète en ce sens que la lumière incréée est à la lumière créée ou entendement comme le créateur à la créature, alors qu'elle est non seulement créatrice mais lumière qui éclaire ${ }^{781}$; même attachement à la preuve ontologique de saint Anselme ${ }^{782}$. Il ne faut pas croire pourtant que tous les Franciscains partageaient les mêmes idées : Richard de Middletown n'admettait pas non plus que Dieu éclairât immédiatement l'âme ${ }^{783}$, et il rejetait la preuve ontologique. Ainsi pensait également le Franciscain Guillaume de Ware qui enseignait à Paris vers la fin du XIII ${ }^{\mathrm{e}}$ siècle ; il est attaché à la représentation thomiste d'une nature qui, créée par Dieu, trouve en elle les forces d'agir ; s'il en est ainsi des choses de la nature, «l'âme, à plus forte raison, étant plus noble, doit avoir des instruments à elle par lesquels elle puisse produire son action naturelle, qui est de connaître par l'intelligence ${ }^{784}$ ", p348 Henri de Gand, qui fut maître séculier à Paris en 1277, soutient au contraire la thèse des augustiniens purs ; « il n'est pas vrai que Dieu enseigne seulement à la manière d'une cause universelle qui donne au disciple ses facultés cognitives ou comme un moteur universel ${ }^{785} "$; mais il ne veut pas non plus que toute connaissance, même naturelle, ait besoin d'une illumination divine spéciale ; cela, disait-il exactement comme son contradicteur Guillaume de Ware, " dérogerait à la dignité de l'âme raisonnable qui, au moins autant que les choses inférieures, doit avoir un mouvement suffisant pour quelque opération qui convienne à sa nature ». Sa position est donc intermédiaire ; il pense que, sauf la connaissance sensible, toute connaissance est relative à un exemplaire ; mais les thomistes conçoivent cet exemplaire comme « abstrait de la réalité par les sens, purifié et rendu universel, autant que faire se peut, si bien qu'il n'y aurait aucune conception dans l'intellect qui n'ait été auparavant dans le sens ${ }^{786}$ " ; l'exemplaire, ainsi postérieur à la chose et formé en partant

\footnotetext{
780 Ibid., 215.

781 Ibid., p. 203, 205, 220.

782 DANIELS, CCIV.

783 Quaestiones disputatae, éd. Quaracchi, p. 235.

784 UeBeHWEG, p. 458 ; d’après DANIELs, Festgabe für Bauemker, p. 313.

785 I Somme théologique, qu. 7, art. 1.

${ }^{786}$ Non est aliquid conceptum in intellectu, quod non erat prius in sensu.
} 
des choses singulières, ne peut être une règle véritable; c'est l'exemplaire créé dont parle Platon au Timée. La vérité pure ne peut être saisie que par rapport à un exemplaire éternel. Seulement cet exemplaire n'est pas l'objet naturel de la connaissance, mais une règle pour elle (ratio cognoscendi) ; il ne peut devenir objet sans une illumination spéciale qui n'arrive que par un don exceptionnel de Dieu, celui qui a été fait à Moïse ou à saint Paul ; mais, lorsque Platon dit que toute vérité est connue par référence à un exemplaire éternel, cela s'entend de « cette vérité incréée qui s’imprime dans notre conception qu'elle transforme selon son caractère, et qui informe notre esprit par le modèle (similitudine) que la chose à connaître a dans la vérité première. Donc, si l'on exclut toute illumination divine, l'homme n'arrive pas à connaître la vérité d'après ${ }_{\text {} 349}$ ses pures aptitudes naturelles ; d'elles-mêmes, elles ne peuvent agir de manière à atteindre les règles de la lumière éternelle, mais Dieu les présente et les enlève à qui il veut, sans aucune nécessité naturelle ${ }^{787}$.

Dans cette théorie de la connaissance se voit, avec une particulière netteté, le trait capital de l'augustinisme qui place tout progrès d'une chose dans l'addition d'une propriété d'origine transcendante qui la complète, plus que dans son développement interne : c'est que, conformément à l'essence même du platonisme, la notion aristotélicienne d'être en puissance est à peu près absente du système. Ainsi Henri de Gand (et plusieurs Franciscains sont du même avis) explique-t-il la notion capitale de matière : elle est non pas un être en puissance, mais un être capable d'exister par soi, et son idée propre est dans l'intelligence du Créateur ; « elle pourrait être dépouillée de toute forme par l'action du Créateur »; seulement son acte " ne serait pas aussi parfait que celui qu'elle a dans sa composition avec la forme " ${ }^{788}$; la forme sert donc à perfectionner la matière non à la faire exister ; le supérieur est à l'inférieur non pas dans un rapport physique qui l'explique, mais dans un rapport moral qui le complète ; tandis que l'idée d'une matière en acte pour le thomisme est non pas incomplète mais bien contradictoire ${ }^{789}$. Pour la même raison, Henri de Gand ne peut placer dans la matière le principe d'individuation : la

\footnotetext{
787 I Somme, qu. 2, a. 1.

788 Quodlibet I, qu. 10, éd. de Venise, 1608, t. I, p. 13, col. 3, et p. 14, col. 2.

789 Cf. la discussion du Correctorium corruptorii, art. 27, p. 154.
} 
forme reçue dans la matière est par elle-même individuelle parce qu'elle est au bas de l'échelon des formes ; l'individualité n'est pas pour une forme un enrichissement, mais une négation ; la division des formes ne va pas au delà d'une certaine limite, à laquelle elles deviennent incapables de se diviser et restent différentes de toutes les autres ; mais ce n'est pas la matière qui a affecté cette sorte de dialectique interne ${ }_{\mathrm{p} 350}$ par laquelle l'espèce se multipliait en individus. Le Correctorium de Guillaume de la Mare rappelle à ce sujet une comparaison que saint Augustin a empruntée à Plotin, celle du centre d'un cercle qui comprend en son point indivisible l'origine des multiples rayons qui, eux, ne peuvent plus se diviser ${ }^{790}$.

$\underline{\text { Table des matières }}$

II.

\section{LA PLURALITE DES FORMES.}

Même opposition sur les autres thèmes qu'avait introduits la philosophie albertino-thomiste : distinction de l'essence et de l'existence, unité de la forme, rapports de la volonté et de l'entendement, possibilité des accidents réels, toutes questions que sous-tend toujours le grand débat sur les rapports de la raison et de la foi. Mais il y a chez tous, adversaires et partisans, une volonté de traiter ces questions selon la méthode technique de discussion, ce qui en masque souvent l'intérêt profond.

Dans la question de l'unité de la forme ${ }^{791}$, on part en tout cas de ce principe, commun avec l'adversaire, que l'homme est une unité par soi (unum per se) ${ }^{792}$; la doctrine de la pluralité des formes ne doit en aucun cas atteindre ce principe: c'est donc en des limites assez étroites que se meut la discussion. Les mêmes arguments reviennent d'un côté et de l'autre non sans monotonie ; comme toujours, on tâche moins d'établir sa thèse que de ruiner celle de l'adversaire : les partisans de la pluralité accusent les partisans de l'unité de rabaisser l'âme en lui donnant des fonctions corporelles ; si l'âme intelligente est la

\footnotetext{
790 Dans Correctorium corruptorii, p. 521.

791 Cf. p. 323.

792 Cf. DE WuLf, Introduction, CCXVI, p. 98.
} 
forme unique de l'homme, il faudra qu'elle donne à la matière toutes les propriétés vitales, et même qu'elle joue le rôle de la forme élémentaire en donnant aux diverses parties p351 du corps gravité ou légèreté $^{793}$. Gilles de Lessines, en son De Unitate formae, donne un résumé très net de l'argumentation en faveur de la pluralité des formes ${ }^{794}$. Un des arguments et sans doute le plus important, c'est que le corps vivant est engendré d'un autre corps vivant, tandis que l'âme créée de rien s'unit à lui de l'extérieur ; après cette génération, il faudrait que l'âme en survenant détruisît toutes les formes pour les remplacer à elle seule, ce qui rendrait inutile tout le travail de formation organique accompli par la nature avant l'arrivée de l'âme. Mais la réduction à l'âme intelligente de toutes les actions et puissances physiques qui sont dans le corps laisse soupçonner que les partisans de l'unité de la forme iront encore plus loin en expliquant toutes les fonctions physiques et vitales de tous les corps de la nature par un intellect commun à tous les êtres ; la doctrine de l'unité de la forme tend donc vers un panthéisme, vers une doctrine étrangère à la foi, a que répudie la raison et que déteste la science philosophique ».

Il est clair que, pour les augustiniens, il s'agit avant tout de ne pas faire de l'âme un facteur de l'explication physique de l'univers, ou de la genèse particulière d'un corps humain, ni, à plus forte raison, d'y voir une nature universelle dont toutes les forces existant au monde ne seraient que des aspects ; il s'agit de réserver l'intégrité de la vie spirituelle qu'il pense atteinte par la nouvelle philosophie. Mais les thomistes leur répliquent unanimement que l'unité de l'homme ne saurait être assurée que par l'unité de la forme substantielle ; ils répètent inlassablement l'adage de saint Thomas que « de deux choses ne peut, s'en faire une seule, si l'une d'elles n'est à l'autre comme l'acte à la puissance " ${ }^{795}$; s'il $y_{\text {p352 }}$ avait plusieurs formes substantielles dans un être, cet être serait composé d'autant d'êtres substantiellement distincts. Si, à la thèse de l'unité, on oppose qu'elle tend au panthéisme, on reprochera à la thèse inverse de faire revivre une sorte de réalisme

793 Par exemple, Guillaume DE LA MARE, Correctorium, inséré dans R. KLAPWELL, Correctorium corruptorii, art. XXXI (édit. de Cologne 1624, p. 125).

794 Les philosophes belges, t. II, p. 7 s q.

795 Contra Gent., II, ch. LVIII ; cf. Godefroi DE FONTAINES Quodlibet, I, 7, p. 107. 
platonicien ${ }^{796}$; le genre animal est comme une forme substantielle identique en toutes les espèces et tous les individus : or, selon Godefroi de Fontaines, il n'en est ainsi que par une abstraction de logique ; le genre ne se dit des espèces et des individus que d'une manière équivoque ; l'animalité de l'homme n'est pas celle du cheval, alors que l'humanité de l'homme blanc est identique à celle de l'homme noir ; si le premier cas revenait au second, la différence spécifique ne s'unirait au genre que comme un accident à la substance, et l'unité de l'espèce serait atteinte ${ }^{797}$.

On voit à quel point l'opposition est profonde : ce monde disloqué, les Franciscains l'adoptent parce qu'ils savent que l'unité vient d'en haut, de Dieu qui rapproche les choses distinctes ; la dualité substantielle du corps et de l'âme n'empêche pas l'unité de l'homme, disentils, parce que la nature a disposé la matière de telle façon qu'elle convienne à l'action surnaturelle créatrice des corps ; et les Dominicains y répugnent parce qu'ils veulent que l'unité vienne de la nature même des choses; au point de vue des règles de la nature, l'âme, si elle s'ajoute à un corps qui est déjà une substance une, ne pourra lui advenir que comme un accident ${ }^{798}$. Vainement répond-on qu'il peut y avoir des substances incomplètes, qui aspirent à se faire compléter par d'autres ; il n'y a d'incomplet, dans la physique péripatéticienne, que l'être en puissance de la matière.

Toutefois la solution dominicaine, qui rattachait entièrement, à la solution du problème physique des mixtes, celle ${ }_{\mathrm{p} 353}$ des rapports de l'âme et du corps n'était pas sans inquiéter quelque peu ceux mêmes qui penchaient vers la thèse de l'unité des formes. Qu'on lise la conclusion de Godefroi de Fontaines : «A parler absolument, la thèse de l'unité des formes, prise en général, est plus probable que la thèse contraire ; mais dans le cas de l'homme, la thèse de la pluralité des formes est moins improbable, pour autant que l'homme est un être fort différent des autres composés matériels. »

\footnotetext{
796 Cf. Correctorium corruptorii, art. XXXII, éd. de Cologne, 1624, p. 210.

797 Godefroi DE FONTAINES p. 103-104.

798 Cf. l'ensemble de la discussion, ibid., p. 113-117.
} 
III.

\section{L’ESSENCE ET L'EXISTENCE.}

Le débat concernant la seconde question, les rapports de l'essence et de l'existence ${ }^{799}$, est beaucoup moins net que le précédent, tellement il répond à des préoccupations diverses : on va voir pourtant que les adversaires des thomistes, leur ayant reproché, dans la précédente question, d'avoir uni là où il fallait distinguer, les blâment ici d'avoir distingué alors qu'il fallait identifier. Ce qui complique la discussion, c'est que la solution qu'en donnent les thomistes se rattache à celle d'une question toute différente ; c'est ensuite que les adversaires ne paraissent pas entendre la même chose par le mot essence. Sur le premier point, rappelons que saint Thomas avait nié que les substances spirituelles, les anges, se composassent de matière et de forme, et que, à l'objection que les anges auraient ainsi une simplicité qui ne convient qu'à Dieu, il répondait en utilisant la distinction admise entre l'essence (quo est) et l'existence (quod est) pour faire voir comment ils peuvent être composés : cette distinction se trouve donc solidaire de la négation de la composition hylémorphique chez les anges ${ }^{800}$. Pour le second point, rappelons que, par essence, on ${ }_{\mathrm{p} 354}$ peut entendre soit la raison créatrice d'une créature telle qu'elle est dans le Verbe de Dieu, soit l'essence créée qui se réalise effectivement ; lorsque saint Thomas rapporte l'essence à l'existence comme la puissance à l'acte, c'est de l'essence au second sens qu'il parle. Ajoutons que saint Thomas n'a jamais dit que la distinction qu'il institue ici était une « distinction réelle »; en effet, c'est une distinction telle que l'unité de l'ange ne soit pas compromise par elle ; chez Aristote, en effet, la réalité en puissance est la même, au degré de perfection près, que la réalité en acte ; la distinction est donc bien réelle, mais non en ce sens qu'elle a lieu entre deux choses qui pourraient subsister distinctement ; car la réalité en puissance n'est telle que par relation à l'être en acte.

\footnotetext{
799 Cf. p. 319.

800 Cf. Godefroi DE FonTAINES, p. 156-157.
} 
Cette comparaison du rapport de l'essence à l'existence, avec celui d'une puissance à un acte, est-elle possible, voilà ce que demande Godefroi de Fontaines. L'existence, dont on fait un acte, est une chose tout à fait indéterminée, c'est l'être pur du livre des Causes ; or on déclare d'autre part qu'il n'y a d'autres êtres que des êtres déterminés, que le mot être n'a qu'une signification analogique, et qu'il n'y a pas de genre universel de l'être ${ }^{801}$; on dit, pour prouver la réalité de la distinction, que l'essence peut être conçue sans l'existence ; mais il faudrait aussi que l'existence pût être conçue sans l'essence ; or ce n'est pas le cas, puisque l'existence ne peut être conçue sans un existant et sans une essence déterminée ${ }^{802}$. Aussi ruineuse est la comparaison de l'essence avec une puissance : sans doute, toute chose a en Dieu un exemplaire idéal qui est la raison par laquelle il connaît cette chose et même par laquelle il la fait, si la volonté s’y ajoute ; « et ainsi l'essence, avant d'être, est un être possible, mais non pas à la manière du sujet de la génération qui passe du non-être à ${ }_{\mathrm{p} 355}$ l'être ou d'un sujet qui reçoit réellement l'être, mais comme une chose qui est, par soi, le terme d'une action productrice. L'essence de la créature ne doit pas être compris comme un sujet en puissance à la façon de la matière, et l'être comme une chose reçue en elle à la façon d'une forme... ; mais l'essence doit, avant d'être, être conçue comme l'objet ou le terme possible de l'action divine, qui peut être produit de rien et non pas de quelque chose comme d'un principe matériel ${ }^{803} »$. On retrouve le même type d'argumentation dans la Somme attribuée à Robert Grosseteste : l'existence, dont on dit qu'elle est un acte, ne peut être, si on la sépare de l'essence, que l'existence tout à fait indéterminée qui ne convient qu'à Dieu ; dire que l'essence est en puissance par rapport à l'existence, c'est dire qu'elle est en puissance relativement à l'être de Dieu ; et, d'autre part, comment faire de l'essence une puissance, puisque l'essence comme telle est acte et forme ${ }^{804}$ ?

Le but de ces discussions est bien visible, c'est de montrer l'inconvénient qu'il y a à employer les notions d'acte et de puissance, issues de la physique aristotélicienne et bonnes pour les choses de la

\footnotetext{
801 Tertium Quodlibetum, p. 163-164.

802 Ibid., 165-170.

803 P. 170.

804 Tract. V, ch. V, p. 328-329 ; cf. Roland-Gosselin, CLXXXV, p. 202-203.
} 
génération, en des régions qui ne les comportent pas ; c’est toujours le surnaturalisme augustinien et franciscain qui s'oppose au naturalisme thomiste. La tradition néoplatonicienne, issue du livre des Causes, a encore son écho dans un traité de Thierry de Fribourg : dès qu'on pose l'être, on pose l'essence dans toute sa richesse, et l'on ne peut poser un existant limité sans que cette limitation soit fondée dans son essence même ; donc on ne saurait séparer l'existence de l'essence ; mais on ne peut pas davantage penser l'essence sans l'existence ; « je ne puis comprendre l'essence d'un homme sans comprendre son être actuel ; je n'affirme pas d'ailleurs pour cela qu'il existe; mais je le perçois par l'intelligence ${ }_{p 356}$ comme étant actuellement ${ }^{805}$ ". La thèse thomiste institue donc une division dans une intention indivisible. C'est ce qu'exprime Henri de Grand lorsque, disant que l'essence et l'existence sont "la même chose en réalité », il admet pourtant une « distinction intentionnelle », c'est-à-dire une distinction de point de vue ${ }^{806}$.

Qu'on appelle donc ou non " distinction réelle » la distinction que saint Thomas établit entre l'essence et l'existence, cela ne fait rien au fond du débat ${ }^{807}$, qui a trait, dans tous les cas, à la portée de l'analyse du réel tentée par saint Thomas à l'aide des concepts aristotéliciens.

Table des matières

IV.

INTELLECT ET VOLONTE.

La conception que saint Thomas se fait des rapports de la volonté et de l'intellect est tout à fait en accord avec sa théorie de la nature : à

805 Traité publié par KREBS, CCIX, pars II, ch. I.

806 Quodlibet, I, qu. 10.

${ }^{807}$ Mandonnet, appuyé par Roland-Gosselin, soutient que saint Thomas est bien l'auteur de cette distinction ; Chossat (L'Averroïsme de saint Thomas, Arch. de Ph., vol. IX, cahier III, p. 129-177) veut que Gilles de Rome soit le premier à l'avoir soutenue peu avant 1276 ; en 1316, dit-il, un tiers seulement des Dominicains l'attribuait à saint Thomas. Pourtant les textes de Gilles cités par Chossat ne rendent pas un son différent de ceux de saint Thomas ; pour celuici, l'existence était déjà « l'acte et le complément de l'essence » (p. 153), et nous ne voyons pas que, par existence, saint Thomas entende l'esse que la forme donne à la matière. 
la détermination précise de la matière par la forme dans la nature correspond, dans l'âme humaine, la détermination de la volonté par l'entendement ${ }^{808}$. Cette prépondérance de l'intellect atteignait profondément la doctrine des Augustiniens ; aussi se trouve-t-elle parmi les articles condamnés en 1277 : la volonté passive indéterminée et incapable d'agir par elle-même, la prévalence nécessaire, dans la ${ }_{\mathrm{p} 357}$ décision, du parti qui est jugé le meilleur par l'entendement, la rectitude de la raison condition nécessaire et suffisante de la rectitude de la volonté (erreur que l'on ramenait à celle de Pelage puisque la science rendait la grâce inutile), voilà toutes les propositions que les Augustiniens, dont Tempier représentait les tendances, trouvaient à condamner chez saint Thomas ${ }^{809}$, en y intercalant d'ailleurs ${ }^{810}$ des propositions de nature toute différente sur le fatalisme astrologique. A cette prépondérance de l'intellect dans la vie terrestre s'associait la thèse que la béatitude des élus consistait en un acte d'intelligence.

Le rôle positif, sinon total, que la volonté joue par elle-même dans la détermination est, au contraire, pour les Augustiniens, une évidence; plusieurs dominicains, contemporains de saint Thomas, l'enseignent ; à Oxford, Richard Fitsacre enseigne, vers 1240, que, si la volonté complète, décision ou assentiment (consensus), appartient à la raison en tant qu'elle connaît le bien, elle a dû être précédée d'une "volonté incomplète » qui incline déjà à l'acte. Robert Kilwardby, vers 1250, enseigne que cet état acquis (habitus), que constitue le libre arbitre, appartient à la fois à la raison et à la volonté, et que l'aptitude de la raison à discerner le bien du mal est renforcée par l'aptitude de la volonté à choisir le bien ${ }^{811}$. Après la condamnation, le séculier Henri de Gand, à Paris, va plus loin; il enseigne que «l'acte d'intelligence n'est qu'une condition indispensable et non pas la cause de l'acte de la volonté ; la volonté n'est nullement passive ; elle est une faculté qui se détermine elle-même sans être déterminée par rien autre ${ }^{812}$ ». La théorie du primat de la volonté résulte, chez Henri, de la supériorité que, avec tous les Augustiniens et avec saint Bernard, il

\footnotetext{
808 Sicut materia ab agente, dit la Condamnation de 1277, art. 161.

809 Art. $150-152$ et $157-169$.

810 Art. 153-156.

811 O. LOTTIN, CCXII.

812 Quodlibet, III, qu. 17.
} 
accorde, avec saint Paul, à l'amour sur le savoir, au p358 bien sur le vrai, car l'amour est une aptitude de la volonté et le savoir, de l'intelligence; le bien est la fin de la volonté, et le vrai, celle de l'intelligence ; la volonté se dirige vers sa fin par sa propre action, et elle est active ; l'intellect y est déterminé par son objet, et il est passif ; "c'est même la volonté qui meut l'intellect, le pousse et le dirige ainsi qu'elle fait de toutes les autres forces de l'âme et des membres du corps »; et c'est par l'amour plus que par le savoir que l'élu s'unit à Dieu ${ }^{813}$.

Les Franciscains présentent à ce moment les mêmes thèses : pour Pierre de Falco, qui écrit vers 1285 des Questions disputées, «la volonté est libre par elle-même, elle possède une liberté intime et innée (intus genitam) »; la raison, sans doute, propose le bien, mais ne l'impose nullement; la volonté décide librement, conformément ou non au jugement ; « cette puissance qui, de soi, est le principe premier des mérites, est libre de soi et non par autre chose ». Richard de Middletown, dans les Questions disputées, à la fin de 1284, soutient la prééminence de la volonté, dont le mouvement vient de Dieu comme cause principale, mais d'elle-même comme cause immédiate ; « elle n’a pas la liberté sous le rapport de la fin, mais elle l'a quant aux moyens qui y conduisent ${ }^{814} »$. Pour les Franciscains, les puissances de l'âme ne sont pas, on le sait, distinctes de son essence, mais elles l'expriment d'une manière plus ou moins profonde, et la volonté est plus près de l'essence que l'entendement; la relation plus ou moins intime à l'essence est pour eux la question principale. Pour le thomisme, toutes les puissances sont, en quelque sorte, à un égal niveau métaphysique, et ce qui importe, c'est leurs relations mutuelles; l'assujétissement absolu de la volonté au jugement, telle est la thèse qui, à l'encontre de l'augustinisme, est exposée par Godefroi de Fontaines et qui sera reprise au début du $\mathrm{XIV}^{\mathrm{e}}$ siècle par une longue série d'auteurs ${ }^{815}$.

\footnotetext{
813 O. DitTrich, XII, t. III, p. 182.

814 O. LOTTIN, CCXIII.

815 A. PELZER, CCXIV.
} 


\section{V.}

\section{DOCTRINES POLITIQUES.}

p359 L'opposition que l'on trouve entre l'augustinisme et la philosophie nouvelle dans la vision du monde se rencontre aussi dans les doctrines politiques. Sans doute le thomisme comme l'augustinisme, admet la hiérarchie platonicienne appliquée aux choses politiques ; ainsi, chez Gilles de Rome, qui fut, en 1269, précepteur du futur Philippe le Bel, on trouve, dans le De Ecclesiastica potestate, le schème connu de la hiérarchie des deux pouvoirs : il l'exprime avec les mots mêmes d'Hugues de Saint-Victor : " Le pouvoir spirituel a à instituer le pouvoir terrestre, et si le pouvoir terrestre ne se conduit pas bien, le pouvoir spirituel pourra être son juge ${ }^{816}$ " ; le premier a sur le second la précellence de l'âme sur le corps, et selon le mot de l'Aréopagite : « La loi divine consiste à ramener les choses d'en bas aux choses d'en haut par les intermédiaires »; " il faut ramener le glaive temporel par le glaive spirituel, et il faut ordonner l'un sous l'autre, comme l'inférieur sous le supérieur »; il en est comme dans le monde matériel où les corps inférieurs sont régis par les supérieurs, les plus grossiers par les plus subtils, les moins puissants par les plus puissants ${ }^{817}$. Seulement cette hiérarchie est interprétée dans un tout nouvel esprit : le degré inférieur a comme sa nature propre qui le fixe au niveau où il est, il n'aspire point de lui-même au supérieur, et c'est pourquoi il doit être maintenu dans les cadres qui lui sont propres par le pouvoir supérieur, au besoin par la force et la violence ${ }^{818}$; pour l'unité ordonnée qu'il s'agit ${ }_{\mathrm{p} 360}$ d'atteindre, il ne s'agit plus d'une soumission seulement spirituelle mais temporelle. C'est ce que l'on voit mieux en lisant son De regimine principum : il y a en effet un vif contraste entre le caractère absolu qu'il donne au pouvoir du roi dans ce domaine, pouvoir qui est «naturel » dès qu'il est subordonné à la raison, et la sujétion également absolue du pouvoir laïc au pape ; le parallèle est, à ce point de vue, rigoureux entre les choses naturelles et les choses po-

${ }^{816}$ De Ecclesiastica potestate, CCXV, ch. IV, p. 11; cf. Hugues, VI, t. CLXXVI, 418-c.

817 Ch. VI, où est suivi saint Augustin, De Trinitate, III, ch. IV. On sait que le traité de Gilles préparait la bulle Unam sanctam, de Boniface VIII, du 2 novembre 1302.

818 Cf. sur ce point les excellentes réflexions de B. LANDRY, CXLIII, p. 101, 
litiques ; la société civile est fondée sur la nature humaine comme le monde sur la nature des essences ; mais, "de même que Dieu a un pouvoir (dominium) universel sur toutes les choses de la nature, selon lequel il peut faire que le feu ne brûle pas et que l'eau ne mouille pas, de même que, pourtant, il gouverne le monde selon la loi commune, et, s'il n'y a pas d'obstacle du côté spirituel, permet que les choses achèvent leur cours, sans empêcher le feu de brûler ni l'eau de mouiller ; de même le souverain pontife, vicaire de Dieu, a, à sa manière, un universel pouvoir (dominium) sur les choses temporelles, mais, voulant l'exercice selon la loi commune, s'il n'y a pas d'obstacle spirituel, il convient qu'il permette aux puissances terrestres, à qui sont confiées les choses temporelles, d'achever leur cours et d'exercer leur jugement ${ }^{819}$. » Le pouvoir temporel n'est donc tout-puissant dans sa tâche que parce qu'il y est asservi, sans qu'il y ait en lui aucune ébauche ni lueur des choses spirituelles.

Le De Regimine christiano de l'ermite augustinien, Jacques de Viterbe, qui écrit en 1302, présente le même caractère que l'œuvre de Gilles de Rome. Le De Regimine principum, commencé par saint Thomas et achevé vers 1301 par Ptolémée de Lucques, quoique beaucoup plus tempéré dans ses idées théocratiques, donne au pouvoir royal le même genre d'autonomie, qui n'existe que s'il n'y a pas en jeu des intérêts spirituels, sur lesquels le pouvoir civil est sans compétence. 


\section{Chapitre VII}

\section{PHILOSOPHIE ET EXPANSION DE LA CHRÉTIENTÉ}

I.

ROGER BACON.

Parmi les livres visés dans la condamnation de 1277 se trouvent des livres de géomancie et de nécromancie, ainsi que d'autres qui « contiennent des expériences de sortilèges, des invocations des démons ou des conjurations contre le péril des âmes ${ }^{820 ~ " ; ~ d e ~ p l u s, ~ l ' u n e ~}$ des propositions condamnées (178) affirme la réalité de la divination par signes. L'astrologie trouva un défenseur dans le franciscain Roger Bacon, qui écrivit, contre sa condamnation, le Speculum astronomiae ; il fut condamné à l'incarcération ; il faut ajouter que, dans ses œuvres précédentes, il avait attaqué et les Dominicains et même l'ordre des Franciscains, dont il faisait partie, et qu'il avait exercé sa critique sur le pape lui-même ; c'est à sa doctrine tout entière que l'on s'en prit ensuite, en interdisant aux Mineurs la lecture de ses livres ${ }^{821}$ : tel fut l'accueil fait à ce génie indiscipliné que l'on a tantôt rabaissé au rang d'un illuminé et d'un réactionnaire en philosophie, tantôt exalté comme le précurseur d'une méthode expérimentale, complètement inconnue au Moyen Age.

p362 Le caractère très particulier des œuvres (Opus majus, Opus minus, Opus tertium) par lesquelles Bacon est le plus connu tient en partie aux circonstances exceptionnelles où elles ont été écrites : elles n’ont aucun lien avec l'enseignement universitaire. Bacon, né vers

820 MANdonnet, CXCVI (textes), p. 176.
821 MANdonnet (étude critique), p. 244-246. 
1215 et élève, à Oxford, de Robert Grosseteste, pour qui il gardera, sa vie entière, une profonde admiration, a été d'abord maître à la Faculté des Arts de Paris entre 1240 et 1250 . Vers 1250, il composa des Questions sur la Physique et la Métaphysique, où on le voit soutenir les thèses que va nier saint Thomas : unité de la matière, existence de la matière dans le composé spirituel, existence des raisons séminales, unité de l'essence et de l'existence, possibilité de démontrer que le monde a commencé ${ }^{822}$; après avoir enseigné à Oxford, il entre dans l'ordre des Franciscains en 1257, et il est envoyé à Paris : surveillé et suspect, il se lie en 1264 avec Guido Fulcodi, qui, en 1265, est élu pape et prend le nom de Clément IV. Dans l'imagination de son ami franciscain, le nouveau pape est celui qui doit réaliser sur terre, par la force matérielle comme par la persuasion, l'unité de foi dans le christianisme ; il doit surmonter tous les ennemis du Christ, réunis sous la conduite de l'Antéchrist, dont l'apparition, selon Bacon, est prochaine. De cette œuvre immense, Bacon doit fournir les moyens : l'Opus majus, que le pape lui demande et qu'il écrit en 1266 et 1267 avec l'Opus minus et l'Opus tertium, montre que les conditions de l'entreprise sont dans une rénovation intellectuelle : cette rénovation a deux caractères essentiels : un retour à de très anciennes idées sur l'unité de la sagesse, dont la source unique est l'Écriture, et l'annonce d'une «science expérimentale » qui doit assurer la domination de l'homme sur la nature : mettre cette science au service de la domination du pape sur le monde, tel est son but.

Quant à l'unité de la sagesse, Bacon est fort loin des combinaisons p363 de toutes sortes que cherchent les penseurs de son temps pour concilier la foi et la philosophie nouvelle : il se détache résolument de la méthode scolastique de discussion. Il revient à saint Augustin, pour qui les arts libéraux n'ont d'autre justification que de servir à interpréter l'Écriture, à Bède qui ne veut utiliser la philosophie païenne que pour réfuter les erreurs des Gentils ${ }^{823}$; tout savoir ne sert donc qu'à dégager la sagesse totale qui est dans l'Écriture : «Car toute créature, en elle-même ou en son semblable, en général ou en particulier, du sommet des cieux jusqu'à leur terme, se trouve dans l'Écriture, si bien que Dieu, ayant fait les créatures et l'Écriture, a voulu mettre dans

\footnotetext{
822 Cf. DuHEM, XV, t, V, p. 375-411.

${ }^{823}$ Opus majus, II, 3-4, CCXIX, édit. Bridges.
} 
l'Écriture les créatures elles-mêmes, pour l'intelligence de son sens tant littéral que spirituel ${ }^{824}$ ». Toute émancipation de la philosophie est condamnée ; au besoin on emploie la contrainte, il faut « forcer la sagesse des philosophes à s'asservir à la nôtre ${ }^{825}$ ». Ce principe, loin d'amener à la stagnation, comme on pourrait le craindre, est un principe positif de progrès ; car l'interprétation de l'Écriture exige une quantité de connaissances positives, que Bacon trouvait peu développées ou même méprisées de son temps; toutes ces connaissances se rapportent à ces arts libéraux qui étaient restés bien négligés, sinon à Oxford, du moins à Paris, dans le développement qu'avait pris la discussion des idées et des thèses. Bacon se plaint vivement de l'ignorance de son temps : ignorance d'abord de la langue grecque et des langues orientales, dont la connaissance serait indispensable à qui veut étendre la sagesse chrétienne ; Bacon cite plusieurs exemples d'erreurs commises par les traducteurs d'Aristote sur des points capitaux, tels que la théorie de l'intellect agent ou de la p364 matière ${ }^{826}$; ignorance des mathématiques, dont on ne voit pas la portée à la fois spéculative et pratique ; car on se contente, dans les autres sciences, d'arguments dialectiques ou sophistiques, alors qu'elles devraient procéder «par des démonstrations mathématiques qui descendent jusqu'aux vérités et aux opérations des autres sciences pour leur donner leurs règles ${ }^{827}$ » : par cet usage pratique des mathématiques, Bacon peut songer et à l'optique, que Robert Grosseteste mettait à la tête des sciences, et à l'astronomie, dont les calculs rendent possible l'astrologie et rendent ceux qui en connaissent les secrets, maîtres en partie des influences sidérales, en utilisant, pour produire les effets que l'on veut, les objets terrestres qui en sont chargés ${ }^{828}$.

Mais cette idée de la sagesse qui, dans ses formules, est empruntée au plus ancien Moyen Age, rend ici un son bien différent : c'est que Bacon, un des premiers, a recherché le savoir en extension plus qu'en

824 Ibid., p. 43 ; on trouve dans la Bible même des connaissances physiques, comme celle de la cause finale de l'arc-en-ciel qu'a ignorée Aristote! Ct. CARTON, CCXXI, p. 59.

825 Ibid., p. 57.

${ }^{826}$ Opus majus, III, p. 120-121 ; I, p. 39-40, p. 67, p. 124-125 ; II, p. 462.

${ }^{827}$ Ibid., II, p. 108.

828 CARTON, CCXXI, p. 147. 
compréhension ; il a essayé de l'augmenter plus que d'en assurer les principes ; il est frappé surtout par "l'infinité des vérités concernant Dieu et les créatures »; de cette infinité l'homme ne peut en connaître qu'un petit nombre, et, pour le reste, il est dans l'obligation d'en rester à la croyance. Comment est-il arrivé à la science de ce petit nombre de vérités ? Par un moyen unique, par l'expérience; mais il y a une double expérience : aux deux sortes de réalités, à Dieu et aux créatures, correspondent deux sortes d'expériences : " par l'expérience de l'illumination intérieure, l'homme reçoit de Dieu l'intelligence, à savoir dans les saintes vérités de la grâce et de la gloire, et, éveillé par l'expérience sensible pour les secrets de la nature et de l'art, il trouve la raison ${ }^{829}$ ». Ainsi, selon la tradition augustinienne, l'intellect p365 est au niveau du divin, et la raison au niveau de la nature : mais ni l'une ni l'autre de ces facultés ne jaillissent pour ainsi dire spontanément de la nature ; il faut à chacune une expérience qui vient du dehors. Il y a plus ; la seconde sorte d'expérience, «l'expérience humaine et philosophique », qui, par les instruments convenables, nous fait atteindre le ciel, et, par la vue, nous fait connaître les choses d'en bas, ne suffit pas à la science des arcanes de la nature ; il faut que l'intelligence de l'homme soit aidée d'ailleurs, et c'est pourquoi les patriarches et les prophètes qui ont donné des sciences au monde ont reçu des illuminations intérieures, et ne s'arrêtaient pas au sens, et de même beaucoup de fidèles depuis la venue du Christ ; car la grâce de la foi et l'inspiration de Dieu illuminent souvent non seulement au sujet des choses spirituelles, mais au sujet des choses corporelles et des sciences philosophiques ». Ainsi Bacon se refuse à faire dépendre les sciences de la nature de l'expérience sensible ; l'illumination divine collabore avec elle pour en surprendre les secrets qu'elle seule ne nous découvrirait pas : Bacon se réfère ici aux secrets immémoriaux que se transmettent hermétistes, alchimistes, astrologues, à ces sciences occultes qu'il devait défendre dans le Speculum astronomiae et dont les vérités lui paraissaient dépasser les forces de l'esprit humain, domaines où la technique allait toujours de pair avec le mysticisme. Cette illumination intérieure qui, de la surnature, s'étend donc parfois jusqu'à la nature, ne correspond pas à l'exercice normal de la raison humaine ; c’est une illumination spéciale, donnée par grâce à

${ }^{829}$ Opus majus, III, p. 22 ; II, p. 169-180 ; cité par CARTON, CCXXI, p.-7-8. 
des individus déterminés, et quelquefois même à des philosophes païens, toujours surnaturelle par conséquent et ressortissant à l'ordre de la grâce ${ }^{830}$; elle est immédiate ; elle est indispensable, car pour Bacon, comme on l'a dit ${ }^{831}$, l'expérience sensible « ne saurait nous manifester toute la vérité du monde physique, parce qu'elle ne peut rien révéler de la vérité sacrée qui la p366 commande, vérité d'ordre surnaturel qui ne peut être révélée à l'homme qu'intérieurement ». Bacon s’applique donc à montrer la nécessité d'unir ce que saint Thomas séparait si soigneusement, la raison et l'illumination, la nature et la surnature. De là, la nécessité d'un enseignement traditionnel qui remonte à la révélation primitive ; sans lui, les hommes «sont comme des oiseaux qui voudraient voler sans ailes et être maîtres avant d'avoir atteint le niveau d'un bon élève ${ }^{832}$ ". De cette illumination intérieure, spéciale et immédiate, la connaissance qu'elle nous donne de la nature en s'ajoutant à l'expérience sensible n'est d'ailleurs que le plus bas degré ; au-dessus de lui, Bacon, qui a beaucoup lu et médité les Victorins ${ }^{833}$, admet toute l'échelle d'illuminations qui monte à son degré suprême jusqu'à l'extase. Il y a donc, on le voit, pour Bacon, contrainte parfaite dans cette vie spirituelle qui va de l'expérience sensible à l'extase, comme il y a unité parfaite dans l'Écriture dont le sens spirituel nous révèle la vérité divine, tandis que son sens littéral ouvre devant nous tout le monde des créatures.

Il y a un contraste frappant entre cette conception de la vie spirituelle, réservée à un petit nombre d' " experts », qui peuvent devenir par elle (puisqu'elle comprend aussi la science pratique) maîtres du monde, et la conception augustinienne de la connaissance intellectuelle par illumination que soutient d'autre part Bacon : c'est une conception peu personnelle qui ressemble à celle de Mathieu d'Aquasparta et surtout à celle d'Henri de Gand : les idées ou raisons éternelles en Dieu ne sont pas l'objet direct de notre vision, comme le soutenaient à cette époque quelques augustiniens, elles sont une lumière qui irradie en notre âme et par l'influence de laquelle nous con-

\footnotetext{
830 Cf. CARTON, CCXXI, p. 55.

831 Ibid., p. 89.

832 Opus majus, III, p. 7.

833 CARTON, p. 272.
} 
naissons ${ }^{834}$. Les raisons éternelles jouent donc ici le rôle ${ }_{p 367}$ de l'intellect agent chez Aristote, celui d'une lumière et non d'un objet, et Bacon reprend l'opinion de Guillaume d'Auvergne et de Robert Grosseteste en identifiant à Dieu l'intellect agent du Philosophe; l'intellect possible ou passif, qui est le nôtre, opère la connaissance grâce au concours de l'intellect agent et des espèces intelligibles ${ }^{835}$, qui, sous son influence, sortent de la puissance de notre intellect.

Quel est le rapport de cette illumination universelle, qui n'est que le correspondant augustinien de la théorie aristotélicienne de l'abstraction, avec l'illumination spéciale, seule source de la science des experts ? Pour Bacon, celle-ci paraît être subordonnée à la première comme à sa fin; elle est le moyen naturel par lequel tout homme peut arriver au niveau de la vérité révélée ${ }^{836}$; elle est antérieure à l'illumination spéciale qui, en quelque sorte, l'achève.

Table des matières

II.

\section{LA SCIENCE EXPERIMENTALE.}

On voit dans quelle atmosphère paraît, chez Bacon, la notion d'expérience : insuffisance de l'autorité, dégoût des disputes, et essai pour renouer avec une tradition expérimentale ignorée des hommes de science : la certitude est à ce prix, car « nous avons bien trois moyens de connaître: l'autorité, l'expérience et le raisonnement; mais l'autorité ne nous fait pas savoir, si elle ne nous donne pas la raison de ce qu'elle affirme ; et le raisonnement de son côté ne peut distinguer le sophisme de la démonstration, à moins d'être vérifié dans ses conclusions par les œuvres certificatrices de l'expérience... Il se trouve pourtant que personne de nos jours n'a cure de cette méthode, ou plutôt qu'elle n'est pratiquée que dans ce qu'elle a de vil et ${ }_{\mathrm{p} 368}$ d'indigne de l'étude du savant ; c'est pourquoi tous les secrets, ou peu s'en faut, et les plus grands, de la science sont ignorés de la foule de ceux qui

834 Sur le conflit entre Augustiniens, cf. CARTON, L'expérience mystique, etc., p. 178-185, particulièrement 178, n.4 et 179, n. 3. Cf. Opus majus, III,48-49.

835 Opus tertium, p. 74.

836 Cf. CARTON, CCXXI, p. 160-161. 
s'adonnent au savoir ${ }^{837}$ ». Comment entendait-il cette certification ou vérification ? Dans ses traités d'optique et de mathématiques, Bacon est moins un expérimentateur original qu'un interprète de la science arabe $^{838}$; on se demande "s'il n'a pas plutôt pratiqué les auteurs qui ont pratiqué l'expérience qu'il n'a pratiqué l'expérience luimême ${ }^{839}$ ". Il en est de l'expérience sensible comme de l'expérience intérieure des secrets de la nature, comme des secrets de la grâce et de la gloire ; nul d'entre eux ne peut être atteint par le raisonnement, et, étant en quelque sorte en droit objets d'expérience, celui qui ne les connaît pas effectivement par expérience «doit commencer par les croire, en faisant foi à ceux qui ont fait eux-mêmes l'expérience ou l'ont tenue fidèlement d'expérimentateurs fidèles ${ }^{840}$ ". Aussi Bacon n’a institué aucune méthode expérimentale au sens moderne du mot : cette méthode est l'ensemble des moyens par lesquels une expérience est contrôlée par d'autres ; pour Bacon, resté à une conception naïve de l'expérience, à l'expérience, qui est simple vue, l'expérience vérifie et contrôle mais n'a pas à être vérifiée ; l'important est donc de voir et de savoir de ceux qui ont vu. Non pas cependant que l'expert lui-même reste passif dans l'expérience : au contraire, «il aide la nature par l'art " ${ }^{841}$; mais son activité est avant tout opératrice et manuelle: il distille ou calcine comme les alchimistes; il s'aide d'instruments ; il compare, dans la recherche des causes de l'arc-enciel par exemple, les cas divers où l'arc-en-ciel p369 se produit, sur des cristaux, sur l'eau jaillissante d'un moulin, « et ainsi d'une infinité de manières, tant naturelles qu'artificielles, les couleurs de l'arc-en-ciel apparaissent comme un expérimentateur sait les trouver ${ }^{842}$ ».

837 Compendium philosophiae, p. 397-398, trad. CARTON, L’expérience physique, p. 54.

838 LiTTLE, Roger Bacon Essays, p. 31.

839 CARTOn, CCXXI, p. 56 ; Avicenne en médecine, Alhazen en optique, Pline en zoologie, telles sont ses constantes autorités.

840 CARTON, CCXXI, La synthèse doctrinale, p. 13. Opus majus, II, 2.

841 Opus majus, I, 113.

842 Cf. Carton, CCXXI, L'Expérience physique, p. 87 sq., qui cite Pierre de Maricourt (cité par Bacon lui-même), qui, dans ses recherches sur l'aimant, emploie un procédé analogue, et le dominicain Thierry de Fribourg, qui résout le problème de l'arc-en-ciel. Plusieurs des expériences citées par Bacon se trouvent déjà dans les Météorologiques d’ARISTOTE (III, 4). 
De plus, la certification ou vérification a un sens assez différent de celui qu'on serait porté à lui donner : on comprendra ce sens, lorsqu'on saura que l'on peut vérifier une vérité aussi bien par les mathématiques que par l'expérience : or, on vérifie par les mathématiques, lorsque l'on considère les événements à vérifier comme étant l'image plus ou moins fidèle de réalités mathématiques. Ainsi, on peut déterminer combien il y a de nombres parfaits (c'est-à-dire égaux à la somme de leurs parties aliquotes) dans la série des nombres entiers jusqu'à un nombre déterminé : dans un même nombre d'hommes, le nombre des hommes parfaits sera au plus égal mais pourra être très inférieur à celui des nombres parfaits. Ainsi encore on sait que le rayon lumineux progresse en ligne droite, se réfracte et se réfléchit : or il est ainsi assuré que l'illumination divine arrive droit aux âmes parfaites, se réfracte chez les imparfaits et se réfléchit, sans les pénétrer, dans les âmes mauvaises ${ }^{843}$. De tels procédés puérils rappellent les procédés, traditionnels depuis Philon d'Alexandrie, de la méthode allégorique. On voit ce que Bacon peut vouloir dire, lorsqu'il dit que « la mathématique a des expériences universelles qui s’appliquent à toutes les sciences, et que nulle science ne peut être sue sans la mathématique ${ }^{844} "$; ce n'est rien autre chez lui que l'affirmation biblique que toutes choses ont été faites en poids et en mesure ; c'est le pythagorisme augustinien qui continue, celui qui rend compte des choses en p370 $\mathrm{y}$ découvrant un schème numérique ou géométrique, " dans lequel la nature se plaît à opérer ${ }^{845}$ ». La vérification est donc ici la découverte que le phénomène est l'image d'un certain modèle, qui est la vérité ; le problème de la perspective, par exemple, est de trouver la «vraie figure » des rayons, c'est-à-dire de dessiner une ligne brisée qui soit comme la règle de la marche des rayons.

Bacon, d'ailleurs, ne cherche pas de justification rationnelle de la science expérimentale : cette science se justifie par le pouvoir qu'elle donne sur la nature, et ce pouvoir à son tour par l'usage qui en sera fait pour le salut des hommes et la victoire définitive du christianisme. Bacon, lorsqu'il parle de ce pouvoir, a donc surtout en vue les applications qu'un souverain en peut faire, lorsqu'il a à son service des ex-

\footnotetext{
843 Cf. CARTOn, CCXXI, L'Expérience physique, p. 64-67.

844 Opus majus, 11, 173.

845 Opus tertium, p. 110.
} 
perts : maître des influences atmosphériques, il peut transformer le caractère et le génie des peuples qui en sont dépendants ; capable de construire des machines de guerre qui augmentent les forces humaines, navires sans rames ni voiles, chars qui roulent d'eux-mêmes, machines volantes, capable d'envoyer, au moyen de réflecteurs et de miroirs, des vapeurs empoisonnées ou des rayons brûlants sur l'ennemi, il aura une victoire facile ${ }^{846}$. Il y a beaucoup de Jules Verne chez Bacon.

Table des matières

III.

L'AVENIR CHRETIEN.

Mise au pouvoir de l'Église, la science lui assurerait la place qu'elle doit avoir : une théocratie appuyée sur la science expérimentale, tel est le cadre de la société. Bacon voit d'un très mauvais œil l'importance et l'autonomie que prend alors le droit civil, enseigné surtout à l'Université de Bologne et issu ${ }_{\mathrm{p} 371}$ du droit romain ; tandis que, pour saint Thomas, la société civile, issue du droit naturel, a une autonomie pareille à celle que Dieu a donnée à la nature, pour Bacon, le droit civil, autant qu'il existe, doit se réduire à une simple routine qui dépend du droit canon, lui-même inspiré de l’Écriture ; conseillés par les clercs, les chefs de la Cité doivent s'occuper de l'organisation rationnelle de leur ville, organisation qui rappelle la République de Platon avec sa hiérarchie en quatre classes : clercs, savants, soldats et artisans, avec ses lois d'eugénique, mais qui institue en outre des écoles techniques pour les ingénieurs, des caisses d'assurance contre la maladie et la vieillesse et le plébiscite comme source de l'autorité ${ }^{847}$. Ces institutions ne concernent que les conditions matérielles de la vie humaine. Au-dessus d'elles, l’Église, qui les a ordonnées, doit avoir une puissance qui sera toute fondée sur la science ; les grands desseins des papes du Moyen Age, réunion de l’Église grecque, conversion des Tartares, destruction des Sarrasins, s'exécuteront alors par des moyens pacifiques et guerriers ; la mission apostolique sera rendue possible par le progrès des connaissances

\footnotetext{
846 Cf. LANDRY, CXLIII, p. 69-73.

847 CARTON, CCXXI, La synthèse doctrinale, p. 83, note.
} 
géographiques, lorsque l'on pourra gagner les Indes par l'Occident ; et c'est par la science et par l'étude de langues que la vérité de l’Évangile sera démontrée ${ }^{848}$.

Ainsi se mêlent, dans ses visions d'organisation chrétienne de la terre, pratique et religion, science et mystique. Roger Bacon est un des premiers qui aient eu le sentiment vif du rôle de l'Occident dans le monde ; ce rôle, il l'a exprimé, comme il le devait en son siècle, dans la conception qu'il se fait du christianisme ; le christianisme tendait presque à apparaître dans les Universités et les couvents soit comme un ensemble de dogmes, soit comme une technique du salut personnel ; il est effectivement et dans l'histoire une puissance d'expansion au service de la vérité : c'est ainsi que l'a vu Roger Bacon, et c'est

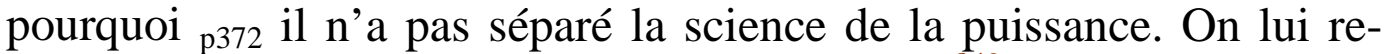
proche parfois de soutenir des thèses surannées ${ }^{849}$, et en effet il allait contre les tendances d'une époque prudente et organisatrice qui voulait séparer, tout en les hiérarchisant, nature et surnature, raison et autorité, science et foi ; aussi bien était-il considéré comme un ennemi, et, dès que son protecteur, le pape Clément, mourut, il fut de nouveau persécuté ; mais cette prudence organisatrice devait aboutir, au XIV siècle, à la dissolution de la scolastique, tandis que l'esprit baconien devait persister dans l'idée vivante et active de la mission de l'Europe.

Table des matières

IV.

RAYMOND LULLE.

L'exemple de Raymond Lulle montre à quel point, vers la fin du XIII ${ }^{\mathrm{e}}$ siècle, la philosophie pouvait être considérée non pas comme un hors-d'œuvre, mais comme une exigence impérative de la vie chrétienne. Raymond Lulle appartenait par sa naissance (il est né à Majorque en 1235) à cette partie du monde méditerranéen qui était en perpétuel contact avec le monde arabe ; il écrit en langue vulgaire des livres par centaines, et il est l'auteur de poèmes et d'ouvrages mystiques non moins que de l'Ars generalis. A partir de 1265, année où il

\footnotetext{
${ }^{848}$ LANDRY, CXLIII, p. 76-82.

849 MANDONNET, CXCVI (étude critique), p. 241.
} 
eut une vision, le but unique de sa vie et de ses œuvres fut la conversion des infidèles. S'il entreprit ce vaste travail logique, connu sous le nom d'Ars generalis, s’il essaya de le répandre, de le rendre populaire, d'en faciliter le maniement au point de le réduire à un mécanisme, c'est que, comme autrefois les hommes du XII ${ }^{\mathrm{e}}$ siècle, il utilisait le raisonnement à la défense de la foi. C'est pourquoi aussi, comme autrefois saint Anselme, il donne grande place à la raison, et « il entend prouver les articles de foi par des raisons nécessaires », soumettant ${ }_{\mathrm{p} 373}$ d'ailleurs entièrement la philosophie aux buts de la théologie. C'est donc un pur dialecticien, et, bien qu'il ait les mêmes ambitions que Roger Bacon, il est tout à fait en dehors du courant des sciences de la nature. En revanche, comme lui, il insiste sur la nécessité, pour les missionnaires, d'apprendre les langues orientales; possédant luimême la connaissance de la langue arabe, il réussit au Concile de Vienne, en 1311, à faire adopter la décision d'enseigner l'arabe et l'hébreu à la curie romaine et dans les grandes universités. Lui-même, il passe ses années à parcourir la chrétienté pour répandre ses idées ; en 1288, il enseigne à Paris son Ars generalis ; plus tard, en 1294, il soumet un plan de croisade au pape Célestin V, puis à Boniface VIII en 1295, à Philippe le Bel en 1298, à Clément V en 1302. En 1298 et en 1310, il séjourne à Paris pour combattre l'influence qu'y avait l'averroïsme. Plusieurs fois, il va en pays mahométan, en 1296 à Tunis, en 1306 à Bougie, où il retourna et où il est assassiné en 1315.

Dans ces conditions, on comprend le caractère pratique qu'il prétendit donner à son Ars generalis. Le problème qu'il veut résoudre est né d'Aristote. Celui-ci distingue les principes communs à toute science et les principes propres à chacune. Il s'agit de trouver « une science générale pour toutes les sciences, et telle que, dans ses principes généraux, soient contenus les principes de toutes les sciences particulières, comme le particulier dans l'universel ». Le Grand Art est donc la science suprême, d'où dépendent toutes les autres. Ce qui le distingue entièrement de la logique, c'est qu'il est un art d'invention et de découverte. Chez Aristote (chapitre final des Analytiques), les principes n'étaient pas fondés en démonstration, mais ils reposaient sur l'expérience et l'induction. D'autre part, toute démonstration suppose que l'on a découvert le moyen terme, et il faut recon- 
naître que les préceptes donnés par Aristote pour cette découverte ${ }^{850}$ restent assez vagues. p374 Raymond Lulle se vante de résoudre du même coup ces deux problèmes. Il part de cette idée que toute proposition se réduit à des termes, et que tous les termes complexes sont composés de termes simples. Si l'on suppose que l'on a dressé la liste de tous les termes simples ou principes, on obtiendra, en les combinant de toutes les manières possibles, toutes les vérités possibles. Ce principe de la combinaison, ébauchée par Aristote, est l'idée originale et essentielle apportée par Lulle. Les difficultés étaient de deux sortes : découvrir les termes simples et trouver une règle pour en déterminer les combinaisons. Lulle a bien vu que ces termes devaient comprendre, outre des termes absolus, tels que bonté, sagesse, etc., des relations (telles que différence, contrariété) qui fussent comme les cadres des combinaisons, des questions qui sont comme les cadres de l'invention du moyen terme, des sujets desquels peuvent se dire les autres termes ; mais il y a beaucoup d'arbitraire dans le choix des neuf prédicats absolus, qui sont neuf attributs de Dieu, des neuf relations, des neuf questions, des neuf sujets, à quoi s'ajoutent neuf vertus et neuf vices. Sur le second point, il manque à Lulle le calcul des combinaisons, dont Leibniz devait se servir dans son De Arte combinatoria, pour résoudre le même problème. 


\title{
CINQUIÈME PARTIE
}

\section{La dissolution de la scolastique (XIV ${ }^{\mathrm{e}}$ siècle)}

\author{
Chapitre premier
}

DUNS SCOT

I.

\section{LA DIALECTIQUE AU XIV ${ }^{\mathrm{E}}$ SIECLE.}

Le $\mathrm{XIV}^{\mathrm{e}}$ siècle mérite, plus encore que le XIII ${ }^{\mathrm{e}}$, d'être appelé le siècle de la dialectique. L'exposition doctrinale, accompagnée de démonstration, recule de plus en plus devant la question qui met aux prises un demandant et un répondant. Tout exercice de l'esprit qui n'est pas le recueillement mystique est une joute ; « la démonstration, procédant seulement de la vérité, ne prouve qu'une partie ; aussi on ne propose pas de discussions démonstratives entre un opposant et un répondant ; le discuteur, c'est proprement le dialecticien qui prouve l'une et l'autre partie, en s'appuyant sur des propositions probables, p376 vraies ou fausses ${ }^{851}$ ». Aussi on s'habitue à considérer comme le champ naturel et presque unique de la philosophie l'opinion probable. La logique est alors considérée moins comme une science spéculative

${ }^{851}$ Cité par Michalski, CCXLV, p. 15. 
que comme un arsenal contenant les moyens d'argumenter. On utilise beaucoup alors des abrégés de logique écrits au milieu du XIII siècle ; celui de Guillaume de Shyreswood néglige les Analytiques pour les Topiques, celui de Lambert d'Auxerre appelle le syllogisme argumentatio dialectica. Le plus répandu est celui de Pierre d'Espagne, qui annonce son intention de ne s'occuper que de preuves probables ; et l'on ajoute à son manuel un Ars obligatoria qui détermine les règles de la dispute.

L'on n’arrive donc qu'à des opinions : il est vrai que, d'après Grégoire de Rimini, l'opinion pourra devenir science par accumulation d'arguments probables; mais d'autres, comme Jean Baconthorp, reconnaissent que la science est une limite jamais atteinte. Dans ces conditions, on fait passer dans les probables bien des propositions considérées jusqu'ici comme certaines, en particulier les propositions théologiques; et aussi on peut présenter comme très probables des propositions contraires à la théologie, telles que l'éternité du monde, avec cette réserve que ces propositions sont fausses, puisqu'elles sont contraires à la foi ; aussi inversement peut-il arriver, selon Jean de Mirecourt, que « tel article de foi paraisse faux à qui ne considère que la lumière naturelle ». Il n’y a aucune correspondance entre le degré de probabilité et le degré de vérité. Déjà saint Thomas se plaignait que, sous prétexte de "réciter » les théories subversives pour les combattre, on argumentât trop en leur faveur. $\mathrm{Au} \mathrm{XIV}^{\mathrm{e}}$ siècle, on trouve un moyen d'introduire, " en vue de la discussion ", des thèses que l'on approuve secrètement, mais que l'on est d'ailleurs prêt à révoquer : la limite du pouvoir des papes chez Guillaume d'Occam, Dieu p377 auteur du péché chez Buckingham, la négation de l'existence des accidents chez Nicolas d'Autrecourt, telles sont les thèses que, avec une « ruse de renard », l'on se permet de soutenir ainsi ${ }^{852}$.

Table des matières

852 Cf. Michalski, CCXLV, p. 15-30. Par décret de 1340, on est obligé d'interdire à la faculté des arts l'emploi des distinctions qui rendaient une même opinion fausse ou vraie selon le sens que l'on donne aux mots; MiCHALSKI, CCXLIII, p. 27. 


\section{Émile Bréhier \\ La philosophie du Moyen âge}

II.

JEAN DUNS SCot : L'UNIVOCITE DE L'ETRE, LA MATIERE.

La carrière de Duns Scot fut fort courte ; né en 1270, il entra de bonne heure dans l'ordre des Franciscains, et il fut, à Oxford, l'élève de Guillaume de Ware ; il enseigna à Oxford jusqu'en 1304, puis à Paris de 1305 à 1308 ; envoyé à Cologne, il y mourut à la fin de 1308.

L'intuition thomiste de l'univers est fondée sur deux principes essentiels, issus l'un et l'autre d'Aristote : la notion d'être en puissance qui permet de définir un aspect de la réalité, uniquement par sa relation avec un autre aspect, si bien que la composition inhérente à l'être fini n'en détruit pas pour cela l'unité ; la notion d'analogie qui permet à notre intelligence, dont la vocation est de connaître les choses corporelles, d'atteindre pourtant, comme on l'a vu, des niveaux de réalité supérieurs aux choses matérielles. Ces deux principes étaient contestés par les Augustiniens, mais ils en avaient d'autres qui, pensaient-ils, les conduisaient aux mêmes résultats : à la notion d'être en puissance répondait la notion d'être incomplet, c'est-à-dire d'un être qui, entièrement défini pour l'intelligence, aspirait, par le désir et par l'amour, à s'unir à un être supérieur à lui ; à la notion d'analogie, ils préféraient celle des exemplaires et des raisons divines, qui étaient sinon l'objet, du moins l'appui d'une connaissance intellectuelle, faite d'ailleurs tout autant pour saisir les choses spirituelles que matérielles.

Or, la critique de Duns Scot s'exerce aussi bien sur les notions ${ }_{\mathrm{p} 378}$ thomistes que sur les notions augustiniennes ; avec les augustiniens, il critique la notion thomiste de matière et d'être en puissance; il ne veut pas entendre parler d'analogie ; contre les augustiniens, il est porté à voir, dans les liens qui maintiennent unis des êtres divers, le résultat d'une volonté extérieure à eux plutôt que d'une aspiration, et il condamne tout exemplarisme qui voit le modèle des créatures dans l'être divin lui-même : il n'y a donc, dans son système, rien d'intelligible ni dans les relations des êtres les uns avec les autres, ni dans les relations des êtres à Dieu. Sa critique ferme ainsi les deux voies par lesquelles les penseurs du Moyen Age avaient tenté de faire communiquer la raison et la foi, celle de saint Anselme qui cherchait à penser les dogmes avec des notions philosophiques, celle de saint Thomas qui voyait dans la foi le stimulant de la raison, capable, avec son secours, de s'élever jusqu'à discourir des choses divines. Dans le monde 
sans relation de Duns Scot, la foi et la raison tendent à s’isoler, chacune en sa sphère.

Envisageons d'abord l'aspect négatif du système de Scot : nous pouvons parler de l'être de Dieu, disent les thomistes, parce qu'il est analogue à l'être des créatures. Mais nous ne savons qu'un être est analogue à un autre que lorsque nous connaissons l'un et l'autre et que nous pouvons les réunir sous un concept commun ; l'analogie ne peut être en tout cas un moyen de passer de l'un à l'autre ; l'être des créatures, analysé de tout côté, ne peut nous faire sortir de lui-même, si, par ailleurs, nous ne connaissons l'être de Dieu ${ }^{853}$; et si l'on sait vraiment quels sont les attributs de la créature qu'on doit donner à Dieu ou lui refuser, c'est que l'on a préalablement son concept ${ }^{854}$.

La notion d'être en puissance, véritable ressort de tout le péripatétisme, est pour Duns Scot une notion vide. Il soutient, avec les augustiniens, que la matière est une réalité positive, p379 qui a son idée et qui peut exister sans la forme ${ }^{855}$. Le De rerum principio, qui n'est sans doute pas de Duns Scot, a sur ce point les mêmes thèses que le Commentaire des Sentences : "La matière est en acte, sans être l'acte de rien ; elle est chose en acte, puisqu'elle est une chose qui n'est pas le néant, un effet de Dieu et un terme de sa création ; et elle n'est l'acte de rien, puisqu'elle est elle-même fondement de tous les actes, puisque, en outre, son actualité n'est d'aucun genre, puisque, enfin, si elle était acte de quelque chose, c'est cette chose qui devrait être appelée matière »; il faut se représenter une actualité complètement indéterminée et déterminable. Il suit de là que le composé de forme et de matière naît de l'addition d'un être actuel à un autre être actuel ; « rien n'est dans la matière qui exige telle forme ; elle demeure toujours indéterminée à recevoir telle forme ${ }^{856}{ }^{\prime}$. Albert le Grand, pour expliquer comment la forme s'ajoutait de la matière, admettait avec saint Augustin que celle-ci contenait des raisons séminales ; il voulait distinguer la création ex nihilo de la génération naturelle; mais il faut bien admettre, dit Duns Scot, que, même dans ce cas, il y aurait créa-

\footnotetext{
853 In Sentent., I, d. 8, n. 12.

854 Ibid., I, d. 3, n. 10 ; cf. LANDRY, CCXXX, p. 293-294.

855 II Sentent., dist. 12, qu. 2.

${ }^{856}$ Reportata parisiensia, III, dist. 16, qu. 1, n. 13.
} 
tion de ce qui s'ajoute à la raison séminale pour produire la forme complète ; à la vérité, toute causalité suppose la production de quelque chose d'absolument nouveau, sans être pour cela créatrice, et, d'autre part, l'aptitude de la matière à changer, étant tout à fait indéterminée, ne vient pas en elle d'un principe interne défini ${ }^{857}$. Il s'ensuit que la matière admet arbitrairement une forme quelconque et qu'il n'y a plus dans le composé cette unité tenant à ce qu'une partie est en puissance ce que l'autre est en acte.

Dans la question de la matière, Duns Scot est donc hostile à la fois à l'être en puissance des thomistes et aux raisons séminales des augustiniens ; de même, dans la question, très ${ }_{\mathrm{p} 380}$ voisine, de la pluralité des formes, il échappe au dilemme qui semble s'imposer entre péripatéticiens et augustiniens; contrairement aux uns et aux autres, il lui semble que le cas des corps qu'on appelle des mixtes, où plusieurs éléments se mélangent pour former un corps composé, n'est pas comparable au cas de l'animal ou de l'homme, en qui s'unissent une âme et un corps ; là-bas, il n'y a qu'une forme, celle du mixte, et les formes élémentaires ont entièrement disparu, car l'expérience montre que ces formes n'agissent plus, et Duns Scot n'admet pas qu'elles puissent continuer à exister comme raisons séminales, puisqu'il refuse toute existence à ces raisons. Il n'en est pas de même dans le composé du corps et de l'âme ; ici le corps a sa forme substantielle, la forme de corporéité, qui persiste identique pendant la vie et après la mort ; elle informe la matière du corps ; l'âme, de son côté, n'est pas, comme le dit saint Thomas, une simple forme, mais un composé de forme et de matière, car l'être spirituel n'a pas moins besoin d'une matière que l'être corporel ; si l'être vivant, dans ces conditions, n'est pas un simple assemblage, c'est qu'il y a entre le corps et l'âme une subordination hiérarchique. D'autre part, il ne soutient pas la pluralité des formes au même sens que Robert Kilwardby et les Franciscains adversaires de saint Thomas; il n'admet pas, à l'intérieur de l'âme, des formes hiérarchisées et distinctes, âme végétative, âme sensitive, âme intellective ; l'expérience intérieure manifeste l'unité de l'âme ${ }^{858}$ : si bien que sa thèse de la pluralité des formes apparaît, sous un aspect, très semblable à celle de saint Thomas, en affirmant l'unité de forme à

857 II Sentent., dist. 18 ; t. VI, p. 708-801.

858 Report, paris., IV, dist. 43, qu. 2, n. 5 à 7 ; cf. LANDRY, CCXXX, p. 170-171. 
l'intérieur de l'âme, et très différente d'autre part, puisqu'elle ne fait pas du corps un être vivant en puissance ; sous sa forme scotiste, cette thèse, comme celle qui concernait la matière, n’a d'autre résultat que d'accentuer le caractère discontinu de la vision des choses.

p381 Un autre moyen pour le thomisme d'établir la continuité est la notion de l'analogie de l'être qui unit tout en distinguant ; pour Duns Scot, au contraire, être est un terme univoque qui a même signification appliqué aux accidents ou à la substance, à Dieu ou aux créatures, à la matière et à la forme. Sans l'univocité de l'être, aucune connaissance de la substance n'est possible. Des choses sensibles, l'intelligence perçoit seulement les accidents et non pas la substance ; si elle peut se représenter la substance, c'est grâce à la notion d'être que lui fournissent les accidents. Sans cette univocité, aucun jugement même n'est possible, car on ne peut énoncer un attribut d'un sujet, si l'être n'a pas le même sens dans l'un et dans l'autre ${ }^{859}$. Sans elle enfin, nous ne pourrions parvenir à la connaissance de Dieu; la théorie de l'analogie la fondait en effet sur le rapport de participation qui existait entre Dieu et les créatures ; mais ce rapport suppose, bien loin de la fonder, la connaissance du terme participé ; et de fait on ne pourrait rien attribuer à Dieu, si, avant toute attribution, on ne possédait de lui un concept qui nous permette de distinguer entre ce qui peut être nié et ce qui peut être affirmé de lui ; ce concept, nous le possédons grâce à l'univocité de l'être ; grâce à elle, nous avons dès l'abord une connaissance de Dieu, si faible qu'elle soit, puisque son être n'a pas d'autre signification que celui des créatures ; et c'est sans doute grâce à elle que prend un sens la preuve de l'existence de Dieu a contingentia mundi que Duns Scot préfère à la preuve aristotélicienne du premier moteur ; pour qu'il y ait quelque être réel, "il est nécessaire de poser une entité réelle, unique, première, qui n’en exige aucune autre avant elle ${ }^{860}$ ", un être qui donne l'être parce qu'il est l'être même, qui possède l'être " par soi et de soi ».

Il semble, au premier abord, que l'univocité de l'être devrait p382 avoir pour conséquence une continuité beaucoup plus assurée que l'analogie ; or, il n'en est rien ; car, tandis que l'analogie établissait un

${ }^{859}$ I Sent., dist. 3, qu. 3, n. 10.
${ }^{860}$ I Quodl., n. 2. 


\section{Émile Bréhier \\ La philosophie du Moyen âge}

rapport entre le contenu même des êtres, l'univocité, en affirmant seulement qu'un attribut de même sens, être, convient également à tous, ne nous donne aucune lumière sur leurs relations ; si donc l'idée d'être est la source de nos connaissances, si, grâce à elle, l'intelligence a une portée infinie, pourtant cette intelligence est, chez l'homme et dans son état actuel, extrêmement limitée ${ }^{861}$; l'idée d'être rend tout possible, mais ne produit rien par elle-même. Et, bien que Duns Scot ait admis la preuve de l'existence de Dieu, il paraît parfois douter que l'intelligence humaine puisse aller des êtres sensibles jusqu'à Dieu, en vertu de la seule notion d'être : attribuer la vie, l'intelligence, la volonté à Dieu, ce n'est point possible, puisque ces attributs sont inconcevables pour nous, sinon chez des êtres corruptibles ou finis ; Dieu serait alors sans pensée et sans vie ${ }^{862}$; et, d'autre part, lui attribuer le pouvoir créateur, c’est enlever toute efficacité aux créatures ; son existence supprime alors celle de la créature ${ }^{863}$. On voit comment l'univocité de l'être le pousse, quoi qu'il en ait, vers l'agnosticisme ; les assertions sur le Dieu vivant, créateur, providentiel, gardent la certitude que leur donne la foi, mais elles ne sont pas susceptibles d'être philosophiquement interprétées: on entrevoit un renoncement au grand problème du Moyen Age.

Le problème de la distinction des attributs de Dieu, tel ${ }_{\mathrm{p} 383}$ qu'il se posait dans la tradition à laquelle appartient Duns Scot, est à cet égard tout à fait caractéristique. Nous ne pouvons parler de Dieu (et donc il ne peut y avoir de théologie) qu'en énonçant de lui des attributs distincts les uns des autres, sagesse, volonté, bonté, etc., qui s’ajoutent à son essence. Mais quelle est la valeur de cette distinction ? Est-ce une distinction de raison, comme celle qu'il y a dans une colonne entre le droit et le gauche et qui est relative à notre propre position par rapport

\footnotetext{
861 I Sent., dist, 3, qu. 3, n. 24.

862 Theorema, 16, n. 14-19. Il est vrai que le P. Ephrem Longpré (CCXXXI, p. 112-113) conteste l'authenticité du Theorema, mais seulement parce qu'il ne trouve pas un accord suffisant entre la doctrine de ce Theorema et le fait que Duns Scot admet par ailleurs des preuves de l'existence de Dieu ; on pourrait tout aussi bien dire que ce désaccord manifeste une logique interne de la pensée de Duns Scot, qui arrive comme malgré lui à des conséquences qu'il ne voudrait pas accepter. Cf. d'ailleurs la discussion de J. BAUDRY, CCXXVIII, 1934, p. 175.

863 Reportata paris., dist. 37, qu. 2, n-4. Cf. LANDRY, CCXXX, p. 232-233.
} 
à la colonne ? Est-ce une distinction réelle comme celle qu'il y a dans notre âme entre nos facultés?

Tout le monde est d'accord sur la simplicité de Dieu : il s’agit, par conséquent, de découvrir un mode de distinction qui n'affecte pas cette simplicité, tout en permettant la pluralité des attributs. Or, selon saint Thomas et Gille de Rome, toute distinction autre que la distinction de raison détruirait cette simplicité : car, dire que les attributs de Dieu sont distincts ex parte rei, ce serait introduire en lui des formes ou quiddités et, par conséquent, des essences diverses ${ }^{864}$. Mais tout le monde est aussi d'accord sur la possibilité d'une théologie ; or, avec la simple distinction de raison, on ne peut rien dire de Dieu avec vérité : « $\mathrm{Si}$, aux concepts distincts que nous formons de Dieu selon les raisons distinctes de ces attributs ne correspondaient des raisons distinctes ex parte rei, tout concept de ce genre serait faux et fictif ${ }^{865}$. "

Le problème naît donc du conflit entre deux exigences : celle de la simplicité de Dieu et celle de la science de Dieu, qui ne peut s'exprimer que dans des propositions à sujet prédicat. Une première solution consisterait à chercher s'il y a des cas où nous pouvons légitimement énoncer d'un sujet des prédicats qui nous le font voir divers

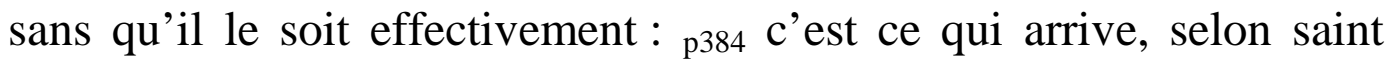
Thomas et Gille de Rome, lorsque nous parlons de la sagesse et de la bonté de Dieu, par analogie avec la sagesse et la bonté saisies par l'intellect créé dans les choses créées, où elles sont réellement distinctes ; notre intellect introduit une diversité qui, seule, lui permet de penser Dieu. D'autres, allant plus loin, attribuent cette sorte de propriété dissociatrice non à une déficience de l'intellect créé mais à l'intellect en général : c'est ainsi qu'Henri de Gand fonde la diversité des attributs dans la manière dont Dieu s’appréhende lui-même par son propre intellect; Richard de Middletown, précisant ce point, montre l'intellect de Dieu dans l'intuition de sa propre essence, se représentant à lui-même comme conçu par un intellect créé sous différents attributs. Mais on peut procéder tout à l'inverse et se demander si une diversité d'attributs ne peut exister effectivement en un sujet

\footnotetext{
864 Guillaume DE Nottingham, dans Ludwig MeIER, CCXXXIII. Meier édite (p. 257-266) un commentaire de cet oxfordien, mort en 1336, sur la distinction 22 du livre I ${ }^{\mathrm{er}}$ des Sentences.

865 Guillaume DE NotTingham, ibid., p. 259.
} 
sans que sa simplicité en soit atteinte : c'est ce que Duns Scot et, avant comme après lui, plusieurs Franciscains de l'Université d'Oxford, ont essayé avec la notion de distinction formelle. Il y a là, chez les Franciscains, une tradition fort ancienne, puisqu'elle remonte jusqu'à saint Bonaventure ${ }^{866}$ et continue avec Jean-Pierre Olivi, Matthieu d'Aquasparta et Alexandre d'Alexandrie : la partie du Commentaire des Sentences de Guillaume de Nottingham, publiée par Ludwig Meier, nous fait voir qu'elle était soutenue à Oxford avant Duns Scot. La distinction formelle est définie par Guillaume, " celle par laquelle des choses se distinguent de telle manière que la raison de l'une ne soit pas par elle-même dans les choses qui appartiennent à la raison de l'autre, si bien que l’on puisse dire : ceci est cela ; par là, vérité, bonté, sagesse et autres termes de cette sorte sont une seule et même essence divine et par conséquent identiquement la même chose ; et pourtant cette formalité, qui est la bonté ou la raison formelle de la p385 bonté, n'est pas cette formalité, qui est la vérité ; on les distingue comme des modes distincts, qui accompagnent une unique et identique chose simple ${ }^{867} »$.

Mais il faut remarquer en outre que, chez Duns Scot, cette thèse de la distinction formelle repose sur l'univocité de l'être ; l'intelligence infinie reste intelligence au même sens que l'intelligence finie, bien que l'infinité s'y ajoute ${ }^{868}$; mais une intelligence infinie garde-t-elle un sens pour nous ? Voilà qui, de l'aveu même de Duns Scot, est fort douteux.

$\underline{\text { Table des matières }}$

III.

LE VOLONTARISME.

Il faudrait pourtant se garder de croire que Duns Scot lui-même ait rejeté une vue rationnelle de l'ordre des choses. Ce qu'on appelle son « volontarisme » ne renferme pas du tout les conséquences radicales qu’on lui attribue parfois. Dans l'âme humaine, la volonté est pour lui

\footnotetext{
866 B. JANSEN, CCXXIX, p. 317-344, 517-544.

867 Guillaume DE NotTINGHAM, p. 263.

${ }^{868}$ I Sent., d. 8, q. 4, n. 18.
} 
un appétit raisonnable, qui n'agit que par des motifs tirés de l'entendement ${ }^{869}$; il insiste seulement, contre Henri de Gand, sur ce point (mais c'était déjà la thèse de saint Thomas) que la volonté n'est pas déterminée nécessairement, mais demeure libre dans son adhésion au motif. Seulement il reste dans la tradition franciscaine en déclarant que le bien, parce qu'il est capable de communiquer quelque chose de lui à l'être qui le désire (communicabile sui), est supérieur au vrai et que, par conséquent, la volonté dont l'objet est le bien est supérieure à l'entendement ${ }^{870}$. La fin suprême de l'homme est dans l'amour, c'està-dire dans la volonté, cela contre Aristote qui la voyait dans la contemplation, p386 mais avec saint Augustin et avec Denys l'Aréopagite, qui, dans la Hiérarchie céleste, place les anges aimants plus près de Dieu que les anges sages. De ce que la représentation d'un bien est la condition nécessaire du vouloir, il ne faut pas d'ailleurs conclure que l'intellect est sans action sur la volonté ; sans doute il y a une "pensée première » qui, venant de l'impression sensible, échappe à notre pouvoir ; mais il y a aussi beaucoup de pensées secondes, de ces pensées indistinctes et obscures, qui ne deviennent actuelles que grâce au concours que leur prête notre volonté, capable, selon qu'elle s'y applique ou qu'elle s'en détourne, de les renforcer ou de les affaiblir ${ }^{871}$.

Mais, au sein de l'intelligence même, Duns Scot reconnaît une certaine activité à l'intelligence, et il refuse de souscrire à l'adage aristotélicien : intelligere est pati. Mais il est aussi défavorable à la thèse d'Henri de Gand, qui pense que, dans l'acte d'intelligence, toute l'activité appartient à l'âme, qu'à celle de Godefroid de Fontaines, pour qui l'unique cause active de l'intellection, c'est l'objet même en tant qu'il apparaît dans l'image, le phantasme éclairé par l'intellect agent. Si la thèse de Godefroid avilit la nature de l'âme, en la rendant toute dépendante de l'objet, celle d'Henri n'explique pas comment la connaissance n'est pas toujours en acte dans l'âme ; il faut dire plutôt que la cause totale de l'intellection est faite de deux causes partielles, l'objet et l'âme, « qui ne concourent pas comme deux causes égales, mais qui sont ordonnées comme le père et la mère dans la génération,

869 Opus Oxon., II, d. 6, q. 2, n. 8.

870 Ibid., IV, d. 49, q. 4.

871 Cf. Ottmar DitTriCh, XII, III, 15C-154 ; Opus Oxon., II, d. 42, qu. 4, n. 5. 
la mère ayant une causalité indépendante quoique moins parfaite, et ajoutant quelque chose à la cause parfaite ${ }^{872}$ ».

C'est cette notion mesurée de l'activité intellectuelle qui lui donne quelque méfiance contre le platonisme d'Henri de Gand, qui fait dépendre toute connaissance infaillible d'un p387 exemplaire incréé : Duns Scot lui oppose des sources de certitude qui sont à la fois dans l'âme ou dans l'objet, la certitude des premiers principes, énoncés en des propositions à deux termes (tels que : le blanc n'est pas noir), dont l'identité ou la différence sont aperçues avec évidence ; la certitude par expérience qui permet de prévoir l'avenir d'après le passé, selon ce principe "sommeillant en l'âme » que tout ce qui arrive dans la plupart des cas par une cause qui n'est pas libre est l'effet naturel de cette cause ; enfin la certitude interne de nos actes, de nos sensations par exemple, qui persiste, même si nous nous trompons sur l'objet qui les a produites.

Il en est de même du " volontarisme » en Dieu qui, dans l'intention de Duns Scot, n'introduit nulle irrationalité dans l'action divine. En premier lieu, selon lui, Dieu crée les possibles : par là, Duns Scot veut éviter que l'on admette en dehors de Dieu, éternel comme lui et s'imposant à lui, une sorte de fatum d'après lequel se guideraient son intelligence et sa volonté ; il faut remarquer pourtant que ces possibles, pris en eux-mêmes, ne sont pas fort différents de ce qu'ils étaient chez saint Thomas ; chez celui-ci, ils sont les idées que conçoit l'intelligence de Dieu, quand il conçoit les diverses manières dont les créatures peuvent participer à son essence ; et chez Duns Scot aussi, ils sont comme les images et imitations diverses de son essence infinie ${ }^{873}$. Il s'ensuit que cette formation ou création n'est pas du tout libre ; elle est le fait de l'intelligence, et la volonté n’y a aucune part ; «l'acte par lequel Dieu conçoit tous les principes premiers est naturel ; il les pense pour ainsi dire avant tout acte de volonté, car leur vérité ne dépend d'aucun acte volontaire et ils seraient encore connus, si, par impossible, Dieu n'avait pas de volonté ${ }^{874}$. " Cette création des possibles est d'ailleurs limitée par le principe p388 de contradiction,

\footnotetext{
${ }^{872}$ I Sentent., d. 3, q. 7.

${ }^{873}$ I Sentent., d. 35, n. 10.

${ }^{874}$ Ibid., d. 39, n. 23, cité par LANDRY, CCXXX, p. 320.
} 
puisque Dieu est incapable de rendre possible ce qui est logiquement impossible, c'est-à-dire ce qui implique contradiction ${ }^{875}$.

S'il s'agit maintenant non plus de l'intelligence, mais de la volonté par laquelle Dieu produit les êtres, il faut dire que toujours, selon Duns Scot, la volonté est libre, mais il ne faut pas faire de cette liberté le synonyme d'indétermination, et il faut distinguer avec soin les cas où cette volonté est déterminée et ceux où elle ne l'est pas. Quant à lui-même et à son essence, Dieu est absolument déterminé à s'aimer lui-même ; cette détermination de la volonté existe dès qu'il connaît cette essence. En revanche, quant au monde qu'il a créé, l'on doit dire que tout ce qu'il a effectivement créé s'accorde avec les lois de sa justice et de sa sagesse ; mais, " s'il avait fait autrement, l'ordre qu'il aurait pu choisir aurait été également juste et sage, par le seul fait qu'il l'aurait voulu, puisque sa volonté est toujours juste »; " la justice de Dieu est aussi large que sa puissance »; elle est donc égale, qu'elle tende à un possible ou à son opposé ${ }^{876}$. Il en résulte que l'ordre prescrit et choisi par Dieu n'est jamais déterminé par des exigences dues à la nature même des créatures. Il s'ensuit que, dans l'ordre surnaturel, le lien qui unit en fait les œuvres bonnes accomplies par l'homme au bonheur éternel, qui en est la récompense, n'existe pas parce que ces œuvres méritent d'elles-mêmes la récompense, mais parce que Dieu l'a décrété ainsi ; "le mérite, considéré en soi, sans l'acceptation divine, n'aurait pas été, selon la stricte justice, digne d'une telle récompense d'après sa bonté intrinsèque ${ }^{877}$ ». La prédestination est donc aussi tout à fait gratuite ; Dieu ayant voulu que la charité conduise à la béatitude, donne à l'âme prédestinée pour laquelle ${ }_{\mathrm{p} 389}$ il veut le bonheur éternel la vertu de charité qui, d’après son décret, doit les y conduire,

Table des matières

\footnotetext{
875 Cf. Aug. Faust, XVII, II, p. 251.

${ }^{876}$ Cf. Paul VignauX, CCXXXV, p. 10-11; Rep. par., IV, d. 1, qu. 5, n. 2 ; d. 46, qu. 4, n. 8.

877 Id., p. 19 ; Op. Oxon., 1, d. 22, qu. 3, n. 26.
} 


\section{L'HÆCCEITE.}

Le volontarisme de Duns Scot est donc bien loin de supprimer l'ordre ; il nie seulement qu'il y ait un ordre qui soit imposé à Dieu par la nature des choses. Disons aussi que sa fameuse théorie de l'individualité, selon laquelle, contrairement à l'aristotélisme thomiste, il voit le principe d'individuation non pas dans la matière mais dans une entité positive qu'il appelle l'hæccéité, n’a pas du tout pour conséquence de réduire la réalité à des individus isolés et juxtaposés ; bien au contraire, il est l'adversaire du nominalisme, et il admet la valeur des genres et des espèces, selon lesquels l'univers s'ordonne et peut être objet de savoir ${ }^{878}$. Quel est donc le sens de sa théorie de l'hæccéité ? On sait que, en 1277, Tempier avait condamné les propositions suivantes : "Dieu ne peut connaître le particulier. Si le sens n'existait pas, l'intellect distinguerait l'homme de l'âne, mais non Socrate de Platon. " Malgré les efforts de saint Thomas, la théorie qui attribuait l'individuation à la matière et qui faisait ainsi d'elle quelque chose d'inintelligible paraissait avoir quelque affinité avec la thèse condamnée qui refusait à l'intelligence, même divine, la connaissance des choses singulières. On était, à vrai dire, néoplatonicien quand il s'agissait de Dieu (ou même de l'ange), admettant que, en lui, la connaissance des universaux contient celle des individus. Mais, à l'égard de l'intelligence humaine, l'on admettait (par exemple Godefroid de Fontaines) que l'espèce infime était indivisible et contenait tout ce qu'il y a d'être positif ${ }_{\mathrm{p} 390}$ dans les individus qui sont au-dessous d'elle ; ils ne se distinguent entre eux que numériquement, par la place distincte (ou quantité) qu'ils occupent: mais pareille thèse, selon Duns Scot, non seulement en revient à poser les Idées de Platon, mais retourne au "maudit Averroès ", puisqu'il faudrait admettre, en appliquant la thèse à l'espèce humaine, que la nature humaine est indivisible d'elle-même, et que les individus ne se distinguent entre eux que par la quantité, l'espèce étant comparable à une masse homogène d'eau qui se divise.

Sans doute, « il n'y a pas de science du singulier », et Duns Scot admet cet adage aristotélicien ; mais cela tient aux limites de notre 
intelligence et non à la réalité. C'est un principe général que l'unité implique toujours une entité correspondante; dès que l'on admet l'unité de l'individu, sa répugnance à être divisée, il faut donc admettre une certaine entité ; cette entité ne peut être celle de la «nature » de l'individu, celle de l'humanité en Socrate, par exemple ; car cette « nature » a une unité propre différente de celle de l'individu, et elle suit donc d'une entité différente ; comme l'entité de l'espèce infime répugne à la division de l'espèce infime en espèces distinctes, l'entité de l'individu s'oppose à la division de l'individu en sujets divers.

Qu'est-ce que cette hæccéité ? L'aristotélisme distinguait dans un être la forme, la matière et le composé des deux ; l'hæccéité n'est aucun de ces trois éléments, mais plutôt quelque chose qui s'ajoute à chacun d'eux: en effet toute nature en général, par exemple l'humanité, comporte forme, matière et composé ; mais un homme singulier comporte une forme elle-même individuée et une matière qui l'est également : c'est telle ou telle matière avec telle ou telle forme, qui fait tel ou tel individu ; l'hæccéité s'ajoute donc à la matière, à la forme et au composé ; elle est comme la "réalité dernière » de la nature ; elle constitue, avec l'humanité, un individu p391 humain qui est une unité par soi ; humanité et hæccéité ne sont pas précisément en lui deux réalités distinctes à la manière dont le sont le genre et la différence spécifique ; elles ont pourtant entre elles cette « distinction formelle » qu'ont des réalités qui appartiennent à la même chose. On voit donc que l'individualité n'est pas tout à fait un intelligible au sens où le sont les universaux ; les hæccéités sont des éléments discrets dont on ne voit pas du tout qu'ils forment un système. Si exagéré qu'il soit de dire que Duns Scot ait supprimé tout principe d'ordre et de synthèse, on voit donc que tous ces principes tendaient, qu'il le voulût ou non, à dissoudre cette organisation qui unissait la foi et la raison, le dogme et la philosophie ${ }^{879}$.

Table des matières

879 Cf. P. Vignaux, Humanisme et théologie chez J. Duns Scot (La France franciscaine, Recherches, III $^{\mathrm{e}}$ série, t. XIX, 1936), montrant comment Duns Scot rattache la dignité de l’homme à la théologie. 


\section{Chapitre II}

\section{GUILLAUME D’OCCAM}

I.

Preludes du NOMinalisMe.

La philosophie d'Occam naquit et se développa dans un milieu déjà profondément imprégné de thèses nominalistes. Durand de SaintPourçain, maître de théologie à Paris en 1312, et mort évêque de Meaux en 1334, écrivit de 1310 à 1312 un Commentaire sur les Sentences qui refusait d'accepter la description thomiste de la connaissance, en se fondant, comme le fera Occam, sur l'expérience. D'abord il nie l'existence des "espèces ", intelligibles ou sensibles, dont nul ne peut constater l'existence. Il nie l'existence de l'intellect agent ; cet intellect n'a en effet d'autre rôle que de permettre l'abstraction en éclairant les images venues des sens; or l'abstraction s'explique, d'une manière bien plus simple, par la façon dont l'intellect possible considère les images (secundum considerationem). Il nie l'existence des universaux, d'abord parce que toute existence est, par elle-même, singulière ; il n'y a nullement besoin d'un " principe d'individuation » particulier, puisque toute forme et toute matière existantes sont telles ou telles : universalité n'est rien qu'indétermination ; une même réalité est un singulier quand elle est saisie d'une ${ }_{p 393}$ manière déterminée, un universel si elle est conçue d'une manière indéterminée : or cette conception suit l'opération par laquelle nous la considérons » séparée des conditions individuelles ; l'universel n'est rien avant cette opération ni indépendamment d'elle.

Un peu plus tard, Pierre d'Auriole, qui enseigna à Bologne (1312), à Toulouse (1314), devint maître de théologie à Paris en 1318 et mourut en 1320, soutint des idées très analogues dans un Commentaire des 
Sentences dont les deux rédactions ont été écrites entre 1312 et 1318. Comme Durand, Pierre d'Auriole conteste la prétendue valeur et dignité de l'universel ; c'est avant tout par son rôle dans la connaissance qu'il est attaqué ; la connaissance de l'universel est confuse et indistincte ; " il est plus noble de connaître une chose individuelle et désignée, que de la connaître d'une manière abstraite et universelle ; la connaissance de l'individu est l'exemplaire et le signe de la connaissance de l'universel ; elle l'éclairé et l'explique parce qu'elle est plus claire et plus certaine ». Cette conception de l'universel se rattache à une idée toute nouvelle de la connaissance ; pour les thomistes, il y a la chose et l'esprit, et entre les deux la species ou forma specularis, qui est le moyen par lequel on connaît la chose : pour Auriole, cette espèce ou apparence n'est pas un moyen d'atteindre la chose, elle est elle-même l'objet et le seul objet de connaissance. Cette apparence, qui est un être intentionnel, est née grâce à l'assimilation de l'esprit à la chose ; mais c'est à elle, à cette conception de l'esprit, que se termine la connaissance ; or cette apparence peut être plus ou moins parfaite, et c'est par son imperfection que s'explique le genre ; lorsque l'impression est plus complète et plus distincte, naît alors l'individu.

Cette simplification de la théorie de la connaissance est dominée par le principe d'économie que l'on attribue en général à Guillaume d'Occam, mais dont Auriole donne la formule suivante : "Multitudo ponenda non est, nisi ratio evidens necessaria ${ }_{\mathrm{p} 394}$ illud probet aliter per pauciora salvari non posse » ou : « Frustra fit per plura quod fieri potest per pauciora. »

Chez Pierre d'Auriole, ce nominalisme n'aboutit pas pourtant, comme chez Guillaume d'Occam, à nier un ordre fixe et nécessaire au fond des choses. Comme plusieurs nominalistes, Pierre est platonicien lorsqu'il s'agit de théologie : les essences des choses créées ne sont pas produites arbitrairement par Dieu, comme chez Duns Scot; Dieu connaît toutes les natures dans la simplicité de son essence, de la manière dont on pourrait concevoir qu'on connaisse toutes les roses individuelles en connaissant la quiddité de la rose ; seulement chez nous, cette quiddité n'est qu'un être objectif intentionnel, un être diminué. Il s'ensuit qu'il y a une règle à l'amour de Dieu, et aucun arbitraire dans la prédestination ; Dieu, qui se complaît en son essence, se complaît en même temps dans les créatures à proportion de leur perfection ; la puissance, par laquelle il donnera la vie éternelle aux prédestinés, 
n'est donc pas du tout arbitraire, bien qu'elle ne soit pas non plus nécessaire, mais qu'elle résulte d'un acte libre de sa volonté ${ }^{880}$.

Table des matières

II.

GUILLAUME D’OCCAM : SON ATTITUDE POLITIQUE.

Les doutes que l'on pouvait tirer de l'enseignement de Duns Scot s'accentuent encore chez Guillaume d'Occam malgré tous les traits qui opposent le nominalisme, pris en lui-même, au scotisme. Né vers la fin du XIII ${ }^{\mathrm{e}}$ siècle à Occam, bourg du Survey, il entre assez jeune dans l'ordre des Franciscains ; il est possible mais non pas sûr que, jusqu'en 1324, il ait enseigné à Oxford et à Paris. En 1324, il est cité à Avignon, devant le pape Jean XXII, pour hérésie ; en 1328, il prend parti p395 pour le général de son ordre, Michel de Césena, dans une discussion sur la pauvreté du Christ ; Michel avait refusé d'adhérer à une bulle où Jean XXII proclamait que Jésus et les apôtres avaient possédé des biens en toute propriété ; Guillaume, menacé d'arrestation, dut s'enfuir d'Avignon avec Michel et se réfugier en territoire impérial, à Pise ; de là, les Franciscains écrivent une protestation en appelant du pape au futur concile. Guillaume reste alors près de l'empereur Louis de Bavière, qu'il accompagne à Munich : c'est à cette époque qu'il écrit tous ses pamphlets politiques contre le pape, entre autres le traité De dogmatibus Johannis XXII papae (1333), où il le déclare hérétique ; les Allegationes de potestate imperiali (1338), où il défend le décret impérial qui décide que l'élection suffit à faire l'empereur, sans la consécration du pape ; le Dialogus (1345), enfin le De imperatorum et pontificum potestate, et le De electione Caroli IV, l'empereur élu en 1346 sous la pression du pape. Au milieu de ces luttes très dures et sans fin, Guillaume mourut à Munich en 1348.

Il avait composé sans doute déjà à Oxford un Commentaire sur les Sentences, où sa doctrine philosophique se trouve tout entière ; de la même époque datent sans doute sa première œuvre logique Expositio aurea et les Summulae in libros Physicorum. A sa période de maturité, celle de Munich, appartiennent le Centilogium theologicum, exposé 
net et bref de cent thèses théologiques, la Summa totius logicae ${ }^{881}$ et diverses œuvres physiques (Quaestiones in octo libris Physicorum, Expositio Physicae, Quaestiones super libros Physicorum) ${ }^{882}$.

Son œuvre politique s'efforça de séparer la juridiction du pape et celle de l'empereur: "L'autorité du pape ne s'étend pas, selon la règle, aux droits et aux libertés d'autrui, pour les supprimer ou les troubler, surtout à ceux des empereurs, rois, princes et autres laïcs, parce que des droits et des libertés de ${ }_{\mathrm{p} 396}$ ce genre sont au nombre des choses du siècle et que le pape n'a pas autorité sur elles... C'est pourquoi le pape ne peut priver personne d'un droit que l'on tient non de lui, mais de Dieu, de la nature ou d'un autre homme ; il ne peut priver les hommes de libertés qui leur ont été concédées par Dieu ou par la nature ${ }^{883}$. " Ainsi, dans la source du droit, Guillaume admet, de Dieu (ou de la nature) à l'homme, une relation directe qui ne passe pas par l'intermédiaire de l'Église ; l’Église, où l'autorité souveraine est non le pape, mais le concile, n’a à s'occuper que de la destinée surnaturelle de l'homme.

Cette dissociation entre les choses de la foi et les choses du siècle ruine une idée de la chrétienté, fondée sur la dépendance hiérarchique de toutes les formes sociales à l'égard de l'Église. Si l'aristotélisme thomiste avait introduit l'idée d'une nature qui agit selon ses règles propres, Guillaume va beaucoup plus loin en confiant à cette nature une sorte de droit tout aussi divin et aussi directement rattaché à Dieu que le droit de la religion. Ainsi sépare-t-il la foi de la raison. Les titres même des questions de ses Quodlibet expriment des doutes sur la possibilité de lier philosophie et théologie : «Peut-on prouver par la raison qu'il n'y a qu'un seul Dieu ? Peut-on prouver par la raison naturelle que Dieu est la première cause efficiente de toute chose et qu'il est doué d'une puissance infinie ? Est-ce la même vérité sur Dieu qui peut être prouvée en théologie et en physique ? " Ainsi le monothéisme et la toute-puissance de Dieu pourraient n'être que des vérités de foi, inaccessibles à la raison ; la science de Dieu et la science de la nature pour raient suivre des voies si différentes qu'elles

\footnotetext{
881 Cf. J. BAudry, CCXXXIX, Archives, 1934, p. 299 sq.

882 Cf. AbBagnano, CCXXXVI, p. 1-52.

883 Dialogues, III, traité II, liv. 1, ch. XXIII (ABBAGNANO, p. 312).
} 
n’arriveraient jamais à rencontrer la même vérité ; il n’y a entre elles ni pénétration comme le rêvait saint Anselme, ni hiérarchie comme le pensait saint Thomas ${ }^{884}$.

Table des matières

III.

\section{CRITIQUE DU REALISME : LA CONNAISSANCE INTUITIVE.}

p397 Il n'est pas douteux que, dans l'aristotélisme arabe, la théorie de l'intellect humain était l'intermédiaire grâce auquel il pouvait y avoir communication entre la philosophie et la théologie, et saint Anselme, d'autre part, avait déclaré la réalité des concepts indispensable à l'interprétation philosophique de la foi. Par son nominalisme, Guillaume d'Occam ruine du même coup la théorie thomistico-arabe de l'intellect et le réalisme ; mais en débarrassant la connaissance humaine de toute superstructure métaphysique, il la laisse dans le pur donné intuitivement connu, et il la prive de toute relation avec la foi.

Sa critique du réalisme est radicale : "Il n'y a en dehors de l'âme nulle réalité universelle ni par elle-même, ni par quelque élément surajouté (qu'il soit un être réel ou un être de raison) ni de quelque façon qu'on le considère ou l'entende ; l'existence de l'universel est aussi impossible qu'il est impossible que l'homme soit un âne ${ }^{885}$. " Guillaume conclut ainsi après avoir examiné toutes les formes du réalisme : celui qui veut que l'universel, réellement distinct de l'individu, existe, un et immuable, bien que distribué entre plusieurs individus : ce serait attribuer, selon Guillaume, retournant curieusement un argument de saint Anselme, une propriété qui n’appartient qu'à l'essence divine se divisant, sans se multiplier, entre les trois personnes de la Trinité. L'universel, selon d'autres, pourrait se multiplier avec les individus ; mais alors, il faut dire que l'humanité de Socrate a une marque particulière qui la distingue de celle de Platon ; l'universel, comme réalité, disparaît. p398 Reste à dire, et c'est ce qu'a fait Duns Scot, que la distinction entre l'universel et les individus n'est pas réelle mais formelle : mais il n’y a pas, selon Guillaume, de distinc-

884 Cf. P. VignauX, CCXLI.
${ }^{885}$ I Sentent., dist. 2, q. 7. 
tion formelle qui ne soit réelle : si la nature commune et l'hæccéité qui s'y ajoute ne sont pas identiques, on peut affirmer de l'une ce qu'on nie de l'autre, et ce sont alors deux choses diverses.

D'autres philosophes, tout en admettant que l'universel n'est pas réellement différent des individus, croient pourtant qu'il a sa réalité en eux. Par exemple, un condisciple de Guillaume, Walter Burleigh, soutenait que, réellement identique aux individus, l'universel s'en distingue pourtant «selon la raison et par la considération de l'entendement »; il y a, dans les créatures, une forme qui, en réalité, « n'a aucune unité en soi et se divise, mais qui a une unité de raison ». Guillaume critique aussi ces réalistes; il somme Burleigh de choisir entre une distinction réelle, qui ramène aux doctrines déjà réfutées et une pure distinction de raison, c'est-à-dire une simple différence entre deux manières de concevoir une même chose. Il réfute Gille de Rome, qui pensait sauver l'universel, en disant qu'une seule et même chose, considérée selon son être effectif, est singulière, et selon son être dans l'entendement, universelle ; il conteste en effet qu'il soit inhérent à l'entendement de rendre universelles les choses qu'il pense, par exemple l'essence divine. Il désapprouve encore la thèse d'Henri de Harclay, selon qui l'universel ne serait qu'un concept confus par lequel l'esprit est encore incapable de distinguer un individu d'un autre ; même sous cette forme, pourtant modeste, où s'annonce la fameuse théorie de Spinoza sur les universaux Guillaume rejette une doctrine qui aboutit à dire, par exemple, que Socrate n'est que Platon confusément conçu.

Le véritable et profond motif de l'aversion de Guillaume d'Occam pour les universaux, c'est que, contrairement à toutes les doctrines nées de l'aristotélisme, il voit le type de la connaissance dans la connaissance intuitive qui est celle d'une ${ }_{\mathrm{p} 399}$ existence et d'une existence contingente, et non plus dans la connaissance des essences nécessaires. « La connaissance intuitive d'une chose est la connaissance en vertu de laquelle il peut être su si la chose existe ou non... D'une manière générale, c'est toute connaissance incomplexe d'un ou plusieurs termes, d'une ou plusieurs choses, grâce à laquelle peut être connue avec évidence une vérité contingente, en particulier relative au pré- 
sent ${ }^{886}$.» La connaissance abstraite (notitia abstractiva) est toute connaissance qui ne répond pas à ces conditions, en particulier les « complexes », comme les jugements et les raisonnements, et l'acte par lequel on leur donne son assentiment.

Ce qui a dissimulé la supériorité de la connaissance intuitive, c’est qu'elle a pour objet l'individuel, et que l'on n'admet en général d'autre moyen d'atteindre l'individuel que la connaissance sensible qui est au plus bas degré. L'intelligence n'atteint que l'universel qu'elle sépare par abstraction de l'individu donné au sens. Rien n'est plus faux pour Occam : l'entendement a des connaissances intuitives ; il connaît les choses sensibles ; sans quoi, il ne pourrait jamais former les jugements contingents dont les termes sont des choses sensibles ; comment réunirait-il des termes qui en eux-mêmes lui échapperaient ? De plus, il a une connaissance intuitive de lui-même et de ses propres actes.

La connaissance intuitive est, pour Guillaume, une connaissance évidente ; elle n'est pas, pour cela, une connaissance certaine ${ }^{887}$; supposons que Dieu, par miracle, détruise l'objet d'une vision sans détruire la vision qu'en a l'esprit humain ; nous aurions alors la connaissance intuitive d'une chose qui n'existe pas, nous en connaîtrions l'existence avec évidence. Mais, bien qu'elle ne soit pas liée nécessairement à la certitude, p 400 la connaissance intuitive est immédiate; elle porte sur l'objet lui-même. Occam abolit complètement les « espèces ", ces intermédiaires que le thomisme plaçait entre les choses et l'esprit ; s'il y avait besoin d'un tel intermédiaire, n'en faudrait-il pas un autre entre l'esprit et l'espèce, et ainsi à l'infini ?

Partant de cette connaissance intuitive, Occam construit à son tour une théorie de l'universel, mais bien différente de celle des réalistes. Un terme est universel, en tant que prédicat commun d'un ensemble de sujets ; "il est donc universel par la prédication, non pour luimême, mais pour les choses qu'il signifie ${ }^{888}$ " ; mais ce terme n'est pas une fiction, ni une qualité intérieure à l'âme, distincte de l'acte par

Sentent., Prol., qu. 1.

${ }^{887}$ II Sent., qu. 25. « On peut donner un assentiment ferme et certain à un complexe sans aucune évidence. »

888 Expositio aurea, Préf. du Periermeneias. 
lequel on la comprend; elle est l'acte d'intellection lui-même ; le terme homme est universel en ce qu'il peut être vrai indifféremment de tel ou tel individu ; il est universel par sa signification, ou en tant que signe ; mais c'est non pas un signe arbitraire et d'institution, mais un signe naturel indépendant du terme linguistique qui l'exprime. Occam arrive donc à cette conclusion positive que l'universel est non pas un objet, mais une fonction. C'est cette fonction qu'il appelle signe ou symbole. Et au lieu de composer la science d'idées, il la compose de signes ; il donne grande importance à l'expérience et à l'induction qui dérive d'une ou plusieurs connaissances intuitives, grâce à ce principe que « les causes de même sorte ont des effets de même sorte ${ }^{889}$ ».

$\underline{\text { Table des matières }}$

IV.

LOGIQUE ET THEORIE DE LA CONNAISSANCE.

Sur cette idée du signe ou symbole, Occam construit toute la théorie de sa connaissance et toute la logique ${ }^{890}$. La logique ${ }_{\mathrm{p} 401}$ est une science purement pratique, non pas au sens de la morale qui dit ce qu'il faut vouloir, mais au sens de la mécanique, qui indique les opérations à faire pour atteindre le but que l'on s'est assigné. L'objet premier de la logique, ce sont les termes, éléments des propositions dont se forment les syllogismes. Mais les termes sont toujours considérés par Occam dans leur référence aux choses qu’ils désignent ; ce sont des signes ou des « intentions » : intentions premières ou espèces, lorsqu'ils se réfèrent aux choses réelles intuitivement connues, intentions secondes ou genres, lorsqu'ils se réfèrent aux intentions premières : ces intentions naissent d'un processus naturel et non d'une construction intellectuelle ou volontaire; le rapprochement se fait de lui-même entre les semblables. Dans la logique occamiste, les termes sont donc considérés uniquement en extension, et ils sont une production spontanée de l'esprit.

\footnotetext{
889 Sentent., Prol., qu. 2.

890 Sur cette logique, cf. ABbagnano, CCXXXVI, p. 109-158 ; Michalski, CCXLIII, p. 42-46.
} 


\section{Émile Bréhier \\ La philosophie du Moyen âge}

La logique commence traditionnellement par l'étude des catégories, qui sont, pour Occam, des intentions secondes. Il admet les dix catégories d'Aristote, mais avec cette réserve que la distinction entre les catégories n'implique pas une distinction entre autant de choses réelles. Le quantum ou le quale désignent la même chose que la substance ; le quando et l'ubi n'en sont que des déterminations adverbiales qui n'ajoutent rien de réel aux choses. Enfin, et c'est là un des points les plus importants de l'occamisme, la relation n’a aucune réalité, sauf celle des termes rapportés l'un à l'autre : Occam ne se dissimule pas les paradoxes qui doivent résulter de cette irréalité des relations : un composé ne sera rien de différent de ce qu'étaient ses termes avant leur union ; l'ordre de l'univers n'existera pas dans les choses, mais dans notre esprit.

Aussi accumule-t-il les arguments contre la réalité des relations : il emploie notamment contre elle un procédé qui lui est favori, celui du progrès à l'infini : si une relation comme la ${ }_{\mathrm{p} 402}$ diversité diffère des choses diverses, ce sera en raison d'un rapport de diversité entre elle et les choses ; si ce rapport est réel, il faudra poser un nouveau rapport de diversité entre lui et la première relation, et ainsi à l'infini. Ou encore : si $\mathrm{A}$ est semblable à $\mathrm{B}$, la relation de $\mathrm{A}$ à $\mathrm{B}$ sera semblable à celle de $\mathrm{B}$ à $\mathrm{A}$; cette relation est un nouvel être $\mathrm{C}$, à son tour semblable à $\mathrm{A}$ et à $\mathrm{B}$, et ainsi à l'infini. Ou encore : je ne puis remuer le doigt sans créer une infinité d'êtres nouveaux, puisque, par ce mouvement, changent toutes les relations de position de mon doigt aux autres objets.

Parmi les relations dont la négation est la plus paradoxale se trouve celle de cause à effet : Occam montre qu'elle ne peut être ni antérieure à l'effet, puisque la relation suppose l'existence des deux termes ; ni simultané, puisque l'effet en est la conséquence ; ni postérieure, puisqu'il faudrait dire alors qu'elle se produit elle-même.

Un terme doit pouvoir toujours être remplacé par une chose réelle et intuitivement perçue, tel est le grand principe d'Occam, pour lequel il trouvait un appui dans une notion introduite par un logicien fort lu à ce moment, Pierre d'Espagne, celle de suppositio: "supposition, c'est-à-dire position à la place d'autres choses », ainsi la définit Occam. Le terme peut d'ailleurs être mis soit pour choses singulières dont il est le prédicat ( «l'homme est un être vivant » où l'homme est 
mis pour tous les hommes), soit pris pour un simple symbole ( "l'homme est une espèce », où il s'agit de l'homme en tant que signe, non de ce qu'il signifie) ; autrement dit, la supposition peut être « personnelle » ou « simple ». La supposition personnelle à son tour peut être "discrète " (dans les jugements singuliers) ou " commune » (dans les jugements particuliers ou universels), et la supposition commune peut être déterminée ou confuse, selon que le jugement général nous permet ou non de passer à des jugements singuliers relatifs à tel ou tel individu. Jamais dans ce classement, qui est emprunté ${ }_{\mathrm{p} 403}$ à Raymond Lulle ${ }^{891}$, le sujet n'est considéré autrement que comme un substitut.

Mais l'origine première de cette constante référence à l'intuition du singulier est certainement la logique stoïcienne, la logique sans concept. A l'inspiration stoïcienne se rattache aussi toute la thèse occamiste sur la participation de la volonté dans le jugement : «A l'acte par lequel est appréhendé un complexe, écrit-il, concourt l'action de la volonté »; les notions des termes, par elles-mêmes, ne nous inclinent pas plus à former une proposition vraie qu'une fausse ; c'est la volonté qui la forme ${ }^{892}$. Il faut donc distinguer entièrement la connaissance intuitive, qui porte toujours sur une chose simple, du jugement qui est un complexe ; il arrive qu'il y ait des jugements qui ne fassent rien de plus que de reconnaître l'existence de la chose dont ils sont les symboles (par exemple l'homme existe) ; mais tout jugement se rapporte à la réalité existante ; cela est vrai même des définitions ; toujours suivant les Stoïciens, Occam affirme que la définition de l'homme est une proposition vraie ou fausse selon qu'il y a des hommes ou qu'il n'y en a pas; la formule complète d'une définition vraie est par exemple : " si l'homme existe, il est un animal raisonnable " ${ }^{893}$; c'est en ce sens que toute proposition est, selon Occam, une proposition contingente.

Cette logique, reposant uniquement sur la correspondance des termes à la réalité, fait évanouir la question de la distinction de l'essence et de l'existence : l'existence ne signifie rien de distinct de

\footnotetext{
891 N. AbBagnano, CCXXXVI, p. 132.

892 II Sent., q. 25.

893 Quodl., V, q. 15.
} 
la chose même ; elle ne peut être en effet un accident de la chose, car elle tomberait sous quelqu'une des catégories (qualité, quantité, etc.) ; elle ne peut être substance, car elle serait alors forme, matière ou composé des deux; enfin, si elle était réellement distincte de l'essence, Dieu pourrait ${ }_{\mathrm{p} 404}$ détruire l'essence sans détruire l'existence, ce qui est absurde ${ }^{894}$.

Grâce à sa méthode, Occam a donc prétendu supprimer une foule de distinctions artificielles : le principe de cette méthode est le fameux « rasoir d'Occam », qu'il énonçait non pas sous la forme traditionnelle connue, mais de la manière suivante ${ }^{895}$ : «Pluralitas non est ponenda sine necessitate », et " Frustra fit per plura quod potest fieri per pauciora ». Son empirisme lui permet de sacrifier toute la superstructure compliquée des intellects; il fait jouer au symbole, au «terme », le rôle réservé jusqu'ici au concept.

$\underline{\text { Table des matières }}$

\section{V. \\ LA METAPHYSIQUE.}

Les notions aristotéliciennes fondamentales, substance et accident, cause et effet, matière et forme, cause finale, avaient pour essentielle destination chez leur auteur de boucler en quelque manière l'expérience en introduisant dans l'univers mouvement, unité et continuité. Mais, passées à l'épreuve de l'expérience, elles sont critiquées et transformées par Occam de manière à devenir incapables de jouer ce rôle. La substance, d'abord (et la remarque avait été faite par Plotin), n'est connue que par des caractères généraux ; elle est ce qui subsiste en soi, ce qui n'est pas en autre chose, ce qui est sujet des accidents ; autant de caractères qui laissent ignorer ce qu'elle est en soi : la seule donnée de l'expérience, ce sont les qualités ou propriétés ; ce que nous connaissons du feu, c'est la chaleur. Il y a, dit-on, entre la substance et sa propriété un lien de cause à effet, si bien que l'on pourrait conclure de l'une à l'autre. Ce lien consiste évidemment en ce que, « si la chose absolue (cause) est posée, l'effet est posé, et si elle

894 Summa tot. Log., Ill, 2, c. 27 ; ABBAgnAnO, CCXXXVI, p. 157.
895 ABbagnAno, p. 159. 
n'est pas p405 posée, l'effet n’est pas posé non plus » : cause et effet sont donc deux choses différentes : or " jamais la connaissance d'une chose simple n'est la cause suffisante de celle d'une autre chose simple »; car la connaissance d'une chose ne peut venir, médiatement ou immédiatement, que de cette chose même et non d'une autre ; entre la notion de la cause et celle de l'effet, il n'y a aucun autre lien que celui que l'expérience a établi ; l'expérience nous révèle que la chaleur a la puissance d'échauffer ; mais nous ne connaissons rien dans la chaleur qui exige cet effet. Occam ne nie pas le principe de causalité et sa valeur ; mais il nie que nous puissions connaître en un être une puissance active, c'est-à-dire quelque chose qui, en lui, se réfère à un être autre que lui ; la connaissance d'un être se termine à lui-même ${ }^{896}$.

C'est ce principe même qui amène Occam à transformer très profondément la notion de matière et de forme. Pour Aristote, on le sait, tout devenir a lieu, dans la matière, de la privation à la forme ; sous le nom de privation, il introduit une réalité qui se réfère à ce qui n'existe pas encore, à la forme ; Occam, au contraire, ramène la privation à la matière ; la privation n'est qu'une expression métaphorique pour désigner la matière. Restent donc purement et simplement la matière et la forme. Mais la matière, chez Aristote, est essentiellement être en puissance ; rien de pareil chez Occam, pour qui l'être en puissance ou être indéterminé ne peut pas du tout exister ; la matière existe en acte, comme tout être de la nature ; mais par là, Occam prive la matière de la fonction qu'elle avait chez Aristote ; car, en tant qu'être en puissance, elle aspire à la forme et devient ainsi, dans l'univers, un principe de continuité et d'union; si elle est un être en acte, il n'y a rien en elle qui exige la forme ; indépendante de celle-ci, elle ne change nullement en s'unissant à elle : que la matière soit inséparable ${ }_{\mathrm{p} 406}$ de la forme, c'est un fait universel ; en fait, l'expérience ne donne jamais que des composés concrets où forme et matière, indissolublement unies, ne peuvent être séparées que par analyse ; mais cette union n’a en soi rien d'intelligible ${ }^{897}$.

Aristote avait été conduit, par ses principes, à la notion d'une matière première, entièrement indéterminée, et dénuée même de quantité

896 AbBagnano, CCXXXVI, p. 165-173 ; ci. surtout Sentent., Prol., q. 9.
897 ABbagnano, 173-181 ; cf. Summulae, I, ch. xv. 
ou d'étendue ; la quantité n'est qu'un accident qui vient s’ajouter à la matière : Occam ne peut du tout accepter cette matière indéterminée ; il en résulterait que ce que l'on tient pour un accident, la quantité, serait le principe de distinction des êtres ; ou alors, il faudrait supposer que, la quantité supprimée, les êtres restent distincts, ce qui revient à dire qu'ils sont situés, dans l'étendue, les uns par rapport aux autres, et, donc, que la quantité n’a pas été effectivement abolie. «L’étendue ou quantité ne désigne donc pas une réalité absolue ou relative, en dehors de la substance et de la qualité, mais elle est une voix ou concept qui désigne principalement la substance, et qui connote plusieurs autres choses, parmi lesquelles peut être le mouvement local ${ }^{898}$. »

Avec la critique de la cause finale, Occam s'attaque au point central de la métaphysique aristotélicienne. « On est en doute, écrit-il, sur la causalité de la cause finale ; on dit communément que cette causalité est capable de mouvoir un agent ; mais mouvoir, pour elle, veut dire seulement que la fin est aimée par l'agent ; d'où suit que ce mouvement n'est pas réel, mais métaphorique. » D’autre part, l'uniformité d'action que l'on constate dans les êtres de la nature ne permet pas ${ }^{899}$ de prouver en eux l'action d'une cause finale. Ainsi achèvent de s'effriter, grâce à l'empirisme d'Occam, toutes les notions qui faisaient l'armature de l'univers d'Aristote.

Table des matières

VI.

\section{LES NOTIONS FONDAMENTALES.}

p407 Les notions fondamentales de la physique d'Aristote s'appuyaient sur sa métaphysique : elles sont remplacées chez Occam par des notions toutes différentes. La physique est l'étude du mouvement ; en lui, Aristote voit la réalisation progressive d'une forme ; Occam ne veut y voir que la forme qui y est réalisée à chaque moment ; ainsi, dans le mouvement local, il n'y a rien que le corps et sa position ; ce mouvement est « la coexistence successive, sans repos intermédiaire, d'une réalité continue, existant en divers lieux ». Le mouvement n’a

\footnotetext{
898 ABBAGNANO, 181-186 ; IV Sentent., q. 4.

899 ABBagnANO, 189-192 ; II Sentent., q. 3 ; VI Quodlib., q. 2.
} 
pas de réalité propre distincte des réalités permanentes que l'expérience nous montre seule : le temps lui-même n'est rien de distinct ni de ces réalités, ni du mouvement ; il est, au sens strict, le mouvement le plus rapide connu, c'est-à-dire celui du premier ciel ${ }^{900}$.

Dans les transformations profondes que subit l'image de l'univers, l'on voit apparaître les notions d'une physique entièrement nouvelle : Aristote attribuait l'ordre universel à l'unité d'un principe hégémonique ; Occam pense qu'il suffit, pour l'expliquer, des relations réciproques des parties, dépendant de leurs distances. Aristote introduisait une hiérarchie entre la matière céleste ou quintessence et la matière des éléments ; Occam veut qu'il y ait une matière unique, et il constate, comme un simple fait, que la matière céleste, relativement aux agents naturels connus, est incorruptible. Aristote croit avoir démontré, au moyen de sa théorie des lieux naturels, que le monde est un et qu'il est fini ; car, si l'on suppose un élément placé en dehors de ce monde, il tendra, selon cette théorie, à retourner en son lieu naturel : mais d'abord, cette théorie est ${ }_{\mathrm{p} 408}$ contestée par Occam ; elle est liée à cet axiome fondamental que toute action à distance est impossible ; lorsqu'un élément regagne son lieu naturel, ce n'est pas parce qu'il est attiré par la masse corporelle qui est en ce lieu, c'est parce qu'il est poussé par un principe interne de mouvement qui le fait tendre vers ce lieu comme vers sa perfection ; une autre application de cet axiome, c'est la paradoxale théorie des projectiles, selon laquelle le mouvement du corps lancé ne continuerait pas un instant, s'il n'était accompagné d'un moteur qui le pousse par derrière. Or cette négation de l'action à distance est, selon Occam, démentie par l'expérience : le soleil illumine la terre sans que le milieu intermédiaire soit illuminé ; l'aimant attire le fer immédiatement et sans aucune vertu existant dans le milieu ou dans le fer. Si le grave tend à regagner la terre, ce n'est donc pas afin de réaliser sa perfection en atteignant son lieu naturel, mais parce qu'il est attiré par la masse terrestre. Rien ne s'oppose à ce qu'il y ait ailleurs d'autres masses terrestres qui attirent les éléments situés plus près d'elle. D’autre part, les projectiles n'ont pas besoin pour continuer leur route du renouvellement continuel de l'impulsion. L'unité du monde est donc indémontrable, et la pluralité des mondes reste physiquement possible. La finité de l'univers n'est pas davantage

900 ABBagnano, p. 217-229. 
susceptible de preuve; quel que soit le nombre des individus d'une espèce, on peut en effet toujours le supposer augmenté par la toutepuissance divine ; suivant une distinction que Guillaume emprunte à Pierre d'Espagne, si l'infinité du monde n'est pas «catégorématique ", c’est-à-dire si elle ne désigne pas une quantité actuelle du monde, elle est "syncatégorématique », c'est-à-dire qu'elle est possibilité pour le monde de grandir au-delà de toute limite. Occam, en cette question, voit donc la possibilité de substituer à la considération d'une quantité fixe celle d'une quantité fluente et variable.

La spéculation d'Occam sur l'éternité du monde fait voir ${ }_{\mathrm{p} 409}$ qu'il ne s'en prend pas spécialement à Aristote ; il attaque en effet ici ceux qui, contrairement à Aristote, ont cru pouvoir démontrer que le monde était limité dans le temps ; le principe de leur démonstration prétendue est pourtant emprunté à Aristote, puisqu'il n'est rien autre que l'impossibilité d'un nombre infini en acte, tel que serait, à partir de maintenant, le nombre des révolutions passées du ciel : Occam réplique ici, comme tout à l'heure, qu'il s'agit moins d'un nombre fixe que d'un progrès à parcourir sans fin (pertranseundum) ${ }^{901}$. Occam examine d'autres arguments des finitistes qui l'amènent à des intuitions tout à fait neuves sur le calcul de l'infini ; il montre comment l'axiome : «la partie est plus petite que le tout », n'est valable que dans le cas d'un tout extensif composé de parties finies dont il est la somme, non dans le cas d'un tout infini qui n'est pas une somme ${ }^{902}$.

L'univers aristotélicien était celui sur lequel saint Thomas appuyait la preuve de l'existence de Dieu, et, par elle, ce qui, dans la théologie révélée, est accessible à la raison. La ruine de cet univers risque donc d'ébranler la théologie sous cet aspect, et c'est bien en effet ce qui est arrivé. Que l'on puisse arriver à l'existence de Dieu par une preuve, Occam ne le pense pas, en vertu de son grand principe empiriste qu'une existence ne peut être que donnée à l'intuition, et jamais conclue; or, une connaissance intuitive de Dieu n'est pas possible à l'homme dans l'état actuel ${ }^{903}$. Mais, de plus, la preuve cosmologique repose sur deux prétendus axiomes, l'un et l'autre inacceptables : le

\footnotetext{
901 ABbagnano, CCXXXVI, p. 193-216.

902 ABBAgNANO, 243.

903 ABBAGNANO, 247-249.
} 
premier, c'est que rien ne peut se mouvoir soi-même, à quoi contredisent les expériences, celle de l'âme qui produit ses propres mouvements et celle du corps grave qui descend de lui-même ; le second, c'est l'impossibilité du processus à l'infini, lorsque l'on remonte de cause en cause ; l'axiome ne s'applique pas, lorsqu'un effet se propage dans un ${ }_{p 410}$ milieu continu, comme une vibration le long d'une corde, où chaque partie meut la suivante, bien qu'il y ait une infinité de telles parties ; et, comme on l'a vu à propos de l'éternité du monde, il ne s'applique pas davantage à une série temporelle de causes et d'effets provenant l'un de l'autre.

Que, en général, on puisse s’appuyer sur le principe de causalité, c'est ce qu'Occam croit impossible ; rappelons-nous qu'un lien causal ne peut se fonder que sur des expériences, dont ici nous sommes démunis; nous ne savons pas si les corps célestes ne sont pas capables de produire tels effets merveilleux que l'on attribue à Dieu comme à leur cause immédiate; nous ne savons pas en revanche si, posé que Dieu est cause immédiate de certaines choses, sa causalité ne rendrait pas inutiles toutes les autres causes efficientes ${ }^{904}$.

Occam n'est d'ailleurs pas moins sévère pour les preuves de type augustinien. L'argument de saint Anselme vaut, à condition que la notion de : " ce qui est tel que rien de plus grand ne puisse être pensé » ait un sens, ce qui a lieu seulement si « dans les choses existantes il n'y a pas de processus à l'infini vers le plus grand ou le plus petit ». Ici, comme dans la critique de la preuve du premier moteur, c'est donc la possibilité d'un progrès à l'infini qui vient nous empêcher de borner la pensée à un terme suprême ${ }^{905}$.

Parmi les vérités théologiques que l’on considérait comme pouvant être atteintes par la raison se trouvent les suivantes : monothéisme, immutabilité de Dieu, toute-puissance, infinité, création. Aucune d'elles, selon Occam, n'est démontrable : d'une manière générale, à défaut d'intuition, Dieu n'est pas plus connu de nous que la couleur ne l'est des aveugles-nés. Le monothéisme ? Rien n’empêche d'expliquer

\footnotetext{
904 ABBagnANO, 249-252.

905 ABBagnANO, p. 245-247. On sait comment Leibniz a tenu compte de la difficulté en imposant à la preuve ontologique la tâche de démontrer que la notion d'un être suprême n'est pas contradictoire,
} 
les choses par une ${ }_{\mathrm{p} 411}$ pluralité de causes premières, qui gouvernent ensemble le monde. L'immutabilité ? Elle est démontrée par la perfection ; mais il y a tels changements qui n'amènent aucune imperfection, par exemple l'incarnation de Dieu sur la terre. La toute-puissance? Elle ne peut être démontrée à partir de l'essence divine ; mais une fois admise, elle a les conséquences les plus étranges ; si Dieu peut faire tout ce qui n'inclut pas contradiction, si son action n'est pas bornée par une nature qui lui serait propre, il peut se transformer en quelque nature que ce soit, fût-ce celle d'une pierre ou d'un âne ; l'on dirait en un mot que, pour Occam, le panthéisme est au bout de la toutepuissance. L'infinité ? On ne peut la démontrer à partir des effets de la causalité divine, puisque ces effets, étant finis, ne supposent qu'une cause finie, non plus qu'à partir de la cause finale, puisque le bien vers lequel incline la volonté humaine, quoique, par un progrès à l'infini, il pense devenir toujours plus grand, reste cependant toujours fini ${ }^{906}$.

Le chrétien est certain, par la Bible, que Dieu a créé le ciel et la terre : mais la création n'est aucunement démontrable. La création dans le temps amène des difficultés : si, comme le dit saint Augustin après le Timée, le temps a commencé avec le monde, il n'est, avant le premier instant, aucun instant où Dieu ait existé. On réplique qu'il existe éternellement, mais il n’y a, dans l'éternité, ni avant ni après, de telle sorte que l'on ne peut pas conclure, de son éternité, que Dieu a été avant la création du monde, ni qu'il continuera à exister, lorsque, au jugement dernier, le temps, avec le ciel, s'arrêtera : dire que Dieu a existé avant le monde ou existera après, c'est donc, pour affirmer son éternité, la nier ${ }^{907}$.

Table des matières

\section{VII.}

\section{LA NATURE ET LA GRACE.}

p412 On voit ainsi le principe de tout l'occamisme. L'aristotélisme chrétien reposait sur l'idée d’une certaine fixité dans les formes des

\footnotetext{
906 ABBAGNANO, 256-260.

907 ABBagnano, p. 260-263 ; Centiloquium, concl. 47,
} 
êtres, qui ont chacun une nature qui leur assigne une place dans la hiérarchie. C'est cette idée de nature que le nominalisme fait disparaître : il n'y a nulle chose dans l'univers qui n'ait pu être autre qu'elle n'est ; nul effet auquel sa cause ait pour ainsi dire droit par nature. En particulier, comme il n'y a plus aucun concept fixe, il n'y a plus moyen de créer aucun lien rationnel et systématique entre les vérités qui nous sont révélées par Dieu : comme saint Anselme l'avait vu, la négation du réalisme enlève toute possibilité à la foi de "rechercher l’intelligence. »

Il faudrait se garder de faire de l'œuvre d'Occam une œuvre purement négative ; elle contient beaucoup d'éléments positifs, dont la critique n'est que l'envers. Sans que sa pensée aboutisse à un système, elle a pourtant une tendance unique et permanente, c'est d'introduire une notion qui ne rentre point dans les cadres connus de l'infinité du créateur et de la finité de la créature, celle du progrès à l'infini. En logique, au concept il substitue le symbole, qui ne s'arrête à aucune réalité définie, mais qui peut être pris arbitrairement ; en philosophie, il se refuse à réaliser quelque centre de référence fixe, que ce soit lieu naturel, ou être suprême, ayant comme l'intuition que ce qui est à rechercher dans toute réalité est moins son point d'aboutissement que son progrès. Cette nécessité d'une structure naturelle, qu'il supprime dans sa vision de l'univers, il la rejette aussi dans sa conception des rapports de l'homme avec Dieu. A Pierre d'Auriole selon qui « une forme créée plaît au créateur par sa nature, avec une nécessité telle qu'elle ${ }^{4} 413$ emporte, pour l'âme ainsi informée, l'acceptation divine ${ }^{908}$, il oppose que ce serait faire dépendre la complaisance de Dieu envers la créature de la nature de cette créature, ce qui introduit en Dieu une nécessité ; et si l'âme acquiert la vertu surnaturelle de la charité, elle n'en devient pas plus aimable par elle-même ; « elle n'est pas acceptée par Dieu, en raison de ce qu'elle est, sinon au sens où Dieu accepte toute les créatures ; si elle est acceptée spécialement par lui, c'est en vertu de la bienveillance et d'un décret divin ${ }^{909}$ ". C'est la tradition qui, de fait, nous enseigne que la justification requiert la charité ; la charité est la condition de l'acte d'amour de Dieu, et cet acte seul est méritoire ; mais rien n’empêchait Dieu d'instituer telle

\footnotetext{
908 P. VignAUX, CCXXXV, p. 99.

909 Id., p. 106.
} 


\section{Émile Bréhier}

La philosophie du Moyen âge

autre condition qu'il voulait ; son acceptation est absolument libre ${ }^{910}$. Il est antipélagien, parce que Pelage liait la justification à des actions dont l'homme est naturellement capable, alors que Dieu aurait pu se passer entièrement de toute cause seconde ${ }^{911}$. Il n'y a aucun moyen de rendre intelligible l'économie de la grâce, pas plus que celle de la nature; l'acceptation de Dieu, comme l'a dit un interprète d'Occam ${ }^{912}$, est " au suprême degré un acte gratuit », dont on ne doit même pas chercher un motif, tel que serait le désir de se communiquer.

\footnotetext{
910 P. VignauX, p. 119-122.

${ }^{911}$ Id., 126 et 129.

${ }^{912}$ Id., p. 188.
} 


\section{Chapitre III}

\section{LES OCCAMISTES}

Guillaume d'Occam trouva, au XIV ${ }^{\mathrm{e}}$ siècle, de nombreux partisans ; des franciscains comme Adam Wodham, maître de théologie à Oxford en 1340 ; des dominicains comme Robert Holkot, maître de théologie à Cambridge, mort en 1349 ; un ermite augustinien, Grégoire de Rimini, qui fut maître de théologie à Paris en 1345 ; le cistercien Jean de Mirecourt, qui enseigna à Paris jusqu'en 1345 ; Nicolas d'Autrecourt, maître à Paris en 1340 ; Jean Buridan, recteur de l'Université de Paris en 1327 et en 1348, et ses élèves Albert de Saxe, recteur en 1353 ; Nicolas d'Oresme, maître de théologie de Paris, qui mourut évêque de Lisieux en 1382 ; Marsile d'Inghen, qui enseigna à la Faculté des Arts en 1362 ; Henri de Hainbuch, maître de philosophie à Paris en 1363 ; Henri de Oyta, qui quitta Paris en 1372 pour enseigner à Prague.

\section{LE SCEPTICISME :}

\section{NiCOLAS D’Autrecourt.}

L'idée centrale de cet immense mouvement qui est loin d'avoir une unité doctrinale, c’est la séparation radicale de la philosophie et de la théologie. Mais cette séparation ne peut naturellement laisser intactes les conceptions que l'on se faisait ${ }_{\mathrm{p} 415}$ de Dieu et de la nature, alors qu'elles étaient unies. Si les deux disciplines se séparent, c'est que la structure de la nature, telle qu'on la conçoit maintenant, n'est pas ce qu'il faut pour nous orienter vers le Dieu de la théologie ; on tend, d'autre part, à faire ressortir en Dieu une puissance nue qui ne laisse aucune possibilité à notre raison de saisir, même par analogie, quelque chose de la nature et de l'essence divine. L'image de la nature comme 
la théologie se trouvent donc l'une et l'autre transformées par ce divorce. La théologie : en 1347, la faculté parisienne de théologie condamne quarante thèses de Jean de Mirecourt, qui nie en Dieu toute justice semblable à celle que l'homme peut concevoir : "Dieu est cause du péché comme péché ; le péché est plutôt un bien qu'un mal ; la haine du prochain ne fait démériter que parce que Dieu l'a temporairement défendue ; Dieu peut faire par lui seul que l'âme haïsse son prochain et Dieu lui-même sans démériter. " La nature: Nicolas d'Autrecourt développe, sur la causalité et la substance, des thèses d'ailleurs plus qu'en germe dans la doctrine d'Occam ; elles ne laissent plus aucune place à la nature, telle que la concevait Aristote. Il est impossible, en utilisant le seul fondement certain indiqué par Aristote, c'est-à-dire le principe de contradiction, d'inférer, de la connaissance de l'existence d'une chose, celle de l'existence d'une autre chose ; la physique d'Aristote prétendait déduire de l'essence d'une chose ses puissances et ses effets ; nous connaissons seulement des successions uniformes : "Lorsque j'ai approché la main du feu, j’ai eu chaud, c'est pourquoi j'estime probable que, si je l'approchais maintenant, j'aurais chaud. » Cette critique de l'idée de cause est liée à celle de substance ; car, si nous connaissions la substance, nous connaîtrions a priori ses effets ; mais Nicolas conteste que nous connaissions non seulement la nature des substances, mais même leur existence : en apparence, rien de plus simple que de le prouver : car tout accident suppose un sujet ; mais ce n'est là que la définition de ${ }_{p 416}$ l'accident ; et rien ne prouve qu'il existe autre chose que les objets de nos sens et que nos expériences ; on ne peut davantage conclure, et pour les mêmes raisons, de l'expérience intérieure de nos actes, tels que l'acte volontaire, à l'existence de facultés, telles que la volonté. Rien ne reste de la conception d'une nature faite d'essences fixes: ainsi Nicolas d'Autrecourt considère au moins comme possible, comme les premiers théologiens arabes, que Dieu soit la cause unique et qu'il n'ait laissé aucun pouvoir à des causes naturelles. Comme eux encore, il admet l'atomisme de Démocrite, d’où il déduit la négation de la finalité et, en général, des rapports hiérarchiques de perfection que l'on établit entre les choses.

Conception de la nature et théologie philosophique sont donc, au $\mathrm{XIV}^{\mathrm{e}}$ siècle, atteintes du même coup ; une tendance fort générale se montre à faire passer au rang de purs objets de foi des vérités que le 
XIII ${ }^{\mathrm{e}}$ siècle avait considérées comme pouvant être prouvées par la raison ; d'où un changement d'équilibre qui atteint jusque dans ses fondements la pensée médiévale. Beaucoup croient décidément Aristote inutilisable pour le théologien : ainsi, vers le milieu du siècle, un moine augustin, Hugolin d'Orvieto, écrit qu'Aristote ne parle pas des mêmes choses que le théologien ; son Dieu n'est pas créateur ni toutpuissant ; son âme forme du corps, tout à fait indéterminée, est une sorte de matière première plutôt qu'un être immatériel ; sa morale n'a rien à voir avec l'économie de la grâce ; elle exalte la magnanimité aux dépens de l'utilité, et la justice selon la loi qu'elle cherche n'a rien à voir avec la justification par le Christ ${ }^{913}$.

Les théologiens se replient et se retranchent ; d'après Jean de Jandun, comme la foi seule nous fait croire à la résurrection, seule aussi elle peut nous faire croire à la création ou à l'immortalité de l'âme. Ce sont les bases mêmes de la démonstration ${ }_{\mathrm{p} 417}$ aristotélicienne qui sont ébranlées : Aristote part en effet de l'existence de substances sensibles extérieures à nous: or, l'on revient au scepticisme académique ; d'après Fitz Ralph, la certitude ne s'étend pas plus loin qu'aux notions communes, à notre existence et à celle de nos actes ; mais nous ne savons pas si des substances sensibles existent, pas même si notre corps existe ${ }^{914}$. On collectionne, comme Pierre d'Auriole, des cas où il y a connaissance intuitive, sans qu'il y ait aucun objet réel : rêves, images consécutives, hallucinations ; c'est la collection d'exemples, pris des anciens sceptiques, qui passera à Montaigne et à Descartes; et l'on fait appel à la puissance de Dieu, qui a toujours le pouvoir de produire dans l'âme les sensations sans les sensibles ; la connaissance sensible (et c'est là aussi l'opinion d'Hervé de Nédellec) n’atteint que «l'être objectif » des choses, c'est-à-dire un être qui n'est pas irréel, mais qui n'appartient à la chose qu'en tant qu'elle est connue, « Un être qui est dans l'intellect comme la chose connue dans un sujet sant ${ }^{915}$ ». Ceux mêmes qui discutent Pierre d'Auriole se placent sur le même terrain que lui, et ne sont guère disposés à admettre une certitude absolue; Guillaume d'Occam, ainsi que Grégoire de Rimini, pense que, surnaturellement du moins, Dieu peut faire que l'intuition

\footnotetext{
913 MiCHALSKI, CCXLIII, p. 18-21.

914 MiCHALSKI, CCXLV, p. 31.

915 MiChALSKI, CCXLV, p. 52-55 ; 48-52.
} 
de l'objet subsiste dans l'âme sans l'objet ; les plus hostiles, comme Chatton ou Jean de Marchia, admettent la même restriction ; Jean Baconthorp, comme les stoïciens critiques des sceptiques dans les Académiques de Cicéron, veut qu'il y ait une différence toujours appréciable entre les apparitions sur lesquelles s'appuie Auriole et les intuitions. Ce qui indispose le plus les occamistes contre Pierre d'Auriole, c'est que, sous le nom d'esse objectivum, il a admis entre la chose et l'esprit un intermédiaire analogue à la species, tant honnie par eux ; le rasoir d'Occam fonctionne ${ }_{\mathrm{p} 418}$ contre lui ; Jean Rodington emploie l'argument du progrès à l'infini : si un intermédiaire est nécessaire entre l'objet et l'esprit, un autre sera indispensable entre lui et l'esprit, et ainsi à l'infini ; et Jean de Marchia (avec Occam) ne veut pas que l'on distingue l'être objectif de l'acte même de vision ou intention ; cette réduction de l'être objectif à l'intention fait songer à la manière dont Arnauld interprétait Descartes, dans sa critique de la théorie des idées de Malebranche.

Vers 1350, Nicolas d'Autrecourt reprend avec plus de fermeté les thèses de Pierre d'Auriole : la science certaine ne peut jamais dépasser le fait de conscience ; la connaissance n'est que la certitude de son propre être (certitudo sui esse) ; l'on peut donc toujours douter qu'une réalité corresponde à l'objet, et la certitude n'est entière que si l'objet ne diffère pas de l'acte de connaître. A la même époque, Jean de Mirecourt soutient la même thèse ; mais il établit en outre une gradation dans les chances d'erreur ; ces chances vont en augmentant à partir de notre affirmation de l'existence du monde extérieur jusqu'à la connaissance qui va de l'effet à la cause ${ }^{916}$. Sur toutes ces doctrines plane l'idée que, dès que nous dépassons les données immédiates, un agent surnaturel peut nous tromper, de telle sorte que, par une espèce de cercle, on fait appel à une puissance infinie possible pour appuyer les thèses qui doivent nous défendre, en attaquant la certitude du monde sensible, d'employer les arguments aristotéliciens pour établir l'existence de cette puissance.

Mais non seulement la base même du raisonnement est enlevée ; l'on conteste encore les principes qui permettraient de passer du

916 Pour tout ce qui précède, cf. les beaux travaux de Michalski, CCXLV, p. 4874 ; CCXLIII, p. 38-40. 
monde à la réalité spirituelle. Selon Gérard le Carmélite comme selon Occam, la preuve de Dieu comme premier moteur suppose à tort qu'aucun être n'est capable de se mouvoir lui-même et que la chaîne des causes et des effets doit ${ }_{\mathrm{p} 419}$ avoir un terme, ce qui est mis en doute aussi par Swinshead, par l'abbé cistercien Jacques d'Eltville ; au reste, le premier moteur, s’il était prouvé, ne serait pas le Dieu unique et tout-puissant des Chrétiens ${ }^{917}$. D’une manière générale, l'on ne voit aucune possibilité de passer du monde, qui est une réalité finie, à une réalité infinie ; à un effet fini, dit Brinkel, doit correspondre une cause finie. Gérard remarque que, si Dieu est tout-puissant, l'étendue pourrait et, peut-être même, devrait être infinie. Jean Rodington pense que l'explication du monde serait suffisamment assurée par une multiplicité de dieux façonnant une matière éternelle ; la réalité de la création se déduit de la toute-puissance divine, une fois posée, mais non pas du monde, tel qu'il est donné. Tout au plus accorde-t-on parfois, comme le franciscain André de Novo Castro, une valeur probable aux thèses de théodicée, un degré de certitude équivalent à celui d'une théorie physique qui sauve l'expérience ou à la certitude purement morale d'une thèse qui est simplement d'accord avec l'expérience, mais dont la négation aurait de funestes conséquences. Même le dominicain Robert Holkot, tenu par les règles de son ordre à enseigner le thomisme, considère que saint Thomas n'a pas eu l'intention d'enseigner la valeur absolue des preuves qu'il donne; il aurait voulu dire seulement que, en soi, ces preuves sont possibles bien qu'elles soient sans portée, quant à nous ${ }^{918}$.

La logique de Jean Buridan ne se distingue pas foncièrement de celle d'Occam; il admet, lui aussi, que la connaissance est dans l'assentiment, bien que la science totale soit non pas une collection d'assentiments, mais comme un tissu de rapports logiques ; il modifie aussi la terminologie ; mais il garde la distinction essentielle entre les signes des choses, p420 qu'il appelle concepts premiers, et les signes des signes, qui sont les concepts seconds. Il l'abandonne seulement dans la théorie des catégories ; tandis, que pour Occam, la quantité

\footnotetext{
917 Chez tous ces critiques, Aristote n’est plus interprété chrétiennement, comme chez saint Thomas ; on en a la conception qui a persisté à la Faculté des Arts, où les commentaires d'Averroès font loi. Cf. MiCHALSKI, CCXLIV p. 25-27.

918 Michalski, CCXLIV, p. 34-48 ; CCXLV, p. 33-39.
} 
(étendue) est un terme connotatif de la substance, selon Buridan, elle désigne un terme absolu, tout comme la substance et la qualité. Il rétablit une autre des distinctions que le « rasoir d'Occam » avait supprimées : le mouvement désigne non pas le mobile mais « la disposition selon laquelle le mobile se comporte à chaque instant autrement ${ }^{919}$ ».

Cette distinction entre le mouvement et le mobile n'est pourtant pas du tout un retour à Aristote ; elle est liée au contraire à des idées nouvelles en mécanique qui s'étaient fait jour dès le début du siècle et qui sont tout à fait indépendantes du nominalisme : en 1320, François de Marchia, dans son Commentaire des Sentences, avait rejeté, au moins partiellement, la thèse, si artificiellement construite, d'Aristote sur le mouvement des projectiles, et, revenant d'ailleurs à l'intuition, attribué la continuation du mouvement à une vertu motrice (virtus motiva); le résultat immédiat en est que le mouvement éternel des sphères peut s'expliquer, sans l'influence, à chaque instant renouvelée, d'une intelligence céleste, par une impulsion primitive qui conserve indéfiniment le mouvement. Le mouvement, dépendant non de la présence actuelle du moteur, mais de l'impulsion acquise, a donc comme une existence en lui-même. C'est cette force motrice que, par un mot qui fait image et qui a pris dans la physique postérieure un sens très abstrait, Buridan appelle l'élan (impetus).

Occam, avec son goût des réductions, ramène l'impetus au mouvement lui-même et, par conséquent, au mobile, exactement de la même manière qu'il identifiait l'âme avec ses facilités, selon une thèse condamnée par Tempier en 1277 ; conformément à la doctrine

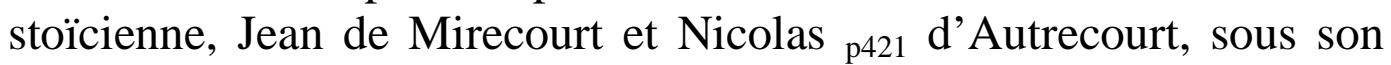
influence, remplacent la notion aristotélicienne d'accident par celle de mode ou manière d'être (modus se habendi) ; le mode n'ajoute aucune réalité à la substance même ${ }^{920}$. Buridan refuse de souscrire à cette théorie des modes; il en donne une raison théologique : la présence réelle dans l'Eucharistie est incompatible avec elle, puisque le mode

${ }^{919}$ Michalski, CCXLIV, p. 47-50.

${ }^{920}$ C'est le prototype d'une conception qui survit chez Descartes et dont l'exposé de Plotin est déjà fort près ; cf. Ennéade, VI, 1, 29, dans la critique des Stoïciens : la théorie des «manières d'être » supprime toute autre réalité que celle de la matière. 
ne saurait se séparer, même surnaturellement, de la substance ; mais cette différence ne paraît pas avoir une grande influence sur l'emploi de la notion d'impetus.

Un des résultats de cet emploi fut le retour à de vieilles idées pythagoriciennes, qui n'avaient jamais disparu puisqu'on les trouve chez Jean Érigène, sur le mouvement de la terre. Dès, en effet, que le mouvement de rotation des sphères célestes était affranchi de la nécessité d'un moteur d'ordre intellectuel continuellement présent, ce mouvement, n'étant pas d'une autre dignité que celui d'un projectile quelconque, il n’y avait aucun inconvénient, tiré de la nature ou essence des choses, pour attribuer à la terre un mouvement, pourvu qu'il y eût par ailleurs quelque avantage ; comme il n'y a plus, de par la hiérarchie des choses, un mouvement privilégié, on doit accepter la relativité du mouvement, donc la possibilité du mouvement de la terre et du repos du ciel : or le mouvement de rotation diurne de la terre a, en outre, l'avantage de "sauver les apparences de la manière la plus simple " (salvare apparentia per pauciora); ce sont les raisons que donne Buridan en son commentaire du De Coelo pour prouver le mouvement de la terre. Buridan ne fut pas universellement suivi : Albert de Saxe et Richard de Clavasio, tout en admettant l'impetus, rejettent la rotation de la terre; mais il reste pourtant évident que l'emploi du principe de la relativité du mouvement, qui ${ }_{\mathrm{p} 422}$ rendait possible une telle thèse, est lié à la ruine de l'image aristotélicienne du ciel. Le cistercien Pierre Caffonds, qui énumère et qui réfute les raisons contre la rotation de la terre, croit du même coup que le mouvement du ciel s'explique soit par un moteur matériel, soit par une force motrice inhérente aux sphères. Nicolas d'Oresme, dans ses trois œuvres successives, le commentaire du De Sphaera, le commentaire latin, puis français, du De Coelo, se déclare de plus en plus convaincu du mouvement de la terre ; mais il se rend bien compte que le principe de relativité du mouvement, qui permet d'y croire, ne permet pas de l'affirmer dogmatiquement comme Aristote faisait du mouvement du ciel : « Cette question peut être l'objet non d'une démonstration mais d'une conviction, et elle donne matière à croyance. » En d'autres termes, la physique de ce temps renonce à déduire le mouvement de l'essence des mobiles : avec Occam et Buridan, l'idée d'une nature à multiples puissances auxquelles on peut rapporter ses effets cesse de 


\section{Émile Bréhier \\ La philosophie du Moyen âge}

s’imposer ; la théorie qui « sauve les phénomènes » remplace la théorie qui les explique.

Table des matières 


\section{Chapitre IV}

\section{LE MYSTICISME SPÉCULATIF}

I.

\section{DIETRICH DE FREIBERG.}

Le mysticisme spéculatif d'Eckart ne détruit pas moins, à sa manière, la notion de nature, que ne font les nominalistes ; et ses intuitions théologiques comportent la négation de tout être fini et partiel. A la fin du XIII ${ }^{\mathrm{e}}$ siècle et au XIV $\mathrm{X}^{\mathrm{e}}$, les conditions de la vie intellectuelle et religieuse étaient assez différentes en Allemagne de ce qu'elles étaient devenues en France ; le développement des couvents y favorisait un mysticisme que le reste de la chrétienté avait surtout connu au $\mathrm{XII}^{\mathrm{e}}$ siècle, au temps de saint Bernard et des Victorins. Ce mysticisme s'exprimait souvent, non seulement par des traités en latin, mais par des prédications en langue vulgaire destinées aux couvents de femmes et au peuple. Au XIII siècle, Mechtilde de Magdebourg (1207-1282), qui, après avoir mené la vie de charité et de pénitence d'une béguine, acheva sa vie au couvent de Helfta, dont les moniales étaient dirigées par des maîtres dominicains, est l'auteur de traités mystiques en langue vulgaire, qui sont un témoignage de la force de ce mouvement ; le dialogue lyrique entre l'âme et les sens, puis entre l'âme et le Seigneur, se termine par une effusion sur «l'amour p424 éternel qui ignore la mort » ${ }^{921}$. A la fin du siècle, en 1290, le provincial dominicain de Germanie, Hermann de Minden, prescrivait des prédications dans les couvents de femmes ${ }^{922}$. C'est dans pareil milieu que se forme le mysticisme spéculatif des deux maîtres dominicains, Dietrich

921 Jeanne AnCELET-HustaCHe, CCLVIII, p. 115-120.
922 Denifle, CCL. 
de Freiberg (mort en 1310) et maître Eckart (1260-1327), qui, venu de l'inspiration de Denys, du Livre des Causes et de Jean l'Érigène, a exprimé un trait essentiel de la pensée allemande.

Saint Augustin et Proclus, tels sont ceux qui ont inspiré à maître Dietrich son interprétation mystique de la théorie de l'intellect agent ; cet intellect, émané de Dieu, est « un individu, un être singulier qui se multiplie selon la multiplication de ceux dont il est de principe ${ }^{923}$ ». Il est, en même temps, selon le mot augustinien, la partie secrète de l'âme (abditum mentis) d'où viennent science, vision et intelligence. C'est par le moyen de l'intellect agent que l'intellect possible passe à l'acte et saisit les intelligibles ; cette action aboutit non à une abstraction à partir des données sensibles, mais à une vision des règles éternelles et de la vérité immuable présente au secret de l'âme. Ce n'est pas par une nécessité naturelle, comme chez les Arabes, mais c'est par une grâce et une volonté providentielle que l'intellect agent est devenu forme de l'intellect possible ; de sorte que la vision béatifique ne sera pas due, comme le pense saint Thomas, à une lumière incréée qui, surnaturellement, élève l'intellect possible en dehors de son acte intellectuel, mais à la lumière créée, augmentée encore par la grâce ${ }^{924}$. On voit à quel point est contraire à l'esprit thomiste cette indécision de frontière entre nature et surnature.

Table des matières

\section{II. \\ JEAN ECKART.}

p425 Jean Eckart, né en 1260, est entré de fort bonne heure chez les dominicains ; il a, dans l'ordre, d'importantes fonctions : il est élu provincial pour la Saxe en 1303, vicaire général pour la Bohême en 1307, provincial d'Allemagne en 1310, désigné pour une chaire à Paris en 1311 ; en 1314, il prononce des sermons en allemand à Strasbourg, et il est soupçonné de relations avec la secte des Beghards ; en 1326, à Cologne, commence contre lui un procès intenté par l'archevêque ; on fait une collection de propositions hérétiques tirées

\footnotetext{
923 KreBs, CCLIII, Appendice, p. J61.

924 KREBS, CCLIII, p. 70-80.
} 
de ses œuvres ; mais la condamnation ne fut portée qu'en 1329 ; il était mort deux ans avant, en 1327.

Les vingt-huit propositions condamnées affirment l'éternité du monde, créé par Dieu en même temps que son fils, la transformation, dans la vie éternelle, de la nature humaine dans la nature divine, l'identité parfaite entre l'homme saint et Dieu, l'unité parfaite et sans distinction de Dieu, le néant de toute créature, l'indifférence de toutes les œuvres extérieures, l'intellect incréé comme étant quelque chose de l'âme. Cette doctrine, par la place qu'elle donne à l'homme divin, rappelle celle de Jean Scot, et plusieurs hérésies qui se rattachent à lui. Pour en juger, l'on possède quatre questions, deux datant du premier séjour à Paris (1302), sur l'identité de l'intellect et de l'être en Dieu et chez les anges, deux de son second séjour (1311) sur le corps du Christ et sur l'éternité du mouvement, un Opus tripartitum connu par fragments, et les écrits allemands, Livre de la divine consolation et Sermons.

C'est une thèse connue de saint Thomas que, en Dieu, être et comprendre (esse et intelligere) sont une seule et même chose ; c'est à cette thèse que s'attaque Eckart : il part d'une proposition connue de Plotin et de Proclus : la cause ne doit ${ }_{\mathrm{p} 426}$ rien contenir de ce que contient l'effet. Dieu, étant le principe de tout être, ne doit point avoir d'être en lui ; mais (et sur ce point Eckart paraît abandonner le néoplatonisme), ce Dieu qui n'est pas être est intelligence: il renverse l'ordre de perfection généralement accepté qui subordonne l'être à l'intelligence ; « c'est l'intelligence qui occupe le premier degré dans les perfections, et ensuite l'être ». Sa preuve est que ce qui appartient à l'intelligence est un non-être : « Car si l'espèce qui est en l'âme était un être, par elle on ne connaîtrait pas la chose dont elle est l'espèce ; si elle était un être, elle conduirait à la connaissance d'elle-même et elle détournerait de la connaissance de la chose dont elle est espèce. » C'est donc même chose de dire que Dieu est au-dessus de l'être, qu'il est cause de l'être et qu'il est intelligence ${ }^{925}$.

Ses spéculations sur les anges confirment cette absolue différence entre l'intelligence et l'être ; il s'appuie sur le texte connu d'Aristote

925 Cf. textes dans R. N., 1927, p. 69-85 ; GALVANO DELla VolPE, CCLI, p. 116124. 
pour montrer que l'intelligence doit être, pour connaître, complètement vide de tout être ; l'acte intellectuel, indéterminé en lui-même, est déterminé d'après son objet et n'a pas d'être intrinsèque. L'image intellectuelle n'est pas davantage un être, puisqu'elle n'est ni une substance, ni un accident, étant dans l'âme comme en un lieu, non comme un sujet. Enfin notre acte intellectuel, ayant sa cause dans l'être, n'est pas l'être, en vertu de ce principe que la cause ne contient rien de ce que contient l'effet. L'intelligence est donc pour Eckart la plus haute forme de la réalité, ce qui allait aussi bien contre le volontarisme des Franciscains ${ }^{926}$ que contre le thomisme. De plus, étant tout à fait indéterminée, elle ne peut pas être, dans l'homme, une réalité différente de ce qu'elle est en Dieu. Il est impossible que l'intellect soit créé ; p427 "l'intellect est propre à Dieu ; autant donc chaque chose a d'intellect, autant elle a de Dieu, autant elle a d'un ou d'être ; monter jusqu'à l'intellect, c'est s'unir à Dieu ${ }^{927}$ "; la créature, c'est tout être qui est en dehors de l'intellect.

Eckart n'a pas toujours gardé le même langage que dans les Questions, mais il a gardé la même doctrine. Il pense comme Plotin ; selon celui-ci, puisque l'Un est le principe de tous les êtres, on doit dire qu'il n'est point ces êtres, puisqu'ils sont au-dessous de lui, mais on doit dire aussi qu'il est tous ces êtres, puisqu'ils viennent de lui. Dans les Questions, Eckart a préféré le premier langage ; il emploie le second lorsqu'il affirme dans l'Opus tripartitum : " Dieu est l'être »; sa raison principale est que «toute chose qui est a, par l'être et de l'être, tout ce qu'elle est ; si donc l'être est différent de Dieu, elle tient l'être d'autre chose que de Dieu ${ }^{928}$. " Et il n'y a là que des formules fort habituelles. Ce qui est particulier à Eckart, c'est l'usage qu'il en fait : dans la doctrine thomiste, la créature a un être dérivé, distinct de l'être du créateur et qui n'a avec lui que des rapports d'analogie. Eckart ignore cet être dérivé et analogue : l'être, chez lui, est comme d'un bloc ; donc la créature ou bien est identique à l'être, ou bien n'est rien du tout; il s'agit de savoir, dans ce cas, comment on interprétera

926 GRABMANN, CCLII, a imprimé, après les Questions d’Eckart, la réfutation qu'en fit le franciscain Gonsalve de Vallebone.

927 Sermon latin inédit dans Grabmann, CCLII, p. 81 ; GALVANO DELLA VolPE, CCLI, p. 145.

928 DeNIFLE, CCL, p. 537 ; cf. PfeIfFER, p. 263, 
l'existence de l'homme dans le monde, et son activité morale ou religieuse. C'est l'union de ce problème spéculatif et pratique qui fait l'originalité d'Eckart.

Dieu est « l'être pur et plein », sans mélange de multiplicité et de négation ; l'un lui convient donc, plus encore que le vrai ou le bien ; " l'unité désigne la moelle ou le sommet de l'être, l'être en lui-même, exclusion faite de toute négation »; l'un est donc « la négation de la négation »; toute créature a une contradiction en elle ; chacune refuse d'être l'autre ; Dieu ${ }_{\mathrm{p} 428}$ exclut, au contraire, toute altérité ; il est celui qui est. Dans cette indistinction absolue, Eckart introduit pourtant des distinctions de deux ordres, d'abord la distinction philosophique que Gilbert de la Porrée avait déjà faite entre la Déité et Dieu, puis la distinction dogmatique des trois personnes. La déité (Gottheit), c'est Dieu, abstraction faite de toutes ses relations, c'est l'un, dont on ne peut rien dire, le désert, l'abîme uniforme, l'immobile silence, la lumière qui s'écoule en elle-même ; en Dieu au contraire, il y a opération et activité et distinction de personnes. Pour bien saisir le sens de cette première distinction, il faut la concevoir comme l'envers de l'itinéraire mystique de l'âme : la divinité désigne le terme dernier de cet itinéraire, auquel Dieu est lui-même résorbé dans la divinité ; une distinction de ce genre chez Eckart se comprend moins comme la position de deux termes que dans le retour de l'un à l'autre,

Et c'est la remarque qu'il nous faudra faire sur toutes les distinctions qu'Eckart introduit dans l'être après avoir proclamé qu'il était sans distinction. Ce sont, si l'on peut dire, des distinctions évanouissantes qui ne rentrent pas dans la classification scolastique de distinctio realis, formalis ou rationis. Telle est aussi sa théorie de la Trinité : comme on l'a fait remarquer ${ }^{929}$, «l'unité du processus trinitaire y est plus accentuée que les distinctions de personnes ». Dans la génération du Fils par le Père et la procession du Saint-Esprit, Eckart voit seulement « l'être simple et seul revenant par tout lui-même sur tout luimême par un retour complet ». Le retour sur soi n'est rien ici, comme dans le livre Des Causes, que le séjour en soi ; les personnes ne sont que les moments d'un processus qui serait éternellement achevé ; il

${ }^{929}$ G. DELla VolPe, CCLI, p. 162. 
n'y a pas plus de distinctions entre les personnes que dans la nature divine.

Une autre multiplicité introduite en Dieu est celle des Idées p429 ou raisons des choses, qui existent dans le Verbe, parole de Dieu où s'expriment, idéalement, toutes les créatures ; ici encore Eckart insiste sur l'indivision effective du monde idéal ; les choses n'y ont pas leur être formel, avant d'être produites au dehors dans la création. Dans la création elle-même se retrouvera l'unité : « Dieu créateur affecte tout le créé de sa propre unité, de son égalité, de son indistinction »; il faut raisonner sur l'univers comme sur un organisme, dont toutes les parties sont un être unique ; «ce ne sont pas, dans le tout créé, les parties qui confèrent l'être à leur tout ; inversement, elles reçoivent l'être du tout, à travers le tout et dans le tout ». L'être donc appartient au tout et seulement au tout ; la partie, par elle-même, n'a pas d'être ; elle n'a d'être que rapportée au tout, et le tout est un et simple. Ainsi est encore reprise et résorbée la multiplicité des créatures ; Dieu est partout où est l'être ; " rien n'est aussi un et moins distinct que Dieu et tout le créé »; Eckart admet la thèse classique que être, vie ou sagesse ne se disent du Créateur et des créatures que par analogie ; mais ce n’est pas du tout pour conférer quelque être dérivé aux créatures ; la formule veut dire bien plutôt que « toute créature a, de Dieu et en Dieu, et non pas en elle-même, l'être, la vie et la sagesse, d'une manière positive et radicale ». Et c'est pourquoi l'on doit dire que les créatures n'ont aucun être et ne sont rien ; ce qui est limité, ce qui s'éloigne de l'être n’est rien. L’ubiquité de Dieu veut dire que « Dieu est tout entier en quelque créature que ce soit, en une comme en toutes »; aussi faut-il dire, contrairement à saint Thomas, qu'il aime toute chose également, parce que c'est lui-même qu'il aime en toutes.

Tout est commandé, dans ce système spéculatif, par cette maxime unique : l'unité de l'être ne subit aucune atteinte, aucune déchéance. S’il est très inspiré du néoplatonisme, il en a rejeté implicitement une thèse essentielle, c'est celle de la participation ; chez lui, il ne peut pas y avoir d'images multiples ${ }_{p 430}$ de l'être. Il n'a fait ainsi, il est vrai, que pousser à la rigueur une tendance qui est commune à tous les néoplatoniciens, la tendance à tout résorber dans le transcendant; il s'agit moins d'expliquer l'être qui est en dehors de l'être que de l'annuler dans la mesure où il refuse de se laisser résorber en lui. 
Aussi toute cette construction spéculative ne peut prendre son sens que par la vie mystique où se réalise effectivement cette annulation. Toute sa doctrine est dans ces paroles : " L'être du juste est identique à l'être de la justice ; juste et justice sont par le même être, ils jouissent du même être ; le juste, comme tel, tient et reçoit son être tout entier de la seule justice ${ }^{930}$. " Cette identité foncière du participant au participé est l'aspect d'un intellectualisme profond qui, toujours, dans un être, se refuse à saisir le sujet actif et ne veut en retenir que le contenu représentatif ; la raison est, pour lui, plus noble que la volonté ; " c'est elle qui reçoit Dieu lui-même dans son être propre et nu ». C'est que l'image ne peut rien posséder d'elle-même qui la distingue de son modèle. D'autre part, c'est avant et en dehors de toute volonté que Dieu s'est manifesté dans son Verbe : la production d'une image est une émanation immédiate. Ce qui est vrai de la génération du Fils est vrai de l'image que, d'après la Genèse, Dieu a imprimée en toute âme et qui constitue la plus intime partie de l'âme ; Dieu est en elle immédiatement, et elle est immédiatement en Dieu; elle coïncide avec le Fils, elle est le Fils lui-même; elle se confond avec Dieu comme la flamme d'un brasier avec celle qui l'a allumé ; il s'agit non d'une union, mais d'une unité, non d'une ressemblance, mais d'une identité. "L'âme hait la ressemblance ; elle n’aime pas la ressemblance comme elle est en elle et à cause d'elle ; elle l'aime à cause de l'un, qui est caché en elle... Le semblable, est p431 méchant et trompeur ; si j’étais un, je ne serais pas semblable ${ }^{931}$. "

Les augustiniens voyaient l'image de Dieu dans la trinité des puissances qu'ils trouvaient dans l'âme ; il en est tout autrement chez Eckart. Il y a bien dans l'âme une trinité de puissances, une trinité inférieure, la rationnelle, l'irascible et la concupiscible, et une triade supérieure, mémoire, intelligence et volonté. Mais l'image de Dieu est audessus de cette triade; c'est le fond (grunt), la lumière, l'étincelle (fünkelin) qui n'est pas du tout une puissance de l'âme mais son être même. L’âme, comme image, est incréée ; l'âme, douée de puissances, est au contraire multiple et créée. L'âme image est un être un et simple qui n’a aucun mode ni propriété. Eckart reprend l'idée plotinienne qu’il a pu connaître par Gundissalvi ; par sa partie supérieure,

930 Archiv., p. 507 ; cité par G. DELla VolPE, CCLI, p. 241.

931 Textes cités par G. DELla Volpe, p. 202-207 ; Archives, p. 163 et 184. 
l'âme reste dans l'éternité et n'a aucun rapport avec le temps ni avec le corps. Au-dessus des sens (Sinne), au-dessus de l'entendement (Verstendikeit) est la raison (Vernüftikeit), identique à l'étincelle, qui découvre l'identité de l'âme et de Dieu ${ }^{932}$.

La mystique est donc toute, comme chez Plotin, dans la connaissance de l'être éternel que nous sommes foncièrement et que nous restons éternellement ; elle n'est pas transmutation mais connaissance. Aussi la condition pratique qui s'impose à la vie religieuse est l'ascèse qui supprime les obstacles à cette connaissance, et avant tout la multiplicité. «L'âme est d'autant plus pauvre et misérable qu'elle s'attache à plus de choses. » Non seulement il faut se détacher de toute créature, se libérer de toute influence extérieure, devenir pauvre en esprit, mais être indifférent à toutes choses, fût-ce à l'intimité avec Dieu, à la sainteté et au règne de Dieu : virginité de l'âme, pureté du cœur, liberté du vouloir ${ }_{\mathrm{p} 432}$ ne s'obtiennent qu'à ce prix. Un corollaire de ces règles était le complet mépris des œuvres ; les œuvres, veilles, pénitences ou prières, ont rapport au temps et supposent un salut qui est un événement à venir et qui s'achète ; " l'acte extérieur n'est donc pas proprement bon ni divin, et Dieu ne l'opère ni ne l'engendre, puisqu'il n’opère que sans interruption de temps ». Le mérite des œuvres suppose que l'activité divine pourrait plus ou moins s'insérer dans le temps, ce qui serait revenir à la participation. Avec ces œuvres n'a rien de commun le but de l'âme, « qui est de trouver sa parfaite identité avec Dieu ; l'âme, en qui Dieu est né, n'est rien moins que Dieu ; il ne s'agit plus alors de connaître Dieu ni de l'aimer et en général de rien connaître ni de rien aimer, mais de se créer soi-même, à partir du fond de la divinité ${ }^{933}$ ». L'intellectualisme d'Eckart n'est donc, comme celui de Plotin, que provisoire ; il a pour but final l'être, non le connaître.

932 G. DELLA VOLPE, p. 208-216.

933 G. DELla Volpe, CCLI, p. 216-238. 


\section{Conclusion}

Le Moyen Age intellectuel, c'est-à-dire, Selon notre définition, l'époque où l'enseignement philosophique est donné par le clergé, régulier ou séculier, s'achève avec le $\mathrm{XIV}^{\mathrm{e}}$ siècle. $\mathrm{Au} \mathrm{XV}^{\mathrm{e}}$ siècle naissent des milieux intellectuels tout nouveaux, tels que les Académies italiennes, l'Académie platonicienne dans la Florence de Laurent de Médicis. l'Académie aldine à Venise, où se rencontrent laïques et clercs ; l'humanisme de Marsile Ficin, l'aristotélisme non chrétien de

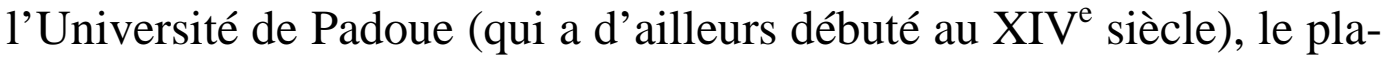
tonisme de Nicolas de Cuse, sont les signes d'un esprit nouveau : la forme littéraire change; elle évolue peu à peu vers le traité, vers l'essai, vers le dialogue ; elle cesse d'être purement dialectique.

Le Moyen Age philosophique a été une vaste expérience intellectuelle, qui, comme toutes les expériences du même genre, a été imposée par les circonstances, mais qui n’a pu être tentée que par des esprits vigoureux : cette expérience, c'est celle de l'introduction de la pensée rationnelle, issue de la Grèce, dans une civilisation chrétienne ; c'est, en gros, la solution du problème des rapports de la raison et de la foi. Mais il faut ici se défier des oppositions tranchées : nous ne connaissons pas d'état de la pensée religieuse chrétienne qui n’ait été lié à l'hellénisme, ne fût-ce que par la langue où elle s'exprimait, et le point de départ du Moyen Age, c'est la littérature patristique, où les Pères grecs et latins introduisent tant de la science p434 $_{4}$ et de la philosophie grecques. Le christianisme n’a donc jamais existé sans la philosophie. Il n'en est pas moins vrai que, dès le début du Moyen Age, on eut la conscience très nette d'une différence, allant parfois jusqu'à l'opposition, entre les lettres sacrées et la tradition profane ; mais en même temps, on sentait la nécessité d'user de la tradition profane (des sciences du trivium et du quadrivium et même de la morale rationnelle) pour donner consistance et forme à la vie chrétienne. Le pro- 
blème s'imposait donc à ces hommes d'Occident, moins cultivés mais plus vigoureux que les Orientaux, et qui répugnaient à laisser la pensée se fixer en un pur verbalisme.

La solution de ce problème fut cherchée dans deux directions différentes, qu'on pourrait appeler la direction anselmienne et la direction thomiste. Dans la première, la raison entre dans la substance même de la vie chrétienne et dans la destinée surnaturelle de l'homme ; intermédiaire entre la foi et la vision, elle nous fait pénétrer dans le domaine des choses spirituelles; elle nous élève vers notre fin. Dans la seconde, qui est dominée par le grand fait de l'introduction de la philosophie aristotélicienne comme une sorte de bloc rationnel et indépendant de la foi, la raison a le pouvoir de constituer, d'elle-même et de sa propre initiative, une philosophie autonome : l'œuvre d'Aristote existe, indépendamment de la révélation chrétienne ; en revanche, la raison est spontanément dirigée vers les choses sensibles; si, de ces choses, elle s'élève jusqu'à l'affirmation d'une existence spirituelle, ce n'est que par une inférence qui en est tirée. Dans ces conditions, elle garde encore un rapport avec la foi, mais un rapport extérieur t la foi se fait le guide de la raison, soit en lui interdisant certaines conclusions que le raisonnement semble autoriser, soit en l'élevant vers la réalité divine, qu'elle ne fait que pressentir. Remarquons que, chez saint Anselme comme chez saint Thomas, il s'agit moins de la solution d'un problème abstrait que d'une direction d'ensemble dans la vie spirituelle.

p435 Dans l'une et dans l'autre direction, qui sont suivies avec rigueur du $\mathrm{XI}^{\mathrm{e}}$ au XIII ${ }^{\mathrm{e}}$ siècle surtout, il apparaît, au XIV ${ }^{\mathrm{e}}$ siècle, qu'il y a eu un complet échec. On voit se dissocier les éléments du tout que les classiques du Moyen Age avaient essayé de former : le nominalisme apparaît, affirmant en même temps l'impossibilité, pour la raison, de s'élever jusqu'à l'existence de Dieu, et la nécessité, pour elle, d'arriver à une conception de la nature que l'on oppose à celle qui était liée traditionnellement à la foi chrétienne. Cette discordance interne est comme symbolisée par l'opposition que l'on voit éclater alors (bien qu'elle fût préparée dès le XII ${ }^{\mathrm{e}}$ siècle) entre la vie intellectuelle et la vie mystique.

En posant, avec une telle continuité et une telle passion, le problème de la raison, le Moyen Age a maintenu le trait essentiel de notre 
civilisation occidentale, qui a commencé à l'est de la Méditerranée, au $\mathrm{VI}^{\mathrm{e}}$ siècle avant notre ère, dans les cités ioniennes, je veux dire l'effort pour faire progresser aussi loin que possible la raison humaine : mais il y a plus, le problème de la nature et des limites de la raison, problème qui a été une condition du développement de la pensée moderne, n'a pu se poser qu'après une époque où l'on avait réfléchi sur les rapports de la raison avec la vie spirituelle dans son ensemble, mieux, où l'on avait senti la nécessité vitale de cette question ; et s'il est vrai qu'au Moyen Age l'on ne pouvait même pas pressentir le rationalisme moderne, parce que l'on avait, de la raison, une conception trop verbale, trop étroite, insuffisamment nourrie par la conscience de ses progrès effectifs, il n'en reste pas moins que son résultat global est d'avoir incité la raison à prendre plus parfaitement conscience d'ellemême et de sa nature. 


\title{
Bibliographie $^{934}$
}

\author{
GÉNÉRALITÉS
}

A. - REVUES

ANNALES DE PHILOSOPHIE AP

Annales de philosophie chrétienne APG

Archiv für Litteratur und Kirchengeschichte des Mittelalters $\quad$ ALK

Archives d'histoire littéraire et doctrinale, publiées par Wilson et Théry AHL

Archiv für die Geschichte der Philosophie AGP

Byzantinische Zeitschrift $\quad$ BZ

Byzantion B

Gregorianum G

Philosophisches Jahrbuch PJ

Revue des études franciscaines $\quad$ REF

Revue de métaphysique et de moraleHMM

Revue néoscolastique $\mathbf{R N}$

Revue de philosophie RP

Revue philosophique RPL

Revue des sciences philosophiques et théologiques RSPT

Sophia S

\section{B. - RECUEILS DE TEXTES ET DE COMMENTAIRES}

(I) BARACH et WRÖBEL, Bibliotheca philosophiae mediae aetatis

934 Les meilleurs instruments bibliographiques pour l'histoire de la philosohie du Moyen Age sont, jusqu'en 1925, le Grundriss der Geschichte der Philosophie d'UEBERWEG, tome II, $11^{\mathrm{e}}$ édition, et, à partir de 1925, les admirables bibliographies périodiques de la Revue des Sciences philosophiques et théologiques. 


\section{Émile Bréhier}

La philosophie du Moyen âge

(II) Beiträge zur Geschichte der Philosophie des Mittelalters. Texte und Untersuchungen. Herausgegeben von Prof.-Dr BAUEMKER, München (depuis 1891 jusqu'en 1941)

(III) HAUREAU, Notices et extraits de quelques manuscrits de la bibliothèque nationale, Paris, 1890-1893, 6 vol.

(IV) L. MAssignon, Recueil de textes inédits concernant la philosophie musulmane, Paris, 1929

(V) Patrologia graeca, cursus completus, accurante Migne

(VI) Patrologia latina, cursus completus, accurante Migne

(VII) Quellen und Untersuchungen zur lateinischen Philologie des Mittelalters

\section{C. - OUVRAGES D’ENSEMBLE}

(VIII) Cl. Bauemker, Die christliche Philosophie des Mittelalters, in : Allgemeine Geschichte der Philosophie, Leipzig, Teübner, 2e éd., 1913.

(IX) E. BAKER, Mediaeval Contributions to modern civilisation, London, Arrap, 1921.

(X) Ad. Bonilla y San Martin, Historia de la filosofia espanola, tome I, Madrid, 1908.

(XI) U. ChEVALIER, Biobibliographie (dans Répertoire des sources historiques du Moyen Age, tome I, 1894) .

(XII) O. DitTRICH, Geschichte der Ethik, tomes II et III, Leipzig, 1925.

(XIII) A. DufourcQ, Histoire moderne de l'Église, tome VI ; Le Christianisme et l’organisation féodale (1049-1294), Paris, 1932.

(XIV) Dictionnaire de théologie catholique, de VACAND.

(XV) P. DuHEM, Le système du monde, de Platon à Copernic, Paris, 5 vol. 19131917.

(XVI) Ad. HARNACK, Lehrbuch der Dogmengeschichte, $3^{\mathrm{e}}$ éd., 3 vol., 1894.

(XVII) A. FAUST, Der Möglichkeitsgedanke, tome II, Heidelberg, 1932.

(XVIII) E. GILSOn, La philosophie au Moyen Age, Payot, 3éd., 1944.

(XIX) E. GILson, Études de philosophie médiévale, Strasbourg, 1921.

(XX) E. GILSON, L’Esprit de la philosophie médiévale, Paris, Vrin, 1932, 2 vol.

(XXI) Encyclopédie de l'Islam (depuis 1907) .

(XXII) Grabmann, Geschichte der scholastischen Methode, 2 vol., 1909-1911.

(XXIII) Grabmann, Mittelalterliches Geistesleben, München, 1926.

(XXIV) HAUREAU, Histoire de la philosophie scolastique, 2 vol., Paris.

(XXV) K. JoEL, Wandlungen der Weltanschauung, Tübingen, 1928. 


\section{Émile Bréhier}

La philosophie du Moyen âge

(XXVI) F. PICAVET, Essai d'une histoire générale et comparée des philosophies médiévales, Paris, Alcan, 1905, 2e éd., 1913.

(XXVII) Philosophia perennis, Abhandlungen über die Geschichte der Philosophie, Regensburg, 1930.

(XXVIII) PrantL, Geschichte der Logik im Abendlande.

(XXIX) J. TiXeront, Histoire des dogmes dans l'antiquité chrétienne, $8^{\mathrm{e}}$ éd., 3 vol., 1915.

(XXX) Ueberweg, Grundriss der Geschichte der Philosophie, $\mathrm{II}^{\mathrm{er}}$ Theil, $11^{\mathrm{e}}$ éd. par M. Baumgartner, Berlin, 1925.

(XXXI) M. DE WuLF, Histoire de la philosophie médiévale, $6^{\mathrm{e}}$ edit., Louvain, 1936.

(XXXII) M. DE WuLF, Histoire de la philosophie en Belgique, 1910.

\section{INTRODUCTION.}

(XXXIII) G.-L. BuRR, How the middle Age got their name, Americ. Histor. Review, vol. XX, p. 813.

(XXXIV) Christopher Dawson, Les origines de l'Europe, trad. Halphen, Paris, 1934.

\section{PREMIÈRE PARTIE}

\section{Chapitre premier.}

(XXXV) R. Bonnaud, L'éducation scientifique de Boèce, Speculum, vol. IV, 1929.

(XXXVI) J. BIDEZ, Boèce et Porphyre, Revue belge de philosophie et d'histoire, 1923 p. 189-201.

(XXXVII) R. CARTON, Le Christianisme et l'Augustinisme de Boèce, RP, 1932, p. 88.

(XXXVIII) Fr. KLIngneR, De Boethii Consolatione philosophiae, Philologische Untersuchungen, 1921.

(XXXIX) J. Nitzsch, Das System des Boethius und die ihm zugeschriebenen theologischen Schriften, Berlin, 1860.

(XL) A. Oltramare, Les origines de la diatribe romaine, Paris, 1926.

\section{Chapitre II.}

(XLI) J. DE GHELLINCK, L'entrée de Jean de Damas dans le monde littéraire occidental, BZ, 1912, p. 448.

(XLII) SAUTER, Die peripatetische Schule bei den Syrern und Arabern, AGP, XVII, 1904. 


\section{Émile Bréhier}

La philosophie du Moyen âge

(XLIII) Meyerhof, Sur les versions arabes et syriaques de Galien, B, III, 1928.

(XLIV) KAYSER (traduction du livre anonyme) : Das Buch von der Erkenntniss der Wahrheit oder der Ursache aller Ursachen, Strasbourg, 1893.

\section{DEUXIÈME PARTIE}

\section{Chapitre premier.}

(XLV) H.-X. ARQUILLIERE, L'Augustinisme politique, Essai sur la formation des théories politiques du Moyen Age, Paris, 1934.

(XLVI) G. BRUnHES, La foi chrétienne et la philosophie au temps de la Renaissance carolingienne, Paris, 1903.

(XLVII) J. ENDRES, Ueber den Ursprung und Entwicklung der scholastischen Methoden, PJ, t. II.

(XLVIII) J. ENDRES, Studien zur Geschichte des Frühscholastik, PJ, t. XXV et XXVI.

(XLIX) L. HalPhen, Les Barbares (Peuples et civilisations, vol. V) , Paris, 1926.

(L) A. SCHNEIDER, Die Erkenntnisslehre bei Beginn der Scolastik, Fulda, 1921.

(LI) A. VAn DE Vyver, Les Étapes du développement philosophique du Haut Moyen Age, Revue Belge de Ph. et d'Hist., VIII, 1929. (Cf. Archeion, vol. XIX, 1937, p. 12-16).

\section{Chapitre II.}

(LII) Dom Cappuyns, Jean Scot Erigène. Sa vie, son œuvre, ses écrits, 1933.

(LIII) J. DRÆSEKE, Zu Scotus Erigena, Zeitschr. f. wissensch. Theol., XLVI et XLVII.

(LIV) J. DRÆSEKE, Scotus und dessen Gewährsmänner in «de Divisione naturae », Bonwetsch Seebergs Studien, IX, 2, 1902.

(LV) R. P. JACQUIN, Le néoplatonisme de Jean Scot, RSPT, I, 1907.

(LVI) E. K. RAND, Johannes Scotus (Quellen und Unt. zur lat. Philol. des M. A., I, 1906) .

(LVII) P.-G. THERY, Scot Erigène traducteur de saint Denys, Bulletin du Cange, 1931.

(LVIII) P.-G. THERY, Études dionysiennes, I. Hilduin traducteur de Denys, Paris, Vrin, 1932.

(LIX) ENDRES, Fredegisus und Candidus. Ein Beitrag zur Geschichte Frühscolastik, PJ, XIX, 1912.

(LX) Gerberti, Opera mathematica, éd. Bubnov, Berlin, 1899.

(LXI) S. Hellmann, Sedulius Scotus, Quell, und Unters., I I Band, 1906.

(LXII) VAN DE VYVER, Les œuvres inédites d'Abbon de Fleury, Revue bénédictine, 1935. 


\section{Émile Bréhier}

La philosophie du Moyen âge

\section{Chapitre III.}

(LXIII) De BOER, Zu Kindi und seiner Schule, AGP, XIII.

(LXIV) A. BorIsOn, La version latine de la Théologie d'Aristote, Mélanges Kratchovski, Leningrad, 1930 (Cf. Paul Kraus, Abstracta Islamica, Rev. des Études islam., 1934) .

(LXV) DieTERICI, Die Philosophie der Arabern im X. Jahrhundert, 4 vol., Leipzig, 1865-1870.

(LXVI) L. GAUTHIER, Scolastique musulmane et scolastique chrétienne, Rev. d'Hist. de la Philos., 1928.

(LXVII) M. Horten, Die Philosophie des Islams, München, 1934.

(LXVIII) I. MAKDOUR, La place d'Al Farâbi dans l'école philosophique musulmane, Paris, 1934.

(LXIX) J. POLLAK, Entwicklung der arabischen und jüdischen Philosophie, AGP, XVII, 1904.

(LXX) Aug. Perier, Yayha ben Adi, un philosophe arabe chrétien du $X^{e}$ siècle, Paris, 1920 ; Petits traités (texte et traduction), Paris, 1920.

(LXX bis) SALOMon Pines, Beiträge zur islamischen Atomenlehre, Berlin, 1936.

(LXXI) D. Neumark, Geschichte der jüdischen Philosophie, Bd. I, Berlin, 1908.

(LXXII) C. SAUTER, Die peripatetische Philosophie bei den Syrern und Arabern, Archiv, f. die Gesch. d. Phil., XVII.

(LXXIII) Ventura, La philosophie de Saadja Gaon, Paris, 1934.

(LXXIV) $\mathrm{M}^{\mathrm{me}}$ LOT-BORODINE, La doctrine de la déification dans l'Église grecque jusqu'au XI ${ }^{\mathrm{e}}$ siècle, Rev. Hist. des Rel., 1932.

(LXXV) I. MAKDOUR, L'Organon d'Arisfote dans le monde arabe, Paris, 1934.

(LXXVI) S. Horowitz, Die Stellung des Aristoteles bei den Juden des Mittelalters, Leipzig, 1911.

(LXXVII) J. GutTmann, Die Religions philosophie des Saadja, Göttingen ; 1882.

\section{TROISIÈME PARTIE}

Chapitre premier.

(LXXVIII) ARQUILLIERe, Saint Grégoire VII, Paris, 1934.

(LXXIX) L. BreHIER, L'Église et l'Orient au Moyen Age, 4 e éd., 1921.

\section{Chapitre II.}

(LXXX) Clerval, Les Écoles de Chartres au Moyen Age, 1895.

(LXXXI) PFIster, De Fulberti Carnotensis episcopi vita et operibus, Paris, 1885. 


\section{Émile Bréhier}

La philosophie du Moyen âge

(LXXXII) Pare, A. Brunet, P. Tremblay, La Renaissance au XII ${ }^{e}$ siècle, Paris, 1934 (refonte de l'ouvrage de Robert) .

(LXXXIII) G. RoBert, Les Écoles et l'enseignement de la théologie pendant la première moitié du XII ${ }^{\mathrm{e}}$ siècle, 1909.

(LXXXIV) C. BERnARD, De l'enseignement élémentaire en France aux XI ${ }^{\mathrm{e}}$ et $\mathrm{XII}^{\mathrm{e}}$ siècles, Paris, 1894.

(LXXXV) J. EnDREs, Die Dialetkiker und ihre Gegner im XI Jahrhundert, Phil. Jahrb., 1906, 1913.

(LXXXVI) J. ENDRES, Manegold von Lautenbach, HJ, XXV, 1904.

(LXXXVII) J. DE GHELLINK, Réminiscences de la dialectique de Marius Victorinus dans les conflits idéologiques des $\mathrm{XI}^{\mathrm{e}}$ et XII ${ }^{\mathrm{e}}$ siècles, Rev. néosc, 1911.

(LXXXVIII) HeurteVEnT, Durand de Toarn et les origines de l'hérésie bérengarienne, Paris, 1912.

(LXXXIX) EBersolt, Essai sur Bérenger de Tours et la controverse sacramentaire au XI ${ }^{\mathrm{e}}$ siècle, Rev. Hist, des Relig., XLVIII, 1903.

(XC) D.-M. MAtronola, Un Testo inedito di Berengario di Tours e il Concilio del 1079, Milana, 1936.

(XCI) BAUEMKER, Die Lehre Anselms von Canterbury, über den Willen und seine Wahlfreiheit, Münster, 1912.

(XCII) Domet DE Vorges, Saint Anselme, 1902.

(XCIII) J. DRÆSEKE, Sur la question des sources d'Anselme, Rev. de philosophie, 1901.

(XCIV) Ch. Filliatre, La philosophie de saint Anselme, 1920.

(XCV) E. GILsOn, Sens et nature de Vargument de saint Anselme, AHL, VIII, 1934.

(XCVI) A. Koyre, L’idée de Dieu dans la philosophie de saint Anselme, Paris, 1923.

(XCVII) Ch. DE Remusat, Saint Anselme de Cantorbery, $2^{\mathrm{e}}$ éd., Paris, 1868.

(XCVIII) A. Stolz, Zur Theologie Anselme im Proslogion (Catholica, II, 1933) .

(XCIX) F. PICAVET, Roscelin, philosophe et théologien, d'après la légende et d'après l'histoire, Paris, 1896.

(C) J. ReINERS, Der Nominalismus in der Frühscolastik, Beiträge, t. VIII, 1910.

(CI) Adelard v. BATHS, Traktat De eodem et diverso, herausg. von Wilner, Beiträge, vol. IV, 1903.

(CII) E. Gilson, La cosmogonie de Bernardus Silvestris, AHL, 1928, p. 5 (Cf. GILson, Le Moyen Age et le naturalisme antique, AHL, VII, 1933) .

(CIII) J. DE GHELLINK, Le mouvement théologique du XII ${ }^{\mathrm{e}}$ siècle, Paris, 1914.

(CIV) V. Cousin, Ouvrages inédits d'Abélard, Paris, 1836.

(CV) H. DeHove, Qui praecipui fuerint labente seculo XII temperati realismi antecessores, Lille, 1908. 


\section{Émile Bréhier}

La philosophie du Moyen âge

(CVI) G. LefEVRe, Les variations de Guillaume de Champeaux (Travaux de l’Université de Lille, 1898) .

(CVII) HeITZ, La philosophie et la foi dans l'œuvre d'Abélard, RSPT, 1907.

(CVIII) Ch. DE REMusAt, Abélard, Paris, $2^{\mathrm{e}}$ éd., 1855.

(CIX) E. Michaud, Guillaume de Champeaux et les écoles de Paris du XII ${ }^{\mathrm{e}}$ siècle, Paris, 1867.

(CX) E. GILson, La théologie mystique de saint Bernard, Paris, 1934.

(CXI) P. LAsserre, Un conflit religieux au XII ${ }^{\mathrm{e}}$ siècle, Abélard contre saint Bernard, Paris, 1930.

(CXII) Rousselot, Pour l'histoire du problème de l'amour au Moyen Age, Münster, 1908.

(CXII bis) Guillaume DE SAINT-THIERRY, Un traité de la Vie Solitaire, Introduction, édition et traduction par M. M. Davy, 2 vol., Paris, 1940.

(CXIII) M. LENGLART, La théorie de la contemplation mystique dans l'œuvre de Richard de Saint- Victor, Paris, 1936.

(CXIV) M. M. DAVY, Un traité de l'amour du XII ${ }^{\mathrm{e}}$ siècle (Pierre de Blois) , Paris, 1932.

(CXV) B. Haureau, Nouvel examen de l'édition des œuvres de Hugues de SaintVictor, Paris, 1859.

(CXVI) R.-M. MARTIN, Euvres de Robert de Melun, Louvain, 1932.

(CXVII) F. Protols, Pierre Lombard, Paris, 1881.

(CXVIII) J. WARICHEZ, Les Disputationes de Simon de Tournai, Louvain, 1932.

(CXIX) R. ARnOU, Quelques idées néoplatoniciennes de David de Dinant, Philosophia perennis, I, 113, Regensburg, 1930.

(CXX) R. DE VAuX, Sur un texte retrouvé de David de Dinant, RSPT, XXII, 1933.

\section{Chapitre III}

(CXXI) H. BIDEZ, Psellos et le Timée, Revue de philosophie, 1905.

(CXXII) H. BIDEZ, Catalogue des manuscrits alchimiques grecs, tome VI (Psellos), Bruxelles, 1928.

(CXXIII) B. CARRA DE VAuX, Gazali, Alcan, 1903.

(CXXIV) B. CARra de VauX, Avicenne, Alcan, 1900.

(CXXV) DiETERICI, Al Farabis philosophische Abhandlungen, Leyde, 1890.

(CXXVI) L. GAUThIER, La théorie d'Ibn Rochd sur les rapports de la religion et de la philosophie, Paris, 1909.

(CXXVII) GARDNER, Al Ghazali’s Lampas luminum (trad.) , Londres, 1924.

(CXXVIII) Munk, Mélanges de philosophie juive et arabe, Paris, 1859 (réimprimé, 1927). 
(CXXIX) Miguel Asin Palacios, En justo medio en la creancia, compendio de teologia dogmatica d’Algazel (traduction) , Madrid, 1929.

(CXXX) RENAN, Averroès et l'Averroïsme, 1852.

(CXXXI) D. SAliBA, Étude sur la métaphysique d’Avicenne, Paris, 1926.

(CXXXII) K. Svoboda, La démonologie de Psellos, Brno, 1927.

(CXXXIII) P. TANnERY, Sur les nombres chez Psellos, Rev. des Et, grecques, 1892.

(CXXXIV) Ch. Zervos, Le philosophe néoplatonicien Michel Psellos, Paris, 1919.

(CXXXV) J. Guttmann, Die Philosophie des Salomon von Gebirol, Göttingen, 1889.

(CXXXVI) J. GuTTMAnN, Die philosophischen Lehren des Isaak ben Salomon Israëli, Münster, 1911.

(CXXXVI) J.-T. MucKLe, Isaac's Israëli Definition of Truth, AHL, 1933.

(CXXXVII) L. LEVY, Maïmonide, Paris, 1911.

(CXXXVIII) Avicebron, Fons Vitae (trad, latine de Dominique Gondisalvi), Beiträge I.

\section{QUATRIÈME PARTIE}

\section{Chapitre premier.}

(CXXXIX) M. D. CHEnu, La théologie comme science au XIII ${ }^{\mathrm{e}}$ siècle, AHL, 1927.

(CXL) H. Denifle et Chatelain, Chartularium universitates parisiensis (12001350), Paris, 1889-1891.

(CXLI) H. DenIFLE, Die Universitäten des M. A. bis 1400, Bd. I, Berlin, 1885.

(CXLII) M. GorCE, L’Essor de la pensée au Moyen Age, 1933.

(CXLIII) B. LANDRY, L’idée de chrétienté chez les scolastiques du XIII ${ }^{\mathrm{e}}$ siècle, 1929.

\section{Chapitre II.}

(CXLIV) A. et Ch. JouRdAIn, Recherches critiques sur l'âge et l'origine des traductions d'Aristote, $2^{\mathrm{e}}$ éd., Pâtis, 1843.

(CXLV) Louis Halphen, Les Universités au XIII siècle, Revue Historique, CLXVII, 1931.

(CXLVI) Dominicus Gundissalinus, De Immortalitate animae, éd. G. Bülow, Beiträge, II ; De divisione philosophiae, Beiträge, IV.

(CXLVII) Et. GILson, Les sources gréco-arabes de l'augustinisme avicennisant, AHL, 1929.

(CXLVIII) B. LANDRY, L’originalité de Guillaume d'Auvergne, RHP, 1929. 


\section{Émile Bréhier}

La philosophie du Moyen âge

(CXLIX) A. Masnovo, Guglielmo d'Auvergne, Riv. di filos. neosc, 1927.

(CL) J. ROHMER, La théorie de l'abstraction dans l'école franciscaine, AHL, III, 1928.

(CLI) A. MAsnovo, Da Guglielmo d'Auvergne a San Thomaso d'Aquino, 2 vol, Milano, 1930.

(CLII) M. DE WULF, L'augustinisme « avicennisant », Revue néosc, 1931.

(CLIII) J. EnDRES, Des Alexander v. Hales Leben und psychologische Lehren, Philos. Jahrb,, 1888.

(CLIV) Alexandre DE HALES, Summa, 4 vol., Venise, 1575.

\section{Chapitre III.}

(CLV) Saint BONAVENTURE, Opera, 10 vol., éd. Quaracchi, 1882-1902.

(CLVI) EBERLE, Die Ideenlehre Bonaventuras, Strasbourg, 1911.

(CLVII) E. GILSON, Saint Bonaventure, Paris, 1924.

(CLVIII) Jules D’ALBI, Saint Bonaventure et les luttes doctrinales.

(CLIX) J.-M. BISSEN, L'exemplarisme divin selon saint Bonaventure, Paris, 1931.

(CLX) Menneson, La connaissance de Dieu d'après saint Bonaventure, RP, 1910

(CLXI) R.-P. SYMPHORIEN, L'Itinéraire de l'esprit vers Dieu chez saint Bonaventure, Annales Institut Louvain, 1924.

\section{Chapitre IV.}

(CLXII) Albert le Grand, Euvres, éd. Borgnet, 36 vol., Paris, 1890.

(CLXIII) U. DÆHNERT, Die Erkenntnislehre des Albertus Magnus, Leipzig, 1934.

(CLXIV) K. SCHMIEDER, Alberts des Grossen Lehre vom natürlichen Gotteswissen, Freiburg, 1932.

(CLXV) A. SCHNEIDER, Die Psychologie Alberts d. G., Beiträge, vol. IV .

(CLXVI) Pelster, Kritische Studien zum Leben und zu den Schriften Alberts des Grossen, Freiburg, 1920.

(CLXVII) R. ARnou, De quinque viis S. Thomae ad demonstrandam Dei existentiam, Rome, 1932.

(CLXVIII) J. BAumann, Die Staatslehre d. h. Thomas v. Aquino, Leipzig, 1909.

(CLXIX) Chossat, L'averrö̈sme de saint Thomas, Arch. de Ph., vol. IX, cahier III, p. 129.

(CXX) J. DuRANTEL, Le retour à Dieu dans la philosophie de saint Thomas, Paris, 1919.

(CLXXI) J. DuRAntel, Saint Thomas et le pseudo-Denys, Paris, 1919. 


\section{Émile Bréhier}

La philosophie du Moyen âge

(CLXXII) A. FOREST, La structure métaphysique du concret selon saint Thomas, Paris, 1931.

(CLXXIII) Et. GILson, Le Thomisme, nouvelle édit., 1923.

(CLXXIV) Et. GILSON, Pourquoi saint Thomas a critiqué saint Augustin, AHL, 1926.

CLXXV) M. Grabmann, Die Lehre des Jacob v. Viterbo, Philosophia perennis, I, p. 230.

(CXXVI) G. SAITTA, Il carattere della filosofia tomistica, Firenze, 1934.

(CLXXVII) J. LAPORTE, Le libre arbitre et l'attention chez saint Thomas, Revue de Métaph., 1931, 1932, 1934.

(CLXXVIII) MANDOnNET, Les écrits authentiques de saint Thomas, Paris, 1910.

(CLXXIX) J. MARITAIN, Sept leçons sur l'être, 1933.

(CLXXX) Michel, La notion thomiste de bien commun, Paris, 1932.

(CLXXXI) L. NoËL, La présence de l'intelligible à la conscience selon saint Thomas et Cajetan, Philosophia perennis, I, p. 161.

(CLXXXI bis) I. Paulus, Le caractère métaphysique des preuves thomistes de l'existence de Dieu, AHL, 1934.

(CLXXXII) Et. Gilson, La servante de la théologie, Et. de Phil, médiévale, p. 30.

(CLXXXIII) Et. GiLson, La signification historique du thomisme, Et. de Phil, med., p. 76.

(CLXXXIV) L. LACHANCE, Le Concept de droit selon Aristote et saint Thomas, Paris, 1933.

(CLXXXV) Roland-Gosselin, Le De Ente de saint Thomas (édition et introduction), Le Saulchoir, 1926.

(CLXXXVI) P. Synave, Le catalogue officiel des œuvres de saint Thomas, AHL, 1928, p. 25.

(CLXXXVII) M. WitTMAnN, Neuplatonisches in der Tugendlehre des Thomas d'Aquin, Philosophia perennis, I, 167.

(CLXXXVIII) J. ZEILLER, L'idée de l'État dans saint Thomas.

(CLXXXIX) Grabmann, Die Werke des hl. Thomas von Aquin, Beiträge XXII, 1931.

(CXC) Mandonnet et Detrez, Bibliographie thomiste (2219 numéros), Le Saulchoir, 1921.

(CXCI) Rousselot, L’intellectualisme de saint Thomas, Paris, $2^{\mathrm{e}}$ éd., 1924? 3e éd., 1936.

(CXCII) L. Sertillanges, Saint Thomas d'Aquin, Paris, 1908.

(CXCIII) A.-M. Festugiere, La notion du péché chez saint Thomas, I, II, 71 et sa relation avec la morale aristotélicienne. The New Scholasticism, V, 1931. 


\section{Émile Bréhier}

La philosophie du Moyen âge

\section{Chapitre V.}

(CXCIV) Et. GILSON, La doctrine de la double vérité (appends : textes de Jean de Jandun), Et. de ph. méd., p. 51.

(CXCV) M. GrabmanN, Neuaufgefundene Quaestiones Sigers von Brabant, Miscellanea Ehrle, vol. I, 1924.

(CXCV bis) Grabmann, Die Opuscula de Summobono und De Sompniis des Boetius von Dacia, AHL, 1931.

(CXCVI) P. MAndonnet, Siger de Brabant (I. Textes. II. Études critiques), Louvain/1911, 1908.

(CXCVII) P. MANDONnEt, Note sur Boèce de Dacie, RSPT, XXII, 1933.

(CXCVIII) Roland-Gosselin, Sur la double rédaction par Albert le Grand de sa dispute contre Averroès, Archives, 1926.

(CXCIX) D. SALMAN, Albert le Grand et l'averroïsme latin, RSPT, 1935, p. 38.

(CC) R. DE VAuX, La première entrée d'Averroès chez les Latins, RSPT, XXII, 1933.

(CCI) R. BARsotTI, Sigeri Brabantii de Æternitate mundi opuscula, Münster, 1933.

(CCII) VAn SteEnBerghen, Siger de Brabant d'après ses œuvres inédites, t. I, Louvain, 1931.

(CCIII) M.-D. CHENU, La première diffusion du thomisme à Oxford, Klapwell, AHL, 1928.

\section{Chapitre VI.}

(CCIV) DANIELS, Quellenbeiträge zur Geschichte des Gottesbeveisen im XIII Jahrb., 1909.

(CCV) EHRLE, Der Augustinismus und der Aristotelismus in der Scholastik gegen Ende des XIII Jahrh., ALK, 1889.

(CCVI) Et. GILsON, Sur quelques difficultés relatives à l'illumination augustinienne, RN, XXXVI, 1934, p. 321.

(CCVI bis) Et. GiLson, Roger Marston : un cas d'augustinisme avicennisant, AHL, 1933.

(CCVII) GlorieuX, La littérature quodlibétique de 1260-1320, Bibliothèque thomiste, t. V.

(CCVIII) E. HocedeZ, Gilles de Rome et Henri de Gand, Gr., 1927.

(CCIX) KREBS, Un traité de Thierry de Fribourg, RN, 1911, p. 519.

(CCX) E. LONGPRE, Thomas d'York et Mathieu dy Aquasparta, AHL, 1926.

(CCXI) E. HocEDEZ, Richard de Middleton, Louvain, 1925.

(CCXII) O. LotTIN, La notion de libre arbitre dans la jeune école dominicaine d'Oxford, RSPT, XXIV, 1935, p. 268. 
(CCXIII) O. LotTin, Le libre arbitre au lendemain de la condamnation de 1277, RN, XXXVIII, 1935, p. 213.

(CCXIII bis) J. PAulus, Henri de Gand et l'argument ontologique, AHL, X, 1936.

(CCXIV) A. Pelzer, Godefroi de Fontaines, RN, 1913, p. 365.

(CCXV) ScHOLZ, Édition de Gille de Rome, De ecclesiastica potestate.

(CCXVI) H.-M. DE Wulf, Le De Unitate de Gille de Lessines, Louvain, 1904.

(CCXVII) EHrLe, G, Peckham über den Kampf des Augustinismus und Aristotelismus in der zweiten Hälfte des 13. Jahrh., Ztschr. f. Kath. Theol., XIII, 1899.

(CCXVII bis) Fr. STEgmulLeR, Der Traktat des Robert Kilavardby, De imagine et vestigio Trinitatis, AHL, X, 1936.

\section{Chapitre VII.}

(CCXVIII) R. BACON, Opera hactenus inedita, éd. Brewer, 1859.

(CCXIX) R. BACon, Opus majus, éd. Bridges, 3 vol., Oxford, 1897-1900.

(CCXX) M. Bouygues, Roger Bacon a-t-il lu des livres arabes ? AHL, 1930.

(CCXXI) R. CARTON, L'expérience mystique chez Roger Bacon ; L'expérience physique chez Roger Bacon ; La synthèse doctrinale, 3 vol. Paris, 1924.

(CCXXII) H. Hoffmann, Roger Bacon, 1908, 1909, et AGP, XX.

(CCXXIII) MANDONnET, Roger Bacon et le speculum astronomiae, RN, 1910 ; Roger Bacon et la composition des trois « Opus », ibid., XX, 1913.

(CCXXIV) ProBst, Caractère et origine des idées du bienheureux Raymond Lulle, Toulouse, 1913.

(CCXXV) S. Bove, El sistema cientifico lulliano : ars magna, Barcelona, 1909.

(CCXXVI) Raymond LuLLE, Euvres, éd. Sabringer 1721-1742.

\section{CINQUIÈME PARTIE}

\section{Chapitre premier.}

(CCXXVII) Duns Scot, Opera, éd. Wadding, Lyon, 1639 (réimprimé Paris, 1891)

(CCXXVIII) G. BAUDRY, En lisant Jean le Chanoine, AHL, 1934, p. 175.

(CCXXIX) B. JANSEN, Beiträge zur geschichtlichen Entwicklung der Distinctio formalis, Zeitsch. f. Kathol. Theol., LUI, 1929.

(CCXXX) R. LANDRY, Duns Scot, Paris, 1922.

(CCXXXI) Et. Gilson, Avicenne et le point de départ de Duns Scot, AHL, 1927.

(CCXXII) J. CARRERAS y ARTAU, La doctrina de los universales en J. Duns Scot, Philosophia perennis, t. I, p. 233. 


\section{Émile Bréhier}

La philosophie du Moyen âge

(CCXXXIII) L. MeIER, Wilhelm v. Nottingham, in : Philosophia perennis, tome I, p. 263.

(CCXXXIV) A. Pelzer, Le premier livre des Reportata parisiensia de Duns Scot, Ann. de l'Institut de Louvain, 1924.

(CCXXXV) P. VignauX, Justification et prédestination au XIV siècle (Duns Scot, Pierre d'Auriole, Guillaume d'Occam, Grégoire de Rimini) , Paris, 1934.

\section{Chapitre II.}

(CCXXXVI) N. AbBagnano, Guglielmo d'Occam, Lanciano, 1931.

(CCXXXVII) B. LANDRY, Pierre Auriol, sa doctrine et son rôle, Rev. d'Hist. de la ÊM., 1928, p. 27.

(CCXXXVIII) H.-D. Simonin, Les « Summulae logicales » de Petrus Hispanus, AHL, 1930.

(CCXXXIX) J. BAUDRY, À propos de la théorie occamiste de la relation, AHL, 1933.

(CCXL) A. Kunlmann, Zur Geschichte des Terminismus, Leipzig, 1912.

(CCXLI) P. VignauX, Art. Occam, Dict, de théol. cath.

(CCXLII) J. LAPPE, Nicolas d'Autrecourt, Münster, 1909.

(CCXLII bis) PATRonnieR DE GANDILLAC, De l'usage et de la valeur des arguments probables dans les Questions de Pierre d'Ailly sur les Sentences, AHL, VIII, 1933.

\section{Chapitre III.}

(CCXLIII) C. Michalski, Les courants critiques et sceptiques dans la philosophie du XIV siècle (Bull. Ac. pol. des Sc.), Cracovie, 1927.

(CCXLIV) C. MichalsKi, La Physique nouvelle et les différents courants philosophiques au XIV siècle (Bull. Ac. polon. des sc. et l.) , Cracovie, 1928.

(CCXLV) C. MichaLSKI, Le criticisme et le scepticisme dans la philosophie du $X I V^{e}$ siècle (Bull. de l'Ac. polon. des sc. et des l.) , Cracovie, 1926.

(CCXLVI) C. MichaLSKI, La lutte pour l'âme à Oxford et à Paris au XIV siècle (Communicat. au Congrès de philosophie d'Oxford de 1930) .

(CCXLVII) E. HARTMANN, D’Aillys Lehre von der sittlicher Erkenntnis, Freiburg, 1904.

\section{Chapitre IV.}

(CCXLVIII) J. ANCELET-HuSTACHE, Mechtilde de Magdebourg, 1926.

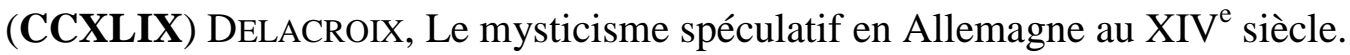




\section{Émile Bréhier \\ La philosophie du Moyen âge}

(CCL) Denifle, Ueber die Anfänge der Predigtweise des deutschen Mystiker, Archiv für Litt. Gesch. des M. A., 1886, p. 650.

(CCLI) Galvano DELlA VolPe, Il misticismo speculativo di Maestro Eckart nei sui rapporti storici, Bologna, 1930.

(CCLII) GRABMANN, Neuaufgefundene Quaestiones ds M. Eckarts, Sitzungsberichte der bayerisch. Akad. d. Wiss, 1921.

(CCLIII) KREBS, Meister Dietrich, Beiträge, t. V, 1906.

(CCLIV) G. THERY, Édition critique des pièces relatives au procès d'Eckart, de la bibliothèque de Soëst, AHL, 1926.

(CCLV) G. THERY, Le commentaire de maître Eckart sur le livre de la sagesse (édition), AHL, 1928 et 1929.

(CCLVI) G. Thery et R. KLIBANSKI, Opera latina M. Eckarti, Leipzig, fasc. 1, 1935.

Table des matières 


\section{Émile Bréhier}

La philosophie du Moyen âge

Table des matières

\section{Index}

AbBagnano, 395, 400.

ABBON, 81, 112.

ABELARD, 48, 111, 130, 136, 140, 146, 148..., 164, 183, 187, 201.

ABou’l HodeIL de Basra, 89.

ABubACER. Cf. Tofaïl.

Académie, 4, 417, 433.

Adam Scot, 194.

ADELARD de Bath, 132..., 141.

ADELMAN de Liège, 115.

Agobard, 42.

AlAIN de Lille, 179, 180, 199, 265.

AlBERT LE GRAND, 208..., 275, 294..., 336, 379.

Albigeois, 184-7, 258.

Alchwarismi, 132.

AlCUIN, 42-3, 46-7, 66,

ALEXANDRE IV, 336.

ALEXANDRE d'Aphrodise, 90, 231-5, 247.

AlEXANDRE de Halès, 267..., 282.

Alfred l'Anglais, 261.

AlgAZEL, 214.

ALGER de Liège, 115,147.

AlHAZEN, 368.

ALLEMAGNE, 144, 423.

AmAury de Bennes, 206.

AMBroise (Saint), 14, 57, 67.

Anacharsis, 18.

Analytiques, 39, 91, 111, 137, 175, 179, 202, 263, 312, 373, 376.

Anaxagore, 229.
Ancelet-Hustache (J.), 424.

ANGLETERRE, 30, 42, 72.

ANSELME (Saint), 121.., 130, 145, 153, 157, 181, 192, 259, 314, 347, 397, 344.

ANSELME de Laon, 147.

Apollon, 34.

ApulEe, 10, 138.

Arabes. V. Islam.

Aréthas, 105.

Arif (Ibn Al), 236.

ARISTIPPE (Henri), 261.

ARISTOTE, 5, 8, 22, 37-8, 52, 63, 67, $80,83 \ldots, 130,134-5,151,2,154$, $163,175,184,195,199,202,212$, 217, 225, 247, 255, 259..., 279..., 294... 373, 377, 405, 407..., 415..., 419-20, 422, 434.

ARIUS, 166, 316.

Arnauld, 418.

Arquillière, 42, 108.

Arts libéraux, 47, 60, 69, 111, 132, 190.

Ascari (Abul Hassan al), 89.

Ascelin, 117.

Asin Palacios (M.), 236.

Athanase, 39.

Atomes, 133.

Augustin (Saint), 2, 4 15, 23, 29, 30 , 52, 54, 69, 72, 77, 120, 123, 126, 151, 198, 202, 255, 281, 294..., 311, 356, 363, 366, 377, 386, 431.

Aulu Gelle, 71. 


\section{Émile Bréhier}

\section{La philosophie du Moyen âge}

Autorité, 49, 133, 136, 244, 395.

AvempaCE, 223, 311.

Averroes, 222..., 264, 268, 319, 321, 390, 419.

Averroïsme, 66, 335...

AVICEBRon, 208, 236..., 261, 263, 269, 275, 285, 299, 325.

AviCEnNE, 211..., 225-30, 237, 247, 250, 261, 263-4, 269, 299, 319, 368.

Babisme, 87.

BABYLONE, 103.

BACON (Roger), 276, 298, 344, 361...

BACONTHORP (Jean), 376, 417.

BAGDAD, 102, 219

BANDINI, 198.

BARTHELEMY l'Anglais, 274.

BARTHELEMY de Messine, 262.

BARUZI (J.), 236.

BASILE, 54, 252.

BAUDRY (J.), 382, 395.

BAUEMKER, 2, 90..., 133, 178.

Baumgartner, 267.

BAUR (Ed.), 273.

BAYLE, 208.

Bede Le Venerable, 30..., 65-6, 143, 169, 190.

Beghards, 425.

BERENGER, 114, 122, 162.

BERNARD (Saint), 108, 132, 140, 143, 148, 162..., 194, 200, 423.

BERNARD de Chartres, 135.

BERNARD de Moélan, 138.

Bernard Sylvestre, 160.

BERNOLD de Constance, 146.

BERTHELOT (R.), 222.
Bible, 31, 61, 70,158, 250.

BIDEZ (H.), 9, 252.

BoecE, 3, 7..., 28, 37, 48, 52-3, 57, 69, 71, 77-8, 80-1, 111, 120, 131, 133-4, 138, 174, 185, 187, 259, 268, 278.

BONAVENTURE (Saint), 268, 279...

BONIFACE VIII, 255, 359.

BONILlA (Ad.), 24.

BONNAUd (R.), 13.

BORGNET (Ed.), 302.

BORISON (A.), 86.

Bouddhisme, 83.

Bouquet (A.), 207.

Bovo, 78.

Brachmanes, 18.

BREHIER (L.), 108, 252.

BRINKEL, 419.

BRunet (A.), 111.

BRUNO de Ségovie, 162.

Buckingham, 377.

BUFFON, 224.

BuRGONDIO de Pise, 198.

BURIDAN (Jean), 414, 419-20.

BuRLEIGH (Walter), 398

BurR (G.-L.), 1.

BYZANCE, 44, 72,104..., 252...

CAFFORD (Pierre), 422.

CAMBRIDGE, 414.

CANDIDUS, 70, 72.

CAPPUYNS (Dom), 48, 64.

Carra de Vaux, 220.

CARTON (R.), 13, 363.

CASSIEN, 15, 20.

CASSIODORE, 21..., 28, 173. 


\section{Émile Bréhier}

\section{La philosophie du Moyen âge}

Catégories, 38-9, 47, 57, 77, 80, 105, 112, 130, 136, 150, 153, 175, 177.

CATON, 18.

Causalité, 62, 64, 86, 102, 136, 242, 354, 405-6, 425-6.

Césaire, 21.

ChalCidius, 52, 54, 115, 133.

Chaldéisme, 252.

Charitas, 196.

Charlemagne, 1, 2, 41..., 83.

CHARTRES, 82, 112, 132...

ChATTON, 417.

Chossat, 356.

Christologie, 33, 73, 114, 116, 161, 430.

CHRYSIPPE, 11, 18.

Ciceron, 3, 4, 9, 14, 18, 22, 29, 47, $66-7,71-2,80,112,114,118$, 140, 185, 195-6, 417.

Cité, 98...

CITEAUX, 163.

Claudien Mamert, 17, 185.

Clavasio (Richard de), 421.

Cléanthe, 78.

Clement V, 362, 372.

Clerval, 82, 112.

CLUNY, 78.

Condillac, 224.

Constantin l'Africain, 132, 141.

Coran, 82, 213.

Cousin, 77, 130, 152.

Croisades, $107 \ldots$

Cyrille, 80.

DAHNERT (U.), 297.

DAMASCIUS, 2, 276.

DANIELS, 347.
DAVID, 38.

DAVID de Dinant, 208.

DAVY (M.-M.), 171, 196.

DAWSON (Chr.), 44.

DEMOCRITE, 89, 416.

DENIFLE, 424, 427.

DENIS l'Aréopagite, 2, 21, 38, 43, 48, 52, 55, 72, 105, 112, 156, 168, 297, 386, 424.

DESCARTES, 170,185, 417, 421.

Dialectique, 36, 60, 69, 77, 113..., 131, 148, 153, 156, 198, 259, $375 .$.

DIETERICI, 84, 94.

Diogène Laërce, 5.

DiTTRICH (O.), 161, 291, 358, 386.

Divination, 34.

Dominicains, 255..., 298, 352, 423, 425.

DONAT, 22.

Droit, 371.

DuHEM, 28, 31, 54, 65, 81, 208, 2134, 243, 265, 268..., 299, 362.

DuNS SCOT, 286, 344, 375..., 398.

DURAND de Troarn, 122.

DURAND de Saint-Pourçain, 392.

ECKART, 423.

Écoles, 256.

Écriture Sainte, 48..., 70, 120, 125, 162, 200.

EGBERT, 79.

Éginhard, 71.

Église, 80, 257, 334.

ÉGYPTE, 105, 132, 244.

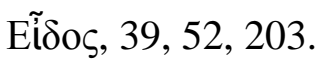

ÉLIAS, 38. 


\section{Émile Bréhier}

\section{La philosophie du Moyen âge}

ENDRES, 78.

ENHARD, 113.

ÉPICTETE, 8, 163-4.

Épicure, 18.

Épicuriens, 4.

ERICH (d'Auxerre), 76-7.

ESPAGNE, 2, 24, 82, 107, 225, 236, 261.

ÉTIENNE de Tournai, 200.

EUCLIDE, 90, 132, 261.

EUSTRATIUS, 253, 262.

Falasifa, 83.

FARABI (Al), 86, 93..., 212, 223, 225, 250, 261, 263, 275, 299.

FAust (Aug.), 65, 388.

FAustus de Riez, 16, 17.

FITSACRE (Richard), 357.

Foi, 4, 8, 82, 113, 116, 119, 124, 138, $143,145,157,167,171,179,204$, 251, 257, 279, 303, 396, 433.

FOREST, 320, 323-4, 326.

Franciscains, 255..., 268, 344, 352, 358, 362, 377, 384, 394, 426.

FranÇOIS (Saint), 257.

FRANÇOIS de Marchia, 420.

Fridugise, 68.

Frowinus, 200.

FULBERT, 82, 112.

FULDA, 68, 70, 72, 78.

GAIUS, 27.

GALIEN, 38, 90, 102, 133.

Galvano della Volpe, 426...

Garnier, 147.

GARNIER de Rochefort, 207.
Gaunilon, 128.

Gennadius, 19.

GAUTHIER de Saint-Victor, 201.

GAZALI (Al), 219..., 225, 261, 335.

Georgius, 39.

GERARD d'Arras, 118.

GERARD de Crémone, 261-2.

GERARD le Carmélite, 418.

GERBERT, 79..., 112.

GHELLINCK (J. de), 37.

GHISLAIN de Soissons, 178.

GILBERT l'Universel, 153.

GILLE de Lessines, 340, 351.

GILLES de Rome, 343, 356, 359, 360, 383.

GILSON, 2, 162, 280.

GODEFROI de Chartres, 168.

GODEFROI de Fontaines, 351-4, 358, 386, 389.

Gondolfe, 118.

GondisALVI (Dominique), 261, 263.

GoNSALVE de Vallebonne, 426.

GorCe (M.-M.), 268, 273, 281, 296.

GOTHS, 24.

Gottschalk, 75.

GRABMANN, 47, 69, 146, 162, 190, 198, 200-2, 297, 336, 426...

Grâce, 62, 74, 166, 171, 412.

GREGOIRE le Grand, 20, 107.

GREGOIRE de Rimini, 376, 414, 417.

GREGOIRE de Nysse, 54, 57, 63, 106, 152.

GROSSETESTE (Robert), 262, 272..., 287, 324, 355, 362.

Guillaume d'Auvergne, 264..., 273, 278, 282, 285, 301, 367.

Guillaume d'Auxerre, 264. 


\section{Émile Bréhier}

\section{La philosophie du Moyen âge}

Guillaume de Champeaux, 147, 149, 154, 176, 178.

Guillaume de Conches, 111, 140, 168, 318.

GuiLlaume de La Mare, 344, 351.

GUILLAUME de Lorris, 274.

GUILlaumE de Malmesbury, 144.

GuILLAUME de Moerbeke, 262, 276, 297.

GuILlaume de Nottingham, 383-5.

GUILLAUME de Saint-Amour, 297.

GuILLAUME Saint-Thierry, 143, 164, 167-8, 171.

GuILLAUME de Shyreswood, 376.

GUILLAUME de Ware, 347.

GUILLAUME le Breton, 207.

Guttmann, 102.

HALPHEN (L.), 42.

Haroun-al-Raschid, 83.

HAUREAU, 77, 82, 150, 178, 199, 208.

Hellénisme, 3.

HELlMANN (S.), 67.

HenRI de Gand, 344, 348..., 356-7, 366, 384, 386.

HENRI Harclay, 398.

HENRI de Hainbuch, 414.

HENRI de Oyta, 414.

HERACLIDE, 54, 115.

Héraclius, 34.

Hérésies, 206, 257.

HERMANN, 261.

Hervé de Nédellec, 417.

HEURTEVENT, 115, 117.

HiLAIRE (Saint), 16, 80.

HILDEBERT de Lavardin, 14.

Hilduin, 55.
HiNCMAR de Reims, 55, 75-6.

HiPPOCRATE, 102, 133.

HolKot (Robert), 414, 419.

HONORIUS d'Autun, 144,147.

HONORIUS III, 266.

HORTEN (M.), 87, 224.

Hroswita, 79.

Hugolin d'Orvieto, 416.

Hugues, évêque de Langres, 115.

Hugues de Saint-Victor, 188, 193, 198, 359.

Humanisme, 70, 76, 79, 257, 391, 433.

IBAS, 38.

Impetus, 420.

INNOCENT II, 166.

INNOCENT III, 107, 208, 255.

IRLANDE, 30, 42.

ISIDORE de Seville, 8, 24..., 58, 66, 69, 133, 190, 332.

Islam, 2, 38, 83..., 107, 132, 184, 211..., 260, 283, 305, 424.

ISRAËLI, 101, 261, 275.

JACQUES de Viterbe, 360.

Jamblique, 94.

JANSEN (B.), 384.

JEAN (Pape), 31.

JEAN VIII, 44.

JEAN XXII, 395.

Jean Climaque, 105.

JEAN DAMASCENE, 35... 72,198.

JEAN d'Espagne, 261.

Jean Italos, 253.

JEAN de Jandun, 416. 


\section{Émile Bréhier}

\section{La philosophie du Moyen âge}

JEAN de la Rochelle, 269.

JEAN de Marchia, 417.

JEAN de Meung, 274.

JEAN de Mirecourt, 376, 414, 418.

JEAN de Salisbury, 111，135，178, 201-4.

JEAN SCOT ÉRIGENE, 47..., 73, 76, 80, 82, 112, 132, 138, 140, 144, 188, 207, 421, 424-5.

JEROME (Saint), 17, 151.

Joachim de Flore, 206.

Judaïsme, 101, 236.

JuLes d'Albi, 281.

Justin, 158.

JuVENAL, 15, 205.

Kabbale, 101.

Kadarites, 88.

Kalam, 88.

KILWARDBY (Robert), 343, 357, 380.

KINDI (Al), 90..., 261, 335.

KLAPWELL (R.), 351.

Kleutgen, 320.

Klinger, 11.

KREBS, 424.

Lactance, 68.

LAMBERT d'Auxerre, 376.

LANDRY (B.), 359, 371, 378, 382, 387, 389.

LANFRANC, 116, 121.

LAPORTE (J.), 331.

LEFEVRE (G.), 151.

LEHMAN (M.), 199.

LEIBNIZ, 410.

LENGLART (M.), 193.
LEON IX, 115.

Licianus, 19.

LITTLE, 368.

Logique, 376, 400..., 419.

Lóros, 39, 57, 60, 62, 74, 139, 430.

Lot-Borodine, 105.

LOTTIN (O.), 357.

LUCAIN, 3, 15, 195.

LUCRECE, 133, 142.

Macarius Scot, 66.

MACROBE, 65, 67, 71, 78, 121, 157-9, 205, 262, 292.

MAÏMONIDE, 236, 244...

MAKDOUR (IB.), 93.

Malebranche, 418.

MANDONNET (P.), 335..., 356, 361.

MANEGOLD de Lautenbach, 120.

Manichéens, 118, 184, 187, 316.

MaRCianuS CAPELla, 4, 7, 10,22, 52, 78, 133.

Marinus, 8.

MARITAIN (J.), 319.

Marius Victorinus, 9, 28, 114.

MARSILE d'Inghen, 414.

Marsile Ficin, 433.

MARSTON (Roger), 344...

MARTIN de Braga (évêque), 14, 67.

MARTIN de Pologne, 207.

MARTIN (R.-M.), 198.

MASNOVO (A.), 266.

Mathieu D'Aquasparta， 344..., 366, 384.

MaXime Le Confesseur, 51-2, 57-8, 63, 72, 105.

Mazdéisme, 57.

MeIER (L.), 383. 


\section{Émile Bréhier}

\section{La philosophie du Moyen âge}

Mechtilde de Magdebourg, 423.

MELiTON (Guillaume de), 269.

Ménippe, 11.

MÉSOPOTAMIE, 103.

Meyerhof, 38.

MiCHALSKI, 377, 400, 416...

Michel Cérulaire, 252.

Michel le Bègue, 48, 55.

Michel de Césena, 395.

MichEL d'Éphèse, 38, 253, 262.

Michel Scot, 261.

Michel (Suzanne), 331.

Migne, 5, 161.

Mithra, 87.

Modoin, 41.

Monoénergisme, 34.

Monophysites, 33, 100.

Monothélisme, 34.

Montaigne, 417.

Motazilites, 88.

Motekallemin, 88, 222, 244, 320.

MunK, 212, 222.

Mysticisme, 165, 188, 224, 236, 423...

Nahawendi, 10a.

Nature, 50, 63, 132, 135, 139, 149, 182-3, 333, 365, 412, 415, 424.

Nestorianisme, 38.

Nestorius, 167.

NiCOLAS de Cuse, 59, 433.

NiCOLAS d'Autrecourt, 377, 414, 416.

Nicolas d'Oresme, 414, 422.

NICOMAQUE de Gérase, 22.

NIL (Saint), 15, 67, 105.

Nominalisme, 129, 149, 153, 178, $392 .$.
Notker Labeo, 78.

Noũ $\varsigma, 39,133,135-9,160 ， 208$, $230 \ldots, 264,188,306,384,397$, 424-6.

Novo Castro (André de), 419.

OCСАм (Guillaume d'), 386, 392.

ODON, 79.

Olivi (Pierre-Jean), 344, 384.

Oltramare (A.), 11.

Omar Khayyam, 222.

Organon, 9, 36-7, 39, 104, 111-2.

Origène, 20.

OrOSE, 66.

OSNABRUCK (Guy d'), 108.

OTLOH, 120.

OTTON le Grand, 78.

OVIDE, 205.

OXFORD, 362, 377, 384, 394-5, 414.

PADOUE, 433.

PARE (E.), 111.

PARIS, 200.

Paschase Radbert, 73.

PAUL (Saint), 17, 44, 51, 55, 151, 188.

PAUL I ${ }^{\mathrm{er}}, 55$.

Péché, 61, 76, 78, 161, 415.

Peckham (Jean), 269, 344...

Pelage, 30, 166, 413.

Pelstner (Fr.), 297.

PELZER (A.), 358.

PERSE, 83, 224.

PERSE, 195.

Pfeiffer, 427.

PHILIPPE de Grève, 265. 


\section{Émile Bréhier}

\section{La philosophie du Moyen âge}

Philon, 20, 36, 72, 119, 173, 369.

PHILOPON (Jean), 38.

Photios, 105.

Pierre D'Auriole, 393, 412, 417.

Pierre Comestor, 199.

Pierre Damien, 117.

Pierre Le Chanteur, 199, 200.

Pierre Lombard, 58, 169, 197-8, 201.

PIERRE de Blois, 195.

PIERRE de Chelles, 200.

Pierre d'Espagne, 253, 376.

PIERRE de Falco, 358.

PIERRE de Maricourt, 369.

PIERRE de Poitiers, 198-9, 201.

PIERRE de Riga, 196.

PITRA, 199.

Platon, 8, 9, 17-8, 22, 52, 54, 57, $67,83 \ldots, 126,134-5,142,150$, $157-8,163,169,171,176,227$, 264, 273, 275..., 348, 371, 390, 397.

Pline l'Ancien, 3, 31, 54.

Plotin, 2, 10, 35, 37, 53-4, 61-3, 84..., 94, 123, 142, 163-4, 171, 213, 239, 244, 271, 275, 280, 321, 323, 421, 425, 427, 431.

Plutarque, 204.

PollaK (C.), 40.

PoRPHYRe, 9, 22, 69, 81, 101, 112, 130, 148, 155, 177, 252.

Porree (Gilbert de la), 111, 142, 174..., 199, 201, 428.

Præchter, 38.

PRANTL, 29, 52.

Prevostin de Crémone, 199.

Priscien, 195.

Probus, 171.
Proclus, 2, 12, 86, 98, 252, 261, 276, 298, 425.

Prosper (Saint), 16.

PSELlus, 252.

Ptolemee, 90, 137, 249, 261.

Ptolemee de Lucques, 360.

PulLus (Robert), 111, 198.

Pythagore, 52.

Pythagoriciens, 18, 85, 421.

RABAN MAUR, 68, 75, 190.

Rabbula, 38.

RAIMOND d'Aurillac, 80.

RAYMOND LULLE, 344, 372..., 403,

Raison, 49, 60, 76, 81, 103, 116, 122 -

$3,133,145,153,167,171,189$, 193, 197, 203, 205, 250, 279, 303, 396, 409, 433, 435.

RALPH (Fritz), 417.

RAND (E.-K.), 48, 77.

Ratramne, 74.

RAYMOND de Tolède, 261.

Réalisme, 397...

REIMS, 79, 129.

REINERS (J.), 130.

REMUSAT, 169.

REMY, évêque de Lyon, 75.

REMY, évêque d'Auxerre, 77, 79.

RICHARD de Middletown, 344, 347, 358, 384.

RICHARD de Saint-Victor, 192.

Richer, 80,

Rigaud (Eudes), 269.

ROBERT, 111, 157.

ROBERT de Melun, 198.

RoDingTON (Jean), 418.

ROHMER (J.), 270. 


\section{Émile Bréhier}

\section{La philosophie du Moyen âge}

RolAnd-Gosselin, 302，321，328, 356.

ROME, 3.

RosCELIN, 129..., 149,152.

RUSSIE, 107.

Saadja Gaon, 101.

SABIEN de Marseille, 19.

SAINT-GALL, 78.

SAINT-VICTOR, 188.

SALMAN (D.), 336.

SAUTER, 38.

Sciences, 69, 81, 175, 207, 263, 277, $365 .$.

Scolastique, 372, 375.

Sedulius Scotus, 66.

SENEQUE, 3, 14, 26, 66, 135, 137, 140, 163.

SERGIUS de Reschaïna,38.

Servatus Lupus, 70, 76.

Sextii, 18.

SEXTIUs le Pythagoricien, 14, 66.

Sibylles, 34.

Sidoine Apollinaire, 24, 33.

SIGER de Brabant, 336...

SIMON de Tournai, 199.

Simplicius, 8, 276.

SOCRATE, 19, 24.

Sommes, 58, 147, 198, 264, 269-71, 277, 297, 309...

Soufis, 223, 236.

Sozomène, 24.

SPINOZA, 208.

Stoïciens, 4, 12, 85, 118, 291, 403, 421.

STOLZ (S.), 128.

Suhrawardi, 224.
SVOBODA (K.), 252.

SYLVESTRE II. Cf. Gerbert.

Syriaques (traducteurs), 39.

SYRIE, 83, 105.

TAIUS, 30.

Talmud, 102, 244.

Térence, 79.

Thémistius, 232.

THEODORE de Mopsuète, 38.

THEODORE de Smyrne, 253.

THEODORE de Tassa, 72.

Théodoret, 24.

Théologie, 84, 113, 131, 156, 182, 197, 277, 339, 391, 409, 415.

Théophraste, 232.

THERY (R.-P.), 55.

THIERRY de Chartres, 137.

THIERRY de Fribourg, 355.

THOMAs (Saint), 27, 129, 208, 250, 262, 275, 277, 294..., 340..., 37680.

Thora, 103.

TIXERONT (J.), 29.

TOFAÏL (IBN), 222.

TOURS, 68, 70, 128-9, 132.

Transsubstantiation, 114, 116.

TREMBLAY (P.), 111.

Trinité, 57, 60, 79, 101, 123, 129, $138,147,154,156,160,166,181$, 188, 198, 428.

Trithéisme, 131, 316.

UEBERWEG, 253, 347.

ULGER, 154. 178, 345, 398.

Universaux, 130,149,178, 345, 398, 


\section{Émile Bréhier \\ La philosophie du Moyen âge}

Université, 256, 341, 370-371.

VALDO (Pierre), 258.

Valère Maxime, 67.

Varron, 4.

Vaudois, 188.

VENTURA, 104.

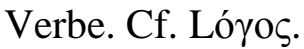

VignAuX (P.), 388, 391..., 413.

Vikings, 43.

ViNCENT de Lérins (Saint), 16, 20.

VIRGILE, 71, 79-80, 185, 205.

VISCHER, 114.

VYVER (Van de), 10, 82.

Walafried Strabo, 70, 72.
WARICHEZ (J.), 199.

WASIL, 89.

WITELO, 276.

WODHAM (Adam), 414.

WORMS, 213.

WulF (de), 350.

Xenophane d’Élée, 209.

Xiphilin, 252.

Yayha Ben Adi, 100.

YvES de Chartres, 157, 162.

ZEILLER (J.), 333.

Zoroastre, 18, 


\section{Émile Bréhier \\ La philosophie du Moyen âge}

Table des matières

\section{Appendice}

Cet appendice a pour but de donner quelques indications essentielles sur les travaux relatifs à la Philosophie du Moyen Age parus depuis la première édition de ce livre (1937). La nouvelle édition de La Philosophie au Moyen Age d'Ét. Gilson (1944), les publications du P. Chenu (Les Études de philosophie médiévale, fascicules périodiques, dont le premier a paru en 1939, le second [sur les publications de 1939 à 1945] et le troisième [publications de 1946 à 1948] doivent paraître en 1949) sont à consulter.

Introduction. - P. 1. - Dans son étude Problème de la Volonté à Paris et à Oxford au XIV $V^{e}$ siècle (Cracovie, 1937), l’abbé K. Michalski énonce des idées de grande portée sur la nature de la philosophie médiévale : on la comprend mal, ditil, et l'on nie même son existence « parce qu'on lui demande, comme à la philosophie moderne, de nouveaux systèmes et qu'elle n'offre que des problèmes nouveaux ». Nul penseur médiéval ne cherche un système et surtout un système personnel, parce qu'il s'appuie sur la doctrine chrétienne : mais à l'intérieur de cette doctrine, on veut résoudre des problèmes ; on conteste d'ailleurs moins les thèses elles-mêmes que la valeur des arguments qui sont donnés pour ou contre : d'où l’intérêt capital qu'il y aurait à faire une histoire de la pensée médiévale par problèmes.

La Pensée au M. A. de P. Vignaux (1938) pourrait s’intituler l'Humanisme et le Naturalisme au Moyen Age. «Dignificare naturam », telle est la formule scotiste dans laquelle il résume toute cette pensée. Soit par exemple le thomisme qui, pour expliquer la connaissance humaine, admet, au lieu d'un «donneur de formes » dont l'intellect recevrait passivement l'impression, une conception interne, une nature intellectuelle qui accomplit son opération propre. (Il est d'ailleurs clair, par cet exemple même, que la pensée médiévale vient souvent se heurter à l'affirmation d'un Transcendant tout-puissant.)

$I^{\text {re }}$ Partie, Ch. I. - P. 7. - Le livre de P. Courcelle, Les Lettres grecques en Occident, Paris, 1943, a renouvelé la question du passage de la littérature grecque à la littérature latine dans la période qui a précédé le Haut Moyen Age. Les chapitres sur Boèce (p. 257-312), sur Cassiodore (313-341), sur les moines au service de l'hellénisme (342-388) nous font voir dans quelle mesure les Latins ont conservé le contact avec les Grecs, jusqu'à une interruption qui fut à peu près complète, comment Boèce plagie les commentaires d'Ammonius, de quels modèles grecs (Platon, les lieux communs de la diatribe, le commentaire du Timée de Pro- 


\section{Émile Bréhier \\ La philosophie du Moyen âge}

clos, les commentaires d'Ammonius) s'inspire sa Consolation de la Philosophie. Ce livre sera bien utile à qui veut se rendre compte de ce que le Moyen Age a pu retenir de la pensée grecque avant la reprise de contact avec les richesses de la philosophie hellénique.

II Partie, Ch. I. - P. 42. - R. Bonnaud-Delamare, L'idée de Paix à l'époque carolingienne (Paris, 1939), a excellemment souligné l'idée essentielle qui a présidé à la renaissance carolingienne, Charlemagne est couronné comme empereur de la Paix et pour la paix de l'Église, il assemble des conciles , à l'extérieur, il traite avec les souverains du proche Orient pour garantir la sécurité aux chrétiens qui vont en terre sainte.

Ch. II - P. 48. - Les connaissances positives que Jean Scot pouvait atteindre sont assez bien déterminées dans ses Annotationes in Marcianum, ses Notes sur Martianus Capella que C. E. Lutz vient d'éditer (Cambridge, Mass., 1939) d'après le man. 12960 de la Bibliothèque nationale. Il y exalte la philosophie plus que dans ses autres ouvrages ; par elle on atteint l’immortalité. « Nemo in trat in caelum nisi per philosophiam. »

III $^{\mathrm{e}}$ Partie, Ch. II. - P. 121. - Au sujet de saint Anselme, il convient de signaler un important travail de l'abbé A. Combes, Un inédit de saint Anselme ? Le traité «De imitate divinae essentiae et pluralitate creaturarum », d'après Jean de Ripa, Paris, 1944. C’est, d’après M. Gilson (Rev. philosoph., 1945, p. 184), « une des contributions les plus surprenantes et les plus originales que l'on ait faites depuis longtemps à l'histoire de la philosophie médiévale ». Il s'agit des citations étendues que Jean de Ripa, un auteur du $\mathrm{XIV}^{\mathrm{e}}$ siècle, fait d'un traité qu'il attribue à saint Anselme, M. Combes, sans affirmer absolument l'authenticité du traité, la considère comme possible et même probable. Or ce traité soutient une thèse curieuse ; c’est que les Idées divines sont créées par Dieu. Cette thèse rappelle celle de Philon d'Alexandrie, qui faisait de Dieu l'auteur du monde intelligible créé avant le monde sensible, et aussi celle d'Origène : ce serait là une face nouvelle et bien curieuse du platonisme de saint Anselme ; la fameuse preuve de l'existence de Dieu ne suppose-t-elle pas d'ailleurs l'antériorité de l'être intelligible (esse in intellectu) sur l'être réellement existant (esse in re) ?

- P. 132. - Le platonisme chartrain nous offre un moment important de La tradition platonicienne pure que R. Klibansky, The Continuity of the platonic tradition during the Middle Ages (London, 1939) veut isoler de l'influence néoplatonicienne ; il n'en est encore malheureusement qu'aux préfaces, indiquant comment devrait être fait un Plato latinus, qui comprendrait toutes les traductions latines de Platon, fragmentaires ou non, accessibles au Moyen Age.

— P. 148. — Les Beiträge zur Gesch. d. Philos, des Mittelalters donnent une édition critique et complète du Tractatus de unitate et divina Trinitate (1941) due aux recherches d'Ostlender, 


\section{Émile Bréhier \\ La philosophie du Moyen âge}

- P. 148. - Mgr Grabmann (Kommentare zur Aristotelischen Logik aus dem 12. und 13. Jahrhundert, Berlin, 1938) a mis en lumière, grâce à l'étude des commentaires d'Aristote, l'existence d'une école de logique issue de l'enseignement d'Abélard. La logique à cette époque touchait à la théologie, et les dialecticiens embarrassaient fort les théologiens en appliquant à la réalité divine les règles de la dialectique ; l'un de ceux-ci, Albéric de Reims, connu surtout jusqu'ici par la critique qu'a faite de lui Abélard (cf. p. 153), est quelquefois cité dans ces Commentaires. C'est dans ces conditions que l'étude des sophismes a donné lieu à toute une littérature que Mgr Grabmann étudie, au long du XII ${ }^{\mathrm{e}}$ et XIII ${ }^{\mathrm{e}}$ siècle, dans les Beiträge, 1941.

- P. 171. - $\mathrm{M}^{\text {lle }}$ Davy, en continuant ses études sur Guillaume de SaintThierry, donne une excellente contribution à l'étude de la mystique. Sa thèse sur ce sujet n'est malheureusement pas imprimée ; mais elle a donné une édition et une traduction du Traité de la Vie solitaire (Paris, 1940, 2 volumes) avec une introduction développée. Il s'agit de règles et de conseils donnés aux moines du cloître de Mont-Dieu. Le cloître est essentiellement une école de charité, et la charité est identique à Dieu ou à l'Esprit Saint. La solitude monastique est donc bien loin d'être l'isolement, et le moine n'est jamais moins seul que quand il est avec Dieu dans sa cellule. $\mathrm{M}^{\mathrm{lle}}$ Davy a en outre édité un volume d'extraits de saint Bernard (Paris, 1945).

- P. 192. - La mystique des Victorins touche, comme on l'a vu, de beaucoup plus près à la pensée de saint Anselme qu'à la mystique bernardine ; c'est ce qu'a montré A. M. Éthier dans son étude, Le «De Trinitate » de Richard de SaintVictor, Paris, 1939 ; M. Forest (Rev. philos., 1946, p. 373) voit en Richard un aspect particulier du « rationalisme chrétien »; il s'agit d'un effort de la raison procédant de la foi et cherchant à arriver à la certitude dans les choses divines.

- P. 175. - $\mathrm{M}^{\text {lle }}$ Anneliese Maier donne une très intéressante étude : Das Problem der intensiven Grösse in der Scholastik, Leipzig, 1939. Il s'agit du problème «de intensione et remissione formarum ». D’après les Catégories d'Aristote, le plus et le moins n'existent que dans la qualité, mais jamais dans la forme qui donne à chaque être une essence permanente et invariable ; tel est l'avis de Gilbert de la Porrée dans le De sex principiis. La question touche à la théologie quand Pierre Lombard se demande si le Saint-Esprit peut s'accroître dans l'homme ; l' ' augmentum caritatis » semblerait prouver qu'il y a du plus et du moins dans les formes. Henri de Gand se décide nettement le premier pour l'affirmation du plus et du moins dans la forme ; cette propriété est liée pour lui à l'indétermination et à l'infinité (la «latitude ») qu'il y a dans l'essence. C'est de là, semble-t-il, que partent les Scotistes: la forme individuelle, chez eux, l' " haecceitas », ajoute à la forme universelle des «degrés essentiels ». D’autres ont tenté de comparer la continuité qualitative, qui concilie le changement de degré avec la permanence de la forme, au mouvement local qui laisse le mobile inaltéré dans le changement. On voit l'importance d'un problème dont la solution pouvait atteindre gravement la notion traditionnelle de forme. 


\section{Émile Bréhier \\ La philosophie du Moyen âge}

III Partie, Ch. III. - P. 212. - L. Gardet, en deux articles remarquables de la Revue thomiste (Islam et Démocratie, mai et septembre 1946), présente des considérations qui aident à comprendre la pensée musulmane. Il définit l'Islam, après Massignon, comme une théocratie égalitaire, dans laquelle est absente cette image de la hiérarchie qui a joué un si grand rôle dans la théorie néoplatonicienne : il y a égalité entre les croyants comme croyants, puisqu'il n'y a d'autre autorité que celle de Dieu ; cette égalité, qui fonde le compagnonnage, ne conduit pas du tout en revanche au respect inconditionnel de la personne individuelle. Dans un autre article (Rencontre de la théologie musulmane et de la pensée patristique, ibid., 1947, $\mathrm{n}^{\circ} 1$ ), il fait voir que les Jacobites sont à la source de l'influence des néoplatoniciens sur les Arabes ; les Nestoriens, Jean Damascène, l'école d'Antioche avaient une prédilection pour l'interprétation littérale des Écritures et s'opposaient à l'allégorie des Alexandrins; ce fut l'attitude même des Arabes. Mais dans leur théologie, ils ne devaient pas trouver un saint Anselme, et ils ignorent la fides quaerens intellectum; ils recherchent non pas l'intelligence des mystères (il n’y a pas chez eux de spéculation philosophique sur les rapports de la raison et de la foi), mais l'apologie des dogmes.

- P. 214. - La distinction de l'Essence et de l'Existence chez Ibn Sina, de $M^{\text {lle }}$ A.-M. Goichon (Paris, 1937), traite un sujet capital : Dieu, chez qui l'essence est identique à l'existence, s'oppose par là aux êtres créés où l'une se distingue de l'autre, et le monisme paraît ainsi évité. Simple apparence, pense $\mathrm{M}^{\text {lle }}$ Goichon, puisque l'essence des êtres dits créés est en Dieu et que leur existence n'est que le débordement nécessaire de cette essence hors de Dieu. Les essences sont comme données à l'intelligence divine, et la création des existences imposée à sa volonté : la fameuse distinction ne peut jouer le rôle qu'Avicenne veut lui faire jouer. Par son Lexique de la langue philosophique d'Ibn Sina, parue en même temps, $\mathrm{M}^{\text {lle }}$ Goichon donne une excellente contribution à l'établissement du vocabulaire philosophique de l'époque arabe.

— P. 220. - Une des dernières études sur Al Gazel (A. J. Wensinck, La pen-

sée de Ghazzali, Paris, 1940) affirme l'extrême complexité de sa pensée: "Comme théologien, Ghazzali est musulman, comme penseur et homme de science, néoplatonicien, comme moraliste et mystique, chrétien. » C'est justement une œuvre morale importante de lui, le Critère de l'action, qui a été traduite en français par Hikmat Hachem : c’est là qu'on trouve la première formule développée du célèbre pari, dont on admet aujourd’hui que Pascal aurait eu connaissance. Cette œuvre montre aussi bien clairement la vitalité de la tradition de la morale grecque, et surtout de celle d'Aristote : la valeur comparée de la contemplation et de l'action, la théorie des vertus sont traitées comme dans l'Éthique à Nicomaque; et les méthodes d'éducation morale rappellent beaucoup les moralistes stoïciens.

- P. 224. - H. Corbin, qui publie une édition des œuvres de Suhrawardi (tome I, Opera metaphysica et mystica, Istanbul, 1945), a exposé, dans une pla- 


\section{Émile Bréhier \\ La philosophie du Moyen âge}

quette fort intéressante, les Motifs zoroastriens dans la philosophie de Suhrawardi, d'après la Sagesse de l'Orient (Hikmat ol-Ishraq), Téhéran, 1946. On y trouve cette métaphysique de la lumière incréée si répandue en Orient, vieille tradition persane qui a joué un grand rôle dans le néoplatonisme ; métaphysique presque physique, où la lumière qui révèle instantanément toute chose devient facilement l'image de la réalité suprême. A cette métaphysique est liée une mystique de l'Amour ; l'Amour universel ne trouve d'autre obstacle en nous que notre moi détaché de la nature parfaite. — La revue Hermès (Bruxelles, novembre 1939) contient une traduction de deux épîtres mystiques de Suhrawardi, ainsi que divers textes sur la mystique musulmane. Le Journal asiatique (juillet 1935) donne la traduction du Bruissement de l'Aile de Gabriel.

- P. 236. - L. Gardet, La connaissance et l'amour de Dieu selon quelques textes sufis du premier siècle de l'hégyre [Revue thomiste, janvier 1946), fait connaître au lecteur français le traité Du soufisme de Kâlâbâhdi (mort en 995). Ces textes, dont la beauté apparaît à travers la traduction qui nous en est donnée, enseignent la réciprocité de l'amour entre Dieu et l'homme : c'est tout l'opposé de la mystique plotinienne qui absorbait le moi dans un principe impersonnel ou plutôt supérieur à toute personne.

— P. 235. — Le livre important de L. Gauthier (Ibn Rochd, Paris, 1948) conclut au caractère profondément religieux de la pensée d'Averroès, bien qu'il affiche, comme philosophe, un rationalisme intégral. La légende d'Averroès libre penseur est bien finie. La position de M. Gauthier paraît être aussi celle des historiens musulmans si nous en jugeons par la thèse, encore inédite, de Moussa (Paris, 1948). Averroès résout lui-même la contradiction en distinguant trois classes d'esprits : les philosophes, les théologiens, les hommes seulement religieux. Il admet, il est vrai, qu'Aristote est presque infaillible, mais seulement quand il s'agit de physique ou de métaphysique comme science universelle de l'être. Averroès a été ainsi l'initiateur de la conciliation scolastique entre la science et la foi. Mais, dirons-nous, ce compartimentage et cette distribution convenue des rôles ; ont-ils rien à voir avec une conciliation réelle?

- P. 236. - Parmi les sciences de tradition grecque cultivées en pays arabe, la physiognomonie était fort répandue. C'est l'histoire de cette science qu'a faite Y. Mourad, La Physiognomonie arabe, Paris, 1939. Il a accompagné son étude d'une édition et d'une traduction du Traité de physiognomonie de Fakhr al Dîn Al Râzi (début du XIII ${ }^{\mathrm{e}}$ siècle). Cette science, paraît-il, était surtout un art pratique permettant par exemple de déceler les défauts moraux et physiques des esclaves vendus sur le marché.

- P. 236. - Il manquait un livre en français sur l'ensemble de la philosophie juive. Cette lacune vient d'être comblée par G. Vajda, Introduction à la pensée juive du Moyen Age, Paris, 1947. Le caractère public, non initiatique, de la révélation divine donne d'après lui son caractère particulier à la pensée juive ; il n’envisage pas dans ce livre la dispersion juive à ses débuts ; mais en effet la facilité avec laquelle la diaspora des premiers siècles de notre ère a accepté tout ce 


\section{Émile Bréhier \\ La philosophie du Moyen âge}

qu'il y avait d'universel dans la pensée grecque, sans se laisser tenter par les mystères de l'Orient, montre combien, dès le début, elle était loin de poser en problème la conciliation de la foi et de la raison et d'accepter rien qui ressemble à une double vérité. La pensée juive a eu, au Moyen Age, la même attitude, à la fois critique et réceptive, vis-à-vis de la philosophie arabe. Sans doute il faut bien admettre que la cosmogonie renfermée dans l'étrange livre de la Création (Sefer Yeçira) et dans la Cabale est du judaïsme teinté de gnosticisme ; mais les auteurs de ces livres bizarres ont effacé toute trace du dualisme gnostique.

- P. 244. - S. Pines donne une nouvelle contribution à l'histoire de la physique médiévale dans une étude sur un philosophe juif peu connu, Abu'l Barakat al-Baghdadi (Rev. des Et. juives, juillet 1938) : il est antiaristotélicien et antiavicennien ; il admet la possibilité de l'infini spatial ; il pense que deux inclinations à des mouvements opposés peuvent coexister dans un même corps ; et il est ainsi amené à expliquer l'accélération dans la chute des corps par la diminution continuelle de la tendance vers le haut (cf. p. 175 le travail d'A. Maièr, De remissione formarum).

- P. 252. - La philosophie byzantine n'avait pas été jusqu'ici en France l'objet d'un exposé d'ensemble. Le livre de B. Tatakis, La philosophie byzantine, Paris, 1949, qui constitue le fascicule supplémentaire $\mathrm{n}^{\circ}$ II de mon Histoire de la philosophie, comble cette lacune. Cet exposé libère la pensée byzantine de la quasi-obligation qu'on lui imposait d'être un intermédiaire peu original entre l'hellénisme et la Renaissance occidentale. L'auteur montre comment elle se rattache à la Grèce classique et à la patristique orientale ; il montre les aspects divers de ces deux traditions ; il insiste sur un mysticisme monastique qui a pris nettement parti dans les mouvements à la fois théologiques et politiques qui agitaient Byzance : enfin il voit le véritable héritier de la philosophie byzantine dans les pays orthodoxes, de la Grèce à la Russie.

IV Partie, Ch. II. - P. 262. - Au sujet des traductions de l'arabe, qui ont commencé dès le XII ${ }^{\mathrm{e}}$ siècle, il faut citer les travaux de H. Bédoret (Les premières versions tolédanes de philosophie, Euvres d'Alfarabî, Rev. néoscol., fév. 1938. Euvres d'Avicenne, Rev. néoscolast., août 1938, et L'auteur et le traducteur du Liber de causis, ib., novembre 1938). Les auteurs et les dates de ces traductions sont souvent assez incertains ; on y voit un archevêque de Tolède commander au juif Avendauth une traduction du De anima d'Avicenne peu après le milieu du $\mathrm{XII}^{\mathrm{e}}$ siècle. Quant au Liber de causis, H. Bédoret conclut, de l'examen des manuscrits, que cette fameuse compilation a pour auteur Alfarabi et pour traducteur Gérard de Crémone ; l'ouvrage traduit par celui-ci sous le nom de Liber de expositione bonitatis purae ne diffère en effet que par le titre du Liber de causis. Au sujet des traductions du grec, L. M. Palhueto (Rivista de filosofia neoscolast. mars 1947) montre, par la stylistique et les habitudes de traduction, que la traduction latine de la Poétique d'Aristote, achevée le $1^{\mathrm{er}}$ mars 1278 , est l'œuvre de Guillaume de Mœrbeke, l'ami de saint Thomas. 


\section{Émile Bréhier \\ La philosophie du Moyen âge}

- P. 268. - P. V. Doucet, De Summa fratris Alexandri Halensis (Riv. de filosof. neosc. janvier 1948), revient sur la question de l'authenticité de la Somme attribuée à Alexandre de Halès. Il conclut que les trois premiers livres sont une compilation dont les sources (surtout Jean de la Rochelle) sont antérieures à 1245, date de la mort d'Alexandre, tandis que le livre IV cite des auteurs postérieurs à cette date.

- P. 268 (cf. pp. 272, 279, 344, 362, 377). - S. Vanni Rovighi, L'immortalità dell'anima nei maestri franciscani del secolo XIII (Milan, 1936), fait porter son enquête sur les maîtres franciscains depuis Alexandre de Halès: saint Bonaventure et son école, puis l'école d'Oxford. Un appendice important donne des fragments des Commentaires des Sentences d'Odon Rigaldi, de Guillaume de la Mare, de Matthieu d'Acquasparta, de Pierre de Tralibus sur la question : "Utrum anima rationalis sit immortalis », du Sapientiale de Thomas d'York, enfin la Quaestio disputata 38 de Richard de Middleton. On trouve, chez plusieurs de ces auteurs, quelques doutes sur la valeur des arguments rationnels en faveur de l'immortalité de l'âme, et une disposition à la fonder seulement sur l'autorité. Ainsi se prépare l'esprit fidéiste qui régnera au XIV ${ }^{\mathrm{e}}$ siècle.

IV Partie, Ch. IV. - P. 309. - G. van Riet, l'Épistémologie thomiste (Louvain, 1946), écrit un livre très utile et très instructif, non pas sur saint Thomas luimême, mais sur les interprétations de son épistémologie qui se rencontrent chez les auteurs modernes, depuis la restauration du thomisme par Léon XIII. La variété de ces interprétations est impressionnante. La restauration du thomisme venait du désir de rendre au christianisme sa philosophie propre, une philosophia perennis ; ses interprètes ont le désir d'armer la philosophie chrétienne contre le matérialisme du XVIII ${ }^{\mathrm{e}}$ siècle, tout autant que contre le subjectivisme kantien et protestant qui repoussait l'argumentation rationnelle en matière de théologie ; toutefois, depuis Maurice Blondel et Bergson, on fait ressortir en outre l'aspect dynamique de cette épistémologie. Le thomisme, sans cesse remanié et modernisé en des sens divers, est-il encore celui que l'on trouve chez saint Thomas ? En 1946, encore, P. Hœnen, La Théorie du jugement chez S. Thomas (Rome), donnait de cette théorie une interprétation que l'on pourrait appeler cartésiano-thomiste (cf. Van Riet, Rev. philos, de Louvain, fév. 1948, p. 101) ; saint Thomas distingue l'appréhension et le jugement : l'appréhension ne fournit pas l'être, mais la matière de la connaissance ; elle serait séparée du jugement par la réflexion intellectuelle qui porterait sur la nature de son acte et produirait le jugement. — G. Rabeau, Species Verbum, L'activité élémentaire selon S. Thomas (Paris, 1937), insiste beaucoup, mais avec plus de prudence critique, sur le travail d'élaboration, de construction de concepts qui caractérise l'intelligence humaine selon saint Thomas. Il étudie avec une grande précision les divers aspects du problème de la connaissance, le rôle de l'intellect agent, de l'espèce intelligible, de la forme intelligible, de l'image, du mot, puis la connaissance du singulier, la connaissance réflexive et la connaissance médiate ; et il fait voir que l'activité intellectuelle consiste en trois actes : identifier, distinguer et ordonner. Il reconnaît pourtant que 


\section{Émile Bréhier \\ La philosophie du Moyen âge}

saint Thomas n’a pas donné une théorie générale de cette activité. Ce dynamisme, A. Hayen veut le mettre en lumière en étudiant la pensée de saint Thomas, sur une notion dont les philosophes modernes parlent beaucoup, celle d'intentionnalité (L'Intentionnel dans la philosophie de S. Thomas, Louvain, 1940). Pour saint Thomas, tout être naturel a une intentio en ce sens qu'il possède une vertu qui le dépasse et peut le faire servir à l'esprit; il cherche non pas à persister dans l'existence, mais à se transcender. Mais cette propriété appartient surtout à l'être au sens plein qui est l'esprit ; l'esprit fini est intentionnellement infini ; il ne pourrait, s'il restait en lui-même, se donner par l'amour. L'intention est donc finalement ce qui permet « le retour à Dieu de l'esprit et du monde où il est engagé », retour à Dieu autrefois si profondément étudié dans un livre de Durantel. C'est aussi la thèse essentielle du P. de Finance, Etre et agir dans la philosophie de S. Thomas, Paris, 1945 ; c'est l'acte plus encore que l'exister qui caractérise l'être ; le thomisme, loin d'être une philosophie du concept statique, est un dynamisme ; l'être, si limité qu'il soit, tend à sortir de lui-même à communier avec l'acte pur.

Tous ces travaux révèlent clairement, sans l'énoncer expressément, tout ce qu'il y a de platonisme dans la vision thomiste du réel. Au reste, le statisme dont on lui fait grief concerne non point sa vision de l'univers, mais sa méthode de raisonnement qui suppose des concepts fixes et bien délimités. La qualité et la nature de ce platonisme ont été étudiées avec précision dans le livre substantiel de L. B. Geiger, La participation dans la philosophie de S. Thomas, Paris, 1945. L'auteur nous montre avec quelles précautions saint Thomas emploie cette notion et comment il la concilie avec la création.

- P. 321. - Dans la quatrième édition de son célèbre ouvrage Le Thomisme (1942), Et. Gilson débute par un nouveau chapitre, Existence et réalité, qui fait ressortir l'importance et l'intérêt de ce que l'on pourrait appeler l'existentialisme thomiste ; saint Thomas affirme positivement que les essences ne sont rien avant qu'elles n'aient l'existence. (Cette assertion est-elle bien différente de celle d'Aristote, dont on connaît la règle: ne pas chercher l'essence de choses qui n'existent point, et s'assurer de la réponse positive à la question an sit avant de poser la question quid sit ?) Sans doute, «l'exister est inconcevable autrement que dans et par une essence, mais toute essence signale un acte d'exister ». On sait que, dans Etre et Essence (1948), Et. Gilson veut faire partir la philosophie moderne du moment où Suarez a nié cette thèse thomiste ; alors a commencé cet idéalisme qui détermine les essences et les possibles comme conditions de l'existence ; de Descartes, il est passé à Leibniz-Wolff et à Hegel dont la dialectique est le mouvement interne de l'essence. Kierkegaard enfin aurait réclamé les droits de l'existence, mais sans l'ontologie thomiste (disons peut-être sans une théologie qui affirme l'identité en Dieu de l'essence et de l'existence).

- P. 334. - Selon le P. L. Lachance, L’humanisme politique de saint Thomas (2 vol., Paris, 1939), la pensée politique de nos jours part de l'idée que toute personne est naturellement capable de la vision béatifique, et elle ne fait aucune place à la grâce divine ; ainsi elle surestime la personne au mépris du pouvoir de l’État. Il montre à quel point saint Thomas, séparant l'ordre de la nature et de la 


\section{Émile Bréhier \\ La philosophie du Moyen âge}

grâce, est éloigné de cette thèse. Le pouvoir de l'État trouve alors ses limites non dans la souveraineté de la personne, mais dans la souveraineté divine ; et c'est en raison de cette souveraineté que l'État doit respecter la personne. «L'État, dans la direction de l'individu, n'a qu'une mission complétive. Le guide premier et principal de l'individu demeure toujours la prudence et la conscience morale », c'està-dire ce qu'il y a de divin en l'homme. Cette mission de l'État est pourtant nécessaire, parce que le bien humain est trop complexe pour être atteint autrement que par une croyance collective.

- P. 312. - G. Verbeke (Rev. philos, de Louvain, nov. 1947) montre que, dans son commentaire du De anima, saint Thomas s'est toujours inspiré de la paraphrase de Thémistius et non pas seulement, comme le disait M. de Corte, dans le livre I.

$I V^{e}$ Partie, Ch. V. - P. 336. - De récentes études et découvertes paraissent présenter Siger de Brabant et son averroïsme sous un jour assez nouveau. Quant aux dates de la polémique, L. W. Keeler, dans l'édition qu'il a donnée du Tractatus de unitate intellectus de saint Thomas (Rome, 1936), fait dater ce traité de 1269, c'est-à-dire au moins un an avant la première condamnation des averroïstes, qui est du 10 décembre 1270. D’autre part, M. F. Van Steenberghen, Les œuvres et la doctrine de Siger de Brabant, Bruxelles, 1938, se fondant sur les manuscrits découverts depuis les publications du P. Mandonnet, date le De anima intellectiva de Siger de 1272 ou 73, et il y voit une réponse au De unitate intellectus de saint Thomas. Quant au fond de la polémique, Siger y aurait été beaucoup moins ardent qu'on ne se le représente d'habitude : d'abord il aurait abandonné progressivement la thèse averroïste de l'intellect séparé ; de plus, il serait toujours resté soigneusement dans le domaine de la Faculté des arts et n'aurait jamais songé à intégrer la théologie dans son système ; il serait loin de la théorie de la double vérité qu'on lui prête, et par conséquent il aurait une position analogue à celle que L. Gauthier a décrite chez Ibn Rochd. Il y a, en général, chez les historiens de la philosophie médiévale, une tendance à atténuer les hétérodoxies ; Jean Scot, maître Eckhart, comme Siger, rentrent, plus qu'on ne le croyait, dans le giron de l’Église.

On a contesté l'attribution à Siger des Quaestiones in Physicam, insérées sous son nom dans le tome XV des Philosophes Belges. $\mathrm{M}^{\text {lle }}$ Anneliese Maier (Revue philos. de Louvain, novembre 1946) tire de nouveaux arguments contre l'authenticité de l'examen de Nouvelles Questions sur la Physique qui ont pour auteur Siger; il y soutient une théorie averroïste de la gravitation entièrement différente de celle qui est présentée dans les Questions du tome XV. Il est vrai que J.-J. Duin (même revue, novembre 1948) conteste l'importance de ces divergences et soutient l'authenticité des premières Questions.

- P. 336. - B. Nardi, L'averroismo bolognese nel secolo XIII e Taddeo Alderotto (Rivista di Stor. della Filosofia, 1949, p. 11) édite et étudie un fragment du commentaire de Johannitius par un médecin bolonnais, T. Alderotto ; ce commentaire écrit peu après 1277, prouve l'existence à Bologne d'une controverse 


\section{Émile Bréhier \\ La philosophie du Moyen âge}

autour des idées averroïstes, qui suit de près celle qui a eu lieu à Paris ; le fragment édité contient dix arguments en faveur de la thèse averroïste de l'unité des âmes humaines, appuyés tous sur des textes d'Aristote ; après leur avoir opposé neuf arguments affirmant la pluralité des âmes, Taddeus, bien qu'acceptant avec l'Église la pluralité des âmes, refuse de réfuter les dix premiers arguments, «non, dit-il, en raison de son ignorance, mais à cause d'une certaine timidité, puisque, comme on l'a dit, les philosophes et l'Église diffèrent d'opinion ».

IV Partie, Ch. VI. - P. 344. - Un texte intéressant l'école franciscaine, les Quaestiones de fide de Barthélémy de Bologne, a été édité par le P. Mücksdorf dans les Beiträge, 1940 ; ce texte aurait inspiré Matthieu d’Aquasparta.

- P. 345. - O. Lottin (Rev. néoscolast., mai 1939) fait connaître trois inédits du milieu du XIII ${ }^{\mathrm{e}}$ siècle, qui sont des commentaires des Éthiques d'Aristote ; ils viennent de la Faculté des arts. On y voit soutenu : la distinction de l'âme et de ses facultés et la distinction des deux faces de l'âme tournées l'une vers l'extérieur, l'autre vers l'intérieur ; ces thèses rappellent Avicenne, Algazel et Gundissalvi ; la théorie de l'intellect agent est celle d'Avicenne.

— P. 356. - L'abbé K. Michalski, poursuivant ses admirables études, traite du Problème de la Volonté à Oxford et à Paris au XIV siècle, Leopoli, 1937. Il donne un appendice contenant un tableau extrêmement intéressant des thèses accusées et des propositions condamnées en 1347. Les auteurs dont il s’agit opposaient les autorités les unes aux autres. D’un texte fameux du De interpretatione d'Aristote, ils tiraient l'affirmation que les propositions concernant les futurs contingents ne sont ni vraies ni fausses (ce qui est admettre une logique à trois valeurs) et que, par conséquent, Dieu n'en a pas la science, puisqu'il n'y a de science que du vrai. De la théologie on concluait à l'inverse que Dieu en a la science. Dans un opuscule inédit, le De praedestinatione, Occam se déclare pour la théologie ; mais il nie alors, avec la contingence, la logique à trois valeurs.

- P. 357. - Dans Henri de Gand : Essai sur les tendances de sa métaphysique, Paris, 1938, M. Paulus a montré en Henri de Gand un penseur séculier entièrement indépendant des ordres monastiques; plus avicennienne qu'augustinienne, sa métaphysique se concilie mal avec le dogme de la création. L'auteur souligne en lui le nominaliste précurseur d'Occam qui exclut les espèces, qui identifie l'âme avec ses puissances, qui considère comme équivoques les termes du langage humain appliqués à Dieu, qui ne distingue pas l'essence de l'existence. M. Paulus cite plusieurs auteurs qui ne veulent pas reconnaître ce nominalisme, puisque, dit-on, Henri est platonicien ; il nie avec raison cette incompatibilité. J'ajoute qu'il faut bien mal connaître l'histoire du platonisme pour ne pas savoir que, en règle générale, le réalisme de l'Idée en Dieu va de pair avec le nominalisme en ce qui concerne les formes des créatures. P. Bayerschmidt, Die Seins und Formmetaphysik des Henricus von Gent in ihrer Anwendung auf die Christologie, Beiträge, 1941, nous fait connaître un aspect de la théologie 


\section{Émile Bréhier \\ La philosophie du Moyen âge}

d'Henri : l’unité d'être et l'unité de forme substantielle dans le Christ, telles sont les thèses d'Henri.

V ${ }^{\mathrm{e}}$ Partie, Ch. I. - P. 376, (cf. app. à la p. 148). - Mgr Grabmann, Bearbeitungen und Auslegungen der aristotelischen Logik von P. Abaelard bis Petrus Hispanus, Berlin, 1937, décrit dans cet ouvrage des manuscrits. Dans les comptes rendus de Bayerische Akad. d. Wissensch., Philol.-hist. Abteilung, 1937, 10, il donne une étude sur un " artiste » parisien, Guillaume de Shyreswood (mort après 1267), qui traite en particulier de locis dialecticis.

$V^{e}$ Partie, Ch. II. - P. 392. — On connaît les analogies psychologiques (notamment la triplicité des opérations de connaissance) que saint Augustin introduit pour donner une image de la Trinité divine. M. D. Philippe consacre une étude spéciale (Rev. thomiste, 1947, II) aux raisons qui empêchent Durand de SaintPourçain d'accepter la méthode d'analogie dans cette question ; dans les opérations immanentes à l'intelligence, il s'agit, en effet, d'actes notionnels et non essentiels comme dans les relations entre les personnes de la Trinité : c'est la tendance à la négation de l'analogie qui domine au XIV ${ }^{\mathrm{e}}$ siècle.

- P. 394. - Dans sa belle étude, Philosophie et théologie chez Guillaume d'Ockham, Paris, 1947, R. Guelluy a fait ressortir avant tout le pluralisme extrême dans la conception occamiste de la connaissance. La connaissance d'un individu ne nous fait connaître que lui ; il est donc impossible de saisir dans un être la moindre relation avec un autre ; la relation n'est au plus qu'une évidence de fait. Ce n'est pas Occam, mais bien Pierre d'Espagne qui est l'inventeur de la logique terministe, où le terme est le simple substitut de choses singulières.

- P. 394. - L. Baudry a publié une édition critique du Breviloquium de potestate Papae, de Guillaume d'Occam, Paris, 1937, découvert par R. Scholz qui n'en avait publié en 1928 que le prologue ; il est sans nom d'auteur, mais l'auteur renvoie comme à une de ses propres œuvres au Dialogue, qui est bien de Guillaume. L’ouvrage a été composé sous Benoît XII en 1339 et 1340 . Il y soutient que c’est au théologien qu'il appartient de discuter du pouvoir du pape ; ce pouvoir, institué pour le bien des fidèles, ne peut d'ailleurs s'étendre au delà de ce que prescrit le bien commun. - Le même éditeur a publié en 1936 un Tractatus de Principiis theologiae dont l'attribution à Occam est moins sûre. Il y soutient une thèse de la toute-puissance divine qui doit débarrasser la pensée chrétienne des thèses platoniciennes et arabes sur l'émanation nécessaire. Mais le traité s'occupe d'un grand nombre de sujets : relations et nombres, suppositions, être par soi, définitions, distinction des sciences, habitudes intellectuelles, connexion des vertus, mouvement, mesure, lieu et surface, quantité, volonté, mobilité du lieu, principe d'économie, connaissance angélique, causalité, annihilation et production, liberté de la volonté. C’est, au total, un véritable manuel d'occamisme qui nous est donné ici. 


\section{Émile Bréhier \\ La philosophie du Moyen âge}

$V^{e}$ Partie, Ch. III. - P. 405. - P. Vignaux, Philosophie et théologie chez Guillaume d'Occam, Paris, 1948, mettant à profit, outre ses propres travaux, ceux de P. Bœhner et de R. Ghelluy, a, dans la conférence Albert le Grand, qu'il édite ici, cherché à dégager le principe essentiel de l'occamisme ; il oppose d'une manière particulièrement intéressante la théologie scotiste qui considérait Dieu comme un objet de savoir (scibile) à celle d'Occam où les termes qui désignent Dieu : ens, sapientia, bonitas, etc., désignent tout aussi bien des choses créées et ne désignent Dieu qu'en s'ajoutant l'un à l'autre. L'important chez Occam est toujours la critique de l'abstraction ; mais cette critique est liée essentiellement à une théologie qui admet en Dieu le pouvoir de séparer dans l'être ce qui est séparé dans la pensée. Un moderne serait porté à voir chez Occam avant tout la critique de la connaissance ; mais il faut bien entendre que, s'il faisait cette critique, c'est qu'il craignait que la connaissance non critiquée engendre ce Dieu nature ou nécessité, avec toutes les conséquences théoriques et pratiques qu'en tirait une tradition issue d'Avicenne.

- P. 414. - Les logiciens du XIV ${ }^{\mathrm{e}}$ siècle étaient d'accord pour trouver la connaissance dans la conclusion d'un raisonnement, c'est-à-dire non dans un terme simple mais dans un complexe. Mais la connaissance est-elle l'énoncé même de la conclusion, comme le pense Guillaume d'Occam ? C'est là que se place la théorie de Grégoire de Rimini, étudié par H. Élie (Le Complexe significabile, Paris, 1937) ; la connaissance est non dans l'énoncé, mais dans le «signifié » de l'énoncé complexe, ou plutôt dans ce qui est signifiable par complexe, c'est-àdire dans ce qui serait susceptible d'être signifié par la conclusion, si cette conclusion était énoncée. Ce qui est signifiable par un complexe est une relation et non une entité ; la connaissance n’aurait donc pas pour objet la réalité ; le dictum auquel correspond le signifiable peut d'ailleurs être vrai ou faux, sans que le signifiable, seul objet de la connaissance, en soit en rien affecté : conclusion qui lui attire beaucoup de critiques, celles de Robert Holkot, de Marsile d'Inghen, de Pierre d'Ailly. Mais l'étude d'H. Élie porte surtout sur André de Neuchâteau, auteur étudié ici pour la première fois. Malheureusement le livre d'H. Élie, qui analyse mot à mot les discussions fort compliquées et embrouillées de ces dialecticiens, ne s'élève point assez au-dessus du détail de cette argumentation pour en faire saisir la portée. Toutefois il faut signaler le rapprochement qu'il fait de la théorie de Grégoire avec les idées de Meinong qui considère l'assomption pure, la signification du jugement, sans considérer l'assentiment que nous pouvons ou non y donner, ni le fait qu'il est positif ou négatif.

- P. 422. - Par ses deux livres, Jean Gerson commentateur dionysien, Paris, 1940, et Jean de Montreuil et le chancelier Gerson, qui reposent sur une connaissance étendue de manuscrits inédits, l'abbé $\mathrm{A}$. Combes a ajouté un chapitre très important à notre connaissance des courants doctrinaux à Paris à la fin du XIV et au début du $\mathrm{XV}^{\mathrm{e}}$ siècle. Il attribue à Gerson des Notulae super quaedam verba Dionysii (ms. B.N. lat. 14905); il indique les points sur lesquels l'interprétation gersonienne du texte de Denys diffère de celle de saint Thomas ; Gerson, par delà 


\section{Émile Bréhier \\ La philosophie du Moyen âge}

le péripatétisme thomiste, se rapprocherait de Jean Scot et de Denys, notamment dans sa doctrine de l'émanation du monde à partir de Dieu. L'auteur trouve les mêmes préoccupations chez le franciscain Jean de Ripa (p. 548 sq.), qui attache un intérêt renouvelé à ce problème : comment les créatures sortent-elles de Dieu ? En morale, contrairement à saint Thomas, Jean de Ripa fait de la charité le fondement des vertus naturelles. - Son second livre, sur Jean de Montreuil rectifie d'une manière heureuse les idées courantes sur l'origine de l'humanisme, et aussi sur celle du gallicanisme « qui, écrit-il, a pu subir dès son berceau l'influence plus ou moins diffuse et bâtarde des grands révoltés d’Oxford et de Prague », savoir Wyclif et Jean Huss.

$V^{e}$ Partie, Ch. IV. - P. 425. - Il est à souhaiter que puisse se poursuivre la grande édition des œuvres de maître Eckhart, dont le $1^{\mathrm{er}}$ volume, comprenant neuf fascicules, parus de 1936 à 1938, contient les œuvres latines. — Une utile traduction française de ses Traités et Sermons a paru en 1942. De plus la revue Hermès (juillet 1937, à Bruxelles) a publié la traduction de plusieurs de ses œuvres et des pièces concernant son procès.

— P. 432. - Il ne manque pas actuellement d'interprètes qui seraient désireux d'atténuer l'hétérodoxie de maître Eckhart. Dans l'introduction qu'il a donnée à la traduction des Traités et Sermons, M. de Gandillac a bien marqué comment la mystique d'Eckhart qui, sur bien des points, suit la doctrine thomiste de l'être, s'écarte d'elle quand il met l'intellect ou unité pure au-dessus de l'être, et, audessus de Dieu, la Déité, désert ou abîme insondable qui n’est atteint par aucune détermination.

- P. 432. - Il convient de signaler l'importance du mouvement mystique italien du XIII ${ }^{\mathrm{e}}$ et du $\mathrm{XIV}^{\mathrm{e}}$ siècle, qui se rattache à saint François d'Assise et à saint Bonaventure. Les Noces mystiques de saint François et de Dame Pauvreté, les Fioretti de saint François, tous deux d'auteur inconnu, et beaucoup d'autres œuvres mystiques italiennes, prédications, lettres, méditations, ont été rassemblées et traduites en partie par A. Levasti, Mistici del duecento e del trecento, Milan, 1938. Je cite tout spécialement l'accent qu'on pourrait dire «pascalien » du traité d'Agnelo Torini Sur la misère humaine, qui oppose l'excellence de la nature humaine à la condition misérable des hommes. 